\title{
WestVirginiaUniversity
}

THE RESEARCH REPOSITORY @ WVU

Graduate Theses, Dissertations, and Problem Reports

2005

\section{Performance evaluation of FRP bridge deck under shear loads}

Woraphot Prachasaree

West Virginia University

Follow this and additional works at: https://researchrepository.wvu.edu/etd

\section{Recommended Citation}

Prachasaree, Woraphot, "Performance evaluation of FRP bridge deck under shear loads" (2005). Graduate Theses, Dissertations, and Problem Reports. 4186.

https://researchrepository.wvu.edu/etd/4186

This Dissertation is protected by copyright and/or related rights. It has been brought to you by the The Research Repository @ WVU with permission from the rights-holder(s). You are free to use this Dissertation in any way that is permitted by the copyright and related rights legislation that applies to your use. For other uses you must obtain permission from the rights-holder(s) directly, unless additional rights are indicated by a Creative Commons license in the record and/ or on the work itself. This Dissertation has been accepted for inclusion in WVU Graduate Theses, Dissertations, and Problem Reports collection by an authorized administrator of The Research Repository @ WVU.

For more information, please contact researchrepository@mail.wvu.edu. 


\title{
Performance Evaluation of FRP Bridge Deck under Shear Loads
}

Woraphot Prachasaree

\author{
Dissertation Submitted to the \\ College of Engineering and Mineral Resources \\ at West Virginia University \\ in partial fulfillment of the requirements \\ for the degree of
}

\author{
Doctor of Philosophy \\ in \\ Civil Engineering \\ Hota V.S. GangaRao, Ph.D. Chair \\ Udaya B. Halabe,Ph.D. \\ P.V. Vijay, Ph.D. \\ Charles F. Stanley, Ph.D. \\ Nithi T. Sivaneri, Ph.D. \\ Shekar Vimala, MSCE
}

Department of Civil and Environmental Engineering

\section{Morgantown, West Virginia \\ 2005}

Keywords: FRP, Torsional Shear, In-plane Shear, Out-of-plane Shear, Punching Shear, Racking Shear, Web-flange Junction Shear

Copyright 2005 Woraphot Prachasaree 


\section{ABSTRACT \\ Performance Evaluation of FRP Bridge Deck under Shear Loads}

\section{Woraphot Prachasaree}

Shear behavior of glass fiber reinforced polymer (FRP) composite coupons, components, and systems is studied under torsional shear, in-plane shear, racking shear, outof-plane shear, punching shear, and shear of web-flange junction. In addition, local deflection including web buckling of different FRP deck types has been evaluated and reported. FRP composites have been tested under a wide range of shear load conditions and their data has been compared with theoretical evaluations. Experimental data revealed that the shear modulus of FRP bridge decks ranged from 0.25 to $0.5 \mathrm{msi}$, shear stress ranged from 3 to 12 ksi, while the shear strain to failure was about 10,000 microstrain. Experimental shear modulus under torsion and in-plane shear correlated well $(<10 \%)$ with the results from the Simplified Classical Lamination Theory (SCLT) and finite element method. In addition, inplane shear strain based on SCLT, is found to be in good agreement with the experimental results for specific locations of a test specimen. It is found that plate action on torsional rigidity at system level after neglecting joint inefficiency (100\% load transfer across joints) is found to be about $20.0 \%$ higher than in terms of a beam model. Moreover, plate action under torsion of refined model with joint efficiency ( $80 \%$ load transfer) is found to be $6 \%$, different from the case where $100 \%$ load transfer across a joint is assumed.

In-plane shear behavior with joint efficiency are studied under V-notched, cantilever beam (shear parallel to cell direction) and racking shear test (shear perpendicular to cell direction). Experimental results under in-plane shear loading are compared with results from the classical finite element method. Out-of-plane shear strength and stiffness of an FRP composite deck are experimentally evaluated utilizing data from under short beam shear testing, and beam bending testing. Using experimental and numerical results, reduction in bending rigidity due to shear deformation under several loading conditions are calculated. In addition, size limits (depth to length ratio) due to shear deformation under transverse loading are established as: L/d > 22 (for multi-cell specimen with and without joints).

A theoretical model based on specific types of FRP deck specimens for predicting punching shear capacity is proposed and validated through our experimental data. In addition, failure modes of test specimens are reported. To study the web-flange junction behavior, both open and closed FRP sections are tested under shear-bending effect. It is clear that the webflange junction shear strength is only one half of the shear strength obtained from flange specimens under V-notched beam tests. The failure modes of both open and closed sections are similar. Cracks and layer delamination around web-flange junctions are found and extended along the thickness of the web portion with increasing applied loads leading to web shear-off failure.

Local deflection is generally computed under a patch load of AASHTO HS25 truck tire print. Bending tests of components are conducted to find local deflection of test specimens. Local deflection limit state is proposed to be one percent of span length (distance between two contiguous web). It is found that the local deflection of the top flange is under partial fixity due to contiguous webs. Under simply support condition accounting for $10 \%$ deflection due to shear deformation, the average percent fixity of ProDeck4 is about $20 \%$. Web-buckling strength is experimentally evaluated at coupon and component levels. By based on local buckling strain and finite element results, the size limits (dw/tw and bf/tf) of multi-cell ProDeck 4 cross sections are established as: dw/tw $<8.5$ and bf/tf $<12$ assumed failure torque of 360000 lbs-in. 


\section{ACKNOWLEDGEMENTS}

The author wishes to express his sincere thanks and appreciation to his academic and research advisor, Dr Hota V.S. GangaRao, for his numerous scientific contributions and practical guidance, philosophical conversations, and continuous moral. The author would also like to thank Dr. Nithi T. Sivaneri and Dr. Udaya Halabe for providing important advice and suggestion in this research. Thanks also to Dr. P.V. Vijay and Charles F. Stanley for participating in the Examining Committee and their comments. In addition, the author would like to express his appreciation to Mrs. Vimala Shekar for valuable comments.

Also, thanks are appropriate to Bedford Reinforced Plastics, Inc., for supplying, in part, materials for this research. The author wishes to thank all individuals, my friends, and technicians for their help and support through different phase of this research. In addition, thanks are proper to the staff of the Constructed Facilities Center for their continuous help during this research.

Finally, the author would like to thank his wonderful wife, Janjira, and his family for their love and patience helping him to complete this research. 


\section{DEDICATION}

This dissertation is dedicated to my parents and wife for their moral support and appreciation shown in the completion of this research work. 


\section{TABLE OF CONTENTS}

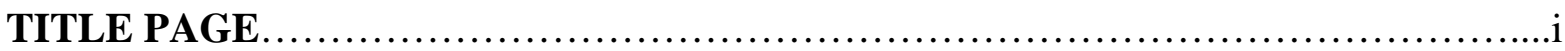

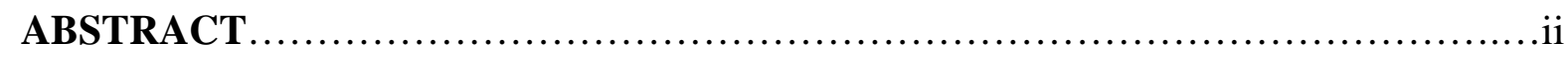

ACKNOWLEDGEMENTS.............................................................

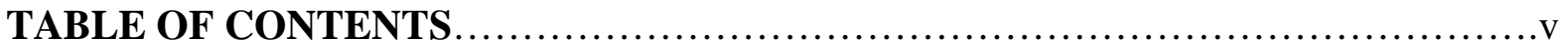

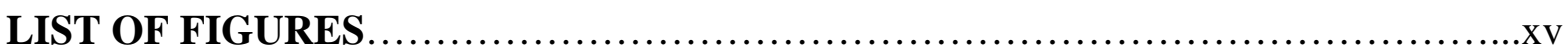

LIST OF TABLES.........................................................xiii

\section{CHAPTER 1: INTRODUCTION}

1.1 General Remarks and Background Information.....................................

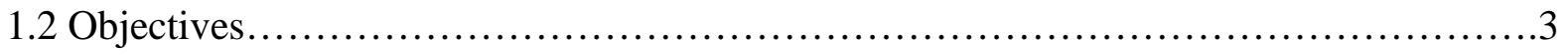

1.3 Scope.....................................................................4

\section{CHAPTER 2: LITERATURE REVIEW}

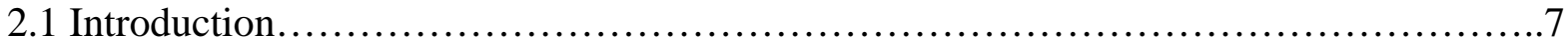

2.2 Review of Previous Researches...................................................

2.2.1 Review of Structural Theory..........................................8

2.2.2 Review of Experimental FRP Beam and Deck Results......................13

2.2.3 Review of In-Plane Shear Behavior................................... 15

2.2.4 Review of Out-of-Plane Shear Behavior..................................16

2.2.5 Review of Web-Flange Junctions.......................................18 


\section{CHAPTER 3: EXPERIMENTAL PROGRAM AND TEST SET-UPS}

3.1 Introduction.....................................................................

3.2 Experimental Programs.......................................................... 19

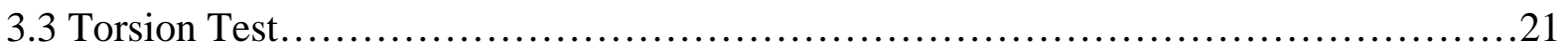

3.3.1 Coupon Testing.....................................................21

3.3.1.1 Coupon with Unidirectional Fiber.................................21

3.3.1.2 Coupon with Multi-Directional Fabrics...........................23

3.3.1.3 Coupon with Three Dimensional Fiber (Stitching)..................24

3.3.1.4 Sandwich FRP-Wood Coupon...................................25

3.3.1.5 Circular Solid Rebar...............................................26

3.3.1.6 Circular Tube...............................................28

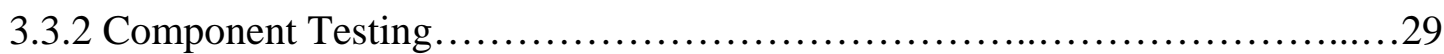

3.3.2.1 ProDeck4 Component Specimen.................................29

3.3.2.2 ProDeck8 Component Specimen................................31

3.3.3 Component with Joint Testing........................................34

3.3.4 Test Set-Up..........................................................

3.4 V-Notch Beam (Iosipescu) Shear Test.............................................40

3.4.1 Test Set-Up......................................................40

3.5 Cantilever Beam Test..........................................................41

3.5.1 Component Testing...................................................41

3.5.2 Test Set-Up............................................................

3.6 Racking Shear Test.............................................................43

3.6.1 Test Set-Up...................................................43

3.7 Short Beam Shear Test.........................................................45

3.7.1 Coupon Testing Level...............................................45 
3.7.1.1 ProDeck4 Coupon Specimen........................................45

3.7.1.2 ProDeck8 Coupon Specimen.......................................46

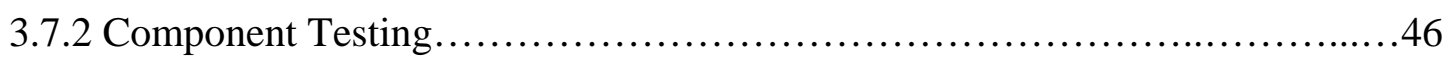

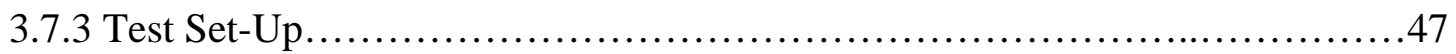

3.8 Three and Four Point Bending Test................................................

3.8.1 Component Testing ..............................................................

3.8.2 Component with Joint Testing...............................................50

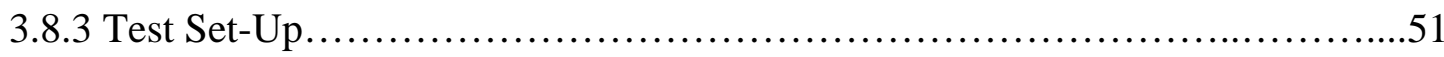

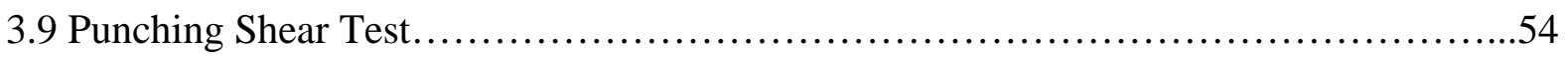

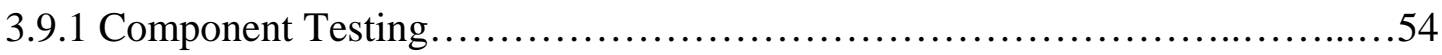

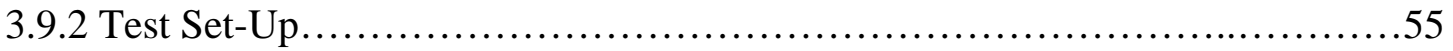

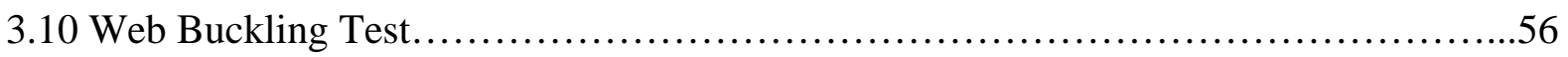

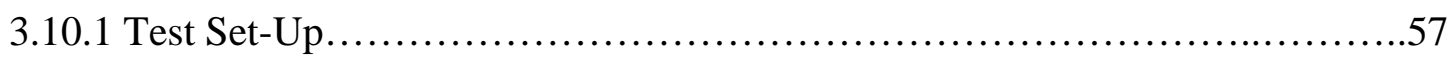

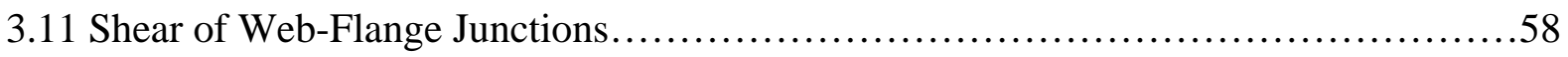

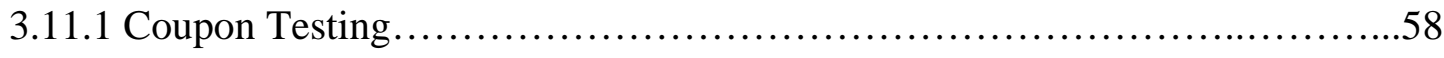

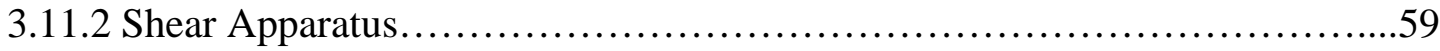

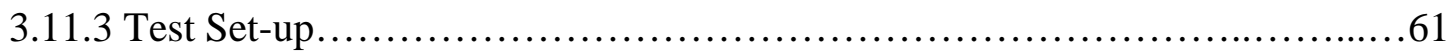

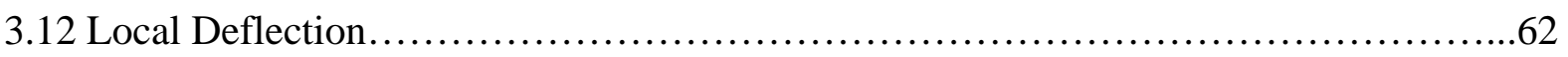

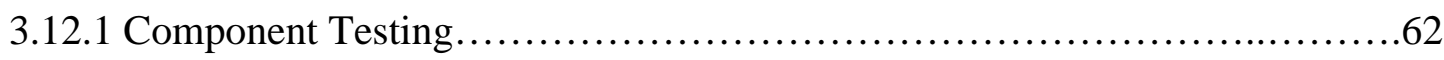

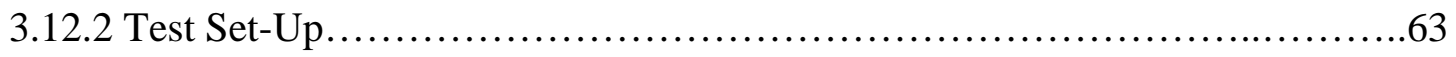

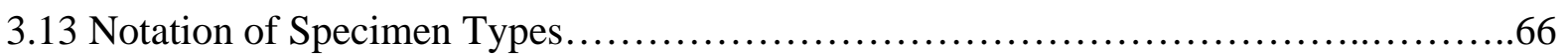

\section{CHAPTER 4: IN-PLANE SHEAR BEHAVIOR UNDER TORSION TEST}

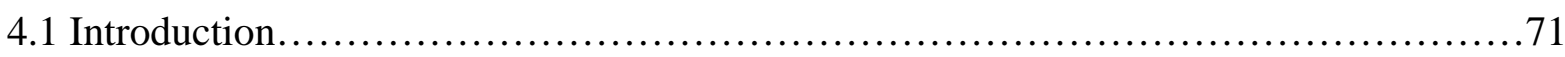

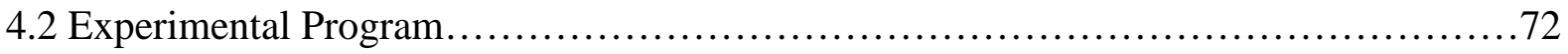


4.3 Simplified Classical Lamination Theory for Torsion................................76

4.4 Evaluation of Torisonal Rigidity.............................................. 81

4.4.1 Torsional Rigidity and In-Plane Shear Strain of FRP Rectangular Plate........81

4.4.2 Torsional Rigidity of FRP Sandwich Beam..............................86

4.4.3 Torsional Rigidity and In-Plane Shear Strain of FRP Circular Tube.............89

4.4.4 Torsional Rigidity and In-Plane Shear Strain of Single Cell

Thin-Walled Rectangular FRP Beam...................................96

4.4.5 Torsional Rigidity and In-Plane Shear Strain of Multi-Cell

Thin-Walled Rectangular FRP Beam...................................101

4.4.6 Torsional Rigidity and In-Plane Shear Strain of Multi-Cell

Thin-Walled Triangular FRP Beam....................................107

4.5 Evaluation of Theoretical Results using SCLT .....................................111

4.6 Evaluation of Experimental Results...........................................118

4.6.1 Coupon Level...................................................118

4.6.1.1 Discussion of Unidirectional Fiber Specimen......................122

4.6.1.2 Discussion of 2D Fabric and Stitching Specimen...................124

4.6.1.3 Discussion of Sandwich Specimen..............................124

4.6.1.4 Discussion of In-Plane Shear Strain (Coupon)...................125

4.6.2 Component without Joints.........................................129

4.6.2.1 Discussion of Experimental and SCLT Results.....................131

4.6.2.2 Discussion of Finite Element Results............................132

4.6.2.3 Discussion of In-Plane Shear Strain.............................138

4.6.3 Component with Joints...........................................143

4.6.3.1 Discussion of Experimental, SCLT and FE Results................145

4.6.3.2 Discussion of In-Plane Shear Strain.............................149 


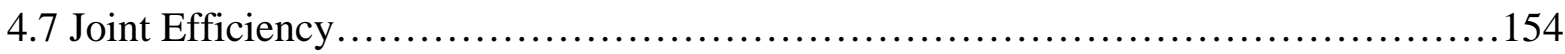

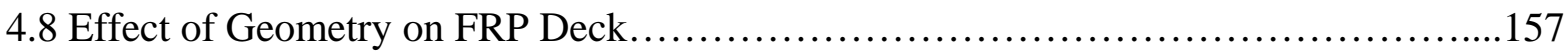

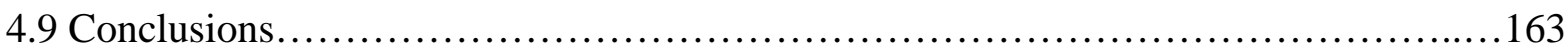

\section{CHAPTER 5: IN-PLANE SHEAR BEHAVIOR UNDER V-NOTCHED,} CANTILEVER BEAM AND RACKING SHEAR TEST

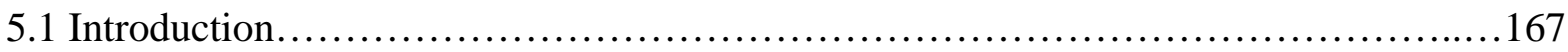

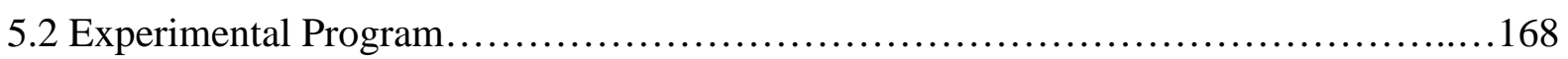

5.2.1 V-Notched Beam Shear Test.............................................168

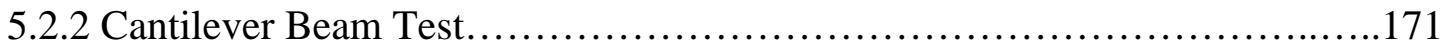

5.2.3 Racking Shear Test.............................................................

5.3 Evaluation of Experimental Results..............................................174

5.3.1 V-Notched Beam Test..........................................................174

5.3.1.1 Discussion of V-Notched Beam Results............................177

5.3.1.2 Failure Mode of V-Notched Beam Test.............................178

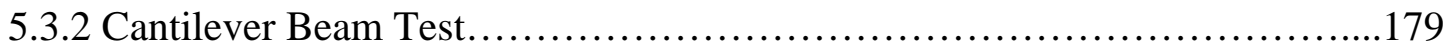

5.3.2.1 Analytical Results by Finite Element Method........................181

5.3.2.2 Comparison of In-Plane Shear (xy) Modulus.........................183

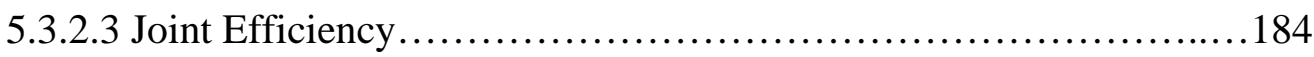

5.3.2.4 Discussion of Cantilever Experimental Results......................186

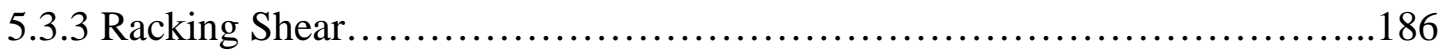

5.3.3.1 Results by Finite Element Method.....................................189

5.3.3.2 Experimental versus Analytical of In-Plane Shear (xy) Modulus.....192

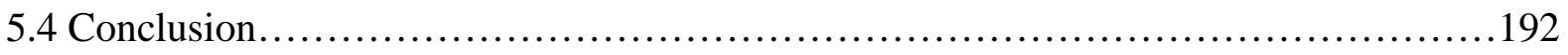




\section{CHAPTER 6: OUT-OF-PLANE SHEAR STRENGTH AND STIFFNESS}

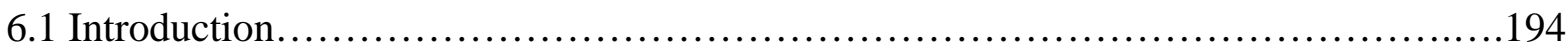

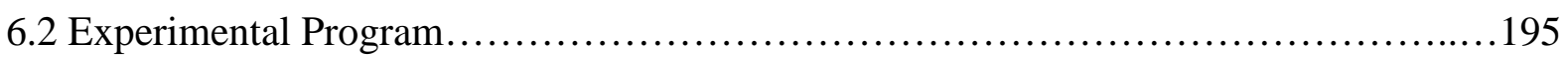

6.2.1 Out-of-Plane Shear Strength.............................................

6.2.2 Out-of-Plane Shear Modulus............................................196

6.2.2.1 Back Calculation Method Based on Experimental Deflections.......197

6.2.2.2 Back Calculation Method Based on Experimental Strain and

Deflections............................................................. 199

6.3 Evaluation of Experimental Results............................................200

6.3.1 Evaluation of Out-of-Plane Shear Strength...............................200

6.3.1.1 Comparison between Out-of-Plane and In-Plane Shear Strength.....204

6.3.1.2 Failure Mode of Out-of-Plane Shear..............................205

6.3.1.3 Out-of-Plane Shear Strength..................................207

6.3.2 Evaluation of Out-of-Plane Shear Modulus.............................210

6.3.2.1 Out-of-Plane Shear (xz) Modulus..............................210

6.3.2.2 Numerical Out-of-Plane Shear (xz) Modulus......................221

6.3.2.3 Comparison of Out-of-Plane Shear (xz) Modulus..................225

6.3.2.4 Out-of-Plane Shear (yz) Modulus...............................222

6.3.2.5 Comparison of Out-of-Plane Shear (yz) Modulus...................230

6.4 Evaluation of Reduction Factors of Bending Rigidity due to Shear Deformation.........231

6.5 Evaluation of Joint Efficiency...............................................241

6.5.1 Joint Efficiency of Longitudinal Specimen................................241

6.5.2 Joint Efficiency of Transverse Specimen...............................242

6.6 Discussion of Experimental Results.........................................242

6.7 Size Limits due to Shear Deformation........................................243 


\section{CHAPTER 7: PUNCHING SHEAR}

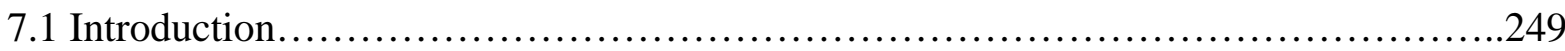

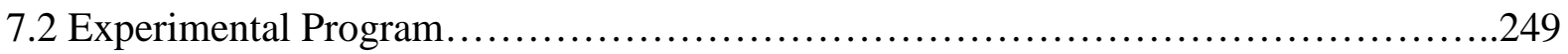

7.3 Theoretical Prediction........................................................ 250

7.3.1 Stress Prediction.....................................................250

7.4 Evaluation of Experimental Results...........................................254

7.5 Discussion of Experimental Results.........................................255

7.6 Failure Mode of Punching Shear...............................................257

7.7 Conclusion................................................................. 259

\section{CHAPTER 8: SHEAR BEHAVIOR OF WEB-FLANGE JUNCTIONS}

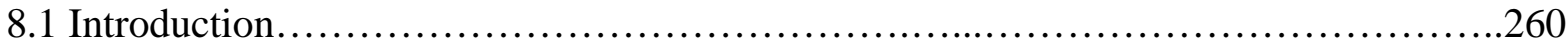

8.2 Experimental Result............................................................260

8.3 Evaluation of Experimental Results............................................263

8.4 Comparison Web-Shear Strength of Closed Sections..............................267

8.5 Discussion of Experimental Results.........................................268

8.6 Failure Mode of Web-Flange Junction........................................270

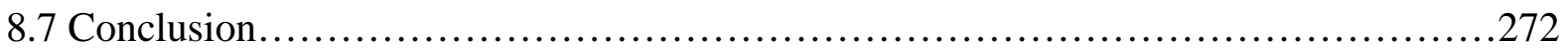

\section{CHAPTER 9: CONCLUSIONS AND RECOMMENDATIONS}

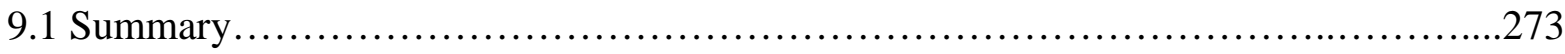

9.1.1 In-Plane Shear Behavior under Torsion Test..............................274 
9.1.2 In-Plane Shear Behavior under V-Notched, Cantilever and. ...

Racking shear

9.1.3 Out-of-Plane Shear Strength and Stiffness.................................280

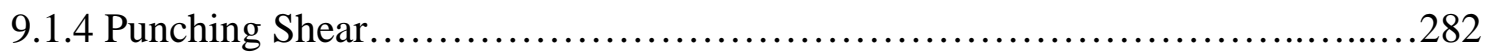

9.1.5 Shear Behavior of Web-Flange Junction.................................283

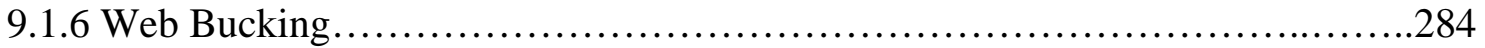

9.1.7 Local Deflection......................................................284

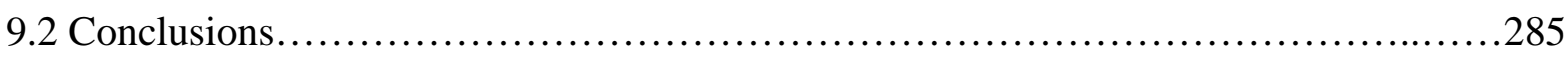

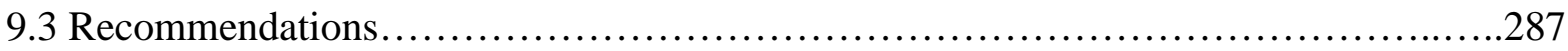

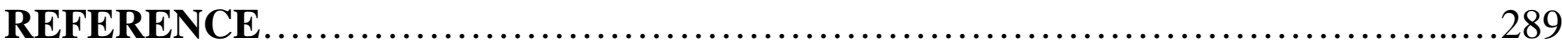

APPENDIX A: Simplified Classical Lamination Approach for

In-Plane Shear (xy) Modulus

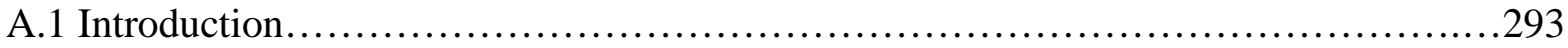

A.2 Simplified Classical Lamination Approach.....................................293

\section{APPENDIX B: Torsion Constants of Non-Circular Structural Shapes}

B.1 Introduction..............................................................299

B.2 Open Profiles.............................................................. 299

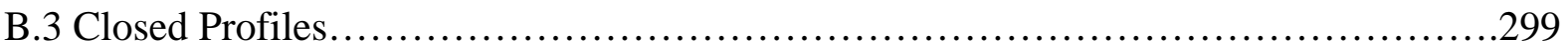
APPENDIX C: Evaluation of Composite SCLT

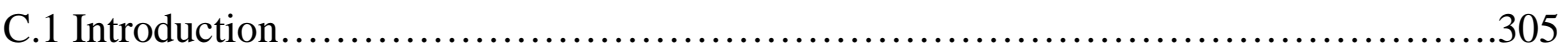
C.2 Computation of Material Properties.......................................... 305 
C.3 Determination of Composite Thickness.........................................306

C.4 Computation of Fiber Volume Fraction.......................................307

C.5 Evaluation of Lamina Properties..................................................308

C.6 Computation of $G_{x y}$ of Lamina............................................ 311

C.7 Computation of $G_{x y}$ of Laminate Fabric.........................................

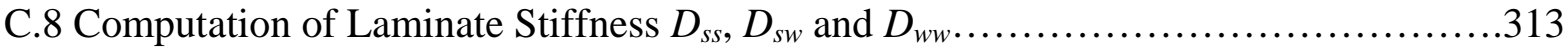

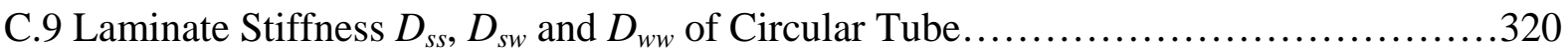

\section{APPENDIX D: Compatibility Relation of Closed section}

D.1 Compatibility Relation......................................................

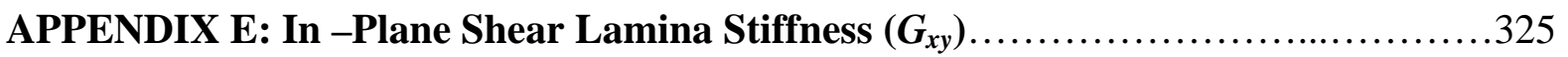

\section{APPENDIX F: Web Buckling}

F.1 Introduction..............................................................329

F.2 Experimental Program....................................................... 329

F.3 Evaluation of Experimental Results............................................333

F.4 Numerical Results by Finite Element Method....................................334

F.5 Prediction of Web-Buckling Strength..........................................337

F.6 Comparison of Buckling Strength................................................

F.7 Discussion of Experimental Results.........................................343

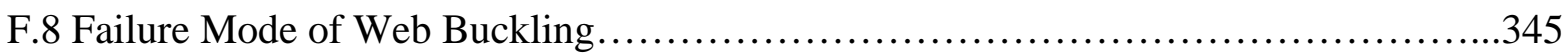

F.9 Size Limits due to Local Buckling............................................346

F.10 Conclusion................................................................. 


\section{APPENDIX G: Local Deflection}

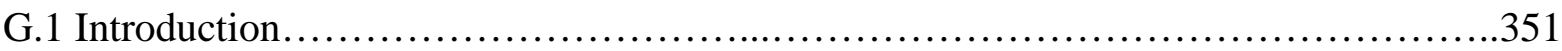

G.2 Experimental Program.......................................................352

G.3 Evaluation and Discussion of Experimental Results...............................354

G.4 Conclusion................................................................. 356

APPENDIX H: Closed Form Series Solution Approach of One and Two

\section{Dimensional Laminationed Composites}

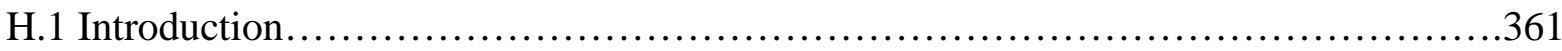

H.2 Basic Method...............................................................

H.3 One Dimensional Problem....................................................

H.4 Two Dimensional Problem........................................................

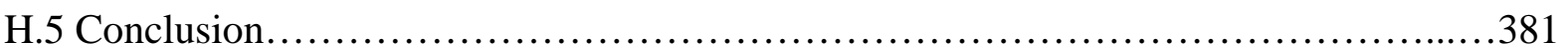

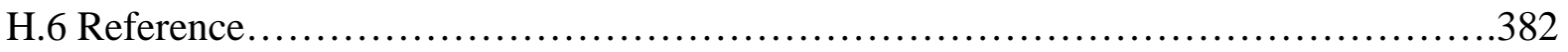




\section{LIST OF FIGURES}

Figure 2.1 Description and Orientation of Possible Shear Failure Modes...................15

Figure 3.1 Coupon with unidirectional fibers......................................... 22

Figure 3.2 Strain gage position of coupon specimens with 1inch wide....................22

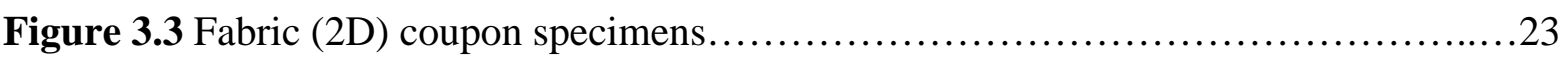

Figure 3.4 Stitching (3D) coupon specimens...................................25

Figure 3.5 Sandwich FRP-wood specimens....................................... 26

Figure 3.6 Strain gage position of sandwich FRP wood specimens with

1 inch wide............................................................ 26

Figure 3.70 .5 inch diameter of FRP reber specimens...............................27

Figure 3.81 .0 inch diameter of FRP reber specimens..............................27

Figure 3.9 FRP circular tube specimen..............................................

Figure 3.10 ProDeck4 longitudinal component specimen............................30

Figure 3.11 Transverse component specimens.......................................31

Figure 3.12 Strain gage position of transverse ProDeck4 specimen.......................31

Figure 3.13 Longitudinal specimen of ProDeck8................................ 32

Figure 3.14 Strain gage position of transverse ProDeck8 specimen......................33

Figure 3.15 Multi-cell longitudinal ProDeck4 with glass fabric reinforcement at components with joints. .36

Figure 3.16 Multi-cell transverse ProDeck4 with glass fabric reinforcement at components with joints........................................................37

Figure 3.17 Small scale of torsion machine....................................... 39 
Figure 3.18 Large scale of torsion machine..........................................40

Figure 3.19 V-notched beam specimens and test set-ups..............................41

Figure 3.20 Test-set up of cantilever beam.......................................43

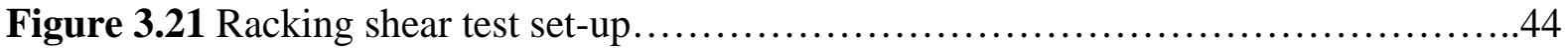

Figure 3.22 Short beam shear set-up of coupon specimen.............................48

Figure 3.23 Single cell ProDeck4 specimen for three and four point bending tests...........49

Figure 3.24 Multi-cell ProDeck4 specimen for three and four point bending tests..........49

Figure 3.25 Multi-cell ProDeck4 specimen with joints for

three and four point bending tests....................................50

Figure 3.26 Three point bending test set-ups of a longitudinal specimens................52

Figure 3.27 Four point bending test set-ups of longitudinal specimens..................53

Figure 3.28 Four point bending test set-ups of transverse specimens.....................53

Figure 3.29 single cell component specimens of punching shear test....................55

Figure 3.30 Punching shear test set-up of component specimens........................56

Figure 3.31 Test specimens of web buckling experiment............................57

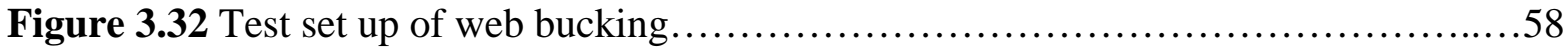

Figure 3.33 Test specimens of web-flange junctions...............................59

Figure 3.34 Web-flange shear apparatus.........................................60

Figure 3.35 Test set-up of web-flange junction test...............................61

Figure 3.36 Test set-up of web-flange junction test................................62

Figure 3.37 Local deflection experiments of ProDeck4 specimens.......................64

Figure 4.1 Test Set-up for Torsion Test (Sotiropoulos, 1995)........................73

Figure 4.2 Schematic of position $A$ and $B$ for torsion test..............................75

Figure 4.3 Measurement of angle of twist...................................... 75

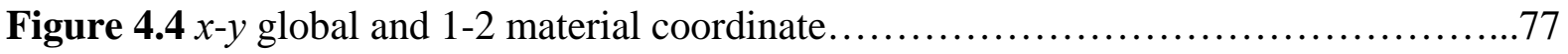




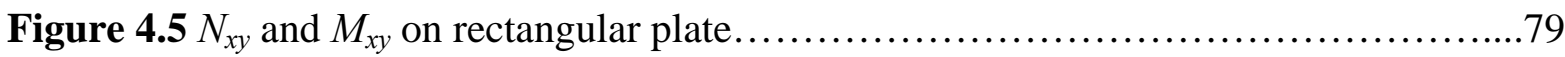

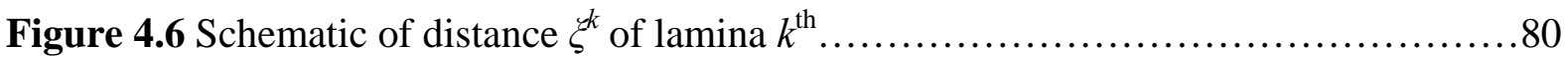

Figure 4.7 Rectangular plate under torsion load...................................82

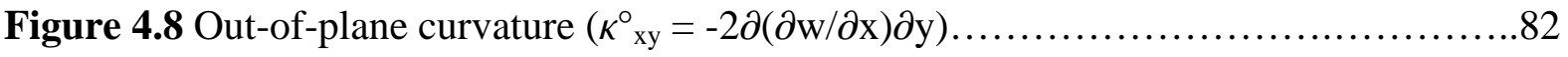

Figure 4.9 Rotational angle of solid cross section under torsion load......................83

Figure 4.10 Deformation of a plate in the $x-z$ or $y-z$ plane........................... 85

Figure 4.11 Cross section of sandwich beam.....................................87

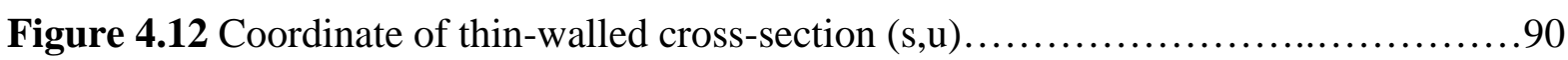

Figure $4.13 \mathrm{~A}_{\text {os }}$ area swept out from o to s.........................................

Figure 4.14 An enclosed area by the mid-line of cross section........................92

Figure 4.15 Shear flow around the wall segment..................................93

Figure 4.16 Ellipse cross sectional tube............................................94

Figure 4.17 $S_{f}, S_{w}$ and $A$ of rectangular cross section................................97

Figure 4.18 Integration around a closed cross section.............................99

Figure 4.19 Warping displacement of single cell cross section.......................100

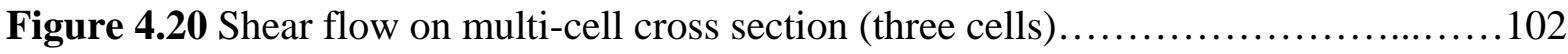

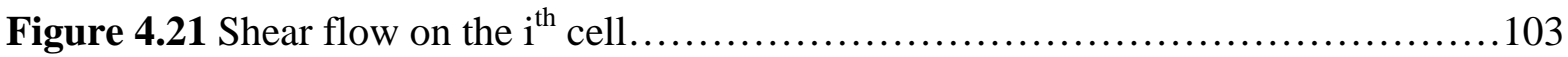

Figure 4.22 Spring Analogy for strain calculation...................................106

Figure 4.23 Warping displacement of multi cell cross section.......................107

Figure 4.24 Shear flow on double cells of trapezoidal thin-walled cross section............108

Figure 4.25 Shear flow on $\mathrm{i}^{\text {th }}$ and $\mathrm{i}+1^{\text {th }}$ cell of double cell triangular cross section..........108

Figure 4.26 $S_{w}$ and $S_{f}$ of a single cell (ProDeck4)................................114

Figure 4.27 Relation between applied torque and rate of twist $\left(\mathrm{CP} 4_{2.3 \mathrm{~L}}\right) \ldots \ldots \ldots \ldots \ldots \ldots \ldots . . .120$

Figure 4.28 Relation between applied torque and rate of twist (COP4 $4_{144 \mathrm{~L}}$ sample2)........130

Figure 4.29 Relation between applied torque and rate of twist $\left(\mathrm{COP} 8_{144 \mathrm{~L}}\right) \ldots \ldots \ldots \ldots \ldots \ldots . . .130$ 
Figure 4.30 In-plane shear strain of $\mathrm{COP}_{18 \mathrm{~T}}$ under torsion load.......................135

Figure 4.31 In-plane shear strain of $\mathrm{COP}_{12 \mathrm{~T}}$ under torsion load.........................135

Figure 4.32 Transverse displacement of COP $4_{144}$ under torsion load.....................136

Figure 4.33 In-plane shear strain of $\mathrm{COP}_{144}$ under torsion load......................136

Figure 4.34 Transverse displacement of COP8 ${ }_{144}$ under torsion load....................137

Figure 4.35 In-plane shear strain of $\mathrm{COP}_{144}$ under torsion load......................137

Figure 4.36 Strain gage positions for longitudinal components........................140

Figure 4.37 Relation between torque-rate of twist (MP4 $4_{144 \mathrm{~L}}, \mathrm{MP} 4_{144 \mathrm{~J} \mathrm{~L}}$ and $\left.\mathrm{MP} 4_{144 \mathrm{JFL}}\right) \ldots \ldots .144$

Figure 4.38 Transverse displacement of specimen (MP4 $\left.4_{144} \mathrm{~L}\right)$ under torsion load...........147

Figure 4.39 In-plane shear strain of specimen $\left(\mathrm{MP}_{144 \mathrm{~L}} \mathrm{~L}\right)$ under torsion load................147

Figure 4.40 Transverse displacement of specimen $\left(\mathrm{MP} 4_{144 \mathrm{~L}}\right)$ under torsion load...........148

Figure 4.41 Transverse displacement of specimen (MP4 $\left.4_{144} \mathrm{~L}\right)$ under torsion load............148

Figure 4.42 In-plane shear strain positions......................................150

Figure 4.43 Transverse displacement of a system model under torsion..................158

Figure 4.44 Transverse displacement of a system model under torsion and in-plane shear perpendicular to cell direction............................159

Figure 4.45 Transverse displacement of a system model under torsion and in-plane shear parallel to cell direction...............................159

Figure 4.46 Spring elements and connection models................................161

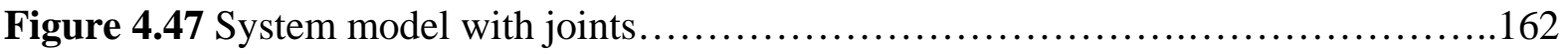

Figure 4.48 Vertical displacement of system model with joints.......................163

Figure 5.1 Force, shear and moment diagram.......................................169

Figure 5.2 Schematic of cantilever beam test set-up...............................172

Figure 5.3 Schematic of racking shear test set-up..................................174

Figure 5.4 Load-deflection curve VP4 $4_{\mathrm{L}}$ under V-notched beam test...................176 
Figure 5.5 Stress-strain curve under V-notched beam test..........................177

Figure 5.6 Failure mode of V-notched beam test specimen............................178

Figure 5.7 In-plane shear test by using cantilever method.............................179

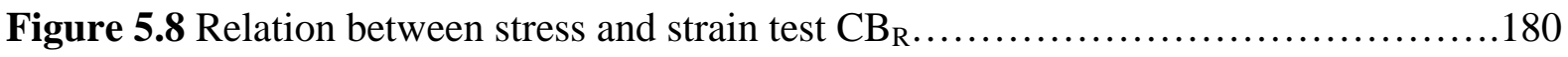

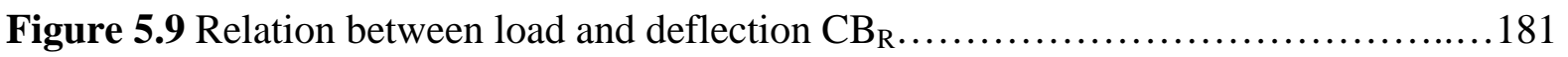

Figure 5.10 Finite element model of cantilever test specimens.........................182

Figure 5.11 Deflection of y direction at specific positions under racking shear.............187

Figure 5.12 Relation of in-plane shear modulus and applied load under racking shear......188

Figure 5.13 Finite element model of racking shear test...........................191

Figure 5.14 Displacement of y direction under racking shear test.....................191

Figure 6.1 Short beam shear specimens......................................195

Figure 6.2 Delamination of coupon specimens under short beam shear test..............205

Figure 6.3 Crack and delamination of top and bottom flange...........................206

Figure 6.4 Delamination and web-buckling of test specimens.........................206

Figure 6.5 Cracks on cross section of ProDeck8 component specimen...................207

Figure 6.6 Relation between load and deflection $\left(\mathrm{SBP} 4_{s}\right)$ under short beam shear test......209

Figure 6.7 Relation between load and deflection $\left(\mathrm{SBP}_{\mathrm{M}}\right)$ under short beam shear test......209

Figure 6.8 Longitudinal specimens under bending test...............................210

Figure 6.9 Load-deflection curve $\mathrm{BP} 4_{\mathrm{S}}$ under 3 point bending $\ldots \ldots \ldots \ldots \ldots \ldots \ldots \ldots \ldots \ldots \ldots \ldots \ldots \ldots$

Figure 6.10 Load-deflection curve $\mathrm{BP} 4_{\mathrm{s}}$ under 4 point bending $\ldots \ldots \ldots \ldots \ldots \ldots \ldots \ldots \ldots \ldots \ldots \ldots \ldots \ldots$

Figure 6.11 Load-deflection curve $\mathrm{BP} 4_{\mathrm{M}}$ under 3 point bending.......................212

Figure 6.12 Load-deflection curve $\mathrm{BP} 4_{\mathrm{M}}$ under 4 point bending......................212

Figure 6.13 Load-deflection curve $\mathrm{BP} 4_{\mathrm{M}}$ under 3 point bending.......................213

Figure 6.14 Load-deflection curve $\mathrm{BP} 4_{\mathrm{MJ}}$ under 4 point bending....................213

Figure 6.15 Load- net deflection curve $\mathrm{BP} 4_{\mathrm{S}}$ under 4 point bending...................214 
Figure 6.16 Load-net deflection curve $\mathrm{BP} 4_{\mathrm{M}}$ under 4 point bending.....................214

Figure 6.17 Load-net deflection curve $\mathrm{BP} 4_{\mathrm{MJ}}$ under 4 point bending......................214

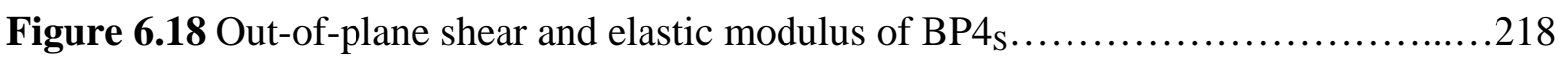

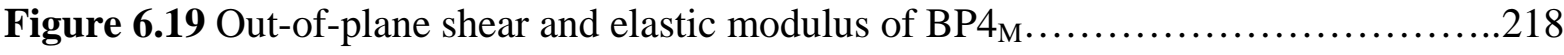

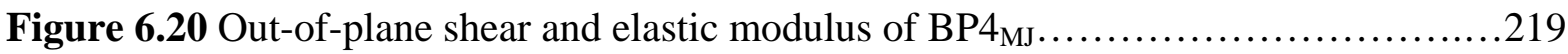

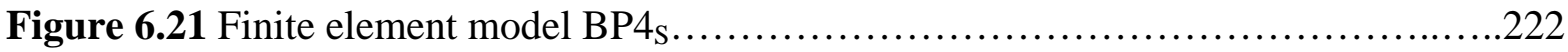

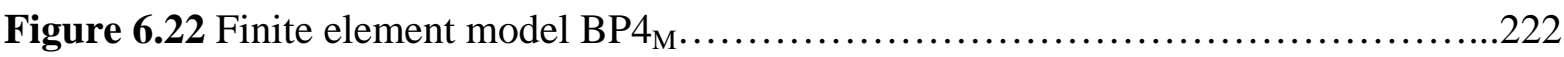

Figure 6.23 Y-deflection of $\mathrm{BP} 4_{\mathrm{S}}$ under three-point bending (bottom flange).............223

Figure 6.24 Y-deflection of BP4s under four-point bending (bottom flange).............223

Figure 6.25 Y-deflection of $\mathrm{BP} 4_{\mathrm{M}}$ under three-point bending (bottom flange)............224

Figure 6.26 Y-deflection of $\mathrm{BP} 4_{\mathrm{M}}$ under four-point bending (bottom flange)..............224

Figure 6.27 Transverse specimens under testing.................................227

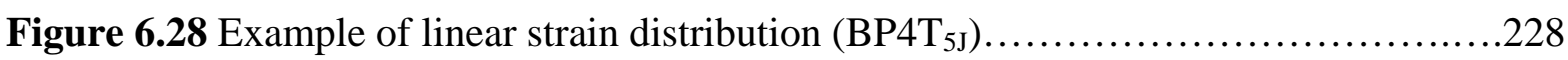

Figure 6.29 Extrapolation curve of bending stiffness for transverse specimen.............229

Figure 6.30 Shear reduction factor of $\mathrm{BP} 4_{\mathrm{s}}$ under three-point bending $\ldots \ldots \ldots \ldots \ldots \ldots \ldots \ldots \ldots \ldots \ldots \ldots$

Figure 6.31 Shear reduction factor of $\mathrm{BP} 4_{\mathrm{M}}$ under three-point bending.................237

Figure 6.32 Shear reduction factor of $\mathrm{BP}_{\mathrm{MJ}}$ under three-point bending.................238

Figure 6.33 Shear reduction factor of $\mathrm{BP} 4_{\mathrm{s}}$ under four-point bending...................238

Figure 6.34 Shear reduction factor of $\mathrm{BP} 4_{\mathrm{M}}$ under four-point bending.................239

Figure 6.35 Shear reduction factor of $\mathrm{BP} 4_{\mathrm{MJ}}$ under four-point bending.................239

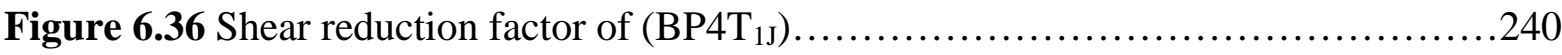

Figure 6.37 Size limit due to shear deformation of single cell specimen.................245

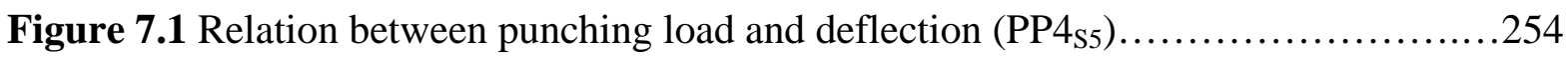

Figure 7.2 Cracks around punching area of single cell specimens.....................258

Figure 7.3 Layer delamination of single cell specimens.............................258 
Figure 7.4 Cracks around punching area of multi-cell specimens......................259

Figure 8.1 Cantilever beam model of web-flange junction test..........................261

Figure 8.2 Load versus deflection of open cross section specimen $\left(\mathrm{WJ}_{\mathrm{O} 1.5}: 3\right) \ldots \ldots \ldots \ldots \ldots .266$

Figure 8.3 Load versus deflection of closed cross section specimen $\left(\mathrm{WJ}_{\mathrm{C} 1}: 3\right) \ldots \ldots \ldots \ldots \ldots .266$

Figure 8.4 Crack and delamination of web-flange junction (open section)...............270

Figure 8.5 Crack through thickness of open sectional specimens.....................271

Figure 8.6 Crack and delamination of web-flange junction (closed section)..............271

Figure 8.7 Crack through thickness of closed sectional specimens....................271

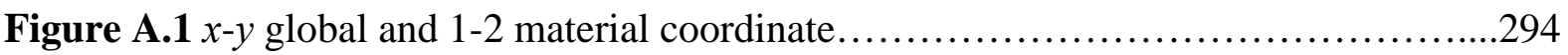

Figure D.1Coordinate on thin-walled cross section...............................322

Figure F.1 Simple beam model of double web specimens...........................331

Figure F.2 Continuous beam model of module specimens.............................331

Figure F.3 Web-buckling mode of single web.....................................335

Figure F.4 Web-buckling mode of double web...................................336

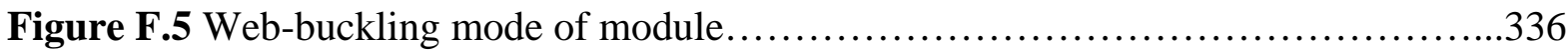

Figure F.6 Two-dimensional plate under buckling load.............................339

Figure F.7 Relation between buckling stress and slenderness ratio of ProDeck4...........342

Figure F.8 Stress-strain relation of single web specimen..............................344

Figure F.9 Failure mode of web buckling......................................345

Figure F.10 Failure mode of web crippling (Punyamurthula, 2004) $\ldots \ldots \ldots \ldots \ldots \ldots \ldots \ldots . \ldots . \ldots . \ldots$

Figure F.11 High longitudinal strains at flange-web junctions........................347

Figure F.12 Size limit $\left(\mathrm{d}_{\mathrm{w}} / \mathrm{t}_{\mathrm{w}}\right)$ for multi-cell ProDeck4 ..............................348

Figure F.13 Size limit $\left(\mathrm{b}_{\mathrm{f}} / \mathrm{t}_{\mathrm{f}}\right)$ for multi-cell ProDeck4 ...............................348

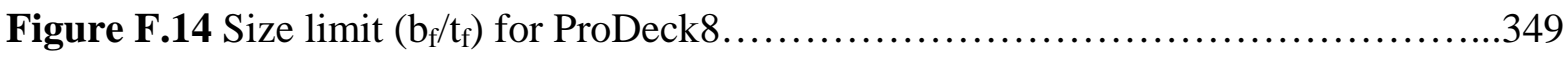

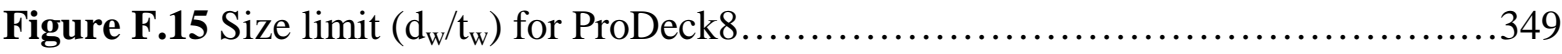




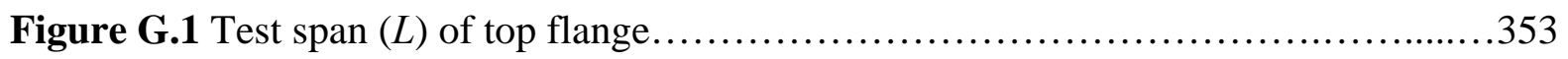

Figure H.1 Convergence of deflection in Table G.3.................................381 


\section{LIST OF TABLES}

Table 3.1 Test specimen size of one dimensional fiber coupon.......................22

Table 3.2 Test specimen size of fabric (2D) coupon...............................24

Table 3.3 Component specimen sizes of torsion test................................33

Table 3.4 Component with joint specimen sizes of torsion test...................... 35

Table 3.5 Test specimen sizes of cantilever beam test.............................42

Table 3.6 Summary of racking shear test....................................... 45

Table 3.7 Coupons for short beam shear test...................................46

Table 3.8 Component specimen sizes of short beam shear test.......................47

Table 3.9 Test specimen sizes under three and four point bending...................51

Table 3.10 Test specimen sizes of punching shear.................................54

Table 3.11 Test specimen sizes of web buckling test..............................56

Table 3.12 Specification of web-flange junction specimens........................59

Table 3.13 Test specimen sizes of local deflection...............................64

Table 4.1 Torsional rigidity using SCLT of FRP structural plates...................112

Table 4.2 $D_{s s}, D_{s w}, D_{w w}, S_{w}$ and $S_{f}$ values of ProDeck4 flange and web portions........114

Table 4.3 $D_{s s}, D_{s w}, D_{w w}, S_{w}$ and $S_{f}$ values of both ProDeck8 flange and web............117

Table 4.4 Experimental data $\mathrm{CP}_{2.3 \mathrm{~L}}$ (sample 1) under torsion test....................119

Table 4.5 Comparison of $\left(G_{x y}\right)_{\mathrm{e}}$ for unidirectional coupon specimens................120

Table 4.6 Comparison of $\left(G_{x y}\right)_{\mathrm{e}}$ for unidirectional rebar specimens.................121

Table 4.7 Comparison of $\left(G_{x y}\right)_{\mathrm{e}}$ for multi directional fabric and stitching coupons......122

Table 4.8 Comparison of $\left(G_{x y}\right)_{\mathrm{e}}$ for sandwich coupon specimens....................125 
Table 4.9 Theoretical in-plane shear (xy) strain of coupon specimen $C P 4_{2.3 L} \ldots \ldots \ldots \ldots 126$

Table 4.10 Comparison of in-plane shear strain for coupon.........................126

Table 4.11 Comparison of in-plane shear strain for rebar............................129

Table 4.12 Comparison of in-plane shear modulus for component specimens (no joints). .131

Table 4.13 Finite element models for component level. .133

Table 4.14 Comparison of in-plane shear modulus for component specimens (F.E.)...134

Table 4.15 In-plane shear strain of component specimens 141

Table 4.16 Comparison of in-plane shear strain for component specimens. .142

Table 4.17 Torsional rigidity and equivalent in-plane shear (xy) modulus at component with joint level 145

Table 4.18 Comparison of percent difference of torsional rigidity and equivalent in-plane (xy) shear modulus at component with joint level. .146

Table 4.19 In-plane shear strain of component specimens with joints. 152

Table 4.20 In-plane shear strain of component specimens .153

Table 4.21 Comparison of joint efficiency .157

Table 4.22 Finite element models for system level. 158

Table 4.23 Torsional rigidity of system models using finite element..................160

Table 4.24 Summary of Plate action on the FRP deck system.......................162

Table 5.1 In-plane shear strength and modulus by V-notched beam test...............175

Table 5.2 Comparison of in-plane shear stiffness...............................175

Table 5.3 In-plane modulus using cantilever beam test.............................180

Table 5.4 Summary of finite element models under cantilever beam test................182

Table 5.5 Nodal results of cantilever beam model................................183

Table 5.6 In-plane shear modulus comparison of cantilever beam test.................184 
Table 5.7 Comparison of joint efficiency

Table 5.8 In-plane shear (xy) modulus based on deflection data under racking shear.... 188

Table 5.9 Summary of finite element models under cantilever beam test. 189

Table 6.1 Ultimate shear strength of coupon specimens (ProDeck4). .201

Table 6.2 Ultimate shear strength of coupon specimens (ProDeck8)..... .202

Table 6.3 Shear strength of component specimens. .203

Table 6.4 Comparison between out-of-plane and in-plane shear strength (coupon) 204

Table 6.5 Slope of load-deflection curve from three and four point bending test

Table 6.6 Experimental results (slope approach) of longitudinal bending (x) and out-of-plane shear (xz) modulus. 216

Table 6.7 Experimental results (load step approach) of longitudinal bending (x) and out-of-plane shear (xz) modulus.

Table 6.8 Experimental results based on strain-deflection data of longitudinal bending (x) and out-of-plane shear (x-z) modulus .220

Table 6.9 Summary of finite element models for three-four point bending. .221

Table 6.10 Slope of load-deflection curve from three and four point bending test based on finite element results. .225

Table 6.11 Summary of longitudinal elastic (x) and out-of-plane shear (xz) modulus. .226

Table 6.12 Percent difference between experimental and finite element results.........226

Table 6.13 Experimental results (strain approach) transverse modulus .229

Table 6.14 Experimental results (strain approach) of out-of -plane shear (yz) modulus. .230 
Table 6.15 Summary of elastic and out-of-plane shear modulus .230

Table 6.16 Shear reduction factor of specimen $\mathrm{BP} 4_{\mathrm{s}}$ under three point bending. .233

Table 6.17 Shear reduction factor of specimen $\mathrm{BP} 4_{\mathrm{M}}$ under three point bending.........233

Table 6.18 Shear reduction factor of specimen $\mathrm{BP} 4_{\mathrm{MJ}}$ under three point bending.......234

Table 6.19 Shear reduction factor of specimens BP $4_{\text {S }}$ under four point bending........234

Table 6.20 Shear reduction factor of specimen $\mathrm{BP} 4_{\mathrm{M}}$ under four point bending........235

Table 6.21 Shear reduction factor of specimen $\mathrm{BP} 4_{\mathrm{MJ}}$ under four point bending.........235

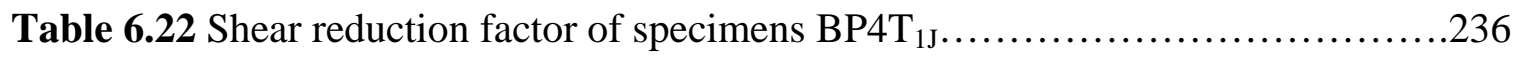

Table 6.23 Joint efficiency of longitudinal specimens............................241

Table 6.24 Joint efficiency of Transverse specimens.............................242

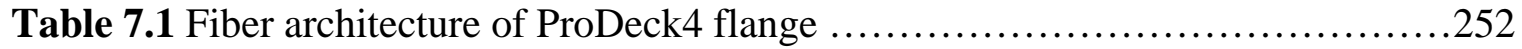

Table 7.2 Theoretical results of failure punching shear stress

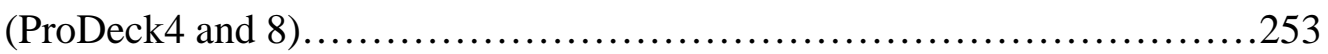

Table 7.3 Comparison of theoretical and experimental punching shear results..........255

Table 8.1 Shear stress of web-flange junctions for open sectional specimens..........264

Table 8.2 Shear stress of web-flange junctions for closed sectional specimens.........265

Table 8.3 Comparison of web-flange junction shear strength........................267

Table B.1 Torsion constant of rectangular coupon................................300

Table B.2 Torsion constant of circular bar and tube..............................301

Table C.1 Fiber volume fraction for CDBM 3415 laminate........................308

Table C.2 Fiber volume fraction for DDBM 4015 laminate..........................308

Table C.3 Fiber volume fraction for 113 roving layer..............................308

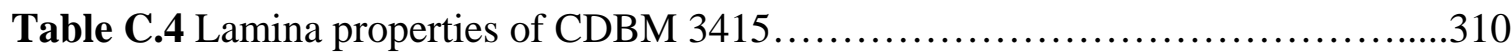

Table C.5 Lamina properties of DDBM 4015.................................310

Table C.6 Lamina properties of 113 Yield Roving............................... 310 


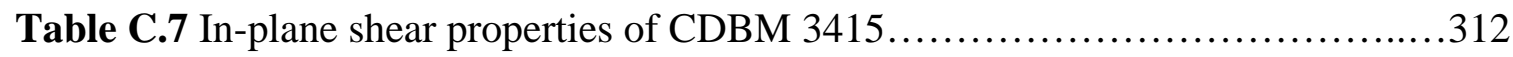

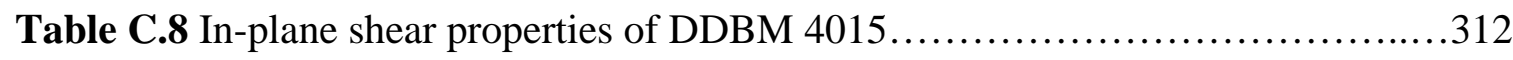

Table C.9 In-plane shear properties of 113 Yield Roving.............................312

Table C.10 $\mathrm{D}_{\mathrm{ss}}, \mathrm{D}_{\mathrm{sw}}$ and $\mathrm{D}_{\mathrm{ww}}$ of ProDeck4 flange...................................

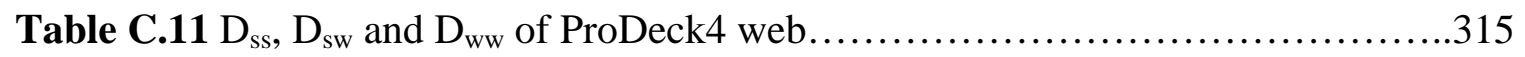

Table C.12 Fiber volume fraction for CDBM 3415 laminate.......................315

Table C.13 Fiber volume fraction for CDB 400 laminate...........................316

Table C.14 Fiber volume fraction for roving layer................................316

Table C.15 Lamina properties of CDBM 3415...................................316

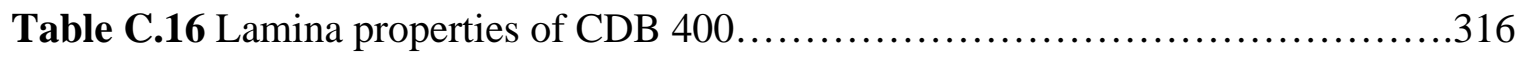

Table C.17 Lamina properties of 113 Yield Roving..............................317

Table C.18 In-plane shear properties of CDBM 3415..............................317

Table C.19 In-plane shear properties of CDB 400...............................317

Table C.20 In-plane shear properties of 113 Yield Roving.........................317

Table C.21 $D_{s s}, D_{s w}$ and $D_{w w}$ of ProDeck8 flange (thickness 0.5 inch).................318

Table C.22 $D_{s s}, D_{s w}$ and $D_{w w}$ of ProDeck8 flange (thickness 0.45 inch)...............319

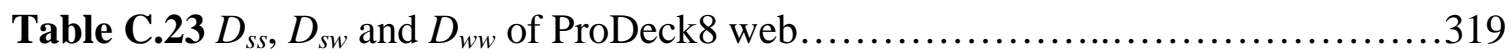

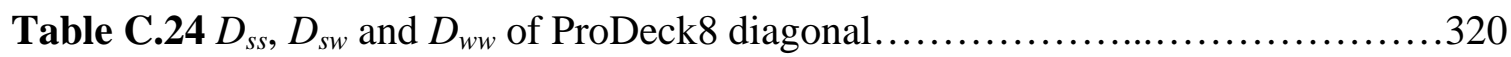

Table F.1 Experimental web-buckling strength................................333

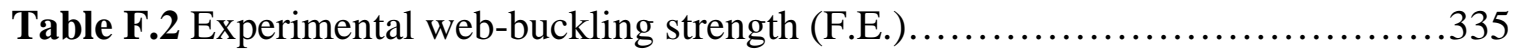

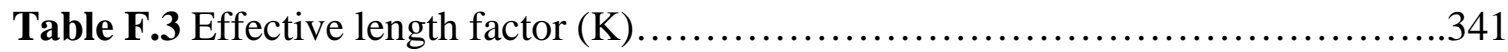

Table F.4 Comparison of web-buckling.....................................343

Table G.1 Classical deflection expression under bending..........................352

Table G.2 Strain expression due to bending...................................354

Table G.3 Deflection and Strain data..........................................357 
Table G.4 Effective span length factor (a)

.359

Table G.5 Effectiveness span length Factor $\left(a_{s}\right)$ (including effect of shear deformation) .360

Table H.1 Deflection and Bending Moment of Long Laminated Composite Beams....367

Table H.2 Deflection and Bending Moment of Strip Laminated Composite Plate... .373

Table H.3 Deflection of Rectangular Laminated Composite Plate with All Fixed Boundaries 380 


\section{CHAPTER 1}

\section{INTRODUCTION}

\subsection{General Remarks and Background Information}

According to the United States Department of Transportation, Federal Highway Administration (FHWA) about $29 \%$ of all the nations’ bridges ( $\cong 587,755$ bridges) are rated as substandard, i.e., either structurally deficient or functionally obsolete (AASHTO 2001). The decrease in the percentage of deficient bridges from $31.4 \%$ in 1996 to $29 \%$ in 2001 is a result of increasing federal bridge investment from $\$ 16.1$ billion over seven years to a level of \$ 20.4 billion over six years. However, this expensive investment has only reduced number of deficient bridges by $2.4 \%$. A primary reason of this deficiency is attributed to material corrosion by the natural and chemical environment and increase in the load capacity of trucks and their frequency. In addition, deficient bridges include two basic types: (1) structurally deficient bridges are restricted to lighter vehicles (load posting) because of deteriorated structural components, and (2) obsolete bridges are restricted to lower speeds, lower traffic volume and restricted vehicle dimensions (Howard 2002).

Most of these bridges were mainly constructed from conventional engineering materials such as steel, concrete, wood and aluminum. However, these conventional materials can limit the effectiveness of a structural system because of their obvious inadequacies including corrosion, low strength to weight ratio, and loss of performance due to mechanical as well as thermal fatigue. To overcome some of the above mentioned drawbacks with 
conventional materials (combination of glass fabrics, polymeric resins \& additives such as inhibitors, retardants etc) fiber reinforced polymer (FRP) composite materials applied to civil construction are being considered as structural elements in bridge decks over conventional steel-reinforced concrete bridge decks. In addition, FRP composite materials having advantages such as higher strength to weight than conventional materials, non-corrosiveness and modularization should help engineers to arrive at more efficient and cost effective structural materials and systems.

Glass fibers and fabrics mainly provide strength to composites, while their stability and shear transfer capacity within a composite comes from polymer resin. Other mechanical properties of FRP composites depend on the properties of fiber type and matrix, fiber volume fraction, orientation of fiber and fabrics and manufacturing process quality.

Unlike conventional materials as steel, shear modulus of FRP composite materials is much smaller than the elastic modulus. Most FRP structural members under a combination of loads at working state are likely to fail in shear mode before failing in other modes. To overcome this problem, shear properties and behavior of FRP structural members under several loading types have to be thoroughly understood. Finally, shear behavior and data in this study will be utilized for better understanding, appropriate analysis and design of FRP composite bridge structures. 


\subsection{Objectives}

The primary objectives of this research effort are: 1) to study the shear behavior of FRP composite decks under static loads of coupons, components and systems through testing, 2) to propose analytical methodologies to predict shear behavior, and 3) to validate analytical response of FRP composites under shear with data from laboratory evaluations. The specific objectives using FRP composite decks are:

1) To develop simplified analytical models for computing torsional rigidity and inplane shear stiffness of cellular FRP composite decks and to experimentally evaluate equivalent in-plane shear stiffness under torsion at coupon and component level. In addition, results from the proposed theoretical method at component level will be validated through experimental results and finite element analysis.

2) To evaluate in-plane shear strength and stiffness at coupon level using V-notched beam test, and also evaluate in-plane shear stiffness of glass composite specimens (systems) that have different types of connections using cantilever beam test method.

3) To compare experimental data of in-plane shear stiffness from different test methods with the results from finite element analysis.

4) To obtain out-of-plane shear strength at coupon and component level using short beam shear test method. Also, failure mode of each test specimen will be reported in those sections.

5) To evaluate out-of-plane (xz and yz) shear stiffness under bending and compare with analytical results. By using experimental results, the reduction factor of bending stiffness due to shear deformation will be evaluated for FRP composite decks under transverse loading. 
6) To experimentally evaluate punching shear strength of FRP deck members at component level and develop a predictive equation for FRP deck under punching shear strength. The theoretically predicted strength will be verified through experimental results.

7) To experimentally study and evaluate web-buckling strength at coupon and component levels and propose appropriate effective length factors based on buckling expression for FRP composite decks.

8) To study strength and failure modes of web-flange junction of open and closed FRP sections. Moreover, web-flange junction strength of closed sections will be compared with the strength from $\mathrm{V}$-notched beam test data.

9) To investigate and establish local deflection limits for FRP composite decks.

10) To study and evaluate shear leakage along joints and establish joint efficiency of FRP composite decks at component level.

\subsection{Scope}

This research describes the results of experiments conducted on FRP composite coupons and components under static load. Simplified analytical models were developed as analytical tools for stiffness prediction. Comparisons between experimental and theoretical results were used to validate the proposed theories and to predict failure modes.

Review of published literature is reported in Chapter 2. In that chapter, previous works on shear behavior of composite materials are reviewed in terms of theories and experimental evaluations. Specially, torsional shear theory and experimental data are presented to lead into development of the proposed simplifications in classical lamination theory. Secondly, a survey of published literature in terms of experimental method of out-ofplane shear behavior has been conducted to study experimental and analytical procedures. 
Additionally, a review of other shear types such as short beam, racking, punching and Vnotched beam shear are also presented in Sections 2.2.3 and 2.2.4. Finally, the most recent work in experimental shear behavior of junctions on open cross sectional beams is reviewed and presented in Section 2.2.5.

To accomplish the objectives (presented in Section 1.2), experimental programs relevant to meet the objectives of Section 1.2 are emphasized in Chapter 3. In addition, descriptions of test specimens and experimental procedures through this research are presented in Sections 3.3 through 3.12. Simplified classical lamination theory (SCLT) for evaluation of torsional stiffness is developed and proposed in Section 4.3. Applications of using SCLT for FRP composite structural members are presented in Section 4.4. Laminated composite plates, single- and multi-cell FRP thin-walled structural members are specially highlighted on throughout chapter 4. Results obtained from SCLT are validated by comparing them with experimental and finite element results. In Section 4.7, joint efficiency under torsional loading is established from experimental data and then through theoretically evaluations.

In-plane shear strength obtained from V-notched beam test is presented in Chapter 5. Also, equivalent in-plane shear moduli data from experiments are compared with the results obtained by using torsion test data in Chapter 4. Cantilever beam test procedure is proposed to study in-plane shear behavior of FRP composite decks. In this study, there are three types of connections for FRP composite decks: rivet, rivet-glue and glue. In-plane shear modulus of different connection specimens are experimentally evaluated and validated through the results of finite element method and torsion testing. In addition, joint efficiency is calculated and presented in Section 5.3.2.3 and racking shear behavior of FRP composite deck is studied and presented in Section 5.3.3. 
In Chapter 6, evaluation of out-of-plane shear strength using short beam shear test is presented at both coupon and component levels and in-plane shear strength obtained from Vnotched beam test is used to compare with the experimental data. Evaluation of out-of-plane shear at component level is considered to be the main task in Section 6.3.2. Back calculation procedures based on deflections and/or strains are presented for evaluation of out-of-plane shear stiffness. Evaluation of reduction factors of bending stiffness due to shear deformation is also presented in Section 6.4. Moreover, finite element results are compared with the experimental data. Joint efficiency under transverse loading is also determined in Chapter 6.

Behavior of FRP composite deck under punching shear was mainly considered in Chapter 7. An empirical prediction of puching shear strength for FRP composite deck is proposed and validated by using experimental results in Section 7.4. Shear strength and behavior of a web-flange junction for both open and closed sectional specimens are studied in Chapter 8. Shear strength of the junction is experimentally evaluated and compared with the shear strength from other experimental data. Web buckling of FRP composite deck is studied in Appendix F. Effective length factor $(\mathrm{K})$ is determined and the relation of buckling stressslenderness ratio is also proposed in Appendix F. In Appendix G, limitation of local deflection of FRP deck is studied and suggested using experimental data corresponding to various types of FRP bridge decks. Finally, conclusions of this work and recommendations for future research on shear behavior of FRP composite deck is presented in Chapter 9. 


\section{CHAPTER 2}

\section{LITERATURE REVIEW}

\subsection{Introduction}

The limited use of FRP composite materials in bridge construction presents a limited understanding of their behavior as bridge decks. In addition, the standard testing approach for FRP composite bridge decks has still not been fully established. Also, the previous research on the behavior of FRP composites under shear loading has been focused mostly on laminated composite plates. In addition, available studies on fiber reinforced polymer (FRP) composite decks are still not adequate to gain full understanding of mechanical behavior, leading to high structural efficiency. However, recent research information on FRP composite decks has been provided by the Constructed Facilities Center at West Virginia University. A brief discussion of partial previous research work is given in the following sections. The following reviews provide significant information about:

- Structural theory and performance of composite member under shear loading

- Development of analytical models for prediction of composite material properties

- Behavior and performance of FRP composite bridge deck

- Shear behavior of composites under several test conditions 


\subsection{Review of Previous Research}

Previous research focusing on theoretical and experimental work is presented below. This research includes torsion of FRP composite thin-walled members, experimental data of FRP beams and decks, V-notched beam test data, out-of-plane shear test data, and web-flange shear strength.

\subsubsection{Review of Structural Theory}

Tsai, Daniel and Yaniv (1990) studied the torsional response of rectangular composite laminates based on the Mindlin-Reissner theory. A general closed form solution of rectangular FRP composite plates under torsional load was given in terms of the geometric parameters and shear properties of laminates. In addition, the resultant shear force was accounted for and related to the transverse shear strains of the middle surface. Unidirectional graphite/epoxy composite coupons in both 0 and 90 degree were tested by (Tsai, et al. 1990) under torsional load to determine shear modulus from the experimental data and compared with the closed form solution. The results from their experiments show that assumption of transverse isotropy is justified. The out-of-plane shear modulus is approximately half of the in-plane modulus.

Savoia and Tullini (1993) studied the elastic response of inhomogeneous orthotropic beams with general cross-section under uniform torsion. A general solution was given in terms of warping and the Prandtl stress function. The following expression for the unit twist is obtained:

$$
\begin{aligned}
& \Theta=\frac{M_{t}}{G_{r} J_{t}} \\
& G_{r} J_{t}=2 \sum_{s=1}^{S} \iint_{A s} \Psi_{s} d A+2 \sum_{k=1}^{K} c^{(k)} A_{c}^{(k)}
\end{aligned}
$$


Where, $M_{t}$ is twisting moments, $J_{t}$ is a torsional constant, $G_{r}$ is a reference shear modulus, $\Theta$ is the angle of relative twist, $c^{(k)}$ are constant values for each hole, irrespective of the number of layers and $\Psi$ is defined to be a potential function (Prandtl stress function). The exact solution for rectangular solid orthotropic beam constituted by arbitrary number of layers is given in series form.

Camomile and Swanson (2002) reviewed the theory for torsion of laminated crosssection and the effects of warping restraint were further developed for thin sections. The governing equation for the $\mathrm{k}^{\text {th }}$ layer of orthotropic laminates is given as:

$\frac{1}{G_{x z k}} \frac{\partial^{2} \phi_{k}}{\partial y^{2}}+\frac{1}{G_{y z k}} \frac{\partial^{2} \phi_{k}}{\partial x^{2}}=-2 \theta$

Where, $G_{x z k}$ and $G_{y z k}$ are two shear moduli of the $\mathrm{k}^{\text {th }}$ layer and $\theta$ is an angle of twist per unit length. In addition, continuity relations are obtained from two conditions which are: 1) the displacement must be continuous across the layer interfaces, and 2) the warping function must also be continuous and thus the derivative with respect to x must also be continuous.

$$
\begin{aligned}
& \left.\frac{1}{G_{x z k}} \frac{\partial \phi_{k}}{\partial y}\right|_{y=h_{k}-1}=\left.\frac{1}{G_{x z k-1}} \frac{\partial \phi_{k-1}}{\partial y}\right|_{y=h_{k}-1} \\
& \left.\frac{\partial \phi_{k}}{\partial x}\right|_{y=h_{k}-1}=\left.\frac{\partial \phi_{k-1}}{\partial x}\right|_{y=h_{k}-1}
\end{aligned}
$$

To arrive at the general solution, the solution of Equation (2.3) is taken in the series form as:

$$
\phi_{k}=\sum_{m} F_{k m} \operatorname{Cos} \frac{m \pi x}{2 a}
$$

Thus, the total solution of orthotropic laminates is given:

$$
\phi_{k}=\theta \frac{32 a^{2}}{\pi^{3}} G_{y z k} \sum_{m=1,3 . .}^{\infty}(-1)^{\frac{m-1}{2}} \frac{1}{m^{3}}\left[1-A_{k m} \operatorname{Cosh} \beta_{k m} y-\beta_{k m} \operatorname{Sinh} \beta_{k m} y\right] \operatorname{Cos} \frac{m \pi x}{2 a}
$$

where, $a$ is an half of cross sectional width. 
In the special case as symmetric lay-up respected to the center line, the term $B_{k m}$ vanishes and results of the term $A_{k m}$ are given by the recursion relation.

$$
\begin{aligned}
& A_{1 m}=\frac{1}{\operatorname{Cosh} \beta_{1 m} b} \\
& A_{1 m}=\frac{1}{\operatorname{Cosh} \beta_{k m} h_{k-1}}\left(1-\frac{G_{y z k}}{G_{y z k-1}}\left(1-A_{k-1 m} \operatorname{Cosh} \beta_{k m} h_{k-1}\right)\right)
\end{aligned}
$$

Thin rectangular rods made of laminations of IM6/3501-6 were tested to compare with theory. The experimental results correlated well with the theoretical stiffness and strain. In addition, failure is generally in agreement with predictions based on interlaminar shear stress.

Massa and Barbero (1998) presented a simple methodology for the analysis of a single cell thin-walled composite beam subjected to bending, shear and axial forces. The cross-section of a structural member is modeled as a collection of flat, arc-circular and concentrated area segments. Classical lamination theory was used to formulate constitutive equations for each laminated segment. Mechanical properties of laminates such as area, first moment of area, center of gravity, etc., were the product between the material and the geometrical properties. It was shown that it is possible to follow closely the theory of beams presented in classical strength of materials text books by transforming the mechanical properties of laminates into equivalent geometrical properties.

Axial stiffness:

$$
E A=\sum_{i=1}^{n} A_{i} b_{i}
$$

Bending stiffness:

$$
\begin{aligned}
& E I_{s}=D_{i} b_{i} \\
& E I_{r}=A_{i} \frac{b_{i}^{3}}{12}
\end{aligned}
$$


Torsional stiffness (open section):

$G J=4 \sum_{i=1}^{n} H_{i} b_{i}$

Torsional stiffness (single cell section):

$G J=\frac{(2 \Gamma)^{2}}{\sum_{i=1}^{n} \frac{b_{i}}{F_{i}}}$

where, $n$ is the number of segments describing the cross section, $A_{i}$ is the axial stiffness per unit length of the segment, $D_{i}$ is the bending stiffness under bending moment, $H_{i}$ is the twisting stiffness under twisting moment, $F_{i}$ is the in-plane shear stiffness under shear, $\Gamma$ is the area enclosed by the contour, $b \mathrm{i}$ is the segment width.

Kollar and Pluzsik (2002) presented the beam theory for open and closed cross sections of composite beams where the lay-ups of each wall segment of a cross-section are arbitrary. The effect of shear deformation and restrained warping are neglected. In addition, local bending stiffness is also neglected in the case of either symmetrical or orthotropic layups. The wall of the beams was made from single or several layers of composite materials. The cross section of the beam can be a symmetrical or unsymmetrical lay-up. In addition, the beam is subjected to a combination of loading as axial force, bending moment and torque. The stiffness of thin-walled open and closed section prismatic beams is given in form of $4 \times 4$ matrix form.

Open section beam:

$\sum_{k=1}^{K}\left[R_{k}\right]^{T}\left[\omega_{k}\right]^{-1}\left[R_{k}\right]$

Closed section beam:

$\sum_{k=1}^{K}\left[R_{k}\right]^{T}\left[\omega_{k}\right]^{-1}\left[R_{k}\right]+[L]^{T}[F]^{-1}[L]$ 
where:

$$
\begin{aligned}
& {\left[R_{k}\right]=\left[\begin{array}{lll}
\alpha_{11} & \beta_{11} & \beta_{16} \\
\beta_{11} & \delta_{11} & \delta_{16} \\
\beta_{16} & \delta_{16} & \delta_{66}
\end{array}\right]_{k}^{-1}} \\
& {\left[\omega_{k}\right]=\frac{1}{b_{k}}\left[\begin{array}{cccc}
\alpha_{11} & \beta_{11} & 0 & -\frac{\beta_{16}}{2} \\
\beta_{11} & \delta_{11} & 0 & -\frac{\delta_{16}}{2} \\
0 & 0 & \frac{12}{\left(A_{11}\right)_{k} b_{k}^{2}} & 0 \\
-\frac{\beta_{16}}{2} & -\frac{\delta_{16}}{2} & 0 & \frac{\delta_{66}}{4}
\end{array}\right]} \\
& {[L]=\left[\begin{array}{cccc}
0 & 0 & 0 & 2 A \\
0 & 0 & 0 & 0
\end{array}\right]-\sum_{k=1}^{K}\left[\begin{array}{cccc}
\alpha_{16} & \beta_{61} & 0 & -\frac{\beta_{66}}{2} \\
\beta_{12} & \delta_{12} & 0 & -\frac{\delta_{26}}{2}
\end{array}\right]_{k}\left[\omega_{k}\right]^{-1}\left[R_{k}\right]} \\
& {[F]=\sum_{k=1}^{K}\left[b_{k}\left[\begin{array}{ll}
\alpha_{66} & \beta_{62} \\
\beta_{62} & \delta_{22}
\end{array}\right]_{k}-\left[\begin{array}{llll}
\alpha_{16} & \beta_{61} & 0 & -\frac{\beta_{66}}{2} \\
\beta_{12} & \delta_{12} & 0 & -\frac{\delta_{26}}{2}
\end{array}\right]_{k}\left[\omega_{k}\right]^{-1}\left[\begin{array}{cc}
\alpha_{16} & \beta_{12} \\
\beta_{61} & \delta_{12} \\
0 & 0 \\
-\frac{\beta_{66}}{2} & -\frac{\delta_{26}}{2}
\end{array}\right]_{k}\right]} \\
& {\left[\begin{array}{ll}
{[\alpha]} & {[\beta]} \\
{[\beta]} & {[\delta]}
\end{array}\right]=\left[\begin{array}{ll}
{[A]} & {[B]} \\
{[B]} & {[D]}
\end{array}\right]^{-1}}
\end{aligned}
$$

where, $[\alpha],[\beta]$, and $[\delta]$ are the inverses of laminate stiffnesses (A-B-D matrix) in each wall segment. $[\omega]$ is the strain-force relationship in the wall segment coordinate. $\left[R_{k}\right]$ is the coordinate relationship between the wall segment and the beam system. $b_{k}$ is the width of the wall segment.

Carbon fiber reinforced composite I-beam and box-beam with unsymmetrical lay-ups $\left[0_{6} / 45_{6}\right]$ were used to verify derived expressions for open and closed section by comparing results from theoretical and finite element methods. For anisotropic beams, neglect of local stiffness, tension-twist and bending-twist coupling effects might lead to unacceptable errors. 


\subsubsection{Review of Experimental FRP Beam and Deck Results}

Nagaraj (1994) studied the behavior of pultruded GFRP beams under static and cyclic loads. Flexural and shear rigidity were found and compared with classical lamination (Jones, 1975) and the proposed simplified classical lamination theory. The dominance of shear influence on deflection was quantified experimentally under static loads and computed theoretically. The behavior of shear lag and warping based on experimental observations indicated that the presence of other factors such as compositeness between web and flange, and asymmetric fiber distribution could have affected the stress distribution across the flange width. In addition, approximate classical lamination theory for flexural stiffness evaluation was presented in this study. Experimental results compared well and corresponded to the proposed simplified classical lamination theory after properly accounting for shear, fiber asymmetry and interfacial slip.

Sotiropoulos (1995) studied behavior of multi-cellular decks in coupon, component, system level and connections under static loading as bending and torsion tests. The multicellular deck was made of E-glass/polyester resin with effective fiber volume fraction of about $22.1 \%$ for deck panels and $29.6 \%$ for wide-flange section. In addition, two connection types including deck-to-stringer and deck-to-deck panel were studied in this research. For torsion testing, single and double cell sections cut from multi-cellular panels and two single cell sections connected with wide flange beams were tested to evaluate their torsional strength and stiffness. After testing, it was found that torsional strength and stiffness from multi-cell were higher than those of the single cell by about 2.5 times. Results of single cell, two cell and two cell with joint were 69,735 N.m², 177,579 N.m² and 191,671 N.m², respectively. A theoretical method based on Bredt's expression was used in his study. For bending test, three and four point bending test data were used to obtain their bending and shear stiffness. Unidirectional and bidirectional wide-flange beams were tested in the 
longitudinal cell direction and unidirectional multi-cellular sections were tested both parallel and perpendicular to the web direction. All specimens were tested within the elastic limits. Zureick’s approach (Zureick, 1994) was used to evaluate experimental values of bending and shear stiffness of structural shapes. It was found that three and four point bending tests are sensitive to error in establishing shear stiffness. Therefore, the small errors in the evaluation of bending stiffness (EI) might lead to significant errors in shear stiffness depending on the specimen span length. In addition, reduction in shear stiffness under bending when compared with theoretical method might be attributed to the following factors: interlaminar shear-lag in the web, loss of composite action between web and flange, second order torsion and warping, variability of matrix properties and accuracy of theoretical and experimental models.

Howard (2002) studied the behavior of FRP bridge deck component under torsional loads with two objectives. The first objective was to determine the out-of-plane torsional stiffness $\left(G_{y z}\right)$ and the second objective was to study the effects of different torsional loadings on the bending stiffness. The multi-cellular light weight FRP bridge decks of 8 inch height with fiber volume fraction of approximately 54\% were made of E-glass fiber with polyester resin. From torsion tests, torsional stiffness and strength were found to be $6.84 \times 10^{8} \mathrm{lb}^{\mathrm{in}}{ }^{2}$ and $0.53 \times 10^{6} \mathrm{psi}$, respectively. Influences of warping and secondary torsion were neglected in these results. However, the difference between the approximate classical lamination theory (ACLT) and the experimental method was approximately $40 \%$ since a large error might have been contributed to the effects of warping and secondary torsion. The results of torsion and bending tests showed the stiffness remained in the same order of magnitude as the results from the pure bending test data $\left(\mathrm{EI} \cong 0.9 \times 10^{9} \mathrm{lb}-\mathrm{in}^{2}\right)$. The magnitude of the applied torque had very little, if any, effect on the bending stiffness of the component. In addition, four major types of shear failures of FRP deck were observed in this study including: longitudinal/horizontal shear failure causing web/flange separation (XY plane), punching 
shear failure (XZ and/or YZ plane), racking shear (Y direction) causing bending or transverse web shear failure, and torsional shear causing web failure (YZ plane).

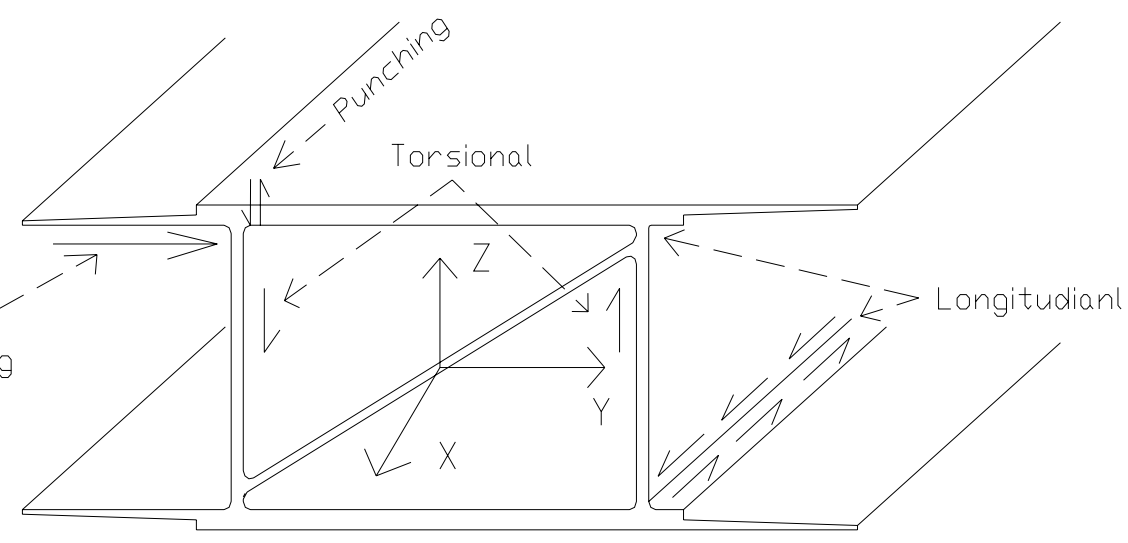

Figure 2.1 Description and Orientation of Possible Shear Failure Modes (Howard, 2002)

\subsubsection{Review of In-Plane Shear Behavior}

Sonti and Barbero (1995) focused on the identification of a reliable test method to determine in-plane shear strength and modulus. In this study, two test methods, Iosipescu shear and torsion test method were used to evaluate shear properties. From experiments, it was found that shear stiffness from the Iosipescu shear tests showed a large scatter (0.3 $0.7 \times 10^{6} \mathrm{psi}$ ) compared with the results from the torsion test. This scatter can be attributed to obtaining test samples from various locations of the FRP composite beam, including a very small cross-sectional area for evaluation of the shear property. In addition, the results of the torsion test were approximately the average of the Iosipescu shear test data. Therefore, the torsion test method is recommended for the evaluation of in-plane shear modulus. 


\subsubsection{Review of Out-of-Plane Shear Behavior}

Zureick, Kahn and Bandy (1994) presented full scale testing, conducted to study the shear behavior, and recommended design criteria for deep I-shape reinforced plastic (RP) pultruded beams subjected to transverse loads in the plane of the web. In their study, all beam specimens with dimensions $(24 \times 3 / 8$ inch) and (7 1/2×3/4 inch) for web and flange, respectively, were made from a vinylester matrix reinforced with E-glass. To experimentally evaluate the full-section elastic and shear moduli, three point bending tests were conducted and deflection response of test beams at mid span and the third-point were measured. By using an approximate engineering analysis, deflection equations at those two positions were presented and simultaneously solved by substituting deflection data into those deflection equations. Elastic and out-of-plane shear moduli based on deflections were reported as 2841 ksi and $510 \mathrm{ksi}$, respectively. In addition, finite element analysis was used to confirm the experimental results. GTSTRUDL structural analysis and design software was used in that study. Test specimens of composite beams were modeled by using 960 SBHQ (stretching Bending Hybrid Quadrilateral) plate elements. Moduli used for modeling were provided by the manufacturer (MMFG). Using the manufacturer's moduli, the mid-span deflection of finite element results was found to be higher than that of experimental results by about $20 \%$. However, percent difference of deflection between experimental and finite element results was significantly reduced to $15 \%$, using experimental moduli in the finite element modeling. Finally, their recommendations were: 1) approximate engineering equations used for deflections may be used with elastic and out-of-plane shear moduli to predict deflections and stiffness of composite beams, and 2) approximate beam theory for bending and twisting of open section composite beams was also used safely to calculate deflection and strain of composite beams. 
Schniepp (2002) studied behavior of hybrid Double-Web composite beams (DWB). Those composite beams were tested under static loads to failure to determine beam properties such as bending modulus, shear stiffness, failure modes and ultimate capacity. The hybrid beam was made of both glass and carbon fibers in a vinyl ester resin matrix and had a fiber volume fraction of approximately 45\%. The primary objective of their research was to evaluate strength and stiffness of hybrid beams for the development of a structural design guide of 36 inch DWB. Nineteen DWB composite beams were tested to determine the above mentioned beam properties. Testing for the DWB composite beams began at 58' span, progressed to the 39' girders, and then to the 18' beams. The bending and shear modulus (kGA) of DWB composite beams were found to be $6.5 \mathrm{Msi}$ and $53 \mathrm{Msi}-\mathrm{in}^{2}$. The delamiantion of carbon-glass in the top flange that began in the vicinity of the loading patches and progressed outward in both directions along the primary beam axis. This was considered to be a failure of DWB composite beams. In addition, a model study was also conducted to understand the shear effects in DWB composite beams to the DWB and in other FRP structures. The deflection due to shear was accounted to be about $16 \%$ of the total deflection. A great deal of variation was found in the experimentally determined value of shear stiffness for DWB composite beams. Inaccurate and high-noise deflection data was believed to be one of the primary sources of the variation as it was found that kGA is extremely sensitive to measured deflections. Moreover, the study of shear effects in FRP beams was conducted on small wide flange (WF) beams of 76x76x6 mm. Four point bending tests were conducted on twenty-seven WF beams to determine bending modulus and shear stiffness. The bending and shear stiffness were found to be 4.62 Msi and 350 ksi, respectively (Schniepp, 2002). 


\subsubsection{Review of Web-Flange Junctions}

Turvey and Zhang (2004) studied shear behavior of web-flange junctions of pultruded GRP WF profiles. In their research, test specimens were transversely cut into different lengths to determine the longitudinal shear strength of the web-flange junctions of their test specimens. To induce shear failure of web-flange junctions, test specimens were modified by making pairs of partly cut through-thickness notches. From the test results, load versus deflection curves of notched test specimens were obviously presented in three stages as well as that of unnotched test specimens. In stage 1, the linear behavior of load-deflection curve was presented up to a maximum load about 2 kip. The applied load gradually dropped and displacement significantly increased during stage 2. After that, a gradual decrease in load with an increase in displacement was followed in stage 3. In addition, general failure mode was in the form of a crack adjacent to the roving rich core at the center of the web-flange junction. Comparison of shear strength between notched and unnotched test specimens was considered. The results showed that the effect of notches reduced the shear strength per unit length by about 50\%. Moreover, shear strength of notched test specimens compared well with that of V-notched beam test. It was shown that the strengths of the web-flange junctions of notched specimens were only about one-seventh of shear strength of web or flange portions that were conducted under V-notched beam test. 


\section{CHAPTER 3}

\section{EXPERIMENTAL PROGRAM AND TEST SET-UPS}

\subsection{Introduction}

The literature research from previous chapter revealed an inadequate understanding of shear behavior of FRP composite deck panels. Therefore, the purpose of this research is to study shear behavior of FRP bridge decks at coupon and component levels. Test specimens, experimental set ups, and testing procedures are described herein as a part of the overall experimental program for the proposed research. These test methods include: 1) torsional response, 2) V-notched beam shear strength, 3) in-plane shear using cantilever beam, 4) racking shear response, 5) short beam shear strength, 6) out-of-plane shear response using three and four point bending, 7) punching shear strength, 8) web-buckling response, 9) shear strength of web-flange junction and 10) local deflection as a function of patch load.

\subsection{Experimental Programs}

In this study, experimental testing and analysis are considered at coupon and component level. In addition, experimental programs are developed as a function of structural geometry, materials, fiber architectures, strength and stiffness of material, specimen size, etc.

Shear behavior of FRP deck components is the focus of this study. Shear behavior is studied under torsional shear (Section 3.3), in-plane shear (Sections 3.4 and 3.5), racking shear (Section 3.6), out-of-plane shear (Sections 3.7 and 3.8), punching shear (Section 3.9), 
and shear of web-flange junction (Section 3.11). In addition, web buckling (Section 3.10) including local deflection (Section 3.12) of different FRP deck types has been studied and reported.

To study the in-plane shear behavior, torsion tests are conducted at coupon and component testing level. Experimental results form testing are evaluated for in-plane shear modulus and joint efficiency. In-plane shear strength of coupon specimens under V-notched beam test is evaluated in Chapter 5. In addition, in-plane shear behavior of FRP decks is also studied using cantilever beam test set-up. The results of in-plane shear modulus from torsion, V-notched and cantilever beam test are compared to study effect of test methods. In-plane shear behavior simulating braking force is conducted through a racking shear test whose details are given in Section 5.3.3 leading to evaluation of in-plane shear modulus.

For out-of-plane shear behavior, three and four point bending test data are used to decouple shear effects from bending. Out-of-plane shear modulus is evaluated in transverse and longitudinal direction. In addition, joint efficiency is found under these loading conditions. Out-of-plane shear strength at coupon and component testing level is experimentally evaluated using short beam shear tests as described in Section 6.3.1.

Punching shear behavior of FRP composite decks is studied and details are given in Chapter 7. Specimens at component level are tested under patch load to induce punching shear failure. Web buckling strength of coupon and component levels are evaluated from experimental data. Web specimens are tested under compression to obtain web buckling strength. For web-flange junction, shear strength of web-flange junction is studied on open and closed sections. Test specimens are conducted under concentrated load at specific position. Additional, information is given in Section 3.11.

Local deflection of different types of FRP decks are obtained from experimental procedures. Experiments are conducted under concentrated and uniform load. Boundary conditions are varied to study their influence on coupon and component response. The 
objective of local deflection response studies is to establish their limit states for FRP deck components.

Since there are various specimen types and dimensions, abbreviated names of specimens are used to conveniently identify them and avoid confusion with their full names for each experiment. Summary of abbreviated names are given in Section 3.13.

\subsection{Torsion Test}

To study in-plane shear (xy) behavior, tests at coupon and component testing levels are conducted under torsion. Torsional stiffness (GJ) and equivalent in-plane shear modulus $\left(G_{x y}\right)$ of structural members are experimentally evaluated. In addition, various fiber architectures, fiber properties of test specimens are varied to study the torsional stiffness behavior.

\subsubsection{Coupon Testing}

Coupon specimens are prepared from many types of FRP composite structural members such as FRP plates, circular solid bars, circular tubes and sandwich FRP-wood plates. Various coupon types of longitudinal and transverse specimens obtained from flange and diagonal portion are tested. Test data corresponding to each specimen type is discussed below.

\subsubsection{Coupon with Unidirectional Fiber}

Flat plates are provided by Bedford Reinforced Plastics, Inc. (BRP). Fiber volume fraction of test specimens is obtained to be about $44 \%$ through burn-out tests. Coupon specimens are cut in both longitudinal and transverse directions. To study the effect of structural shapes on torsional stiffness, coupon specimens are prepared by having an aspect ratio (width/thickness) varying from 4 to 10. In addition, a rosette strain gage is mounted on 
top surface at mid span of each coupon specimens as shown in Figure 3.2. Dimensions and properties of unidirectional coupon specimens are summarized and given in Table 3.1.
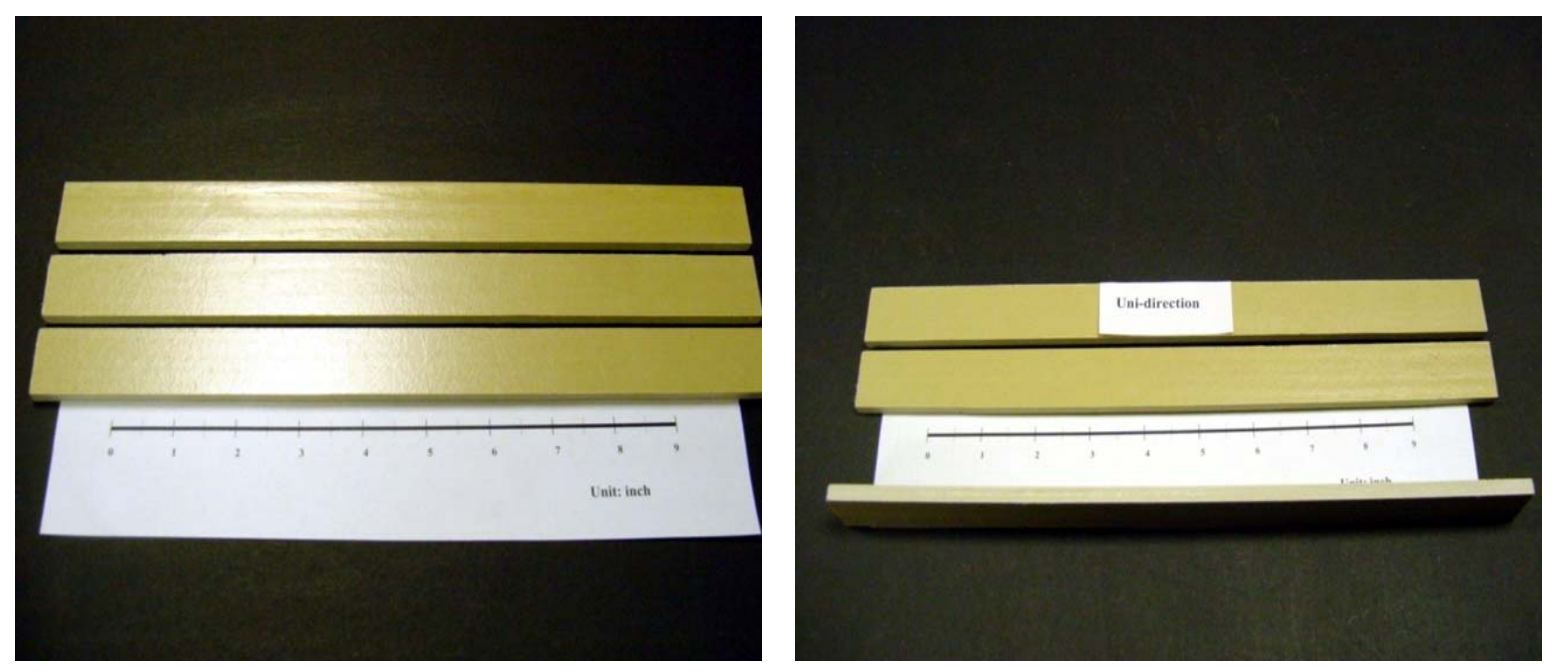

Figure 3.1 Coupon with unidirectional fibers

Table 3.1 Test specimen size of one dimensional fiber coupon

\begin{tabular}{|c|c|c|c|c|c|c|c|}
\hline Specimen & Direction & $\begin{array}{l}V_{f} \\
(\%)\end{array}$ & $(b / t)$ & $\begin{array}{c}\text { No. of } \\
\text { specimens }\end{array}$ & $\begin{array}{l}\text { Width } \\
\text { (in) }\end{array}$ & $\begin{array}{l}\text { Thickness } \\
\text { (in) }\end{array}$ & $\begin{array}{l}\text { Length } \\
\text { (in) }\end{array}$ \\
\hline $\mathrm{C}_{1} \mathrm{D}_{4 \mathrm{~L}}$ & \multirow{4}{*}{$\begin{array}{l}\text { Longitudinal } \\
\qquad\left(0^{\circ}\right)\end{array}$} & 44 & 4 & 4 & 1 & 0.25 & 12 \\
\hline $\mathrm{C}_{1} \mathrm{D}_{6 \mathrm{~L}}$ & & 44 & 6 & 2 & 1.5 & 0.25 & 12 \\
\hline $\mathrm{C}_{1} \mathrm{D}_{8 \mathrm{~L}}$ & & 44 & 8 & 2 & 2 & 0.25 & 12 \\
\hline $\mathrm{C}_{1} \mathrm{D}_{10 \mathrm{~L}}$ & & 44 & 10 & 2 & 2.5 & 0.25 & 12 \\
\hline $\mathrm{C}_{1} \mathrm{D}_{4 \mathrm{~T}}$ & $\begin{array}{c}\text { Transverse } \\
\left(90^{\circ}\right)\end{array}$ & 44 & 4 & 2 & 1 & 0.25 & 12 \\
\hline
\end{tabular}

Note: $V_{f}$ is fiber volume fraction and $(b / t)$ is aspect ratio of (width/thickness).

Figure 3.2 Strain gage position of coupon specimens with 1 inch width 


\subsubsection{Coupon with Multi-Directional Fabrics}

In this study, coupons with multi-directional fabrics are prepared from FRP decks. Structural coupons such as flanges and diagonals are cut from deck modules in both longitudinal and transverse directions. It should be noted that longitudinal and transverse directions are referred to be strong and weak axis directions of test specimens. Two different types of FRP decks (ProDeck4 and 8) are used to prepare test specimens. ProDeck4 flange coupons of longitudinal direction (strong axis) are also prepared by having (width/thickness) ratio varying between 2.3 and 10 , while 2.3 aspect ratio is used to prepare flange coupon specimens in transverse direction (weak axis) . However, ProDeck8 coupon specimens are prepared from both flange and diagonal by having (width/thickness) ratio as about 2.0 and 4.0, respectively. For XM 3215 coupon specimens, only coupon specimens of longitudinal direction are studied and two test specimens with aspect ratio 2 and 10 are used to differentiate between beam versus plate behavior. The longitudinal dimension of all coupon specimens is constantly kept at 12 inches. A rosette strain gage is mounted on the specimen surface at mid span. In addition, fiber architectures, fiber volume fraction, primary mechanical properties of fiber and resin of ProDeck4 and 8 are provided by BRP Inc and are given in Appendix C. Summary of specimen sizes are presented in Table 3.2 and examples of two dimensional coupon specimens are illustrated in Figure 3.3.
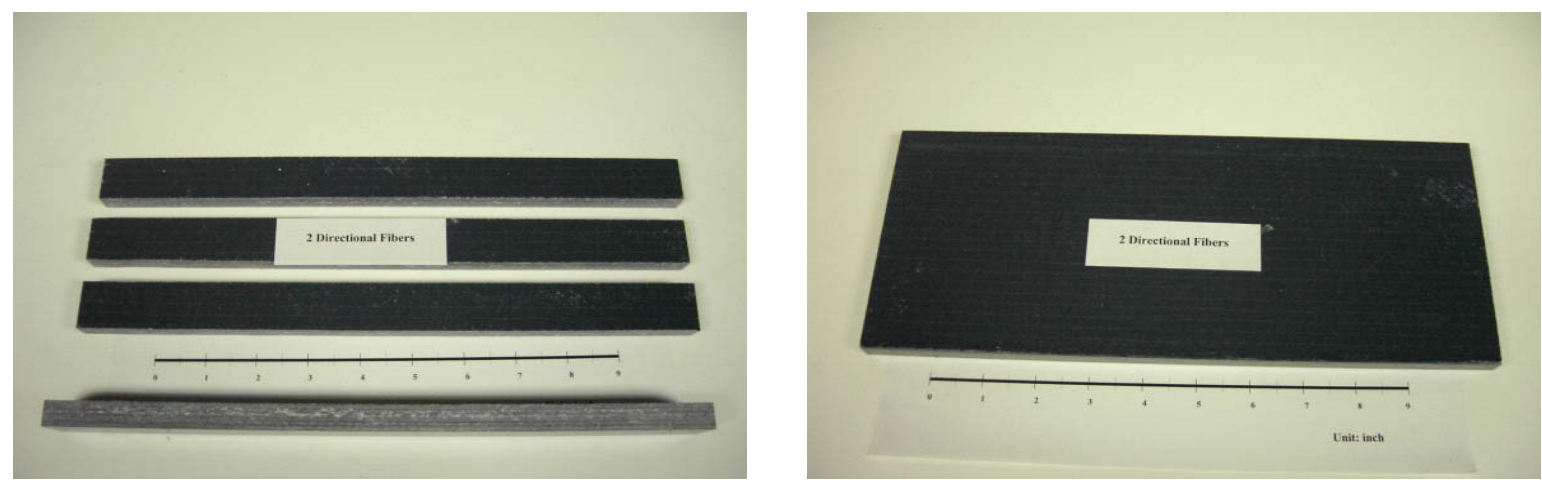

Figure 3.3 Fabric (2D) coupon specimens 
Table 3.2 Test specimen size of fabric (2D) coupon

\begin{tabular}{|c|c|c|c|c|c|c|c|c|}
\hline Specimen & Type & Portion & Direction & $(b / t)$ & $\begin{array}{c}\text { No. of } \\
\text { specimens }\end{array}$ & $\begin{array}{c}\text { Width } \\
\text { (in) }\end{array}$ & $\begin{array}{l}\text { Thickness } \\
\text { (in) }\end{array}$ & $\begin{array}{l}\text { Length } \\
\text { (in) }\end{array}$ \\
\hline $\mathrm{CXM}_{2 \mathrm{~L}}$ & \multirow[t]{2}{*}{ XM 3215} & \multirow[t]{2}{*}{ plate } & $\mathrm{L}$ & 2.0 & 3 & 1 & 0.5 & 12 \\
\hline $\mathrm{CXM}_{10 \mathrm{~L}}$ & & & $\mathrm{~L}$ & 10 & 3 & 5 & 0.5 & 12 \\
\hline $\mathrm{CP}_{2.3 \mathrm{~L}}$ & \multirow{6}{*}{ ProDeck4 } & \multirow{6}{*}{ flange } & $\mathrm{L}$ & 2.3 & 2 & 1 & 0.435 & 12 \\
\hline $\mathrm{CP}_{4 \mathrm{~L}}$ & & & $\mathrm{~L}$ & 4.0 & 2 & 1.688 & 0.435 & 12 \\
\hline $\mathrm{CP} 4_{6 \mathrm{~L}}$ & & & $\mathrm{~L}$ & 6.0 & 2 & 2.489 & 0.435 & 12 \\
\hline $\mathrm{CP}_{8 \mathrm{~L}}$ & & & $\mathrm{~L}$ & 8.0 & 2 & 3.476 & 0.435 & 12 \\
\hline $\mathrm{CP} 4_{10 \mathrm{~L}}$ & & & $\mathrm{~L}$ & 10.0 & 1 & 4.305 & 0.435 & 12 \\
\hline $\mathrm{CP} 4_{2.3 \mathrm{~T}}$ & & & $\mathrm{~T}$ & 2.3 & 4 & 1 & 0.435 & 12 \\
\hline $\mathrm{CP8}_{2.2 \mathrm{~L}}$ & \multirow[t]{2}{*}{ ProDeck8 } & \multirow[t]{2}{*}{ flange } & $\mathrm{L}$ & 2.2 & 4 & 1 & 0.45 & 12 \\
\hline $\mathrm{CP8}_{2 \mathrm{~T}}$ & & & $\mathrm{~T}$ & 2.0 & 2 & 1 & 0.5 & 12 \\
\hline $\mathrm{CP}_{4 \mathrm{~L}}$ & \multirow[t]{2}{*}{ ProDeck8 } & \multirow[t]{2}{*}{ diagonal } & $\mathrm{L}$ & 4.0 & 4 & 1 & 0.25 & 12 \\
\hline $\mathrm{CP}_{4 \mathrm{~T}}$ & & & $\mathrm{~T}$ & 4.0 & 1 & 1 & 0.25 & 12 \\
\hline
\end{tabular}

Note: $\mathrm{L}$ and $\mathrm{T}$ are longitudinal and transverse directions, respectively. $(b / t)$ is aspect ratio of (width/thickness).

\subsubsection{Coupon with Three Dimensional Fiber (Stitching) Orientation}

In this study, three-dimensionally reinforced specimens developed by the Constructed Facility Center at West Virginia University are presented in Figure 3.4. Glass fabrics are reinforced by stitching fibers in orthogonal direction to plane of coupon specimens. After that, compression molding process is used to form the three dimensionally reinforced plates. Coupon specimens $\left(\mathrm{C} 3 \mathrm{D}_{\mathrm{L}}\right)$ with dimensions $\left(1\right.$ ” $\times 0.145$ ” $\left.\times 11^{\prime}\right)$ inch are prepared. A rosette strain gage is attached on the top surface of each specimen. 


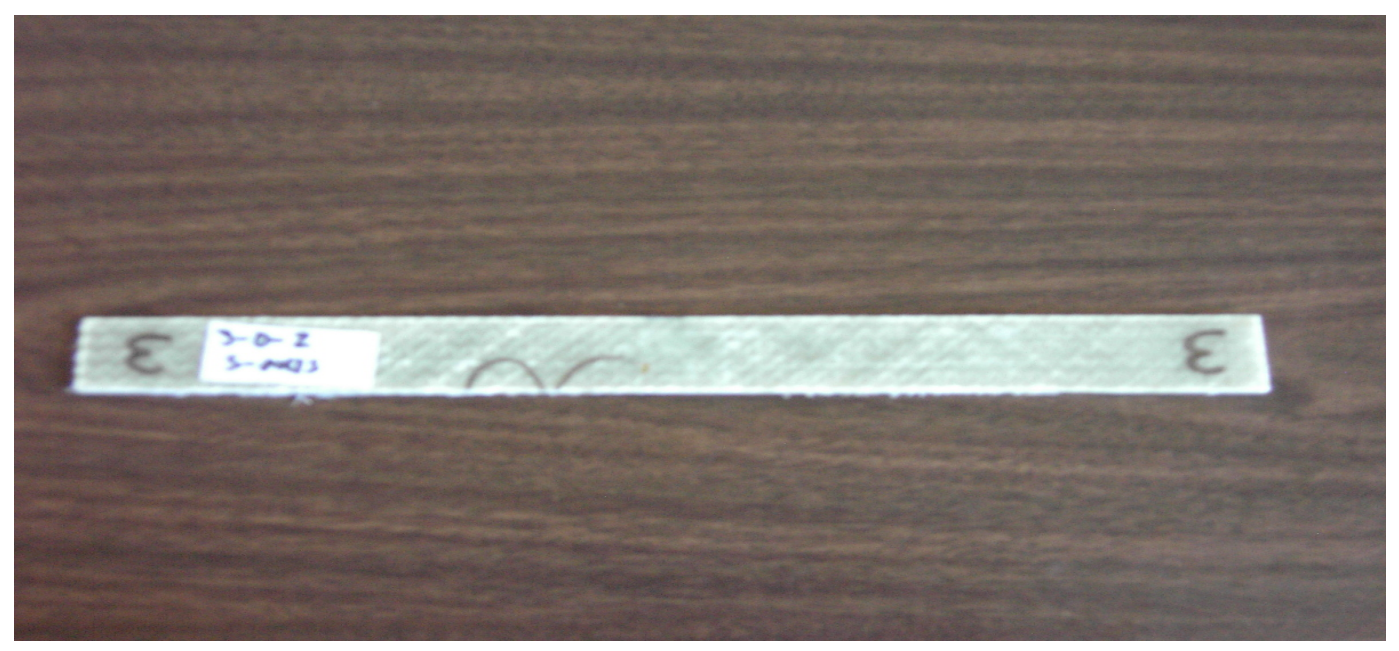

Figure 3.4 Stitching (3D) coupon specimens

\subsubsection{Sandwich FRP-Wood Coupon}

Sandwich FRP-wood coupon specimens are one of the laminated composite forms comprising of a combination of unidirectional and bidirectional fiber laminates on both outer layers with wood as the core material. Specimens are prepared by cutting them in the longitudinal direction as well as in orthogonal direction of the grain of wood core. The test specimens included two aspect ratios (width/thickness), i.e. $1\left(\mathrm{CSF}_{\mathrm{b}}\right)$ and $7\left(\mathrm{CSF}_{\mathrm{p}}\right)$. Thickness of FRP outer plates and balsa wood core are measured to be about 0.125 and 0.75 inch. FRP outer plates included three layers of glass as: 1) 0.015 inch of CFM, 2) 0.06 inch of $0^{\circ}$ glass fiber, and 3) 0.06 inch of $90^{\circ}$ glass fiber.

To measure in-plane shear (xy) strain, top and side surfaces of test specimens are mounted with rosette strain gages at the specimen mid span. All specimens are prepared as for 15 inches in length. In addition, sandwich coupon specimens and dimensions are illustrated in Figures 3.5 and 3.6. 

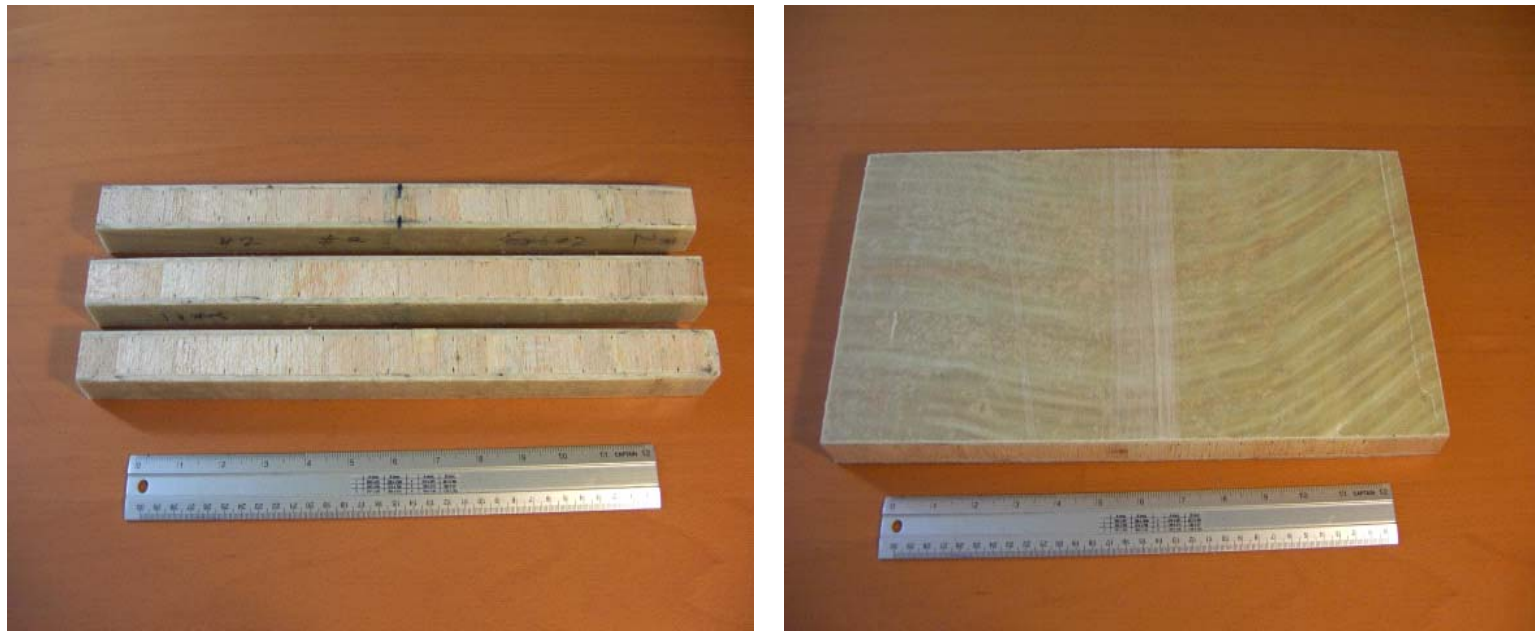

Figure 3.5 Sandwich FRP-wood specimens

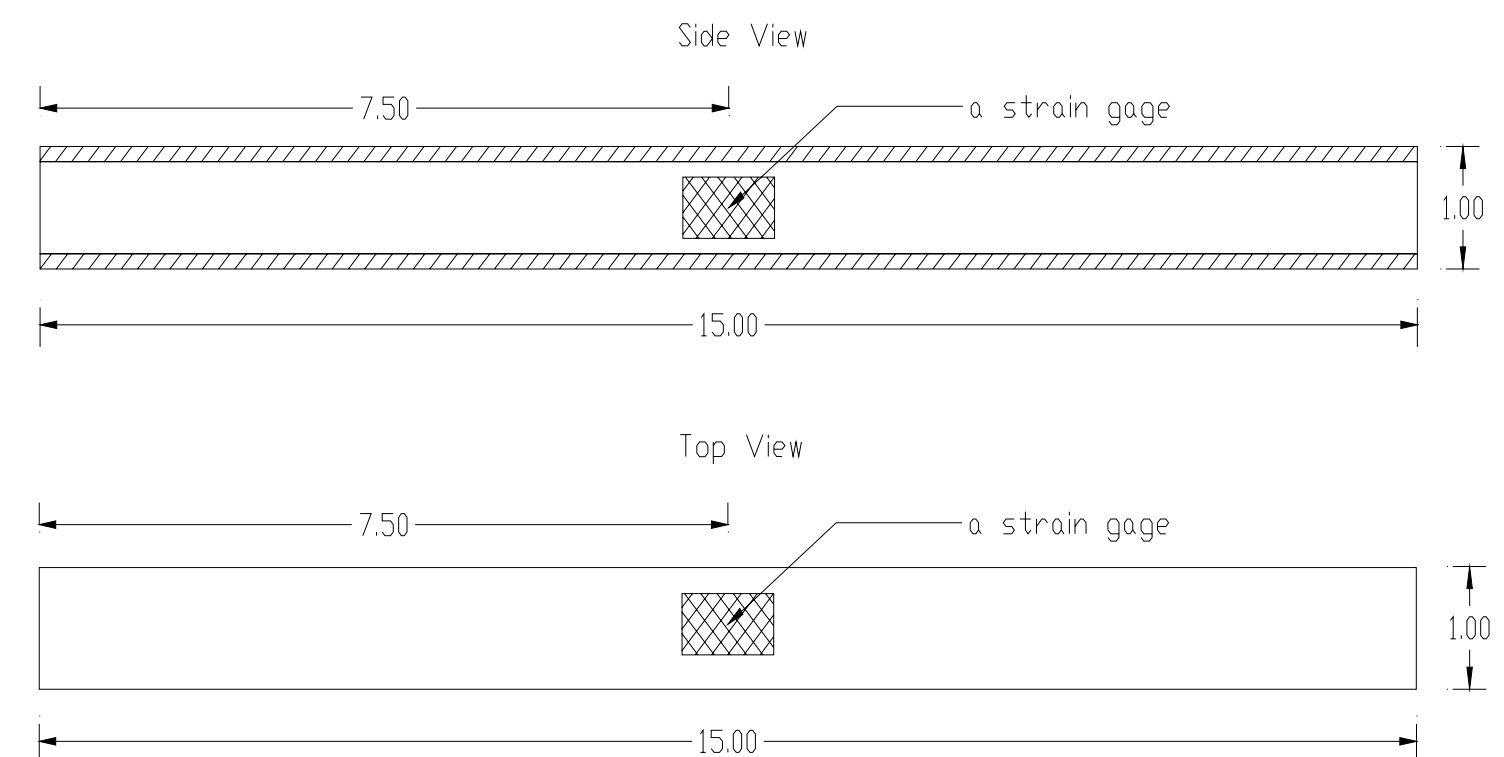

Figure 3.6 Strain gage position of sandwich FRP wood specimens with 1 inch width

\subsubsection{Circular Solid Rebar}

0.5 and 1.0 inch diameter of FRP circular rebars with sand clothing on surface along the bar length are subjected to torsion testing. Circular rebar specimens of 0.5-inch $\left(\mathrm{CSB}_{0.5}\right)$ and 1-inch $\left(\mathrm{CSB}_{1}\right)$ diameter were made of unidirectional glass fiber with $65 \%$ and $60 \%$ volume fractions, respectively. Due to the inappropriate steel grips of the testing machines, 
modified steel grips are used for this purpose. Round steel grips are welded with steel plates and glued at both ends of the specimens by using Pilo-grips. Like the other test specimens, a rosette strain gage was mounted at the mid-span on the surface of the FRP rebars. As the specimen size of 0.5-inch diameter FRP rebar is very small, strain gages could not be installed. Figures 3.7 and 3.8 show 0.5 -inch and 1-inch diameters FRP rebar test specimens.

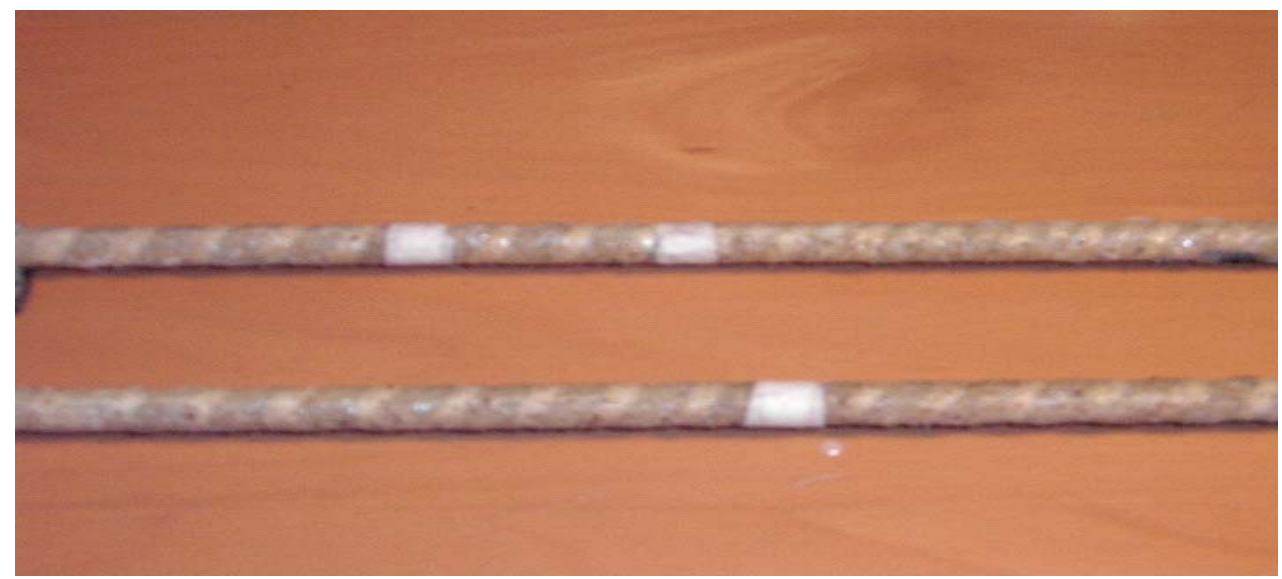

Figure $3.7 \quad 0.5$ inch diameter of FRP reber specimens

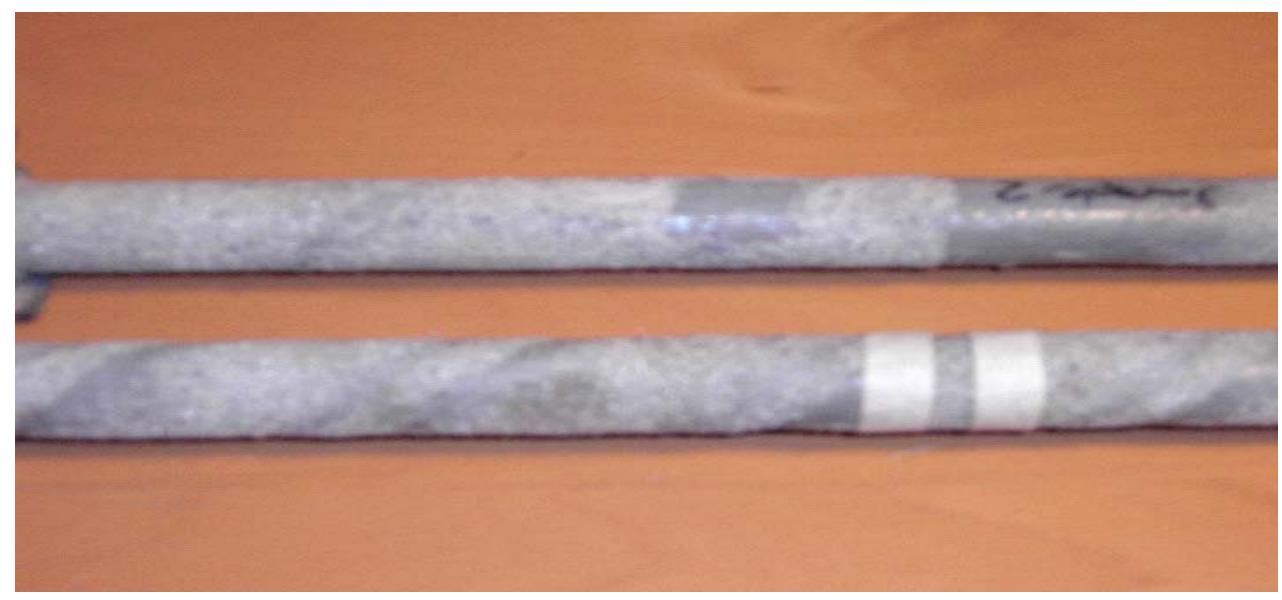

Figure 3.81 .0 inch diameter of FRP reber specimens 


\subsubsection{Circular Tube}

In this study, tubes of size 1-inch diameter with 0.15 inch thick walls and 12 inch length were used as test specimens as shown in Figure 3.9. These specimens (CT) were made from unidirectional fiber with 35\% fiber volume fraction. Round steel grips and a rosette strain gage were used for this specimen in the same manner as in the case of circular solid bars.

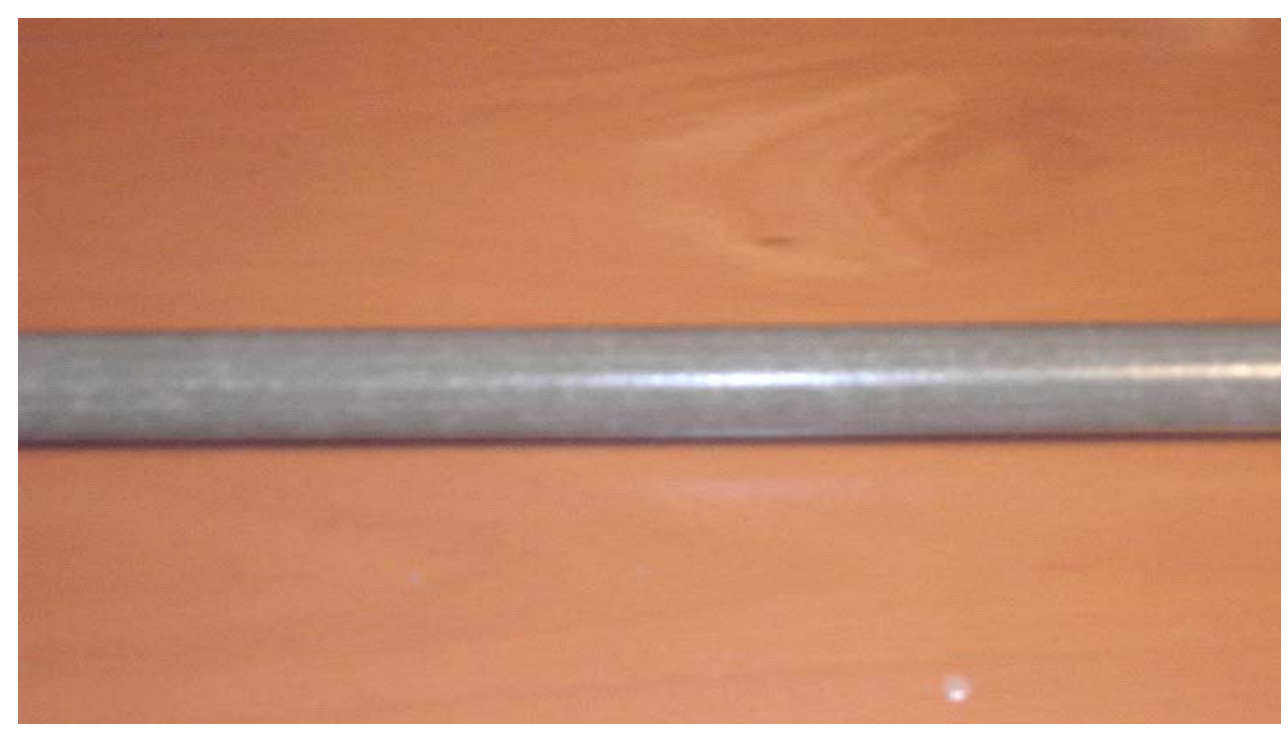

Figure 3.9 FRP circular tube specimen 


\subsubsection{Component Testing}

Component level testing is done on specimens made of FRP bridge deck modules. Two composite decking systems Prodeck4 and Prodeck8 modules provided by Bedford Reinforced Plastics, Inc. are used. However, the wing portions of the top and bottom parts of these FRP bridge deck modules are cut and then are subjected to testing. The fiber architecture and lamina properties are mentioned in appendix C.

\subsubsection{ProDeck4 Component Specimen}

ProDeck4 modules are cut in both longitudinal and transverse directions. Two longitudinal specimens of single cell cross-section and of different lengths 16-inches and 144-inches are prepared for torsion testing. 16-inch specimens along the length include: 1)

joint and 2) no joint. For the preparation of specimens with joints, two FRP deck modules were joined by using Pliogrip and are cured for about 24 hours, which are then cut longitudinally to specimen dimensions. Moreover, multi-cell FRP decks of 144 inches long were also used to prepare longitudinal component specimens. The in-plane shear strain is measured by mounting strain gages at several positions on the top and side surfaces of the test specimens as shown in Figure 3.10.

For preparing transverse specimens, Prodeck4 module is sliced in 1-inch width transversely to longitudinal cell direction. However, for testing, wing portions of these transverse specimens are cut as shown in Figure 3.11. A rosette strain gage is mounted on the flange surface of specimen, where the specification and position of strain gage of transverse specimens are illustrated in Figure 3.12. 


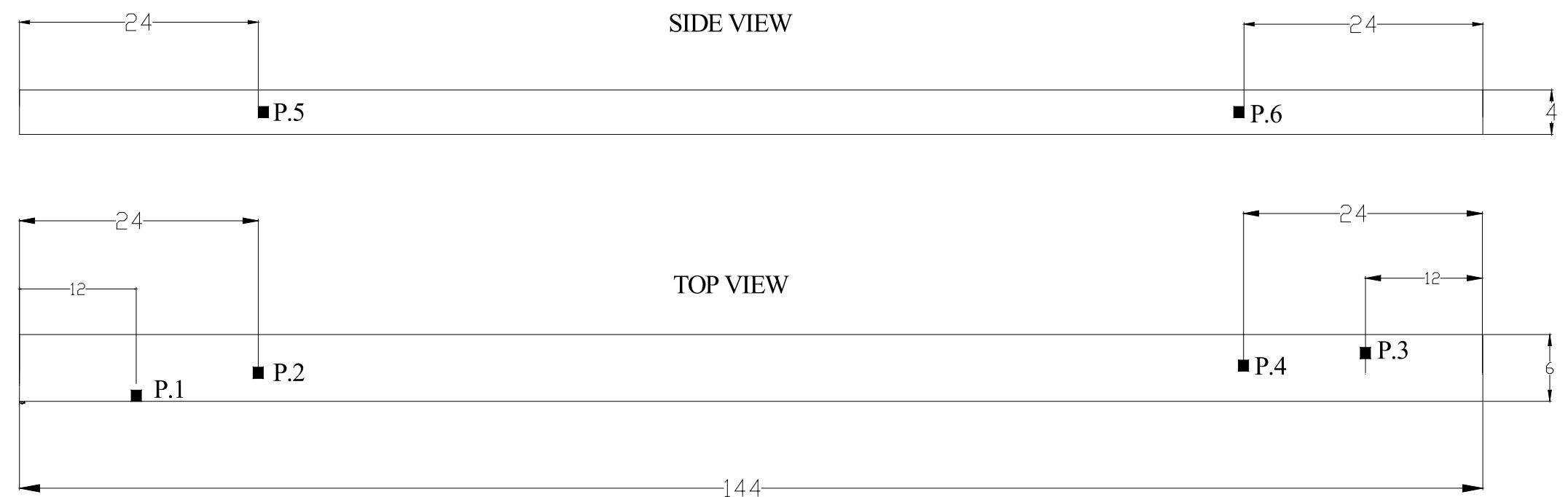

- represents a strain gage

Figure 3.10 ProDeck4 longitudinal component specimen 

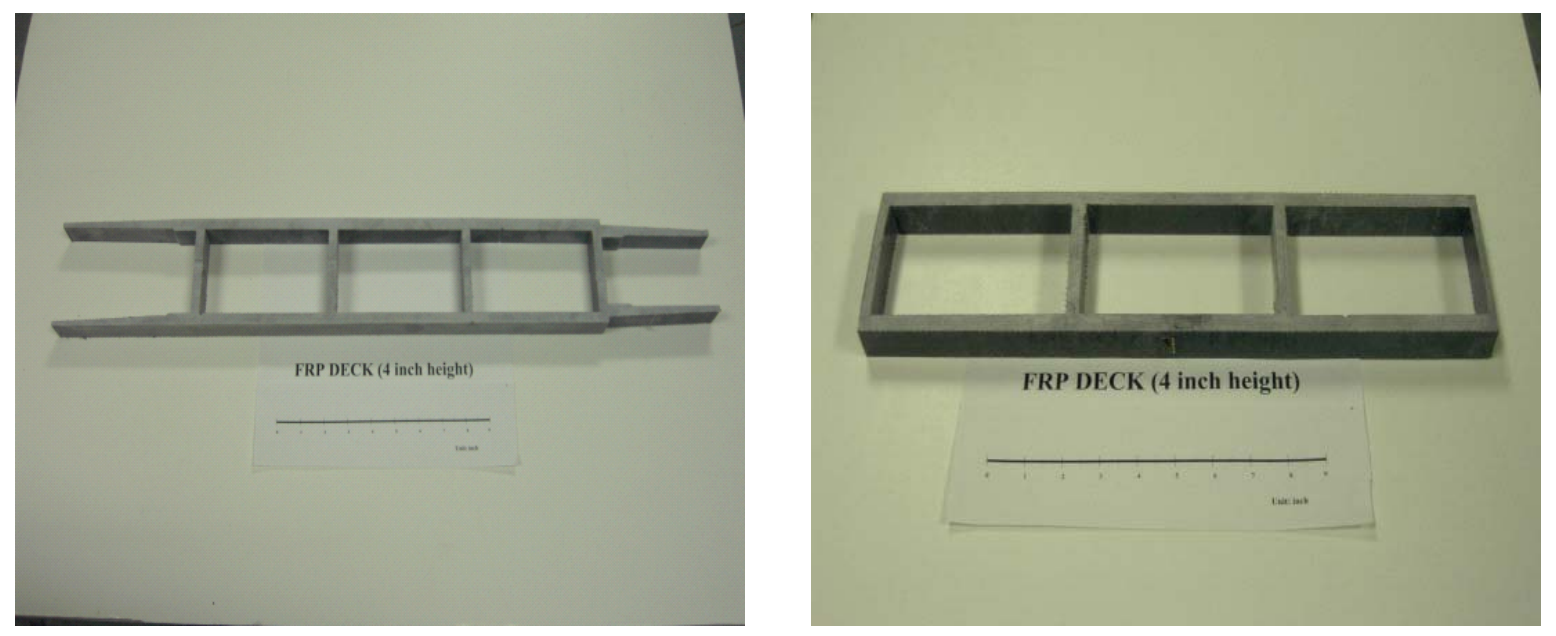

Figure 3.11 Transverse component specimens
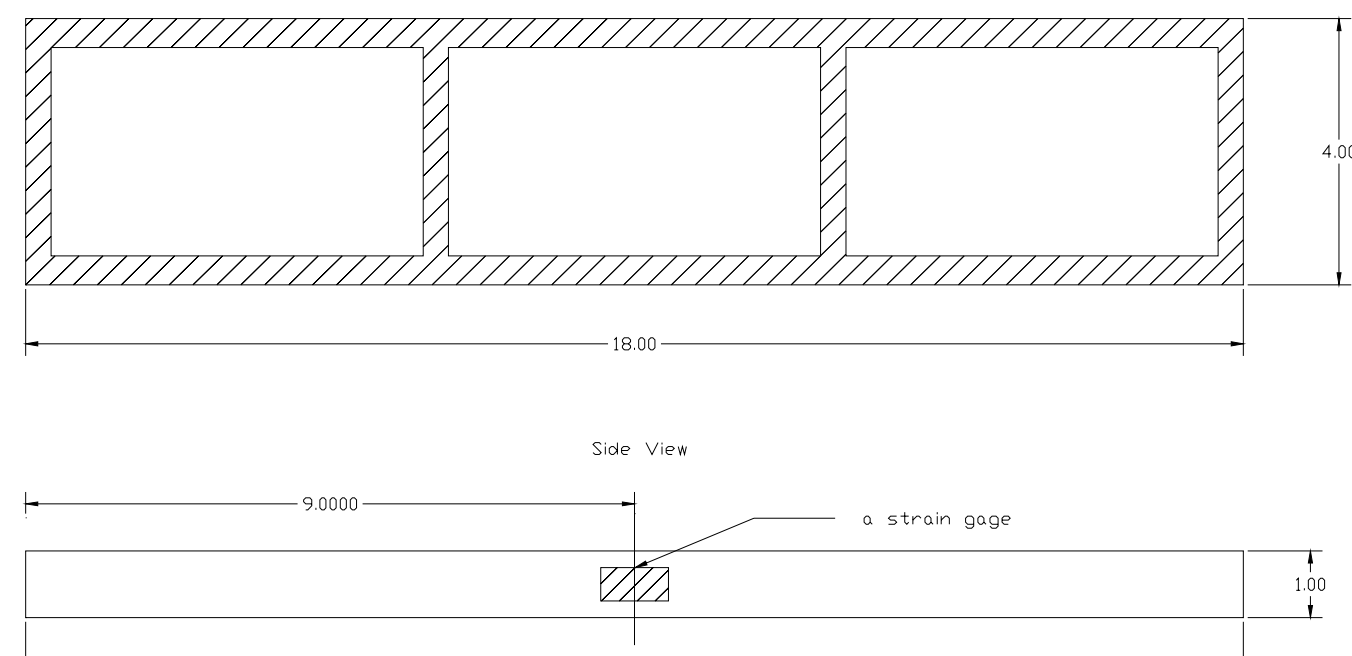

Figure 3.12 Strain gage position of transverse ProDeck4 specimen

\subsubsection{ProDeck8 Component Specimen}

Prodeck8 modules are prepared by removing the wing portions at the top and bottom parts. Longitudinal component specimens of Prodeck8 module are 144-inches in length. Rosette strain gages are mounted at several positions on the flange and web surface of test specimens. The procedure for the manufacture of transverse component specimens of Prodeck8 module is the same as followed for Prodeck4 transverse component specimens. 
Figure 3.13 shows longitudinal specimens made of Prodeck8 module. The strain gage position of the transverse Prodeck8 specimen is illustrated in Figure 3.14. In addition, specification, type, direction, dimensions and number of component specimens prepared are summarized and presented in Table 3.3.

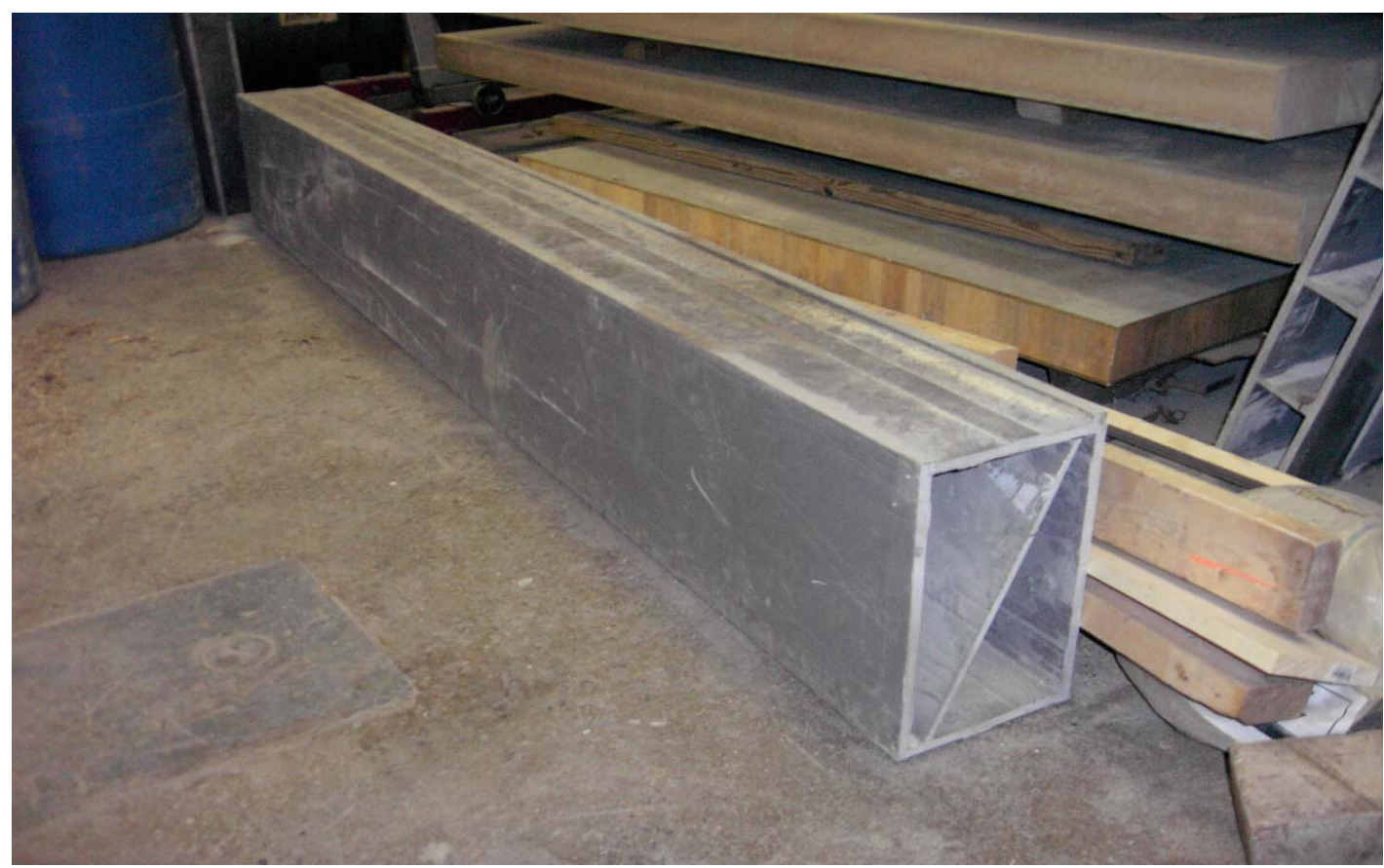

Figure 3.13 Longitudinal specimen of ProDeck8 


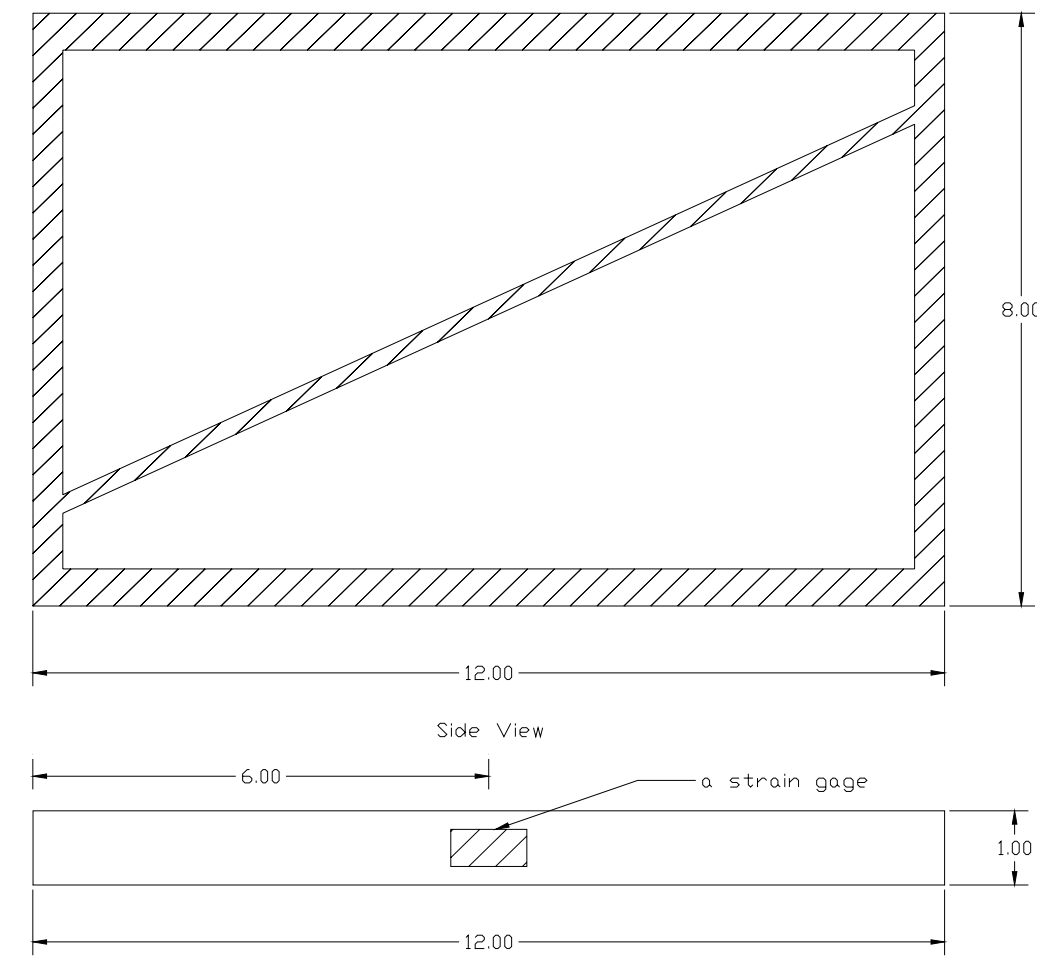

Figure 3.14 Strain gage position of transverse ProDeck8 specimen

Table 3.3 Component specimen sizes of torsion test

\begin{tabular}{|c|c|c|c|c|c|c|}
\hline Specimen & Type & Direction & Joint & $\begin{array}{c}\begin{array}{c}\text { Number } \\
\text { of } \\
\text { specimens }\end{array} \\
\end{array}$ & $\begin{array}{l}\text { Length } \\
\text { (in) }\end{array}$ & $\begin{array}{l}\text { Cross-section } \\
\text { (in) }\end{array}$ \\
\hline $\mathrm{COP}_{16 \mathrm{~L}}$ & \multirow[t]{5}{*}{ ProDeck4 } & Longitudinal & Without & 2 & 16 & $4 \times 6$ \\
\hline $\mathrm{COP}_{144 \mathrm{~L}}$ & & Longitudinal & Without & 2 & 144 & $4 \times 6$ \\
\hline MP44144 & & Longitudinal & Without & 1 & 144 & $4 \times 18$ \\
\hline $\mathrm{COP}_{16 \mathrm{JL}}$ & & Longitudinal & With & 2 & 16 & $4 \times 6$ \\
\hline $\mathrm{COP} 4_{18 \mathrm{~T}}$ & & Transverse & Without & 2 & 18 & $4 \times 1$ \\
\hline $\mathrm{COP8}_{144 \mathrm{~L}}$ & \multirow[t]{2}{*}{ ProDeck8 } & Longitudinal & Without & 1 & 144 & $8 \times 12$ \\
\hline $\mathrm{COP8}_{12 \mathrm{~T}}$ & & Transverse & Without & 2 & 12 & $8 \times 1$ \\
\hline
\end{tabular}




\subsubsection{Component with Joints Testing}

Torsional shear behavior of ProDeck4 specimens with joints are investigated in both longitudinal and transverse directions. Two ProDeck4 modules are chemically bonded together by using Pilo-grip. After that, the assembled modules are also left at room temperature about 24 hours for curing. Then, the assembled modules are longitudinally cut into a multi-cell cross sectional specimen (triple cell) having a longitudinal joint at the center cell of the cross section. Several rosette strain gages are mounted at positions on the flange and web surface of the test specimens as shown in Figure 3.15.

Moreover, another specimen type at this level is also prepared following the same procedures mentioned above and glass fabrics are bonded along longitudinal joints on the top and bottom specimen surfaces to be reinforced. To reinforce longitudinal joints, 6 inch wide glass fabric is bonded to be the first layer of reinforcement for each surface by using epoxy. Following that, 4 inch wide glass fabric is placed over the first layer of reinforcement. This specimen is also left at room temperature at least 24 hours for curing. Rosette strain gages are mounted on the same positions as test specimens without reinforcement as also presented in Figure 3.15.

To prepare transverse specimens, 12 inch wide ProDeck4 modules are transversely cut. Six pieces of cut modules are assembled and chemically joined by using Pilo-grips. Assembled specimens are left for curing at room temperature for 24 hours before testing. In addition, rosette strain gages are mounted on specific positions on specimen surface as shown in Figure 3.16.

To study and establish joint efficiency for transverse specimens, glass fabrics with dimensions $4 \times 12$ and $6 \times 12$ inches are glued with epoxy on all transverse joints on specimen surfaces. After glass reinforcements are attached, test specimens also are left for curing at room temperature for 24 hours. Rosette strain gages are also mounted on the same positions 
transverse specimens without reinforcement. Specimen dimensions and strain gage positions are illustrated in Figure 3.16. In addition, a summary table for specimen sizes and number of test specimens at component with joint are given in Table 3.4.

Table 3.4 Component with joint specimen sizes of torsion test

\begin{tabular}{|c|c|c|c|c|c|c|}
\hline Specimen & Type & Direction & fabric & $\begin{array}{l}\text { Number of } \\
\text { specimens }\end{array}$ & $\begin{array}{c}\text { Length } \\
\text { (in) }\end{array}$ & $\begin{array}{c}\text { Cross-section } \\
\text { (in) }\end{array}$ \\
\hline $\mathrm{MP}_{144 \mathrm{JL}}$ & \multirow[t]{5}{*}{ ProDeck4 } & \multirow[t]{2}{*}{ Longitudinal } & Without & 1 & 144 & $4 \times 18$ \\
\hline $\mathrm{MP}_{144 \mathrm{JFL}}$ & & & With & 1 & 144 & $4 \times 18$ \\
\hline $\mathrm{MP}_{144 \mathrm{~T}}$ & & \multirow[t]{3}{*}{ Transverse } & Without & 2 & 144 & $4 \times 12$ \\
\hline $\mathrm{MP}_{144 \mathrm{~F} 1 \mathrm{~T}}$ & & & With: 1 side & 2 & 144 & $4 \times 12$ \\
\hline $\mathrm{MP}_{144 \mathrm{~F} 2 \mathrm{~T}}$ & & & With: 2 sides & 2 & 144 & $4 \times 12$ \\
\hline
\end{tabular}




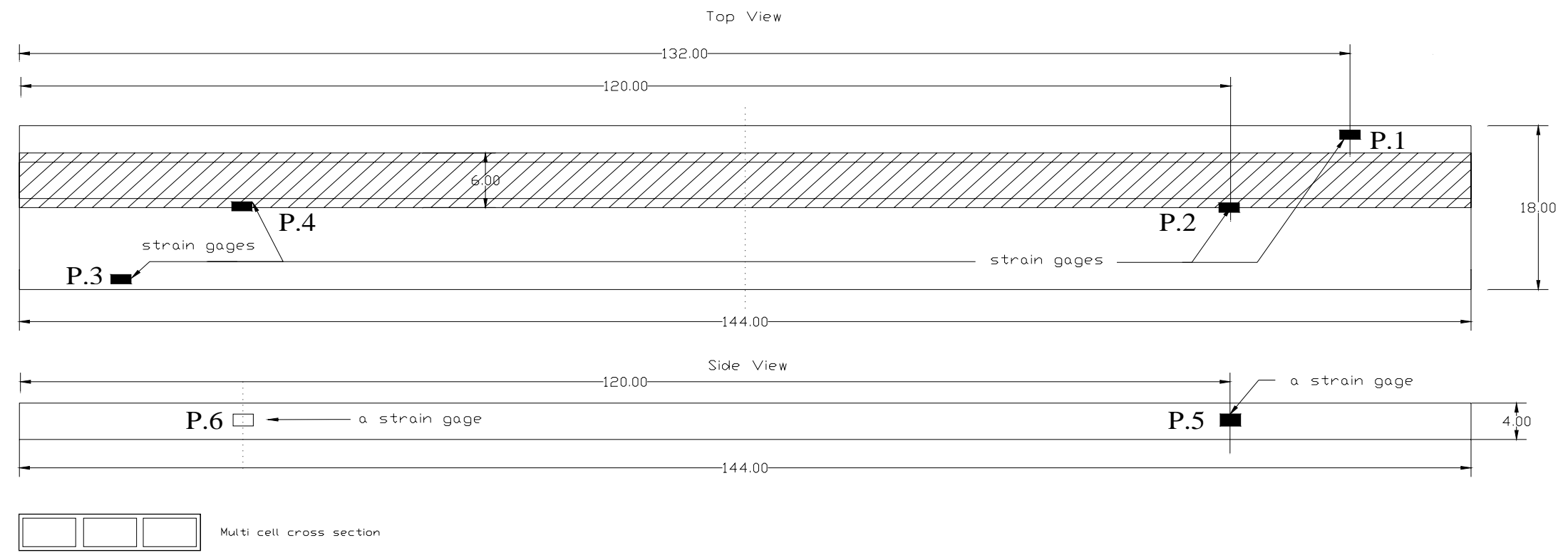

Figure 3.15 Multi-cell longitudinal ProDeck4 with glass fabric reinforcement at component with joints

Note: $\mathrm{P}$ is position of rosette strain gage 


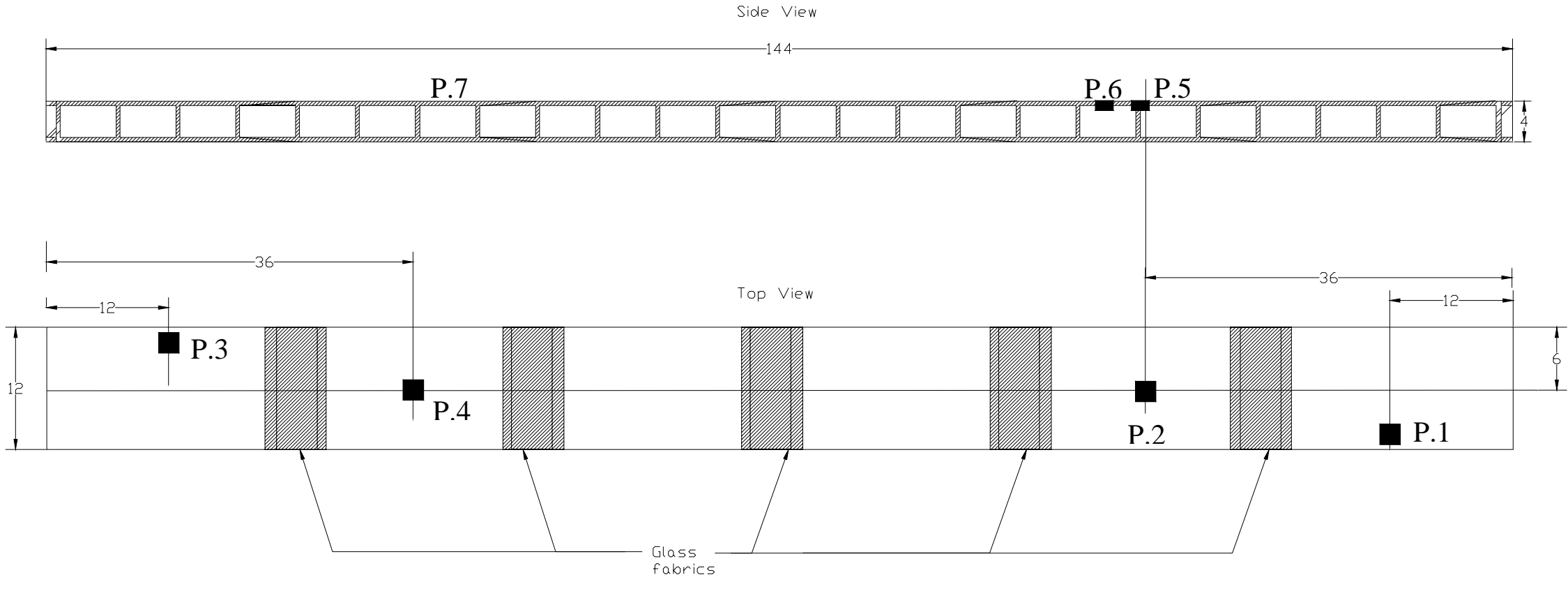

Wepresents a strain gage

Figure 3.16 Multi-cell transverse ProDeck4 with glass fabric reinforcement at component with joints

Note: $\mathrm{P}$ is position of rosette strain gage 


\subsubsection{Test Set-Up}

In coupon testing, a small scale torsion testing machine is used for this purpose. Test specimens are placed in the flat steel grips of that torsion machine. After that, coupon specimens are placed between both steel grips and clamped with a torque wrench to avoid inducing free body rotation in the grip mount during testing. However, free warping or free horizontal deformation is still allowed in cross section of coupon specimens. Any strain gages attached on the specimens are connected to a data acquisition system and computer. Strain smart software is used as a control tool for the data acquisition system. Applied torque data are determined from deflection results by using linear variable differential transducers (LVDT) that are connected with a string to a deflection scale on this machine. Rotation or twist of specimens can directly be read from the rotation scale located on the front side of this torsion testing machine. In component level testing, a small scale torsion machine is also used except for longitudinal specimens of 144 inches in length of both ProDeck4 and 8. Test setups for these component specimens are still the same procedures as in coupon testing. A small scale torsion testing machine is illustrated in Figure 3.17.

For longitudinal specimens of 144 inches in length, a large scale torsion testing machine located in the structural laboratory at West Virginia University is used for this purpose. To prevent free body rotation within steel grips induced during testing, test specimens are positioned between both heavy duty steel angles that are bolted on the side plates of the rotating arms and clamped by applying a small torque in each bolt. However, free warping or free horizontal movement is still permitted. Applied torque is induced at both ends of the specimen by applying a load into the stiff load beam through a hydraulic jack. This load is transferred to the steel arms of the testing machine connected to turn buckles of the torsion steel grips. Moreover, rosette strain gages on test specimens are connected to a data acquisition system to record any strain data during testing. Applied load on the stiff 
beam is measured by using a load cell that is attached on a hydraulic ram. For rotation of test specimens, the angle of twist is monitored by measuring vertical movements of the tips from the four steel bars. These bars are symmetrically connected to the test specimens at about 48 inches from the mid span of both the left and right sides. In addition, linear variable differential transducers (LVDT) are used to measure vertical deflection in this experiment. The large scale torsion testing machine is illustrated in Figure 3.18.

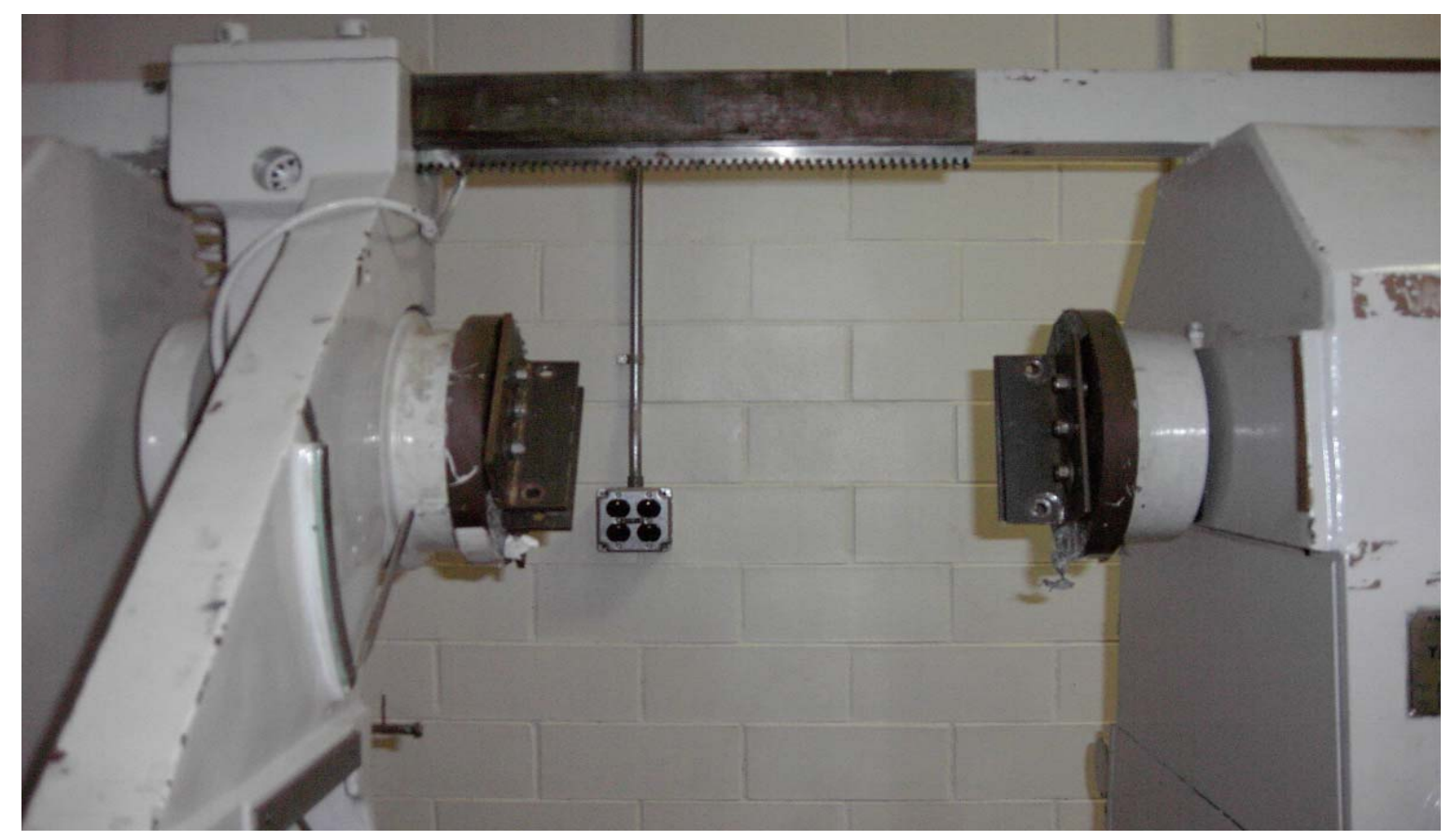

Figure 3.17 Small scale torsion machine 


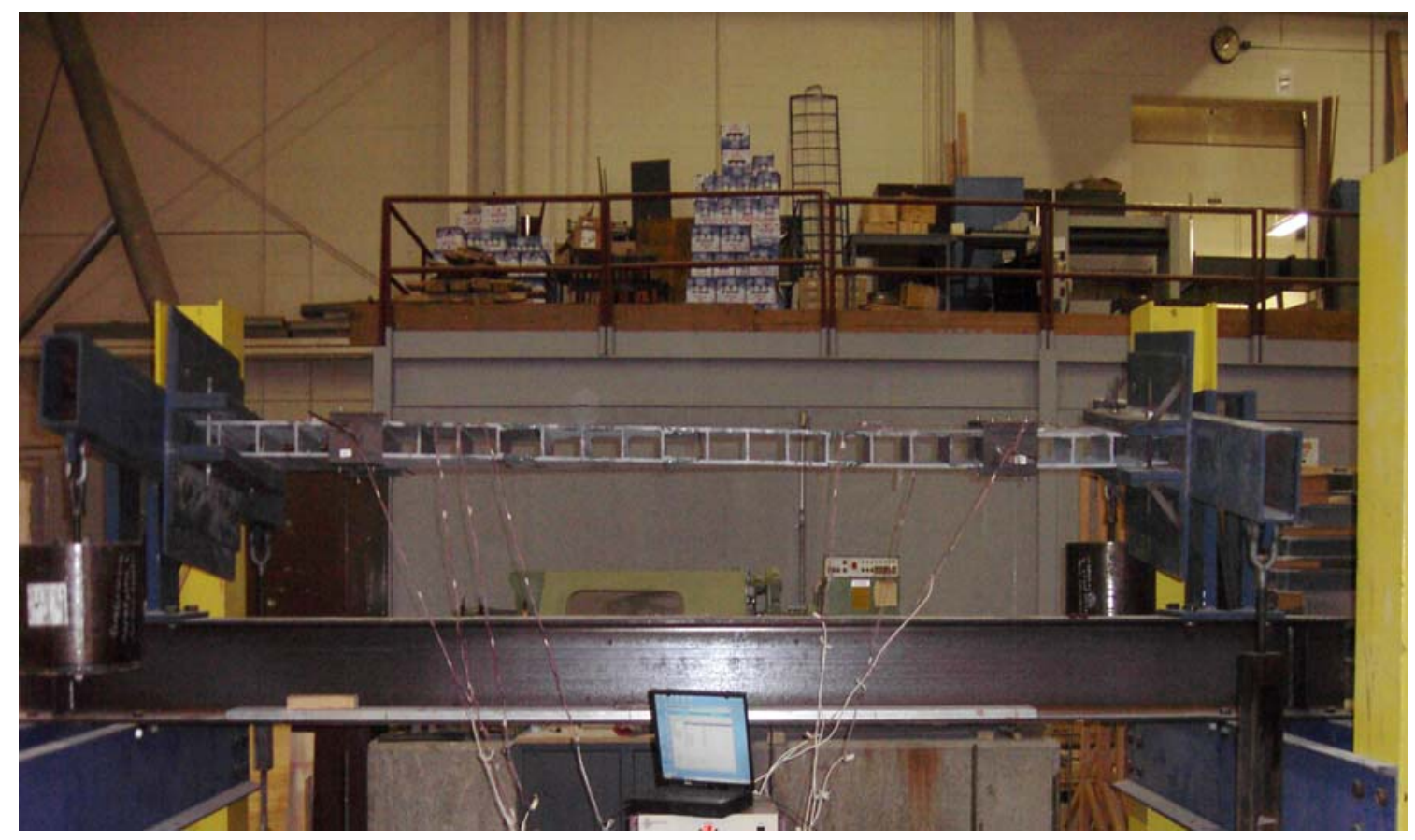

Figure 3.18 Large scale torsion machine

\subsection{V-Notch Beam (Iosipescu) Shear Test}

V-notch beam shear coupons are prepared from the flange of ProDeck4. Test specimens $\left(\mathrm{VP}_{4 \mathrm{~L}}\right.$ and $\left.\mathrm{VP}_{4 \mathrm{~T}}\right)$ are cut in both longitudinal and transverse directions, respectively. Test specimens with dimensions of $0.75 \times 3 \times 0.435$ inches are prepared for a $90^{\circ}$ notch at the center of the specimen at an angle of $45^{\circ}$ for both sides (Refer to Figure 3.19). In addition, a rosette strain gage is mounted at the mid span of specimen surface.

\subsubsection{Test Set-Up}

Specimens are placed into standard V-notch shear apparatus and fastened with trapezoidal blocks by tightening the screws. The apparatus is positioned on a thick steel base of the Instron testing machine. A connecting rod Instron machine is connected to the top portion of the apparatus. A load is applied through the connecting rod into the apparatus, transferring load into the specimen. The test is performed at a loading rate of $0.02 \mathrm{in} / \mathrm{min}$. An applied load can directly obtained from the Instron machine, whereas a data acquisition 
system is required to collect the strain data. V-notched beam specimens and test set-ups are presented in Figure 3.19.
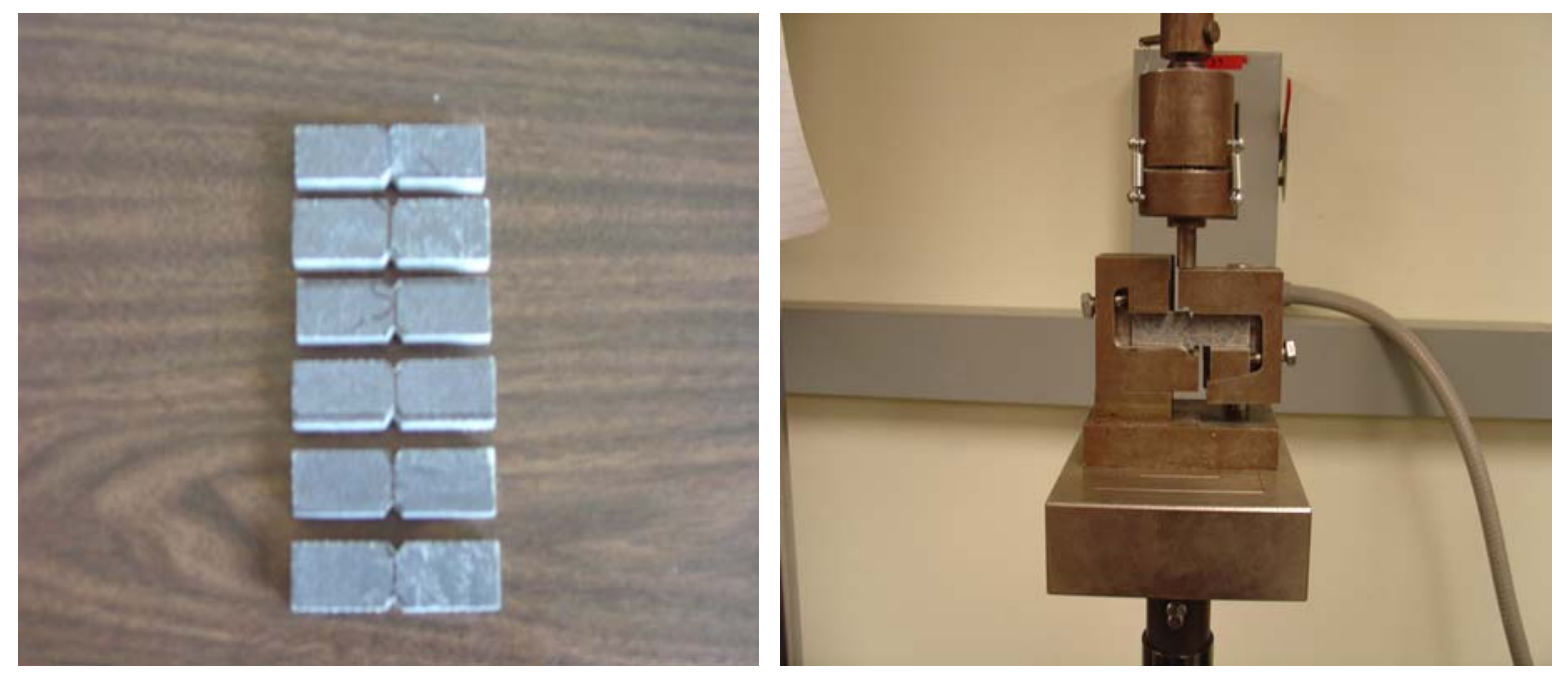

Figure 3.19 V-notched beam specimens and test set-up

\subsection{Cantilever Beam Test}

To evaluate in-plane shear modulus of component specimens under loading in parallel direction with cell direction (strong axis), test specimens are prepared from several ProDeck4 modules of 12 inches in width. Test specimens are tested under point load at one end with free movement, whereas the other end is constrained from movement in all directions. Test procedures for test specimens at component testing are given:

\subsubsection{Component Testing}

ProDeck4 modules are transversely cut 12 inches in width for each piece. Three pieces of cut modules are assembled to be the test specimens. The specimens are joined with chemical and/or mechanical bonds. Three different types of joint mechanisms are studied as: 1) rivet bonding 2) glue bonding and 3) rivet and glue bonding. To measure in-plane shear strain data, a rosette strain gage is attached on the top flange surface. 


\subsubsection{Test Set-Up}

Test specimens are placed on a steel beam that is located on concrete supports. The lengths of test specimens that sit on that steel beam are about 48 and 42 inches for component specimens without joint and with joint, respectively. After that, another steel beam is placed on top of the specimen. To prevent any movement at one end of test specimens, a heavy thick steel plate is placed on top of the steel beam through the length of that beam and a concentrated load is applied into the steel plate to make the distribution of the load through the length of the test specimens. In addition, vertical deflections of the test specimens are measured by using LVDT at both the beginning and end points of the test span. To apply a concentrated load, a small hydraulic jack is positioned under the test specimens at the end of the test span. A load cell is placed in the same position with a small hydraulic jack to measure load value. To record all measured data, a data acquisition system is connected to sensors as strain gages, LVDTs and the load cell. In addition, experimental data are transformed from electrical signals into calibration values by using strain smart software. Cantilever test set-ups are illustrated in Figure 3.27. Test specimen sizes are summarized and presented in Table 3.5.

Table 3.5 Test specimen sizes of cantilever beam test

\begin{tabular}{|c|c|c|c|c|c|c|}
\hline Specimen & Connection & Joint & $\begin{array}{l}\text { Test } \\
\text { span } \\
\text { (in) }\end{array}$ & $\begin{array}{l}\text { Number of } \\
\text { specimens }\end{array}$ & $\begin{array}{l}\text { Length } \\
\text { (in) }\end{array}$ & $\begin{array}{c}\text { Cross-section } \\
\left(\text { in }^{2}\right)\end{array}$ \\
\hline \multirow[t]{2}{*}{$\mathrm{CB}_{\mathrm{R}}$} & \multirow[t]{2}{*}{ rivet } & without & 24 & 1 & 72 & $12 \times 4$ \\
\hline & & with & 30 & 1 & 72 & $12 \times 4$ \\
\hline \multirow[t]{2}{*}{$\mathrm{CB}_{\mathrm{G}}$} & \multirow[t]{2}{*}{ glue } & without & 24 & 1 & 72 & $12 \times 4$ \\
\hline & & with & 30 & 1 & 72 & $12 \times 4$ \\
\hline \multirow[t]{2}{*}{$\mathrm{CB}_{\mathrm{RG}}$} & \multirow{2}{*}{$\begin{array}{l}\text { rivet and } \\
\text { glue }\end{array}$} & without & 24 & 1 & 72 & $12 \times 4$ \\
\hline & & with & 30 & 1 & 72 & $12 \times 4$ \\
\hline
\end{tabular}




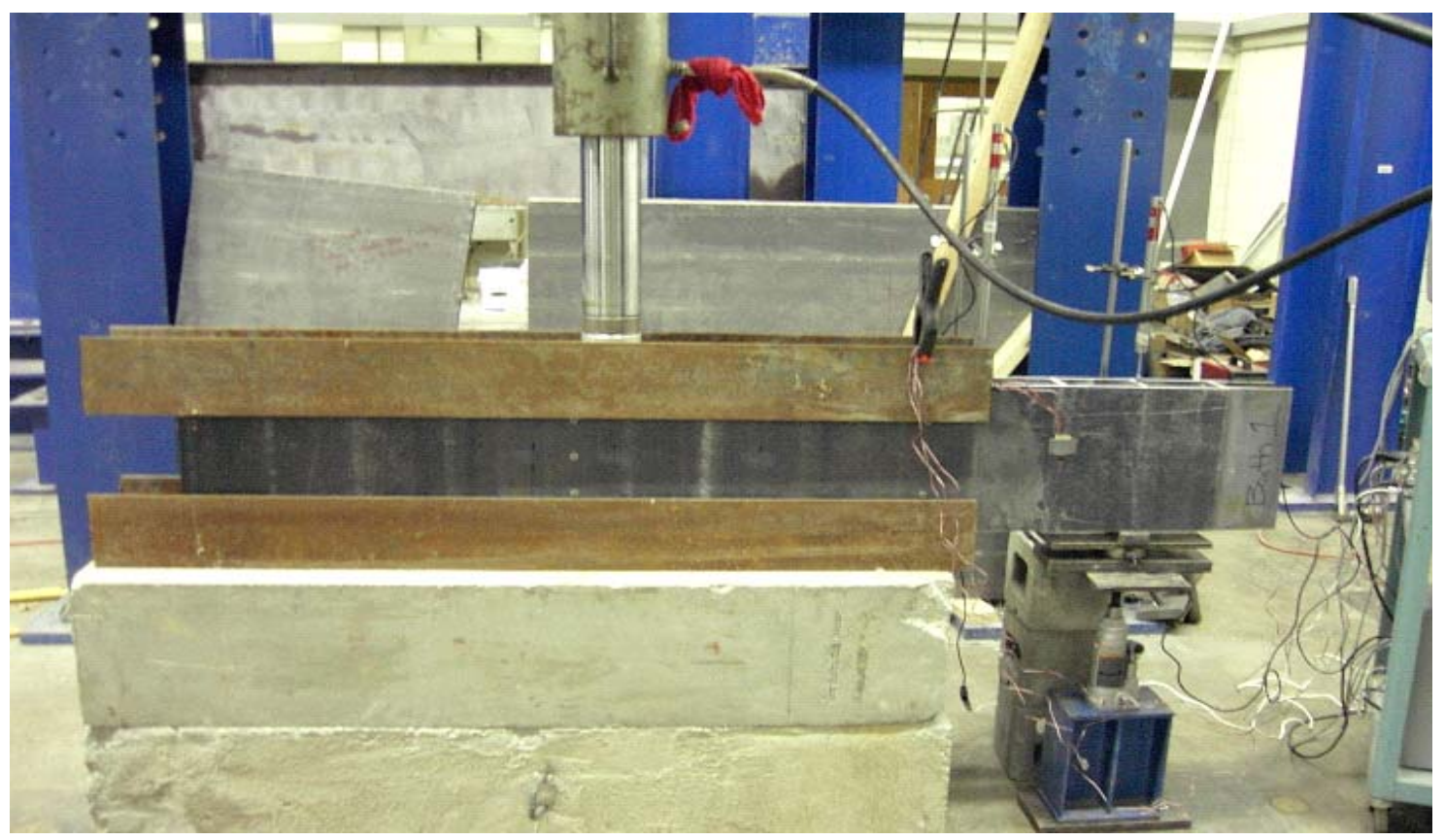

Figure 3.20 Test-set up of cantilever beam

\subsection{Racking Shear Test}

One of the important in-plane shears on bridge decks is racking shear due to braking forces induced by vehicles. To study this shear behavior, FRP deck panels are used as test specimens in this experiment. The ProDeck4 deck panel provided and assembled by BRP Inc is cut into a rectangular shape with dimensions $60 \times 66 \times 4$ inch.

\subsubsection{Test Set-Up}

The test specimen is placed on a steel beam of 20 inches in length measuring from the right end of the test specimen. A special rigid steel frame test is made to prevent displacement in any direction except a vertical direction through test span. Heavy steel triangle frames and columns are welded and bolted to a concrete floor for lateral support. In addition, heavy steel angle bars are also welded with lateral support to be steel tracks. The test specimen is located inside steel tracks running half the length of the test specimens at both ends. Also, two small hydraulic jacks are positioned on the top surface of the test 
specimen at the positions of 10 and 20 inches in length away from the right end. Small loads are applied from hydraulic jacks into the top steel beam of the load frame to prevent vertical displacement through 20 inches from the right end of test specimen. At the top specimen surface of the left end, another hydraulic jack is assembled on steel beam of the load frame and is used to apply load into the test specimen. To distribute the load, a small thick plate is placed over an area of $4 \times 12$ inches on the top surface of the test specimen under applied load position. Therefore, only vertical displacements through the test span are induced during loading at the top specimen surface of the left end. A load cell of 25 kip capacity and rosette strain gages are connected to a data acquisition system for monitoring applied load and strain data, respectively. Also, strain smart software is used as a control tool for the data acquisition system. To monitor the magnitude of vertical displacement, small dial gages are attached along the length of the test span at the bottom surface of the test specimens. The test set-up of the test specimen is illustrated in Figure 3.21. The summary of test specimen size is also given in Table 3.6.

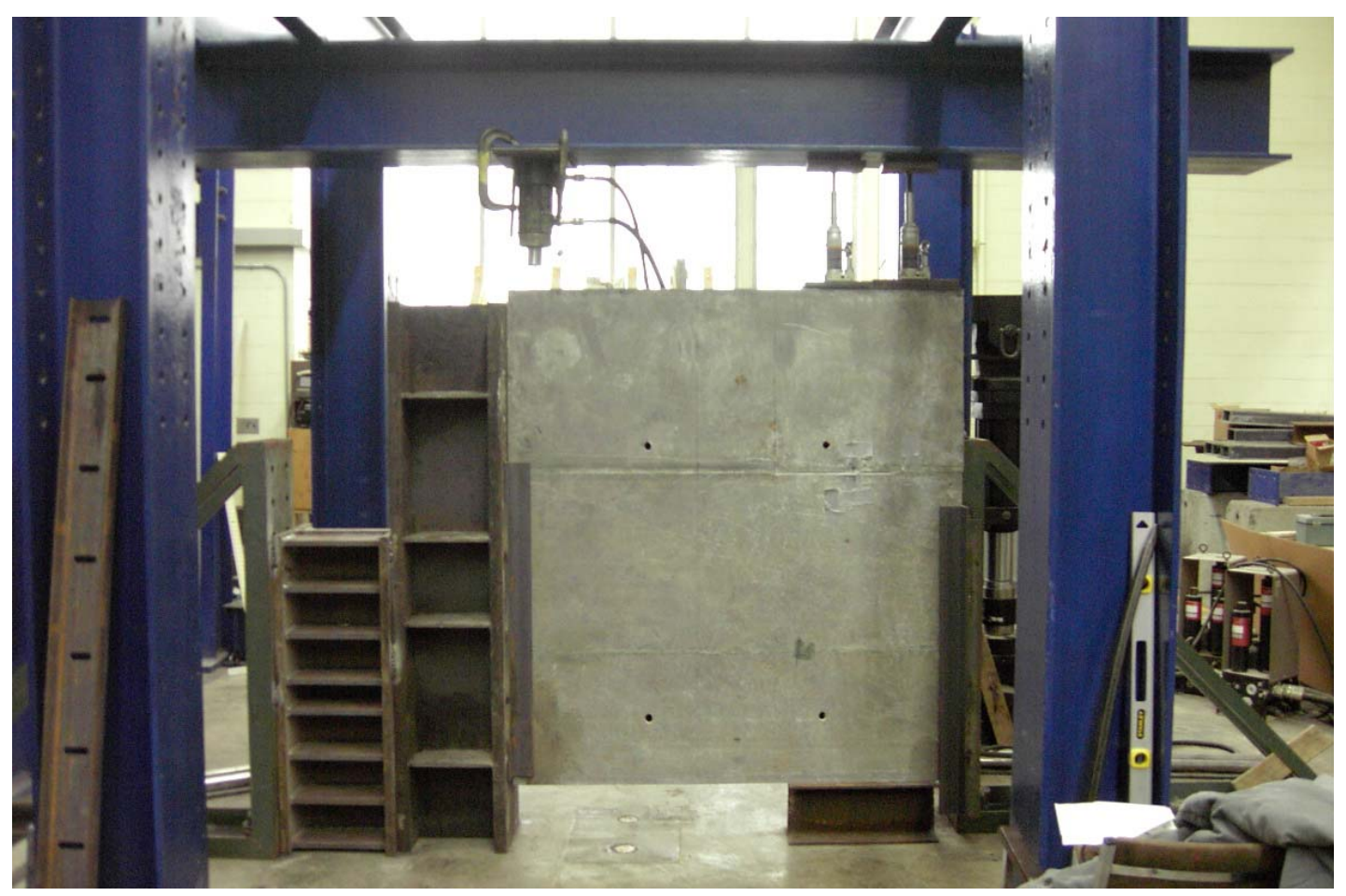

Figure 3.21 Racking shear test set-up 
Table 3.6 Summary of racking shear test

\begin{tabular}{|c|c|c|c|c|c|c|c|c|}
\hline \multirow[t]{2}{*}{ Specimen } & \multirow[t]{2}{*}{ Type } & \multirow[t]{2}{*}{ Level } & \multirow{2}{*}{$\begin{array}{l}\text { Length } \\
\text { (in) }\end{array}$} & \multirow{2}{*}{$\begin{array}{c}\text { Height } \\
\text { (in) }\end{array}$} & \multirow{2}{*}{$\begin{array}{l}\text { Test } \\
\text { span } \\
\text { (in) }\end{array}$} & \multicolumn{3}{|c|}{ Position (from the right end) } \\
\hline & & & & & & $\begin{array}{l}\text { Dial gage } 1 \\
\text { (in) }\end{array}$ & $\begin{array}{l}\text { Dial gage } 2 \\
\text { (in) }\end{array}$ & $\begin{array}{l}\text { Dial gage } 3 \\
\text { (in) }\end{array}$ \\
\hline $\mathrm{RS}$ & ProDeck4 & $\begin{array}{c}\text { Component } \\
\text { with joint }\end{array}$ & 60 & 66 & 40 & 56 & 40 & 24 \\
\hline
\end{tabular}

\subsection{Short Beam Shear Test}

To evaluate out-of-plane shear strength, test specimens are prepared from ProDeck4 and 8 in both coupon and component testings. Test specimens are tested under three point bending by having a test span range according recommendation on ASTM D2344-84. Specimen details and preparation are given below.

\subsubsection{Coupon Testing}

Coupon specimens are prepared from ProDeck4 and 8. Information of each specimen type is discussed as follows:

\subsubsection{ProDeck4 Coupon Specimen}

Short beam coupons of ProDeck4 meet the requirements of standard test method ASTM: D2344-84. Coupon specimens are prepared by cutting in both longitudinal and transverse directions of flange and web. All specimens are also prepared for dimensions of $0.435 \times 0.25 \times 2$ inches. In addition, six specimens are tested to obtain a satisfactory average strength for each specimen type. The recommended test span to thickness ratio as per ASTM: D2344-84 is kept equal to four for this experiment. It should be noted that this recommended ratio is effectively enough to induce laminated delamiantion due to shear effect on test specimens. 


\subsubsection{ProDeck8 Coupon Specimen}

ProDeck8 coupons are prepared from flanges by cutting in both longitudinal and transverse directions. Specimens with dimensions of 0.45 ” $\times 0.25$ ” $\times 2$ ” inches satisfy requirements of ASTM D2344-84 as do the ProDeck4 coupon specimens. Test specimen sizes at coupon testing are summarized and given in Table 3.7.

Table 3.7 Coupons for short beam shear test

\begin{tabular}{|c|c|c|c|c|c|c|}
\hline Specimen & Type & Portion & Direction & $\begin{array}{c}\text { Number } \\
\text { of } \\
\text { specimen }\end{array}$ & $\begin{array}{l}\text { Dimension } \\
\text { (in) }\end{array}$ & $(s / t)$ \\
\hline $\mathrm{SCP} 4_{\mathrm{FL}}$ & \multirow[t]{4}{*}{ ProDeck4 } & flange & Longitudinal & 6 & $0.435 \times 0.25 \times 2$ & 4 \\
\hline $\mathrm{SCP} 4_{\mathrm{FT}}$ & & flange & Transverse & 6 & $0.435 \times 0.25 \times 2$ & 4 \\
\hline $\mathrm{SCP}_{\mathrm{WL}}$ & & web & Longitudinal & 6 & $0.375 \times 0.25 \times 2$ & 4 \\
\hline $\mathrm{SCP}_{\mathrm{WT}}$ & & web & Transverse & 6 & $0.375 \times 0.25 \times 2$ & 4 \\
\hline $\mathrm{SCP}_{\mathrm{FL}}$ & \multirow[t]{2}{*}{ ProDeck8 } & flange & Longitudinal & 6 & $0.450 \times 0.25 \times 2$ & 4 \\
\hline $\mathrm{SCP8}_{\mathrm{FT}}$ & & flange & Transverse & 6 & $0.450 \times 0.25 \times 2$ & 4 \\
\hline
\end{tabular}

Note: $(s / t)$ is ratio of test span to thickness. Dimension is (thickness $\times$ width $\times$ length).

\subsubsection{Component Testing}

ProDeck4 modules are prepared for single and multi-cell cross sections. A longitudinal ProDeck4 single cell and multi-cell cross sections are prepared for dimensions of $4 \times 6 \times 16$ inches and $4 \times 18 \times 16$ inches, respectively. For ProDeck8, the specimen with a dimension of $8 \times 12 \times 36$ inches is used in this experiment. Specimens are tested under threepoint bending with test spans of 12 inches and 32 inches in length for ProDeck 4 and 8 specimens, respectively. The test span to thickness ratio for component specimens is kept at 3. For all specimens, a rosette strain gage is mounted at the mid span of the bottom specimen surface. Test specimen sizes are summarized and presented in Table 3.8. 
Table 3.8 Component specimen sizes of short beam shear test

\begin{tabular}{|c|c|c|c|c|c|c|c|}
\hline \multirow[t]{2}{*}{ Specimen } & \multirow[t]{2}{*}{ Type } & \multirow[t]{2}{*}{ Cell } & \multirow{2}{*}{$\begin{array}{l}\text { Number } \\
\text { of } \\
\text { specimen }\end{array}$} & \multirow{2}{*}{$\begin{array}{l}\text { Test } \\
\text { span } \\
\text { (in) }\end{array}$} & \multicolumn{3}{|c|}{ Dimension } \\
\hline & & & & & $\begin{array}{c}\text { Width } \\
\text { (in) }\end{array}$ & $\begin{array}{c}\text { Depth } \\
\text { (in) }\end{array}$ & $\begin{array}{l}\text { Length } \\
\text { (in) }\end{array}$ \\
\hline $\mathrm{SBP}_{4}$ & ProDeck4 & single & 1 & 12 & 6 & 4 & 16 \\
\hline $\mathrm{SBP} 4_{\mathrm{M}}$ & & triple & 1 & 12 & 18 & 4 & 16 \\
\hline SBP8 & ProDeck8 & Double & 1 & 32 & 12 & 8 & 36 \\
\hline
\end{tabular}

\subsubsection{Test Set-Up}

For coupon specimens, the small scale universal testing machine (Instron) is used in this experiment. Test specimens are conducted under three-point bending. Coupon specimens are placed on simple supports of the testing apparatus and an applied load crosshead is aligned on the mid-span of the test specimens. Test specimens are loaded at a rate of crosshead movement of $0.05 \mathrm{in} / \mathrm{min}$. Short beam shear testing of coupon specimens is illustrated in Figure 3.22.

For component specimens, a Baldwin hydraulic testing machine is used to apply line load on specimens. For ProDeck4 specimens, these specimens are placed on simply supported steel rollers that rest on the testing steel floor of the Baldwin machine. The test span of test specimens is set to 12 inches in length by measuring between both center lines of the simple supports. Thick steel plates with dimensions of $6 \times 8 \times 1$ inches for the single cell specimen and $6 \times 18 \times 1$ inches for the multi-cell specimen are placed on the top specimen surface on the center line of the thick steel plate corresponding to the mid span of the test specimen. Additional small sizes of steel plates are also required to distribute a concentrated load into a line load. The load cell of the Baldwin machine, strain gages and LVDT are connected to a data acquisition system for monitoring applied load, strain, and deflection data, respectively. For the ProDeck8 specimen, the test span is set to 32 inches in length. Thick steel plates that are used for multi-cell ProDeck4 specimens are still required for this 
experiment. To monitor applied load data, a load cell is connected to a data acquisition system and strain smart software.

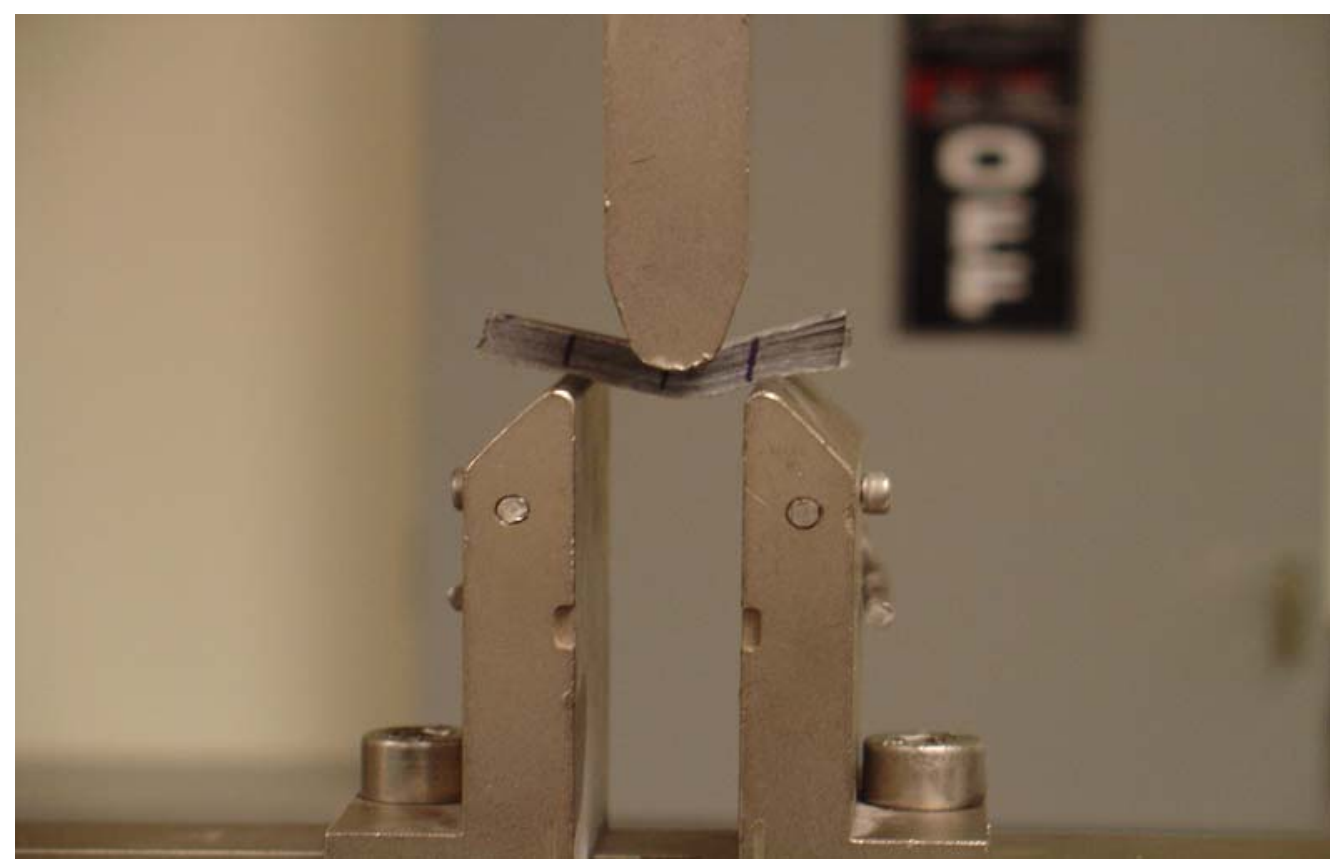

Figure 3.22 Short beam shear set-up of coupon

\subsection{Three and Four Point Bending Test}

To study out-of-plane shear behavior, specimens are tested under three and four point bending for this purpose. In this experiment, test specimens are prepared from ProDeck4 modules. Specimen details and preparation are given as follows:

\subsubsection{Component Testing}

For longitudinal specimens, ProDeck4 modules are cut for single and multi-cell (triple cell) cross sections with dimensions of $4 \times 6 \times 72$ and $4 \times 18 \times 60$ inches, respectively. Specimens are tested under three and four point bending in the cell direction (strong axis) of FRP decks. In addition, rosette strain gages are mounted at the bottom and side surfaces of the test 
specimens. Test specimen dimensions and strain gage positions are illustrated in Figures 3.23 and 3.24.
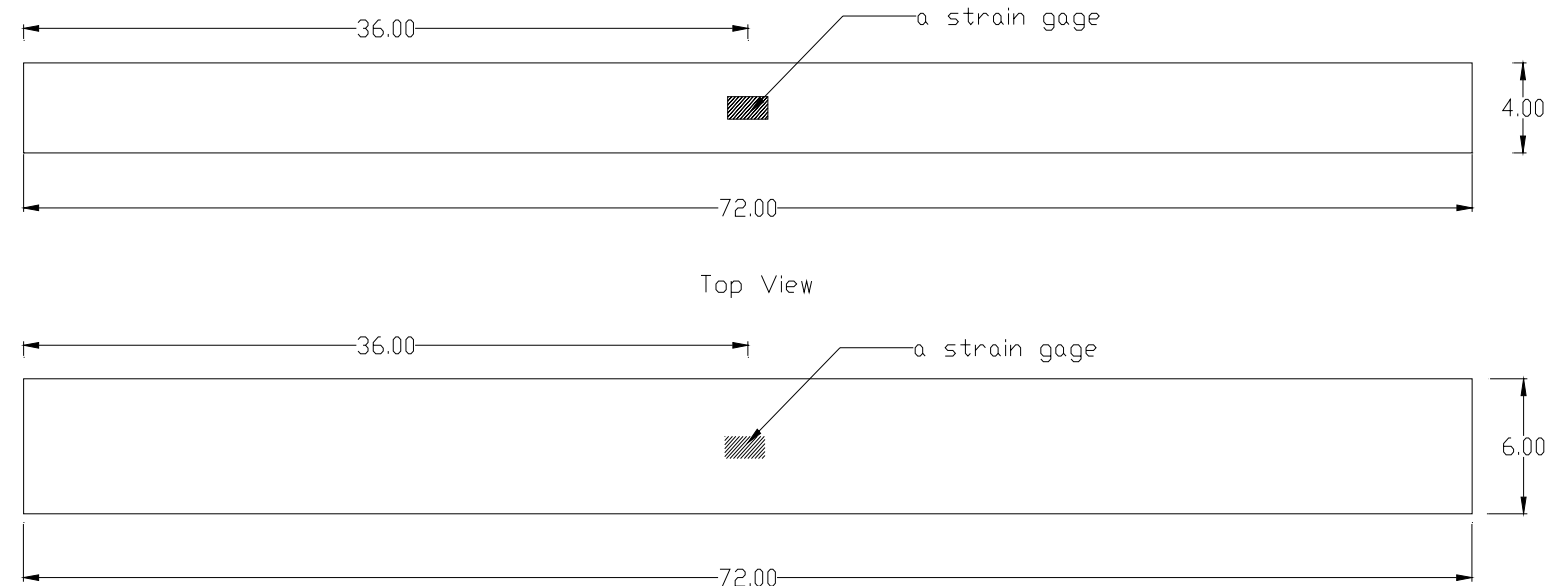

Figure 3.23 Single cell ProDeck4 specimen for three and four point bending

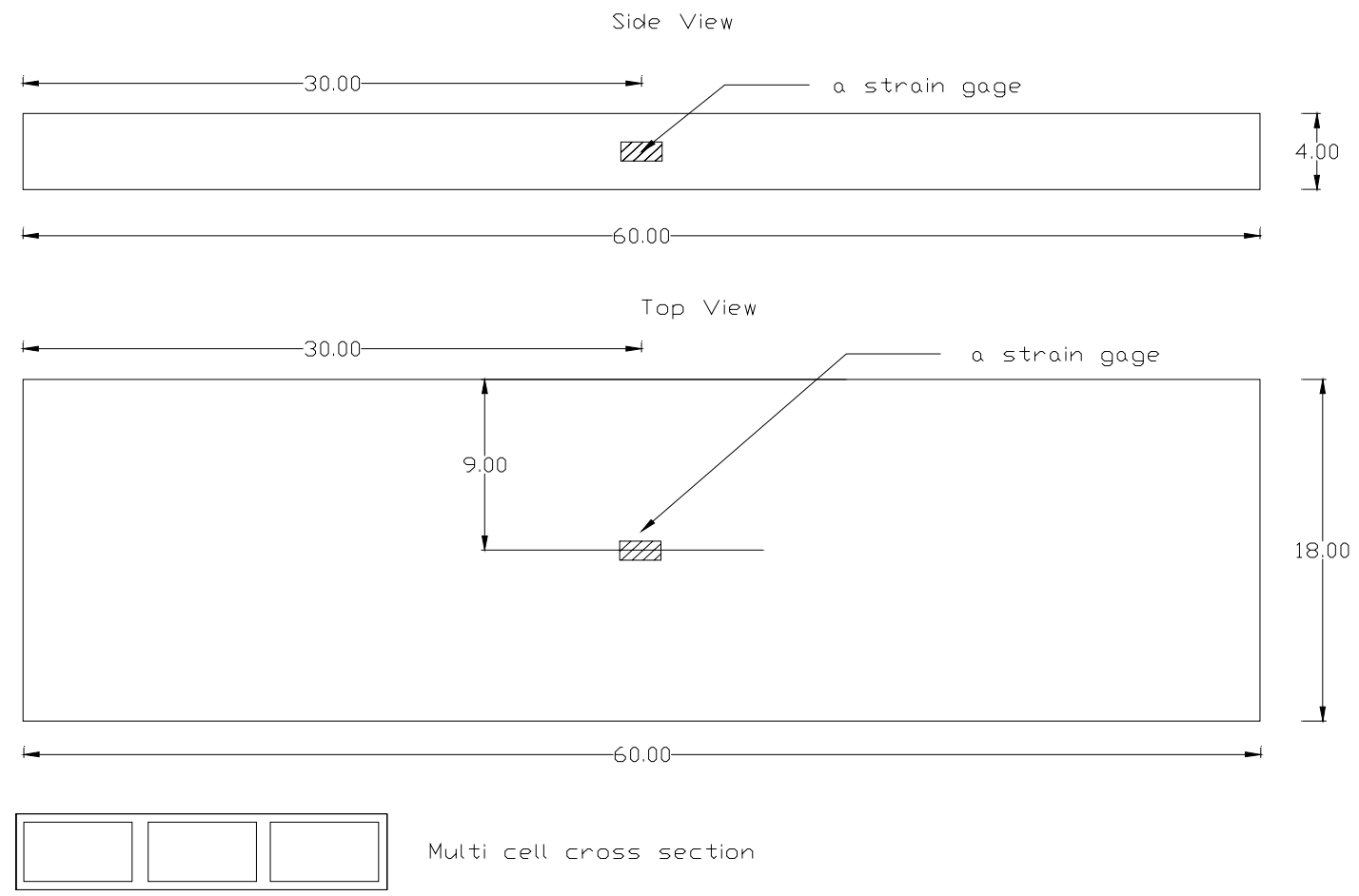

Figure 3.24 Multi-cell ProDeck4 specimen for three and four point bending 


\subsubsection{Component with Joint Testing}

To study out-of-plane (xz) shear behavior of longitudinal specimens with joints, ProDeck4 modules are assembled and chemically bonded by using Pilo-grip. The assembled module is left at room temperature at least 24 hours for curing. The assembled module is cut into a multi-cell (triple cell) specimen with dimensions of $4 \times 18 \times 60$ inches by having longitudinal joint on the center cell of the cross section. As with component specimens without joints, rosette strain gages mounted on specimen surfaces are shown in Figure 3.25.

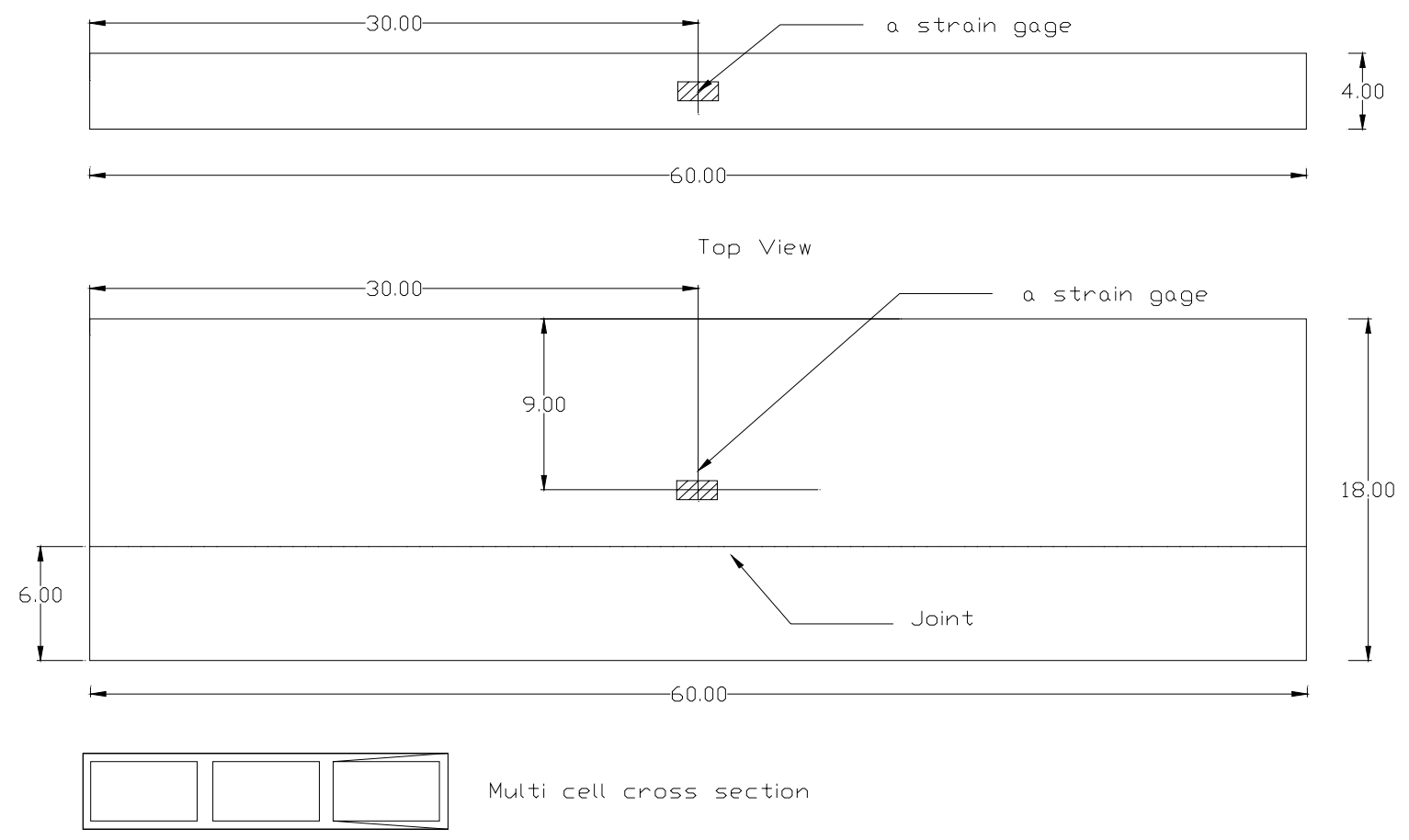

Figure 3.25 Multi-cell ProDeck4 specimen with joints for three and four point bending

For out-of-plane shear (yz) behavior, transverse specimens (BP4T, BP4 $\mathrm{T}_{5 \mathrm{~J}}, \mathrm{BP} 4 \mathrm{~T}_{3 \mathrm{~J}}$, and $\mathrm{BP}_{4} \mathrm{~T}_{1 \mathrm{~J}}$ (refer to Section 3.13)) are used for this purpose. ProDeck4 modules are transversely cut to 12 inches in width into six pieces. Those cut modules are assembled and chemically joined by using Pilo-grips. The assembled specimens are left at room temperature 
for 24 hours for curing. In addition, a longitudinal strain gage is mounted on the bottom surface at the mid span of the test specimens. Specimen sizes are summarized given in Table 3.9.

Table 3.9 Test specimen sizes under three and four point bending

\begin{tabular}{|c|c|c|c|c|c|c|}
\hline & \multicolumn{3}{|c|}{3 point bending } & \multicolumn{3}{|c|}{ 4 point bending } \\
\cline { 2 - 7 } & $\mathbf{1}$ cell & $\mathbf{3}$ cell & $\begin{array}{c}\text { 3 cell } \\
\text { (joint) }\end{array}$ & $\mathbf{1}$ cell & $\mathbf{3}$ cell & $\begin{array}{c}\text { 3 cell } \\
\text { (joint) }\end{array}$ \\
\hline Specimen & $\mathrm{BP}_{\mathrm{S}}$ & $\mathrm{BP} 4_{\mathrm{M}}$ & $\mathrm{BP}_{\mathrm{MJ}}$ & $\mathrm{BP} 4_{\mathrm{S}}$ & $\mathrm{BP}_{\mathrm{M}}$ & $\mathrm{BP} 4_{\mathrm{MJ}}$ \\
\hline $\begin{array}{c}\text { Number of } \\
\text { specimen }\end{array}$ & 1 & 1 & 1 & 1 & 1 & 1 \\
\hline $\begin{array}{c}\text { Cross section } \\
\text { (in) }\end{array}$ & $4 \times 6$ & $4 \times 18$ & $4 \times 18$ & $4 \times 6$ & $4 \times 18$ & $4 \times 18$ \\
\hline $\begin{array}{c}\text { length } \\
\text { (in) }\end{array}$ & 72 & 60 & 60 & 72 & 60 & 60 \\
\hline
\end{tabular}

\subsubsection{Test Set-Up}

For the three point bending test, longitudinal single cell and multi-cell specimens are placed on steel roller supports that are welded with steel plates on the top and bottom surfaces. The simple support system is also placed and bolted on trapezoidal concrete blocks. Test specimens are placed on this support system with a test span of 48 inches in length in both single and multi-cell longitudinal specimens. Also, transverse specimens are placed between both simple supports with a test span of 132 inches in length. To apply the load, the MTS loading actuator is used to induce a concentrated load at the mid span of the test specimens. Vertical deflection at mid span is measured by using a linear variable differential transducer (LVDT). Thus, applied load data are directly monitored from the MTS controller, whereas vertical deflection and strain data are acquired by connecting these sensors to a data acquisition system. Those data are managed through using strain smart software. Three point bending test set up is illustrated in Figure 3.26. 


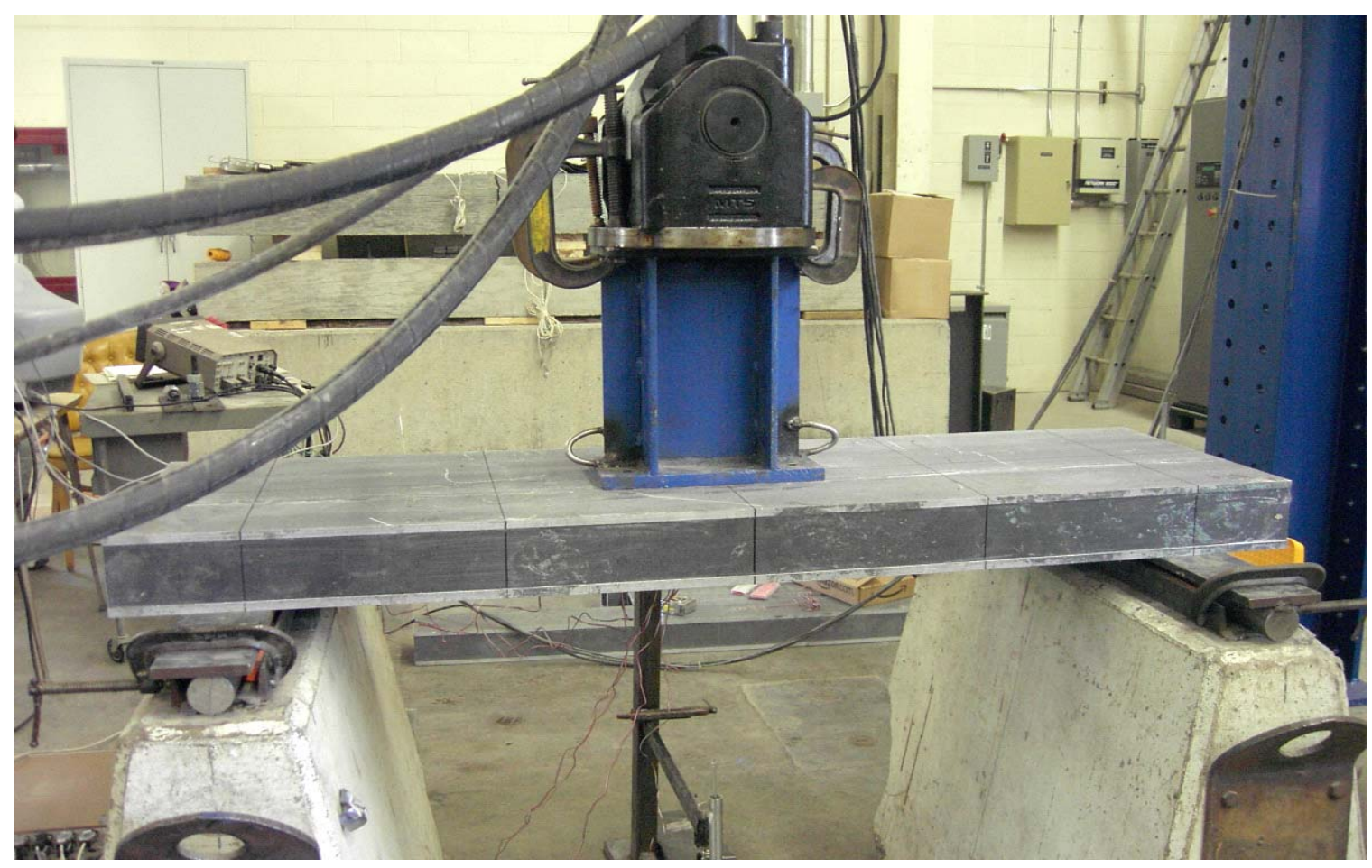

Figure 3.26 Three point bending test set-ups of a longitudinal specimen

For four point bending tests, both longitudinal and transverse specimens are also placed on the same support system that is mentioned before in the three point test set-up. In addition, a stiff transfer load beam is placed on other steel rollers located on the top surface of the test specimens. The distance between both steel rollers on the test specimens is measured to 24 inches in length for the longitudinal specimens. For transverse specimens, the above mentioned distance varies depending on the number of transverse joints for the test specimens. As in the three point bending, a concentrated load is applied into a stiff transfer load beam that induces two equal reactions at steel roller positions over the top surface of the test specimens. The test specimens are bent under four point bending load. To measure vertical deflection data, LVDTs are used to measure vertical deflection at mid span and roller reaction positions. Applied load data is directly obtained from the MTS loading actuator. For recording strain and deflection data, a data acquisition system is connected to those sensors and strain smart software is used to transform electric signals into calibration values. Four 
point bending test set up of both longitudinal and transverse specimens is illustrated in Figures 3.27 and 3.28 .

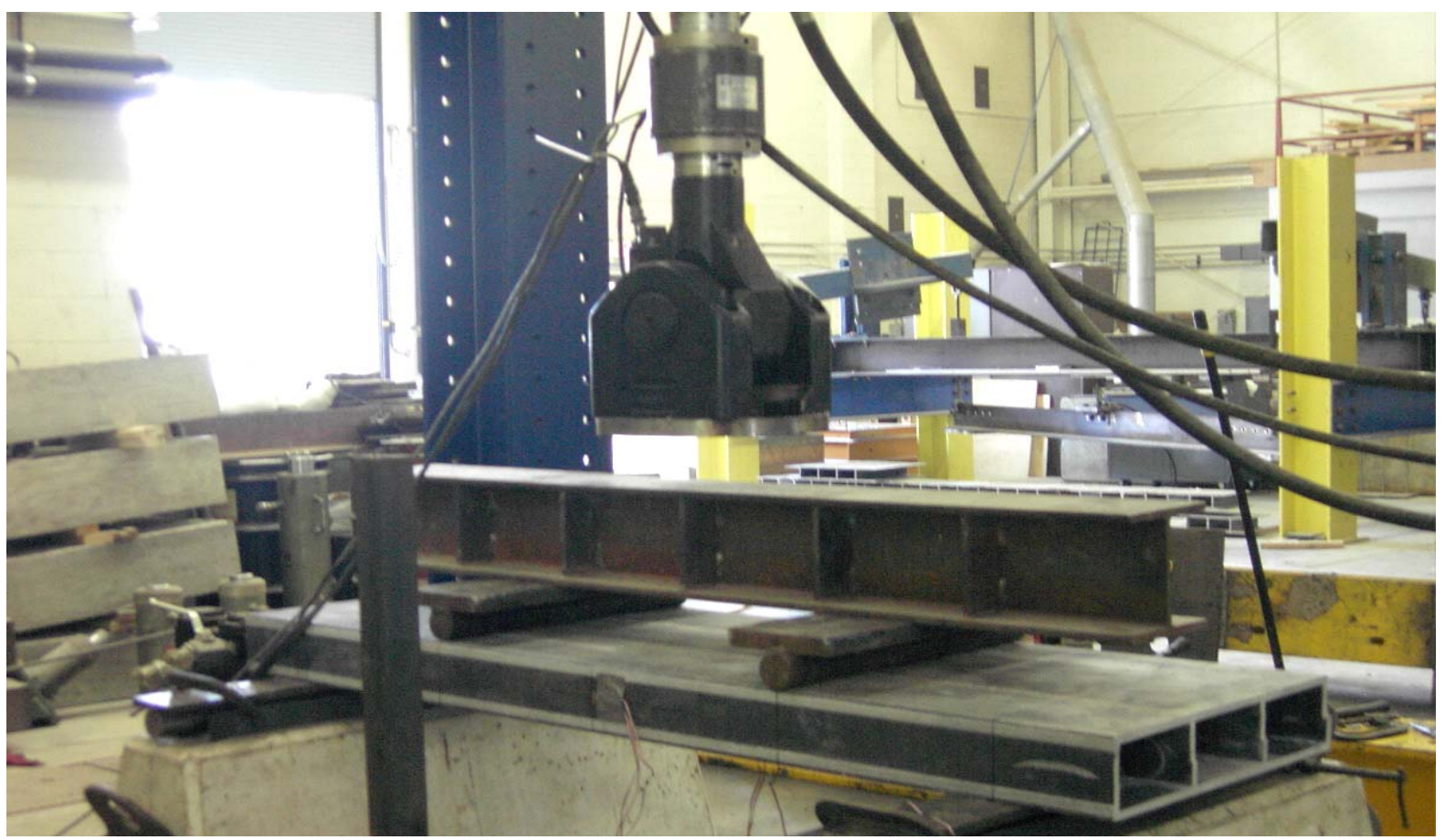

Figure 3.27 Four point bending test set-up of longitudinal specimens

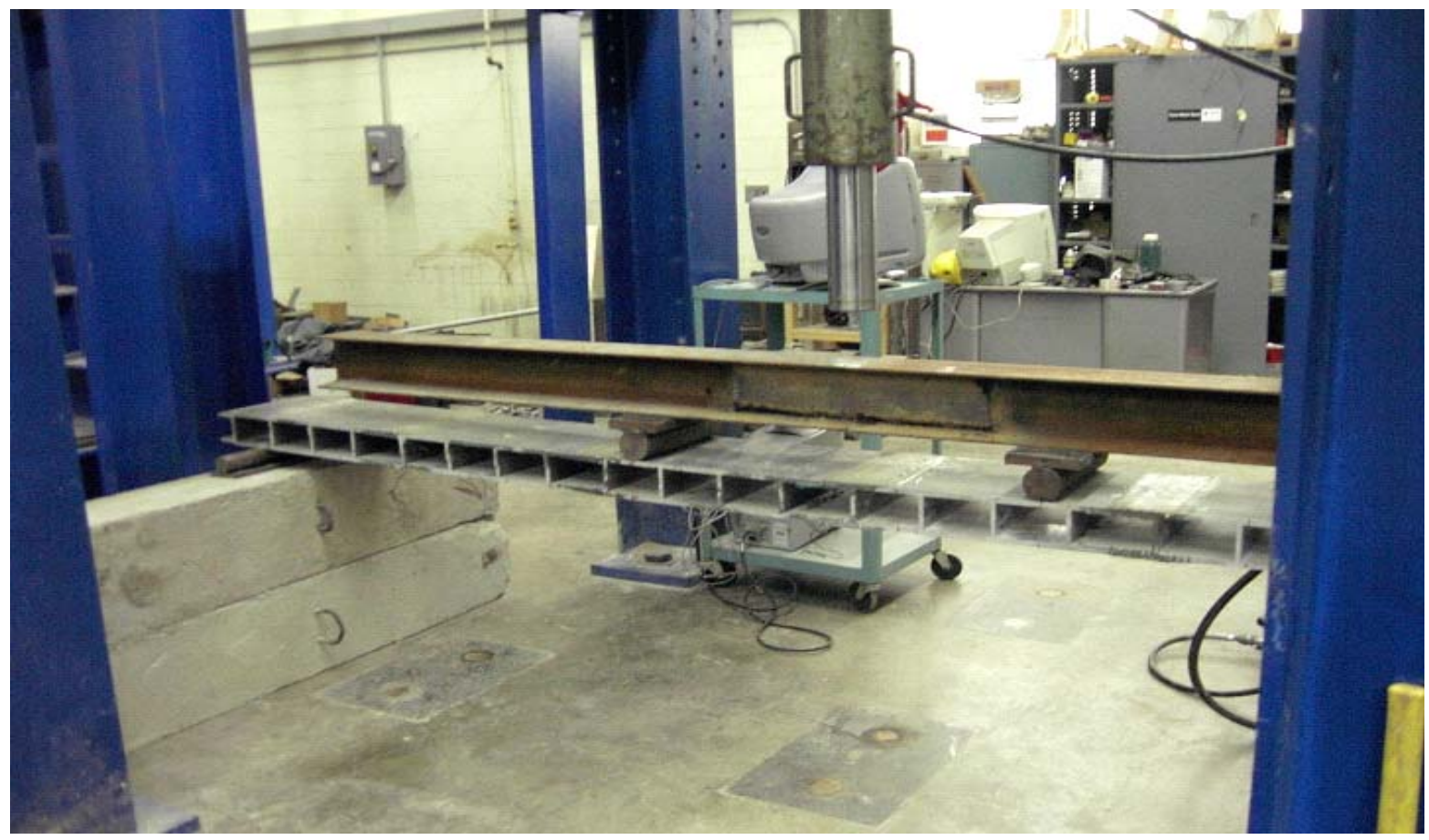

Figure 3.28 Four point bending test set-up of transverse specimens 


\subsection{Punching Shear Test}

Component specimens without and with joints are conducted under compression load over a small patch area to evaluate punching shear strength. In addition, various cross sections and span lengths of test specimens are parameters used in this experiment.

\subsubsection{Component Testing}

ProDeck4 modules are longitudinally cut corresponding to cell direction (strong axis). Three test span to cross section ratios including 3, 4 and 5 are used for single cell cross sections. In addition, a ProDeck 4 module is prepared for dimensions of $4 \times 18 \times 36$ inches to be the multi-cell (triple cell) of components without joints.

ProDeck4 modules are assembled and joined with Pilo-grip. Afterwards, the assembled module is left at room temperature about 24 hours for curing. The assembled module is cut to have the same dimensions as the multi-cell specimen without joints. Summary of the test specimen sizes is given in Table 3.10 and test set-up of single cell specimens is presented in Figure 3.29.

Table 3.10 Test specimen sizes of punching shear

\begin{tabular}{|c|c|c|c|c|c|c|c|c|}
\hline Specimen & Type & Level & Cell & $\begin{array}{l}\text { Number of } \\
\text { specimens }\end{array}$ & $\begin{array}{l}\text { Length } \\
\text { (in) }\end{array}$ & $\begin{array}{l}\text { Test span } \\
\text { (in) }\end{array}$ & $\begin{array}{c}\text { Width } \\
\text { (in) }\end{array}$ & $\begin{array}{c}\text { Depth } \\
\text { (in) }\end{array}$ \\
\hline $\mathrm{PP}_{\mathrm{S} 3}$ & \multirow{5}{*}{ ProDeck4 } & Component & single cell & 1 & 16 & 12 & 6 & 4 \\
\hline $\mathrm{PP}_{\mathrm{S} 4}$ & & Component & single cell & 1 & 20 & 16 & 6 & 4 \\
\hline $\mathrm{PP}_{\mathrm{S} 5}$ & & Component & single cell & 1 & 24 & 20 & 6 & 4 \\
\hline $\mathrm{PP}_{\mathrm{M}}$ & & Component & multi-cell & 1 & 36 & 30 & 18 & 4 \\
\hline $\mathrm{PP} 4_{\mathrm{MJ}}$ & & $\begin{array}{l}\text { Component } \\
\text { with joint }\end{array}$ & multi-cell & 1 & 36 & 30 & 18 & 4 \\
\hline
\end{tabular}




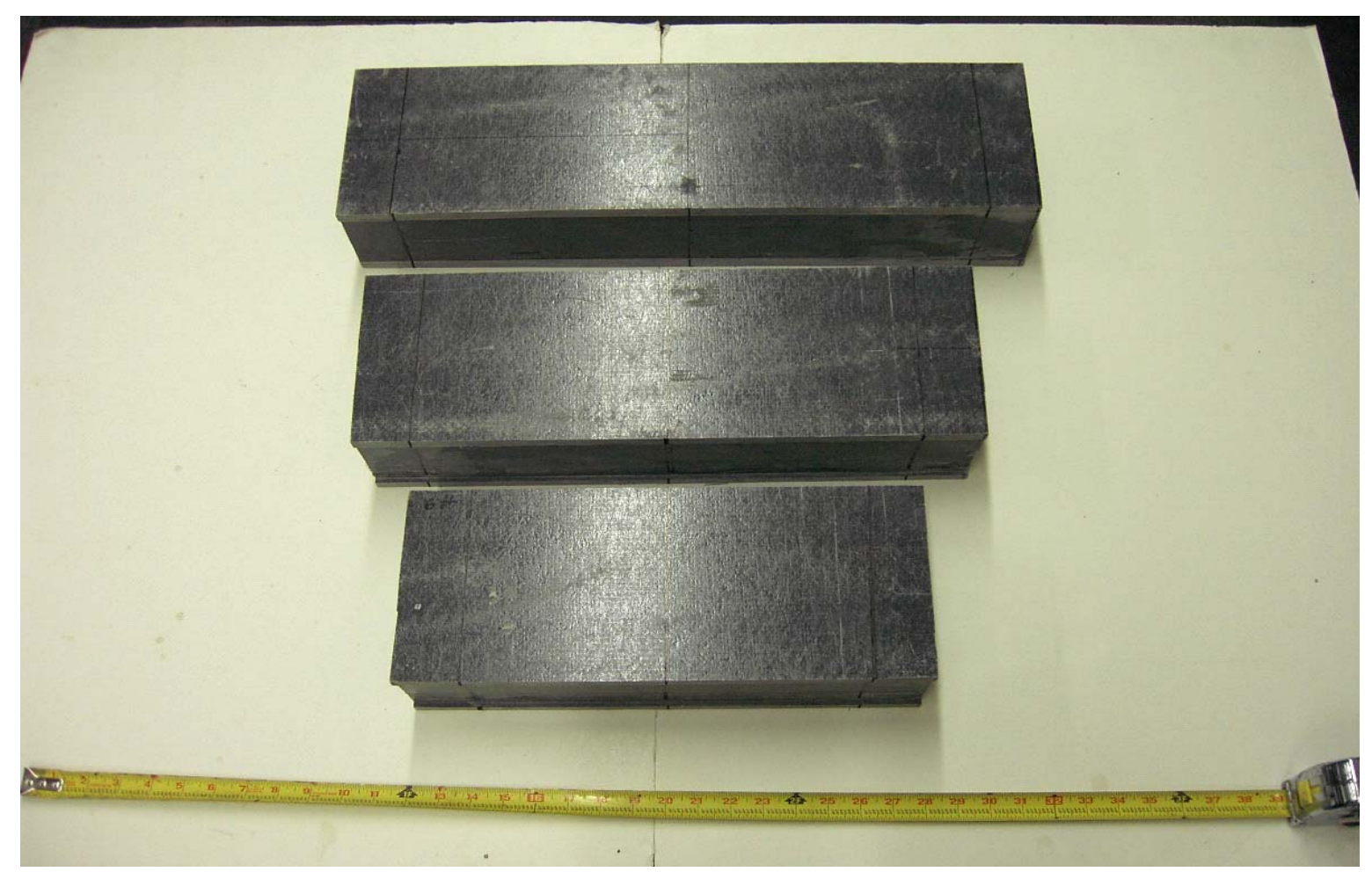

Figure 3.29 single cell component specimens of punching shear test

\subsubsection{Test Set-Up}

For the punching shear test, a Baldwin hydraulic testing machine is used to apply a patch load on the test specimens. For ProDeck4 specimens, these specimens are placed on simply supported steel rollers that rest on the testing steel floor of the testing machine. Test spans of single cell specimens are varied to obtain different cross-section height to test span ratio. Therefore, the test spans of single cell specimens are 12, 16, and 20 inches corresponding to test span to depth ratios of 3, 4 and 5, respectively. A small steel plate with dimensions of $2 \times 2.5 \times 1$ inches is placed on the center of the top specimen surface to induce a punching load over the patch area. To measure vertical deflection, a thin extension plate is attached to the bottom surface of the test specimen. A load cell and LVDT are connected to a data acquisition system for monitoring applied load and vertical deflection data. The punching shear test set-up is presented in Figure 3.30. 


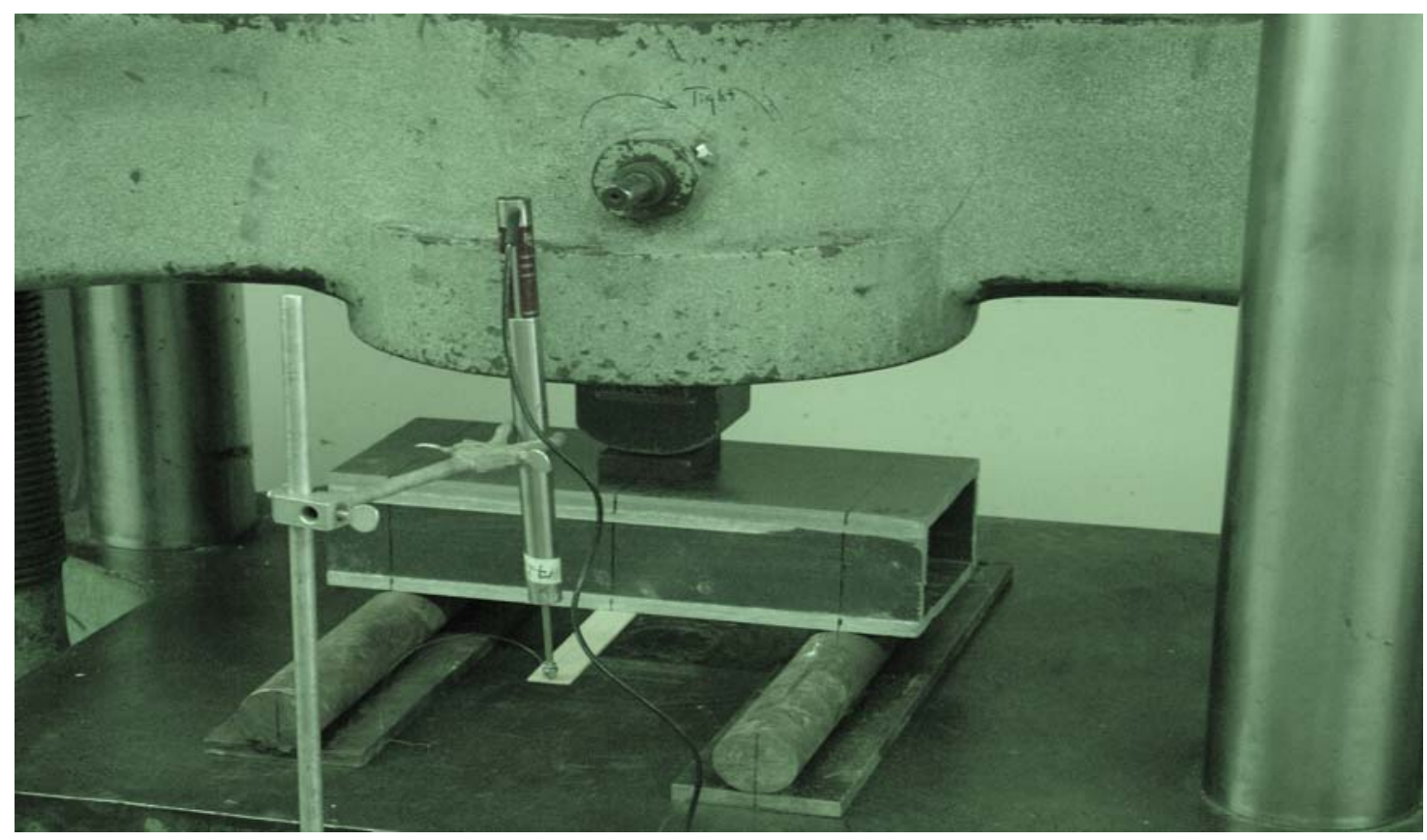

Figure 3.30 Punching shear test set-up of component specimens

\subsection{Web Buckling Test}

To study web buckling behavior of FRP decks, web specimens are tested under compression load. Test specimens are prepared by cutting web portions from ProDeck4 modules. In this experiment, test specimens include single, double and four web types as illustrated in Figure 3.31. To monitor longitudinal strain data, a regular strain gage is attached on the web surface of the test specimens. Sizes and number of test specimens are summarized in Table 3.11.

Table 3.11 Test specimen sizes of web buckling test

\begin{tabular}{|c|c|c|c|c|c|c|c|}
\hline Specimen & Type & Level & $\begin{array}{c}\text { Number } \\
\text { of } \\
\text { webs }\end{array}$ & $\begin{array}{c}\text { Number } \\
\text { of } \\
\text { specimens }\end{array}$ & $\begin{array}{l}\text { Length } \\
\text { (in) }\end{array}$ & $\begin{array}{l}\text { Width } \\
\text { (in) }\end{array}$ & $\begin{array}{l}\text { Depth } \\
\text { (in) }\end{array}$ \\
\hline $\mathrm{WB}_{\mathrm{C} 1}$ & \multirow{5}{*}{ ProDeck4 } & Coupon & 1 & 3 & 1 & 1 & 4 \\
\hline $\mathrm{WB}_{\mathrm{CO} 2}$ & & Component & 2 & 2 & 9 & 1 & 4 \\
\hline $\mathrm{WB}_{\mathrm{CO} 4}$ & & Component & 4 & 2 & 18 & 1 & 4 \\
\hline $\mathrm{WB}_{\mathrm{J} 2}$ & & $\begin{array}{c}\text { Component } \\
\text { with joint }\end{array}$ & 2 & 2 & 9 & 1 & 4 \\
\hline $\mathrm{WB}_{\mathrm{J} 4}$ & & $\begin{array}{l}\text { Component } \\
\text { with joint }\end{array}$ & 4 & 2 & 18 & 1 & 4 \\
\hline
\end{tabular}




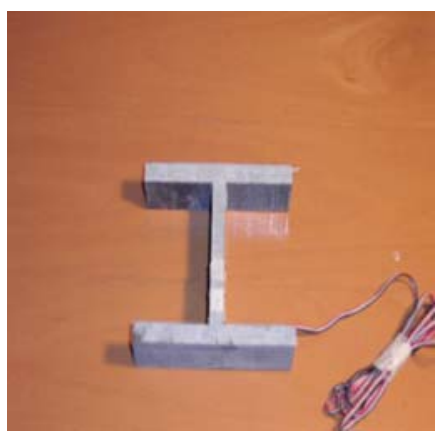

(a)

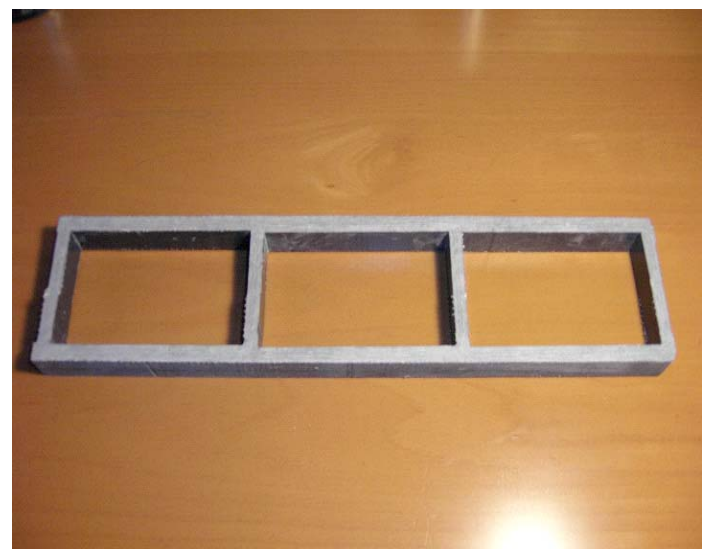

(d)

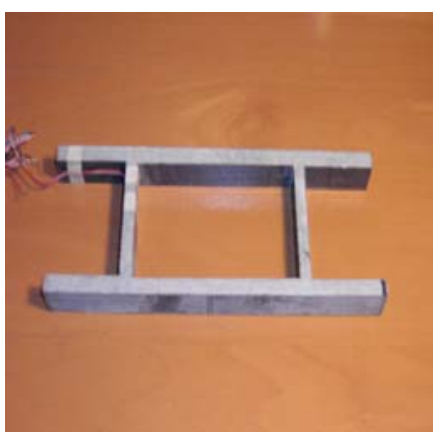

(b)

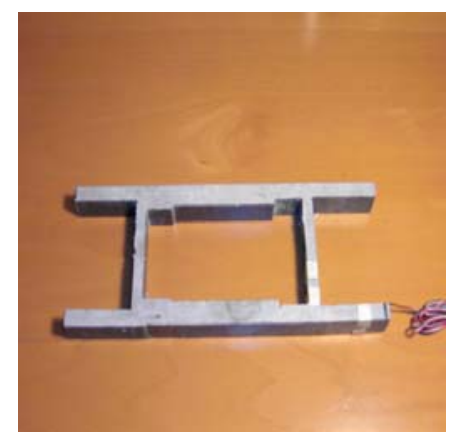

(c)

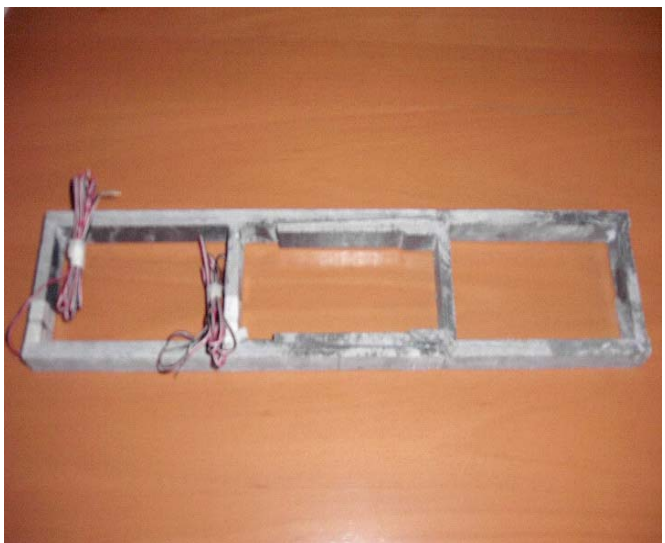

(e)

Figure 3.31 Test specimens of web buckling experiment

(a) Single web-component (b) Double web-component (c) Double web-component with joint (d) Module-component (e) Module- component with joint

\subsubsection{Test Set-Up}

A Baldwin hydraulic testing machine is used to apply compression load. Test specimens are located on a thick steel plate over the testing steel floor of the testing machine. Thick steel beams are placed over the test specimens. Load is applied loaded on to a thick steel beam and transferred from the flange into the web of the test specimens. Load cell and strain gages are also connected to a data acquisition system for monitoring applied load and strain data through strain smart software. The test set-up of the web buckling test is presented in Figure 3.32. 


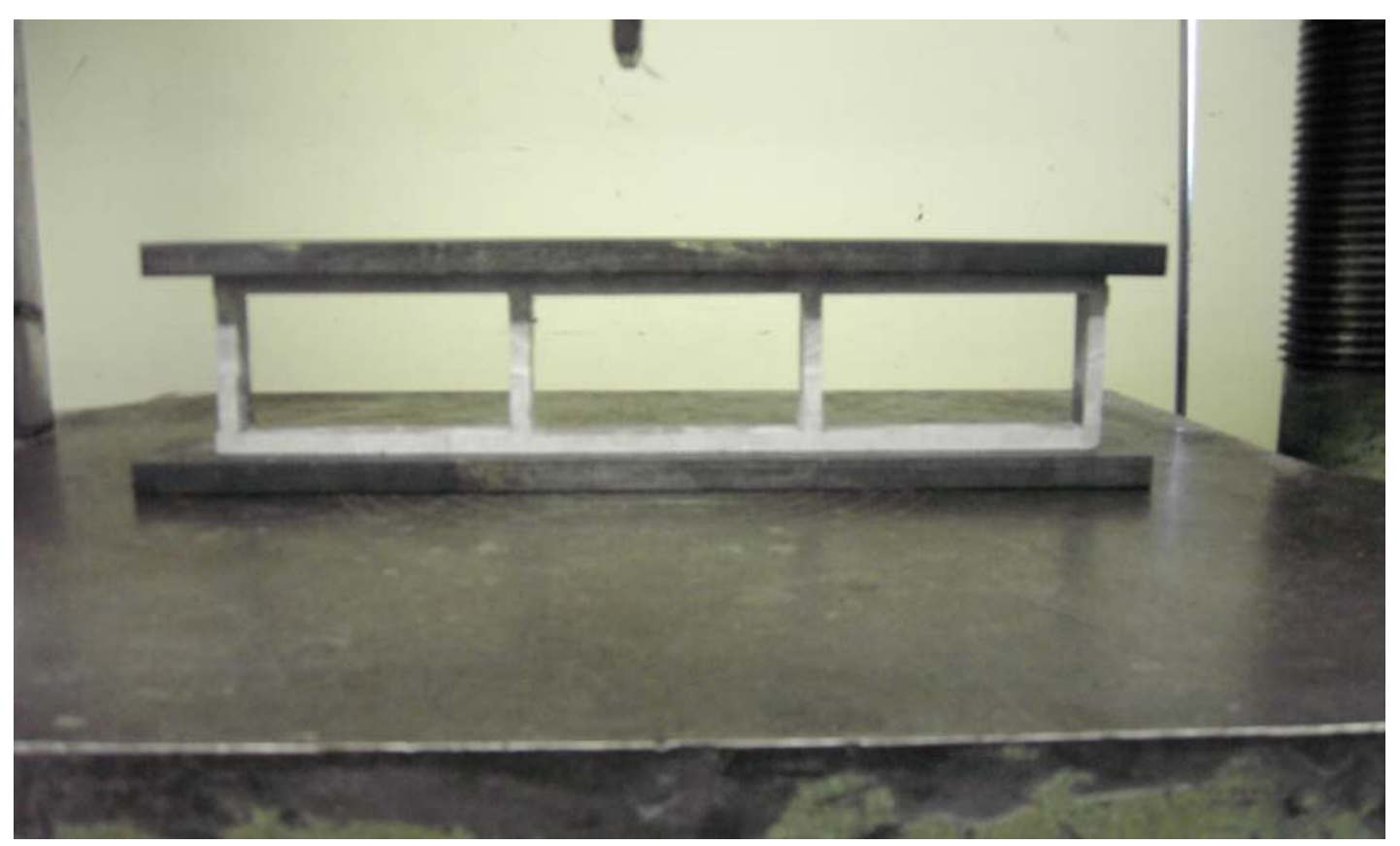

Figure 3.32 Test set up of web bucking

\subsection{Shear of Web-Flange Junctions}

The main purpose in this section is to evaluate the shear behavior and strength of web-flange junctions for open and closed FRP cross sections. Specimens are tested under concentrated loads by using a shear apparatus for the web-flange junctions. This apparatus is modified from an original apparatus that was built by Turvey and Zhang (Turvey 2004). The preparation of test specimens and testing procedures are given as follows:

\subsubsection{Coupon Testing}

Open and closed FRP cross section specimens are transversely cut into specific lengths to provide a series of shear test specimens for this experiment. Three different lengths of test specimens (1, 1.5 and 2 inches) are chosen. The test specimens are illustrated in Figure 3.33. In addition, the sizes and number of the test specimens are summarized in Table 3.12. 


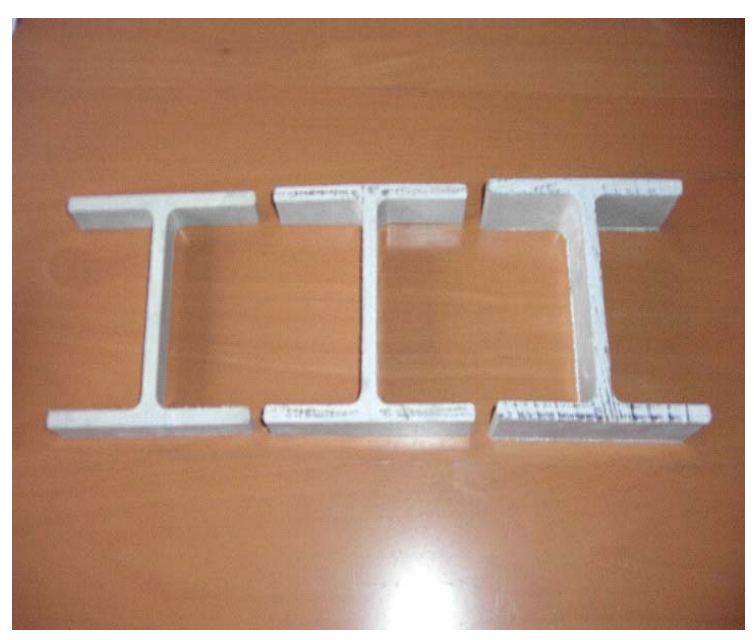

(a)

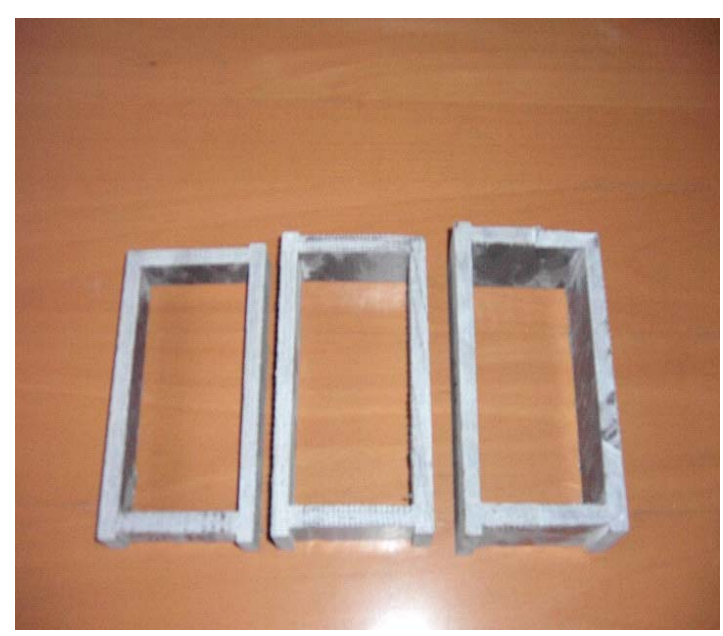

(b)

Figure 3.33 Test specimens of web-flange junctions

(a) Test specimens of open sectional members

(b) Test specimens of closed sectional members

Table 3.12 Specification of web-flange junction specimens

\begin{tabular}{|c|c|c|c|c|c|c|}
\hline Specimen & Type & $\begin{array}{l}\text { Cross } \\
\text { section }\end{array}$ & $\begin{array}{c}\text { Number } \\
\text { of } \\
\text { specimens }\end{array}$ & $\begin{array}{l}\text { Thickness } \\
\text { (in) }\end{array}$ & $\begin{array}{l}\text { Width } \\
\text { (in) }\end{array}$ & $\begin{array}{l}\text { Length } \\
\text { (in) }\end{array}$ \\
\hline $\mathrm{WJ}_{\mathrm{O} 1}$ & & \multirow[t]{3}{*}{ Open } & 3 & 1.0 & 0.375 & 6 \\
\hline $\mathrm{WJ}_{\mathrm{O} 1.5}$ & & & 3 & 1.5 & 0.375 & 6 \\
\hline $\mathrm{WJ}_{\mathrm{O} 2}$ & & & 3 & 2.0 & 0.375 & 6 \\
\hline $\mathrm{WJ}_{\mathrm{C} 1}$ & \multirow[t]{3}{*}{ ProDeck4 } & \multirow[t]{3}{*}{ Close } & 3 & 1.0 & 0.435 & 4 \\
\hline $\mathrm{WJ}_{\mathrm{C} 1.5}$ & & & 4 & 1.5 & 0.435 & 4 \\
\hline $\mathrm{WJ}_{\mathrm{C} 2}$ & & & 3 & 2.0 & 0.435 & 4 \\
\hline
\end{tabular}

\subsubsection{Shear Apparatus}

L shape base of steel with dimensions of $11.5 \times 7.75 \times 0.5$ inches is used to be the main part of the load frame. This L-shape frame is placed on the steel plate of the universal testing machine during the test process. Two small steel supports are fixed on the vertical face of the L-shape base providing bearing support to the bottom flange of the test specimens. However, 
these supports can be vertically moved to adjust level of test specimens. Test specimens are placed on the L-shape load frame by clamping the flange with a steel clamping part. Also, steel clamping part can be vertically adjusted depending on the sizes of the test specimens. Small steel blocks that are used as supports are positioned between the load-frame and the bottom web surface of the test specimens. When the specimens are loaded, small steel supports are contacted with the bottom web surface of test specimens during the test process. Therefore, rotation of the web is prevented. A circular steel rod with a diameter of 1 inch is welded to steel plate and used as a load head. This applied load head is vertically located on the top web surface of the test specimens and connected to the loading head of the universal testing machine. Thus, the applied load is transferred from the loading head of the testing machine into the applied load head of the L-shape frame and from this applied load head into the test specimens until the web-flange junctions fail in shear mode. The L shape load frame for this experiment is presented in Figure 3.34.

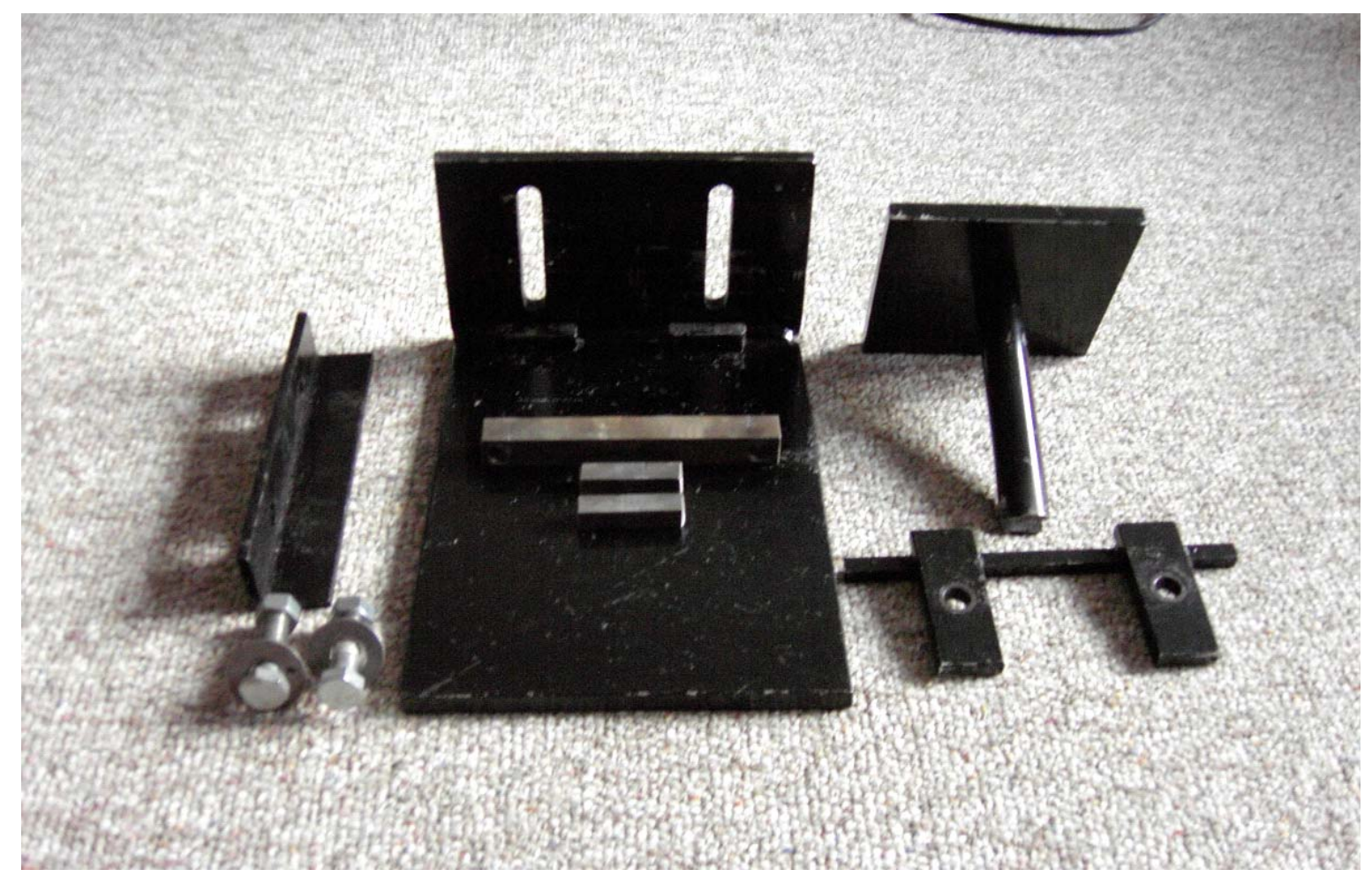

Figure 3.34 Web-flange shear apparatus 


\subsubsection{Test Set-Up}

Test specimens are placed on the web-flange shear apparatus. Specimens are clamped to the end of the vertical plate of the L shape load frame by using bolts and clamping parts. The other end of the specimens sits on the small steel support. The test span of test specimens in this experiment is 4 inches measured from the clamped support to the simple support. To reduce the effect of bending moment induced into web-flange junctions, the loading head should be located about 1 inch from the clamped support. A Baldwin hydraulic testing machine is used to apply a compression load in this experiment. In addition, the vertical displacement of the steel floor of the testing machine is monitored by using an electronic displacement transducer (LVDT). Applied load and displacement data are automatically recorded by a data acquisition system and strain smart software. Test set-up of test specimens is illustrated in Figures 3.35 and 3.36.

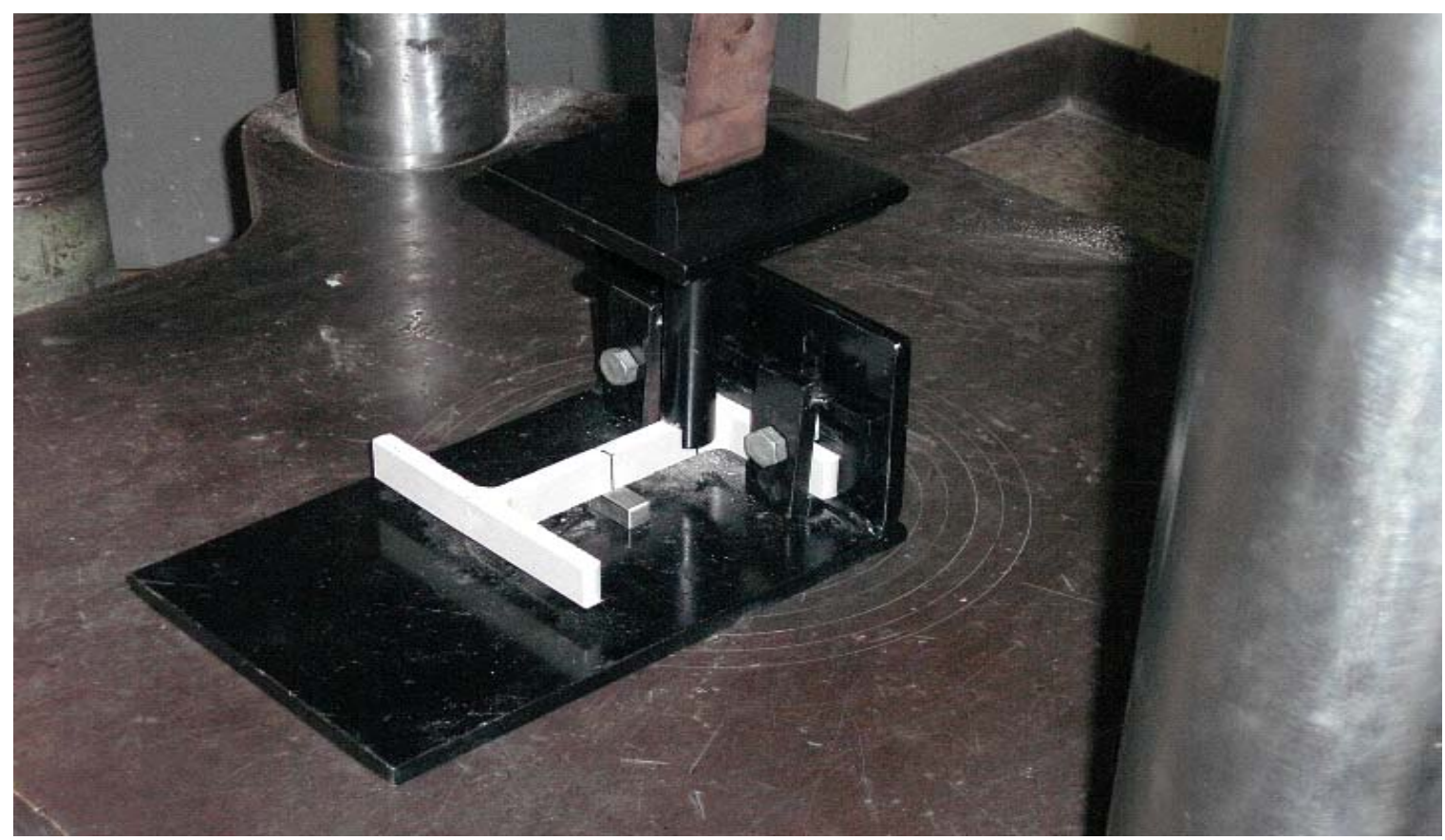

Figure 3.35 Test set-up of web-flange junction test 


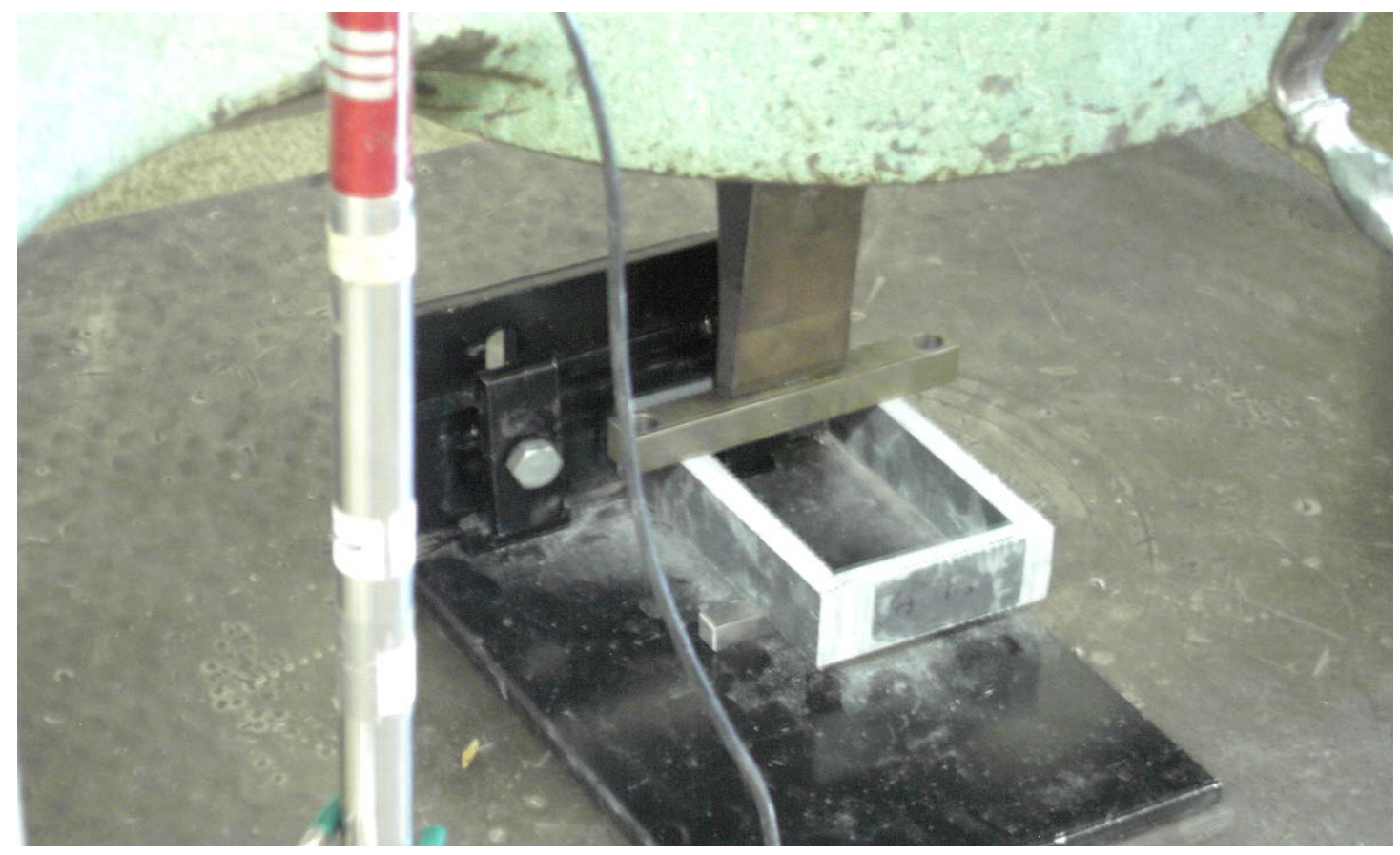

Figure 3.36 Test set-up of web-flange junction test

\subsection{Local Deflection}

Deflection of contiguous flanges of cross section of the test specimens is the focus of this experiment. Four different types of test specimens including ProDeck4, ProDeck4 with joints, ProDeck8, and SuperDeck are tested under concentrated and uniform load. Simple and rigid supports are used for each loading case in specimen testing.

\subsubsection{Component Testing}

For ProDeck4, test specimens are prepared by cutting multi-cell modules along the transverse direction of 1 inch in width. In addition, test specimens with joints at the center cell of the cross section are also prepared by using the same procedure as was used for transverse specimens with joints of the web buckling test in Section 3.10. For ProDeck8 and SuperDeck, specimens are also cut along a transverse direction of 1 inch in width. Regular strain gages are attached at the mid span of both top and bottom flange. 


\subsubsection{Test Set-Up}

Test specimens are placed on pin supports at both ends. The test span of the test specimens depends on specimen types. For rigid base support, specimens are located on a thick steel plate through the length of the test specimen. In addition, pin supports are positioned underneath all web portions of the test specimens for continuous supports. For deflection reading, dial gages are used to measure deflection at the mid span of the bottom and top flange in the case of simple support. Only the mid span deflection of the top flange is measured in the case of rigid base support. A Baldwin hydraulic testing machine is used to apply load in this experiment. For uniform load, a 0.5 inch thick rubber patch is placed through the length of loading area. A thick steel beam is placed over that rubber patch and used to uniformly transfer load from the loading head of the testing machine into the loading span of the test specimens. For the concentrated load, a 0.75 inch length of rubber patch and steel plate are placed over the mid span of the test specimen. An applied load is also transferred from the loading head passing through the steel plate and rubber patch into the test specimens. To monitor the applied load and strain data, load cell and strain gages are connected to the data acquisition system. Strain smart software is used to transform electrical signals during testing into mechanical data. In addition, the summary of specimen dimensions, test span, loading and support conditions are given in Table 3.13. The test set-up of this experiment is illustrated in Figure 3.37. 


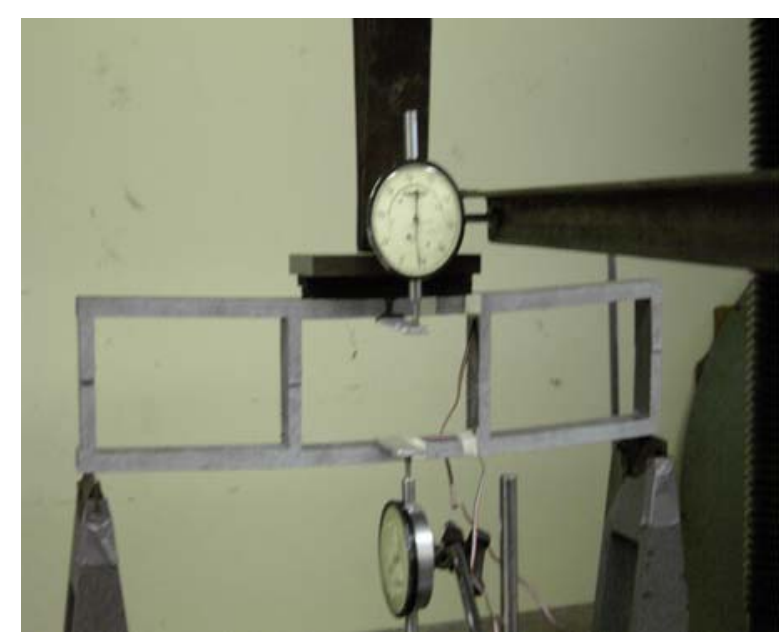

(a)

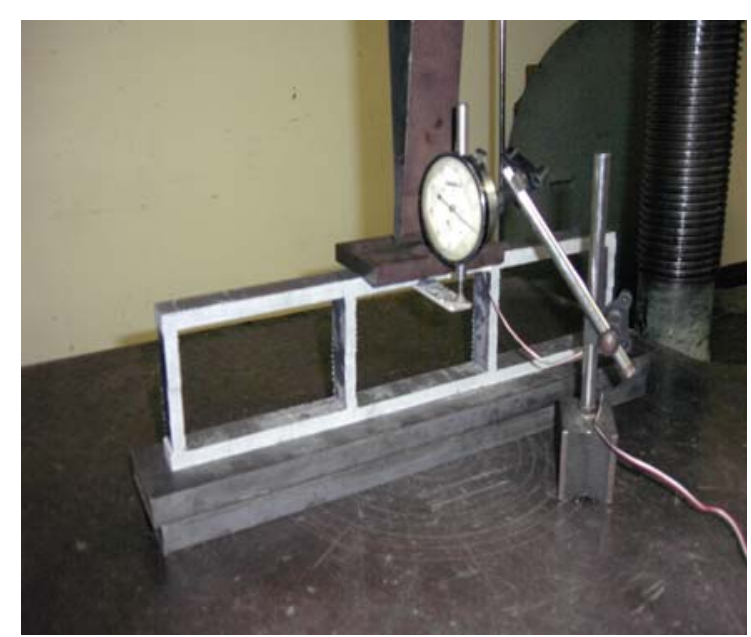

(b)

Figure 3.37 Local deflection experiments of ProDeck4 specimens

(a) simple support

(b) rigid base support

Table 3.13 Test specimen sizes local deflection

\begin{tabular}{|c|c|c|c|c|c|c|c|c|}
\hline \multirow[t]{2}{*}{ Specimen } & \multirow[t]{2}{*}{ Type } & \multirow{2}{*}{$\begin{array}{l}\text { Height } \\
\text { (in) }\end{array}$} & \multirow{2}{*}{$\begin{array}{l}\text { Length } \\
\text { (in) }\end{array}$} & \multirow{2}{*}{$\begin{array}{l}\text { Test } \\
\text { Span } \\
\text { (in) }\end{array}$} & \multicolumn{2}{|c|}{ Load } & \multirow[t]{2}{*}{ Support } & \multirow{2}{*}{$\begin{array}{l}\text { Loading } \\
\text { span } \\
\text { (in) }\end{array}$} \\
\hline & & & & & Condition & $\begin{array}{c}\text { Loading } \\
\text { span } \\
\text { (in) }\end{array}$ & & \\
\hline $\mathrm{LDP}_{4}: 1$ & \multirow[t]{11}{*}{ ProDeck4 } & 4 & 18 & 17.5 & UDL & 5 & S.S & 5.85 \\
\hline $\mathrm{LDP}_{4}: 2$ & & 4 & 18 & 17.5 & point & - & S.S & 5.85 \\
\hline $\mathrm{LDP}_{4}: 3$ & & 4 & 18 & 5.85 & UDL & 5 & S.S & 5.85 \\
\hline $\mathrm{LDP}_{4}: 4$ & & 4 & 18 & 5.85 & point & - & S.S & 5.85 \\
\hline $\mathrm{LDP}_{4}: 5$ & & 4 & 18 & 5.85 & UDL & 5 & C.S & 5.85 \\
\hline $\mathrm{LDP}_{4}: 6$ & & 4 & 18 & 5.85 & point & - & C.S & 5.85 \\
\hline $\mathrm{LDP}_{4}: 7$ & & 4 & 18 & 18 & UDL & 5 & R.S & 5.85 \\
\hline $\mathrm{LDP}_{4}: 8$ & & 4 & 18 & 18 & point & - & R.S & 5.85 \\
\hline $\mathrm{LDP}_{4}: 9$ & & 4 & 18 & 17.5 & UDL & 18 & S.S & 18 \\
\hline $\mathrm{LDP}_{4}: 10$ & & 4 & 18 & 18 & UDL & 18 & R.S & 18 \\
\hline $\mathrm{LDP}_{4}: 11$ & & 4 & 18 & 18 & UDL & 6.5 & R.S & 6.5 \\
\hline $\mathrm{LDPJ}_{4}: 1$ & \multirow{2}{*}{$\begin{array}{l}\text { ProDeck4 } \\
\text { with joint }\end{array}$} & 4 & 18 & 17.5 & UDL & 5 & S.S & 5.85 \\
\hline $\mathrm{LDPJ}_{4}: 2$ & & 4 & 18 & 17.5 & point & - & S.S & 5.85 \\
\hline
\end{tabular}




\begin{tabular}{|c|c|c|c|c|c|c|c|c|}
\hline $\mathrm{LDPJ}_{4}: 3$ & & 4 & 18 & 5.85 & UDL & 5 & S.S & 5.85 \\
\hline $\mathrm{LDPJ}_{4}: 4$ & & 4 & 18 & 5.85 & point & - & S.S & 5.85 \\
\hline $\mathrm{LDPJ}_{4}: 5$ & & 4 & 18 & 5.85 & UDL & 5 & C.S & 5.85 \\
\hline $\mathrm{LDPJ}_{4}: 6$ & & 4 & 18 & 5.85 & point & - & C.S & 5.85 \\
\hline $\mathrm{LDPJ}_{4}: 7$ & & 4 & 18 & 18 & UDL & 5 & R.S & 5.85 \\
\hline $\mathrm{LDPJ}_{4}: 8$ & & 4 & 18 & 18 & point & - & R.S & 5.85 \\
\hline $\mathrm{LDPJ}_{4}: 9$ & & 4 & 18 & 17.5 & UDL & 18 & S.S & 18 \\
\hline $\mathrm{LDPJ}_{4}: 10$ & & 4 & 18 & 18 & UDL & 18 & R.S & 18 \\
\hline $\mathrm{LDPJ}_{4}: 11$ & & 4 & 18 & 18 & UDL & 6.5 & R.S & 6.5 \\
\hline $\mathrm{LDP}_{8}: 1$ & \multirow[t]{4}{*}{ ProDeck8 } & 8 & 24 & 12 & UDL & 11 & S.S & 11 \\
\hline $\mathrm{LDP}_{8}: 2$ & & 8 & 24 & 12 & point & - & S.S & 11 \\
\hline $\mathrm{LDP}_{8}: 3$ & & 8 & 24 & 24 & UDL & 11 & R.S & 11 \\
\hline $\mathrm{LDP}_{8}: 4$ & & 8 & 24 & 24 & point & - & R.S & 11 \\
\hline LDS :1 & \multirow[t]{4}{*}{ SuperDeck } & 8 & 12 & 8 & UDL & 5 & S.S & 8 \\
\hline LDS :2 & & 8 & 12 & 8 & point & - & S.S & 8 \\
\hline LDS :3 & & 8 & 12 & 12 & UDL & 5 & R.S & 8 \\
\hline LDS :4 & & 8 & 12 & 12 & point & - & R.S & 8 \\
\hline
\end{tabular}

Note: UDL is uniform distribution load, Point is concentrated load at mid span. S.S. is simple support, C.S. is continuous support, R.S. is rigid base support. 


\subsection{Notation of Specimen Types}

Since there are various specimen types and dimensions, abbreviated names of specimens are necessary to conveniently identify them and avoid confusion with their full names. An abbreviated name system is divided into 10 groups corresponding to testing types. The following descriptions of the abbreviated name system are given below:

\section{Notation:}

Torsion test:

$\mathrm{C}_{1} \mathrm{D}_{4 \mathrm{~L}} \quad$ : unidirectional fiber coupon in longitudinal direction $(\mathrm{b} / \mathrm{t}=4)$

$\mathrm{C}_{1} \mathrm{D}_{6 \mathrm{~L}} \quad$ : unidirectional fiber coupon in longitudinal direction $(\mathrm{b} / \mathrm{t}=6)$

$\mathrm{C}_{1} \mathrm{D}_{8 \mathrm{~L}} \quad$ : unidirectional fiber coupon in longitudinal direction $(\mathrm{b} / \mathrm{t}=8)$

$\mathrm{C}_{1} \mathrm{D}_{10 \mathrm{~L}} \quad$ : unidirectional fiber coupon in longitudinal direction $(\mathrm{b} / \mathrm{t}=10)$

$\mathrm{C}_{1} \mathrm{D}_{4 \mathrm{~T}} \quad$ : unidirectional fiber coupon in transverse direction $(\mathrm{b} / \mathrm{t}=4)$

$\mathrm{CXM}_{2 \mathrm{~L}} \quad$ : XM 3215 fiber coupon in longitudinal direction $(\mathrm{b} / \mathrm{t}=2)$

$\mathrm{CXM}_{10 \mathrm{~L}} \quad$ : XM 3215 fiber coupon in longitudinal direction $(\mathrm{b} / \mathrm{t}=10)$

CP4 $\quad$ : ProDeck4 coupon in longitudinal direction $(b / t=2.3)$

$\mathrm{CP}_{4 \mathrm{~L}} \quad$ : ProDeck4 coupon in longitudinal direction $(\mathrm{b} / \mathrm{t}=4)$

$\mathrm{CP} 4_{6 \mathrm{~L}} \quad$ : ProDeck4 coupon in longitudinal direction $(\mathrm{b} / \mathrm{t}=6)$

$\mathrm{CP} 4_{8 \mathrm{~L}} \quad$ : ProDeck4 coupon in longitudinal direction $(\mathrm{b} / \mathrm{t}=8)$

$\mathrm{CP} 4_{10 \mathrm{~L}} \quad$ : ProDeck4 coupon in longitudinal direction $(\mathrm{b} / \mathrm{t}=10)$

$\mathrm{CP}_{2.3 \mathrm{~T}} \quad$ : ProDeck4 coupon in transverse direction $\quad(\mathrm{b} / \mathrm{t}=2.3)$

$\mathrm{CP8}_{2.2 \mathrm{~L}} \quad$ : ProDeck8 coupon in longitudinal direction $(\mathrm{b} / \mathrm{t}=2.2)$

$\mathrm{CP8}_{2 \mathrm{~T}} \quad$ : ProDeck8 coupon in transverse direction $\quad(\mathrm{b} / \mathrm{t}=2)$

$\mathrm{CP}_{4 \mathrm{~L}} \quad$ : ProDeck8 coupon in longitudinal direction $(\mathrm{b} / \mathrm{t}=4)$

$\mathrm{CP}_{4 \mathrm{~T}} \quad$ : ProDeck8 coupon in transverse direction $\quad(\mathrm{b} / \mathrm{t}=4)$ 
${\mathrm{C} 3 \mathrm{D}_{\mathrm{L}}}_{\mathrm{S}} \quad$ : Three dimensional fiber coupon in longitudinal direction $(\mathrm{b} / \mathrm{t}=2.3)$

$\mathrm{CSF}_{\mathrm{b}} \quad$ : sandwich FRP-wood coupon (beam)

$\mathrm{CSF}_{\mathrm{p}} \quad$ : sandwich FRP-wood coupon (plate)

$\mathrm{CSB}_{0.5} \quad$ : circular solid bar (0.5 in diameter)

$\mathrm{CSB}_{1} \quad$ : circular solid bar (1.0 in diameter)

CT : circular tube

$\mathrm{COP}_{16 \mathrm{~L}} \quad$ : ProDeck4 component in longitudinal direction (16 in long)

$\mathrm{COP}_{144 \mathrm{~L}} \quad$ : ProDeck4 component in longitudinal direction (144 in long)

$\mathrm{COP}_{16 \mathrm{JL}} \quad$ : ProDeck4 component in longitudinal direction with joint (16 in long)

$\mathrm{COP}_{18 \mathrm{~T}} \quad$ : ProDeck4 component in transverse direction (18 in long)

COP4 $4_{18 \mathrm{~T}} \quad$ : ProDeck4 component in transverse direction (18 in long)

COP8 $144 \mathrm{~L} \quad$ : ProDeck8 component in longitudinal direction (144 in long)

COP8 $_{12 \mathrm{~T}} \quad$ : ProDeck8 component in transverse direction (12 in long)

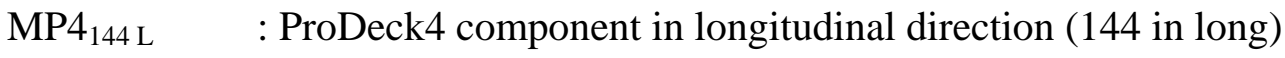

MP4 $4_{144 \mathrm{~J} \mathrm{~L}} \quad$ : ProDeck4 component in longitudinal direction with joint (144 in long)

MP4 $_{144 \mathrm{JFL}} \quad$ : ProDeck4 component in longitudinal direction with joint and fabric (144 in long)

MP4 $_{144 \mathrm{~T}} \quad$ : ProDeck4 component in transverse direction (144 in long)

MP4 $_{144 \text { F1T }}$ : ProDeck4 component in transverse direction with one side fabric (144 in long)

MP4 $_{144 \text { F2T }}$ : ProDeck4 component in transverse direction with two side fabric (144 in long)

$\underline{\text { V-notched beam shear test }}$

$\mathrm{VP}_{\mathrm{L}} \quad$ : ProDeck4 V-notched beam shear specimen in longitudinal direction

$\mathrm{VP}_{\mathrm{T}} \quad$ : ProDeck4 V-notched beam shear specimen in transverse direction 


\section{Cantilever beam test}

$\mathrm{CB}_{\mathrm{R}} \quad$ : ProDeck4 component transverse specimen assembled by using rivet

$\mathrm{CB}_{\mathrm{RG}} \quad$ : ProDeck4 component transverse specimen assembled by using rivet-glue

$\mathrm{CB}_{\mathrm{G}} \quad$ : ProDeck4 component transverse specimen assembled by using glue

\section{$\underline{\text { Racking shear test }}$}

RS

: Racking shear ProDeck4 system specimens

\section{Short beam shear test}

SCP4 $4_{\mathrm{FL}} \quad$ : ProDeck4 short beam shear flange coupon in longitudinal direction

$\mathrm{SCP}_{\mathrm{FT}} \quad$ : ProDeck4 short beam shear flange coupon in transverse direction

SCP4 $4_{\mathrm{WL}} \quad$ : ProDeck4 short beam shear web coupon in longitudinal direction

SCP4 $4_{\mathrm{WT}} \quad$ : ProDeck4 short beam shear web coupon in transverse direction

SCP8 $8_{\mathrm{FL}} \quad$ : ProDeck8 short beam shear flange coupon in longitudinal direction

SCP8 $\quad$ : ProDeck8 short beam shear flange coupon in transverse direction

SBP4 $_{S} \quad$ : ProDeck4 short beam shear component specimen (single cell)

SBP4 $4_{M} \quad$ : ProDeck4 short beam shear component specimen (triple cell)

SBP8 : ProDeck8 short beam shear component specimen

$\underline{\text { Three and four point bending test }}$

$\begin{array}{ll}\mathrm{BP}_{\mathrm{S}} & \text { : ProDeck4 specimen in longitudinal direction (single cell) } \\ \mathrm{BP}_{\mathrm{M}} & \text { : ProDeck4 specimen in longitudinal direction (triple cell) } \\ \mathrm{BP} 4_{\mathrm{M} \mathrm{J}} & : \text { ProDeck4 specimen in longitudinal direction (triple cell with joint) } \\ \mathrm{BP} 4 \mathrm{~T} & \text { :ProDeck4 specimen in transverse direction (system) under three-point } \\ & \text { bending }\end{array}$


$\mathrm{BP}_{4 \mathrm{~J}} \quad$ :ProDeck4 specimen in transverse direction (system) under four-point bending with five joint in bending zone

BP4T $_{3 \mathrm{~J}}$ :ProDeck4 specimen in transverse direction (system) under four-point bending with three joint in bending zone

$\mathrm{BP}_{4} \mathrm{~T}_{1 \mathrm{~J}}$ :ProDeck4 specimen in transverse direction (system) under four-point bending with one joint in bending zone

$\underline{\text { Punching shear test }}$

$\mathrm{PP}_{\mathrm{S} 3} \quad$ : ProDeck4 component punching shear specimen with $(\mathrm{h} / \mathrm{s}=3)$

$\mathrm{PP}_{\mathrm{S} 4} \quad$ : ProDeck4 component punching shear specimen with $(\mathrm{h} / \mathrm{s}=4)$

$\mathrm{PP} 4_{\mathrm{s5}} \quad$ : ProDeck4 component punching shear specimen with $(\mathrm{h} / \mathrm{s}=5)$

$\mathrm{PP} 4_{\mathrm{M}} \quad$ : ProDeck4 component punching shear specimen (multi-cell)

PP4 $\quad$ : ProDeck4 component punching shear specimen (with joint)

$\underline{\text { Web buckling test }}$

$\mathrm{WB}_{\mathrm{C} 1} \quad$ : ProDeck4 single web coupon specimen

WB $\quad$ : ProDeck4 double web component specimen

WB $\quad$ : ProDeck4 module component specimen

$\mathrm{WB}_{\mathrm{J} 2} \quad$ : ProDeck4 double web component with joint specimen

$\mathrm{WB}_{\mathrm{J} 4} \quad$ : ProDeck4 module component with joint specimen

$\underline{\text { Web-flange junction shear test }}$

$\mathrm{WJ}_{\mathrm{O} 1} \quad$ : Open sectional coupon specimen with 1 inch thick

WJ $_{01.5} \quad$ : Open sectional coupon specimen with 1 inch thick

$\mathrm{WJ}_{\mathrm{O} 2} \quad$ : Open sectional coupon specimen with 1 inch thick

$\mathrm{WJ}_{\mathrm{C} 1} \quad$ : ProDeck4 closed sectional coupon specimen with 1 inch thick

$\mathrm{WJ}_{\mathrm{C} 1.5} \quad$ : ProDeck4 closed sectional coupon specimen with 1.5 inch thick 
$\mathrm{WJ}_{\mathrm{C} 2} \quad$ : ProDeck4 closed sectional coupon specimen with 2 inch thick

\section{Local deflection}

$\mathrm{LDP}_{4} \quad$ : Local deflection ProDeck4 specimen with 1 inch in width

LDPJ $_{4} \quad$ : Local deflection ProDeck4 with joint specimen with 1 inch in width

$\mathrm{LDP}_{8} \quad$ : Local deflection ProDeck8 specimen with 1 inch in width

LDS $\quad$ : Local deflection SuperDeck4 specimen with 1 inch in width 


\section{CHAPTER 4}

\section{IN-PLANE SHEAR BEHAVIOR UNDER TORSION}

\subsection{Introduction}

In-plane and out-of-plane displacements of FRP composites are influenced by their low shear modulus $\left(0.25 \sim 0.5 \times 10^{6} \mathrm{psi}\right)$ (Sotiropoulos, 1995). In spite of importance of shear modulus, no existing ASTM standards for shear (such as ASTM-D3518-76) are available (Sotiropoulos 1995). In general, test methods of straight bars under torsion and V-notched beam under concentrated forces are frequently used to evaluate in-plane (xy) shear strength and modulus. The test method under torsion is simpler to use than the V-notched beam shear test method, because the former does not require any special preparation compared to the specimen preparation for V-notched beams (Sonti, 1995).

Generally, the internal resisting moments leading to torsional shear include: 1) primary torsional moment resisted by the cross section that remains perpendicular to the axis of torque and 2) warping moment, induced by non-orthogonality of the cross section to the axis of torsion, called secondary torsion. Primary torsion or classical torsion theory was developed by Saint-Venant in the 1850s. According to Saint-Venant theory, the cross section of a structural member is free to deform out of its plane under torsional loading (Gjelsvik, 1981) which is referred to as free warping or uniform warping, where secondary (or wrapping) stress does not exist. If structural members are supported in a manner to prevent free warping of cross-section under torsional load, then non-uniform warping will be induced resulting in additional shearing stress, which is known as secondary torsion. Secondary 
torsion theory is part of a comprehensive theory of combined flexure and torsion of open thin walled bars developed by Vlasov in the 1930s.

The objective of this chapter is to evaluate the in-plane shear (xy) behavior of composites by both experimental and theoretical analyses. Various types and shapes of FRP (fiber reinforced polymer) composite materials are tested and evaluated under torsion to gain better understanding of their behavior. Simplified Classical Lamination Theory (SCLT) for evaluation of torsional rigidity $(G J)$ under free-warping conditions is developed and validated through experimental data. Moreover, analytical results from classical finite element method are compared with the experimental and theoretical results. A discussion of shear leakage across joints and consequent joint efficiency is presented in this chapter.

In the following section, an experimental program of FRP composite materials under torsion testing is presented.

\subsection{Experimental Program}

Descriptions of test specimens, test set-up and procedures including test apparatus, number of specimens, structural shapes, specimen level, specimen preparation and specimen dimensions are given in Section 3.3.

The experimental data analysis is focused on the plot curves representing the slope of applied torque versus measured rate of twist. The equivalent in-plane shear modulus $\left(\mathrm{G}_{\mathrm{xy}}\right)$ of test specimens is determined from the slope of these plot curves. However, this test procedure is only concerned with Saint Venant's torsional stress induced from warping of a crosssection. The slope of applied torque versus rate of measured twist reveals experimental torsional rigidity as given below:

$$
G J=\frac{T}{\phi}
$$


where, $G J$ is the torsional rigidity of test specimens under applied torsion load $T$ and $\phi$ is the rate of twist.

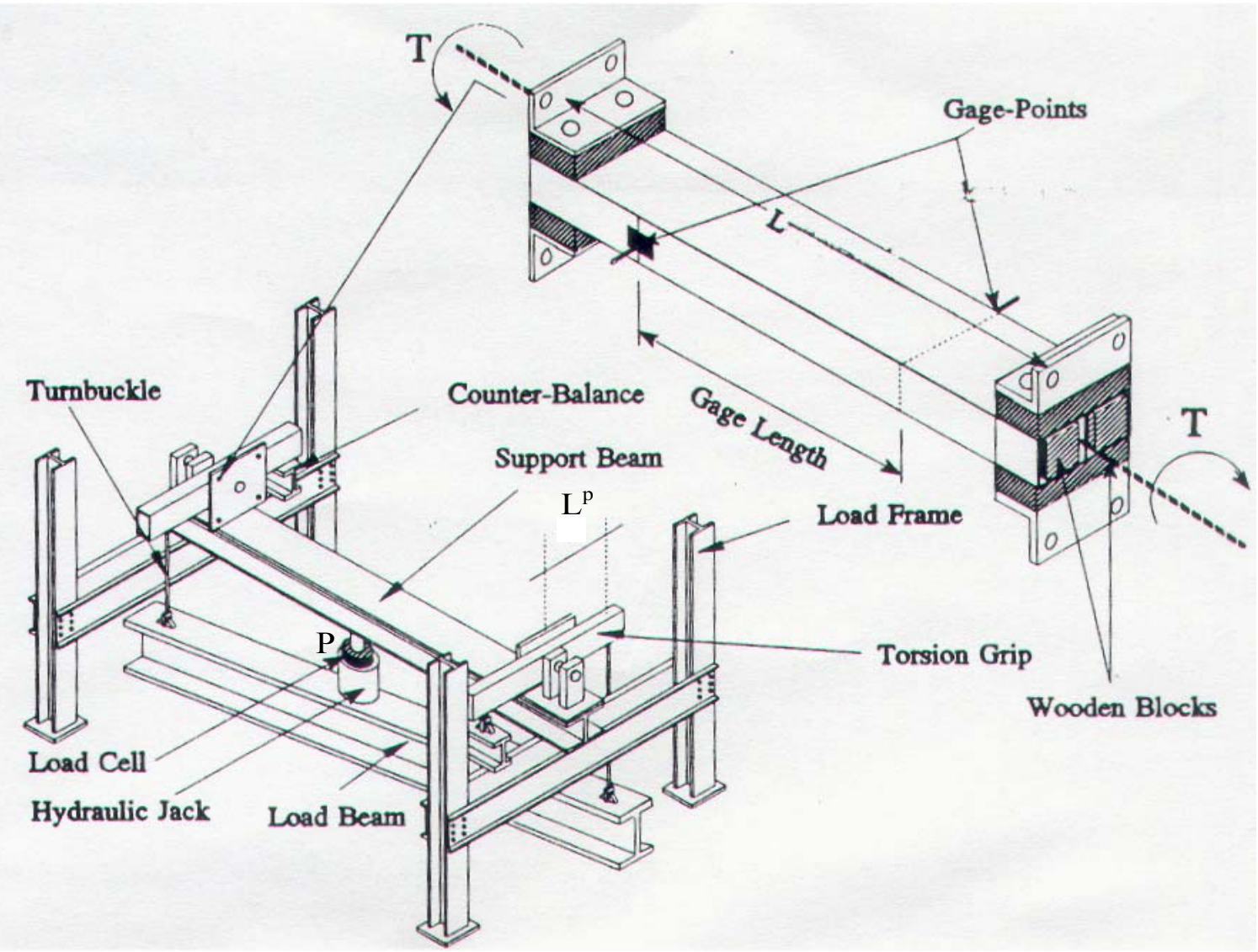

Figure 4.1 Test set-up for torsion test (Sotiropoulos, 1995)

Applied torque at each end of a test specimen is calculated by taking half of the total applied load on the stiff load beam. Therefore, applied torque is determined by multiplying half of the applied load with the distance between the turnbuckle and the pivot point of the testing frame.

$T=\frac{P L^{p}}{2}$

where, $P$ is the applied load on the transfer beam and $L^{p}$ is the distance between the turnbuckle and the pivot point of the testing frame as given in Figure 4.1.

To evaluate the rate of twist $\phi$, angle of twist at different positions is averaged as: 
$\phi=\frac{\left(\theta_{A R}-\theta_{B R}\right)+\left(\theta_{A L}-\theta_{B L}\right)}{2 L^{t}}$

where, $\theta_{A R}, \theta_{B R}, \theta_{A L}$, and $\theta_{B L}$ are the angles of twist at locations $A$ and $B$ as illustrated in Figure 4.2. The $L^{t}$ is the length between the angle measuring points $A$ and $B$.

In addition, the rate of twist at the $\mathrm{i}^{\text {th }}$ location can be calculated from the vertical deflection results as given in Figure 4.3.

$\theta_{i}=\operatorname{Tan}^{-1}\left[\frac{\delta_{i}}{d}\right]$

where, $\delta_{i}$ is the deflection of the extension bar of $\mathrm{i}^{\text {th }}$ location and $\mathrm{d}$ is the length of the arm depending on the dimensions of the test specimens.

The slope of the experimental curve between the applied torque and the measured relative rotation (rate of twist) is represented as torsional rigidity of a test specimen. Therefore, the equivalent in-plane modulus based on the experimental data is defined as the ratio of torsional rigidity to cross-sectional constant.

$\left(G_{x y}\right)_{e}=\frac{G J}{J}$

where, $\left(G_{x y}\right)_{e}$ is an equivalent in-plane shear modulus from the torsion test and $J$ is the torsional constant of the cross section as given in Appendix B. 


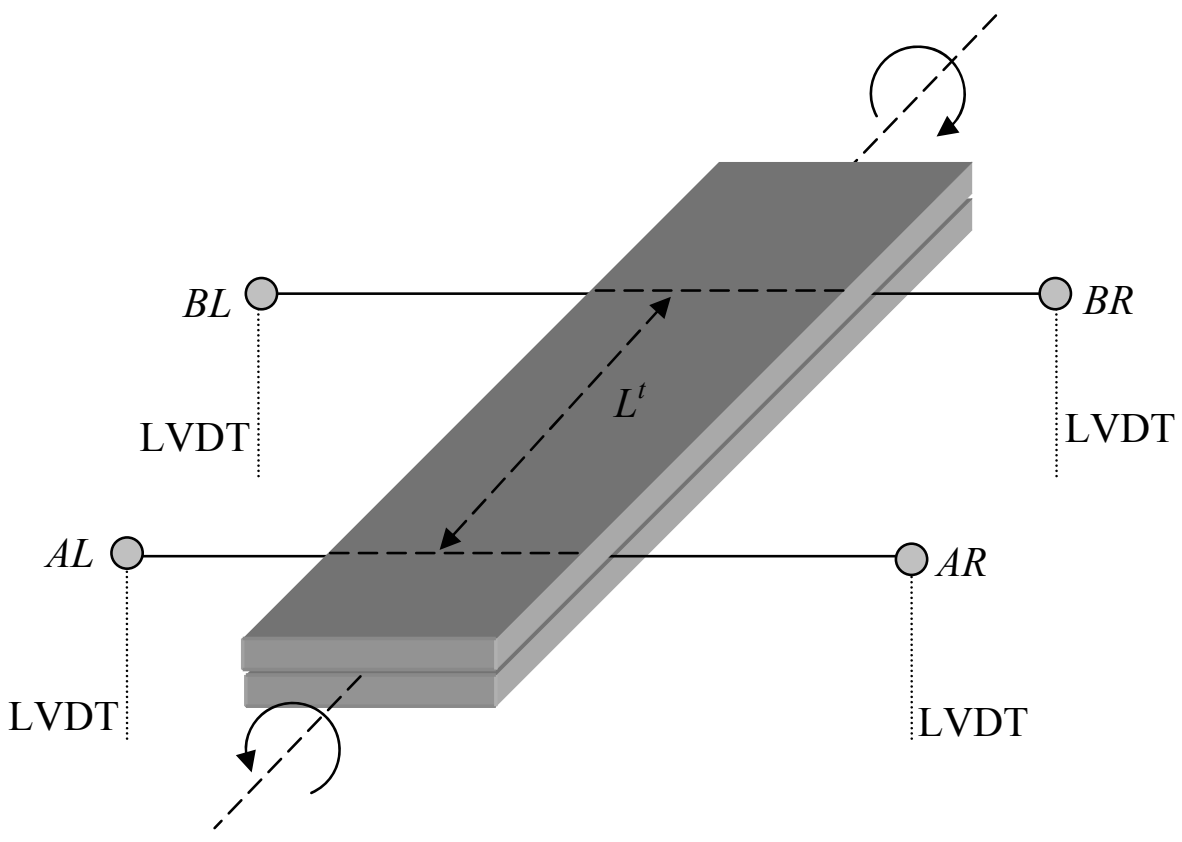

Figure 4.2 Schematic of positions $A$ and $B$ for torsion test

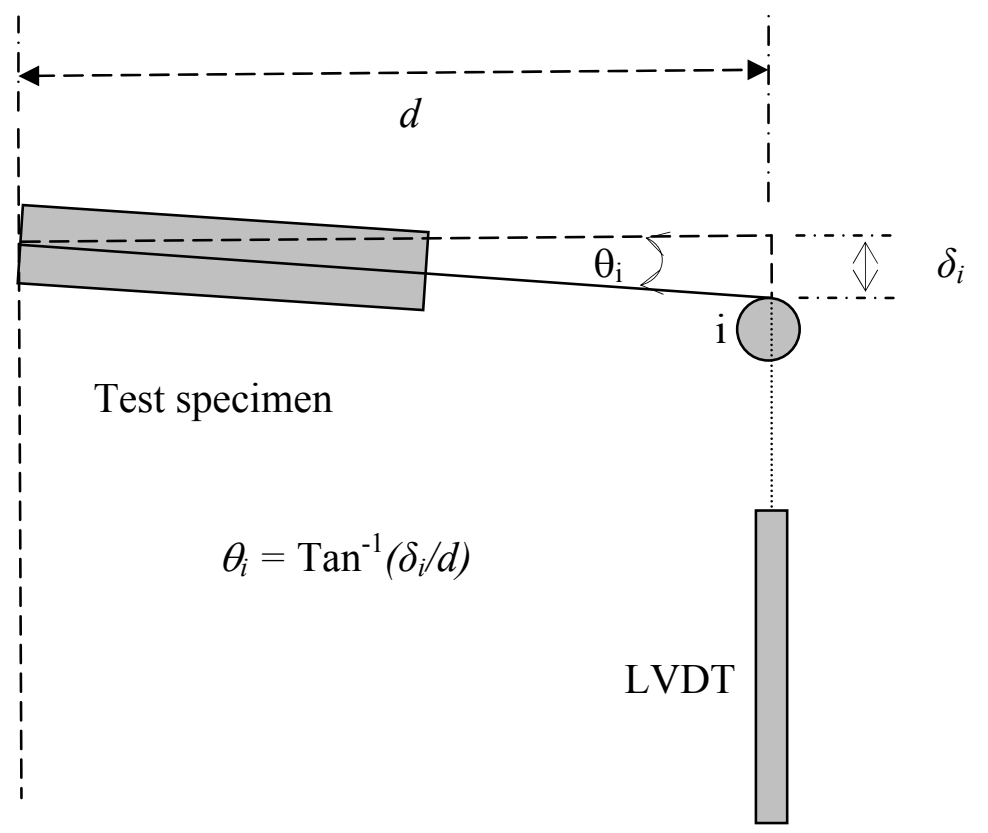

Figure 4.3 Measurement of angle of twist 


\subsection{Simplified Classical Lamination Theory for Torsion}

Generally, FRP composite structures are orthrotropic materials. The mechanical behavior of these structures is much more complex than those of conventional materials such as steel. The torsional behavior of FRP composite structures is not well understood. Therefore, it has become necessary to study the behavior of FRP structural members under torsion.

A Simplified Classical Lamination Theory (SCLT) for bending has been developed to evaluate the bending rigidities by Sotiropoulos (1995). Similar, SCLT for torsion is developed and presented herein. Because of the tedious hand calculations to find stiffness matrix for laminated composites using Classical Lamination Plate Theory (CLPT), the original $6 \times 6$ stiffness matrix is reduced to a $2 \times 2$ matrix without the loss of much accuracy. Also, there are only three necessary elements to be evaluated in the reduced matrix. The results from this research are expected to contribute to the understanding of FRP composite torsional behavior.

Stress-strain relations of composite lamina are presented in both material and global coordinates. These coordinates are referred to throughout this study. In addition, the simplified approach for $G_{x y}$ is derived in appendix A of this report.

Several assumptions are made to simplify the classical lamination theory. The assumptions are: 1) composite laminates are subjected to torsion, 2) laminae in a given laminate are bonded together with no interlaminar slip, 3) no restraints are present at both ends of composite laminates (free-free condition), and 4) normal stresses in $\mathrm{x}$ and $\mathrm{y}$ directions are assumed to be zero while longitudinal $\left(\varepsilon_{\mathrm{x}}\right)$ and transverse $\left(\varepsilon_{\mathrm{y}}\right)$ strains are still allowed. 


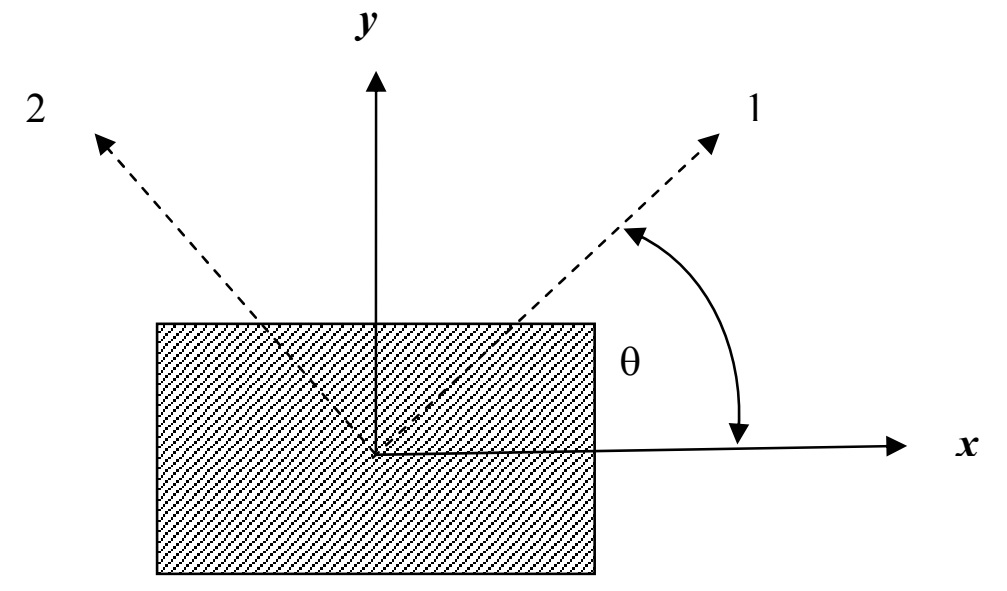

Figure 4.4 $x-y$ global and 1-2 material coordinate

Using these assumptions, the constitutive equations for in-plane stresses are simplified and normal $\left(\varepsilon_{\mathrm{x}}\right.$ and $\left.\varepsilon_{\mathrm{y}}\right)$ strains are rewritten in terms of in-plane shear stress. The global lamina stiffness in terms of sine and cosine functions is then substituted into the constitutive equation. The results are written in terms of Possion's ratio, and fiber, and matrix stiffnesses. It should be noted that lamina stiffness is based on rule of mixture. The terms containing $\left(v_{21}\right)^{2}$ are very small compared to others, and are neglected. Also, the terms of (1$\left.v_{12} v_{21}\right)$ are reduced to unity due to the very small value of the product of $v_{12} v_{21}$. Thus, simplified stress and strain relation based on classical lamination plate theory, derived in Appendix A, is given as:

$\tau_{x y}=\left(\frac{1}{(\operatorname{Cos} 2 \theta)^{2}\left(\frac{1}{G_{12}}\right)+(\operatorname{Sin} 2 \theta)^{2}\left(\frac{1}{E_{11}}+\frac{1}{E_{22}}+\frac{2 v_{21}}{E_{22}}\right)}\right) \gamma_{x y}$

where, $\theta$ is the angle that the $x-y$ coordinate needs to be rotated to coincide with $1-2$ material coordinate, $E_{11}$ is the longitudinal modulus of the lamina, $E_{22}$ is the transverse modulus of the lamina, $G_{12}$ is in-plane shear modulus, and $v_{21}$ is in-plane Poisson's ratio. $\tau_{x y}$ is in-plane shear stress and $\gamma_{x y}$ is in-plane shear strain in global coordinate (refer to Figure 4.4). 
In addition, it is obvious that Equation (4.6) can be divided into two parts, namely:

Contribution of in-plane shear $G_{12}$

$$
g_{x y}^{s}=\frac{(\operatorname{Cos} 2 \theta)^{2}}{G_{12}}
$$

Contribution of $E_{11}$ and $E_{22}$

$$
g_{x y}^{n}=(\operatorname{Sin} 2 \theta)^{2}\left(\frac{1}{E_{11}}+\frac{1}{E_{22}}+\frac{2 v_{21}}{E_{22}}\right)
$$

For each lamina of FRP composites

$$
\begin{aligned}
\tau_{x y} & =\left(\frac{1}{g_{x y}^{s}+g_{x y}^{n}}\right) \gamma_{x y}=G_{x y} \gamma_{x y} \\
G_{x y} & =\left(\frac{1}{g_{x y}^{s}+g_{x y}^{n}}\right)
\end{aligned}
$$

Normally, a layer of fabric in an FRP composite structure includes several laminas. Therefore, $\left(G_{x y}\right)_{\text {fabric }}$ is computed from the average value using the thickness ratio of lamina in that laminate layer.

$\left(G_{x y}\right)_{\text {fabric }}=\frac{\sum_{k=1}^{N}\left[\left(G_{x y}^{k}\right)_{\text {lamina }} \times\left(t^{k}\right)\right]}{\sum_{k=1}^{N}\left(t^{k}\right)}$

Where, $N$ is the total number of lamina and $t^{k}$ is thickness of each lamina in fabric.

It should be noted that $\left(G_{x y}\right)_{\text {fabric }}$ is dominated by the stiffness of cured resin (matrix) and matrix volume fraction. For more details, refer to Appendix E. To compute the laminate rigidities, $D_{s s}, D_{s w}$ and $D_{w w}$ in structural coordinate for a component, a macro-mechanical approach is used to calculate global laminate rigidity $[D]$ so as to evaluate torsional rigidity 
of FRP composite structural shapes. The Kirchhoff hypothesis is in the proposed SCLT to obtain torsional rigidity.

The Kirchhoff's hypothesis states that despite the shear deformation caused by the applied load, lines normal to the horizontal plane through the thickness remain straight and normal to the deformed geometric mid-plane. These lines do not change in length. In addition, all layers are assumed to be perfectly bonded together. Thus, the modified stiffness matrix based on SCLT is (refer to Appendix A) as given below:

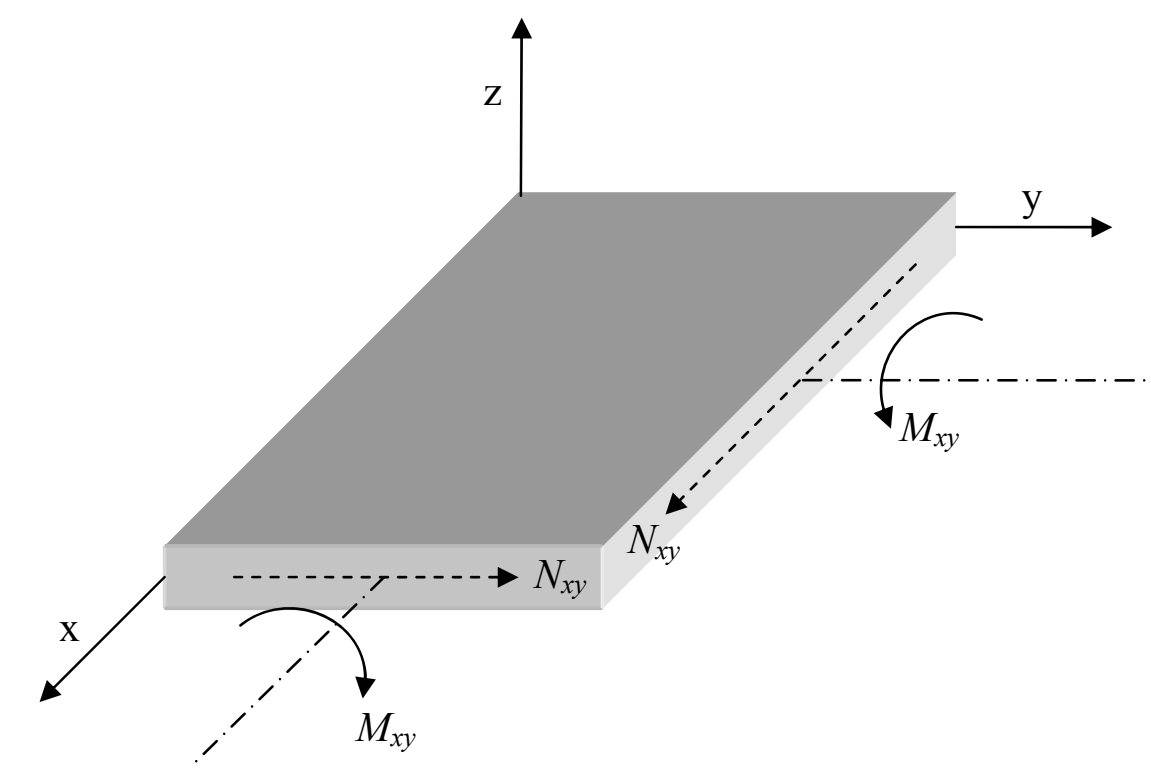

Figure 4.5 $N_{x y}$ and $M_{x y}$ on rectangular plate

$$
\left[\begin{array}{c}
N_{x y} \\
M_{x y}
\end{array}\right]=\left[\begin{array}{cc}
D_{S S} & D_{S W} \\
D_{S W} & D_{W W}
\end{array}\right]\left[\begin{array}{c}
\gamma_{x y}^{0} \\
\kappa_{x y}^{0}
\end{array}\right]
$$

Where, $N_{x y}$ is in-plane shear resultant and $M_{x y}$ is twisting moment resultant (refer to Figure 4.5), $\gamma_{x y}^{0}$ is the reference surface in-plane shear strain, $\kappa_{x y}^{0}$ is the reference surface twisting curvature, $D_{s s}$ and $D_{w w}$ are defined as in-plane shear and twist stiffnesses of laminates; $D_{s w}$ is defined as in-plane and out-of-plane coupling. 


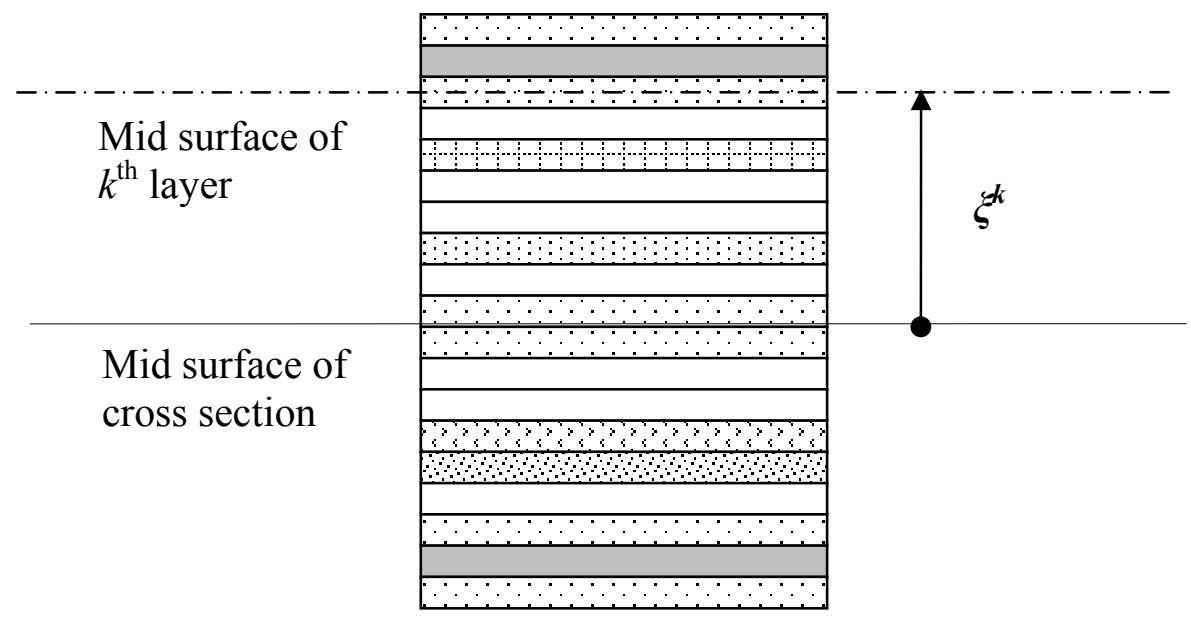

Figure 4.6 Schematic of distance $\xi^{k}$ of lamina $k^{\text {th }}$

$D_{s s}$ (due to in-plane shear) $\quad=\quad \int_{\frac{-h}{2}}^{\frac{h}{2}} G_{x y}^{k} d z=\sum_{k=1}^{N} G_{x y}^{k} t_{k}$

$D_{s w}$ (due to in and out of plane coupling) $=\int_{\frac{-h}{2}}^{\frac{h}{2}} G_{x y}^{k} z d z=\sum_{k=1}^{N} G_{x y}^{k} \xi_{k} t_{k}$

$D_{w w}$ (due to twisting moment)

$$
=\int_{\frac{-h}{2}}^{\frac{h}{2}} G_{x y}^{k} z^{2} d z=\sum_{k=1}^{N} G_{x y}^{k}\left(\xi_{k}^{2} t_{k}+\frac{t_{k}^{3}}{12}\right)
$$

where, $t_{k}$ is thickness of $\mathrm{k}^{\text {th }}$ fabric layer, $\boldsymbol{\xi}_{k}$ is the distance from the centroid of the crosssection to the mid-surface of $k^{\text {th }}$ fabric (refer to Figure 4.6) and $N$ is the number of layers of fabrics.

In the following section, 2-D plate bending and thin-walled beam theories are used to establish the expression for torsional rigidity based on SCLT. Three fundamental relations namely,1) constitutive relations (stress-strain relation), 2) compatibility relation (straindisplacement relation), and 3) equilibrium of forces are simultaneously used to arrive at the governing differential equation corresponding to torsional behavior of FRP composites. Many FRP composite structural members are in the forms of thin plates, circular tubes, single 
cell rectangular thin-walled beams, and multi-cell thin-walled beams. The torsional rigidity based on SCLT is evaluated for the above mentioned sections.

\subsection{Evaluation of Torisonal Rigidity}

Torsional rigidity of structural members developed by using SCLT under free warping of cross section is presented in this section. Torsional rigidity of FRP composite plates is presented in Section 4.4.1. As a follow up, torsional rigidities are presented using SCLT of closed section such as FRP sandwich plates, FRP tubes, single and multi-cell triangular and rectangular cross sections.

\subsubsection{Torsional Rigidity and In-Plane Shear Strain of FRP Rectangular Plate}

Torsional rigidity using SCLT of FRP rectangular plate bending element is presented herein (refer to Figure 4.7). Several assumptions considered herein are: 1) the thickness of the plate is small compared to its length and width $(<0.1), 2)$ the torque is constant along the length of a structural member and is applied to the longitudinal axis of a structural member, and 3) the cross section is free to warp.

From the constitutive relations in Equation (4.12), $N_{x y}$ is assumed to be small and insignificant, then the in-plane shear strain at reference surface is written in term of the reference surface twisting curvature as:

$\gamma_{x y}^{0}=-\frac{D_{s w}}{D_{s s}} \kappa_{x y}^{0}$

It should be noted that negative sign on right side of Equation (4.16) is due to negative sense in out-of-plane curvature $\left(\kappa_{x y}^{\circ}=-2 \partial(\partial w / \partial x) \partial y\right.$, i.e., slope is decreasing with increasing $\left.y\right)$ and positive sense in in-plane shear strain. 
The curvature $\left(\kappa^{\circ}{ }_{x y}\right)$ is illustrated in Figure 4.8. The twisting moment resultant is a combination between the contributions of the reference surface in-plane shear strain and the twisting curvature (refer to Equation (4.12)).

$$
D_{s w} \gamma_{x y}^{0}+D_{s s} \kappa_{x y}^{0}=M_{x y}
$$

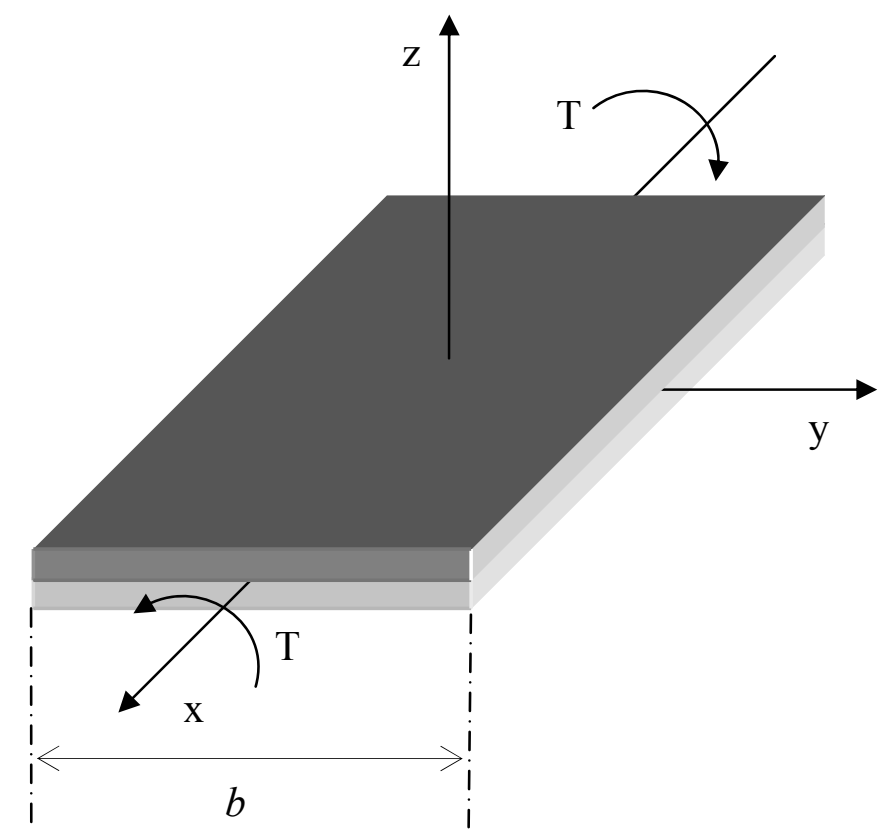

Figure 4.7 Rectangular plate under torsion load

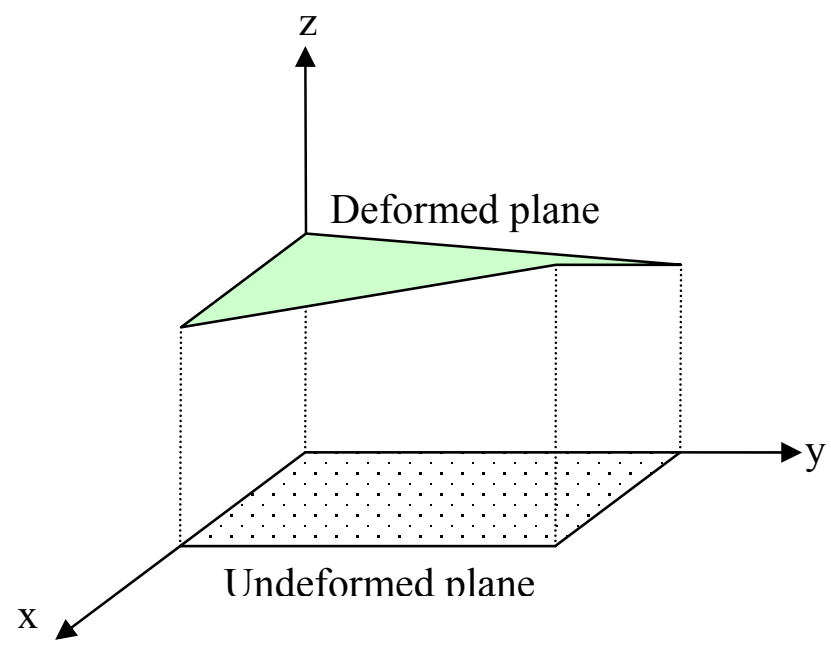

Figure 4.8 Out-of-plane curvature $\left(\kappa_{x y}^{\circ}=-2 \partial(\partial w / \partial x) \partial y\right)$ 
Substituting Equation (4.16) into (4.17) yields a relation between the twisting moment resultant and the reference surface twisting curvature, as:

$$
M_{x y}=\left(D_{w w}-\frac{D_{s w}^{2}}{D_{s s}}\right) \kappa_{x y}^{0}
$$

From Figure 4.9, the compatibility relation between the twisting curvature and rotational angle of the cross-section as given in Figure 4.9 at reference surface is:

$$
\kappa_{x y}^{0}=-\frac{2 \partial}{\partial x}\left(\frac{\partial w}{\partial y}\right)=2 \bar{\theta}
$$

where, $\bar{\theta}$ (rate of twist) relates to the change in the rotational angle in the plane of a crosssection to the length of a beam.

From equilibrium of forces, primary torsion having a relation with twisting moment is:

$$
-M_{x y} b=\frac{T}{2}
$$

where, $b$ is the width of the cross-section (refer to Figure 4.7) and $T$ is the applied torque.

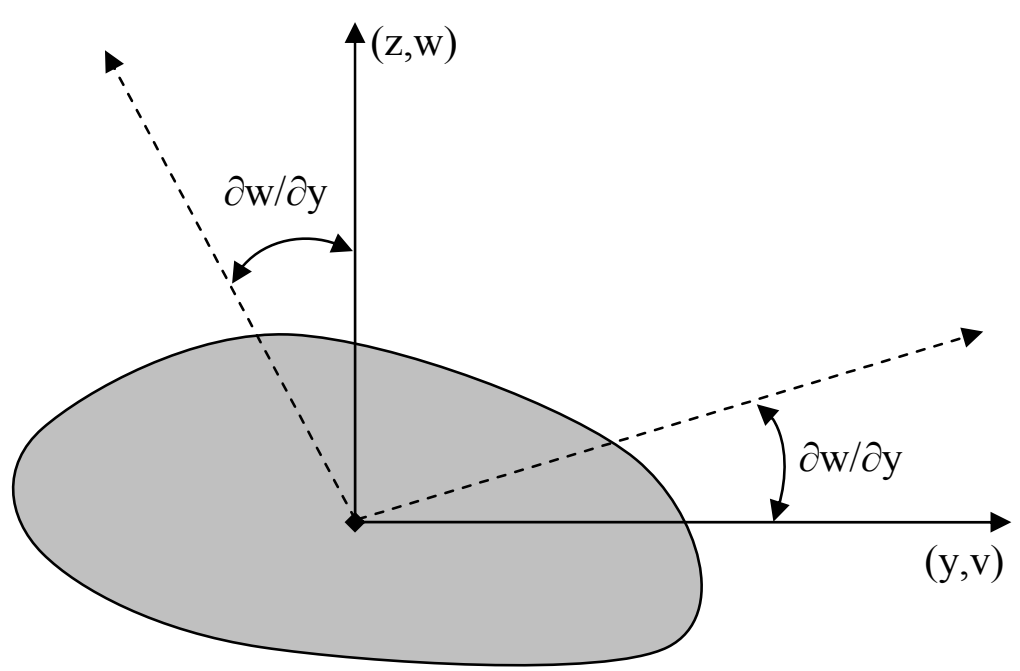

Figure 4.9 Rotational angle of solid cross section under torsion load 
To arrive at torsional rigidity as a function of torque versus rate of twist, three basic relations are needed (constitutive relation-Equation (4.18), compatibility-Equation (4.19), and equilibrium-Equation (4.20)). These equations are simultaneously solved and the result in Equation (4.21).

$T=4 b\left(D_{w w}-\frac{D_{s w}{ }^{2}}{D_{s s}}\right) \bar{\theta}=G J \bar{\theta}$

Where, $G J=4 b\left(D_{w w}-\frac{D_{s w}^{2}}{D_{s s}}\right), G J$ is torsional rigidity, $b$ is the width of the cross-section, $T$ is the applied torque and $\bar{\theta}$ is rate of twist.

If the applied torque is known then, the strain in each layer can be calculated and written in a closed-form. To calculate in-plane strain in each layer, the applied torque is substituted into the constitutive relation. Then, in-plane shear strain and twisting curvature at mid-plane (reference surface) can be resolved as:

$\left[\begin{array}{c}\gamma_{x y}^{0} \\ \kappa_{x y}^{0}\end{array}\right]=\frac{T}{2 b\left(D_{s S} D_{w W}-D_{s w}^{2}\right)}\left[\begin{array}{c}-D_{s W} \\ D_{s s}\end{array}\right]$

By substituting in-plane strain and twisting curvature at the mid plane (reference surface) of the cross section into the in-plane shear of the plate illustrated in Figure 4.10, inplane strain through the cross-section of a plate is given as:

$$
\begin{aligned}
& \gamma_{x y}=\gamma_{x y}^{0}+z \kappa_{x y}^{0} \\
& \gamma_{x y}=\frac{T\left(D_{S W}-z D_{S S}\right)}{2 b\left(D_{s w}{ }^{2}-D_{S S} D_{w W}\right)}
\end{aligned}
$$

Where, $z$ is the vertical distance from the mid-plane (reference surface) to $\mathrm{z}$ location on the cross section. 


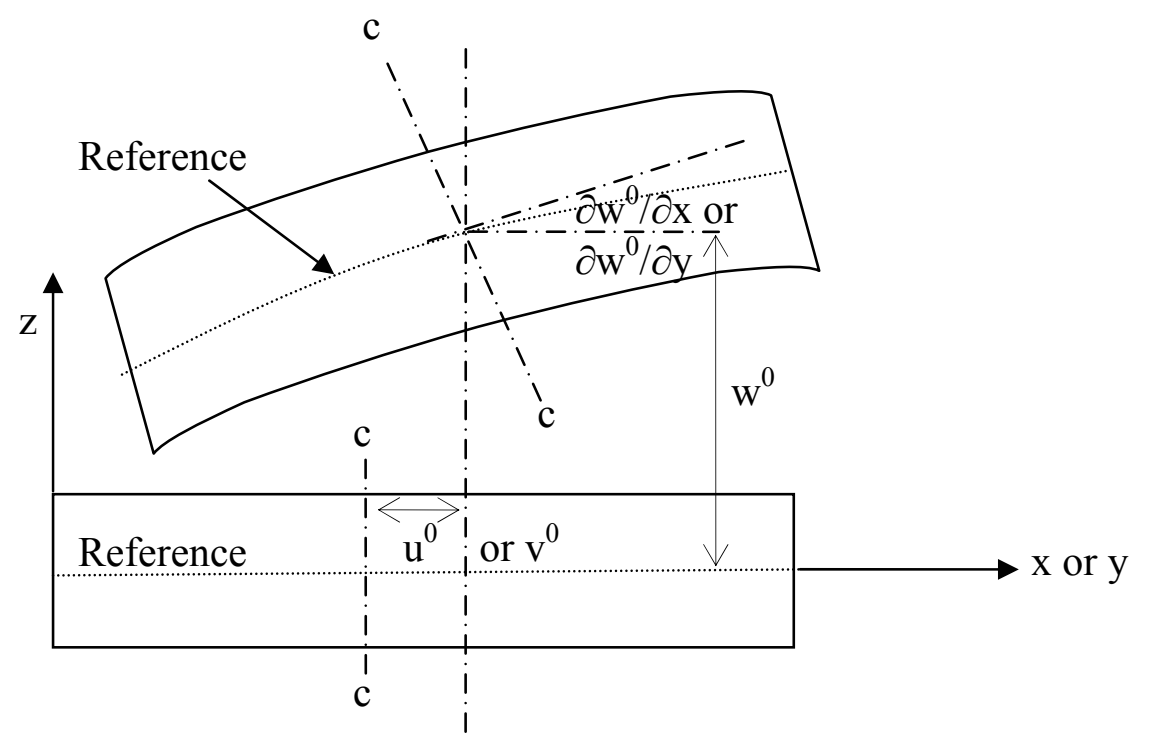

Figure 4.10 Deformation of a plate in the $x-z$ or $y-z$ plane 


\subsubsection{Torsional Rigidity of FRP sandwich Beam}

A sandwich member normally consists of three main parts: 1) two thin stiff and strong faces and 2) a thick core that is lighter and weaker than the facial sheets (Zenkert, 1997). The common facial material includes two main groups: 1) metals fascia such as steel, aluminum, alloys, etc. and 2) non-metallic core such as plywood, cement, fiber reinforced polymers (FRPs), etc. The core includes four types: 1) corrugated, 2) balsa wood, 3) honeycomb, and 4) foams. Only sandwich beams using FRP and balsa wood as facial and core material, respectively, are used in this study (Figure 4.11).

To develop the torsional rigidity expression of FRP sandwich beams, several assumptions are considered that are: 1) shear stiffness of core materials can be neglected in stiffness evaluation because shear stiffness of face material is larger than that of core materials, 2) torque is assumed to be uniform along the length of a structural member and is applied about its longitudinal axis, 3) cross section of a structural member is free to warp, and 4) facial and core material are perfectly bonded together (no delamination).

FRP composite plates (torsional rigidity given in the section 4.4.1) are used for face material. In addition, the concept of transformed cross-sectional area that is used to in conventional composite cross sections, such as a reinforced concrete cross-section, is used in torsional rigidity evaluations of a sandwich beam.

$$
\begin{aligned}
& (G J)_{s w}=\frac{G_{f} b\left(2 t_{f}+t_{c}\right)^{3}}{3}-G_{f} b \frac{t_{c}^{3}}{3}+G_{f}\left(\frac{b G_{c}}{G_{f}}\right) \frac{t_{c}^{3}}{3} \\
& (G J)_{s w}=\frac{G_{f} b\left(2 t_{f}+t_{c}\right)^{3}}{3}-\frac{G_{f} b(1-a) t_{c}^{3}}{3} \\
& a=\frac{G_{c}}{G_{f}}
\end{aligned}
$$




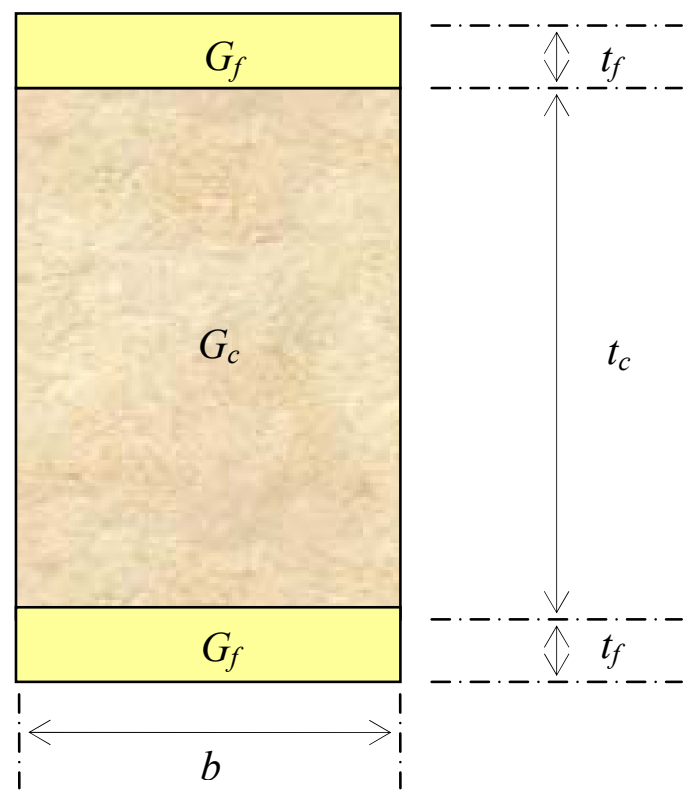

Figure 4.11 Cross section of sandwich beam

where, $G_{f}$ is the equivalent in-plane shear modulus of face material, $b$ is the width of fascia material, $t_{f}$ and $t_{c}$ are thickness of facial and core material, respectively.

Moreover, the torsional rigidity in Equation (4.25) can be rearranged and written in terms of torsional rigidity of facial material and thickness ratio.

$(G J)_{s w}=G_{f}\left(\frac{b t_{f}^{3}}{3}\right) \times 8\left(\left(1+\frac{t_{c}}{2 t_{f}}\right)^{3}-(1-a)\left(\frac{t_{c}}{2 t_{f}}\right)^{3}\right)$

To simplify Equation (4.26), torsional rigidity of the face material in Equation (4.21) is substituted into Equation (4.26). Since, in-plane shear stiffness of facial material is much more than that of core material, the quantity $a$ can be neglected.

$(G J)_{s w}=4 b\left(D_{w w}-\frac{D_{s w}^{2}}{D_{s s}}\right) \times 8\left(\left(1+\frac{t_{c}}{2 t_{f}}\right)^{3}-\left(\frac{t_{c}}{2 t_{f}}\right)^{3}\right)$

The torsional rigidity of the sandwich beam is rearranged and rewritten as follows: 
$(G J)_{s w}=8 b\left(D_{w w}-\frac{D_{s w}^{2}}{D_{s s}}\right)\left(1+3(1+\delta)^{2}\right)$ $\delta=\frac{t_{c}}{t_{f}}$

Where, $\delta$ is the ratio of the thickness of core to facial material, $b$ is the width of facial material, $D_{w w}, D_{s w}, D_{s s}$ are as defined in Section 4.3.

The bond strength between the facial and core material is a very important factor that attributes to the strength and stiffness of sandwich structural members. Since, the bond strength is quite small particularly under torsional load, sandwich structural members mostly fail due to delaminalation between core and facial materials before the materials fail. However, perfect bond between the facial and core materials is assumed to compute theoretical torsional rigidity as given in Equation (4.28). Hence, shear stress is fully transferred through the layers between core and facial materials. Also, torsional rigidity can be calculated by neglecting the effect of core material due to low stiffness compared to facial material. Torsional rigidity in Equation (4.28) seems to be mostly dominated by the torsional rigidity of facial material.

Core materials of sandwich structures are utilized for several purposes such as structural part, sound barrier (non-structural part), fire barrier (non-structural part), case of manufacturing type, and buckling premature. In this study, the core material of test specimens is considered to be non-structural part of sandwich structures. Delamination of glue line between facial and core material is observed on tested specimens. The actual performance of sandwich structures is lower than the resisting capacity of facial material. Thus, the theoretical equation (4.28) will give higher torsional rigidity than the experimental results. 


\subsubsection{Torsional Rigidity and In-Plane Shear Strain of FRP Tubes}

Circular tubes made of FRP composites are widely used in engineering applications. In this section, torsional rigidity based on SCLT of closed circular sections is developed and presented. The limitations and assumptions considered in evaluating torsional rigidity of FRP circular tubes are: 1) torque is uniform along the length of a structural member and applied about its longitudinal axis, 2) circular section is uniform and has no warping restraint at any cross-section (free to warp) but there is no warping of a circular cross section if it is isotropic, 3) cross section warps in the axial direction but does not twist, i.e., cross section does distort from its original plane, and 4) for closed thin-walled specimens, if stresses under torque induced by twisting moment are small compared to shear stress then only shear stress $\left(N_{x y}\right)$ is significant (Kollar et. al., 2002), and $M_{x y}$ is neglected (refer to Figure 4.5). The above assumptions have been used for developing theoretical equations in this section. In addition, other authors (Kollar, 2002) have adopted similar assumptions.

From these assumptions, only $N_{x y}$ is significant in the constitutive relation (Equation (4.12)) and $M_{x y}$ is neglected then the reference surface twisting curvature is written in terms of the reference surface in-plane shear strain as:

$$
\kappa_{x y}^{0}=-\frac{D_{s w}}{D_{w w}} \gamma_{x y}^{0}
$$

In-plane shear force is a combination of in-plane shear strain and twisting curvature. In-plane shear force resultant is presented as (refer to Equation (4.12)):

$$
D_{s s} \gamma_{x y}^{0}+D_{s w} \kappa_{x y}^{0}=N_{x y}
$$


To present in-plane shear force resultant in term of in-plane shear strain at mid plane of the cross-section, Equation (4.29) is substituted into Equation (4.30) as follows:

$$
N_{x y}=\left(D_{s s}-\frac{D_{s w}^{2}}{D_{w w}}\right) \gamma_{x y}^{0}
$$

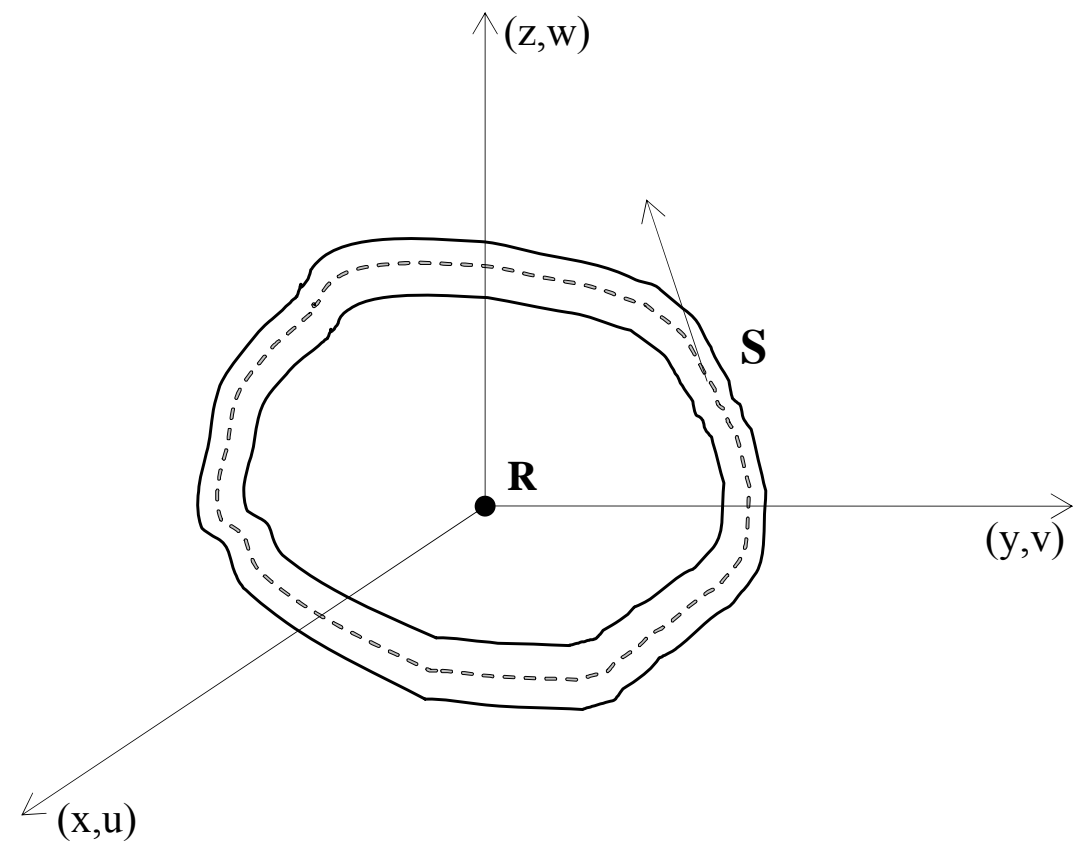

Figure 4.12 Coordinate of thin-walled cross-section (s,u)

Compatibility relation between warping displacement and in-plane shear strain at mid-plane (reference surface) of a cross-section is given in Equation (4.32). Additional, details on the compatibility equation are provided in Appendix D.

$$
\int_{0}^{s} \gamma_{x y}^{0} d s=\left(u_{s}-u_{0}\right)+2\left(A_{0 S}\right) \frac{d \theta}{d x}+z_{R} \frac{d v}{d x}\left(y_{s}-y_{0}\right)+y_{R} \frac{d w}{d x}\left(z_{s}-z_{0}\right)
$$

Where, $u$ is displacement along the in-plane longitudinal axis (x-direction), $v$ is displacement along the in-plane transverse direction (y-direction), $z$ is displacement along transverse 
direction (z-direction) as given in Figure 4.12. $A_{o s}$ is the area swept out by a generator, with its center at the origin $(\mathrm{R})$ of the axes, from the origin to any points $(\mathrm{S})$ around the crosssection and $\theta$ is the angle of twist as illustrated in Figure 4.13.

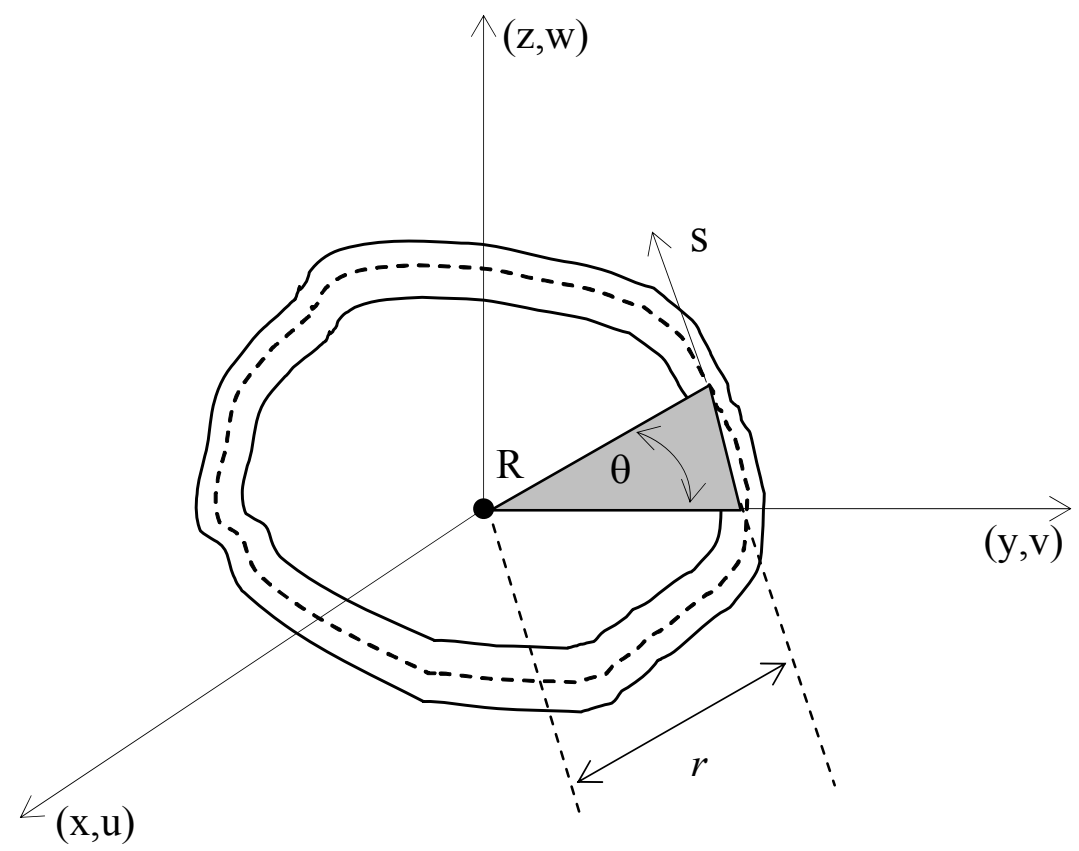

Figure 4.13 $A_{\text {os }}$ area swept out from o to $s$

It should be noted that the last two terms on the right hand side of Equation (4.32) represent the effects of the relation between warping displacement and an arbitrary origin which results in axial displacement due to warping. In the case where the origin coincides with the center of twist $\mathrm{R}$ of the cross-section, Equation (4.32) can be simplified by taking the last two terms to be equal to zero. Integration around a closed cross-section is performed. Due to starting and ending points being identical, difference of axial displacement $(u)$ between both locations is zero $\left(u_{s}=u_{0}\right)$. Therefore, Equation (4.32) is simplified as following:

$\oint \gamma_{x y}^{0} d s=2 A * \frac{d \theta}{d x}$

Where, $A^{*}$ is the area enclosed by the midline of the cross-section as shown in Figure 4.14. It should be noted that this area is not the cross-sectional area of the component under torque. 


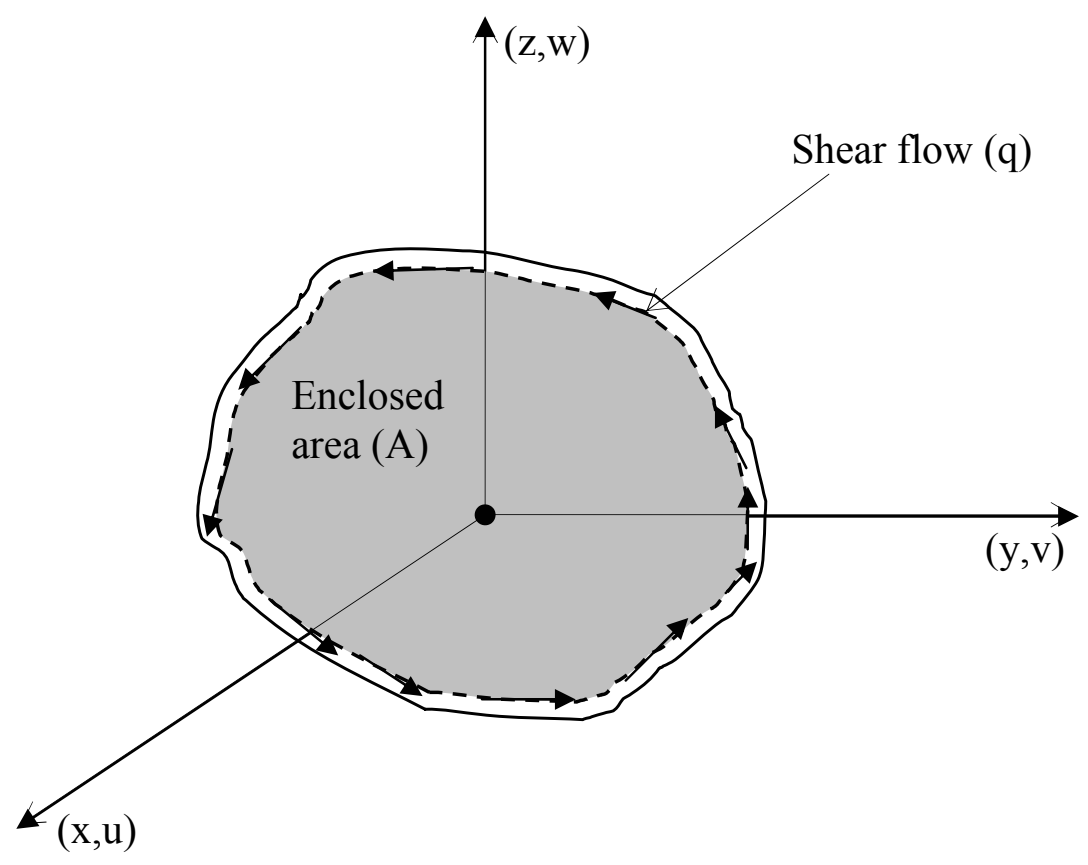

Figure 4.14 An enclosed area by the mid-line of cross section

An equilibrium equation of a closed thin-walled beam is obtained from Bredt-Batho's theory (Megson, 1998). The derivation of Bredt-Batho's theory is provided in Appendix D. Bredt-Batho's theory presents a relation between shear flow on a cross-section and its enclosed area.

$T=2 A^{*} q$

where, $T$ is the applied torque, $A$ is the area enclosed by the midline of the cross-section and $q$ is shear flow on the cross-section of a structural members as shown in Figure 4.14. Shear flow on the cross-section is defined as follows (refer to Figure 4.15):

$q=\int \tau_{x y} d z=N_{x y}$

To arrive at the torsional rigidity of a closed section, three basic relations in Equations (4.31), (4.33) and (4.34) that are constitutive relation, compatibility and equilibrium of forces, are solved. Thus, the relation between torque and rate of twist is given as: 


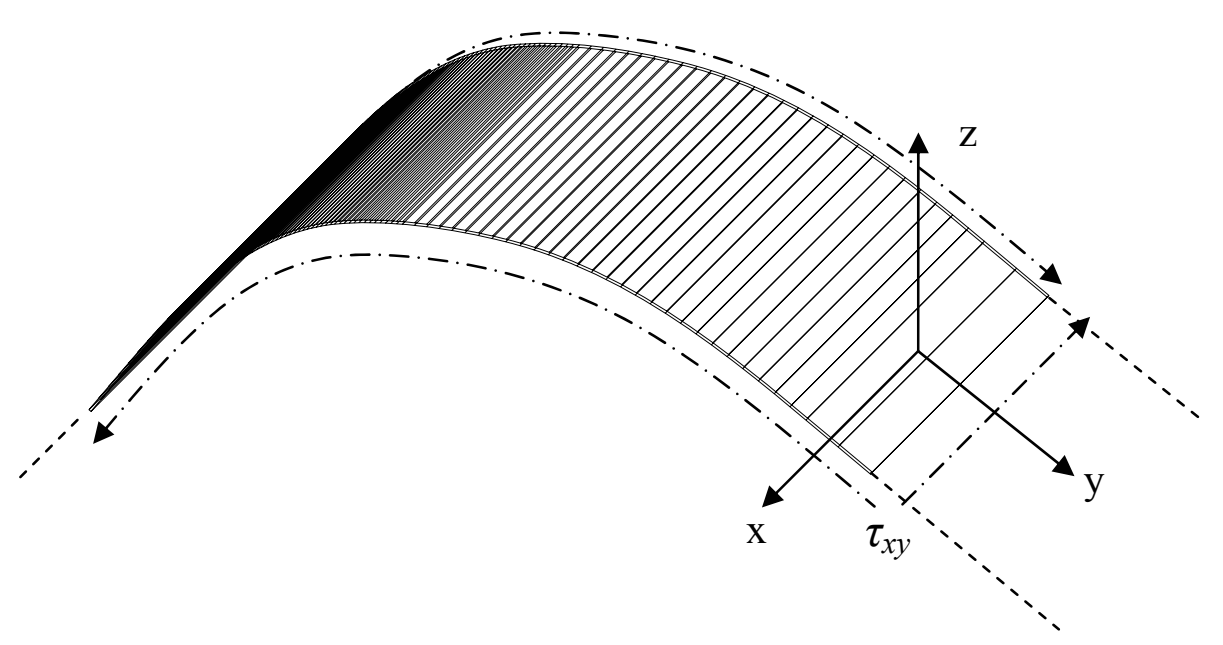

Figure 4.15 Shear flow around the wall segment

$\bar{\theta}=\oint \frac{T}{4\left(A^{*}\right)^{2}\left(D_{s s}-\frac{D_{s w}^{2}}{D_{w w}}\right)} d s$

Where, rate of twist $(\bar{\theta})$ is defined to be the rotational angle about the longitudinal axis per unit length in the longitudinal direction.

For FRP composite circular tubes, integration around the cross-section of a circular tube yields:

$T=\frac{2\left(A^{*}\right)^{2}}{\pi r}\left(D_{s s}-\frac{D_{s w}^{2}}{D_{w w}}\right) \bar{\theta}=G J \bar{\theta}$

where, $G J=\frac{2\left(A^{*}\right)^{2}}{\pi r}\left(D_{s s}-\frac{D_{s w}^{2}}{D_{w w}}\right), G J$ is torsional rigidity, $r$ is radius of the mid-line on the cross-section, $A^{*}$ is the area enclosed by the midline of the cross-section and $T$ is the applied torque and $\bar{\theta}$ is rate of twist. 
For FRP composite elliptical tubes (refer to Figure 4.16), integration around crosssection of an elliptical section yields the relation between applied torque and rate of twist as:

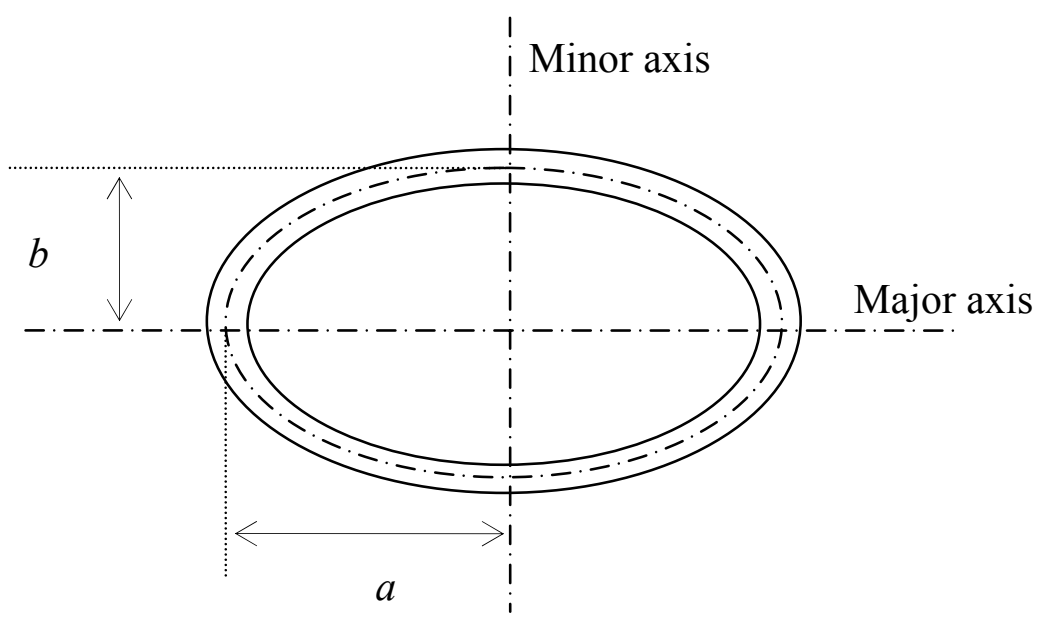

Figure 4.16 Ellipse cross sectional tube

$$
\begin{aligned}
& T=\frac{\left(A^{*}\right)^{2}}{\int_{0}^{\pi / 2} a \sqrt{1-\left(1-\left(\frac{b}{a}\right)^{2}\right) \operatorname{Sin}^{2} \theta}}\left(D_{s s}-\frac{D_{s w}^{2}}{D_{w w}}\right) \bar{\theta}=G J \bar{\theta} \\
& T \cong \frac{2\left(A^{*}\right)^{2}}{\pi \sqrt{\frac{a^{2}+b^{2}}{2}}}\left(D_{s s}-\frac{D_{s w}^{2}}{D_{w w}}\right) \bar{\theta} \cong G J \bar{\theta}
\end{aligned}
$$

where, $G J \cong \frac{2\left(A^{*}\right)^{2}}{\pi \sqrt{\frac{a^{2}+b^{2}}{2}}}\left(D_{s s}-\frac{D_{s w}^{2}}{D_{w w}}\right), G J$ is torsional rigidity, $r$ is the radial coordinate measured from the origin to the mid-line of the cross-section. $a$ and $b$ are the semi length of major and minor axes, respectively (refer to Figure 4.16). The $D_{s s}$ and $D_{w w}$ are defined as inplane shear and twist stiffness of laminates as in Equations (4.13) and (4.15), respectively. In addition, $D_{s w}$ is defined as the coupling term for in-plane shear stiffness and twisting 
curvature and the coupling term for in-plane shear deformation and twisting stiffness in Equation (4.14).

To determine in-plane (xy) shear strain in each layer, the applied torque is substituted into the constitutive relation (Equation (4.12)). Then, in-plane (xy) shear strain and twisting curvature at mid-plane (reference surface) can be resolved as follows:

$$
\left[\begin{array}{c}
\gamma_{x y}^{0} \\
\kappa_{x y}^{0}
\end{array}\right]=\frac{T}{2\left(A^{*}\right)\left(D_{s S} D_{w W}-D_{s w}{ }^{2}\right)}\left[\begin{array}{c}
D_{w W} \\
-D_{s W}
\end{array}\right]
$$

By substituting in-plane shear strain and twisting curvature at the mid-plane (reference surface) of the cross section into Equation (4.23), the in-plane strain through the cross-section is given as follows:

$$
\gamma_{x y}=\frac{T\left(D_{w W}-z D_{s W}\right)}{2\left(A^{*}\right)\left(D_{S S} D_{w W}-D_{s w}{ }^{2}\right)}
$$

where $A *$ is the area enclosed by the midline of the cross section, $T$ is an applied torque and $\mathrm{z}$ is the vertical distance from the mid-plane to $\mathrm{z}$ location on the cross section. $D_{s s}$ and $D_{w w}$ are defined as in-plane shear and twist stiffness of laminates in Equations (4.13) and (4.15), respectively. In addition, $D_{s w}$ is defined as in-plane and out-of-plane coupling in Equation (4.14). 


\subsubsection{Torsional Rigidity and In-Plane Shear Strain of Single Cell Thin-Walled Rectangular FRP Beam}

Thin-walled structures of closed sections are made from thin-plates joined along their edges. The thickness of a plate is small $(L / t$ and $s / t>10)$ compared with the cross-sectional dimensions that are small compared to the overall length of the structural members (Murray 1984). A single cell thin walled rectangular FRP beam that is part of an FRP bridge deck is discussed in this section. It should be noted that assumptions used for an FRP circular tube, still hold true for thin-walled rectangular cross-sections (except warping terms become predominant). For most FRP members with rectangular cross-sections, the top and bottom flanges are typically of the same thickness including fabric architecture. Also, the webs of a rectangular cross section are also of the same rectangular shape and fabric architecture as the flanges. With these conditions, applied torque versus rate of twist of closed cross-sectional structural members as given in Equation (4.36) can be simplified due to symmetry in flanges and webs. Therefore, torsional rigidity $G J$ of a single thin-walled FRP rectangular beam can be established by integrating the circumference of the midline of a rectangular cross section. From Equation (4.36) and Figure 4.17

$$
\begin{aligned}
\bar{\theta} & =\int_{\text {top flange }} \frac{T}{4\left(A^{*}\right)^{2}\left(D_{s s}-\frac{D_{s w}^{2}}{D_{w w}}\right)} d s+\int_{\text {right web }} \frac{T}{4\left(A^{*}\right)^{2}\left(D_{s s}-\frac{D_{s w}^{2}}{D_{w w}}\right)} d s \\
& +\int_{\text {bottom flange }} \frac{T}{4\left(A^{*}\right)^{2}\left(D_{s s}-\frac{D_{s w}^{2}}{D_{w w}}\right)} d s+\int_{\text {left web }} \frac{T\left(A^{*}\right)^{2}\left(D_{s s}-\frac{D_{s w}^{2}}{D_{w w}}\right)}{D_{w s}} d s \\
\bar{\theta} & =\frac{T}{4\left(A^{*}\right)^{2}}\left(\frac{S_{f}}{\left(D_{s s}-\frac{D_{s w}^{2}}{D_{w w}}\right)_{\text {flange }}}+\frac{S_{w}}{\left(D_{s s}-\frac{D_{s w}^{2}}{D_{w w}}\right)_{w e b}}+\frac{S_{f}}{\left(D_{s s}-\frac{D_{s w}^{2}}{D_{w w}}\right)_{\text {flange }}}+\frac{S_{w}}{\left(D_{s s}-\frac{D_{s w}^{2}}{D_{w w}}\right)}\right)
\end{aligned}
$$


$\bar{\theta}=\left(\frac{2 S_{f}}{\left(D_{s s}-\frac{D_{s w}^{2}}{D_{w w}}\right)_{\text {flange }}}+\frac{2 S_{w}}{\left(D_{s s}-\frac{D_{s w}^{2}}{D_{w w}}\right)_{w e b}}\right) \frac{T}{4\left(A^{*}\right)^{2}}$

$T=\frac{2\left(A^{*}\right)^{2}}{\left(\frac{S_{f}}{D^{f}}+\frac{S_{w}}{D^{w}}\right)} \bar{\theta}=(G J) \bar{\theta}$

$D^{f}=\left(D_{s s}-\frac{D_{s w}^{2}}{D_{w w}}\right)_{f l a n g e}$ and $D^{w}=\left(D_{s s}-\frac{D_{s w}^{2}}{D_{w w}}\right)_{w e b}$

Where, $G J=\frac{2\left(A^{*}\right)^{2}}{\left(\frac{S_{f}}{D^{f}}+\frac{S_{w}}{D^{w}}\right)}, G J$ is torsional rigidity, $S_{f}$ is the mid-line length of the flange from the center to the center of the webs, $S_{w}$ is the mid-line length of the web from the center to the center of the flanges, and $A$ is the enclosed area that is surrounded by the mid-line of the flange and the web on a rectangular cross-section as shown in Figure 4.17.

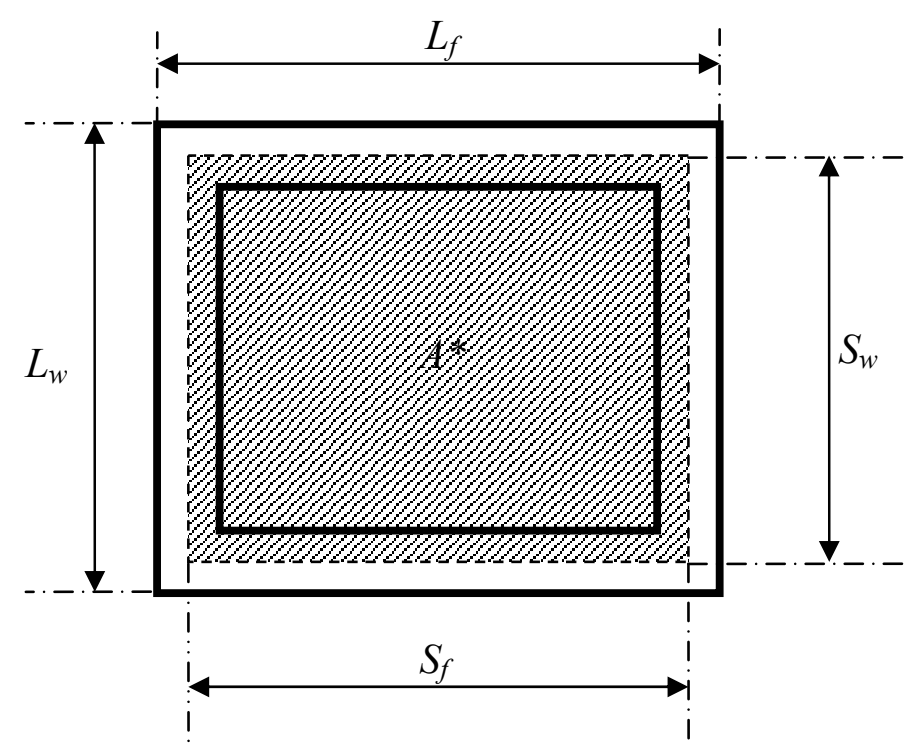

Figure 4.17 $S_{f}, S_{w}$ and $A$ of rectangular cross section 
To evaluate in-plane (xy) shear strain, theoretical strain of both flange and web can be found by substituting applied torque, cross sectional area, and corresponding flange and web stiffness into Equation (4.41).

Constant torque acting along the longitudinal axis of a member under free-warping condition still holds true as an assumption for warping distribution of this beam. Therefore, warping is the longitudinal deformation ( $\mathrm{x}$ direction) of cross sections (function $(\mathrm{y}, \mathrm{z})$ of positions on cross sections) and the deformation in $\mathrm{x}$-direction is independent of the position $\mathrm{x}$ along the beam axis. Moreover, the cross-section through the beam axis is assumed to be free to warp (no other distortions) (Megson, 1999). Warping function of single cell cross section will be presented below:

The compatibility relation between warping displacement and in-plane shear strain in Equation (4.32) is utilized to obtain warping distortion of a beam with single cell rectangular cross section. Furthermore, the origin of the cross-section coincides with its center of twist $(R)$. Therefore, the last two terms of the right hand side of Equation (4.32) no longer vanish.

$$
\int_{0}^{s} \gamma_{x y}^{0} d s=\left(u_{s}-u_{0}\right)+2\left(A_{0 S}\right) \frac{d \theta}{d x}
$$

The relation between in-plane shear strain and rate of twist in Equation (4.33) is substituted into Equation (4.46) to obtain:

$$
\left(u_{s}-u_{0}\right)=\int_{0}^{s} \gamma_{x y}^{0} d s-\frac{\left(A_{0 S}\right)}{A^{*}} \oint \gamma_{x y}^{0} d s
$$

To evaluate warping distribution along the longitudinal axis of a member, Equation (4.31) is substituted into Equation (4.47) that yields: 


$$
\left(u_{s}-u_{0}\right)=\frac{T}{2 A^{*}}\left(\int_{0}^{s} \frac{1}{\left(D_{s s}-\frac{D_{s w}^{2}}{D_{w w}}\right)} d s-\frac{\left(A_{0 S}\right)}{A^{*}} \oint \frac{1}{\left(D_{s s}-\frac{D_{s w}^{2}}{D_{w w}}\right)} d s\right)
$$

Where, $A_{o s}$ is the area swept out by a generator with its center at the origin of axes, from the origin to any point $(s)$ around a cross-section. $u$ is the displacement along longitudinal axis (x-direction).

From Equation 4.48, integration around a closed cross-section is performed (refer to Figure 4.18). Warping displacements are obtained from summation of integrating results that are given below. Warping displacement on the cross section is illustrated in Figure 4.19.

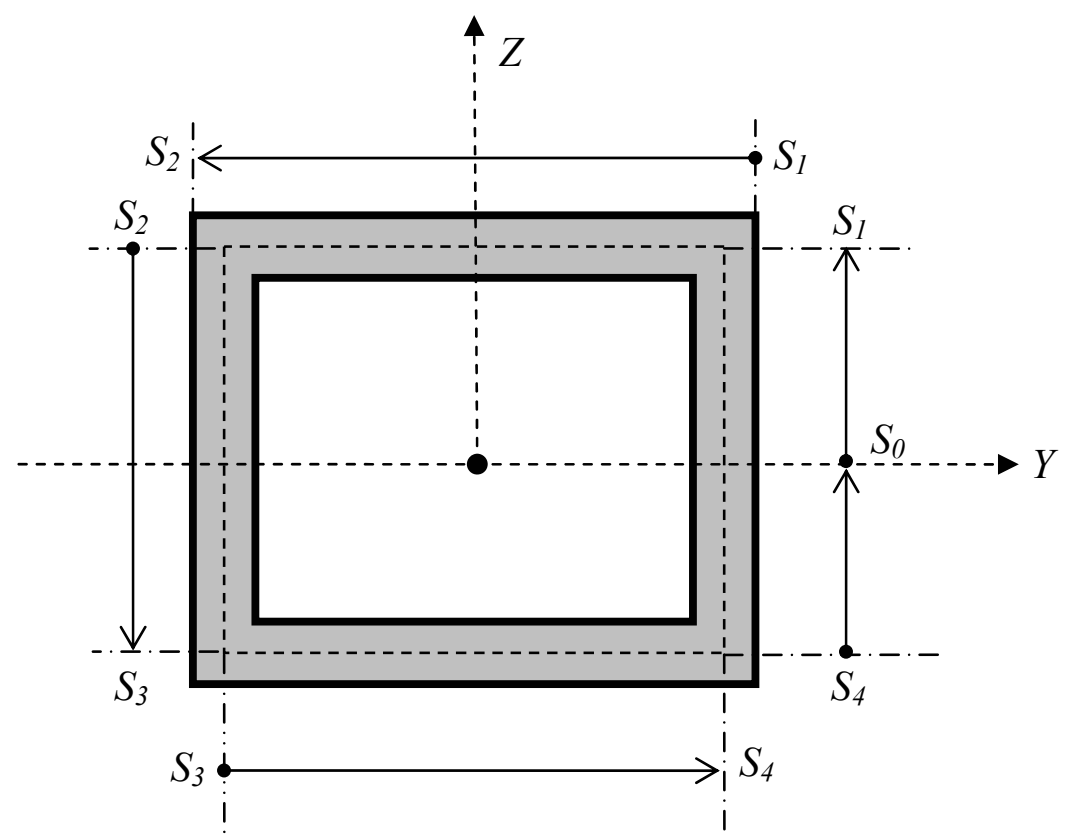

Figure 4.18 Integration around a closed cross section

$$
\left(u_{s 1}-u_{s 0}\right)=\frac{T}{8 A^{*}}\left(\frac{S_{w}}{\left(D_{s s}-\frac{D_{s w}^{2}}{D_{w w}}\right)_{w e b}}-\frac{S_{f}}{\left(D_{s s}-\frac{D_{s w}^{2}}{D_{w w}}\right)_{\text {flange }}}\right)
$$




$$
\begin{aligned}
& \left(u_{s 2}-u_{s 1}\right)=\frac{T}{4 A^{*}}\left(\frac{S_{f}}{\left(D_{s s}-\frac{D_{s w}^{2}}{D_{w w}}\right)_{\text {flange }}}-\frac{S_{w}}{\left(D_{s s}-\frac{D_{s w}^{2}}{D_{w w}}\right)_{w e b}}\right) \\
& \left(u_{s 3}-u_{s 2}\right)=\frac{T}{4 A^{*}}\left(\frac{S_{w}}{\left(D_{s s}-\frac{D_{s w}^{2}}{D_{w w}}\right)_{w e b}}-\frac{S_{f}}{\left(D_{s s}-\frac{D_{s w}^{2}}{D_{w w}}\right)_{\text {flange }}}\right) \\
& \left(u_{s 4}-u_{s 3}\right)=\frac{T}{4 A^{*}}\left(\frac{S_{f}}{\left(D_{s s}-\frac{D_{s w}^{2}}{D_{w w}}\right)_{f l a n g e}}-\frac{S_{w}}{\left(D_{s s}-\frac{D_{s w}^{2}}{D_{w w}}\right)_{w e b}}\right) \\
& \left(u_{s 0}-u_{s 4}\right)=\frac{T}{8 A^{*}}\left(\frac{S_{w}}{\left(D_{s s}-\frac{D_{s w}^{2}}{D_{w w}}\right)_{w e b}}-\frac{S_{f}}{\left(D_{s s}-\frac{D_{s w}^{2}}{D_{w w}}\right)_{\text {flange }}}\right)
\end{aligned}
$$

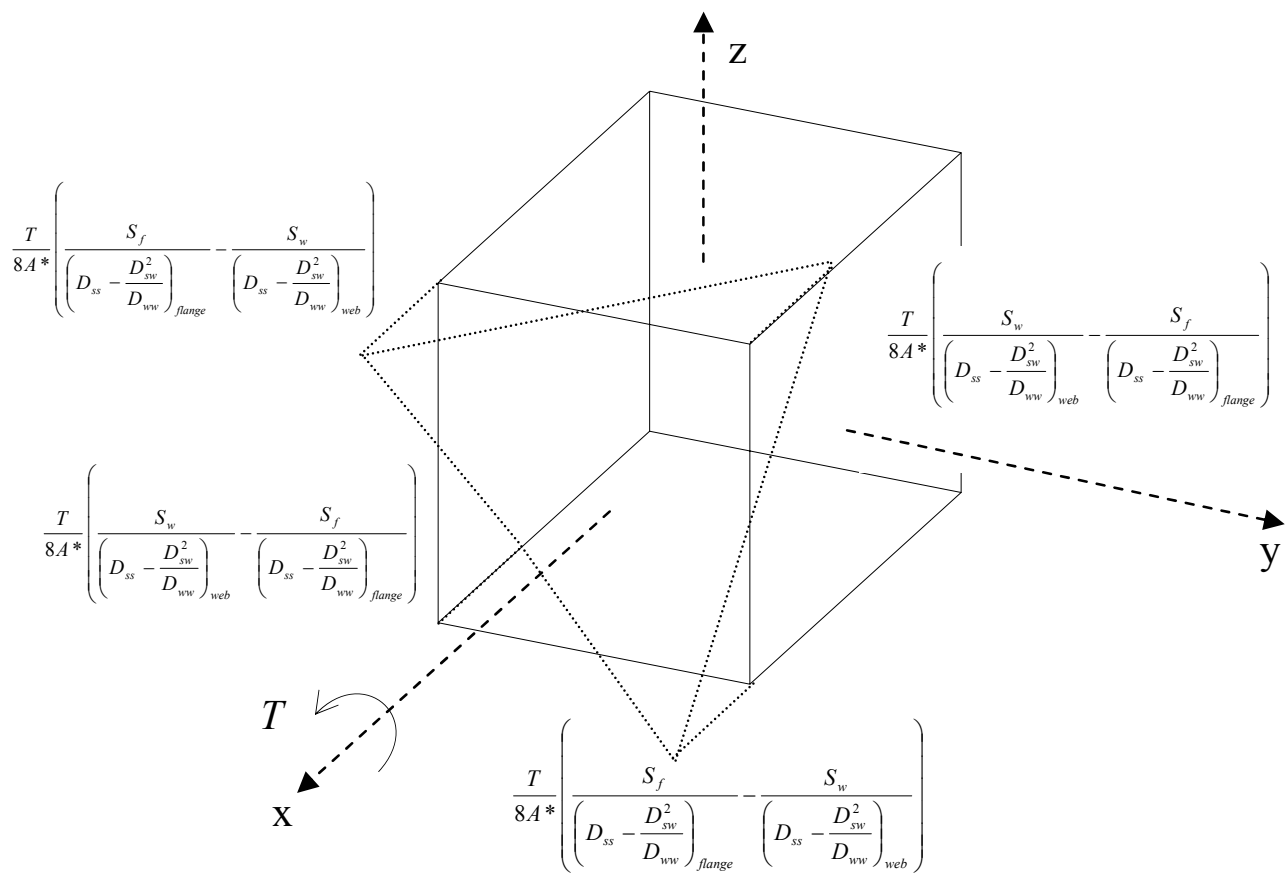

Figure 4.19 Warping displacement of single cell cross section 


\subsubsection{Torsional Rigidity and In-Plane Shear Strain of Multi- Cell Thin-Walled Rectangular FRP Beam}

Multi-cell thin-walled FRP beams for three cell type of a rectangular cross-section are discussed in this section. This multi-cell rectangular FRP beam is a module of FRP composite bridge deck (ProDeck4) developed by CFC, West Virginia University. The limitations and assumptions for a single cell rectangular FRP beam are applicable even for the case of multicell thin-walled rectangular FRP beams recognizing that multi-cell systems are not affected as much from warping as single cell systems for small openings. However, additional equations are needed to solve for general multi-cell cross sections. These additional equations can be found by considering the rate of twist in each cell and compatibility of displacements between cell boundaries where all cells are assumed to possess the same rate of twist.

For multi-cell rectangular FRP beams, total applied torque acting on a cross-section is the sum of the enclosed area of a single cell multiplied by the shear flow on each cell which is:

$$
T=\sum_{i=1}^{n} 2\left(A^{*}\right)_{i} q_{i}
$$

Where, $T$ is total applied torque acting on a multi-cell cross-section, $\left(A^{*}\right)_{i}$ is an enclosed area of $\mathrm{i}^{\text {ih }}$ cell and $q_{i}$ is shear flow around $\mathrm{i}^{\text {th }}$ cell, $\mathrm{n}$ is number of cells in multi-cell cross-section.

To present the relation between shear flow and rate of twist for $\mathrm{i}^{\text {th }}$ cell, the applied torque of the $\mathrm{i}^{\text {th }}$ cell is substituted into the applied torque versus rate of the twist relation of a single cell rectangular cross-section that is given in Equation (4.36). Thus, the relation between shear flow rate and the twist relation of the $i^{\text {th }}$ cell can be written from Equations (4.34) and (4.36). 


$$
\bar{\theta}_{i}=\left(\oint \frac{q}{2\left(A^{*}\right)\left(D_{s s}-\frac{D^{2}{ }_{s w}}{D_{w w}}\right)} d s\right)_{i}
$$

For most multi-cell rectangular cross-sections, the top and bottom flanges are of the same thickness including fabric architecture. All the webs in the multi-cell cross section of a typical FRP deck are identical in thickness and fabric architecture. Similarly, with single cell cross section of FRP composite beam, the relation between shear flow and the rate of twist of the $\mathrm{i}^{\text {th }}$ cell that is given in Equation (4.50) can be simplified due to symmetrical flanges and webs.

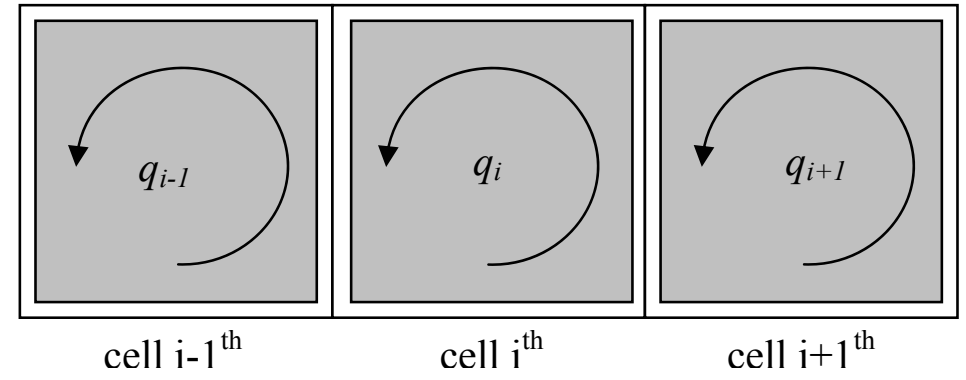

Figure 4.20 Shear flow on multi-cell cross section (three cells)

To integrate around the $\mathrm{i}^{\text {th }}$ cell, $q_{i-1}, q_{\mathrm{i}}$, and $q_{\mathrm{i}+1}$ are considered as enclosed, with shear flow around their respective cells in Figure 4.20. Along a wall shared by two cells, shear flow is the algebraic sum of the shear flows in adjacent cells. Then, the shear flow of the left and right web i ${ }^{\text {th }}$ cell are $q_{i}-q_{i-1}$ and $q_{i}-q_{i+1}$, respectively. While, the shear flows of the top and bottom flange $i^{\text {th }}$ cell are same as $q_{i}$. The shear flow of the $i^{\text {th }}$ cell is graphically illustrated in Figure 4.21. From the above discussion, shear flow versus rate of twist of the $\mathrm{i}^{\text {th }}$ cell is given as: 


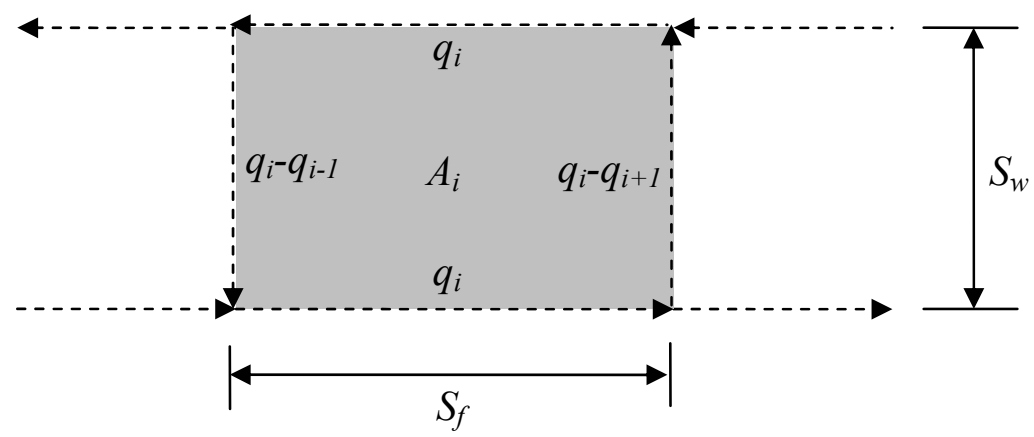

Figure 4.21 Shear flow on the $i^{\text {th }}$ cell

$$
\begin{aligned}
\bar{\theta}_{i} & =\int_{\text {top flange }} \frac{q_{i}}{2\left(A^{*}\right)_{i}\left(D_{s s}-\frac{D_{s w}^{2}}{D_{w w}}\right)_{i}} d s+\int_{\text {right web }} \frac{q_{i}-q_{i+1}}{2\left(A^{*}\right)_{i}\left(D_{s s}-\frac{D_{s w}^{2}}{D_{w w}}\right)_{i}} d s \\
& +\int_{\text {bottom flange }} \frac{q_{i}}{2\left(A^{*}\right)_{i}\left(D_{s s}-\frac{D_{s w}^{2}}{D_{w w}}\right)_{i}} d s+\int_{\text {left web }} \frac{q_{i}-q_{i-1}}{2\left(A^{*}\right)_{i}\left(D_{s s}-\frac{D_{s w}^{2}}{D_{w w}}\right)_{i}} d s
\end{aligned}
$$

$\bar{\theta}_{i}=\left(\frac{S_{w}}{D^{w}}\right)\left(\frac{q_{i}-q_{i-1}}{2\left(A^{*}\right)_{i}}\right)+\left(\frac{2 S_{f}}{D^{f}}\right)\left(\frac{q_{i}}{2\left(A^{*}\right)_{i}}\right)+\left(\frac{S_{w}}{D^{w}}\right)\left(\frac{q_{i}-q_{i+1}}{2\left(A^{*}\right)_{i}}\right)$

where $D^{f}=\left(D_{s s}-\frac{D_{s w}^{2}}{D_{w w}}\right)_{\text {flange }}$ and $D^{w}=\left(D_{s s}-\frac{D_{s w}^{2}}{D_{w w}}\right)_{w e b}$

$S_{f}$ is the mid-line length of the flange portion from the center to the center of the webs. $S_{w}$ is the mid-line length of the web from the center to the center of the flanges. $A_{i}$ is an enclosed area surrounded by $S_{f}$ and $S_{w} . q_{i-1}, q_{i}$ and $q_{i+1}$ are shear flow around $\mathrm{i}-1^{\text {th }}, \mathrm{i}^{\text {th }}$ and $\mathrm{i}+1^{\text {th }}$ cell, respectively.

The three-cell FRP rectangular bridge deck module (ProDeck4) is considered in this study. Shear flow versus rate of twist relation (Equation (4.52)) can be simplified by considering additional equations of the rate of twist. Additional equations that are needed to simplify and arrive at torsional rigidity of the multi-cell cross-section are given for the rate of 
twist in each cell and compatibility of displacement, where all cells possess the same rate of twist (Murray, 1984). Therefore, additional equations are given as:

$\bar{\theta}_{i-1}=\bar{\theta}_{i}=\bar{\theta}_{i+1}$

$\varphi_{i}=\frac{q_{i}}{\bar{\theta}}$

To rewrite Equation (4.51) in terms of $A_{i}$ of the $\mathrm{i}^{\text {th }}$ cell, Equation (4.53) is substituted into Equation (4.52) so that simultaneous equations can be formulated and solved later. Thus, the simultaneous equation for $A_{i}$ of the $\mathrm{i}^{\text {th }}$ cell is given as:

$$
\left(A^{*}\right)_{i}=-\left(\frac{S_{w}}{D^{w}}\right)_{i} \frac{\varphi_{i-1}}{2}+\left(\frac{2 S_{f}}{D^{f}}+\frac{2 S_{w}}{D^{w}}\right)_{i} \frac{\varphi_{i}}{2}-\left(\frac{S_{w}}{D^{w}}\right)_{i} \frac{\varphi_{i+1}}{2}
$$

For multi-cell cross section in this study (three rectangular cells), variables $\left(\varphi_{i}\right)$ can be obtained by solving simultaneous equations of Equation (4.54) where $i=1,2$ and 3 . These equations are presented in Equation (4.55). For symmetrical sections and fiber architecture, the enclosed area $A_{i}$ in each cell is equal. Moreover, symmetrical lay-up of fiber architecture in both web and flange leads to decoupling between in-plane and out-of-plane stiffness, $D_{\text {sw }}$ being zero. Thus, the simultaneous equations to be solved are written in matrix form as:

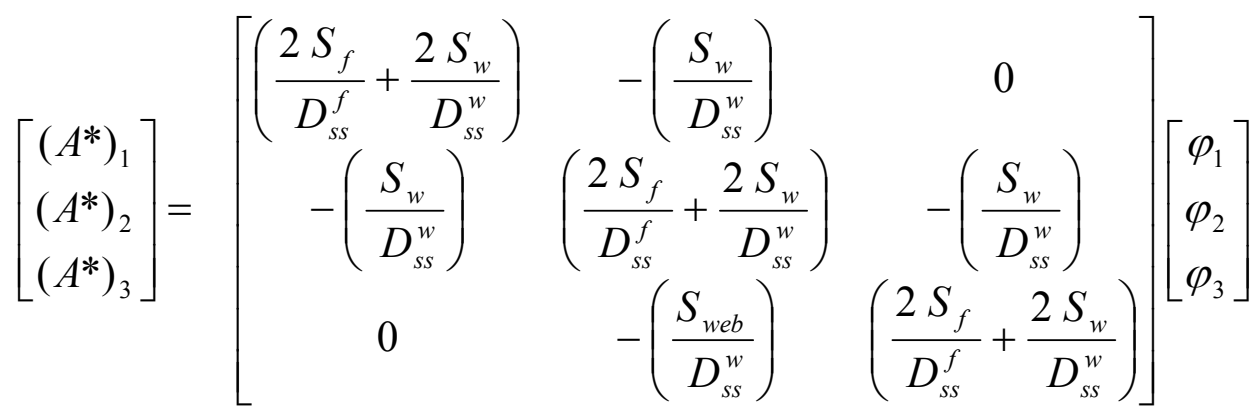




$$
\left[\begin{array}{l}
\varphi_{1} \\
\varphi_{2} \\
\varphi_{3}
\end{array}\right]=\left(A^{*}\right)\left[\begin{array}{c}
\frac{D_{s s}^{f} D_{s s}^{w}\left[3 S_{w} D_{s s}^{f}+2 S_{f} D_{s s}^{w}\right]}{s_{w}^{2}\left(D_{s s}^{f}\right)_{f}^{2}+4 s_{f} S_{w} D_{s s}^{f} D_{s s}^{w}+2 s_{f}^{2}\left(D_{s s}^{w}\right)^{2}} \\
\frac{2 D_{s s}^{f} D_{s s}^{w}\left[2 S_{w} D_{s s}^{f}+S_{f} D_{s s}^{w}\right]}{S_{w}^{2}\left(D_{s s}^{f}\right)^{2}+4 S_{f} S_{w} D_{s s}^{f} D_{s s}^{w}+2 S_{f}^{2}\left(D_{s s}^{w}\right)^{2}} \\
\frac{D_{s s}^{f} D_{s s}^{w}\left[3 S_{w} D_{s s}^{f}+2 S_{f} D_{s s}^{w}\right]}{S_{w}^{2}\left(D_{s s}^{f}\right)^{2}+4 S_{f} S_{w} D_{s s}^{f} D_{s s}^{w}+2 S_{f}^{2}\left(D_{s s}^{w}\right)^{2}}
\end{array}\right]
$$

Where, $S_{f}$ is the flange length from the center to the center of two contiguous webs. $S_{w}$ is length of web portion from center to center of two contiguous flanges, $A^{*}$ is a single enclosed area surrounded by $S_{f}$ and $S_{w}, D_{s s}$ of both flange and web is defined in Equation (4.13).

To arrive at torsional rigidity of multi-cell rectangular FRP cross-section, $\varphi_{i}$ results from Equation (4.56) and additional Equations (4.53) are substituted into relation of total applied torque acting on the cross-section in Equation (4.49) leading to:

$$
\begin{aligned}
& T=2\left(A_{1} \varphi+A_{2} \varphi_{2}+A_{3} \varphi_{3}\right) \bar{\theta} \\
& T=\left(\frac{4\left(A^{*}\right)^{2} D_{s s}^{f} D_{s s}^{w}\left[5 S_{w} D_{s s}^{f}+3 S_{f} D_{s s}^{w}\right]}{\left[s_{w} D_{s s}^{f}+2 s_{f} s_{w} D_{s s}^{w}\right]^{2}-2\left(s_{f} D_{s s}^{w}\right)^{2}}\right) \bar{\theta}=G J \bar{\theta}
\end{aligned}
$$

To calculate in-plane shear strain for multi-cell thin walled rectangular beams in this study, "springs in series" analogy is used for this purpose (refer to Figure 4.22). Applied torque on each cell is found to be the ratio of $\varphi_{i}$ variable due to the same value of the enclosed area $\left(A^{*}\right)$ in each cell. From Equations (4.49) and (4.53), applied torque of the $i^{\text {th }}$ cell $T_{i}=2\left(A^{*}\right)_{i} \varphi_{i} \bar{\theta}$ that is written in terms of total torque $T=\sum_{i=1}^{n} 2\left(A^{*}\right)_{i} \varphi_{i} \bar{\theta}$ is equal to 
$\left(T \varphi_{i} / \sum_{i=1}^{n} \varphi_{i}\right)$ and laminated stiffness of structural portions are substituted into Equation 4.41.

Then, the in-plane (xy) shear strain of the $\mathrm{i}^{\text {th }}$ cell is presented as:

$$
\gamma_{x y}^{i}=\frac{\left(D_{w W}-z D_{s W}\right)}{2\left(A^{*}\right)\left(D_{S S} D_{w W}-D_{s w}{ }^{2}\right)}\left(\frac{T \varphi_{i}}{\sum_{i=1}^{n} \varphi_{i}}\right)
$$

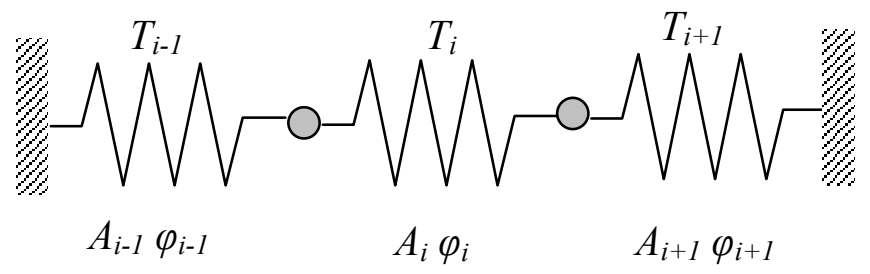

Figure 4.22 Spring Analogy for strain calculation

In addition, warping distribution for multi-cell cross sections can be obtained by using the same procedure of a single cell cross-section. Also, compatibility relation between warping displacement and in-plane shear strain in Equation (4.46) is utilized to present warping distribution. Therefore, warping distribution of the $i^{\text {th }}$ cell of multi-cell cross-section is presented as:

$\left(u_{s}-u_{0}\right)_{i}=\int_{0}^{s}\left(\frac{q}{\left(D_{s s}-\frac{D_{s w}^{2}}{D_{w w}}\right)}\right)_{i} d s-2\left(A_{0 S}\right) \frac{d \theta}{d x}$

Additional Equations (4.53) are substituted into the above equation, to yield: 
$\left(u_{s}-u_{0}\right)_{i}=\left(\int_{0}^{s} \frac{\varphi_{i}}{\left(D_{s s}-\frac{D_{s w}^{2}}{D_{w w}}\right)_{i}} d s-2\left(A_{0 S}\right)\right) \bar{\theta}$

Where, $\varphi_{\mathrm{i}}$ is solution of simultaneous Equation (4.54), $A_{o s}$ is the area swept out by a generator, with its center at the origin of axes, from the origin to any point $(s)$ around the cross-section and $(d \theta / d x)$ is the rate of twist for multi-cell cross-sections. Warping displacement of multi cell cross section is illustrated in Figure 4.23

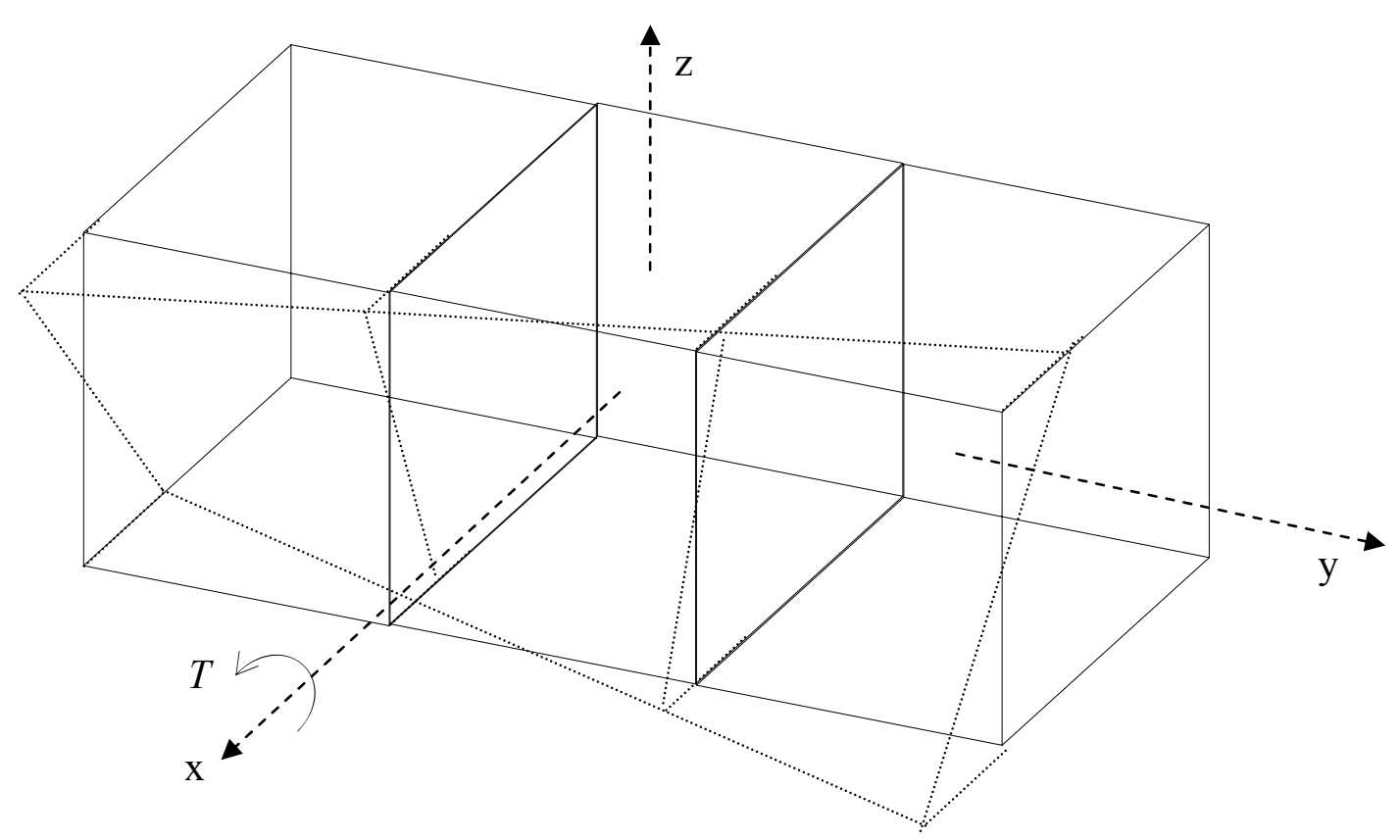

Figure 4.23 Warping displacement of multi cell cross section (ProDeck4)

\subsubsection{Torsional Rigidity of Multi-Cell Thin-Walled Triangular FRP Beam}

A multi-cell thin-walled triangular FRP beam is an FRP composite bridge deck module known as ProDeck8 which was developed, also by CFC, West Virginia University. This multi-cell triangular cross-section includes two trapezoidal sections (assumes to be a 
double triangular cross section) (refer to Figure 4.24). The limitations and assumptions of the multi-cell thin walled rectangular FRP beam as in the previous Section 4.4.5 still hold true for the section shown in Figure 4.24.

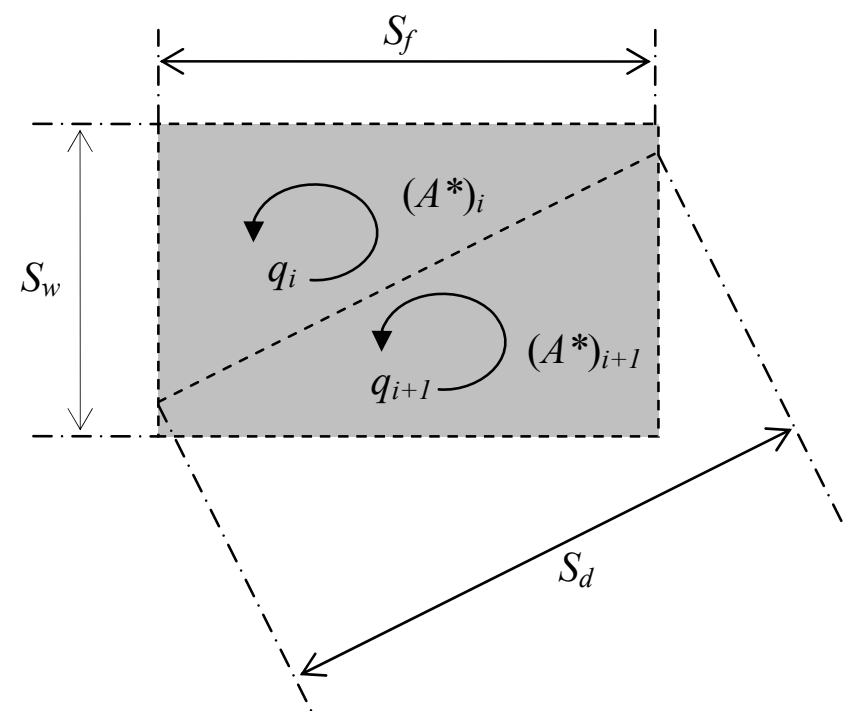

Figure 4.24 Shear flow on double cells of trapezoidal thin-walled cross section

From Figure 4.24, $q_{\mathrm{i}}$ and $q_{\mathrm{i}+1}$ are completely surrounded with their respective cells. Along the wall shared by two cells, total sectional shear flow is the algebraic sum of shear flows in adjacent cells. The results by integrating Equation (4.50) are given in Equation (4.63). Shear flow of right web, diagonal and bottom flange for $\mathrm{i}+1^{\text {th }}$ cell are $q_{i+1}, q_{i+1}-q_{i}$ and $q_{i+1}$, respectively (refer to Figure 4.25). Shear flow versus rate of twist relation of the $\mathrm{i}^{\text {th }}$ cell is given as:

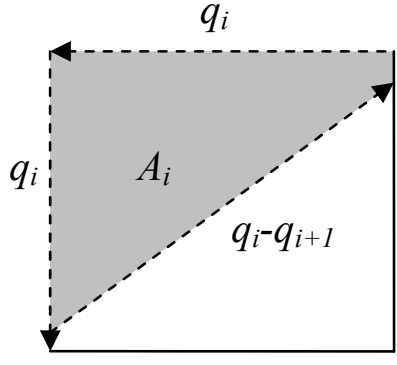

Cell $\mathrm{i}^{\text {th }}$

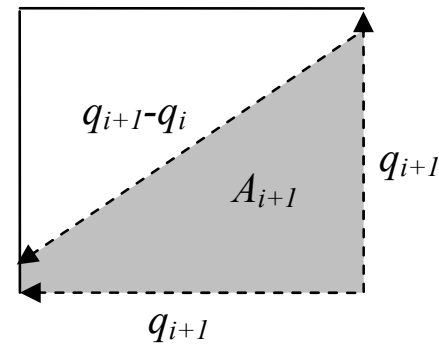

Cell $\mathrm{i}+1^{\text {th }}$

Figure 4.25 Shear flow on $i^{\text {th }}$ and $i+1^{\text {th }}$ cell of double cell triangular cross section 


$$
\begin{aligned}
\bar{\theta}_{i} & =\int_{\text {top flange }} \frac{q_{i}}{2\left(A^{*}\right)_{i}\left(D_{s s}-\frac{D_{s w}^{2}}{D_{w w}}\right)_{i}} d s+\int_{\text {right web }} \frac{q_{i}}{2\left(A^{*}\right)_{i}\left(D_{s s}-\frac{D_{s w}^{2}}{D_{w w}}\right)_{i}} d s \\
& +\int_{\text {diagonal }} \frac{q_{i}-q_{i-1}}{2\left(A^{*}\right)_{i}\left(D_{s s}-\frac{D_{s w}^{2}}{D_{w w}}\right)_{i}} d s
\end{aligned}
$$

$\bar{\theta}_{i}=\left(\frac{S_{f}}{D^{f}}+\frac{S_{w}}{D^{w}}+\frac{S_{d}}{D^{d}}\right)_{i} \frac{q_{i}}{2\left(A^{*}\right)_{i}}-\left(\frac{S_{d}}{D^{d}}\right)_{i} \frac{q_{i+1}}{2\left(A^{*}\right)_{i}}$

where $D^{f}=\left(D_{s s}-\frac{D_{s w}^{2}}{D_{w w}}\right)_{f} \quad D^{w}=\left(D_{s s}-\frac{D_{s w}^{2}}{D_{w w}}\right)_{w} \quad$ and $\quad D^{d}=\left(D_{s s}-\frac{D_{s w}^{2}}{D_{w w}}\right)_{d}$

$S_{f}$ is the mid-line length of the flange from the center to the center of the webs, $S_{w}$ is the midline length of the web from the center to the center of the flanges, $S_{d}$ is the mid-line length of the diagonal and $A^{*}$ is the enclosed area that is surrounded by the midline of the flange, the web and the diagonal on the triangular cross-section.

The double-cell FRP trapezoidal beam, a complete module of FRP bridge deck (ProDeck8), is considered in this study. Shear flow and rate of twist relation (Equation (4.50)) can be simplified by considering additional equations of the rate of twist. Additional equations that are provided in Section 4.4.5 are also used in this section.

$\bar{\theta}_{i}=\bar{\theta}_{i+1} \quad$ and $\quad \varphi_{i}=\frac{q_{i}}{\bar{\theta}}$

To present Equation (4.63) in terms of $\left(A^{*}\right)_{i}$ of the $i^{\text {th }}$ cell, Equation (4.64) is substituted into Equation (4.63) so that those simultaneous equations can be solved later. Thus, the simultaneous equations of the $1^{\text {st }}$ and $2^{\text {nd }}$ cell are written in matrix form as: 


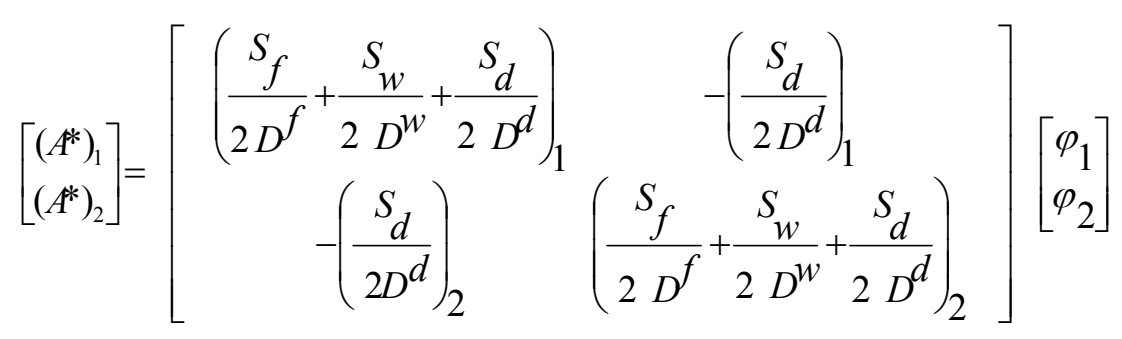

In this study, enclosed areas $\left(A^{*}\right)_{1}$ and $\left(A^{*}\right)_{2}$ of a trapezoidal section that are approximated as triangle are found to be $A^{*}$. Thus, $A^{*}$ is defined to be the enclosed area of single triangular cross section surrounded by mid-line. Variables $\left(\varphi_{i}\right)$ are obtained by solving Equation (4.65) which is given as follows:

$$
\left[\begin{array}{c}
\varphi_{1} \\
\varphi_{2}
\end{array}\right]=\left(A^{*}\right)\left[\begin{array}{c}
\frac{2 D^{f} D^{w}}{S_{w} D^{f}+S_{f} D^{w}} \\
\frac{2 D^{f} D^{w}}{S_{w} D^{f}+S_{f} D^{w}}
\end{array}\right]
$$

To arrive at torsional rigidity of multi-cellular triangular FRP cross-section, $\varphi_{i}$ results from Equation (4.66) and additional Equations (4.64) are substituted into the relation of the total applied torque acting on a cross-section (Equation (4.49)), which is:

$$
\begin{aligned}
& T=2\left(A^{*}\right)\left(\varphi_{1}+\varphi_{2}\right) \bar{\theta} \\
& T=\left(\frac{8\left(A^{*}\right)^{2} D^{f} D^{w}}{S_{w} D^{f}+S_{f} D^{w}}\right) \bar{\theta}=G J \bar{\theta}
\end{aligned}
$$

where, $G J$ is the torsional rigidity, $S_{f}$ is the mid-line length of the flange from the center to the center of the webs, $S_{w}$ is the mid-line length of the web from the center to the center of the flanges. In addition, in-plane (xy) shear strain can be evaluated using Equation (4.58). 


\subsection{Evaluation of Theoretical Results using SCLT}

Torsional rigidities of FRP composite structural members (circular, rectangular and triangular shape) are calculated using SCLT and as per theories given in Section 4.4.1 through 4.4.6. These calculated rigidities are compared herein with experimental results. For FRP rectangular plates, an example showing detailed evaluations of torsional rigidity of coupon specimen $\left(\mathrm{CP} 4_{2.3 \mathrm{~L}}\right)$ is presented below. It should be noted that calculation details of $D_{w w}, D_{s w}$, and $D_{s s}$ are provided in Appendix C.

Example: Evaluate torsional rigidity of coupon specimen $\mathrm{CP} 4_{2.3 \mathrm{~L}}(b=1$ inch wide)

From Appendix C, $D_{s s}=2.34 \times 10^{5} \mathrm{lb} / \mathrm{in}, D_{w w}=3.83 \times 10^{3} \mathrm{lb}-\mathrm{in}^{2}$ and $D_{s w}=0$ due to symmetrical lay-up

To arrive at torsional stiffness, $D_{s s}, D_{s w}, D_{w w}$ and width $b$ are substituted into Equation (4.21).

$$
\begin{aligned}
G J & =4 b\left(D_{w w}-\frac{D_{s w}{ }^{2}}{D_{s s}}\right) \\
& =4 \times 1 \times 3.83 \times 10^{3} \\
& =1.532 \times 10^{4} \quad \mathrm{lb}-\mathrm{in}^{2}
\end{aligned}
$$

In addition, equivalent in-plane (xy) shear modulus $\left(G_{x y}\right)_{e}$ can be found to be a resultant of torsional rigidity divided by torsional constant of a cross section. For torsional constant, calculation detail is provided in Appendix B.

$$
\begin{aligned}
& J=0.0267 \text { in }^{4} \\
& \left(G_{x y}\right)_{e}=0.574 \times 10^{6} \mathrm{psi}
\end{aligned}
$$

Following the same procedure, torsional rigidity $G J$ and equivalent in-plane (xy) shear modulus of other FRP structural plates are obtained and presented in Table 4.1. 
Table 4.1 Torsional rigidity using SCLT of FRP structural plates

\begin{tabular}{|c|c|c|c|c|c|c|c|}
\hline Sample & $\begin{array}{c}\text { Width } \\
\text { (b) } \\
\text { (in) }\end{array}$ & $\begin{array}{l}\mathbf{D}_{\mathbf{W W}} \\
\left(\times 10^{3}\right) \\
(\mathbf{l b}-\mathbf{i n})\end{array}$ & $\begin{array}{c}\mathbf{D}_{\text {sw }} \\
\left(\times 10^{3}\right) \\
(\mathbf{l b})\end{array}$ & $\begin{array}{c}\mathbf{D}_{\text {SS }} \\
\left(\times 10^{5}\right) \\
(\mathbf{l b} / \mathbf{i n})\end{array}$ & $\begin{array}{c}\text { Theor. } \\
\text { torsional } \\
\text { stiffness } \\
(G J) \\
\left(\times 10^{4}\right) \\
\left(l b-\mathbf{i n}^{2}\right)\end{array}$ & $\begin{array}{c}\text { Torsional } \\
\text { constant } \\
(J) \\
\left(\text { in }^{4}\right)\end{array}$ & $\begin{array}{c}\text { Equivalent } \\
\text { in-plane shear } \\
\text { modulus } \\
\left(G_{\mathrm{xy}}\right)_{\mathrm{e}} \\
\left(\times \mathbf{1 0}^{6}\right) \\
(\mathrm{psi})\end{array}$ \\
\hline $\mathrm{C}_{1} \mathrm{D}_{4 \mathrm{~L}}$ & 1 & 0.447 & 0 & 0.859 & 0.1790 & 0.00521 & 0.344 \\
\hline $\mathrm{C}_{1} \mathrm{D}_{6 \mathrm{~L}}$ & 1.5 & 0.447 & 0 & 0.859 & 0.269 & 0.00781 & 0.344 \\
\hline $\mathrm{C}_{1} \mathrm{D}_{8 \mathrm{~L}}$ & 2.0 & 0.447 & 0 & 0.859 & 0.358 & 0.01042 & 0.344 \\
\hline $\mathrm{C}_{1} \mathrm{D}_{10 \mathrm{~L}}$ & 2.5 & 0.447 & 0 & 0.859 & 0.448 & 0.01302 & 0.344 \\
\hline $\mathrm{C}_{1} \mathrm{D}_{4 \mathrm{~T}}$ & 1 & 0.447 & 0 & 0.859 & 0.1790 & 0.00521 & 0.344 \\
\hline $\mathrm{CP} 4_{2.3 \mathrm{~L}}$ & 1 & 3.83 & 0 & 2.34 & 1.532 & 0.0274 & 0.574 \\
\hline $\mathrm{CP}_{4 \mathrm{~L}}$ & 1.74 & 3.83 & 0 & 2.34 & 2.67 & 0.0465 & 0.574 \\
\hline $\mathrm{CP}_{6 \mathrm{~L}}$ & 2.61 & 3.83 & 0 & 2.34 & 4.00 & 0.0697 & 0.574 \\
\hline $\mathrm{CP} 4_{8 \mathrm{~L}}$ & 3.48 & 3.83 & 0 & 2.34 & 5.33 & 0.0929 & 0.574 \\
\hline $\mathrm{CP} 4_{10 \mathrm{~L}}$ & 4.35 & 3.83 & 0 & 2.34 & 6.66 & 0.1160 & 0.574 \\
\hline $\mathrm{CP} 4_{2.3 \mathrm{~T}}$ & 1 & 3.83 & 0 & 2.34 & 1.532 & 0.0274 & 0.574 \\
\hline $\mathrm{CP} 8_{2 \mathrm{~L}}$ & 1 & 4.26 & 1.424 & 2.45 & 1.699 & 0.0304 & 0.559 \\
\hline $\mathrm{CP}_{2 \mathrm{~T}}$ & 1 & 4.26 & 1.424 & 2.45 & 1.699 & 0.0304 & 0.559 \\
\hline $\mathrm{CP}_{4 \mathrm{~L}}$ & 1 & 1.040 & 0 & 1.617 & 0.416 & 0.00693 & 0.600 \\
\hline $\mathrm{CP}_{4 \mathrm{~T}}$ & 1 & 1.040 & 0 & 1.617 & 0.416 & 0.00693 & 0.600 \\
\hline $\mathrm{CXM}_{2 \mathrm{~L}}$ & 1 & - & - & - & - & - & - \\
\hline $\mathrm{CXM}_{10 \mathrm{~L}}$ & 5 & - & - & - & - & - & - \\
\hline $\mathrm{C} 3 \mathrm{D}_{\mathrm{L}}$ & 1 & 0.131 & 0 & 0.982 & 0.0525 & 0.001016 & 0.518 \\
\hline
\end{tabular}

Note: more information of torsional constants $J$ of specimens is provided in Appendix B.

A typical example is presented, evaluating torsional rigidity $G J$ and in-plane shear modulus for a circular tube of 1 inch diameter and 0.15 inch wall thickness with only unidirectional fibers and fiber volume fraction of about $35 \%$. 
Example: Evaluate torsional rigidity of CT circular tube

This circular tube is made from unidirectional fibers with 35 percent of fiber volume fraction $V_{f}$. The circular tube can be considered to be a single lamina that has a total thickness equal to wall thickness of circular tube specimen CT. Because of unidirectional fiber, only $D_{s s}$ is necessarily found to evaluate torsional rigidity $G J$.

From Appendix C.9, $D_{s s}=4.49 \times 10^{4} \mathrm{lb} / \mathrm{in}$ and $D_{s w}=0$

Enclosed area $(\mathrm{A})=0.5675 \mathrm{in}^{2}$ and radius $(r)$ from origin to midline $=0.425$ in

Substituting $D_{s s}, D_{s w}, A^{*}$ and radius ( $r$ ) into Equation (4.37) torsional rigidity of unidirectional circular tube is found to be:

$$
\begin{aligned}
G J & =\frac{2\left(A^{*}\right)^{2}}{\pi r}\left(D_{s s}-\frac{D_{s w}^{2}}{D_{w w}}\right) \\
& =\frac{2 \times 0.5675^{2}}{\pi \times 0.425}\left(4.49 \times 10^{4}\right) \\
& =2.17 \times 10^{4} \quad \mathrm{lb}-\text { in }^{2}
\end{aligned}
$$

Torsional constant $(J)$ of a cross section is provided in Appendix B. Therefore the equivalent in-plane shear (xy) modulus is:

$$
\begin{aligned}
& J=0.0746 \text { in }^{4} \\
& \left(G_{x y}\right)_{e}=0.291 \times 10^{6} \mathrm{psi}
\end{aligned}
$$

Examples of single and multi-cell thin-walled cross-sectional beams are presented. The single cell and multi-cell rectangular thin-walled cross-sectional beams considered in this study are parts of FRP bridge deck module (ProDeck4). To evaluate torsional rigidity $G J$ of single and multi-cell rectangular cross-sectional beam in this study, $D_{s s}, D_{s w}, D_{w w}, S_{w}$ and $S_{f}$ values for ProDeck4 flange and web portions are used and given in Table 4.2. More detailed calculations $\left(D_{s s}, D_{s w}\right.$, and $\left.D_{w w}\right)$ are provided in Appendix C. 
Table 4.2 $D_{s s}, D_{s w}, D_{w w}, S_{w}$ and $S_{f}$ values of ProDeck4 flange and web portions

\begin{tabular}{|c|c|c|c|c|c|c|}
\hline Portion & $\begin{array}{c}\boldsymbol{D}_{W W} \\
\left(\times 10^{3}\right) \\
(\mathbf{l b}-\mathbf{i n})\end{array}$ & $\begin{array}{c}\boldsymbol{D}_{\boldsymbol{S W}} \\
\left(\times 10^{3}\right) \\
(\mathbf{l b})\end{array}$ & $\begin{array}{c}\boldsymbol{D}_{S S} \\
\left(\times 10^{5}\right) \\
(\mathbf{l b} / \mathbf{i n})\end{array}$ & $\begin{array}{c}\boldsymbol{S}_{\boldsymbol{w}} \\
\mathbf{( i n )}\end{array}$ & $\begin{array}{c}\boldsymbol{S}_{\boldsymbol{f}} \\
(\mathbf{i n})\end{array}$ & $\begin{array}{c}\boldsymbol{A}^{*} \\
\left.\mathbf{( i n}^{2}\right)\end{array}$ \\
\cline { 1 - 5 } Flange & 3.83 & - & 2.34 & - & 5.85 & \multirow{2}{*}{20.9} \\
\cline { 1 - 5 } Web & 2.66 & - & 2.14 & 3.57 & - & \\
\hline
\end{tabular}

Example: Evaluate torsion rigidity $(G J)$ of single cell thin-walled rectangular cross-sectional beam (ProDeck4)

Because of symmetrical lay ups for both flanges and webs, $D^{f}$ and $D^{w}$ are simplified to be $D_{s s}$ of flange and web, respectively. Hence, substituting $D_{s s}, S_{w}, S_{f}$ (refer to Figure 4.26) and $A^{*}$ (refer to Table 4.2) into Equation (4.45), torsional rigidity $G J$ of a rectangular crosssectional beam as:

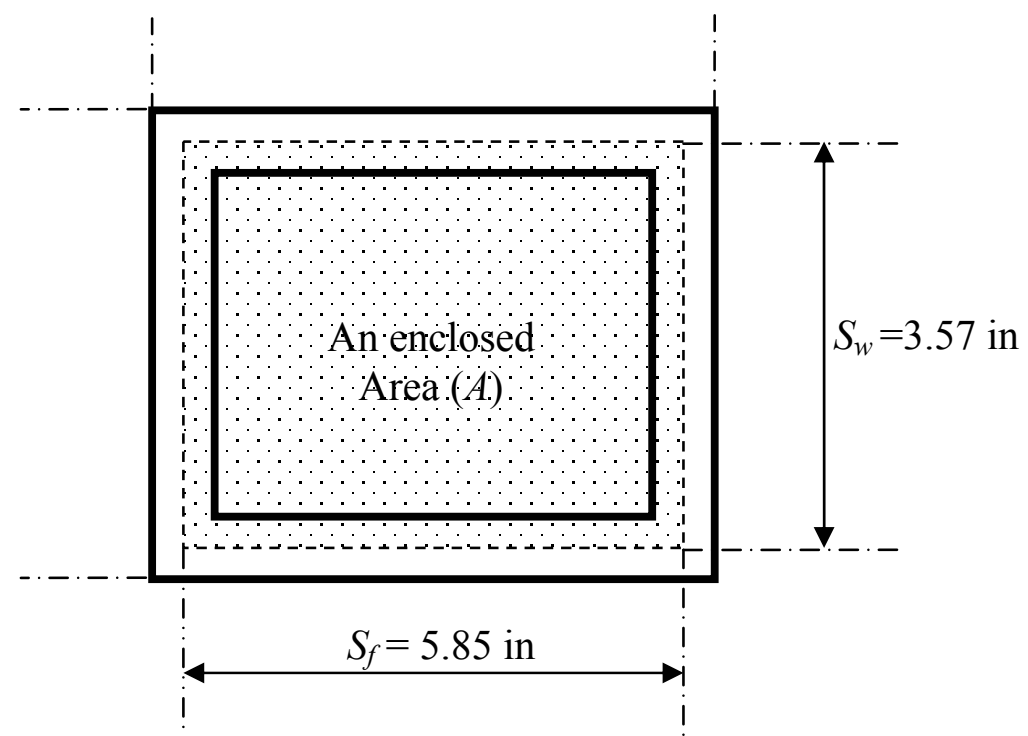

Figure 4.26 $S_{w}$ and $S_{f}$ of a single cell (ProDeck4)

$$
\begin{aligned}
& D^{f}=\left(D_{s s}-\frac{D_{s w}^{2}}{D_{w w}}\right)_{f l a n g e} \text { and } D^{w}=\left(D_{s s}-\frac{D_{s w}^{2}}{D_{w w}}\right)_{w e b} \\
& D^{f}=2.34 \times 10^{5} \mathrm{lb} / \mathrm{in} \text { and } D^{w}=2.14 \times 10^{5} \mathrm{lb} / \mathrm{in}
\end{aligned}
$$




$$
\begin{aligned}
G J & =\frac{2\left(A^{*}\right)^{2}}{\left(\frac{S_{f}}{D^{f}}+\frac{S_{w}}{D^{w}}\right)} \\
& =\frac{2 \times 20.9^{2}}{\left(\frac{5.85}{2.34 \times 10^{5}}+\frac{3.57}{2.14 \times 10^{5}}\right)} \\
G J & =2.09 \times 10^{7} \mathrm{lb}-\mathrm{in}^{2}
\end{aligned}
$$

The equivalent in-plane shear (xy) modulus of a single cell thin-walled rectangular beam is:

$$
J=37.7 \text { in }^{4}
$$

$$
\left(G_{x y}\right)_{e}=0.554 \times 10^{6} \mathrm{psi}
$$

It should be noted that more information on torsional constant for a single cell thinwalled rectangular beam is presented in Appendix B. By following these steps, torsional rigidity and equivalent in-plane (xy) shear modulus of a multi-cell thin-walled rectangular beam are presented in the next example. 
Example: Evaluate torsion rigidity $G J$ of multi-cell (three cells) thin-walled rectangular beam (ProDeck4)

Also, $D^{f}$ and $D^{w}$ in Equation (4.52) are simplified to be $D_{s s}$ of flange and web, respectively due to symmetrical lay ups of both flange and web. $D_{s s}, S_{w}, S_{f}$ and $A^{*}$ (Table 4.2) are substituted into Equation (4.58).

$$
\begin{aligned}
D^{f} & =\left(D_{s s}-\frac{D_{s w}^{2}}{D_{w w}}\right)_{\text {flange }} \text { and } D^{w}=\left(D_{s s}-\frac{D_{s w}^{2}}{D_{w w}}\right)_{w e b} \\
D^{f} & =2.34 \times 10^{5} \mathrm{lb} / \mathrm{in} \text { and } D^{w}=2.14 \times 10^{5} \mathrm{lb} / \mathrm{in} \\
G J & =\left(\frac{4\left(A^{*}\right)^{2} D_{s s}^{f} D_{s s}^{w}\left[5 S_{w} D_{s s}^{f}+3 S_{f} D_{s s}^{w}\right]}{\left[s_{w} D_{s s}^{f}+2 s_{f} s_{w} D_{s s}^{w}\right]^{2}-2\left(s_{f} D_{s s}^{w}\right)^{2}}\right) \\
& =\left(\frac{4 \times 20.9^{2} \times 5.85 \times 3.57 \times\left(5 \times 3.57 \times 2.34 \times 10^{5}\right) \times\left(3 \times 5.85 \times 2.14 \times 10^{5}\right)}{\left(\left(3.57 \times 2.34 \times 10^{5}\right)+\left(2 \times 5.85 \times 3.57 \times 2.14 \times 10^{5}\right)\right)^{2}-2 \times\left(5.85 \times 2.14 \times 10^{5}\right)^{2}}\right) \\
G J & =7.97 \times 10^{7} \mathrm{lb}-\mathrm{in}^{2}
\end{aligned}
$$

The equivalent in-plane shear (xy) modulus of a multi cell thin-walled rectangular cross section is:

$$
\begin{aligned}
& J=157.4 \mathrm{in}^{4} \\
& \left(G_{x y}\right)_{e}=0.506 \times 10^{6} \mathrm{psi}
\end{aligned}
$$

Torsional constant $(J)$ for a multi cell thin- walled rectangular beam is presented in Appendix B. In the next example, evaluation of torsional rigidity for unsymmetrical lay-up composite structural members will be presented. Multi-cell thin-walled beam with triangular section that is known as a high profile FRP deck module (ProDeck8) is used as an illustrative example. To arrive at torsional rigidity of multi-cell triangular cross-section, $D_{s s}, D_{s w}, D_{w w}$, 
$S_{w}, S_{d}$ and $S_{f}$ values for ProDeck8 flange, web and diagonal portions are given in Table 4.3. Calculation details of $D_{s s}, D_{s w}$, and $D_{w w}$ for ProDeck8 flange, web and diagonal are provided in Appendix C.

Table 4.3 $D_{s s}, D_{s w}, D_{w w}, S_{w}$ and $S_{f}$ values of both ProDeck8 flange and web

\begin{tabular}{|c|c|c|c|c|c|c|c|}
\hline Portion & $\begin{array}{c}D_{W W} \\
\left(\times 10^{3}\right) \\
(\text { lb-in) }\end{array}$ & $\begin{array}{c}D_{S W} \\
\left(\times 10^{3}\right) \\
(\mathbf{l b})\end{array}$ & $\begin{array}{c}D_{S S} \\
\left(\times 10^{5}\right) \\
(\mathbf{l b} / \mathbf{i n})\end{array}$ & $\begin{array}{c}S_{w} \\
\text { (in) }\end{array}$ & $\begin{array}{c}S_{f} \\
\text { (in) }\end{array}$ & $\begin{array}{c}S_{d} \\
\text { (in) }\end{array}$ & $\begin{array}{c}A^{*} \\
\left(\text { in }^{2}\right)\end{array}$ \\
\hline flange & 6.06 & 1.424 & 2.77 & - & 11.55 & - & \multirow{3}{*}{43.3} \\
\hline web & 4.41 & 0.736 & 2.62 & 7.5 & - & - & \\
\hline diagonal & 1.041 & - & 1.617 & - & - & 14.24 & \\
\hline
\end{tabular}

Example: Evaluate torsion rigidity $G J$ of multi-cell (double cells) thin-walled triangular cross-sectional beam

$D_{s s}, D_{s w}$, and $D_{w w}$, in Table 4.3 are substituted into Equation (4.63).

$D^{f}=\left(2.77 \times 10^{5}-\frac{\left(1.424 \times 10^{3}\right)^{2}}{\left(6.06 \times 10^{3}\right)}\right) \quad D^{w}=\left(2.62 \times 10^{5}-\frac{\left(0.736 \times 10^{3}\right)^{2}}{\left(4.41 \times 10^{3}\right)}\right)$

$D^{f} \cong 2.77 \times 10^{5} \mathrm{lb} /$ in $\quad D^{w} \cong 2.62 \times 10^{5} \mathrm{lb} /$ in

From Figure 4.24, $S_{w}$ and $S_{f}$ are 7.5 and 11.55 inch. Torsional rigidity is given in Equation (4.68) as:

$$
\begin{aligned}
G J & =\left(\frac{8\left(A^{*}\right)^{2} D^{f} D^{w}}{S_{w} D^{f}+S_{f} D^{w}}\right) \\
& =\frac{8 \times 43.3^{2} \times 2.77 \times 10^{5} \times 2.62 \times 10^{5}}{\left(\left(7.5 \times 2.77 \times 10^{5}\right)+\left(11.55 \times 2.62 \times 10^{5}\right)\right)} \\
G J & =2.13 \times 10^{8} \mathrm{lb}-\mathrm{in}^{2}
\end{aligned}
$$


Equivalent in-plane shear (xy) modulus is found from results of torsional rigidity divided by torsional constant $(J)$. Calculation of torsional constant is given in Appendix B.

$$
\begin{aligned}
& J=377 \quad \text { in }^{4} \\
& \left(G_{x y}\right)_{e}=0.565 \times 10^{6} \mathrm{psi}
\end{aligned}
$$

Theoretical torsional rigidity and equivalent in-plane shear modulus based on SCLT are given in Section 4.5. These values are validated through experimental and finite element results in Section 4.6. Analytical procedure that is descried in Section 4.2 is used to experimentally evaluate torsional rigidity.

\subsection{Evaluation of Experimental Results}

FRP composite deck specimens were tested in longitudinal and transverse direction under torsion test. Coupons, components (single and multi-cell) and components with and without joints (multi-cell with joint) in longitudinal and transverse direction are tested to evaluate for torsional rigidity and equivalent in-plane (xy) shear modulus. Experimental results for coupon specimens are presented in Section 4.6.1 and results for components with and without joints are given in Sections 4.6.2 and 4.6.3, respectively. In addition, experimental test results for component with and without joints are compared with analytical results obtained from SCLT and finite element method.

\subsubsection{Coupon Level}

Test specimens prepared from FRP decks (ProDeck4 and 8), sandwich members, and unidirectional fiber rebars and hollow tubes were tested under torsion. A description of the test specimens including dimensions and test procedures in this study is given in Sections 3.3.1.1 through 3.3.1.5. In this section, test data for torsional rigidity $G J$ and equivalent inplane (xy) shear modulus are evaluated and compared with theoretical results. As an 
example, evaluation of experimental torsional rigidity $G J$ and equivalent in-plane (xy) shear modulus of a coupon cut from the flange of ProDeck4 $\left(\mathrm{CP}_{2.3 \mathrm{~L}}\right)$ are presented in this section.

Example: Experimental evaluation of torsional rigidity of ProDeck4 flange coupon $\mathrm{CP} 4_{2.3 \mathrm{~L}}$

One inch wide by twelve inch long test specimen with 8 inch test span is tested under torsion. Experimental data $\mathrm{CP}_{2.3 \mathrm{~L}}$ included: applied torque, rate of twist and in-plane shear strain in Table 4.4. The measured data are recorded for every two degrees of rotation. From experimental data, torsional rigidity $G J$ is determined using slope of applied torque versus rate of twist curve.

Experimental torsional rigidity $G J$ and torsional constant $J$ of coupons $\mathrm{CP} 4_{2.3 \mathrm{~L} \text {. are }}$ found to be $13534 \mathrm{lbs}-\mathrm{in}^{2}$ and $0.0265 \mathrm{in}^{4}$, respectively. Applied torque versus rate of twist is also illustrated in Figure 4.27. Equivalent in-plane shear (xy) modulus of this specimen is found to be $510707 \mathrm{lbs} / \mathrm{in}^{2}$. Following the same procedure, results of other coupons are determined and presented in Table 4.5.

Table 4.4 Experimental data $\mathrm{CP}_{2.3 \mathrm{~L}}$ (sample 1) under torsion test

\begin{tabular}{|c|c|c|c|c|c|}
\hline $\begin{array}{c}\text { Fiber } \\
\text { Architecture }\end{array}$ & $\begin{array}{l}\text { Dimensions } \\
\text { (in) }\end{array}$ & $\begin{array}{l}\text { Angle of } \\
\text { twist }\left({ }^{\circ}\right)\end{array}$ & $\begin{array}{c}\text { Applied } \\
\text { torque } \\
\text { (in.lb) }\end{array}$ & $\begin{array}{l}\text { Rate of twist } \\
\text { (rad/in) }\end{array}$ & $\begin{array}{c}\text { Experimental } \\
\text { shear } \\
\text { Strain } \\
\left(1^{-6}\right) \\
\end{array}$ \\
\hline \multirow[t]{9}{*}{ 2-D fabric } & \multirow[t]{9}{*}{$0.435 \times 1 \times 12$} & 0 & 0 & 0 & 0 \\
\hline & & 2 & 70.4 & 0.004365 & 1227 \\
\hline & & 4 & 133.0 & 0.00873 & 2405 \\
\hline & & 6 & 191.8 & 0.013095 & 3574 \\
\hline & & 8 & 242 & 0.01746 & 4906 \\
\hline & & 10 & 299 & 0.021825 & 6067 \\
\hline & & 12 & 334 & 0.02619 & 7445 \\
\hline & & 14 & 349 & 0.030556 & 8161 \\
\hline & & 16 & 365 & 0.034921 & 9781 \\
\hline
\end{tabular}




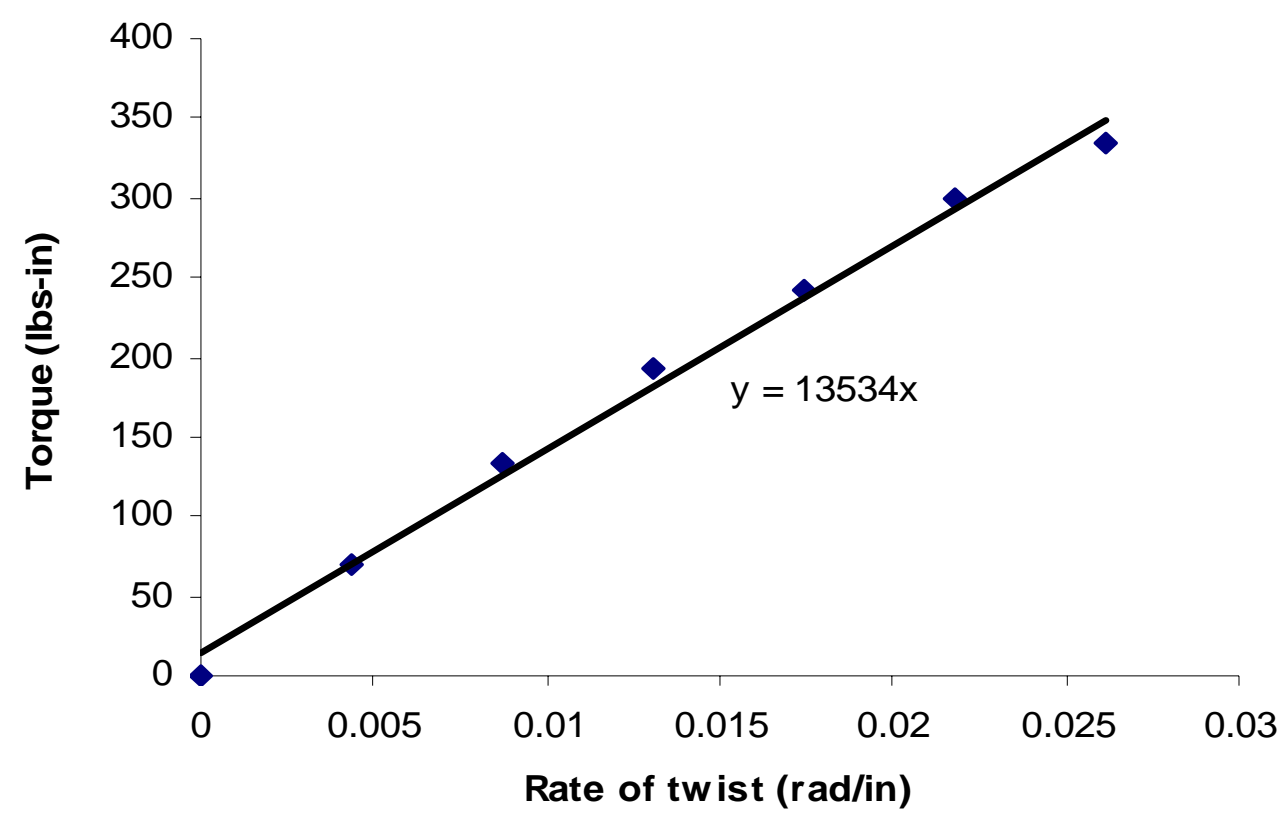

Figure 4.27 Relation between applied torque and rate of twist $\mathrm{CP4}_{2.3 \mathrm{~L}}$

In addition, an average value of equivalent in-plane shear (xy) modulus based on experimental data is compared to that of theoretical results based on SCLT. Percent difference between theory and experimental data is reported for all coupon specimens. The torsional rigidities are presented for all coupon specimens consisting of three types of fiber architecture namely unidirectional fiber, (2-D) multi directional fabric, and (3-D) stitching fabric, including sandwich panels. Results of these are given in Tables 4.5 through 4.8.

Table 4.5 Comparison of $\left(\mathrm{G}_{\mathrm{xy}}\right)_{\mathrm{e}}$ for unidirectional coupon specimens

\begin{tabular}{|c|c|c|c|c|c|c|c|}
\hline \multirow[t]{2}{*}{$\begin{array}{l}\text { Sample: } \\
\text { 1-D fiber }\end{array}$} & \multirow{2}{*}{$\begin{array}{c}\text { (b/t) } \\
\text { (width } \times \\
\text { thickness) }\end{array}$} & \multicolumn{3}{|c|}{ Experimental results } & \multicolumn{2}{|c|}{$\begin{array}{c}\text { Equivalent } \\
\text { in-plane shear modulus }\end{array}$} & \multirow{2}{*}{$\begin{array}{c}\% \\
\text { Avg. } \\
\text { difference }\end{array}$} \\
\hline & & $\begin{array}{c}\text { Torsional } \\
\text { rigidity } \\
\left(\times 10^{3}\right) \\
\left(\mathbf{l b}^{2} \mathbf{i n}^{2}\right)\end{array}$ & $\begin{array}{l}\text { Avg. } \\
\text { torsional } \\
\text { rigidity } \\
\left(\times 10^{3}\right) \\
\left(\mathrm{lb}^{2} \mathbf{i n}^{2}\right)\end{array}$ & $\begin{array}{c}\text { Equivalent } \\
\text { in-plane } \\
\text { shear } \\
\text { modulus } \\
\left(\times 10^{6}\right) \\
(p s i)\end{array}$ & $\begin{array}{c}\text { Avg. expt } \\
\left(\times 10^{6}\right) \\
(\mathrm{psi})\end{array}$ & $\begin{array}{c}\text { SCLT } \\
\left(\times 10^{6}\right) \\
(p s i)\end{array}$ & \\
\hline $\mathrm{C}_{1} \mathrm{D}_{4 \mathrm{~L}}: 1$ & \multirow{4}{*}{$\begin{array}{c}4 \\
(1 \times 0.25)\end{array}$} & 1.805 & \multirow{4}{*}{1.888} & 0.346 & \multirow{4}{*}{0.362} & \multirow{4}{*}{0.343} & \multirow{4}{*}{5.25} \\
\hline $\mathrm{C}_{1} \mathrm{D}_{4 \mathrm{~L}}: 2$ & & 1.746 & & 0.335 & & & \\
\hline $\mathrm{C}_{1} \mathrm{D}_{4 \mathrm{~L}}: 3$ & & 1.959 & & 0.376 & & & \\
\hline $\mathrm{C}_{1} \mathrm{D}_{4 \mathrm{~L}}: 4$ & & 2.04 & & 0.391 & & & \\
\hline $\mathrm{C}_{1} \mathrm{D}_{6 \mathrm{~L}}: 1$ & 6 & 2.79 & 2.78 & 0.357 & 0.357 & 0.343 & 3.92 \\
\hline
\end{tabular}




\begin{tabular}{|c|c|c|c|c|c|c|c|}
\hline $\mathrm{C}_{1} \mathrm{D}_{6 \mathrm{~L}}: 2$ & $(1.5 \times 0.25)$ & 2.77 & & 0.357 & & & \\
\hline $\mathrm{C}_{1} \mathrm{D}_{8 \mathrm{~L}}: 1$ & \multirow{2}{*}{$\begin{array}{c}8 \\
(2 \times 0.25)\end{array}$} & 3.69 & \multirow[t]{2}{*}{3.66} & 0.355 & \multirow[t]{2}{*}{0.352} & \multirow[t]{2}{*}{0.343} & \multirow[t]{2}{*}{2.56} \\
\hline $\mathrm{C}_{1} \mathrm{D}_{8 \mathrm{~L}}: 2$ & & 3.62 & & 0.348 & & & \\
\hline $\mathrm{C}_{1} \mathrm{D}_{10 \mathrm{~L}}: 1$ & \multirow{2}{*}{$\begin{array}{c}10 \\
(2.5 \times 0.25)\end{array}$} & 4.87 & \multirow[t]{2}{*}{4.83} & 0.375 & \multirow[t]{2}{*}{0.371} & \multirow[t]{2}{*}{0.343} & \multirow[t]{2}{*}{7.55} \\
\hline $\mathrm{C}_{1} \mathrm{D}_{10 \mathrm{~L}}: 2$ & & 4.78 & & 0.367 & & & \\
\hline $\mathrm{C}_{1} \mathrm{D}_{4 \mathrm{~T}}: 1$ & \multirow{3}{*}{$\begin{array}{c}4 \\
(1 \times 0.25)\end{array}$} & 1.783 & \multirow{3}{*}{1.784} & 0.342 & \multirow{3}{*}{0.342} & \multirow{3}{*}{0.343} & \multirow{3}{*}{0.292} \\
\hline $\mathrm{C}_{1} \mathrm{D}_{4 \mathrm{~T}}: 2$ & & 1.719 & & 0.330 & & & \\
\hline $\mathrm{C}_{1} \mathrm{D}_{4 \mathrm{~T}}: 3$ & & 1.850 & & 0.355 & & & \\
\hline
\end{tabular}

Note: more information on torsional constants $J$ of specimens is provided in Appendix B.

Table 4.6 Comparison of $\left(G_{x y}\right)_{e}$ for unidirectional rebar specimens

\begin{tabular}{|c|c|c|c|c|c|c|c|}
\hline \multirow[t]{2}{*}{$\begin{array}{l}\text { Sample: } \\
\text { 1-D fiber }\end{array}$} & \multirow[t]{2}{*}{$\begin{array}{l}\text { Diameter } \\
\text { (in) }\end{array}$} & \multicolumn{3}{|c|}{ Experimental results } & \multicolumn{2}{|c|}{$\begin{array}{l}\text { Equivalent } \\
\text { in-plane shear modulus }\end{array}$} & \multirow{2}{*}{$\begin{array}{c}\% \\
\text { Avg. } \\
\text { difference }\end{array}$} \\
\hline & & $\begin{array}{c}\text { Torsional } \\
\text { rigidity } \\
\left(\times 10^{3}\right) \\
\left(\mathbf{l b}^{2} \mathbf{i n}^{2}\right)\end{array}$ & $\begin{array}{c}\text { Avg. } \\
\text { torsional } \\
\text { rigidity } \\
\left(\times 10^{3}\right) \\
\left(\text { lb-in }^{2}\right)\end{array}$ & $\begin{array}{c}\text { Equivalent } \\
\text { in-plane } \\
\text { shear } \\
\text { modulus } \\
\left(\times 10^{6}\right) \\
(p s i) \\
\end{array}$ & $\begin{array}{l}\text { Avg. expt } \\
\left(\times 10^{6}\right) \\
(\mathrm{psi})\end{array}$ & $\begin{array}{c}\text { SCLT } \\
\left(\times 10^{6}\right) \\
(\mathrm{psi})\end{array}$ & \\
\hline $\mathrm{CSB}_{0.5}: 1$ & \multirow{2}{*}{$\begin{array}{c}0.5 \\
\text { (rebar) }\end{array}$} & 3.91 & \multirow[t]{2}{*}{3.78} & 0.636 & \multirow[t]{2}{*}{0.615} & \multirow[t]{2}{*}{0.523} & \multirow[t]{2}{*}{14.96} \\
\hline $\mathrm{CSB}_{0.5}: 2$ & & 3.65 & & 0.594 & & & \\
\hline $\mathrm{CSB}_{1}: 1$ & \multirow{2}{*}{$\begin{array}{c}1 \\
\text { (rebar) }\end{array}$} & 41.6 & \multirow[t]{2}{*}{41.1} & 0.424 & \multirow[t]{2}{*}{0.419} & \multirow[t]{2}{*}{0.465} & \multirow[t]{2}{*}{9.89} \\
\hline $\mathrm{CSB}_{1}: 2$ & & 40.6 & & 0.413 & & & \\
\hline CT:1 & \multirow{2}{*}{$\begin{array}{c}1 \\
\text { (tube) }\end{array}$} & 20.1 & \multirow[t]{2}{*}{20.7} & 0.269 & \multirow[t]{2}{*}{0.278} & \multirow[t]{2}{*}{0.291} & \multirow[t]{2}{*}{4.47} \\
\hline CT:2 & & 21.3 & & 0.286 & & & \\
\hline
\end{tabular}

Note: more information on torsional constants $J$ of specimens is provided in Appendix B. 


\subsubsection{Discussion of unidirectional fiber specimens}

For unidirectional fiber specimens, torsional rigidity and equivalent in-plane (xy) shear modulus based on SCLT are slightly different from those based on experimental results. For rectangular plate specimens, predicted results from SCLT are more accurate when (width/thickness) ratio of plate specimens increases. However, equivalent in-plane shear (xy) modulus based SCLT being a constant value does not depend on test specimen dimensions. It should be noted that plate action (2-dimension geometry effect) is not accounted for in theory (i.e., equilibrium equations of beams are used.). Results based on SCLT are slightly lower than experimental results when width of a test plate exceeds 10 times its thickness. Experimental results do not exhibit any significant difference in equivalent in-plane (xy) shear modulus whether test specimens are cut in longitudinal or transverse direction. Moreover, percent difference of equivalent in-plane shear modulus between experimental and SCLT method for unidirectional rectangular plates varies from $0.292 \%$ to $7.55 \%$.

For circular unidirectional rebars and tubes (Table 4.6), the torsional rigidity and equivalent in-plane shear modulus based on SCLT are moderately different (10\% to $15 \%)$ from experiment data; but smaller magnitude (4\%) of difference between SCLT and test data is found for circular tube specimen.

Table 4.7 Comparison of $\left(G_{x y}\right)_{e}$ for multi directional fabric and stitching coupons

\begin{tabular}{|c|c|c|c|c|c|c|c|}
\hline \multirow[t]{2}{*}{$\begin{array}{l}\text { Sample: } \\
\text { 2-D fabric }\end{array}$} & \multirow{2}{*}{$\begin{array}{c}\text { (b/t) } \\
\text { (width } \times \\
\text { thickness) }\end{array}$} & \multicolumn{3}{|c|}{ Experimental results } & \multicolumn{2}{|c|}{$\begin{array}{c}\text { Equivalent } \\
\text { in-plane shear modulus }\end{array}$} & \multirow{2}{*}{$\begin{array}{c}\% \\
\text { Avg. } \\
\text { difference }\end{array}$} \\
\hline & & $\begin{array}{c}\text { Torsional } \\
\text { rigidity } \\
\left(\times 10^{4}\right) \\
\left(\text { lb-in }^{2}\right)\end{array}$ & $\begin{array}{l}\text { Avg. } \\
\text { torsional } \\
\text { rigidity } \\
\left(\times 10^{4}\right) \\
\left(\text { lb-in }^{2}\right)\end{array}$ & $\begin{array}{c}\text { Equivalent } \\
\text { in-plane } \\
\text { shear } \\
\text { modulus } \\
\left(\times 10^{6}\right) \\
(p s i)\end{array}$ & $\begin{array}{c}\text { Avg. expt } \\
\left(\times 10^{6}\right) \\
(\text { psi) }\end{array}$ & $\begin{array}{l}\text { SCLT } \\
\left(\times 10^{6}\right) \\
(\mathrm{psi})\end{array}$ & \\
\hline $\mathrm{CP} 4_{2.3 \mathrm{~L}}: 1$ & \multirow{2}{*}{$\begin{array}{c}2.3 \\
(1 \times 0.435)\end{array}$} & 1.353 & \multirow[t]{2}{*}{1.369} & 0.511 & \multirow[t]{2}{*}{0.517} & \multirow[t]{2}{*}{0.574} & \multirow[t]{2}{*}{9.93} \\
\hline $\mathrm{CP} 4_{2.3 \mathrm{~L}}: 2$ & & 1.384 & & 0.522 & & & \\
\hline $\mathrm{CP}_{4 \mathrm{~L}}: 1$ & \multirow{2}{*}{$\begin{array}{c}4 \\
(1 \times 0.435)\end{array}$} & 2.48 & \multirow[t]{2}{*}{2.43} & 0.548 & \multirow[t]{2}{*}{0.536} & \multirow[t]{2}{*}{0.574} & \multirow[t]{2}{*}{6.62} \\
\hline $\mathrm{CP}_{4} \mathrm{~L}: 2$ & & 2.38 & & 0.523 & & & \\
\hline
\end{tabular}




\begin{tabular}{|c|c|c|c|c|c|c|c|}
\hline $\mathrm{CP}_{6 \mathrm{~L}}: 1$ & \multirow{2}{*}{$\begin{array}{c}6 \\
(1 \times 0.435)\end{array}$} & 3.59 & \multirow[t]{2}{*}{3.67} & 0.525 & \multirow[t]{2}{*}{0.537} & \multirow[t]{2}{*}{0.574} & \multirow[t]{2}{*}{6.45} \\
\hline $\mathrm{CP}_{6 \mathrm{~L}}: 2$ & & 3.75 & & 0.548 & & & \\
\hline $\mathrm{CP}_{8 \mathrm{~L}}: 1$ & \multirow{2}{*}{$\begin{array}{c}8 \\
(1 \times 0.435)\end{array}$} & 5.28 & \multirow[t]{2}{*}{5.37} & 0.553 & \multirow[t]{2}{*}{0.563} & \multirow[t]{2}{*}{0.574} & \multirow[t]{2}{*}{1.916} \\
\hline $\mathrm{CP}_{8 \mathrm{~L}}: 2$ & & 5.46 & & 0.572 & & & \\
\hline $\mathrm{CP}_{10 \mathrm{~L}}: 1$ & \multirow{2}{*}{$\begin{array}{c}10 \\
(1 \times 0.435)\end{array}$} & 6.73 & \multirow[t]{2}{*}{6.73} & 0.587 & \multirow[t]{2}{*}{0.587} & \multirow[t]{2}{*}{0.574} & \multirow[t]{2}{*}{2.21} \\
\hline $\mathrm{CP}_{10 \mathrm{~L}}: 2$ & & - & & - & & & \\
\hline $\mathrm{CP}_{2.3 \mathrm{~T}}: 1$ & \multirow{4}{*}{$\begin{array}{c}2.3 \\
(1 \times 0.435)\end{array}$} & $1.024^{*}$ & \multirow[t]{4}{*}{1.318} & $0.386^{*}$ & \multirow[t]{4}{*}{0.497} & \multirow[t]{4}{*}{0.574} & \multirow[t]{4}{*}{13.41} \\
\hline $\mathrm{CP}_{2.3 \mathrm{~T}}: 2$ & & $1.239 *$ & & $0.468 *$ & & & \\
\hline $\mathrm{CP}_{2.3 \mathrm{~T}}: 3$ & & 1.320 & & 0.498 & & & \\
\hline $\mathrm{CP}_{2.3 \mathrm{~T}}: 4$ & & 1.315 & & 0.496 & & & \\
\hline $\mathrm{CP}_{2 \mathrm{~L}}: 1$ & \multirow{4}{*}{$\begin{array}{c}2 \\
(1 \times 0.435)\end{array}$} & 1.572 & \multirow[t]{4}{*}{1.563} & 0.518 & \multirow[t]{4}{*}{0.515} & \multirow[t]{4}{*}{0.559} & \multirow[t]{4}{*}{7.87} \\
\hline $\mathrm{CP}_{2 \mathrm{~L}}: 2$ & & 1.599 & & 0.526 & & & \\
\hline $\mathrm{CP}_{2 \mathrm{~L}}: 3$ & & $1.463^{*}$ & & $0.482 *$ & & & \\
\hline $\mathrm{CP8}_{2 \mathrm{~L}}: 4$ & & 1.519 & & 0.500 & & & \\
\hline CP8 ${ }_{2 \mathrm{~T}}: 1$ & \multirow{2}{*}{$\begin{array}{c}2 \\
(1 \times 0.435)\end{array}$} & 1.426 & \multirow[t]{2}{*}{1.388} & 0.469 & \multirow[t]{2}{*}{0.457} & \multirow[t]{2}{*}{0.559} & \multirow[t]{2}{*}{18.25} \\
\hline $\mathrm{CP}_{2 \mathrm{~T}}: 2$ & & 1.350 & & 0.444 & & & \\
\hline $\mathrm{CP}_{4 \mathrm{~L}}: 1$ & 4 & 0.349 & 0.357 & 0.503 & 0.514 & 0.601 & 14.48 \\
\hline $\mathrm{CP}_{4 \mathrm{~L}}: 2$ & & 0.351 & & 0.506 & & & \\
\hline $\mathrm{CP}_{4 \mathrm{~L}}: 3$ & & 0.366 & & 0.528 & & & \\
\hline $\mathrm{CP}_{4 \mathrm{~L}}: 4$ & & 0.360 & & 0.519 & & & \\
\hline $\mathrm{CP}_{4 \mathrm{~T}}: 1$ & 4 & 0.328 & 0.321 & 0.473 & 0.463 & 0.601 & 22.9 \\
\hline $\mathrm{CP}_{4 \mathrm{~T}}: 2$ & $(1 \times 0.435)$ & 0.314 & & 0.453 & & & \\
\hline $\mathrm{CXM}_{2 \mathrm{~L}}: 1$ & 2 & 1.339 & 1.338 & 0.321 & 0.321 & - & - \\
\hline $\mathrm{CXM}_{2 \mathrm{~L}}: 2$ & $(1 \times 0.5)$ & 1.351 & & 0.324 & & & \\
\hline $\mathrm{CXM}_{2 \mathrm{~L}}: 3$ & & 1.325 & & 0.318 & & & \\
\hline $\mathrm{CXM}_{10 \mathrm{~L}}: 1$ & 10 & 7.28 & 7.34 & 0.350 & 0.353 & - & - \\
\hline $\mathrm{CXM}_{10 \mathrm{~L}}: 2$ & $(1 \times 0.5)$ & 7.49 & & 0.360 & & & \\
\hline $\mathrm{CXM}_{10 \mathrm{~L}}: 3$ & & 7.24 & & 0.348 & & & \\
\hline C3D $D_{L}: 1$ & 7 & 0.0594 & 0.0571 & 0.559 & 0.549 & 0.518 & 5.65 \\
\hline C3D $D_{L}: 2$ & $(1 \times 0.145)$ & 0.0548 & & 0.539 & & & \\
\hline
\end{tabular}

Note: more information on torsional constants $J$ of specimens is provided in Appendix B. 


\subsubsection{Discussion of 2D fabric and stitching specimen}

For 2-D coupon with fabrics, average percent difference between SCLT and experimental methods of ProDeck4 coupons is found to vary from $1.9 \%$ to $13.4 \%$. Percent difference gradually decreases with an increase in aspect ratio (width/thickness) of specimen. As in unidirectional coupon specimens, no significant percent difference is found between longitudinal and transverse coupons. For ProDeck8 coupons, equivalent in-plane shear (xy) modulus based on SCLT is higher than that of experimental value. Percent difference between both methods varies between $7.87 \%$ and $22.9 \%$ due to edge effect (cutting coupon from components) and fiber discontinuity particularly in transverse directional coupons. In addition, it is found that equivalent in-plane shear (xy) modulus of longitudinal specimens is higher than that of transverse specimens by about $10 \%$. For $3-\mathrm{D}$ stitched fabric coupon, experimental torsional rigidity and equivalent in-plane shear modulus are slightly higher than those of SCLT by about $5.65 \%$ due to fiber stitching perpendicular to (xy) plane of coupons. It is expected that (3D) stitching will improve delamination strength of laminates. Results of SCLT do not account for effects of fiber stitching in perpendicular direction to (xy) plane of specimens.

\subsubsection{Discussion of sandwich specimen}

For sandwich specimens, equivalent in-plane shear modulus obtained from experimental results is significantly lower than that of SCLT. The SCLT assumes that all layers including FRP laminate (facial material) and wood core are perfectly bonded together. However, in reality lower capacity of in-plane shear resistance of wood core under torsion fail prematurely due to delamination between wood core and FRP laminate, leading to lower shear modulus value. Thus, the experimental torsional rigidity is much lower than that of theoretical method as presented in Table 4.8. 
Table 4.8 Comparison of $\left(G_{x y}\right)_{e}$ for sandwich coupon specimens

\begin{tabular}{|c|c|c|c|c|c|c|c|}
\hline \multirow[t]{2}{*}{$\begin{array}{c}\text { Sample } \\
\text { (sandwich) }\end{array}$} & \multirow{2}{*}{$\begin{array}{c}\text { (b/t) } \\
\text { (width } \times \\
\text { thickness) }\end{array}$} & \multirow{2}{*}{$\begin{array}{c}\text { Torsional } \\
\text { rigidity } \\
\left(\times 10^{3}\right) \\
\left(\mathbf{l b}^{2} \mathbf{i n}^{2}\right)\end{array}$} & \multirow{2}{*}{$\begin{array}{l}\text { Avg. } \\
\text { torsional } \\
\text { rigidity } \\
\left(\times 10^{3}\right) \\
\left(\mathbf{l b}^{2} \text { in }^{2}\right)\end{array}$} & \multirow{2}{*}{$\begin{array}{c}\text { Equivalent } \\
\text { in-plane } \\
\text { shear } \\
\text { modulus } \\
\left(\times 10^{6}\right) \\
(p s i)\end{array}$} & \multicolumn{2}{|c|}{$\begin{array}{c}\text { Equivalent } \\
\text { in-plane shear modulus }\end{array}$} & \multirow{2}{*}{$\begin{array}{c}\% \\
\text { Avg. } \\
\text { difference }\end{array}$} \\
\hline & & & & & $\begin{array}{c}\text { Avg. exp } \\
\left(\times 10^{6}\right) \\
(\mathrm{psi})\end{array}$ & $\begin{array}{l}\text { SCLT } \\
\left(\times 10^{6}\right) \\
(\mathrm{psi})\end{array}$ & \\
\hline $\mathrm{CSF}_{\mathrm{b}}: 1$ & \multirow[t]{3}{*}{1} & 7.39 & \multirow[t]{3}{*}{7.24} & 0.0221 & \multirow[t]{3}{*}{0.0217} & \multirow[t]{3}{*}{0.210} & \multirow[t]{3}{*}{89.7} \\
\hline $\mathrm{CSF}_{\mathrm{b}}: 2$ & & 7.11 & & 0.0213 & & & \\
\hline $\mathrm{CSF}_{\mathrm{b}}: 3$ & & 7.21 & & 0.0216 & & & \\
\hline $\mathrm{CSF}_{\mathrm{p}}: 1$ & \multirow[t]{3}{*}{7} & 114.9 & \multirow[t]{3}{*}{129.2} & 0.0492 & \multirow[t]{3}{*}{0.0553} & \multirow[t]{3}{*}{0.210} & \multirow[t]{3}{*}{73.7} \\
\hline $\mathrm{CSF}_{\mathrm{p}}: 2$ & & 143.2 & & 0.0614 & & & \\
\hline $\mathrm{CSF}_{\mathrm{p}}: 3$ & & 129.4 & & 0.0555 & & & \\
\hline
\end{tabular}

\subsubsection{Discussion of in-plane shear strain (Coupon)}

Theoretical in-plane (xy) shear strain based on SCLT is predicted and compared with the experimental in-plane shear strain at top surfaces. To determine in-plane (xy) shear strain, the applied torque is substituted into Equation (4.24). An example for evaluation of in-plane (xy) shear strain of coupon specimen $\mathrm{CP}_{2.3 \mathrm{~L}}$ is presented below:

Example: In-plane (xy) shear strain of coupon specimen $\mathrm{CP}_{2.3 \mathrm{~L}}$ using SCLT

In-plane (xy) shear strain is given in terms of applied torque and laminate stiffness. Applied torque and laminate stiffness are substituted into relation of in-plane (xy) shear strain. Therefore, in-plane shear strain for a given torque as per Equation (4.24) is given in Table 4.9 after substituting $D_{s s}$ and $D_{w w}$ into Equation (4.24), where $D_{s w}$ is zero and $T$ is 365 in.lb.

From Equation (4.24)

$$
\gamma_{x y}=\frac{T z}{2 b D_{w W}}=\frac{365 z}{2(1 \times 3830)}
$$


To present in-plane (xy) shear strain profile of coupon $\mathrm{CP}_{2.3 \mathrm{~L}}$, in-plane (xy) shear strains through thickness of cross-section are calculated and presented in Table 4.9.

Table 4.9 Theoretical in-plane shear (xy) strain of coupon specimen $C P 4_{2.3 \mathrm{~L}}$

\begin{tabular}{|c|c|c|c|}
\hline Layer & $\begin{array}{c}\text { Distance } \\
\text { (z-direction) } \\
\text { (in) }\end{array}$ & Fabric & $\begin{array}{c}\text { In-plane } \\
\text { shear strain } \\
\mathbf{( 1 0}^{-6} \mathbf{)}\end{array}$ \\
\hline 1 & 0.2175 & CDBM & 1036 \\
\hline 2 & 0.1655 & Roving & 789 \\
\hline 3 & 0.1255 & DDBM & 598 \\
\hline 4 & 0.0685 & Roving & 326 \\
\hline 5 & 0.0285 & DDBM & 135.8 \\
\hline 6 & 0.0285 & DDBM & 135.8 \\
\hline 7 & 0.0685 & Roving & 326 \\
\hline 8 & 0.1255 & DDBM & 598 \\
\hline 9 & 0.1655 & Roving & 789 \\
\hline 10 & 0.2175 & CDBM & 1036 \\
\hline
\end{tabular}

Following the same procedure, theoretical in-plane shear strain profile based on SCLT for coupon specimens is calculated and compared with the experimental data for the same applied torque level. Comparison of in-plane shear (xy) strain for coupon specimens in this study is given in Table 4.10 and 4.11 .

Table 4.10 Comparison of in-plane shear strain for coupon

\begin{tabular}{|c|c|c|c|c|c|c|}
\hline \multirow[t]{2}{*}{ Sample } & \multirow{2}{*}{$\begin{array}{c}\text { (b/t) } \\
\text { (width } \times \\
\text { thickness) }\end{array}$} & \multirow{2}{*}{$\begin{array}{l}\text { Applied } \\
\text { torque } \\
\text { (in.lb) }\end{array}$} & \multicolumn{2}{|c|}{$\begin{array}{c}\text { Avg. in-plane } \\
\text { shear strain }\end{array}$} & \multirow[t]{2}{*}{$\begin{array}{c}\% \\
\text { Difference }\end{array}$} & \multirow{2}{*}{$\begin{array}{c}\% \\
\text { Difference } \\
\text { (Avg.) }\end{array}$} \\
\hline & & & $\begin{array}{c}\text { Experiment } \\
\left(10^{-6}\right)\end{array}$ & $\begin{array}{l}\text { SCLT } \\
\left(10^{-6}\right)\end{array}$ & & \\
\hline $\mathrm{C}_{1} \mathrm{D}_{4 \mathrm{~L}}$ & 4 & 103.6 & 11595 & 14485 & 19.95 & 19.95 \\
\hline $\mathrm{C}_{1} \mathrm{D}_{6 \mathrm{~L}}$ & 6 & 158.5 & 12322 & 13842 & 10.98 & 10.98 \\
\hline $\mathrm{C}_{1} \mathrm{D}_{8 \mathrm{~L}}$ & 8 & 160.5 & 9909 & 11117 & 10.87 & 10.87 \\
\hline $\mathrm{C}_{1} \mathrm{D}_{10 \mathrm{~L}}$ & 10 & 149.9 & 8054 & 8384 & 3.94 & 3.94 \\
\hline $\mathrm{C}_{1} \mathrm{D}_{4 \mathrm{~T}}$ & 4 & 104.7 & 12010 & 14639 & 17.96 & 17.96 \\
\hline $\mathrm{CP} 4_{2.3 \mathrm{~L}}$ & 2.3 & 363 & 8338 & 10307 & 19.10 & 19.10 \\
\hline $\mathrm{CP}_{4 \mathrm{~L}}$ & 4 & 640 & 8372 & 10444 & 19.84 & 19.84 \\
\hline
\end{tabular}




\begin{tabular}{|c|c|c|c|c|c|c|}
\hline $\mathrm{CP}_{6 \mathrm{~L}}$ & 6 & 1131 & 9379 & 12304 & 23.8 & 23.8 \\
\hline $\mathrm{CP} 4_{8 \mathrm{~L}}$ & 8 & 1570 & 9758 & 12810 & 23.8 & 23.8 \\
\hline $\mathrm{CP} 4_{10 \mathrm{~L}}$ & 10 & 2060 & 10390 & 13451 & 22.8 & 22.8 \\
\hline \multirow[t]{5}{*}{$\mathrm{CP} 4_{2.3 \mathrm{~T}}$} & \multirow[t]{5}{*}{2.3} & 303 & 8155 & 8603 & 5.21 & \multirow[t]{5}{*}{11.69} \\
\hline & & 285 & 8803 & 8092 & 8.08 & \\
\hline & & 287 & 9050 & 8149 & 9.96 & \\
\hline & & 328 & 11143 & 9313 & 16.43 & \\
\hline & & 232 & 5352 & 6587 & 18.75 & \\
\hline \multirow[t]{4}{*}{$\mathrm{CP}_{2 \mathrm{~L}}$} & \multirow[t]{4}{*}{2} & 372 & 8884 & 9596 & 7.42 & \multirow[t]{4}{*}{10.76} \\
\hline & & 336 & 7200 & 8667 & 16.93 & \\
\hline & & 354 & 8171 & 9132 & 10.52 & \\
\hline & & 380 & 9004 & 9803 & 8.15 & \\
\hline \multirow[t]{2}{*}{$\mathrm{CP}_{2 \mathrm{~T}}$} & \multirow[t]{2}{*}{2} & 427 & 9737 & 11016 & 11.61 & \multirow[t]{2}{*}{19.51} \\
\hline & & 402 & 7527 & 10371 & 27.4 & \\
\hline \multirow[t]{4}{*}{$\mathrm{CP}_{4 \mathrm{~L}}$} & \multirow[t]{4}{*}{4} & 228 & 17976 & 15058 & 16.23 & \multirow[t]{4}{*}{8.58} \\
\hline & & 218 & 16150 & 14397 & 10.85 & \\
\hline & & 213 & 14531 & 14067 & 3.19 & \\
\hline & & 220 & 15141 & 14529 & 4.04 & \\
\hline \multirow[t]{2}{*}{$\mathrm{CP}_{4 \mathrm{~T}}$} & \multirow[t]{2}{*}{4} & 189 & 14688 & 12482 & 15.02 & 15.02 \\
\hline & & - & - & - & - & - \\
\hline \multirow[t]{3}{*}{$\mathrm{CXM}_{2 \mathrm{~L}}$} & \multirow[t]{3}{*}{2} & - & - & - & - & - \\
\hline & & - & - & - & - & - \\
\hline & & - & - & - & - & - \\
\hline \multirow[t]{3}{*}{$\mathrm{CXM}_{10 \mathrm{~L}}$} & \multirow[t]{3}{*}{10} & - & - & - & - & - \\
\hline & & - & - & - & - & - \\
\hline & & - & - & - & - & - \\
\hline \multirow[t]{2}{*}{$\mathrm{C} 3 \mathrm{D}_{\mathrm{L}}$} & \multirow[t]{2}{*}{7} & 60 & 12330 & 16603 & 25.7 & \multirow[t]{2}{*}{26.25} \\
\hline & & 60 & 12145 & 16603 & 26.8 & \\
\hline
\end{tabular}

Note: all coupon specimens are 12 inches in length and test span is 8 inches 
In-plane shear strains predicted by SCLT in unidirectional coupons are slightly higher than the test data for some $(\sim 4 \%)$ and much higher $(\sim 20 \%)$ for others. In addition, this percent difference gradually decreased when (width/thickness) ratio is increased. For 2-D fabric based ProDeck4, percent difference of in-plane shear strain obtained from experiment and SCLT varies between $19.10 \%$ and $23.8 \%$ because cutting of test specimens and imperfect bond of fabric layer (against with assumption of SCLT) leading to poor bond in the width direction (fiber discontinuity). Experimental in-plane shear strains of ProDeck8 specimens varied when compared with the in-plane shear strain predicted by SCLT. Average percent difference of in-plane shear strain of ProDeck8 specimens also varies from $8.58 \%$ to $19.51 \%$. It should be noted that theoretical strain based on SCLT assumes that laminated fabric is perfectly bonded together. In addition, stress concentration and bond failure of fiber on fabric laminates are not accounted for in SLCT strain calculation. Therefore, experimental strains of coupons are lower than the theoretical values due to several factors. These factors are: bond failure, resin cracking, stress concentration, size effect, edge effect, etc. For fabrics with fiber stitching, experimental strain is lower than the SCLT by about $26.25 \%$ due to several factors that are mentioned above but the main factor affecting the data is fabric stitching (3-D) to improve delamiantion strength and reduce deformation of coupons. For rectangular coupon, it should be noted that plate action (2-dimension geometry effect) will not be accounted for in finding in-plane shear strain. Strain prediction equation results in varying strains through the thickness only (constant strain through the plane for each laminate). Thus, experimental strains should be lower than strains based on SCLT. 
Table 4.11 Comparison of in-plane shear strain for rebar

\begin{tabular}{|c|c|c|c|c|c|c|}
\hline \multirow[t]{2}{*}{$\begin{array}{l}\text { Sample } \\
\text { (rebar) }\end{array}$} & \multirow[t]{2}{*}{$\begin{array}{l}\text { Diameter } \\
\text { (in.) }\end{array}$} & \multirow{2}{*}{$\begin{array}{c}\text { Applied } \\
\text { torque } \\
\text { (in.lb) }\end{array}$} & \multicolumn{2}{|c|}{$\begin{array}{c}\text { In-plane } \\
\text { shear strain }\end{array}$} & \multirow[t]{2}{*}{$\begin{array}{c}\% \% \\
\text { Difference }\end{array}$} & \multirow{2}{*}{$\begin{array}{c}\% \\
\text { Difference } \\
\text { (Avg.) }\end{array}$} \\
\hline & & & $\begin{array}{c}\text { Experiment } \\
\left(10^{-6}\right)\end{array}$ & $\begin{array}{c}\text { SCLT } \\
\left(10^{-6}\right)\end{array}$ & & \\
\hline $\mathrm{CSB}_{0.5}$ & 0.5 & - & - & - & - & - \\
\hline $\mathrm{CSB}_{1}$ & 1 & 1499 & 18809 & 17998 & 4.31 & \multirow[t]{2}{*}{4.97} \\
\hline $\mathrm{CSB}_{2}$ & 1 & 1512 & 19749 & 18638 & 5.63 & \\
\hline CT & 1 & 688 & 13457 & 13500 & 0.319 & 0.319 \\
\hline
\end{tabular}

For circular rebar and tube specimens, experimental in-plane shear strains are slightly higher than the in-plane strains based on SCLT which is attributed to higher torsional rigidity from SCLT than that from experimental data as given in Table 4.6.

\subsubsection{Component without joints}

Longitudinal and transverse components prepared from ProDeck4 and ProDeck8 are tested during this study. It should be noted that all 16 inch long specimens are tested under torsion using a small machine. Results of those specimens are not acceptable because steel grips could not prevent slip (rotation) on a test specimen cross-section during testing. Relations between applied torque and rate of twist for specimens $\left(\mathrm{COP} 4_{144 \mathrm{~L}}\right)$ and $\left(\mathrm{COP} 8_{144 \mathrm{~L}}\right)$ are given in Figures 4.28 and 4.29, respectively. The experimental results for two types of sections (single cell rectangular and double cell triangles) under torsion are presented in Table 4.12. The average values of torsional rigidity and equivalent in-plane (xy) shear modulus based on experimental results are compared with SCLT results which are also given in Table 4.12. 


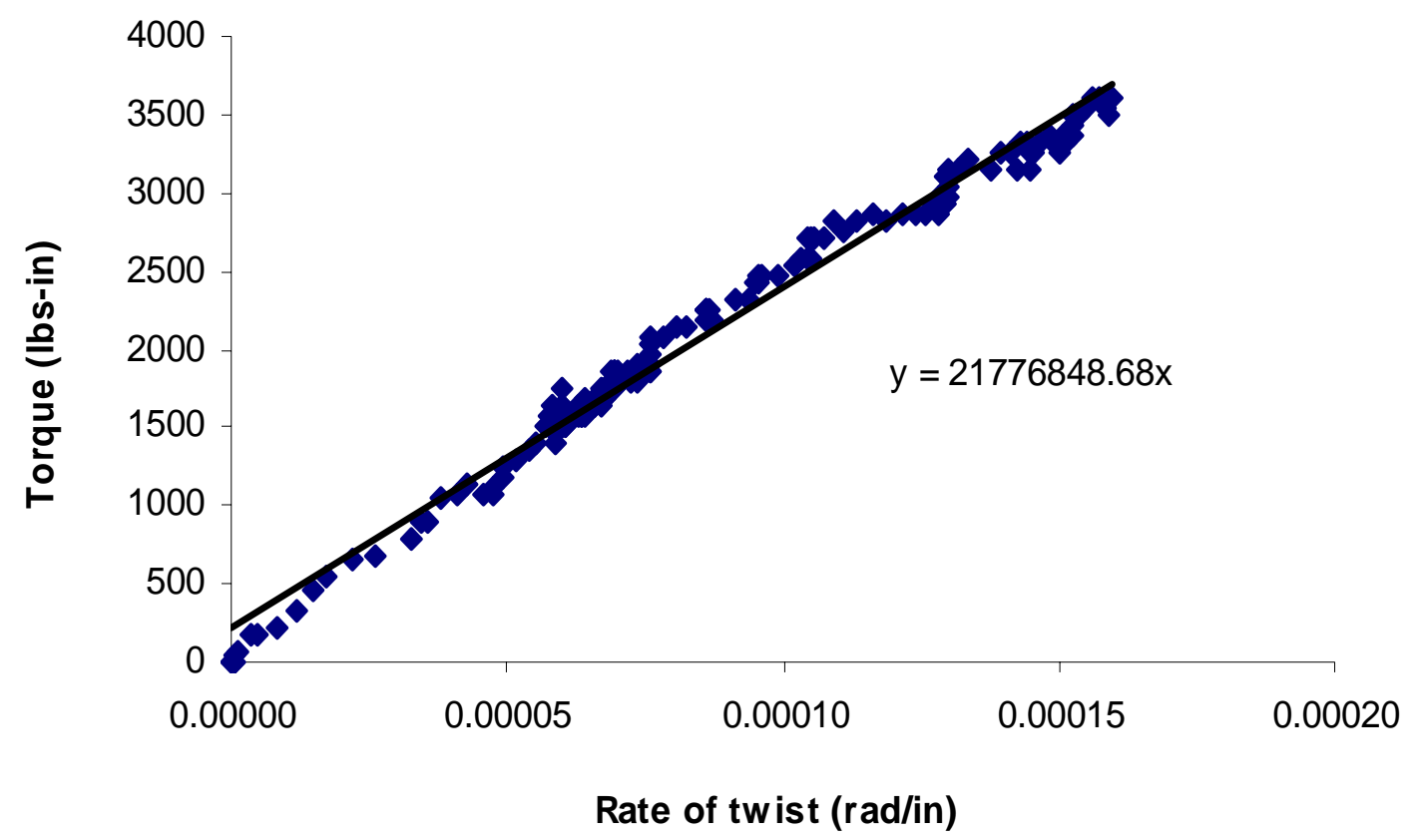

Figure 4.28 Relation between applied torque and rate of twist (COP4 $4_{144 \mathrm{~L}}$ sample2)

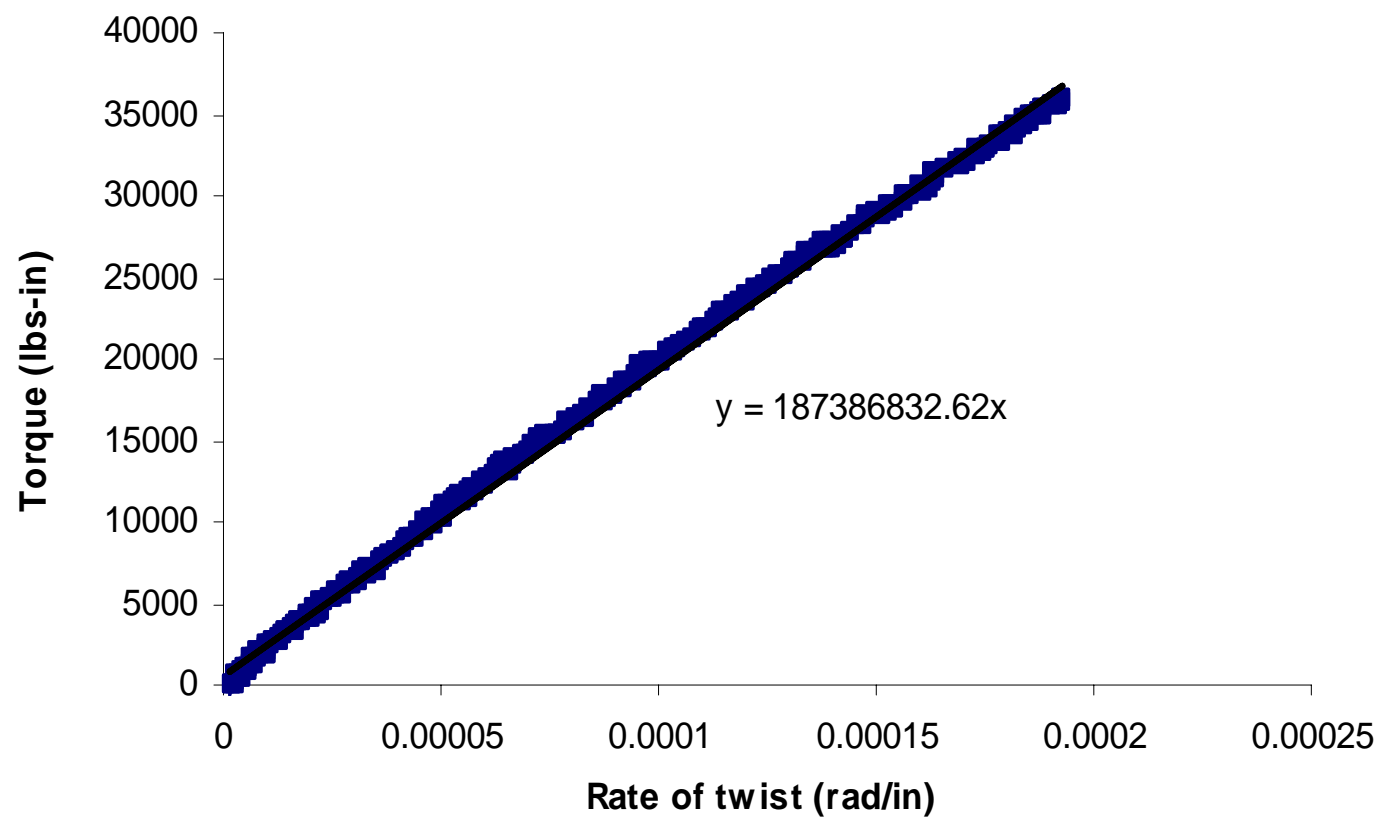

Figure 4.29 Relation between applied torque and rate of twist $\left(\mathrm{COP8}_{144 \mathrm{~L}}\right)$ 
Table 4.12 Comparison of in-plane shear modulus for component specimens (no joints)

\begin{tabular}{|c|c|c|c|c|c|c|c|}
\hline \multirow[t]{2}{*}{ Sample } & \multicolumn{4}{|c|}{ Experimental } & \multicolumn{2}{|c|}{ SCLT } & \multirow{2}{*}{$\begin{array}{l}\text { \% Avg. } \\
\text { difference }\end{array}$} \\
\hline & $\begin{array}{c}\text { Torsional } \\
\text { rigidity } \\
\left(\times 10^{6}\right) \\
\left(\text { lb-in }^{2}\right)\end{array}$ & $\begin{array}{c}\text { Avg. } \\
\text { torsional } \\
\text { rigidity } \\
\left(\times 10^{6}\right) \\
\left(\text { lb-in }^{2}\right)\end{array}$ & $\begin{array}{c}\text { In-plane } \\
\text { shear } \\
\text { modulus } \\
\left(\times 10^{6}\right) \\
(p s i)\end{array}$ & $\begin{array}{c}\text { Avg. } \\
\text { In-plane } \\
\text { shear } \\
\text { modulus } \\
\left(\times 10^{6}\right) \\
(\text { psi })\end{array}$ & $\begin{array}{c}\text { Torsional } \\
\text { rigidity } \\
\left(\times 10^{6}\right) \\
\left(\mathbf{l b}^{2} \mathbf{i n}^{2}\right)\end{array}$ & $\begin{array}{c}\text { In-plane } \\
\text { shear } \\
\text { modulus } \\
\left(\times 10^{6}\right) \\
(p s i)\end{array}$ & \\
\hline $\mathrm{COP}_{18 \mathrm{~T}}: 1$ & 0.0282 & \multirow[t]{2}{*}{0.0268} & 0.488 & \multirow[t]{2}{*}{0.463} & \multirow[t]{2}{*}{0.0306} & \multirow[t]{2}{*}{0.558} & \multirow[t]{2}{*}{17.03} \\
\hline $\mathrm{COP}_{18 \mathrm{~T}}: 2$ & 0.0253 & & 0.438 & & & & \\
\hline $\mathrm{COP}_{144 \mathrm{~L}}: 1$ & 22.0 & \multirow[t]{2}{*}{21.9} & 0.584 & \multirow[t]{2}{*}{0.581} & \multirow[t]{2}{*}{20.9} & \multirow[t]{2}{*}{0.555} & \multirow[t]{2}{*}{4.48} \\
\hline $\mathrm{COP}_{144 \mathrm{~L}}: 2$ & 21.8 & & 0.578 & & & & \\
\hline $\mathrm{COP} 8_{12 \mathrm{~T}}: 1$ & 0.516 & \multirow[t]{2}{*}{0.514} & 0.571 & \multirow[t]{2}{*}{0.569} & \multirow[t]{2}{*}{0.527} & \multirow[t]{2}{*}{0.583} & \multirow[t]{2}{*}{2.40} \\
\hline $\mathrm{COP}_{12 \mathrm{~T}}: 2$ & 0.512 & & 0.567 & & & & \\
\hline $\mathrm{COP}_{144 \mathrm{~L}}: 1$ & 187.4 & 187.4 & 0.497 & 0.497 & 213 & 0.566 & 12.19 \\
\hline
\end{tabular}

\subsubsection{Discussion of experimental and SCLT results}

Longitudinal ProDeck8 components under torsion (up to 35000 in.lb) revealed that torque and twist to failure can not be found due to limitations of test apparatus. From experimental results of FRP deck components, applied torque versus rate of twist is found to be linear. ProDeck4 (single cell cross section) presented a small difference between experimental data and theoretical values, while larger difference is noted in the transverse direction. For transverse components $\left(\mathrm{COP} 4_{18 \mathrm{~T}}\right)$, experimental results are about $17 \%$ lower than the results based on SCLT which might be due to weak positions (joints) in test specimens. Several joints (web-flange joints) caused high stress concentration and resulted in lower in-plane shear modulus in relation to results of SCLT data. From experimental test data, equivalent in-plane (xy) shear modulus of longitudinal single cell specimens is higher than that of transverse specimens by about $20 \%$ due to structural geometry. However, this trend is opposite for ProDeck8. Experimental in-plane (xy) shear moduli of transverse and longitudinal ProDeck8 specimens are found to be $0.569 \times 10^{6}$ and $0.497 \times 10^{6}$ psi, respectively. 
It should be noted that equivalent in-plane shear modulus of ProDeck8 in transverse direction is higher than that of longitudinal specimens because joints on these transverse specimens are placed inside steel grips. The effect of joints contributes to specimen performance. Torsional behavior of transverse components about the axis perpendicular to cell direction is similar to coupons (two flanges and one diagonal) twisted around their own axes. Therefore, equivalent in-plane shear modulus of these transverse specimens is close to that of coupons. However, longitudinal components $\left(\mathrm{COP} 8_{144 \mathrm{~L}}\right)$ behaved differently, because of diagonal-web joints on a component (through the length of components), which results in higher percent differences compared to SCLT. In addition, it should be noted that component results under torsion do not necessarily exhibit static response beyond a certain load. However, combination of static and buckling response is noted. Therefore, size limits (thickness to width of structural portions) are necessary to avoid local and lateral torsional buckling. To avoid buckling, size limits obtained from finite element method will be presented and discussed in Appendix F.

\subsubsection{Discussion of finite element results}

Two canonical configuration approaches in any finite element analysis are: 1) mathematical and 2) physical finite element modeling, depending on the environment in which the finite element analysis is used. The mathematical finite element modeling is found to satisfactorily solve ordinary or partial differential equations in space and time. The physical finite element modeling is used, on the other hand, by properly identifying physical behavior of a system (Felipa, 2001). In this study, the second approach is used to model FRP composite deck specimens. Input properties for structural models are obtained from experimental results at coupon level. FEMAP is used as a pre- and post-processor and ANSYS is chosen to be a solver. Physical behavior of FRP composite deck specimen is modeled into an idealized simulation through the types of elements, i.e., physical modeling.

All finite element models adopted elastic shell elements because experiments in this study are only conducted to study the elastic behavior. Orthotropic rectangular shell elements 
are used with the following properties: 1) both in-plane and normal loads are permitted, 2) the element has six degrees of freedom at each node: translations and rotations in the nodal $\mathrm{x}, \mathrm{y}$, and $\mathrm{z}$ directions, and 3) structural stiffening and large deflection capabilities are included (ANSYS element manual). In addition, model information included test span, number of elements and nodes, capacity of applied load and boundary condition, which are summarized and given in Table 4.13 .

Table 4.13 Finite element models for component level

\begin{tabular}{|c|c|c|c|c|}
\hline Model & Test span (in) & No. elements & No. nodes & Load condition \\
\hline $\mathrm{COP}_{18 \mathrm{~T}}$ & 14 & 416 & 510 & torsion \\
\hline $\mathrm{COP}_{144 \mathrm{~L}}$ & 132 & 11520 & 11560 & torsion \\
\hline $\mathrm{COP}_{12 \mathrm{~T}}$ & 8 & 424 & 525 & torsion \\
\hline $\mathrm{COP} 8_{144 \mathrm{~L}}$ & 132 & 7488 & 7395 & torsion \\
\hline MP4144L & 132 & 7250 & 7488 & torsion \\
\hline MP4144L & 132 & 4706 & 4608 & torsion \\
\hline
\end{tabular}

To evaluate torsional rigidity and in-plane shear (xy) modulus based on linear finite element data, transverse deflection (y-direction) results for any specific torque are used to calculate corresponding to twist angle corresponding to any specific applied load. Torsional rigidity is obtained from applied torque versus rate of twist curve. It should be noted that the above procedure was similar to the one mentioned in section 4.2. Also, the transverse deflections (y-direction) and in-plane shear (xy) strain are illustrated in Figures 4.30 through 4.35 and Figures 4.38 through 4.41. Comparison of torsional rigidity and in-plane shear modulus between experimental and finite element method is provided in Table 4.14. 
Table 4.14 Comparison of in-plane shear modulus for component specimens (F.E.)

\begin{tabular}{|c|c|c|c|c|c|c|c|}
\hline \multirow[t]{2}{*}{ Sample } & \multicolumn{4}{|c|}{ Experimental } & \multicolumn{2}{|c|}{ Finite Element } & \multirow{2}{*}{$\begin{array}{l}\text { \% Avg. } \\
\text { difference }\end{array}$} \\
\hline & $\begin{array}{c}\text { Torsional } \\
\text { rigidity } \\
\left(\times 10^{6}\right) \\
\left(\text { lb-in }^{2}\right)\end{array}$ & $\begin{array}{c}\text { Avg. } \\
\text { torsional } \\
\text { rigidity } \\
\left(\times 10^{6}\right) \\
\left(\mathrm{lb}^{2} \mathbf{i n}^{2}\right)\end{array}$ & $\begin{array}{c}\text { In-plane } \\
\text { shear } \\
\text { modulus } \\
\left(\times \mathbf{1 0}^{6}\right) \\
(\text { psi })\end{array}$ & $\begin{array}{c}\text { Avg. } \\
\text { in-plane } \\
\text { shear } \\
\text { modulus } \\
\left(\times \mathbf{1 0}^{6}\right) \\
\left(\mathbf{l b}^{6}-\mathbf{i n}^{2}\right)\end{array}$ & $\begin{array}{c}\text { Torsional } \\
\text { rigidity } \\
\left(\times 10^{6}\right) \\
\left(\mathbf{l b}^{2} \mathbf{i n}^{2}\right)\end{array}$ & $\begin{array}{c}\text { In-plane } \\
\text { shear } \\
\text { modulus } \\
\left(\times \mathbf{1 0}^{6}\right) \\
(\mathrm{psi})\end{array}$ & \\
\hline \multirow[t]{2}{*}{$\mathrm{COP}_{18 \mathrm{~T}}$} & 0.0282 & \multirow[t]{2}{*}{0.0268} & 0.488 & \multirow[t]{2}{*}{0.463} & \multirow[t]{2}{*}{0.0304} & \multirow[t]{2}{*}{0.525} & \multirow[t]{2}{*}{11.81} \\
\hline & 0.0253 & & 0.438 & & & & \\
\hline \multirow[t]{2}{*}{$\mathrm{COP}_{144 \mathrm{~L}}$} & 22.0 & \multirow[t]{2}{*}{21.9} & 0.584 & \multirow[t]{2}{*}{0.581} & \multirow[t]{2}{*}{22.4} & \multirow[t]{2}{*}{0.594} & \multirow[t]{2}{*}{2.19} \\
\hline & 21.8 & & 0.578 & & & & \\
\hline \multirow[t]{2}{*}{$\mathrm{COP}_{12 \mathrm{~T}}$} & 0.516 & \multirow[t]{2}{*}{0.514} & 0.571 & \multirow[t]{2}{*}{0.569} & \multirow[t]{2}{*}{0.515} & \multirow[t]{2}{*}{0.572} & \multirow[t]{2}{*}{0.18} \\
\hline & 0.512 & & 0.567 & & & & \\
\hline $\mathrm{COP}_{144 \mathrm{~L}}$ & 187.4 & 187.4 & 0.497 & 0.497 & 191.4 & 0.508 & 2.17 \\
\hline
\end{tabular}

For FRP components, torsional rigidity and equivalent in-plane shear modulus based on finite element method is found to be higher than the experimental values for both directions of ProDeck4 as well as ProDeck8 specimen $\left(\mathrm{COP} 8_{144 \mathrm{~L}}\right)$. The maximum percent difference between (finite element and experimental data) is found to be $11.81 \%$ for test specimens $\left(\mathrm{COP}_{18 \mathrm{~T}}\right)$ while the minimum percent difference is $0.18 \%$. Tables 4.12 and 4.14 reveal that experimental data are slightly lower than those of SCLT and finite element. Because perfect continuity and full load transferring of structural models (stiffer elements) are assumed in both theoretical methods (SCLT and finite element), structural models from both methods generally are stiffer than the data from experimental test specimens (i.e., lower compatibility and higher fixity). Also, small percent difference of in-plane shear modulus may lead to high percent difference in stress and strain. 

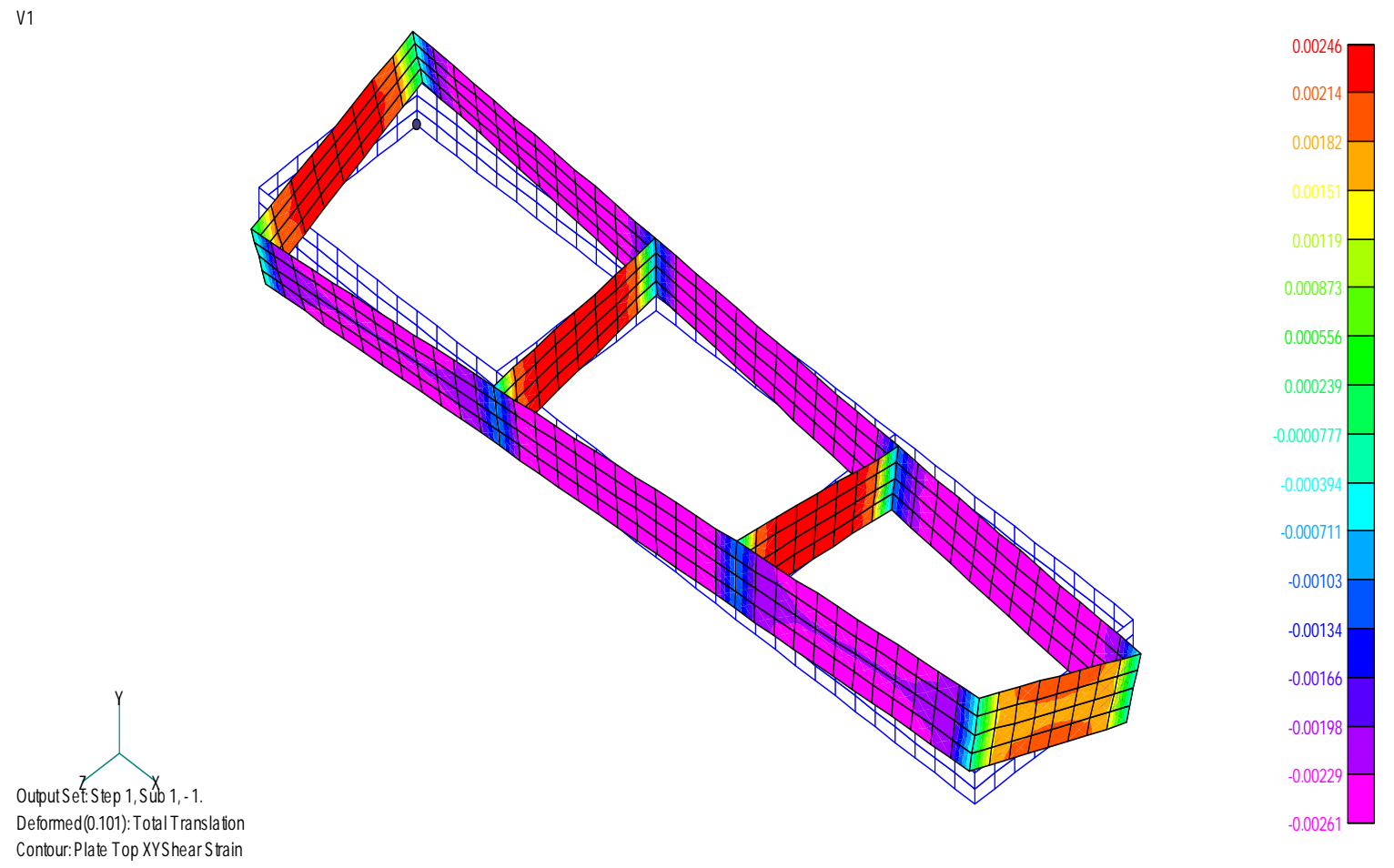

Figure 4.30 In-plane shear strain of COP4 $4_{18 \mathrm{~T}}$ under torsion

V1
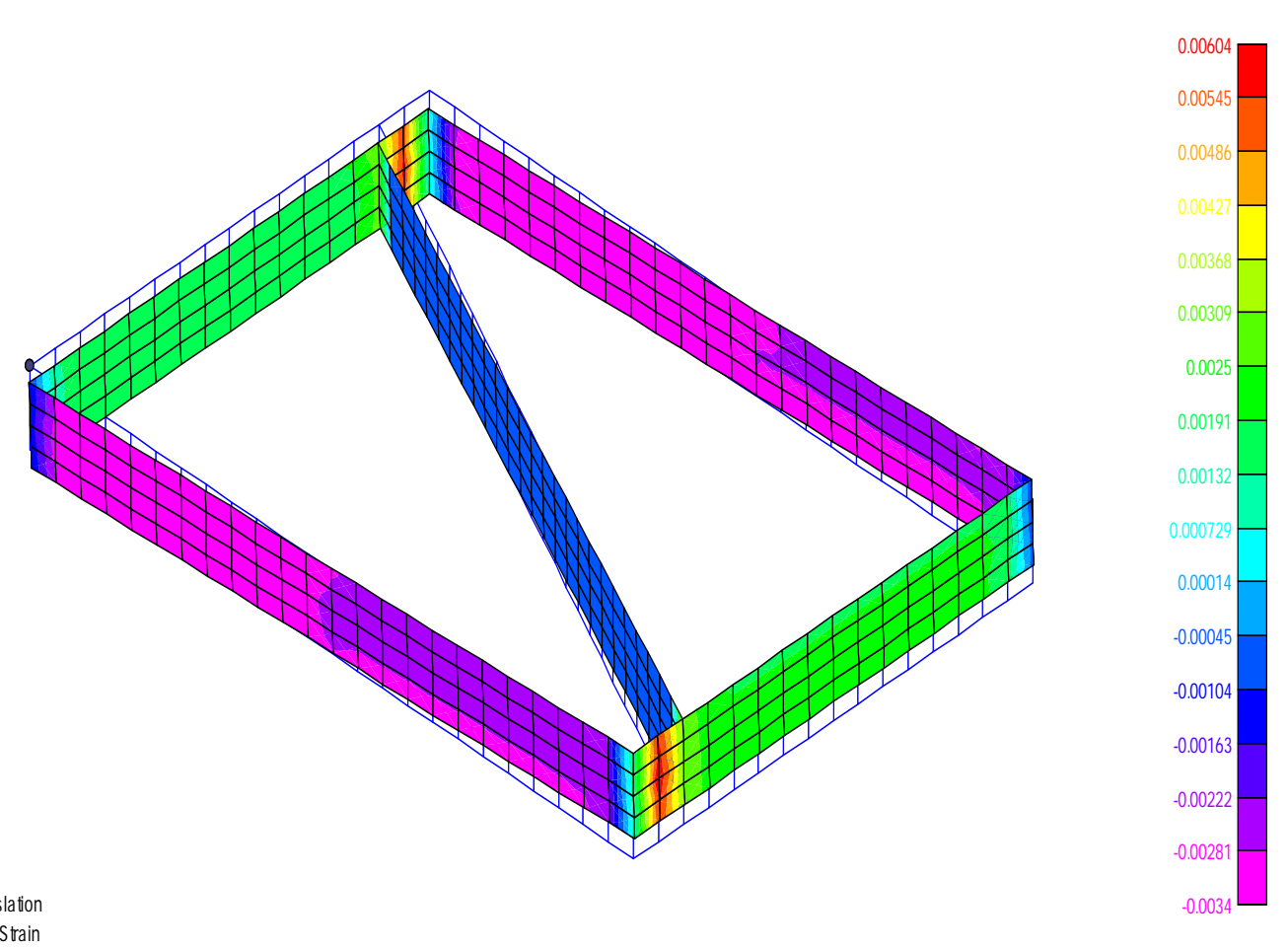

Figure 4.31 In-plane shear strain of $\mathrm{COP8}_{12 \mathrm{~T}}$ under torsion 


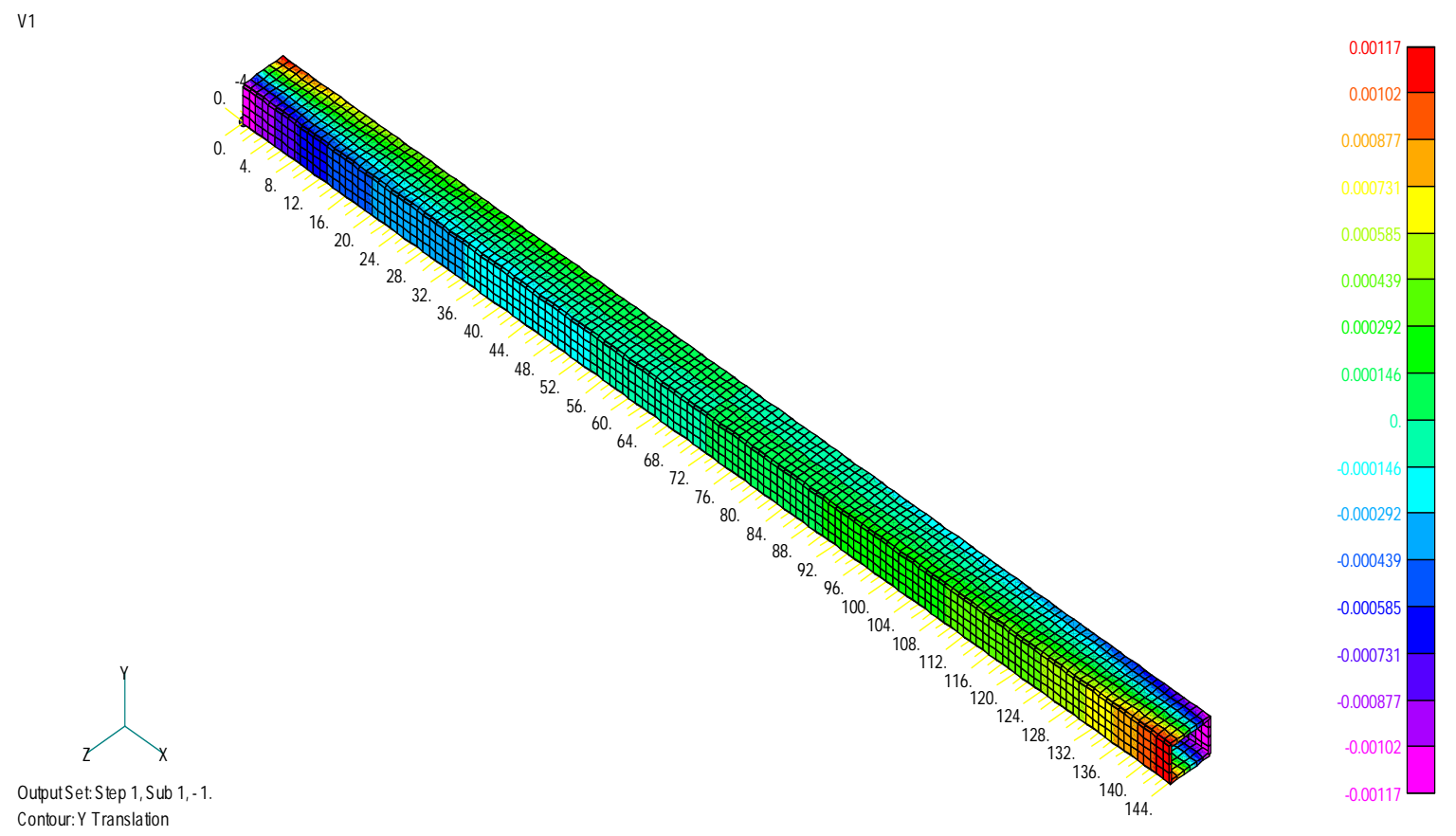

Figure 4.32 Transverse* displacement of COP4 ${ }_{144}$ under torsion

Note: Transverse direction (y) is referred to the coordinate (F.E. model) given on the figure.
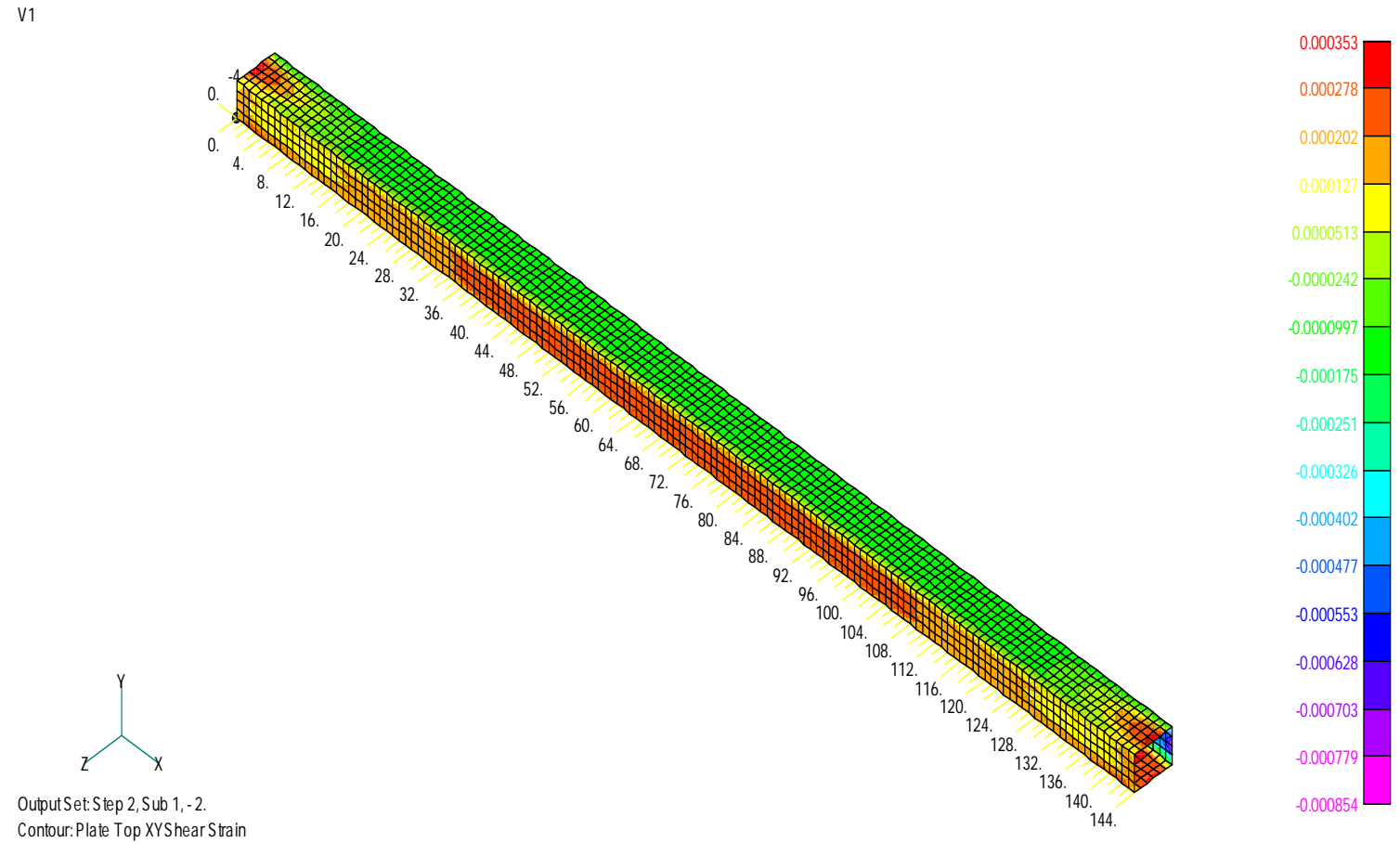

Figure 4.33 In-plane shear strain of COP4 $4_{144}$ under torsion 


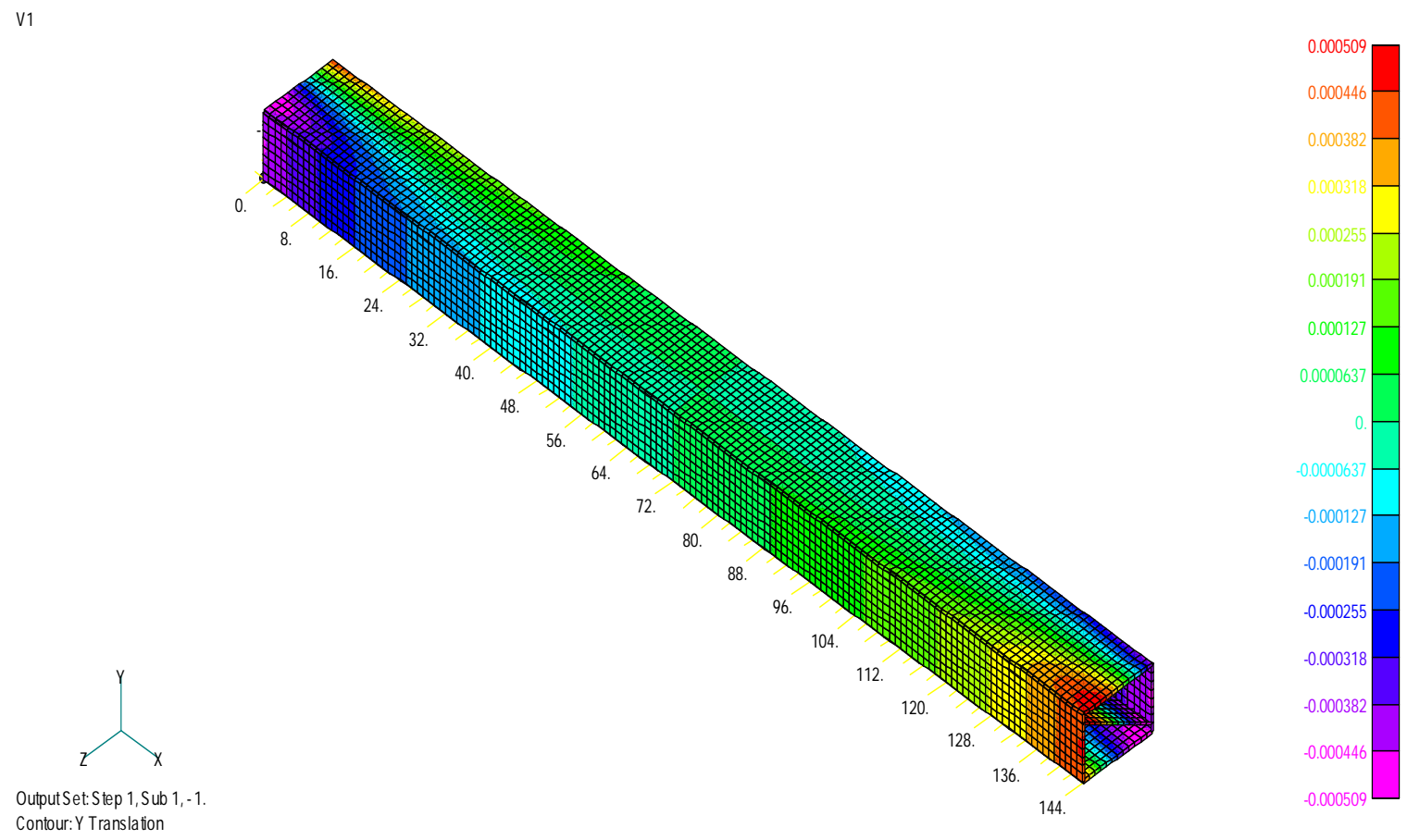

Figure 4.34 Transverse displacement of $\mathrm{COP8}_{144}$ under torsion

Note: Transverse direction (y) is referred to the coordinate (F.E. model) given on the figure.

V1

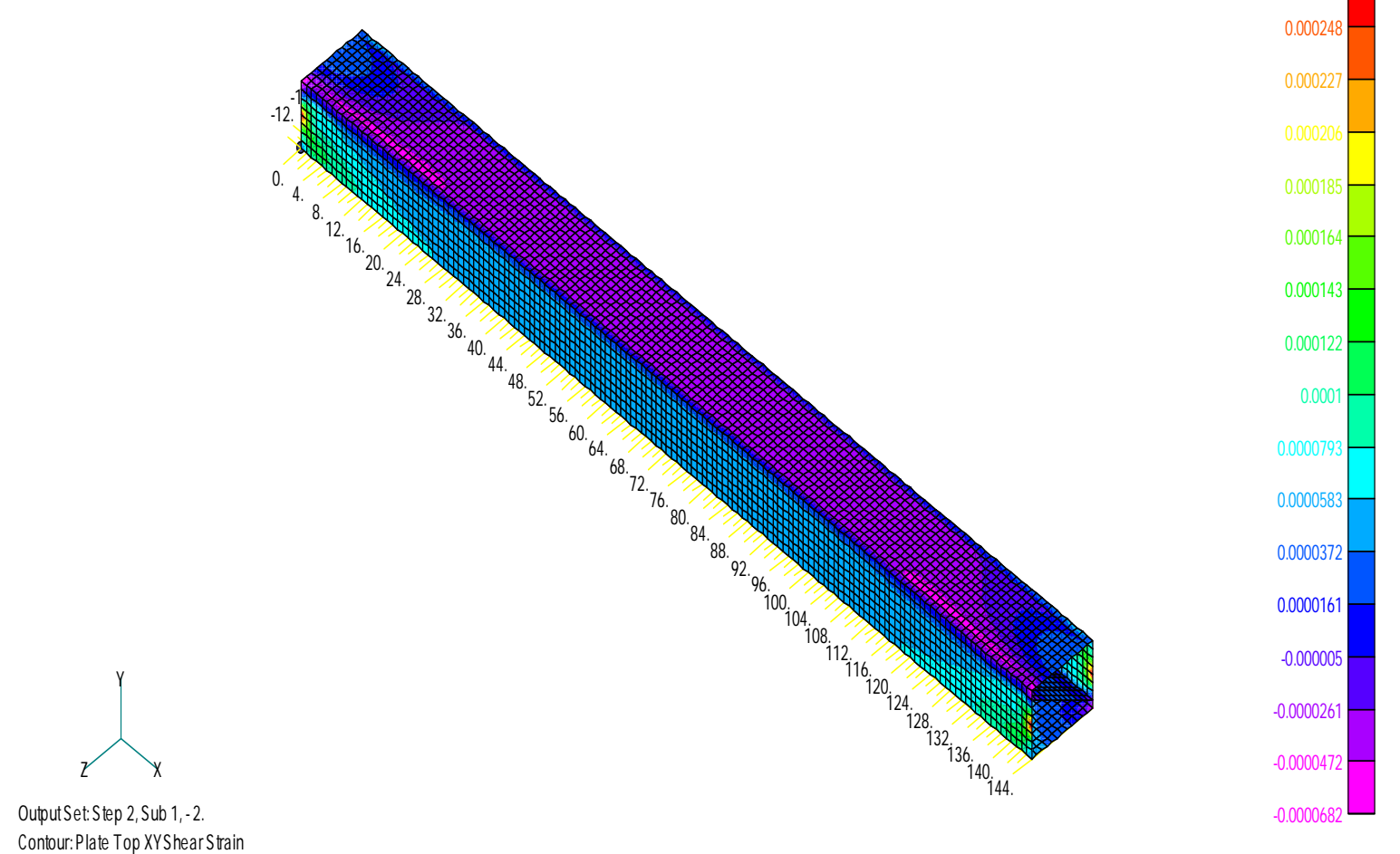

Figure 4.35 In-plane shear strain of $\mathrm{COP8}_{144}$ under torsion 


\subsubsection{Discussion of in-plane shear strain (component without joints)}

To calculate theoretical in-plane shear strain, specific applied torque is substituted into Equation (4.49). As an example, evaluating in-plane (xy) shear strain of specimen $\left(\mathrm{COP} 4_{144 \mathrm{~L}}\right)$ is presented as:

Example: Evaluate in-plane shear (xy) strain of component specimen $\left(\mathrm{COP} 4_{144 \mathrm{~L}}\right)$ using SCLT

In-plane shear strain is given in terms of applied torque and laminate stiffness. Applied torque and laminate stiffness are substituted into in-plane (xy) shear strain. Therefore, in-plane shear strain that corresponds to any specific value of applied torque is given as:

From Equation (4.39)

$\gamma_{x y}=\frac{T\left(D_{w W}-z D_{S W}\right)}{2\left(A^{*}\right)\left(D_{s S} D_{w W}-D_{s w}{ }^{2}\right)}$

Coupling between in-plane and out-of-plane $\left(D_{s w}\right)$ is zero because of symmetrical layup of fiber architecture. The above in-plane shear (xy) strain formula can be simplified as given below. Also, $\left(D_{s S}\right)$ laminated stiffnesses of flange and web are found to be $2.34 \times 10^{5}$ and $2.14 \times 10^{5} \mathrm{lb} / \mathrm{in}$, respectively. Enclosed area $\left(A^{*}\right)$ and applied torque on test specimens are given as $20.9 \mathrm{in}^{2}$ and $1800 \mathrm{lb}$-in, respectively. Hence, in-plane (xy) shear strains of flange and web for specimen $\left(\mathrm{COP} 4_{144 \mathrm{~L}}\right)$ are as follows:

$\gamma_{x y}=\frac{T}{2 A D_{s s}}$

In-plane (xy) shear strain of flange:

$\gamma_{x y}^{f}=\frac{1800}{2\left(20.9 \times 2.34 \times 10^{5}\right)}=184 \times 10^{-6}$ 
In-plane (xy) shear strain of web:

$\gamma_{x y}^{w}=\frac{1800}{2\left(20.9 \times 2.14 \times 10^{5}\right)}=201 \times 10^{-6}$

Following the same procedure, theoretical in-plane shear strains based on SCLT for other test specimens are given and compared with those based on experiment and finite element data as shown in Tables 4.15 and 4.16, respectively. In addition, table 4.15 revealed that experimental strains are consistently higher than those of SCLT and finite element methods due to stiffer structural models of SCLT and finite element method. Reasons for stiffer models are given in Section 4.6.2.2. Strain gage positions for longitudinal components are illustrated in Figure 4.36. 


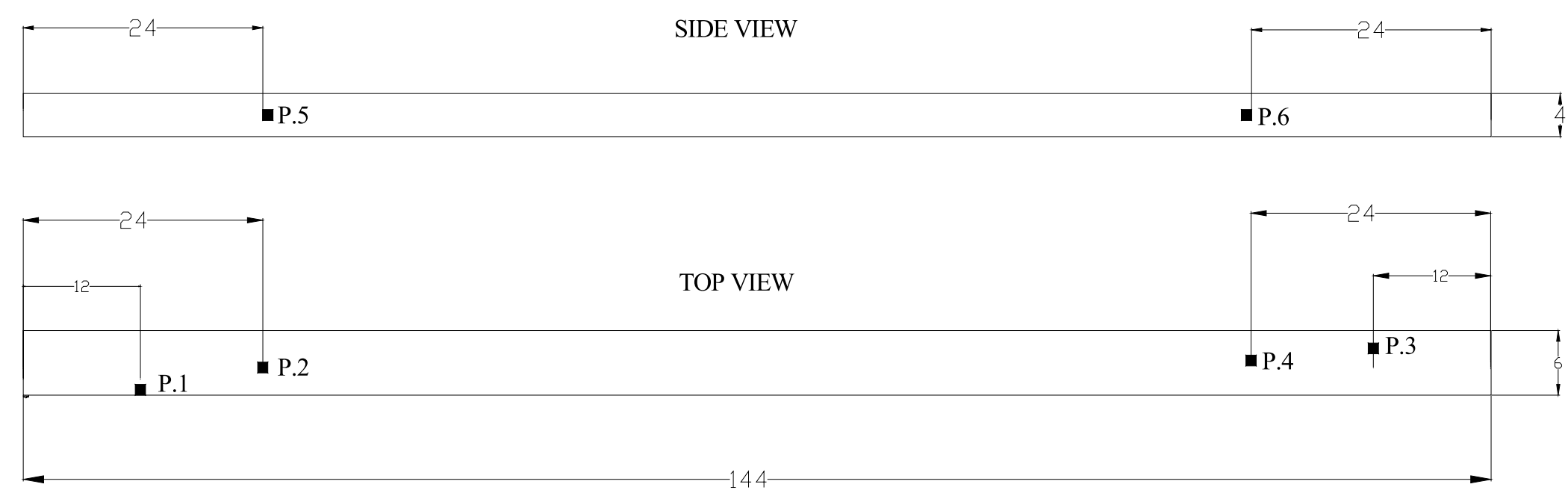

- represents a strain gage

Figure 4.36 Strain gage positions for longitudinal components

(a) Side View and (b) Top View 
Table 4.15 In-plane shear strain of component specimens

\begin{tabular}{|c|c|c|c|c|c|c|c|c|c|c|c|c|c|c|c|c|}
\hline \multirow{4}{*}{ Sample } & \multirow{4}{*}{$\begin{array}{l}\text { Length } \\
\text { (in) }\end{array}$} & \multirow{4}{*}{$\begin{array}{l}\text { Applied } \\
\text { torque } \\
\text { (in.lb) }\end{array}$} & \multicolumn{14}{|c|}{ In-plane shear strain $\left(10^{-6}\right)$} \\
\hline & & & \multicolumn{6}{|c|}{ Experiment } & \multicolumn{2}{|c|}{ SCLT } & \multicolumn{6}{|c|}{ Finite element } \\
\hline & & & \multicolumn{4}{|c|}{ flange } & \multicolumn{2}{|c|}{ web } & \multirow{2}{*}{$\begin{array}{c}\text { flange } \\
\text { (P.2) }\end{array}$} & \multirow{2}{*}{$\begin{array}{l}\text { web } \\
\text { (P.5) }\end{array}$} & \multicolumn{4}{|c|}{ flange } & \multicolumn{2}{|c|}{ web } \\
\hline & & & (P.1) & (P.2) & (P.3) & (P.4) & (P.5) & (P.6) & & & (P.1) & (P.2) & (P.3) & (P.4) & (P.5) & (P.6) \\
\hline $\mathrm{COP}_{18 \mathrm{~T}}: 1$ & 18 & 217 & - & 3613 & - & 3522 & - & - & 2839 & - & - & 2488 & - & 2488 & - & - \\
\hline $\mathrm{COP}_{18 \mathrm{~T}}: 2$ & 18 & 200 & - & 3804 & - & 3725 & - & - & 2839 & - & - & 2488 & - & 2488 & - & - \\
\hline COP8 ${ }_{12 \mathrm{~T}}: 1$ & 12 & 1000 & - & 2932 & - & - & - & - & $6063 *$ & - & - & 2645 & - & 2645 & - & - \\
\hline $\mathrm{COP} 8_{12 \mathrm{~T}}: 2$ & 12 & 1000 & - & 2816 & - & - & - & - & $6063^{*}$ & - & - & 2645 & - & 2645 & - & - \\
\hline
\end{tabular}

\begin{tabular}{|c|c|c|c|c|c|c|c|c|c|c|c|c|c|c|c|c|}
\hline \multirow[t]{4}{*}{ Sample } & \multirow{4}{*}{$\begin{array}{l}\text { Length } \\
\text { (in) }\end{array}$} & \multirow{4}{*}{$\begin{array}{c}\text { Applied } \\
\text { torque } \\
\text { (in.lb) }\end{array}$} & \multicolumn{14}{|c|}{ In-plane shear strain $\left(10^{-6}\right)$} \\
\hline & & & \multicolumn{6}{|c|}{ Experiment } & \multicolumn{2}{|c|}{ SCLT } & \multicolumn{6}{|c|}{ Finite element } \\
\hline & & & \multicolumn{4}{|c|}{ flange } & \multicolumn{2}{|c|}{ web } & \multirow{2}{*}{$\begin{array}{c}\text { flange } \\
\text { (P.2) }\end{array}$} & \multirow{2}{*}{$\begin{array}{l}\text { web } \\
\text { (P.5) }\end{array}$} & \multicolumn{4}{|c|}{ flange } & \multicolumn{2}{|c|}{ web } \\
\hline & & & (P.1) & (P.2) & (P.3) & (P.4) & (P.5) & (P.6) & & & (P.1) & (P.2) & (P.3) & (P.4) & (P.5) & (P.6) \\
\hline $\mathrm{COP}_{144 \mathrm{~L}}: 1$ & 144 & 1800 & 210 & 185 & 212 & 187 & 239 & 242 & 184 & 201 & 135 & 154 & 135 & 154 & 202 & 202 \\
\hline $\mathrm{COP} 4_{144 \mathrm{~L}}: 2$ & 144 & 1800 & 203 & 182 & 207 & 186 & 232 & 240 & 184 & 201 & 135 & 154 & 135 & 154 & 202 & 202 \\
\hline $\mathrm{COP}_{144 \mathrm{~L}}: 1$ & 144 & 1800 & 16.7 & 43.7 & 15.8 & 41.9 & 41.8 & 44.5 & 35.4 & 38.4 & 11.4 & 35.9 & 11.4 & 35.9 & 38.7 & 38.7 \\
\hline
\end{tabular}

Note: *In-plane shear strain based on SCLT for specimen (COP8) is significantly higher than that of others, because results based on SCLT do not account for effect of structural shape. Specimen (COP8) is strongly braced by diagonal portion leading to lower experimental in-plane shear strain which is quite small. P1 and P3 are rosette strain position on top flange toward the left and right side edge @ 12 inches from the left and right end, respectively. P2 and P4 are rosette strain positions on top flange @center (short side) at 24 inches from the left and right end, respectively. P5 and P6 are rosette strain positions on outer side of web @ center (short side) at 24 inches from the left and right end, respectively. More information of strain positions is given in Section 3.3.2. 
Table 4.16 Comparison of in-plane shear strain for component specimens

\begin{tabular}{|c|c|c|c|c|c|c|c|c|c|c|c|c|c|}
\hline \multirow[t]{4}{*}{ Sample } & \multirow{4}{*}{$\begin{array}{l}\text { Applied } \\
\text { torque } \\
\text { (in.lb) }\end{array}$} & \multicolumn{12}{|c|}{ \% Difference } \\
\hline & & \multicolumn{6}{|c|}{ Experiment versus SCLT } & \multicolumn{6}{|c|}{ Experiment versus Finite element } \\
\hline & & \multicolumn{4}{|c|}{ flange } & \multicolumn{2}{|c|}{ web } & \multicolumn{4}{|c|}{ flange } & \multicolumn{2}{|c|}{ web } \\
\hline & & (P.1) & (P.2) & (P.3) & (P.4) & (P.5) & (P.6) & (P.1) & (P.2) & (P.3) & (P.4) & (P.5) & (P.6) \\
\hline $\mathrm{COP}_{18 \mathrm{~T}}: 1$ & 200 & - & & - & & - & - & - & & - & & - & - \\
\hline $\mathrm{COP}_{18 \mathrm{~T}}: 2$ & 200 & - & 25.4 & - & 23.8 & - & - & - & 34.6 & - & 33.2 & - & - \\
\hline $\mathrm{COP}_{12 \mathrm{~T}}: 1$ & 1000 & - & $51.6^{*}$ & - & - & - & - & - & 11.75 & - & - & - & - \\
\hline $\mathrm{COP}_{12 \mathrm{~T}}: 2$ & 1000 & - & $53.6 *$ & - & - & - & - & - & 6.07 & - & - & - & - \\
\hline
\end{tabular}

\begin{tabular}{|c|c|c|c|c|c|c|c|c|c|c|c|c|c|}
\hline \multirow[t]{4}{*}{ Sample } & \multirow{4}{*}{$\begin{array}{c}\text { Applied } \\
\text { torque } \\
\text { (in.lb) }\end{array}$} & \multicolumn{12}{|c|}{ \% Difference } \\
\hline & & \multicolumn{6}{|c|}{ Experiment versus SCLT } & \multicolumn{6}{|c|}{ Experiment versus Finite element } \\
\hline & & \multicolumn{4}{|c|}{ flange } & \multicolumn{2}{|c|}{ web } & \multicolumn{4}{|c|}{ flange } & \multicolumn{2}{|c|}{ web } \\
\hline & & (P.1) & (P.2) & (P.3) & (P.4) & (P.5) & (P.6) & (P.1) & (P.2) & (P.3) & (P.4) & (P.5) & (P.6) \\
\hline $\mathrm{COP}_{144 \mathrm{~L}}: 1$ & 1800 & 12.38 & 0.54 & 13.21 & 1.604 & 15.89 & 16.94 & 35.7 & 16.76 & 36.3 & 17.65 & 15.48 & 16.53 \\
\hline $\mathrm{COP}_{144 \mathrm{~L}}: 2$ & 1800 & 9.36 & 1.087 & 11.11 & 1.087 & 13.36 & 16.25 & 33.5 & 15.38 & 34.8 & 17.20 & 12.93 & 15.83 \\
\hline $\mathrm{COP8}_{144 \mathrm{~L}}: 1$ & 1800 & 52.8 & 18.99 & 55.4 & 15.51 & 8.13 & 13.71 & 31.7 & 17.85 & 31.7 & 17.85 & 7.42 & 13.03 \\
\hline
\end{tabular}

Note: *In-plane shear strain based on SCLT for specimen (COP8) is significantly higher than that of others, because results based on SCLT do not account for effect of structural shape. Specimen (COP8) is strongly braced by diagonal portion leading to lower experimental in-plane shear strain which is quite small. P1 and P3 are rosette strain position on top flange toward the left and right side edge @ 12 inch from the left and right end, respectively. P2 and P4 are rosette strain positions on top flange @ center (short side) at 24 inch from the left and right end, respectively. P5 and P6 are rosette strain positions on outer side of web @center (short side) at 24 inch from the left and right end, respectively. More information of strain positions is given in Section 3.3.2. 
For transverse specimens, in-plane (xy) shear strains based on SCLT and finite element are not comparing well with the experimental results for both ProDeck 4 and 8 specimens. Results from finite element method are generated using stiffer elements than the actual specimens. In case of results from SCLT, the method does not account for the joint flexibility of the cross section (i.e., joint effect between flange, web and diagonal (specimens COP $\left.8_{12 T}\right)$ ). For longitudinal specimens $\left(\mathrm{COP} 4_{144 \mathrm{~L}}\right)$, in-plane $(\mathrm{xy})$ shear strain based on SCLT accurately predicted experimental strains at positions (P2 and P4). In-plane shear strains based on SCLT rely on assumptions that strains are constant throughout for a given laminae (xy-plane) in structural members. Therefore, in-plane shear strains based on SCLT are quite inaccurate for any positions that are located far away from mid-plane (xz-plane) passing through the thickness of each structure portion (webs and flanges). Percent differences of inplane shear strain between experimental and SCLT method at P1 and P3 range from 9.36 to $13.21 \%$ for specimens $\left(\mathrm{COP} 4_{144 \mathrm{~L}}\right)$. Also, percent difference in web specimens $\left(\mathrm{COP} 4_{144 \mathrm{~L}}\right)$ and $\left(\mathrm{COP} 8_{144 \mathrm{~L}}\right)$ are found to vary from 13.36 to $16.94 \%$ and from 8.13 to $13.71 \%$, respectively. In addition, strains based on finite element method are smaller than those from experimental data at all measured positions due to stiffer structural models (high torsional rigidity) leading to smaller strains than the experimental data (refer to Section 4.6.2.2).

\subsubsection{Components with joints}

To evaluate performance of component specimens with joint, multi-cell cross sectional specimens are tested under torsion in both longitudinal and transverse direction. For longitudinal specimens, multi-cell (three cell) specimens without joints are tested to compare the results of specimens with joint and establish joint efficiency. After torsion tests are conducted, fiber reinforcements as (2-D glass fabrics) are attached along a joint. Specimens reinforced with glass fabrics are also tested under torsion. Moreover, transverse specimen testing has been accomplished in the same manner as the longitudinal specimens. For more 
information, specimen descriptions for components with joints are given in Section 3.3.3. To obtain torsional rigidity and equivalent in-plane shear (xy) modulus based on experimental results, the procedure as given in Section 4.2 is followed. Applied torque versus rate of twist of longitudinal specimens is presented in Figure 4.37. In addition, theoretical results based on SCLT are validated by comparing with those results from experiments and finite element method. Displacement in (y) direction and in-plane shear strain results based on finite element are provided in Figures 4.38 through 4.41. It should be noted that results based on finite element method are obtained from models without joints. Results and comparisons of torsional rigidity and equivalent in-plane shear (xy) modulus are given in Table 4.17.

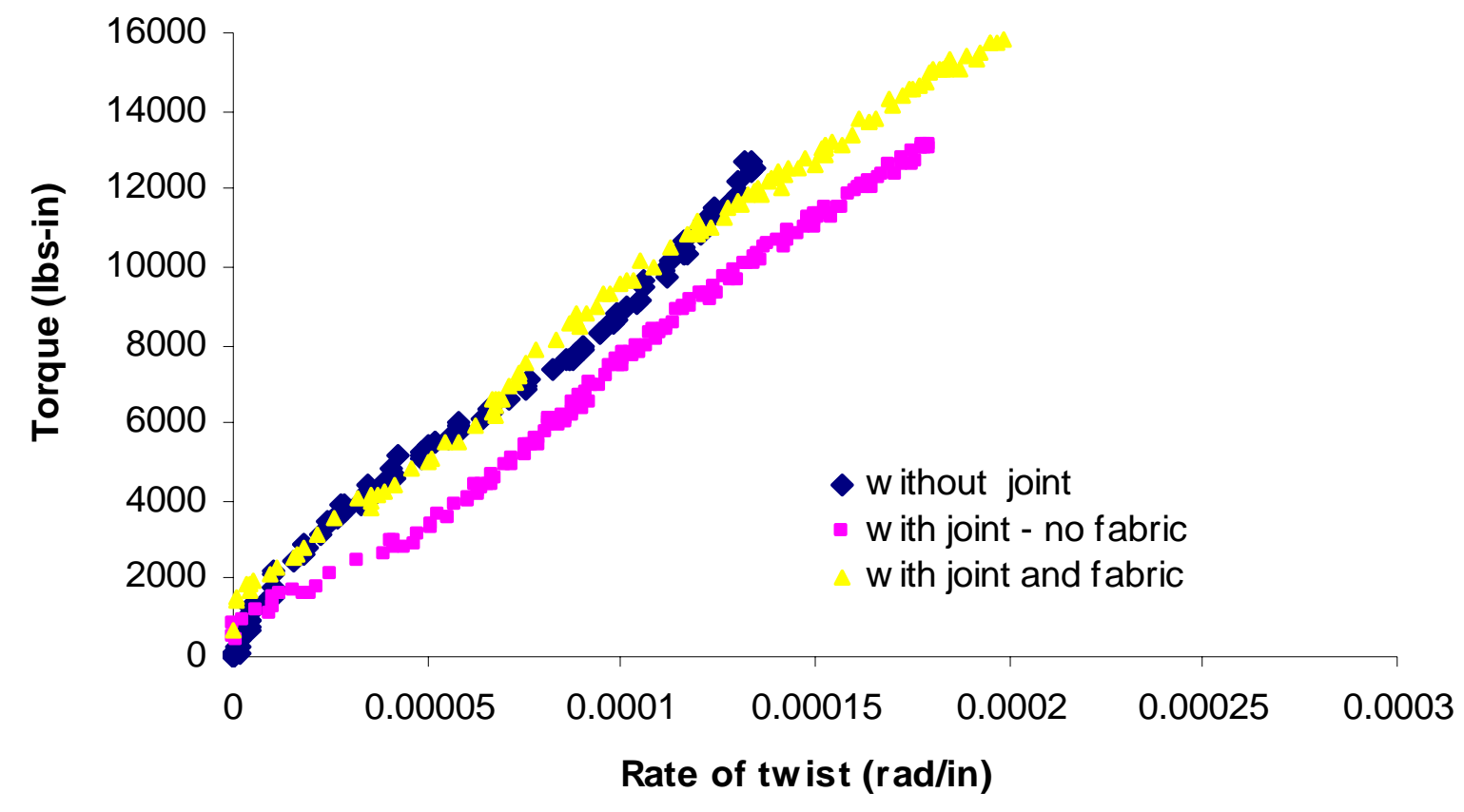

Figure 4.37 Relation between torque-rate of twist (MP4 $4_{144}$, $M P 4_{144 ~} \mathrm{~L}$ and MP4 $4_{144 \mathrm{JFL}}$ ) 
Table 4.17 Torsional rigidity and equivalent in-plane shear (xy) modulus at component with joint level

\begin{tabular}{|c|c|c|c|c|c|c|c|c|}
\hline \multirow[t]{2}{*}{ Sample } & \multirow[t]{2}{*}{ Joint } & \multirow[t]{2}{*}{ fabrics } & \multicolumn{3}{|c|}{$\begin{array}{c}\text { Torsional rigidity } G J \\
\left(\times 10^{6}\right) \\
\left(\mathrm{lb}^{\left.-\mathrm{in}^{2}\right)}\right.\end{array}$} & \multicolumn{3}{|c|}{$\begin{array}{c}\text { Equivalent in-plane shear } \\
\text { modulus } \\
\left(\times 10^{6}\right) \\
(\mathrm{psi})\end{array}$} \\
\hline & & & Exp. & SCLT & FE. & Exp. & SCLT & FE. \\
\hline $\mathrm{MP}_{144 \mathrm{~L}}$ & No & No & 85.3 & \multirow[t]{3}{*}{79.7} & \multirow[t]{3}{*}{90.4} & 0.542 & \multirow[t]{3}{*}{0.506} & \multirow[t]{3}{*}{0.575} \\
\hline $\mathrm{MP}_{144 \mathrm{~J} \mathrm{~L}}$ & Yes & No & 73.3 & & & 0.466 & & \\
\hline $\mathrm{MP}_{144 \mathrm{JFL}}$ & Yes & Yes & 79.6 & & & 0.505 & & \\
\hline \multirow[t]{2}{*}{$\mathrm{MP}_{144 \mathrm{~T}}$} & \multirow[t]{2}{*}{ Yes } & \multirow[t]{2}{*}{ No } & 3.23 & \multirow[t]{6}{*}{3.68} & \multirow[t]{6}{*}{3.60} & 0.389 & \multirow[t]{6}{*}{0.442} & \multirow[t]{6}{*}{0.433} \\
\hline & & & 3.40 & & & 0.409 & & \\
\hline \multirow[t]{2}{*}{$\mathrm{MP}_{144 \mathrm{~F} 1 \mathrm{~T}}$} & \multirow[t]{2}{*}{ Yes } & \multirow[t]{2}{*}{ Yes } & 3.46 & & & 0.416 & & \\
\hline & & & 3.42 & & & 0.411 & & \\
\hline \multirow[t]{2}{*}{$\mathrm{MP}_{144 \mathrm{~F} 2 \mathrm{~T}}$} & \multirow[t]{2}{*}{ Yes } & \multirow[t]{2}{*}{ Yes } & 3.84 & & & 0.462 & & \\
\hline & & & 4.11 & & & 0.494 & & \\
\hline
\end{tabular}

\subsubsection{Discussion of experimental, SCLT and FE results}

Torsional rigidity and equivalent in-plane shear (xy) modulus of $\mathrm{MP}_{144 \mathrm{~L}}$ are higher than those of MP4 $4_{144} \mathrm{JL}$ by about $14.02 \%$. Percent difference between two specimen types is due to shear leakage of joints along longitudinal direction of test specimens. To improve performance of shear transfer across longitudinal joints, specimens $\left(\mathrm{MP}_{144 \mathrm{JL}}\right)$ are reinforced with glass fabric on top and bottom surfaces of the test specimens with joints. Then, percent difference of torsional rigidity and equivalent in-plane shear modulus are reduced to $6.83 \%$. For transverse specimens with fabric reinforcements, average torsional rigidity and equivalent in-plane (xy) shear modulus of transverse specimens (MP4 $\left.{ }_{144 \mathrm{~F} 2 \mathrm{~T}}\right)$ have improved by about $16.53 \%$ compared to specimens $\left(\mathrm{MP}_{144 \mathrm{~T}}\right)$. In addition, equivalent in-plane shear (xy) modulus of specimens $\left(\mathrm{MP}_{144 \mathrm{~L}}\right)$ and $\left(\mathrm{MP} 4_{144 \mathrm{~T}}\right)$ are obviously different. This difference is small in coupons and components without joints. 
Table 4.18 Comparison of percent difference of torsional rigidity and equivalent inplane (xy) shear modulus at component with joint level

\begin{tabular}{|c|c|c|c|c|c|}
\hline \multirow[t]{3}{*}{ Sample } & \multirow{3}{*}{$\begin{array}{c}\text { Theoretical } \\
\text { cross- } \\
\text { sectional } \\
\text { constant } \\
J\left(\text { in }^{4}\right)\end{array}$} & \multicolumn{4}{|c|}{$\begin{array}{l}\text { \% Difference for equivalent in-plane shear } \\
\text { modulus (experiment) compared to }\end{array}$} \\
\hline & & \multicolumn{2}{|c|}{ SCLT } & \multicolumn{2}{|c|}{ FE } \\
\hline & & Each & Avg. & Each & Avg. \\
\hline $\mathrm{MP}_{144 \mathrm{~L}}$ & \multirow[t]{3}{*}{37.7} & 6.57 & 6.57 & 5.64 & 5.64 \\
\hline $\mathrm{MP} 4_{144 \mathrm{~J} \mathrm{~L}}$ & & 8.03 & 8.03 & 18.92 & 18.92 \\
\hline $\mathrm{MP}_{144 \mathrm{JFL}}$ & & 0.1255 & 0.1255 & 11.95 & 11.95 \\
\hline \multirow[t]{2}{*}{$\mathrm{MP}_{144 \mathrm{~T}}$} & \multirow[t]{2}{*}{8.31} & 12.23 & \multirow[t]{2}{*}{9.92} & 10.28 & \multirow[t]{2}{*}{7.92} \\
\hline & & 7.61 & & 5.56 & \\
\hline \multirow[t]{2}{*}{$\mathrm{MP}_{144 \mathrm{~F} 1 \mathrm{~T}}$} & \multirow[t]{2}{*}{8.31} & 5.98 & \multirow[t]{2}{*}{6.53} & 3.89 & \multirow[t]{2}{*}{4.45} \\
\hline & & 7.07 & & 5.00 & \\
\hline \multirow[t]{2}{*}{$\mathrm{MP}_{144 \mathrm{~F} 2 \mathrm{~T}}$} & \multirow[t]{2}{*}{8.31} & 4.17 & \multirow[t]{2}{*}{7.32} & 6.25 & \multirow[t]{2}{*}{9.33} \\
\hline & & 10.46 & & 12.41 & \\
\hline
\end{tabular}

Comparison of percent difference in torsional rigidity and in-plane shear modulus between experimental and finite element method is provided in Table 4.18. In case of specimens without any reinforcement, torsional rigidity and equivalent in-plane shear (xy) modulus predicted by SCLT are different from experimental results by about $6.57 \%$ and 9.92 $\%$ for longitudinal and transverse specimen, respectively. These experimental results are less than those based on finite element method by about $5.64 \%$ and $7.92 \%$. Moreover, equivalent in-plane shear (xy) strain based on SCLT of specimens with joint is evaluated and compared with the experimental and finite element in-plane shear strains in the following section. 


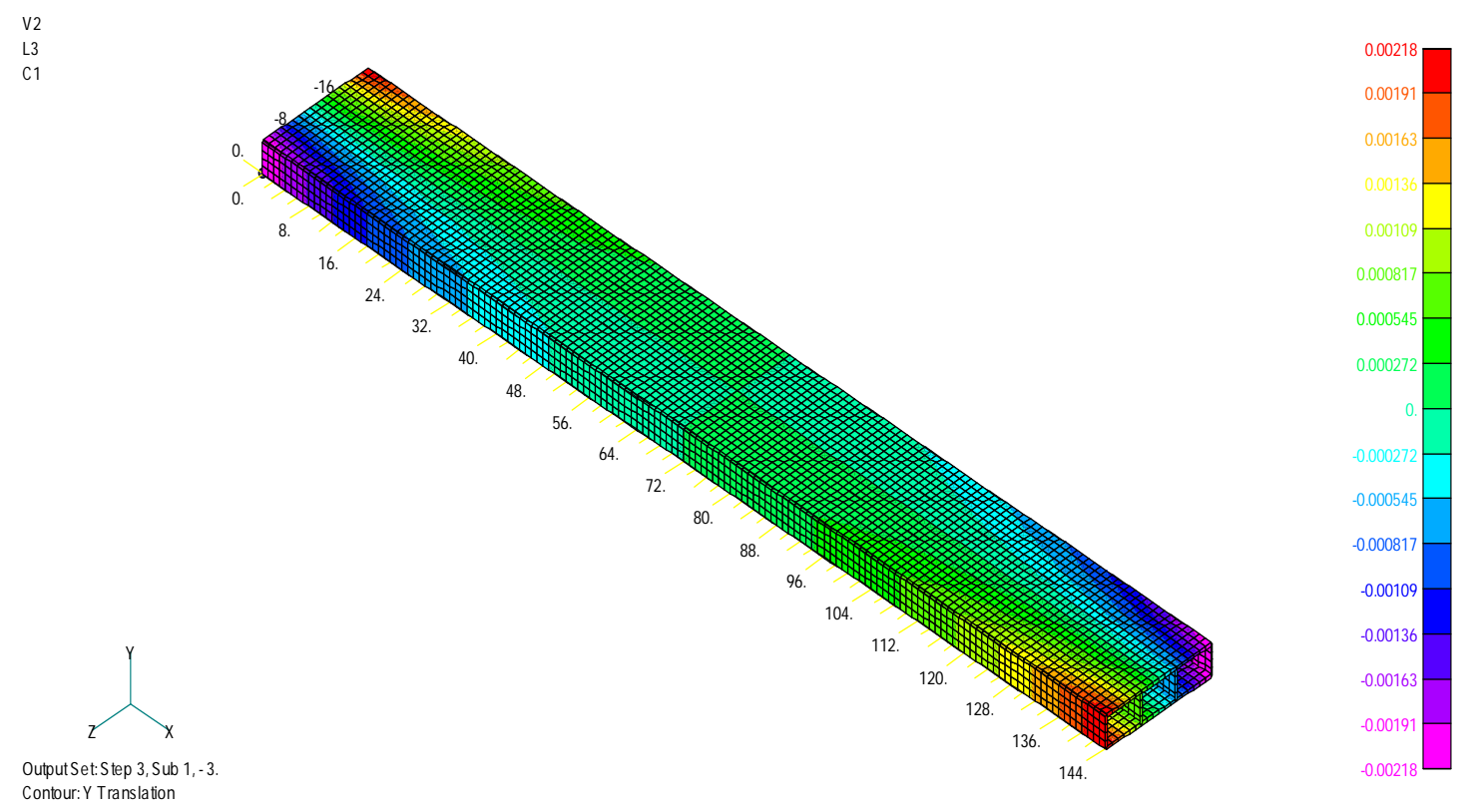

Figure 4.38 Transverse displacement of specimen $\left(\mathrm{MP}_{144} \mathrm{~L}\right)$ under torsion

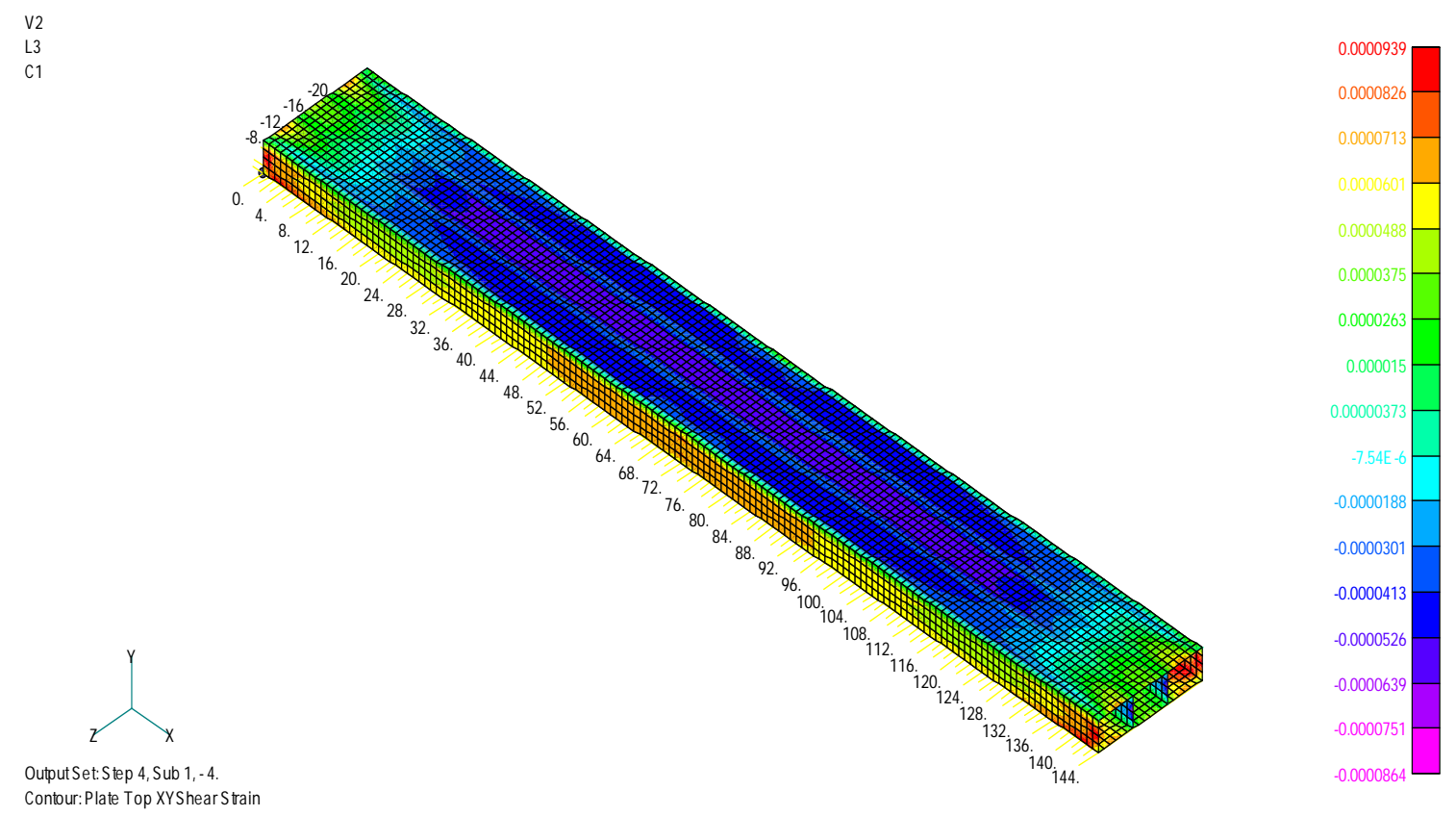

Figure 4.39 In-plane shear strain of specimen $\left(\mathrm{MP} 4_{144} \mathrm{~L}\right)$ under torsion 

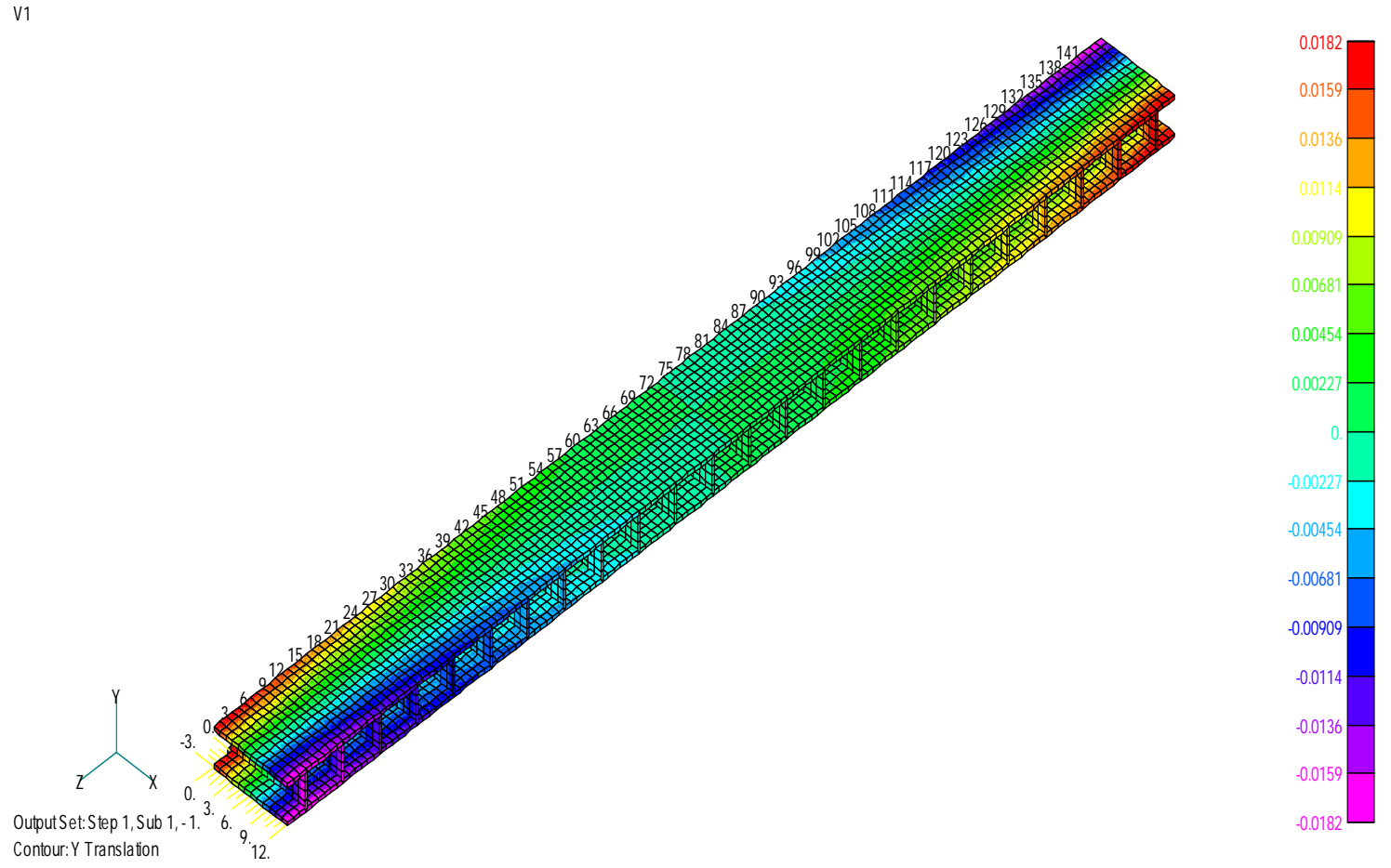

Figure 4.40 Transverse displacement of specimen $\left(\mathrm{MP}_{144 \mathrm{~L}} \mathrm{~L}\right)$ under torsion

V1
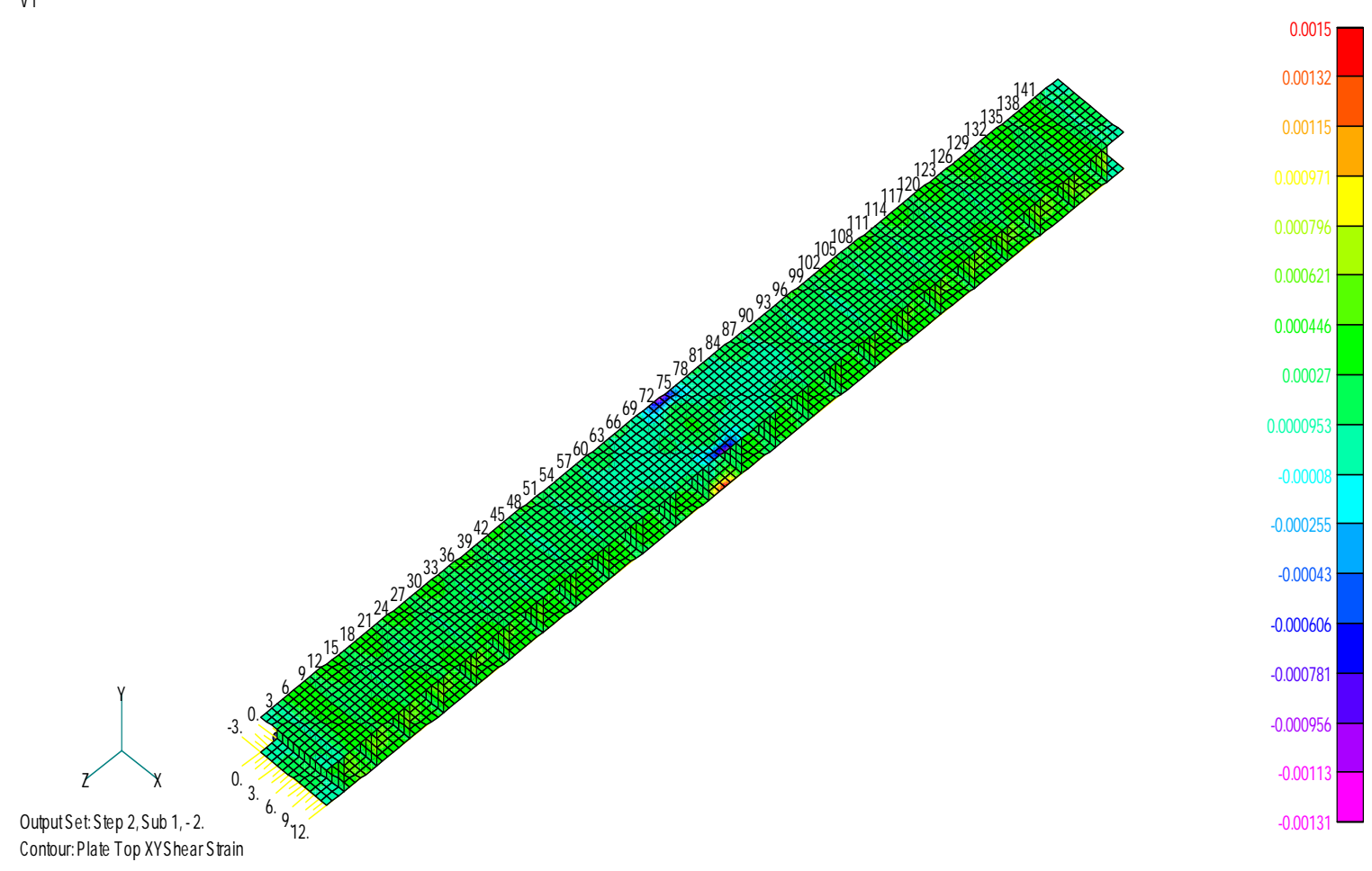

Figure 4.41 Transverse displacement of specimen $\left(\mathrm{MP} 4_{144 \mathrm{~L}}\right)$ under torsion 


\subsubsection{Discussion of in-plane shear strain (components with joints)}

To calculate theoretical in-plane shear strain, specific applied torque is substituted into Equation (4.58). As an example, evaluation of in-plane shear (xy) strain of specimen $\left(\mathrm{MP} 4_{144 \mathrm{~L}}\right)$ is presented as:

Example: In-plane (xy) shear strain of test specimen (MP4 $\left.{ }_{144} \mathrm{~L}\right)$ using SCLT

To calculate in-plane (xy) shear strain for multi-cell thin-walled beam, applied torque, laminated stiffness and $\varphi_{i}$ are substituted into in Equation (4.58). Then, in-plane shear (xy) strain of cell $\mathrm{i}^{\text {th }}$ that corresponds to any specific applied torque is presented as:

From Equation (4.58)

$\gamma_{x y}^{i}=\frac{\left(D_{w W}-z D_{s W}\right)}{2 A^{*}\left(D_{s S} D_{w W}-D_{s w}{ }^{2}\right)}\left(\frac{T \varphi_{i}}{\sum_{i=1}^{3} \varphi_{i}}\right)$

Coupling term between in-plane and out-of-plane $\left(D_{s w}\right)$ is equated to zero because of symmetric fabric lay-up. Hence, the above expression of in-plane (xy) shear strain can be simplified into a constant strain through the thickness of flange and web. Thus, $\left(D_{s s}\right)$ values of flange and web are found to be $2.34 \times 10^{5}$ and $2.14 \times 10^{5} \mathrm{lb} / \mathrm{in}$, respectively. $S_{f}$ and $S_{w}$ are 5.85 and 3.57 inches, respectively (refer to Figure 4.43 ). Area $\left(A^{*}\right)$ of each cell is calculated to be $20.9 \mathrm{in}^{2}$. An applied torque is assumed to be $1800 \mathrm{lb}$-in. For a beam with triple cell, ratios $\left(\varphi_{i} / \sum \varphi_{i}\right)$ of middle and outer cell are found to be 0.369 and 0.316 , respectively. Thus, in-plane shear (xy) strains of flange and web MP4 $4_{144 \mathrm{~L}}$ (refer to Figure 4.42) are presented as: 
For middle cell:

$\gamma_{x y}^{m}=\frac{(0.369 T)}{2 A\left(D_{s S}\right)}$

In plane shear (xy) strain of flange for middle cell:

$\gamma_{x y}^{m f}=\frac{1800 \times 0.369}{2\left(20.9 \times 2.34 \times 10^{5}\right)}=67.9 \times 10^{-6}$

For outer cell:

$\gamma_{x y}^{o}=\frac{(0.316 T)}{2 A\left(D_{s s}\right)}$

In plane shear (xy) strain of flange for outer cell:

$\gamma_{x y}^{o f}=\frac{1800 \times 0.316}{2\left(20.9 \times 2.34 \times 10^{5}\right)}=58.1 \times 10^{-6}$

In plane shear (xy) strain of web for outer cell:

$\gamma_{x y}^{o w}=\frac{1800 \times 0.316}{2\left(20.9 \times 2.14 \times 10^{5}\right)}=63.6 \times 10^{-6}$

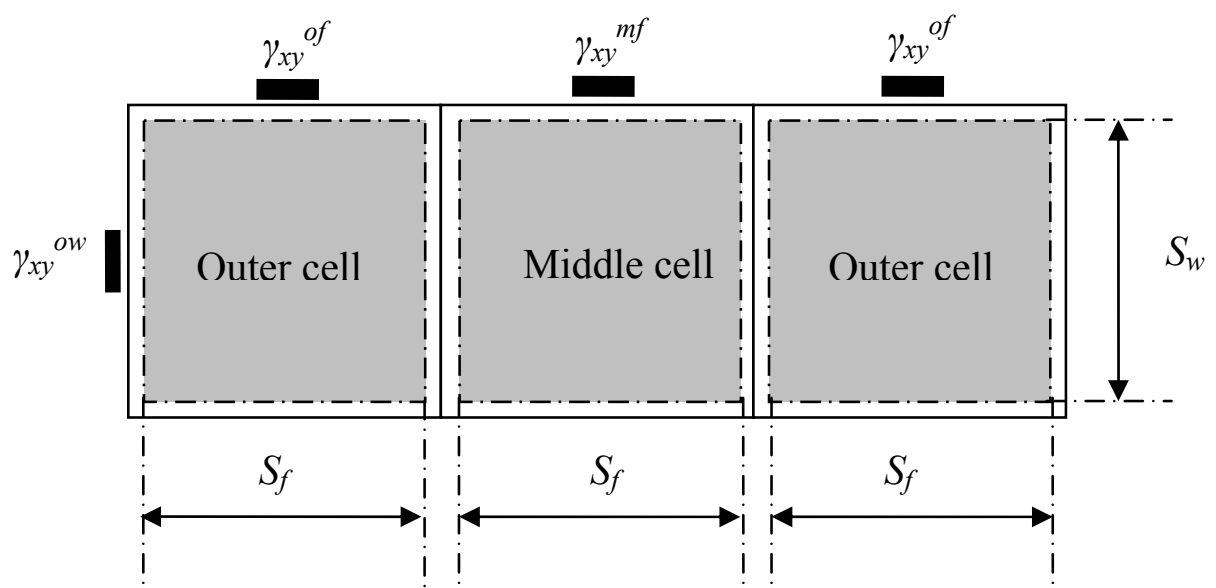

Figure 4.42 In-plane shear strain positions 
Following the same procedure, in-plane shear strains based on SCLT for both longitudinal and transverse specimens are evaluated and compared to those based on experimental and finite element methods (refer to Tables 4.19 and 4.20). 
Table 4.19 In-plane shear strain of component specimens with joints

\begin{tabular}{|c|c|c|c|c|c|c|c|c|c|c|c|c|c|c|c|c|}
\hline \multirow[t]{4}{*}{ Sample } & \multirow{4}{*}{$\begin{array}{c}\text { Applied } \\
\text { torque } \\
\text { (in.lb) }\end{array}$} & \multicolumn{15}{|c|}{ In-plane shear strain $\left(10^{-6} \mathrm{in} / \mathrm{in}\right)$} \\
\hline & & \multicolumn{6}{|c|}{ Experiment } & \multicolumn{3}{|c|}{ SCLT } & \multicolumn{6}{|c|}{ Finite element } \\
\hline & & \multicolumn{4}{|c|}{ flange } & \multicolumn{2}{|c|}{ web } & \multicolumn{2}{|c|}{ flange } & \multirow{2}{*}{$\begin{array}{l}\text { web } \\
\text { (P.5) }\end{array}$} & \multicolumn{4}{|c|}{ flange } & \multicolumn{2}{|c|}{ web } \\
\hline & & (P.1) & (P.2) & (P.3) & (P.4) & (P.5) & (P.6) & (P.1) & (P.2) & & (P.1) & (P.2) & (P.3) & (P.4) & (P.5) & P.6) \\
\hline $\mathrm{MP}_{144 \mathrm{~L}}$ & 1800 & 76.0 & 73.9 & 76.0 & 73.9 & 71.0 & 71.0 & 58.1 & 67.9 & 63.6 & 74.8 & 59.8 & 74.8 & 59.8 & 50.4 & 50.4 \\
\hline $\mathrm{MP}_{144 \mathrm{~J} \mathrm{~L}}$ & 1800 & 85.7 & 79.9 & 85.7 & 79.9 & 83.8 & 83.8 & 58.1 & 67.9 & 63.6 & 74.8 & 59.8 & 74.8 & 59.8 & 50.4 & 50.4 \\
\hline $\mathrm{MP}_{144 \mathrm{JFL}}$ & 1800 & 80.4 & 72.8 & 80.4 & 72.8 & 78.0 & 78.0 & 58.1 & 67.9 & 63.6 & 74.8 & 59.8 & 74.8 & 59.8 & 50.4 & 50.4 \\
\hline
\end{tabular}

Note: P1 and P3 are rosette strain positions on top flange toward the left and right side edge @ 12 inches from the left and right end, respectively. P2 and P4 are rosette strain positions on top flange @ center (short side) at 24 inch from the left and right end, respectively. P5 and P6 are rosette strain position on outer side of web @ center (short side), 24 inches from the left and right end, respectively. More information of strain positions is given in Section 3.3.2. 
Table 4.20 In-plane shear strain of component specimens

\begin{tabular}{|c|c|c|c|c|c|c|c|c|c|c|c|c|c|c|c|c|c|}
\hline \multirow[t]{4}{*}{ Sample } & \multirow{4}{*}{$\begin{array}{l}\text { Applied } \\
\text { torque } \\
\text { (in.lb) }\end{array}$} & \multicolumn{16}{|c|}{ In-plane shear strain $\left(10^{-6} \mathrm{in} / \mathrm{in}\right)$} \\
\hline & & \multicolumn{7}{|c|}{ Experiment } & \multicolumn{2}{|c|}{ SCLT } & \multicolumn{7}{|c|}{ Finite element } \\
\hline & & \multicolumn{5}{|c|}{ flange } & \multicolumn{2}{|c|}{ web } & \multirow{2}{*}{$\begin{array}{c}\text { flange } \\
\text { (P.2) }\end{array}$} & \multirow{2}{*}{$\begin{array}{l}\text { web } \\
\text { (P.5) }\end{array}$} & \multicolumn{5}{|c|}{ flange } & \multicolumn{2}{|c|}{ web } \\
\hline & & (P.1) & (P.2) & (P.3) & (P.4) & (P.5) & (P.6) & (P.7) & & & (P.1) & (P.2) & (P.3) & (P.4) & (P.5) & (P.6) & (P.7) \\
\hline $\mathrm{MP}_{144 \mathrm{~T}}: 1$ & 1800 & 227 & 291 & 190.9 & 271 & 331 & 221 & 241 & 165.3 & 165.3 & 185.5 & 210 & 185.5 & 210 & 311 & 220 & 220 \\
\hline $\mathrm{MP}_{144 \mathrm{~T}}: 2$ & 1800 & 221 & 278 & 218 & 294 & 409 & 254 & 265 & 165.3 & 165.3 & 185.5 & 210 & 185.5 & 210 & 311 & 220 & 220 \\
\hline $\mathrm{MP}_{144 \mathrm{~F} 2 \mathrm{~T}}: 1$ & 1800 & 212 & 273 & 173 & 265 & - & 171 & 235 & 165.3 & 165.3 & 185.5 & 210 & 185.5 & 210 & 311 & 220 & 220 \\
\hline $\mathrm{MP}_{144 \mathrm{~F} 2 \mathrm{~T}}: 2$ & 1800 & 272 & 236 & - & 261 & 294 & 204 & 225 & 165.3 & 165.3 & 185.5 & 210 & 185.5 & 210 & 311 & 220 & 220 \\
\hline
\end{tabular}

Note: P1 and P3 are rosette strain position on top flange toward the left and right side edge @ 12 inches from the left and right end, respectively. P2 and P4 are rosette strain position on top flange @ center (short side) at 24 inches from the left and right end, respectively. P5 is rosette strain position near the joint at 24 inches from the right end. P6 and P7 are rosette strain position on outer side of web @ center (short side) at 24 inches from the left and right end, respectively. More information of strain positions is given in Section 3.3.2. 
Average in-plane shear strains based on experimental results are higher than those from SCLT and finite element results. Several factors led to higher experimental strains, as explained for components in Section 4.6.2.3. Maximum in-plane shear strains are found on specimens $\left(\mathrm{MP}_{144 \mathrm{JL}}\right)$ due to joint effect on the test specimens. In addition, shear flexibility @ joints was not accounted for in SCLT and mainly strain prediction was based on SCLT.

Experimental strains of specimen $\left(\mathrm{MP}_{144 \mathrm{~T}}\right.$ and MP4 $\left.4_{144 \mathrm{~F} 2 \mathrm{~T}}\right)$ are also higher than those of SCLT and finite element method. The above mentioned assumptions, material and manufacturing parameters (e.g., perfect continuity of materials, full load transferring, constant strain on plane in each layer, and joint effects) are some of the many factors that lead to over estimation of in-plane shear strain in these transverse specimens.

\subsection{Joint Efficiency}

Joint efficiency of FRP panels that are bonded/bolted with steel beam system is of concern especially with regards to loss of composite action between jointed FRP members that affect the total stiffness and interaction of FRP members with steel beams (Sotiropoulos 1995). Theoretical and experimental evaluations are compared to find partial composite action between FRP panels and steel beams. The percent of composite action is proportional to joint efficiency (i.e., increase in joint efficiency leads to increase in composite action.). Joint efficiency at coupon level is defined as the strength of jointed coupon versus unjointed coupon. However, joint efficiency of FRP composite decks in this study is defined on stiffness basis which is a function of deflection or strain data.

In this study, joint efficiency of FRP composite deck specimen is obtained by comparing structural performance (strain and deflection) between interested and controlled system. It should be noted that any items that are used to evaluate joint efficiency under a loading condition are dealing with performance of joint efficiency corresponding to a specific 
loading situation. It is clear that joint efficiency under a specific loading situation can not be considered to be the joint efficiency of other loading situations. Therefore, joint efficiency based on stiffness under a specific loading situation can be defined as:

Joint efficiency $=\frac{\text { performanc e of interested system }}{\text { performanc e of control system }}$

Where, performance measure can be defined to be the inverse of maximum deformation (deflection, rotation, strain) or force. In addition, performance can be directly obtained from stiffness or flexibility of system such as bending, shear, and torsion stiffness and flexibility etc.

Generally, performance measures of interested and control systems are directly obtained from experimental results under desired loading conditions. However, other approaches such as analytical and numerical methods are often used to replace experimental methods for achieving system data while evaluation of performance measuring for an interested system involves modifications of original equations that analyze control systems. Using finite element method for modeling of interested system is much more complicated than those of control system. In this study, finite element modeling for joints is not undertaken because of complexities associated with modeling for shear leakage across joints. Experimental testing of interested systems can not be avoided because data of joint properties and behaviors are simulated into mathematical models through different types of elements (such as contact elements required fraction for small or large separation or even for varying forces etc.) or through nonlinear analysis based upon classical numerical methods.

To evaluate joint efficiency under torsion, torsional rigidity is used to measure performance of a system. In addition, measured performance of control systems is obtained from results of experimental, SCLT and finite element. Joint efficiencies using different control systems are evaluated and compared in Table 4.21. An example on joint efficiency $\left(\mathrm{MP}_{144 \mathrm{JL}}\right)$ computations is presented herein: 
Example: Joint efficiency of $\mathrm{MP}_{144 \mathrm{JL}}$

From results in Table 4.15

Torsional rigidity $(G J)_{\exp }$ of interested system (experiment with joints) $=7.33 \times 10^{7} 1 \mathrm{~b}$-in ${ }^{2}$

Torsional rigidity $(G J)_{\exp }$ of control system (experiment without joints) $=8.53 \times 10^{7} \mathrm{lb}_{\text {-in }}^{2}$

Torsional rigidity $(G J)_{\mathrm{SCLT}}$ of control system $\left(\mathrm{SCLT}\right.$ theory) $=7.97 \times 10^{7} \mathrm{lb}_{\text {-in }}{ }^{2}$

Torsional rigidity $(G J)_{\mathrm{FE}}$ of control system (finite element method) $=9.04 \times 10^{7} \mathrm{lb}_{-\mathrm{in}^{2}}$

From joint efficiency definition in Equation (4.67)

Joint efficiency $=\frac{\text { Torsional rigidity of interested system }}{\text { Torsional rigidity of control system }}$

Joint efficiency using torsional rigidity $G J$ from experimental results to be control system is:

Joint efficiency $=7.33 \times 100 / 8.53=85.9 \%$

Joint efficiency using torsional rigidity $G J$ from SCLT to be control system is:

Joint efficiency $=7.33 \times 100 / 7.97=92.0 \%$

Joint efficiency using torsional rigidity $G J$ from $\mathrm{FE}$ to be control system is:

Joint efficiency $=7.33 \times 100 / 9.04=81.1 \%$

The same procedure is followed for transverse specimens to provide joint efficiency results as in Table 4.21. However, joint efficiency of transverse specimens is obtained using results of SCLT and finite element method to be a control system because all transverse specimens are assembled from several deck modules. Thus, there is no specimen without joint has been used as control system for this type of specimen. 
Table 4.21 Comparison of joint efficiency

\begin{tabular}{|c|c|c|c|c|}
\hline Sample & Item & $\begin{array}{c}\text { Interested } \\
\text { system }\end{array}$ & $\begin{array}{c}\text { Control } \\
\text { system }\end{array}$ & $\begin{array}{c}\text { Joint } \\
\text { efficiency } \\
\text { (\%) }\end{array}$ \\
\hline $\mathrm{MP}_{144 \mathrm{~J} \mathrm{~L}}$ & Stiffness & Experiment with joints & Experimental without joints & 85.9 \\
\hline $\mathrm{MP}_{144 \mathrm{~J} \mathrm{~L}}$ & Stiffness & Experiment with joints & SCLT theory & 92.0 \\
\hline $\mathrm{MP}_{144 \mathrm{~J} \mathrm{~L}}$ & Stiffness & Experiment with joints & Finite element & 81.1 \\
\hline $\mathrm{MP}_{144 \mathrm{~T}}$ & Stiffness & Experiment with joints & SCLT theory & 87.8 \\
\hline $\mathrm{MP}_{144 \mathrm{~T}}$ & Stiffness & Experiment with joints & Finite element & 89.7 \\
\hline
\end{tabular}

\subsection{Effect of Geometry on FRP Deck}

In this section, effect of plate (two dimensional) action under torsional and in-plane loads is studied using finite element method. Six FRP deck modules are jointed and modeled to simulate an FRP deck system. FRP decks are modeled under several loading condition. These loading conditions are: 1) torsion, 2) torsion and in-plane shear perpendicular to cell direction, and 3) torsion and in-plane shear parallel to cell direction. Three types of FRP decks are modeled through orthotropic shell elements (FEMAP as preprocessor) with six degrees (translation $\mathrm{x}, \mathrm{y}, \mathrm{z}$ and rotation about $\mathrm{x}, \mathrm{y}, \mathrm{z}$ axis) of freedom for each node. It should be noted that FRP deck joint effects (response) are not included in the initial models. However, refined models did include joints for further analysis as discussed later. To evaluate in-plane (shear) plate action, torsional rigidity is measured for FRP single cell as well as a multi-cell system. Transverse deflection data (orthogonal to plane of FRP deck) under a specific applied torque are used to calculate the corresponding twist angle. Torsional rigidity is obtained from applied torque versus rate of twist curve. Summary of finite element model is given in Table 4.22 . 
Table 4.22 Finite element models for system level

\begin{tabular}{|l|c|c|c|c|}
\hline Model & $\begin{array}{c}\text { Dimensions (in) } \\
\text { (width } \times \text { length } \times \text { depth ) }\end{array}$ & $\begin{array}{c}\text { No. of } \\
\text { Element }\end{array}$ & $\begin{array}{c}\text { No. of } \\
\text { Node }\end{array}$ & Load condition \\
\hline Model:1 & $138 \times 144 \times 4$ & 9024 & 8134 & torsion \\
\hline Model:2 & $138 \times 144 \times 4$ & 9024 & 8134 & $\begin{array}{c}\text { torsion and in-plane shear } \\
\text { perpendicular to cell direction }\end{array}$ \\
\hline Model:3 & $138 \times 144 \times 4$ & 9024 & 8134 & $\begin{array}{c}\text { torsion and in-plane shear } \\
\text { parallel to cell direction }\end{array}$ \\
\hline
\end{tabular}

Transverse displacement results (orthogonal to FRP deck plane) under three loading conditions are illustrated in Figures 4.43 through 4.45 . To establish effect of plate action, torsional rigidity of these models are calculated and compared to the results of a single cell model (refer to Section 4.6.2.2) as given in Table 4.23.
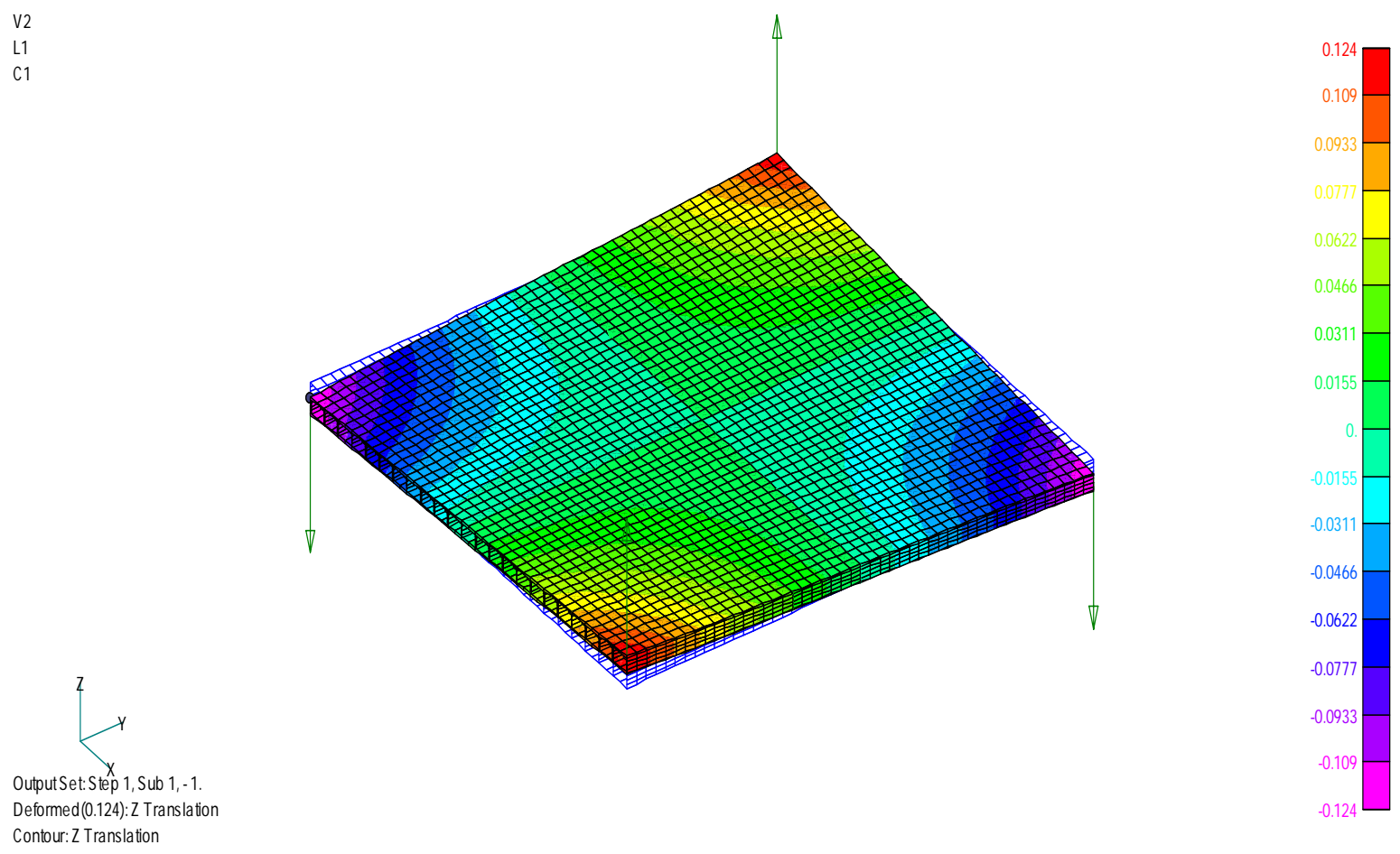

Figure 4.43 Transverse displacement of a system model under torsion 

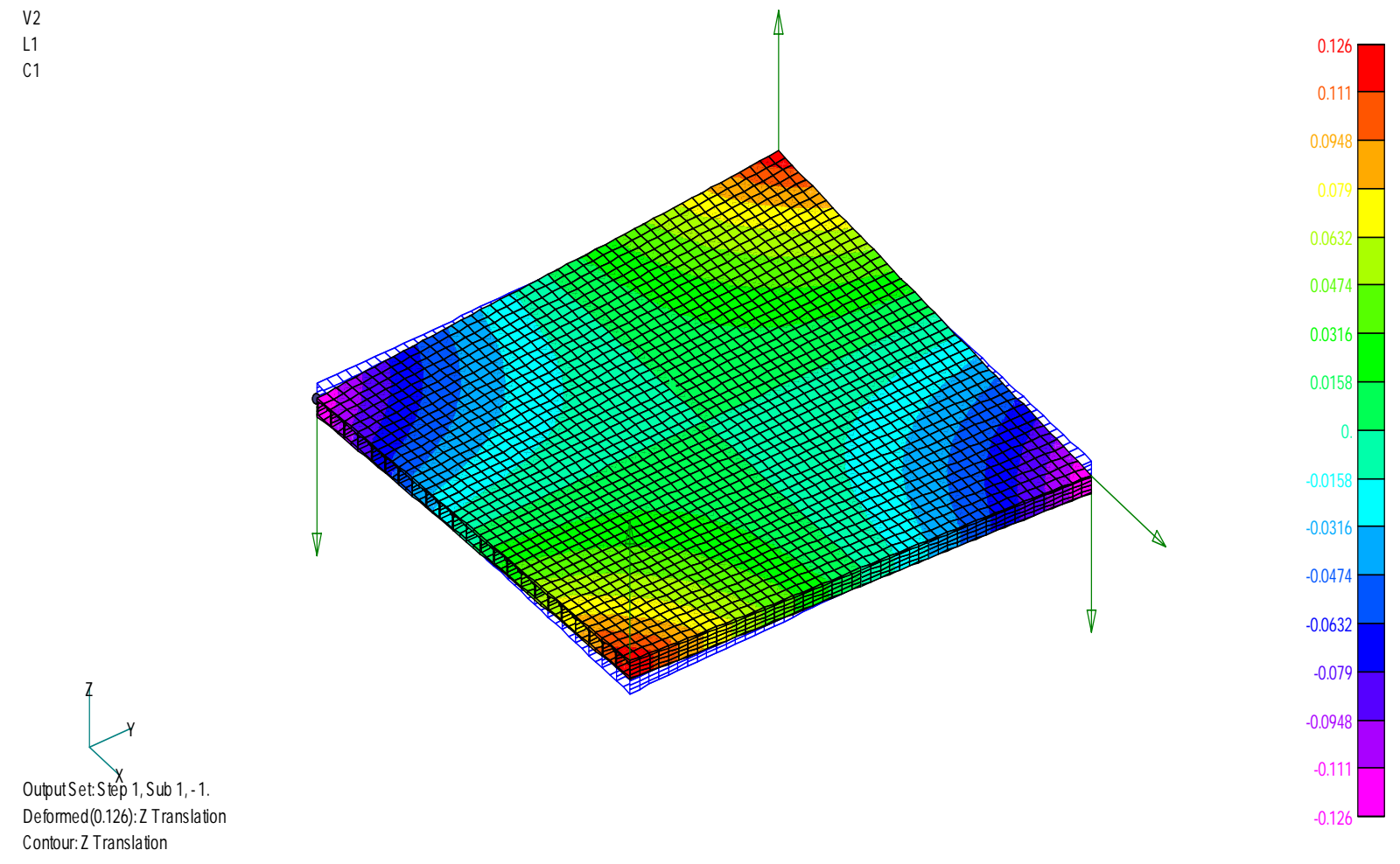

Figure 4.44 Transverse displacement of a system model under torsion and in-plane shear perpendicular to cell direction
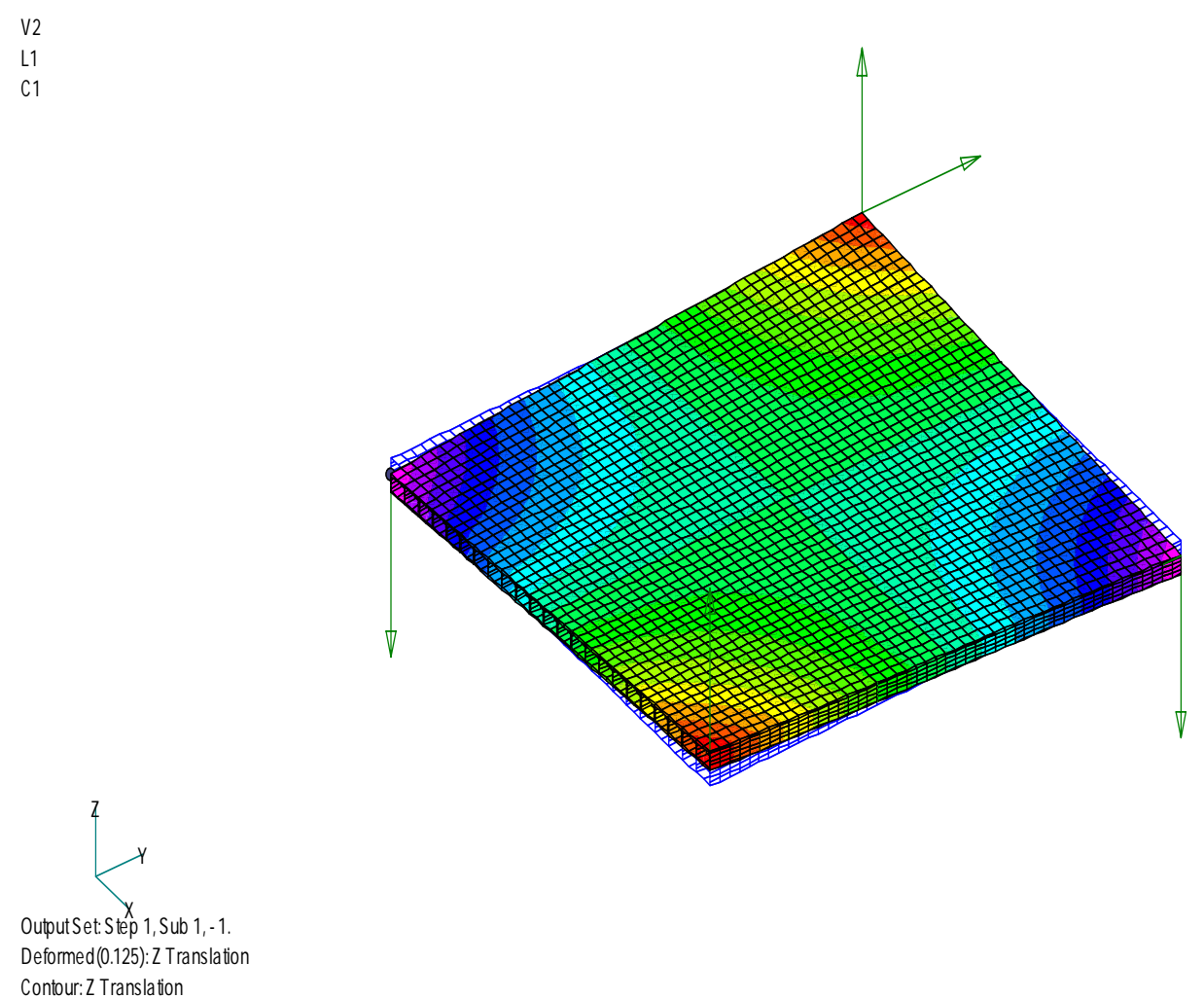

Figure 4.45 Transverse displacement of a system model under torsion and in-plane shear parallel to cell direction 
Table 4.23 Torsional rigidity of system models using finite element

\begin{tabular}{|c|c|c|c|c|c|}
\hline \multirow[t]{2}{*}{ Model } & \multirow[t]{2}{*}{$\begin{array}{l}\text { Rate of twist } \\
\left(\times 10^{-5} \mathrm{rad} / \mathrm{in}\right)\end{array}$} & \multirow{2}{*}{$\begin{array}{c}\text { Torsional } \\
\text { rigidity } \\
(G J) \\
\left(\times 10^{8} \text { lbs-in }^{2}\right)\end{array}$} & \multicolumn{2}{|c|}{$\begin{array}{l}\text { Torsional rigidity/ unit width } \\
\left(10^{6}\right) \text { lbs-in } / \text { in }\end{array}$} & \multirow[t]{2}{*}{$\%$ difference } \\
\hline & & & $\begin{array}{l}\text { *Single cell } \\
\text { (width } 6 \text { in) }\end{array}$ & $\begin{array}{c}\text { System } \\
\text { (width } 138 \text { in) }\end{array}$ & \\
\hline Model:1 & 2.090 & 6.60 & 3.73 & 4.78 & 21.7 \\
\hline Model:2 & 2.135 & 6.46 & 3.73 & 4.68 & 20.0 \\
\hline Model:3 & 2.115 & 6.52 & 3.73 & 4.72 & 20.8 \\
\hline
\end{tabular}

Note: torsional rigidity of single cell cross section is equal to $22.4 \times 10^{6} \mathrm{lbs}_{-} \mathrm{in}^{2}$ (refer to Table 4.14).

Table 4.23 reveals that influence of plate action on torsional rigidity of a system neglecting joint efficiency (full load transfer across joints) under torsional and in-plane shear loads is around $20 \%$ and $22 \%$ higher than that of single cell torsional rigidity.

To incorporate joint efficiency and plate action into a system, joint behavior on FRP deck system is idealized by spring elements (refer to Figure 4.47). Translation and rotation modes of joints are represented by axial and torsional spring elements, respectively. In addition, stiffness of spring elements is assumed to be 80 percent of full load transfer. Three joint movements with connections between shell and spring elements are illustrated in Figure 4.46. Full finite element model and vertical displacement results under torsional loading are presented in Figures 4.47 and 4.48. 
Translation parallel to cell direction

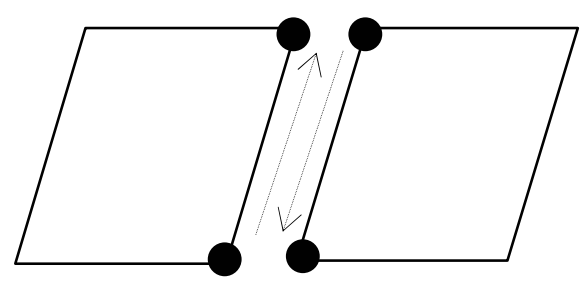

Translation perpendicular to cell direction

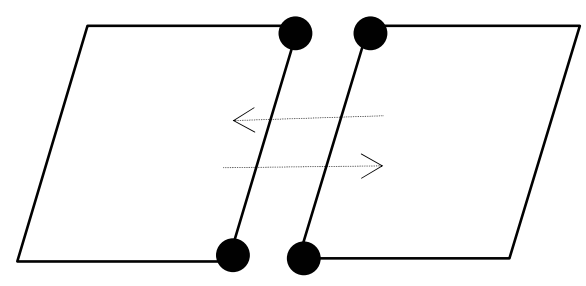

Rotation parallel to cell direction

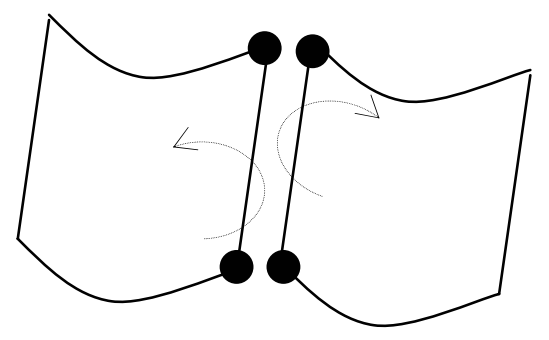

Longitudinal spring

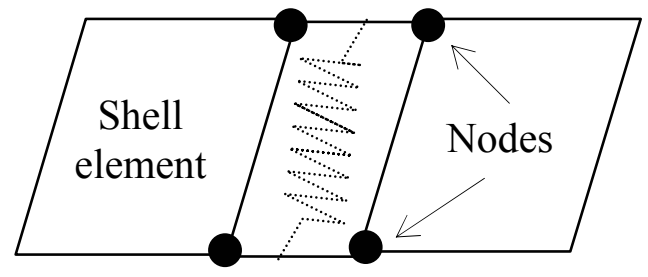

Transverse spring

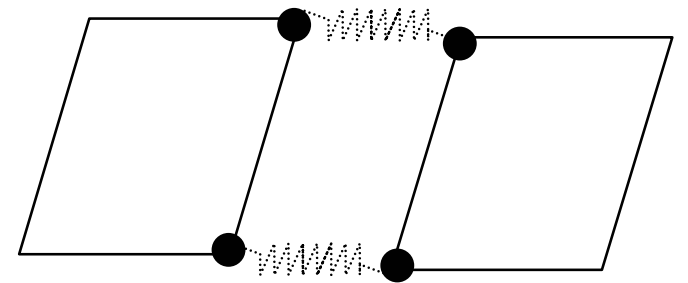

Torisonal spring

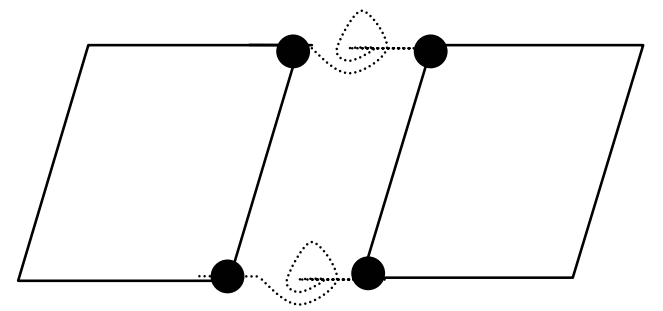

Figure 4.46 Spring elements and connection models

By using linear finite element analysis, rate of twist about the FRP deck cell direction is calculated to be $2.52 \times 10^{-5} \mathrm{rad} /$ in under applied torsion of $13800 \mathrm{in} .1 \mathrm{~b}$ about longitudinal direction. Torsional rigidity from the above loading condition is found to be $5.48 \times 10^{8} 1 \mathrm{bs}-\mathrm{in}^{2}$. Plate action with joint efficiency is evaluated by comparing torsional rigidity per unit width between system model and single cell model. Plate action (based on single cell results) with 80 percent joint efficiency is found to be within $6 \%$ of an FRP deck with 100 percent joint efficiency, i.e., no joints. Summary of plate action on the FRP deck system is given in Table 4.24. 
Table 4.24 Summary of Plate action on the FRP deck system

\begin{tabular}{|c|c|c|c|c|c|}
\hline Item & Single cell & \multicolumn{4}{|c|}{ Multi-cell system } \\
\hline Load & torsion & torsion & $\begin{array}{l}\text { torsion and in- } \\
\text { plane shear } \\
\text { perpendicular to } \\
\text { cell direction }\end{array}$ & $\begin{array}{l}\text { torsion and in- } \\
\text { plane shear } \\
\text { parallel to cell } \\
\text { direction }\end{array}$ & torsion \\
\hline Width (in) & 6 & 138 & 138 & 138 & 138 \\
\hline Joints & no & no & no & no & yes \\
\hline $\begin{array}{l}\text { Rate of twist } \\
\left(\times 10^{-5} \mathrm{rad} / \mathrm{in}\right)\end{array}$ & 2.678 & 2.090 & 2.135 & 2.115 & 2.520 \\
\hline $\begin{array}{l}\text { Torsional rigidity } \\
\left(\times 10^{8} \mathrm{lbs}^{\left.-\mathrm{in}^{2}\right)}\right.\end{array}$ & 0.224 & 6.60 & 6.46 & 6.52 & 5.48 \\
\hline $\begin{array}{l}\text { Torsional rigidity/ unit } \\
\text { width }\left(10^{6}\right) \mathrm{lbs}^{2} \mathrm{in}^{2} / \text { in }\end{array}$ & 3.73 & 4.78 & 4.68 & 4.72 & 3.97 \\
\hline $\begin{array}{c}\text { Plate action based on } \\
\text { single cell }\end{array}$ & - & 21.7 & 20.0 & 20.8 & 6.43 \\
\hline
\end{tabular}

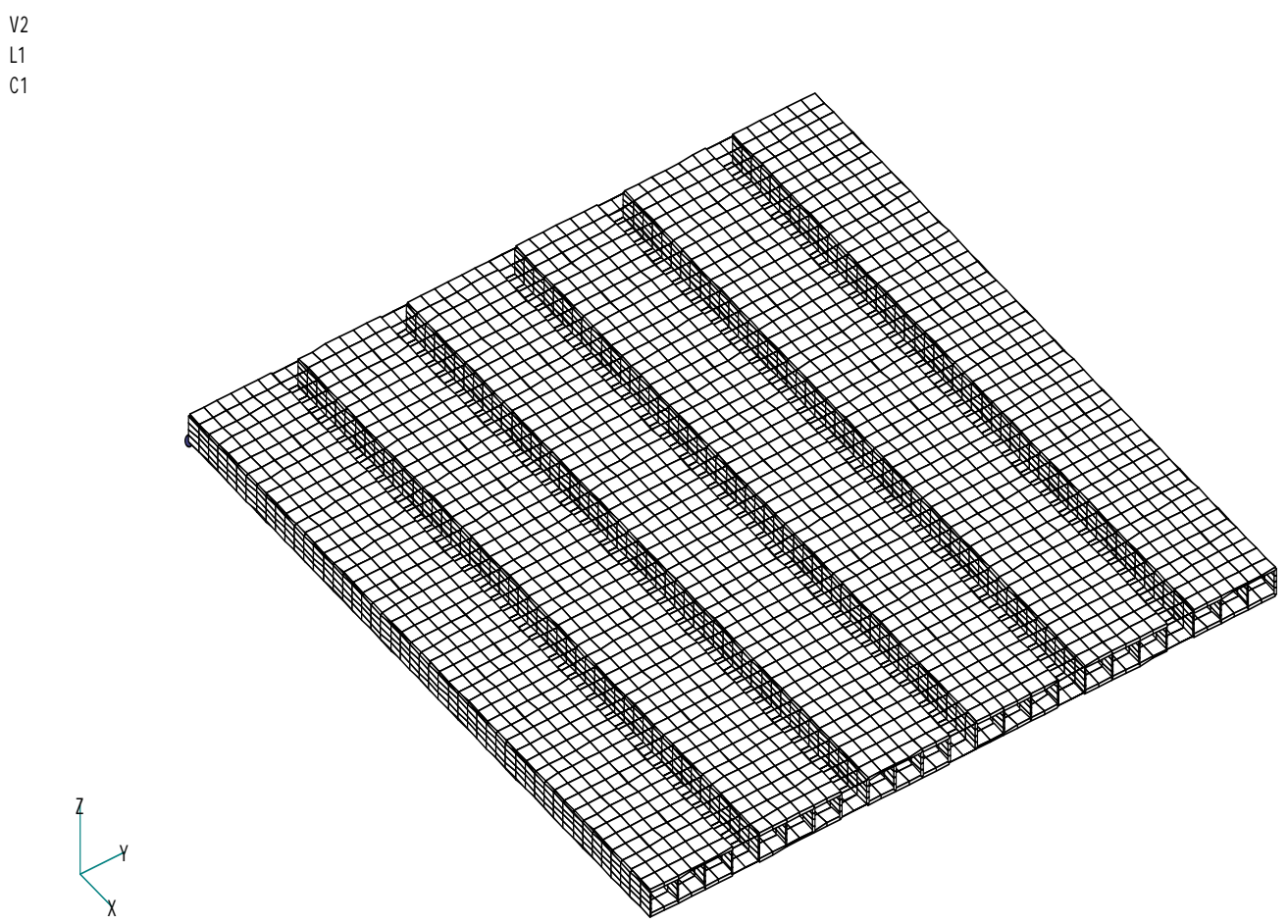

Figure 4.47 System model with joints 


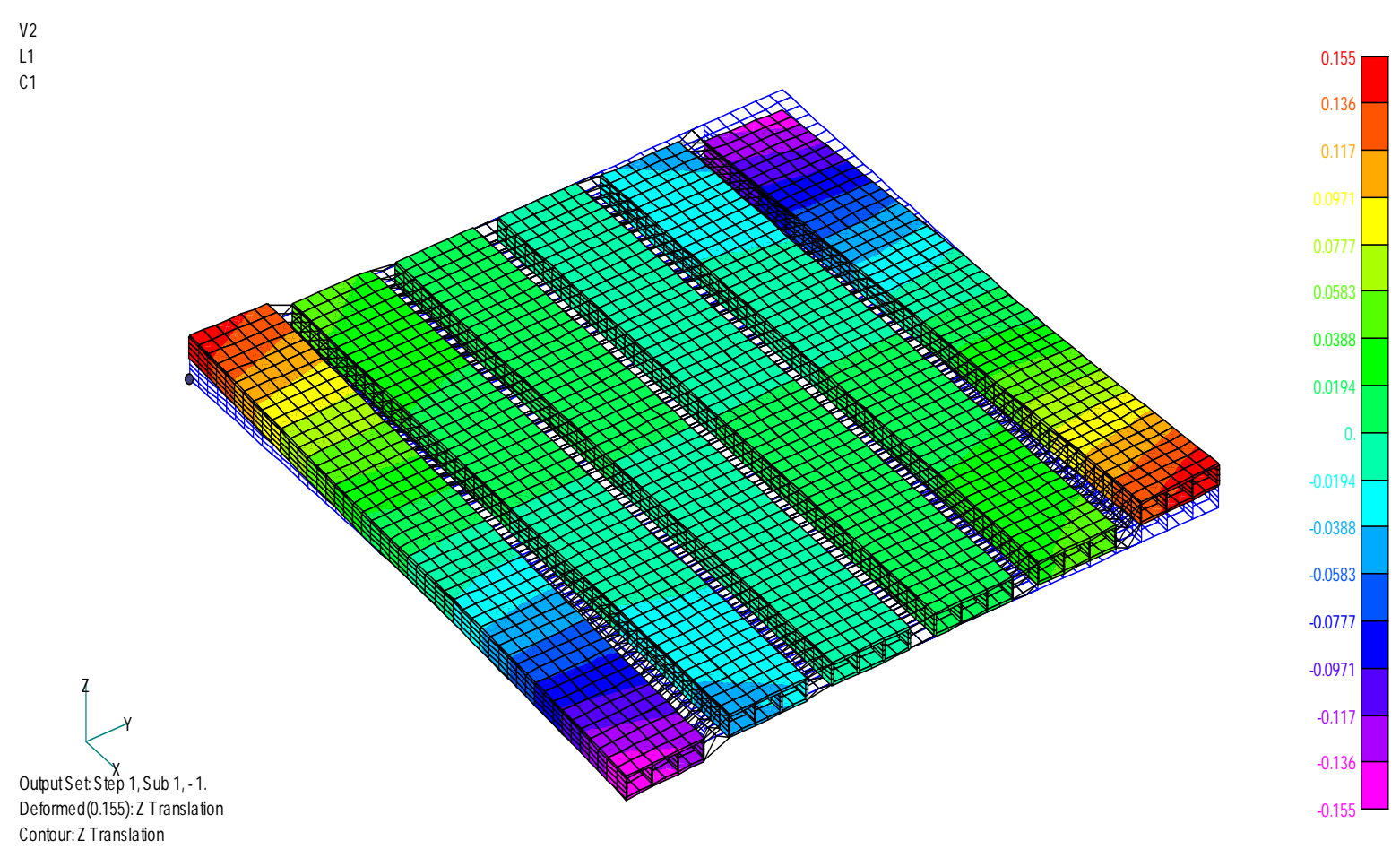

Figure 4.48 Vertical displacement of system model with joints

\subsection{Conclusions}

- Simplified Classical Lamination Theory (SCLT) is developed to compute torsional rigidity, in-plane (xy) shear modulus and strain of FRP structural members in this study. (Section 4.3)

- For unidirectional rectangular solid coupons, torsional rigidity and equivalent in-plane (xy) shear modulus predicted by SCLT are slightly different from the experimental data. Maximum percent difference between the SCLT and experimental data is found to be about $7.55 \%$. More accurate in-plane (xy) shear modulus is predicted from SCLT increase in increase in width to thickness ratio. (Section 4.6.1.1)

- The coupon test data revealed nominal increase in in-plane (xy) shear modulus with an increase in width to thickness ratio. (Section 4.6.1.2) 
- $\quad$ For sandwich specimens, equivalent in-plane shear modulus from SCLT is found to be less accurate because of a low capacity of in-plane shear resistance between core and fascia material. Most specimens failed under delamination while computations from SCLT are based on perfect bond between core and fascia materials. (Section 4.6.1.3)

- Experimental in-plane shear strains of coupons are quite low because of bond failure (cutting specimens) due to cutting of fibers and fabrics while preparing coupons, resin cracking, stress concentration, size effect, edge effect and others.

- In-plane shear strains based on SCLT are inaccurate ( $20 \%$ difference) compared to the experimental data. However, predicted strains from SCLT are much higher than the experimental data because of 1) SCLT assumes perfect bond between lamina, 2) SCLT neglects stress concentration effect, and 3) SCLT neglects loss of load transfer due to fiber discontinuity created by cutting of samples. (Section 4.6.1.4)

- Equivalent in-plane shear modulus of FRP components based on SCLT and finite element method has resulted in good agreement with experimental data except transverse specimens $\left(\mathrm{COP} 4_{144 \mathrm{~T}}\right)$. Joints as in specimens $\left(\mathrm{COP} 4_{144 \mathrm{~T}}\right)$ lead to lower inplane shear modulus while SCLT does not account for joint efficiency. However, small percent difference in in-plane (xy) shear modulus does lead to larger percent difference in stress and strain. (Sections 4.6.2.2 and 4.6.2.3)

- $\quad$ Perfect continuity of materials through specimens and full load transferring are assumed for structural models based on SCLT and finite element methods. In addition, SCLT method does not account for structural geometry effect (joint efficiency) as diagonal bracing. The above assumptions lead to lower strain than the experimental data by about $20 \%$ to $30 \%$. (Section 4.6 .2 .3 )

- In-plane (xy) shear strain based on SCLT yields good accuracy only for locations near mid-plane (xz) passing through the thickness in each cross section of structural 
members and far away from the ends of structural members (boundaries). It is noted that SCLT gives a constant strain for each layer (xy plane) through thickness of structural portions. Thus, theoretical strains on positions far away from the mid-plane (xz) passing through the thickness of cross section in are quite different from experimental strain. Also, complex stress distribution is found near the boundaries (applied torque at both ends) of FRP members. (Section 4.6.2.3)

- For multi-cell specimens without joints, experimental equivalent in-plane shear modulus yields good agreement with that of SCLT and finite element method. However, experimental results of multi-cell specimens with joints are smaller than the results from SCLT and finite element method. Such difference has been attributed to: 1) shear leakage on test specimens, 2) perfect materials (without joint effect), and 3) full load transfer in the analysis based on both SCLT and finite element methods. To improve performance of shear transfer across joints, specimens $\left(\mathrm{MP}_{144 \mathrm{JL}}\right)$ are reinforced with glass fabric along joint length of both top and bottom surfaces. In-plane (xy) shear modulus when reinforced has increased by about 16\%. (Section 4.6.3.1)

- $\quad$ For multi-cell specimens, in-plane (xy) shear strain based on SCLT and finite element methods is smaller than that of experimental strain due to several factors as mentioned before in single cell component specimens (perfect continuity of materials, full load transfer, constant strain on plane in each layer, etc.,). In addition, joint efficiency is the main factor leading to excess strain prediction based on SCLT and finite element method. (Section 4.6.3.2)

- Using torsional rigidity as a measure of performance, joint efficiency of specimens varies from $80 \%$ to $90 \%$. (Section 4.7 )

- $\quad$ Plate action on torsional rigidity of a system was modeled by neglecting joint efficiency (full load transfer across joints) under torsional and in-plane shear loads is found to 
result in $20 \%$ (based on results of single cell cross section). Also, plate action with joint efficiency accounting for 80 percent of load transfer across joints is calculated to be about 6\%. (Section 4.8) 


\section{CHAPTER 5}

\section{IN-PLANE SHEAR BEHAVIOR}

\subsection{Introduction}

V-notched beam test procedures are frequently used to evaluate in-plane shear (xy) strength and modulus of FRP deck coupons, using Iosipecu shear test. The initial purpose of this test method was to evaluate pure shear stress with a normal stress free zone in metals. This test method was improved by Adams and Walrath in 1987.

In 1991, Bank et. al., (1991) and Sonti (1997) used this method to evaluate shear strength of pultruded composite specimens. However, several limitations of this standard Vnotched beam test were highlighted particularly in terms of specimen dimensions. Only coupon level tests can be accomplished using the standard V-notched beam test. However, inplane shear strength of FRP coupons was not enough to measure shear performance of FRP decks. Hence, in-plane shear behavior at component level of test specimens is necessary. Two possible cases of in-plane shear loading are: 1) shear loading in the same direction as the FRP cell direction and 2) shear loading in the direction transverse to FRP cell direction.

The cell direction of FRP deck in some cases is parallel to the traffic direction leading to vehicle induced in-plane shear force parallel to the cell direction (shear force parallel to cell direction). To study this in-plane shear behavior, a cantilever beam test as described in Section 3.5 is conducted to find equivalent in-plane shear (xy) modulus. Also, joint efficiency of component specimens is determined and compared with the results of other test methods later. 
In addition, traffic induced in-plane shear force could lead to FRP deck racking shear (shear perpendicular to cell direction). The top flanges of a bridge deck might be relatively distorted in relation to the bottom part of a deck bolted on steel stringers under induced inplane braking and acceleration forces. Evaluation and inspection of FRP deck using a racking shear test as described in Section 3.6 will be considered in Section 5.3.3. Experimental results under in-plane shear loadings in this chapter are compared to results from the classical finite element method.

\subsection{Experimental Program}

V-notched (coupon level), cantilever beam and racking shear test methods (component level) are used to study in-plane shear (xy) behavior of FRP deck specimens. Inplane shear (xy) strength and stiffness of test specimens at coupon level are evaluated using the V-notched beam test. For component level, equivalent in-plane shear (xy) modulus is determined by using proposed cantilever beam and racking shear tests. Experimental programs and test procedures are presented in the following sections.

\subsubsection{V-Notched Beam Shear Test}

For the V-notched beam test, descriptions of coupon specimens, test procedure and set-up (apparatus, number of specimens, structural shapes, specimen preparation and specimen dimension) are given in Section 3.4. This test aims to achieve a state of pure shear between an applied load on the mid-length of the specimen through the action of couples which produce counteracting moments (Matthews, 1994). For details, please refer to Figure 5.1. Constant shear force is induced while the bending moment is eliminated at the mid span of specimen. In addition, it should be noted that a notch-root radius (as per ASTM D5379M) on the V-notched beam apparatus is also utilized to reduce the elastic stress concentration at the root. In practice, there is still some non-uniformity of shear stress distribution in the test 
section with probably small normal compressive stress (Matthews, 1994). Thus, experimental results obtained from this test have significant influence of material properties, specimen preparation, stacking sequences of materials, test speed, void content, and volume percent of reinforcement.

Analysis of experimental data is focused on ultimate strength and in-plane shear strain. In-plane shear (xy) modulus of composite materials is obtained from the slope of plane shear stress and strain. Shear force distribution on a test specimen with the V-notch is presented in Figure 5.1. Ultimate shear force at the mid-span of test specimens is used to evaluate maximum in-plane shear strength of FRP specimens in this study.

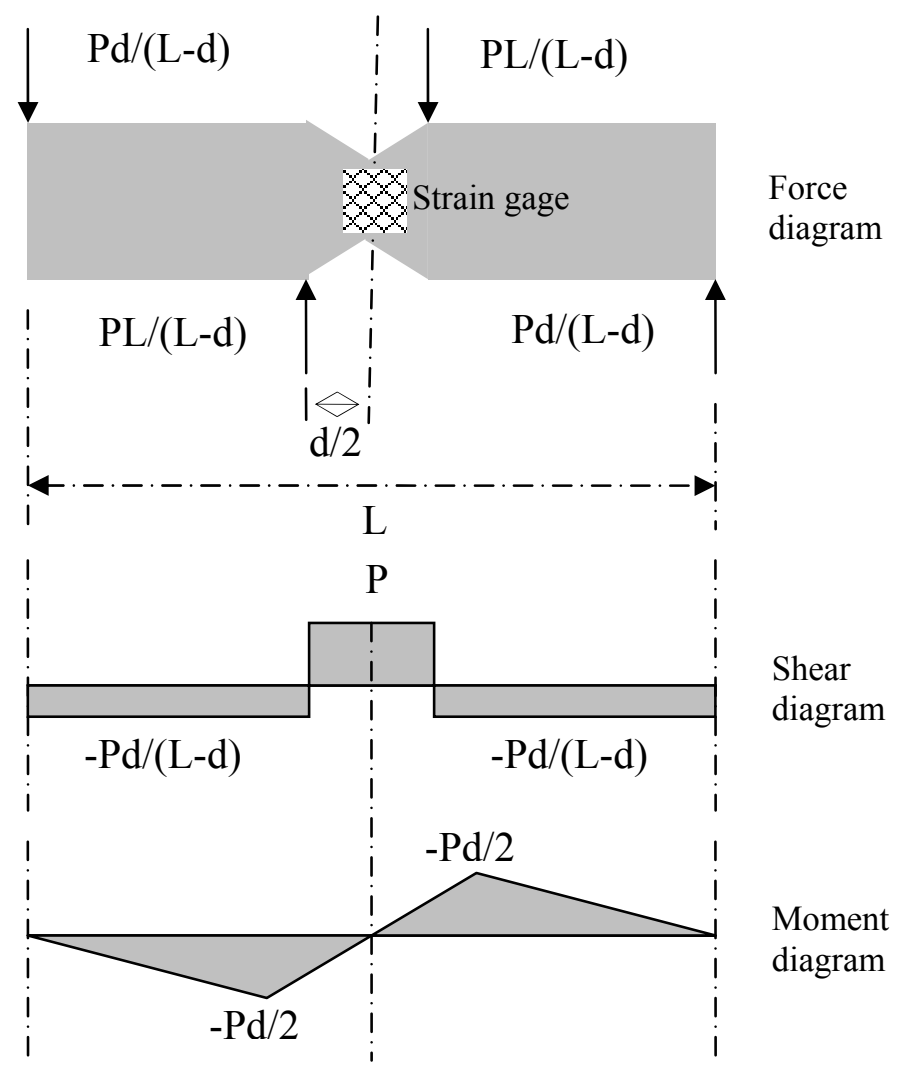

Figure 5.1 Force, shear and moment diagram 
Maximum shear strength on specimens is given:

$$
\tau_{u}=\frac{P_{u}}{A}
$$

Applied shear stress on specimens is given:

$$
\tau_{i}=\frac{P_{i}}{A}
$$

Where, $P_{u}$ is maximum load prior to failure, $P_{i}$ is the load at $\mathrm{i}^{\text {th }}$ data point and $A$ is the crosssectional area between opposite notches. In-plane shear strain data are obtained by measuring normal strain data at gage points on the mid-span of test specimens in different gage lines. If the distance between the gage points is small enough, our laboratory measurement of strains are approximate at a point. If these strain gages are arranged in strain rosette pattern, then the strain data are sufficient to evaluate the state of plain strain at a point for each specimen.

For in-plane strain problems, the strain data on each gage line at an arbitrary angle with respect to the reference $\mathrm{x}$ and $\mathrm{y}$ are given as:

$$
\begin{aligned}
& \varepsilon_{\theta_{i}}=\varepsilon_{x} \operatorname{Cos}^{2} \theta_{i}+\varepsilon_{y} \operatorname{Cos}^{2} \theta_{i}+\gamma_{x y} \operatorname{Sin} \theta_{i} \operatorname{Cos} \theta_{i} \\
& \varepsilon_{\theta_{i}}=\frac{\varepsilon_{x}+\varepsilon_{y}}{2}+\frac{\varepsilon_{x}-\varepsilon_{y}}{2} \operatorname{Cos} 2 \theta_{i}+\frac{\gamma_{x y}}{2} \operatorname{Sin} 2 \theta_{i}
\end{aligned}
$$

In-plane shear strains from strain rosette having three gage lines at $-45^{\circ}, 0^{\circ}$, and $45^{\circ}$ are determined from (modification of Equations (5.3) and (5.4)):

$$
\begin{aligned}
& \varepsilon_{x}=\varepsilon_{45}+\varepsilon_{0}-\varepsilon_{-45} \\
& \varepsilon_{y}=\varepsilon_{0} \\
& \gamma_{x y}=\varepsilon_{45}-\varepsilon_{-45}
\end{aligned}
$$

Thus, in-plane shear modulus of composite materials is given as:

$$
G_{x y}=\frac{\tau_{i}}{\gamma_{x y}}=\frac{P_{i}}{A\left(\varepsilon_{45}-\varepsilon_{-45}\right)}
$$


Where, $P_{i}$ is load at $\mathrm{i}^{\text {th }}$ data point and $A$ is the cross-sectional area between opposite notches, and $\left(\varepsilon_{45}\right.$ and $\left.\varepsilon_{-45}\right)$ are strains measured from the strain rosette.

\subsubsection{Cantilever Beam Test}

Descriptions and test procedures of cantilever beam tests are also given in Section 3.5. The test span of cantilever component and component with joint specimens are 12 and 18 inches (refer to Figure 5.2), respectively. Normally, the bending effect is significant when test span to effective depth ratio is more than 5 for conversional material as concrete (Wang 1992). However, span to depth ratio of test specimens in this study is kept between 1 and 1.5 . This ratio should be small enough to give predominant effect of shear. Thus, the induced bending moment on test specimens is not significant in this ratio range. From this point of view, in-plane shear (xy) modulus is directly obtained from the slope of the applied shear stress versus in-plane shear strain curve. Moreover, applied in-plane shear (xy) stress can be determined from the resultant of constant shear force, through the test span length divided by the cross-sectional area. In-plane shear (xy) strain data are obtained from the strain rosette readings. Average shear stress through the depth of a rectangular cross section and equivalent in-plane shear modulus are determined as given below:

$$
\begin{gathered}
\tau_{i}=\frac{1.5 V_{i}}{A} \\
G_{x y}=\frac{1.5 V_{i}}{A \gamma_{x y}}
\end{gathered}
$$

Where, $V_{i}$ is the load at $\mathrm{i}^{\text {th }}$ data point, $A$ is the cross-sectional area of a rectangular specimen, and $\gamma_{\mathrm{xy}}$ is experimental in-plane shear (xy) strain directly obtained from a rosette strain gage. 


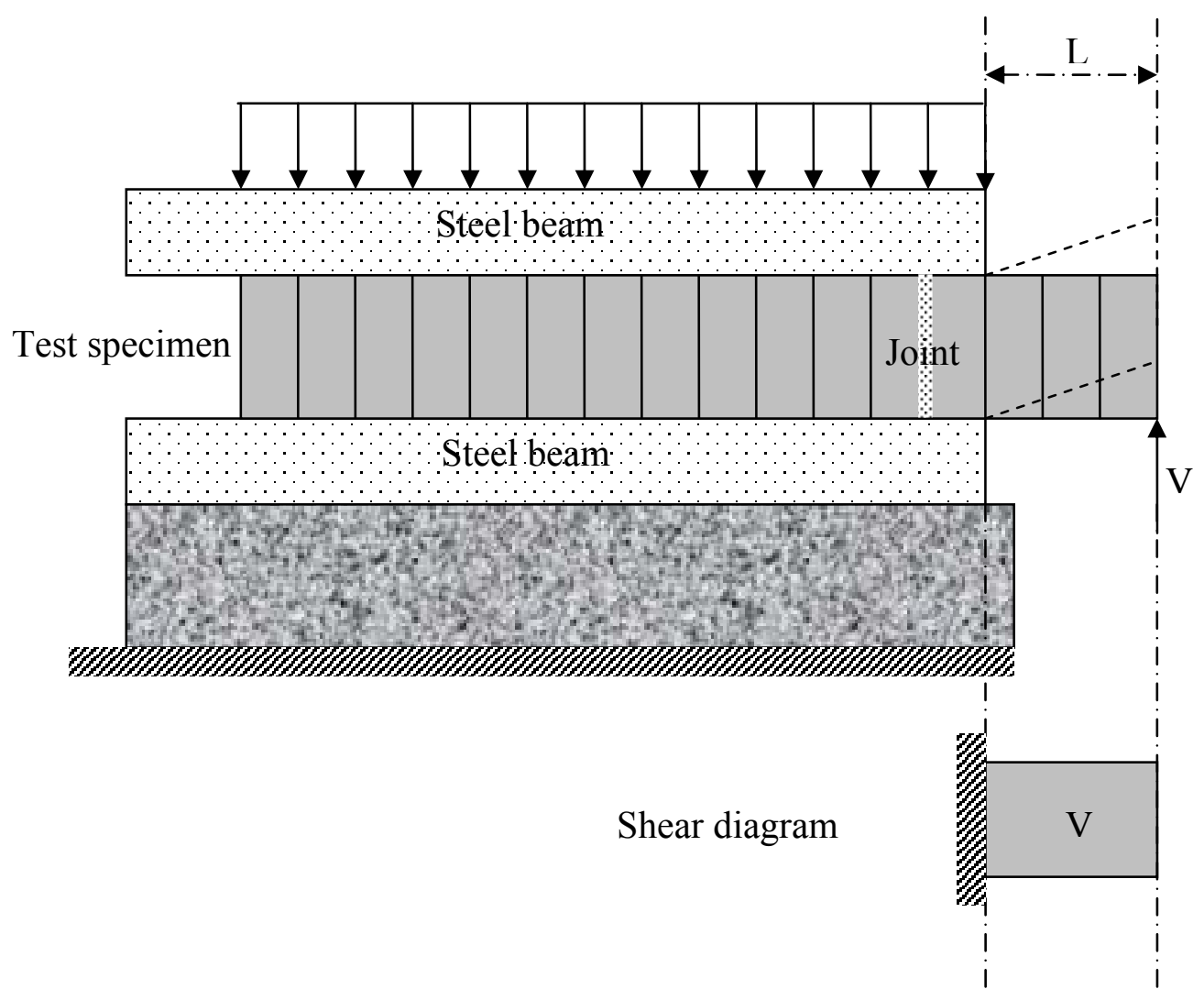

Figure 5.2 Schematic of the cantilever beam test set-up

\subsubsection{Racking Shear Test}

Test set-up and specimen description of racking shear tests are provided in section 3.6. It should be noted that this test method is not a standard test method. The shear leakage of FRP decks is accounted for in the system level testing. The test specimen is placed on a test set-up that allows induced vertical displacement at the left side of the test specimen (refer to Figure 5.3). Also, test span to depth ratio is kept at 0.60 (the limit of test specimen) so that the induced bending moment is very small and plate action is large. Thus, only shear effect is considered and the test specimen is assumed to be under in-plane shear stress only. To evaluate deck performance including in-plane shear (xy) modulus based on deflection results, vertical displacements at specific positions are measured and used to determine induced shear strain as: 
$\gamma=\operatorname{Tan}^{-1}\left(\frac{\delta_{3}-\delta_{1}}{d}\right)$

where, $\gamma$ is in-plane shear (xy) strain, $\delta_{3}$ and $\delta_{1}$ are induced vertical displacement during loading at positions 3 and 1 , respectively. $d$ is the length of the test span.

Maximum in-plane shear stress of the test specimen is given:

Therefore, experimental in-plane shear (xy) modulus based on deflection results can be obtained from the definition of in-plane shear (xy) stress to in-plane shear (xy) strain as:

$$
G_{x y}=\frac{1.5 V_{i}}{A \operatorname{Tan}^{-1}\left(\frac{\delta_{3}-\delta_{1}}{d}\right)}
$$

where, $V_{i}$ is applied load at $\mathrm{i}^{\text {th }}$ point, and $A$ is cross-sectional area of a test specimen. It should be noted that Equation (5.10) is valid only for rectangular cross sections.

For in-plane shear (xy) modulus based on experimental in-plane shear strain data, shear strain results of this method can be directly obtained from rosette strains mounted on the surface of our test specimens. In-plane shear (xy) modulus based on shear strain data is presented below:

$G_{x y}=\frac{1.5 V_{i}}{A\left(\gamma_{x y}\right)_{\exp }}$ 


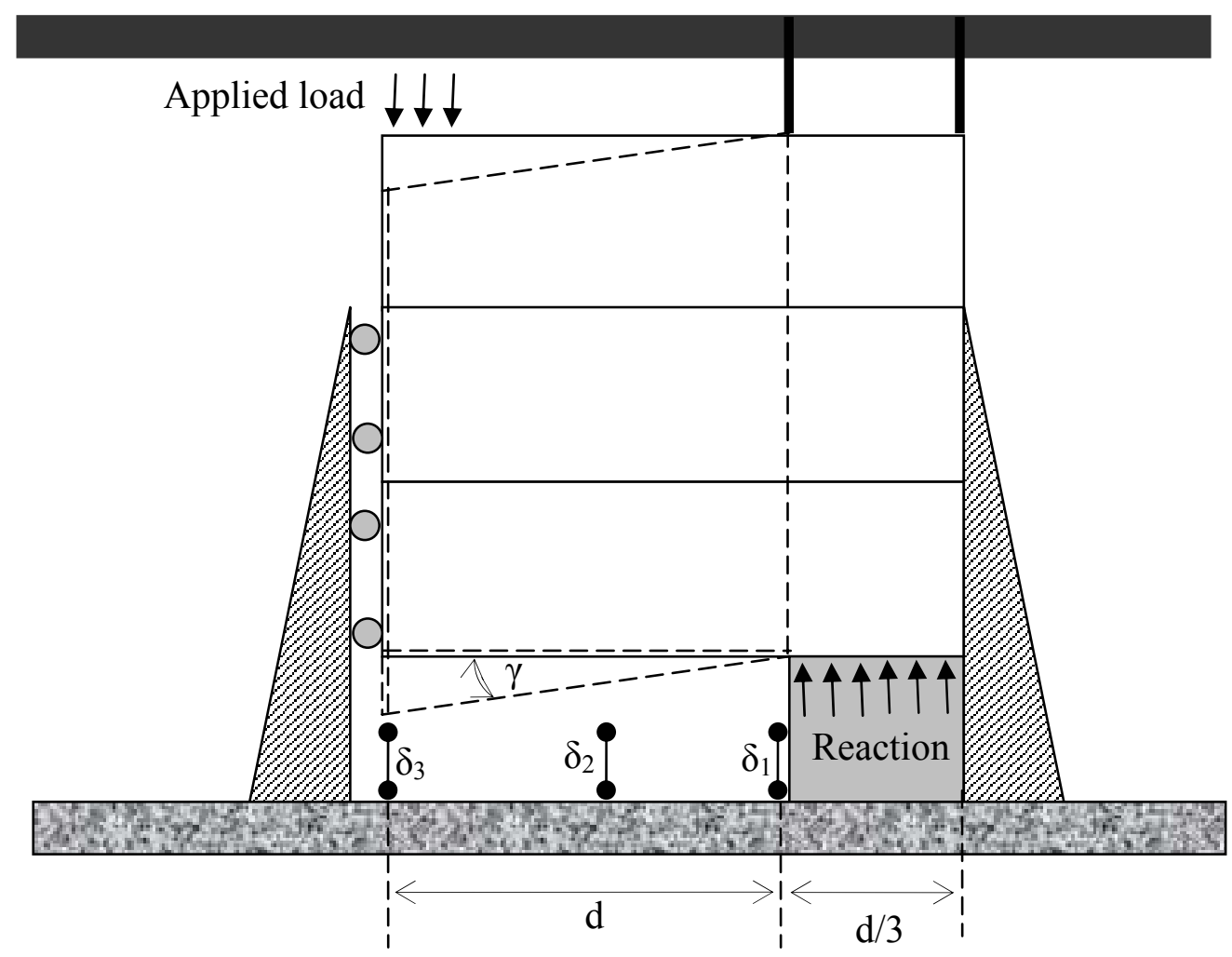

Figure 5.3 Schematic of racking shear test set-up

\subsection{Evaluation of Experimental Results}

Evaluations of equivalent in-plane shear modulus using V-notched, cantilever beam and racking shear tests are presented in this section. In-plane shear strength and modulus of longitudinal and transverse coupon specimens are evaluated by using the standard V-notched beam test. Test specimens at component (without and with joint) level are tested under the cantilever beam test and joint efficiency is also evaluated as given in Section 5.3.2. Finally, racking shear results of the test specimen with joint are presented in Section 5.3.3.

\subsubsection{V-Notched Beam Test}

In-plane shear (xy) strength of V-notched beams greatly depends on the geometry of the test specimen and maximum shear stress is nearly constant with no relation to the specimen gauge area (cross section). However, this stress tends to increase as the aspect ratio, width to thickness decreased to 1 and no less than 0.5 . In-plane shear strength is obtained 
using maximum load prior to failure while in-plane shear modulus is determined from the slope of stress and strain relation in the linear elastic range. Using Equations (5.1) and (5.6), in-plane shear strength and stiffness are evaluated and presented in Table 5.1. To compare inplane shear (xy) modulus, experimental results from V-notched beam testing and torsion testing at coupon level are evaluated and reported in Table 5.2.

Table 5.1 In-plane shear strength and modulus by V-notched beam test

\begin{tabular}{|c|c|c|c|c|c|c|c|}
\hline Specimen & Direction & $\begin{array}{c}\text { Failure } \\
\text { load } \\
\text { (kips) }\end{array}$ & $\begin{array}{c}\tau_{u} \\
\text { (ksi) }\end{array}$ & $\begin{array}{c}\text { Average } \\
\tau_{u} \\
(\mathrm{ksi})\end{array}$ & $\begin{array}{c}G_{x y} \\
\left(\times 10^{6}\right) \\
(p s i)\end{array}$ & $\begin{array}{c}\text { Average } \\
G_{x y} \\
\left(\times 10^{6}\right) \\
(p s i) \\
\end{array}$ & $\begin{array}{c}\text { Avg. } \\
\varepsilon_{u} \\
\left(\times 10^{-6}\right) \\
\text { (in/in) }\end{array}$ \\
\hline $\mathrm{VP}_{L}: 1$ & \multirow[t]{3}{*}{ Longitudinal* } & 2.59 & 14.52 & \multirow[t]{3}{*}{14.01} & 0.639 & \multirow[t]{3}{*}{0.625} & \multirow[t]{3}{*}{18936} \\
\hline $\mathrm{VP}_{4}: 2$ & & 2.45 & 13.73 & & 0.615 & & \\
\hline $\mathrm{VP}_{4}: 3$ & & 2.46 & 13.79 & & 0.621 & & \\
\hline $\mathrm{VP} 4_{\mathrm{T}}: 1$ & \multirow[t]{3}{*}{ Transverse* } & 2.80 & 11.62 & \multirow[t]{3}{*}{11.50} & 0.626 & \multirow[t]{3}{*}{0.608} & \multirow[t]{3}{*}{20086} \\
\hline $\mathrm{VP}_{\mathrm{T}}: 2$ & & 2.59 & 10.75 & & 0.588 & & \\
\hline $\mathrm{VP}_{\mathrm{T}}: 3$ & & 2.92 & 12.12 & & 0.611 & & \\
\hline
\end{tabular}

Note: $\tau_{u}$ is ultimate shear strength, $G_{x y}$ is in-plane shear modulus and $\varepsilon_{u}$ is ultimate in-plane shear strength. Average cross sectional area of longitudinal* and transverse* specimens are determined to be 0.1784 and $0.241 \mathrm{in}^{2}$, respectively. Specimen dimensions are given in Section 3.4.

Table 5.2 Comparison of in-plane shear stiffness

\begin{tabular}{|c|c|c|c|c|c|}
\hline \multirow[t]{2}{*}{ Direction } & \multicolumn{2}{|c|}{ V-notched beam } & \multicolumn{2}{|c|}{ Torsion test } & \multirow{2}{*}{$\begin{array}{c}(\%) \text { Difference } \\
\text { of } \\
\text { Avg. } G_{x y}\end{array}$} \\
\hline & Specimen & $\begin{array}{c}\text { Avg. } G_{x y} \\
\left(\times 10^{6}\right) \\
(\text { psi) }\end{array}$ & Specimen & $\begin{array}{c}\text { Avg. } G_{x y} \\
\left(\times 10^{6}\right) \\
(\text { psi) }\end{array}$ & \\
\hline \multirow[t]{5}{*}{ Longitudinal } & \multirow[t]{5}{*}{$\mathrm{VP}_{\mathrm{L}}$} & \multirow[t]{5}{*}{0.625} & $\mathrm{CP} 4_{2.3 \mathrm{~L}}$ & 0.517 & 17.28 \\
\hline & & & $\mathrm{CP}_{4 \mathrm{~L}}$ & 0.536 & 14.24 \\
\hline & & & $\mathrm{CP}_{6 \mathrm{~L}}$ & 0.537 & 14.22 \\
\hline & & & $\mathrm{CP} 4_{8 \mathrm{~L}}$ & 0.589 & 5.76 \\
\hline & & & $\mathrm{CP} 4_{10 \mathrm{~L}}$ & 0.590 & 5.60 \\
\hline Transverse & $\mathrm{VP} 4_{\mathrm{T}}$ & 0.608 & $\mathrm{CP}_{2.3 \mathrm{~T}}$ & 0.497 & 18.26 \\
\hline
\end{tabular}

Note: $G_{x y}$ is in-plane shear modulus 
It should be noted that percent difference of equivalent in-plane shear modulus between V-notched beam and torsion tests decreases when test specimens width to thickness ratio increases (equivalent in-plane shear modulus increases) to 0.5. From the previous chapter, experimental equivalent in-plane shear modulus increases when width to thickness ratio increases (width to thickness ratio $<10$ ). Equivalent in-plane shear modulus from Vnotched beam test using is higher than that from torsion testing due to several factors as: more bending and local punching of V-notched specimens because of improper set-up on shear apparatus, improper representation for shear strength (it is not designed for fabric laminates. Also, it is normally used for unidirectional fiber and fabrics that have only $0^{\circ}$ and $90^{\circ}$ orientation), etc. Different failure modes on V-notched beam specimens compared to specimens under torsion test is observed and may have been led to higher strength. All specimens are tested as V-notched beams till failure. Load-deflection response and stressstrain relations of test specimens are also presented in Figures 5.4 and 5.5, respectively.

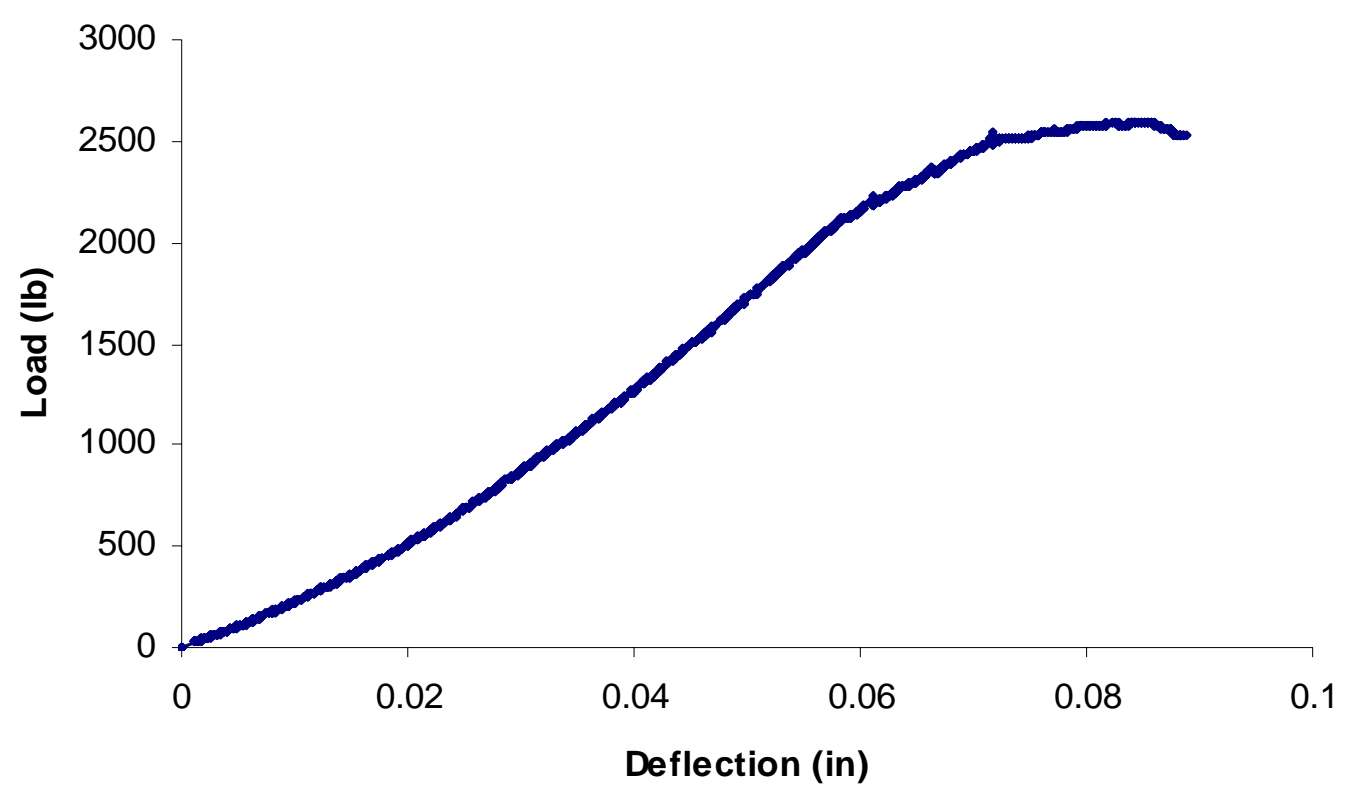

Figure 5.4 Load-deflection curve VP4 $4_{L}$ under V-notched beam test 


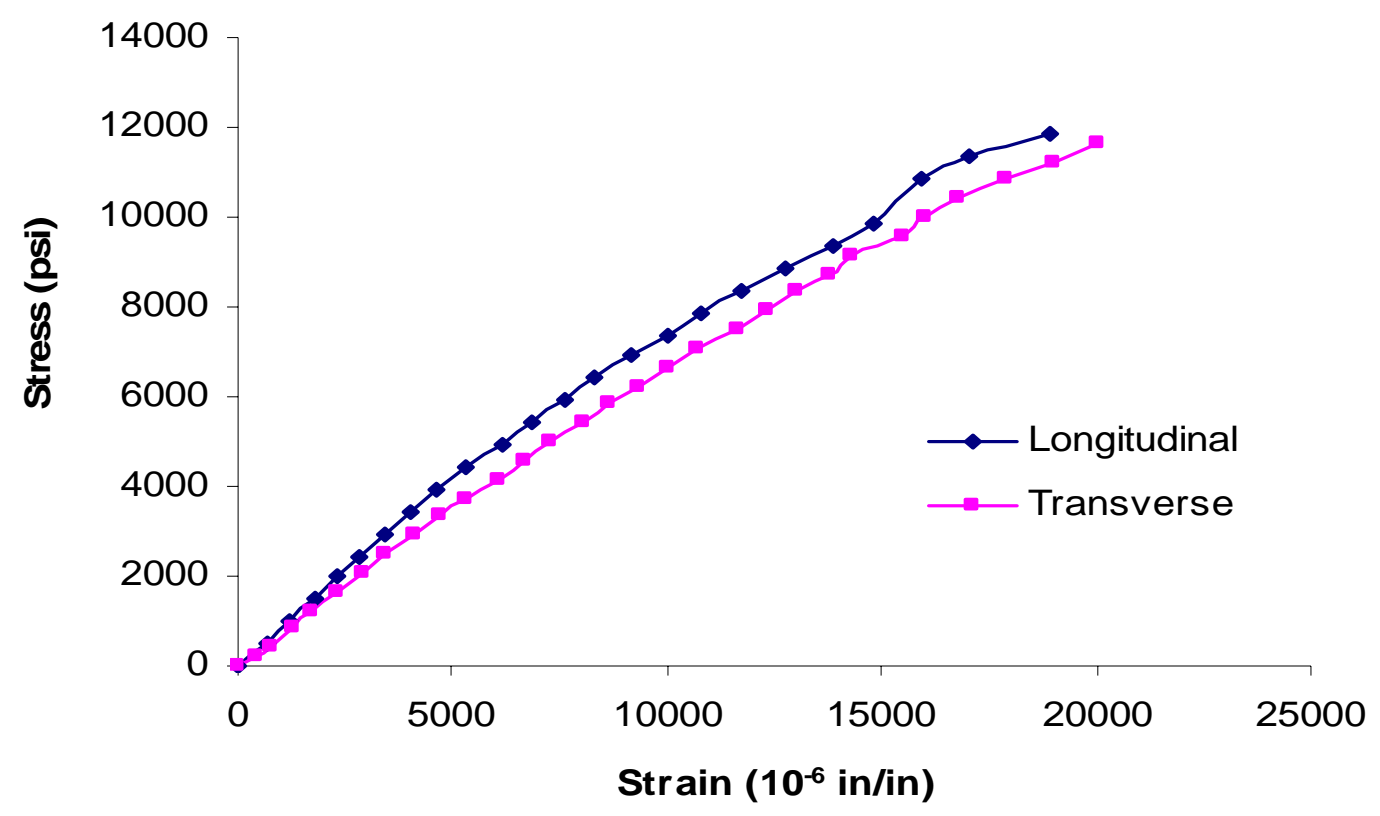

Figure 5.5 Stress-strain curve under V-notched beam test

\subsubsection{Discussion of V-Notched Beam Results}

Load versus deflection response of all specimens revealed a near linear behavior up to about $80 \%$ of the failure load, with the remaining $20 \%$ resulting in non-linear response. The linear stress-strain response is found also up to $80 \%$ of the failure load in both longitudinal and transverse test specimens (refer to Figure 5.5.)

From the experimental data, the average in-plane shear (xy) strength of longitudinal specimens is found to be higher than that of transverse specimens by about $18 \%$ because different percent of roving is not same in different directions (weak and strong direction). However, the average in-plane shear modulus in both specimen types is nearly the same as that reported in Table 5.1. For longitudinal specimens VP4 $4_{L}$, average in-plane shear modulus is reported to be $\sim 0.625 \times 10^{6}$ psi and percent difference between $\mathrm{V}$-notched and torsion test data are found to vary from $5.60 \%$ to $17.28 \%$. Percent difference in Table5.2 has decreased with an increase in width to thickness ratio of torsion test specimens since equivalent in-plane shear modulus from torsion test data revealed an increase corresponding to the increase of width to thickness ratio due to geometry and test procedure effect. For transverse specimens 
$\mathrm{VP} 4_{\mathrm{T}}$, average in-plane shear modulus $\left(0.608 \times 10^{6} \mathrm{psi}\right)$ is slightly less than that of longitudinal specimens $V P 4_{L}$. The percent difference of in-plane shear $(x y)$ modulus of transverse specimens between the V-notched and torsion data method is $\sim 18 \%$. It is found from the V-notched test data that average in-plane shear (xy) modulus of both longitudinal and transverse specimens is high and less conservative than those results provided by torsion test data. It may be that V-notched beam specimens may have more direct bearing of fiber shear than torsion test data where resin influence is more.

\subsubsection{Failure Mode of V-Notched Beam Test}

For transverse specimens $\mathrm{VP} 4_{\mathrm{T}}$, small cracks between notches on a test specimen are obviously observed during loading. Small cracks initially formed around notches at small magnitudes of the applied load. When the applied load increased, cracks are vertically extended from both notches through the test specimen length until test specimens failed at ultimate loads. The failure pattern for longitudinal specimens $V P 4_{L}$ as well as transverse specimens $\mathrm{VP}_{\mathrm{T}}$ is observed through our experiments. However, small cracks through the thickness are not clearly visible on this type of test specimen. The failure modes of longitudinal and transverse specimens are shown in Figures 5.6(a) and 5.6(b), respectively.

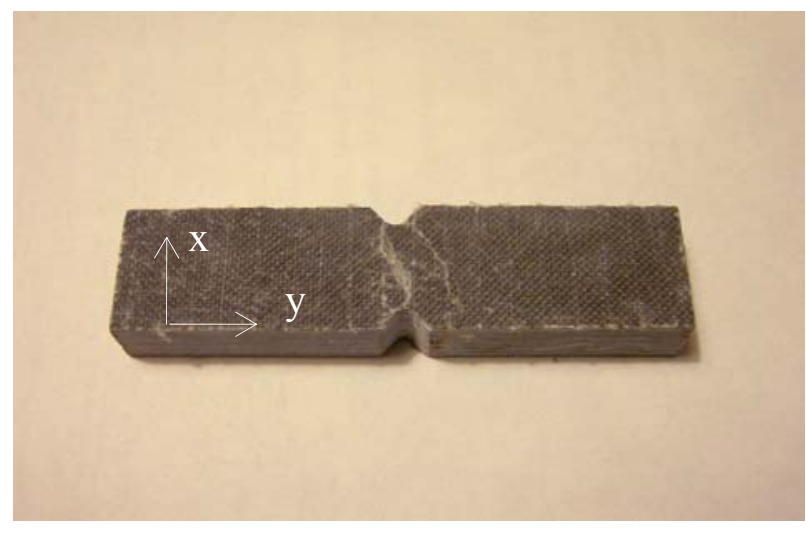

(a) transverse specimen $\left(\mathrm{VP}_{\mathrm{T}}\right)$

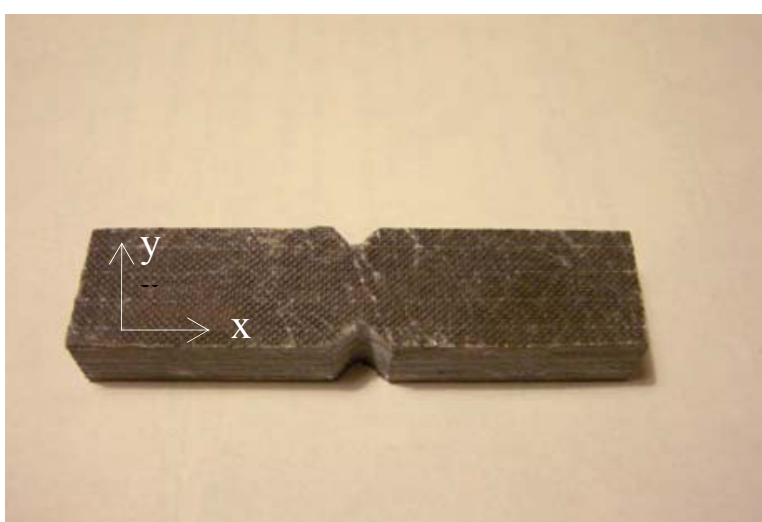

(b) longitudinal specimen $\left(\mathrm{VP}_{\mathrm{L}}\right)$

Figure 5.6 Failure mode of V-notched beam test specimen 


\subsubsection{Cantilever Beam Test}

In this section, equivalent in-plane shear modulus at component level is evaluated using a cantilever beam test. The performance of joints on test specimens (refer to Figure 5.7) is also studied to determine joint efficiency. Experimental results are validated and compared with results from the torsion test method. Analytical results based on finite element method are also used to compare with experimental data. Three different types of connections that we studied are: 1) rivet 2) glue and 3) rivet-glue. Moreover, the effectiveness of connection type is evaluated and reported in Section 5.3.2.3. Experimental test results and equivalent in-plane shear modulus corresponding to all test specimens are presented in Table 5.3.

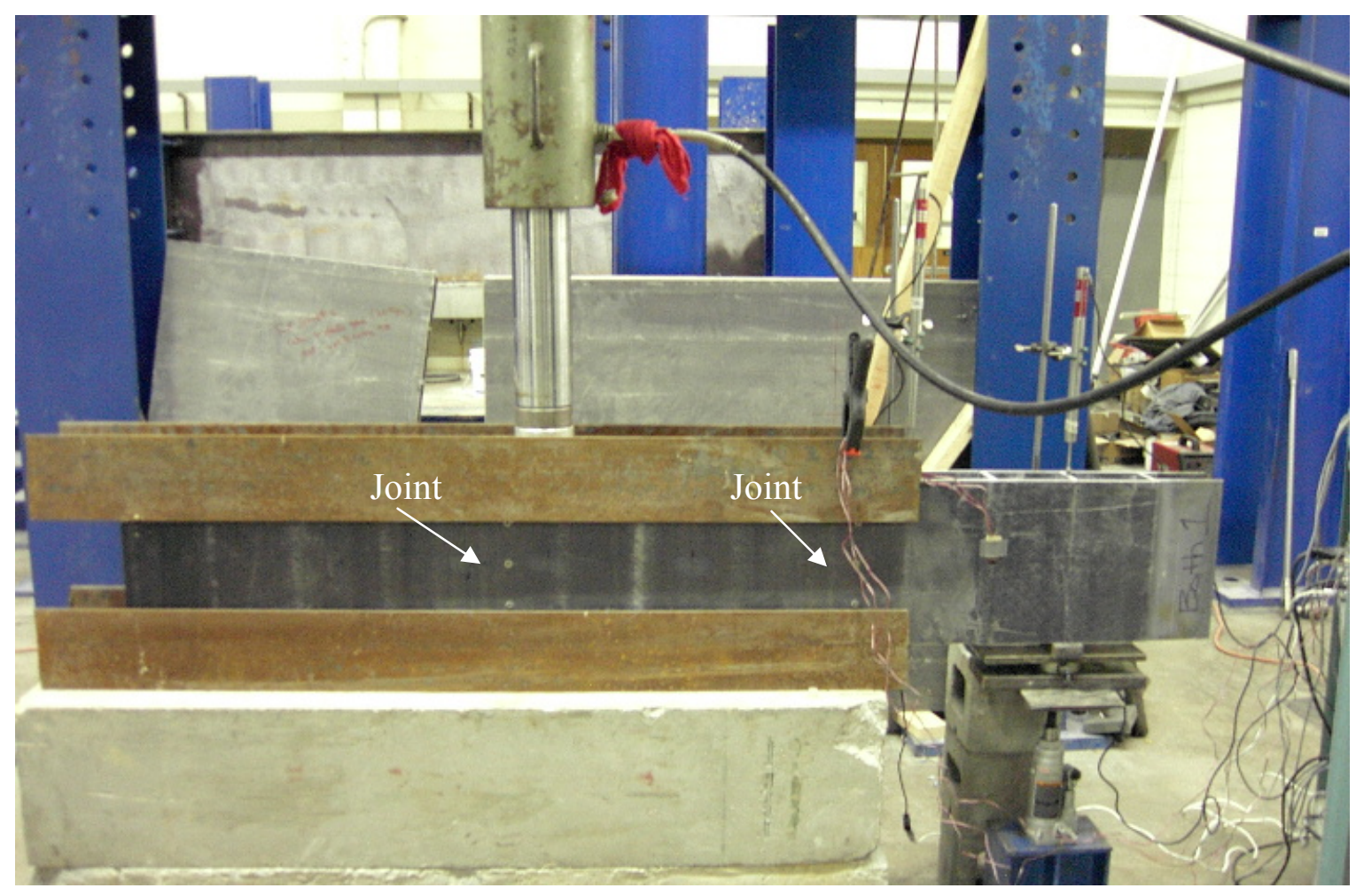

Figure 5.7 In-plane shear test using cantilever method 
Table 5.3 In-plane modulus using cantilever beam test

\begin{tabular}{|c|l|c|c|c|c|c|}
\hline Specimen & \multicolumn{1}{|c|}{ Level } & Joint & $\begin{array}{c}\text { Test span } \\
\text { (in) }\end{array}$ & $\begin{array}{c}\text { Depth } \\
\text { (in) }\end{array}$ & $\begin{array}{c}\text { Area } \\
\left.\text { (in }^{2}\right)\end{array}$ & $\begin{array}{c}\boldsymbol{G}_{\boldsymbol{x y}} \\
\left(\times \mathbf{1 0}^{6}\right) \\
(\mathbf{p s i})\end{array}$ \\
\hline $\mathrm{CB}_{\mathrm{R}}: 1$ & component & - & 12 & 12 & 13.97 & 0.579 \\
\hline $\mathrm{CB}_{\mathrm{R}}: 2$ & component & rivet & 18 & 12 & 15.14 & 0.451 \\
\hline $\mathrm{CB}_{\mathrm{G}}: 1$ & component & - & 12 & 12 & 13.97 & 0.582 \\
\hline $\mathrm{CB}_{\mathrm{G}}: 2$ & component & glue & 18 & 12 & 15.14 & 0.481 \\
\hline $\mathrm{CB}_{\mathrm{RG}}: 1$ & component & - & 12 & 12 & 13.97 & 0.586 \\
\hline $\mathrm{CB}_{\mathrm{RG}}: 2$ & component & rivet-glue & 18 & 12 & 15.14 & 0.534 \\
\hline
\end{tabular}

Note: $G_{x y}$ is in-plane shear modulus of transverse specimens

In-plane shear stress versus strain response of specimen $\mathrm{CB}_{\mathrm{R}}: 1$ is illustrated in Figure 5.7. It is obvious that in-plane shear stress versus strain curve displays non-linear behavior. From the stress versus strain relation in Figure 5.8, the equivalent in-plane shear modulus using bi-linear approximation is presented. It should be noted that load-deflection curve is a tri-linear response as shown in Figure 5.9

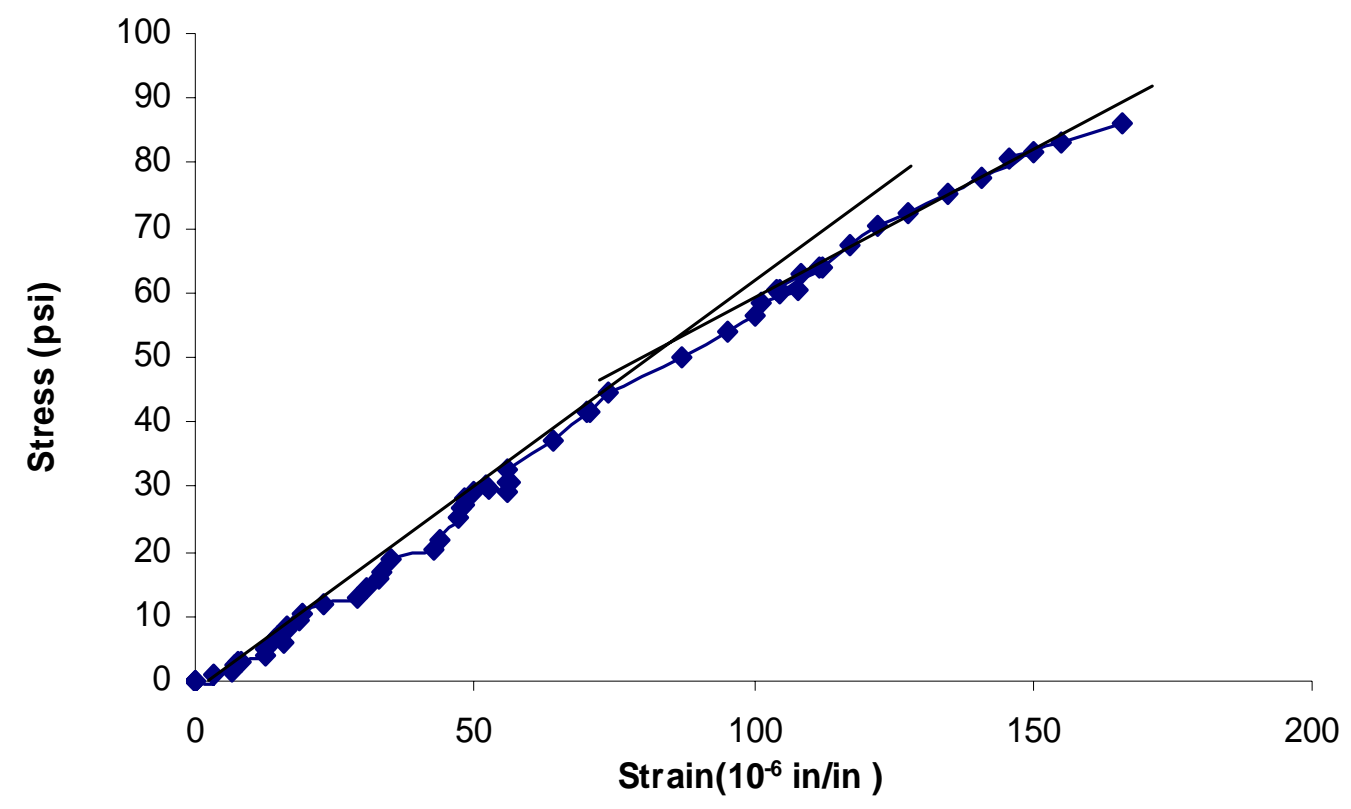

Figure 5.8 Relation between stress and strain $\mathbf{C B}_{\mathbf{R}}$ 


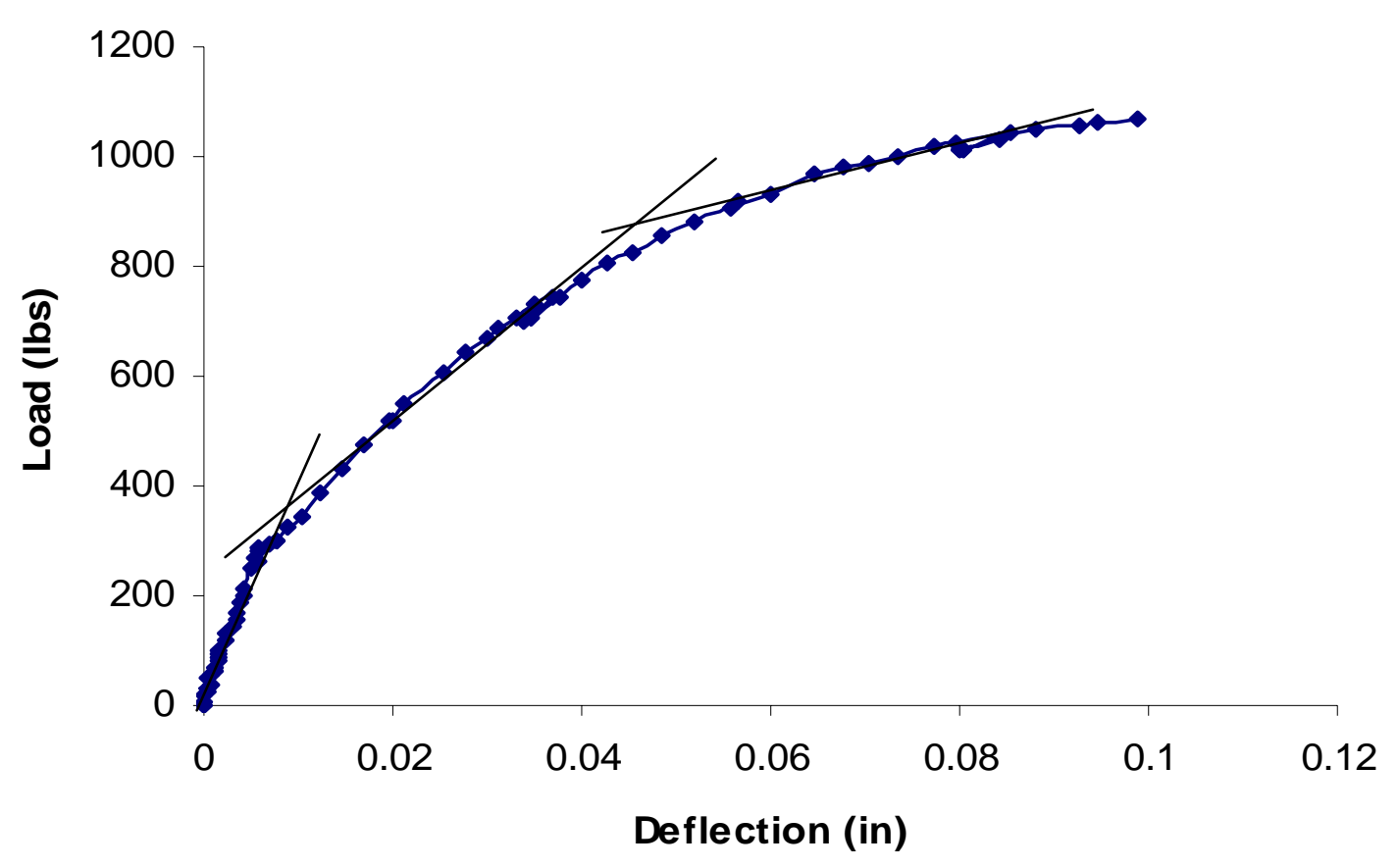

Figure 5.9 Relation between load and deflection $C_{R}$

\subsubsection{Analytical Results by Finite Element Method}

Test specimens are modeled using orthotropic shell63 (rectangular) provided by ANSYS. The specimen models are assumed with boundary conditions that are fixed at left end and free at right end. A concentrated load is directly applied at the center node of the web that is located at the right end on the top surface of the specimen model shown in Figure 5.10. In-plane shear (xy) modulus based on finite element results is calculated using in-plane shear stress and strain outputs. In addition, the mechanical response of a specimen using the finite element model is expected to be stiffer than that of experimental specimens with joints because connections are not modeled through finite element models, accounting for shear weakness. In addition, the inputs of the mechanical properties of test specimens (elastic modulus) are provided by Punyamurthula (2004). In-plane shear modulus for finite element modeling is obtained from the average experimental coupon data under torsion. Summary of results from the finite element model is provided in Table 5.4 and the specimen model is illustrated in Figure 5.10. 
Table 5.4 Summary of finite element models under cantilever beam test

\begin{tabular}{|c|c|c|c|c|c|}
\hline \multirow{2}{*}{$\begin{array}{c}\text { Analysis } \\
\text { type }\end{array}$} & \multirow{2}{*}{$\begin{array}{c}\text { Test span } \\
\text { (in) }\end{array}$} & \multicolumn{2}{|c|}{ Number of } & \multicolumn{2}{|c|}{ Conditions } \\
\cline { 3 - 6 } & elements & nodes & load & boundary \\
\hline Static & 12 & 1680 & 1743 & $\begin{array}{c}\text { Point load } \\
\text { at right end }\end{array}$ & fix-free \\
\hline
\end{tabular}

From the finite element data, in-plane shear stress and strain results for several positions are given in Table 5.5. From nodal results, equivalent in-plane shear (xy) modulus is determined from average in-plane shear (xy) modulus at those nodes.

V1<smiles>[X]C([Z])[X]</smiles>

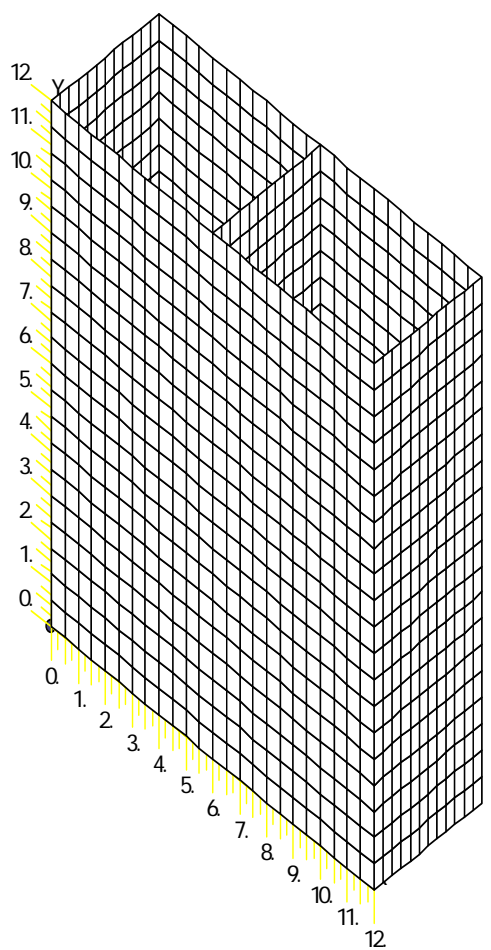

Figure 5.10 Finite element model of cantilever test specimens 
Table 5.5 Nodal results of cantilever beam model

\begin{tabular}{|c|c|c|c|c|c|}
\hline \multirow{2}{*}{ Node } & \multicolumn{2}{|c|}{ Position } & \multirow{2}{*}{$\begin{array}{c}\boldsymbol{\tau} \\
(\mathbf{p s i})\end{array}$} & $\begin{array}{c}\boldsymbol{\gamma} \\
\left(\times \mathbf{1 0}^{-4}\right) \\
(\mathbf{i n} / \mathbf{i n})\end{array}$ & $\begin{array}{c}\boldsymbol{G}_{\mathbf{x y}} \\
\left(\times \mathbf{1 0}^{6}\right) \\
(\mathbf{p s i})\end{array}$ \\
\cline { 2 - 3 } & $\begin{array}{c}\mathbf{x} \\
(\mathbf{i n})\end{array}$ & $\begin{array}{c}\mathbf{y} \\
(\mathbf{i n})\end{array}$ & & 1.319 & 0.589 \\
\hline 2 & 6.00 & 6.00 & 77.8 & 2.02 & 0.596 \\
\hline 3 & 6.50 & 6.00 & 120.4 & 1.798 & 0.587 \\
\hline 4 & 6.00 & 6.50 & 76.2 & 1.292 & 0.583 \\
\hline 5 & 6.50 & 6.50 & 116.7 & 2.04 & 0.580 \\
\hline 6 & 5.50 & 6.50 & 103.1 & 2.01 & 0.587 \\
\hline 7 & 6.00 & 5.50 & 0.535 & 0.01075 & $0.497 *$ \\
\hline 8 & 6.50 & 5.50 & 121.6 & 2.24 & 0.543 \\
\hline 9 & 5.50 & 5.50 & 108.7 & 1.843 & 0.559 \\
\hline Average & - & - & - & - & 0.578 \\
\hline
\end{tabular}

Note: *the result of node 7 is not accounted for average in-plane shear modulus

\subsubsection{Comparison of In-Plane Shear (xy) Modulus}

Equivalent in-plane shear (xy) moduli, from cantilever beam test of test specimens $\mathrm{MP}_{144 \mathrm{~L}}$ and $\mathrm{MP}_{144 \mathrm{LJ}}$ under torsion (refer to Section 4.6.3), are used to compare the finite element results. Average equivalent in-plane shear modulus of specimens $\mathrm{MP}_{144 \mathrm{~L}}$ and $\mathrm{MP}_{144 \mathrm{LJ}}$ is $0.542 \times 10^{6}$ and $0.466 \times 10^{6} \mathrm{psi}$, respectively. Numerical results based on finite element method are also discussed in the next section. To validate results from the cantilever beam test, experimental results (refer to Section 5.3.2) are compared with the torsional and numerical results that are provided in Sections 4.6.3 and 5.3.2.1, respectively. Comparison of these results in terms of equivalent in-plane shear (xy) modulus is presented in Table 5.6. 
Table 5.6 In-plane shear modulus comparison of cantilever beam test

\begin{tabular}{|c|c|c|c|c|c|c|}
\hline \multirow{2}{*}{ Specimen } & \multirow{2}{*}{ Joint } & \multicolumn{3}{|c|}{ In-plane shear modulus } & \multicolumn{2}{c|}{$\begin{array}{c}\text { \% difference } \\
\text { compared with }\end{array}$} \\
\cline { 3 - 7 } & & $\begin{array}{c}\text { Exp. } \\
\left(\times \mathbf{1 0}^{\mathbf{6}}\right) \\
\mathbf{p s i}\end{array}$ & $\begin{array}{c}\text { F.E. } \\
\left(\times \mathbf{1 0}^{\mathbf{6}}\right) \\
\mathbf{p s i}\end{array}$ & $\begin{array}{c}\text { Torsion** } \\
\left(\times \mathbf{1 0}^{\mathbf{6}}\right) \\
\mathbf{p s i}\end{array}$ & F.E. & Torsion \\
\hline $\mathrm{CB}_{\mathrm{R}}: 1$ & - & 0.566 & 0.578 & 0.542 & 2.08 & 4.24 \\
\hline $\mathrm{CB}_{\mathrm{R}}: 2$ & rivet & 0.451 & 0.578 & 0.466 & 21.9 & 3.22 \\
\hline $\mathrm{CB}_{\mathrm{G}}: 1$ & - & 0.553 & 0.578 & 0.542 & 4.32 & 6.87 \\
\hline $\mathrm{CB}_{\mathrm{G}}: 2$ & glue & 0.481 & 0.578 & 0.466 & 16.78 & 3.12 \\
\hline $\mathrm{CB}_{\mathrm{RG}}: 1$ & - & 0.560 & 0.578 & 0.542 & 3.11 & 7.51 \\
\hline $\mathrm{CB}_{\mathrm{RG}}: 2$ & rivet-glue & 0.514 & 0.578 & 0.466 & 11.07 & 12.73 \\
\hline
\end{tabular}

Note: Torsion**: In-plane shear modulus of specimens with and without joints is provided from specimens $\mathrm{MP}_{144 \mathrm{~L}}$ and $\mathrm{MP}_{144 \mathrm{LJ}}$, respectively.

Test specimens in this study are prepared from several modules of ProDeck4 specimens with $1 \mathrm{ft}$ width. To assemble FRP deck modules, three different types of jointconnections are used (refer to Figure 5.3.2). Joint efficiency of each specimen under the cantilever test method is evaluated and studied in Section 5.3.2.3

\subsubsection{Joint Efficiency}

Following the definition of joint efficiency in Chapter 4, in-plane shear (xy) modulus is used to measure joint efficiency. The measured performance of the control system is obtained using experimental and analytical results from the torsion and finite element results. As a control (experimental) system, the measured performance of specimens without joints is used, while performance provided by finite element method is used to be another control (i.e., analytical) for joint efficiency. It should be noted that finite element results in this study are accomplished by using the geometric model without joints. Joint efficiency evaluations of specimen $\mathrm{CB}_{\mathrm{R}}$ are presented as: 
Example: Joint efficiency of specimen $\mathrm{CB}_{\mathrm{R}}$

From results in Table 5.6

In-plane shear modulus of interested system $\mathrm{CB}_{\mathrm{R}}: 2($ Expt $)=0.451 \times 10^{6} 1 \mathrm{~b}-\mathrm{in}^{2}$

In-plane shear modulus of control system $\mathrm{CB}_{\mathrm{R}}: 1(\mathrm{Expt})=0.566 \times 10^{6} \mathrm{lb}-\mathrm{in}^{2}$

In-plane shear modulus of control system $(\mathrm{FE})=0.578 \times 10^{6} \mathrm{lb}^{\mathrm{in}}{ }^{2}$

joint efficiency $=\frac{\text { in }- \text { plane shear modulus for interested system }}{\text { in - plane shear modulus for control system }}$

This joint efficiency definition is under the assumption that the control system is perfect.

Joint efficiency $=$ In-plane shear modulus (Expt.)/ In-plane shear modulus (without joints)

Joint efficiency $=0.451 \times 100 / 0.566=79.7 \%$

Joint efficiency $=$ In-plane shear modulus (Expt.)/ In-plane shear modulus (F.E.)

Joint efficiency $=0.451 \times 100 / 0.578=78.0 \%$

The same procedure is followed for other test specimens to find joint efficiency as summarized in Table 5.7.

Table 5.7 Comparison of joint efficiency

\begin{tabular}{|c|c|c|c|c|c|c|}
\hline Specimen & \multirow{2}{*}{$\begin{array}{c}\text { Joint } \\
\text { type }\end{array}$} & \multirow{2}{*}{$\begin{array}{c}\text { Measured } \\
\text { performace }\end{array}$} & \multicolumn{2}{|c|}{$\begin{array}{c}\text { Control } \\
\text { performance }\end{array}$} & \multicolumn{2}{c|}{$\begin{array}{c}\text { (\%) Joint efficiency } \\
\text { based on }\end{array}$} \\
\cline { 4 - 7 } & & & Exp. & FE. & Exp. & FE. \\
\hline $\mathrm{CB}_{\mathrm{R}}$ & rivet & 0.451 & 0.566 & 0.578 & 79.7 & 78.0 \\
\hline $\mathrm{CB}_{\mathrm{G}}$ & glue & 0.481 & 0.553 & 0.578 & 86.9 & 83.2 \\
\hline $\mathrm{CB}_{\mathrm{RG}}$ & rivet-glue & 0.514 & 0.560 & 0.578 & 91.7 & 88.9 \\
\hline
\end{tabular}

Note: Specimens are not taken at failure. 


\subsubsection{Discussion of Cantilever Experimental Results}

From the cantilever beam test data, in-plane shear (xy) modulus of the specimen $\mathrm{CB}_{\mathrm{RG}}$ is higher than that of other specimens in specimens, i.e., with and without joints. Percent difference of in-plane shear (xy) modulus between experimental and finite element results varies from $2.08 \%$ to $4.32 \%$ for specimens without joints, and from $11.07 \%$ to $21.9 \%$ for specimens with joints. In addition, percent difference of in-plane shear (xy) modulus between the experimental and torsion result is from $4.75 \%$ to $7.51 \%$ for specimens without joints and from $3.12 \%$ to $12.73 \%$ for specimens with joints. In-plane shear modulus of specimens CB provided by the cantilever beam test is slightly higher than that under torsion test without joints. For specimens with joints, in-plane shear (xy) modulus of test specimens is found to depend on the types of connections for each specimen. In this study, maximum inplane shear (xy) modulus of specimens with joints is a response of the test specimens with rivet-glue connection. Moreover, joint efficiency based on experimental and analytical control data varied from $79.7 \%$ to $91.7 \%$, and from $78.0 \%$ to $88.9 \%$, respectively.

\subsubsection{Racking Shear}

Equivalent in-plane shear (xy) modulus based on deflection data is evaluated at each load level using Equation (5.11). Induced load versus vertical deflections at specific positions are shown in Figure 5.11. These data are used to determine average in-plane shear (xy) strain of the FRP deck panel in Table 5.8. The relation of equivalent in-plane shear modulus and applied load of each load level is illustrated in Figure 5.12. The fluctuation of in-plane shear modulus results shows the possibility that the specimen is overcoming some friction and building up shear modulus before falling down again. Also, slipping of the test specimen at the support may have been one of several causes leading to the fluctuation of results. In addition, equivalent in-plane shear (xy) modulus of other experimental and analytical results 
is used to compare with the equivalent in plane shear modulus of this study. From test data shown in Table 5.8, equivalent in-plane shear modulus for each load level varied between $0.256 \times 10^{6}$ and $0.384 \times 10^{6} \mathrm{psi}$ for load range from 1.0 to $4.0 \mathrm{kips}$. Therefore, average equivalent in-plane shear (xy) modulus during the above mentioned load range is defined as equivalent in-plane shear (xy) modulus of an FRP deck panel. Thus, average equivalent inplane shear (xy) modulus is found to be $0.298 \times 10^{6} \mathrm{psi}$.

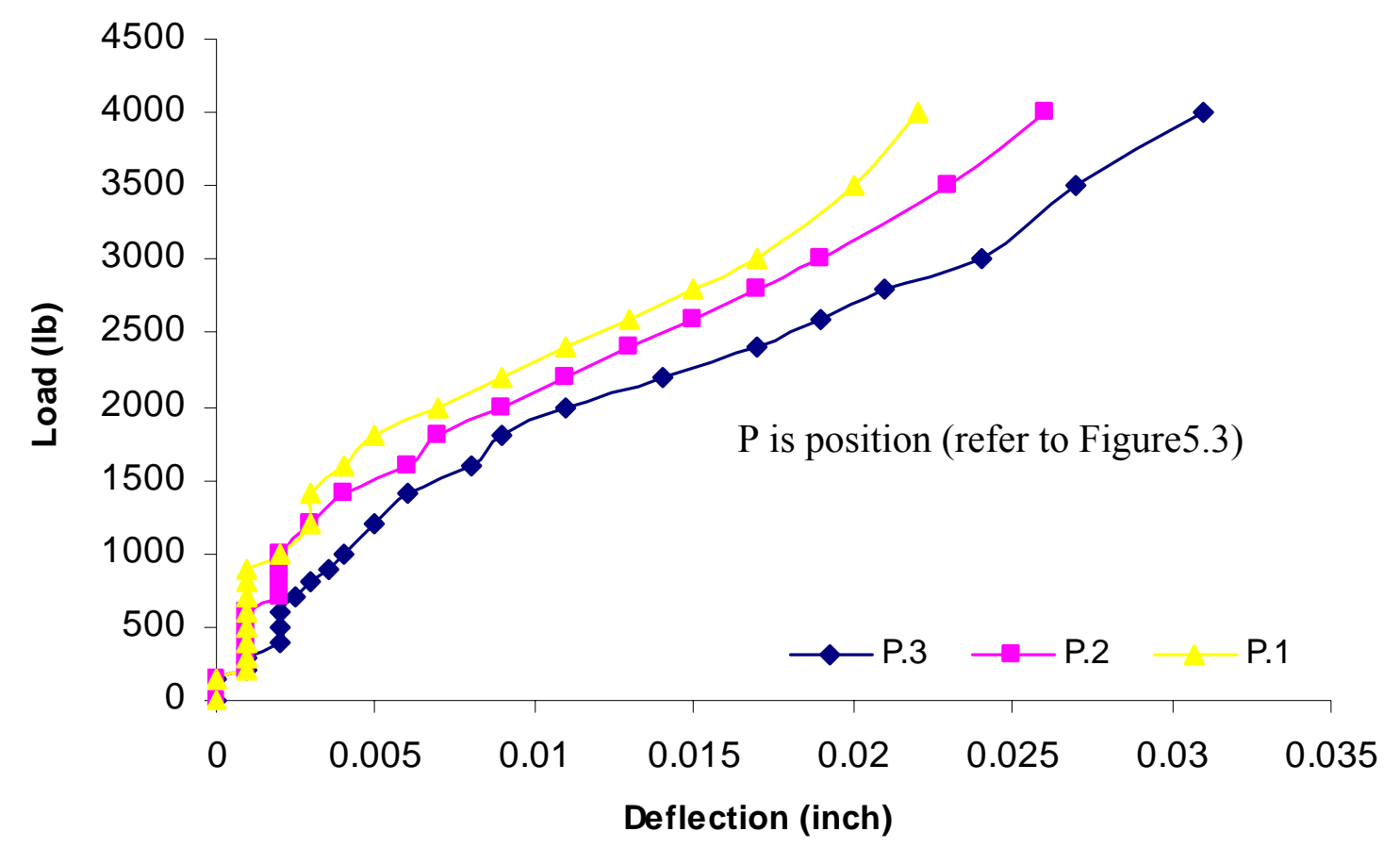

Figure 5.11 Deflection of vertical direction at specific positions under racking shear 


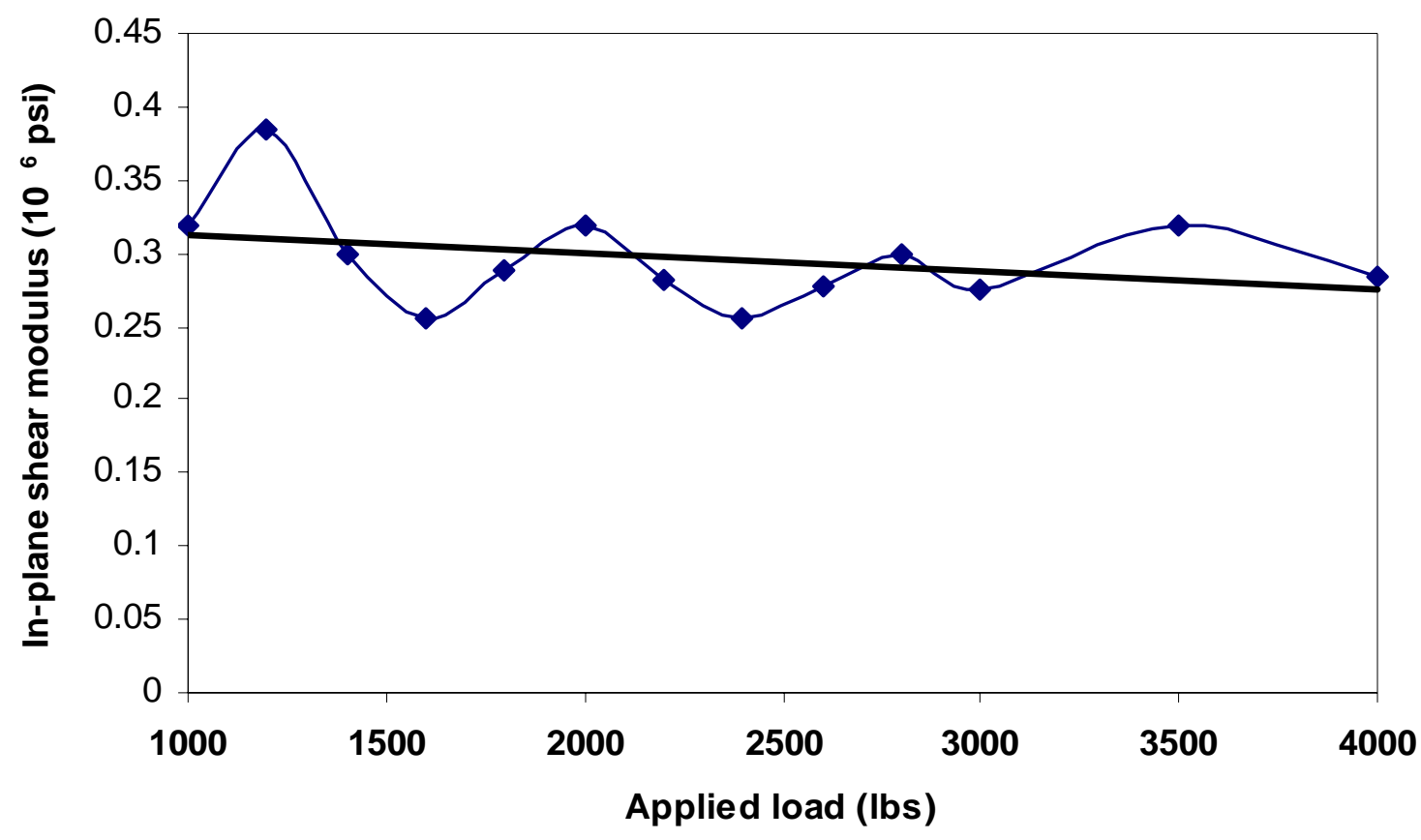

Figure 5.12 Relation of in-plane shear modulus and applied load under racking shear

Table 5.8 In-plane shear (xy) modulus based on deflection data under racking shear

\begin{tabular}{|c|c|c|c|c|c|c|c|}
\hline \multirow[t]{2}{*}{$\begin{array}{l}\text { Load } \\
\text { (kip) }\end{array}$} & \multicolumn{3}{|c|}{$\begin{array}{c}\text { Deflection } \\
\text { (position) }\end{array}$} & \multirow{2}{*}{$\begin{array}{c}\text { Net } \\
\text { Deflection }\end{array}$} & \multirow{2}{*}{$\begin{array}{c}\gamma_{i} \\
\times 10^{-4} \\
(\text { in/in) }\end{array}$} & \multirow[t]{2}{*}{$\begin{array}{c}\tau_{i} \\
(\mathbf{k s i})\end{array}$} & \multirow{2}{*}{$\begin{array}{c}\left(G_{x y}\right)_{i} \\
\times 10^{6} \\
(p s i)\end{array}$} \\
\hline & $\begin{array}{c}\text { P.3 } \\
\text { (inch) }\end{array}$ & $\begin{array}{c}\text { P.2 } \\
\text { (inch) }\end{array}$ & $\begin{array}{c}\text { P.1 } \\
\text { (inch) }\end{array}$ & & & & \\
\hline 1.0 & 0.004 & 0.002 & 0.002 & 0.002 & 0.625 & 13.33 & 0.320 \\
\hline 1.2 & 0.005 & 0.003 & 0.003 & 0.002 & 0.625 & 16.00 & 0.384 \\
\hline 1.4 & 0.006 & 0.004 & 0.003 & 0.003 & 0.938 & 18.67 & 0.299 \\
\hline 1.6 & 0.008 & 0.006 & 0.004 & 0.004 & 1.250 & 21.3 & $0.256^{*}$ \\
\hline 1.8 & 0.009 & 0.007 & 0.005 & 0.004 & 1.250 & 24.0 & 0.288 \\
\hline 2.0 & 0.011 & 0.009 & 0.007 & 0.004 & 1.250 & 26.7 & 0.320 \\
\hline 2.2 & 0.014 & 0.011 & 0.009 & 0.005 & 1.563 & 29.3 & 0.282 \\
\hline 2.4 & 0.017 & 0.013 & 0.011 & 0.006 & 1.875 & 32.0 & $0.256^{*}$ \\
\hline 2.6 & 0.019 & 0.015 & 0.013 & 0.006 & 1.875 & 34.7 & 0.277 \\
\hline 2.8 & 0.021 & 0.017 & 0.015 & 0.006 & 1.875 & 37.3 & 0.299 \\
\hline 3.0 & 0.024 & 0.019 & 0.017 & 0.007 & 2.19 & 40.0 & 0.274 \\
\hline 3.5 & 0.027 & 0.023 & 0.02 & 0.007 & 2.19 & 46.7 & 0.320 \\
\hline 4.0 & 0.031 & 0.026 & 0.022 & 0.009 & 2.81 & 53.3 & 0.284 \\
\hline Avg. & & & & & & & 0.304 \\
\hline
\end{tabular}

Note: *In-plane shear modulus is not accounted for the average value. 


\subsubsection{Results by Finite Element Method}

The orthotropic shell element provided by ANSYS is used to simulate the physical behavior of the FRP deck panel. For the boundary conditions of the test specimen, all displacements along the vertical direction of the specimen edges are prevented, except the displacement in y direction with respect to global model system (refer to Figure 5.12). In addition, $62.5 \mathrm{lbs} / \mathrm{in}^{2}$ of uniform load is applied over $4 \times 12$ inch area of top specimen surface from the left end. However, horizontal joints along the specimen width are not modeled into this finite element model. Hence it can lead to a stiff physical behavior from the model data. Elastic modulus of the test specimen obtained from earlier test data (Deepthi 2004) is used while shear modulus is provided by using average experimental results of coupons (Section 4.6.1). Summary of the finite element model is provided in Table 5.9. To calculate in-plane shear (xy) modulus from the finite element results, the same procedure used for the experimental results based on the deflection data in Section 5.2.3, is utilized. The net deflection is taken as the resultant of the deflection difference between two positions at the bottom surface of the test specimen (refer to Figure 5.3). The test specimen model and displacement of y direction are also given in Figures 5.13 and 5.14, respectively.

Table 5.9 Summary of finite element models under cantilever beam test

\begin{tabular}{|c|c|c|c|c|c|}
\hline \multirow{2}{*}{$\begin{array}{c}\text { Analysis } \\
\text { type }\end{array}$} & \multirow{2}{*}{$\begin{array}{c}\text { Test } \\
\text { span } \\
\text { (in) }\end{array}$} & \multicolumn{2}{|c|}{ Number of } & \multicolumn{2}{|c|}{ Conditions } \\
\cline { 3 - 6 } & 40 & 11668 & 10662 & Uniform load & Only (y) displacement of \\
over $4 \times 12$ inch & load & nodes & left end is available. \\
\hline Static & 40 & & & &
\end{tabular}

From the finite element results, the bottom surface displacements in y direction at node $3482(x=60, y=2, z=0)$ and $3807(x=20, y=2, z=0)$ are found to be 0.01091 and 0.00569 inches, respectively. The test specimen model, loaded to $3000 \mathrm{lbs}$ with a span between nodes 3482 and 3807 is 40 inches long. 
The equivalent in-plane shear (xy) modulus from the finite element data is computed as: Total cross sectional area $(A)=A_{\text {web }}+A_{\text {flange }}=(0.375 \times 3.25 \times 12)+(0.43 \times 66 \times 2)=71$ in $^{2}$ It should be noted that the total cross sectional area (A) is obtained under the assumption that FRP deck is rigid and no distortion with the deck.

Maximum shear stress on FRP deck panel $\left(\tau_{\max }\right)=1.5(3000 / 71)=63.4 \mathrm{psi}$

Using Equation (5.9) and finite element data, in-plane shear strain is:

$\gamma=\operatorname{Tan}^{-1}\left(\frac{\delta_{3}-\delta_{1}}{d}\right)=\operatorname{Tan}^{-1}\left(\frac{0.01090-0.00569}{40}\right)=1.302 \times 10^{-4} \mathrm{in} / \mathrm{in}$

Equivalent in-plane shear (xy) modulus is found to be $0.487 \times 10^{6} \mathrm{psi}$, and it is compared with the experimental data in Section 5.3.3.2. Comparison of equivalent in-plane shear (xy) modulus from experimental data and finite element results are discussed in Section 5.3.3.2. 


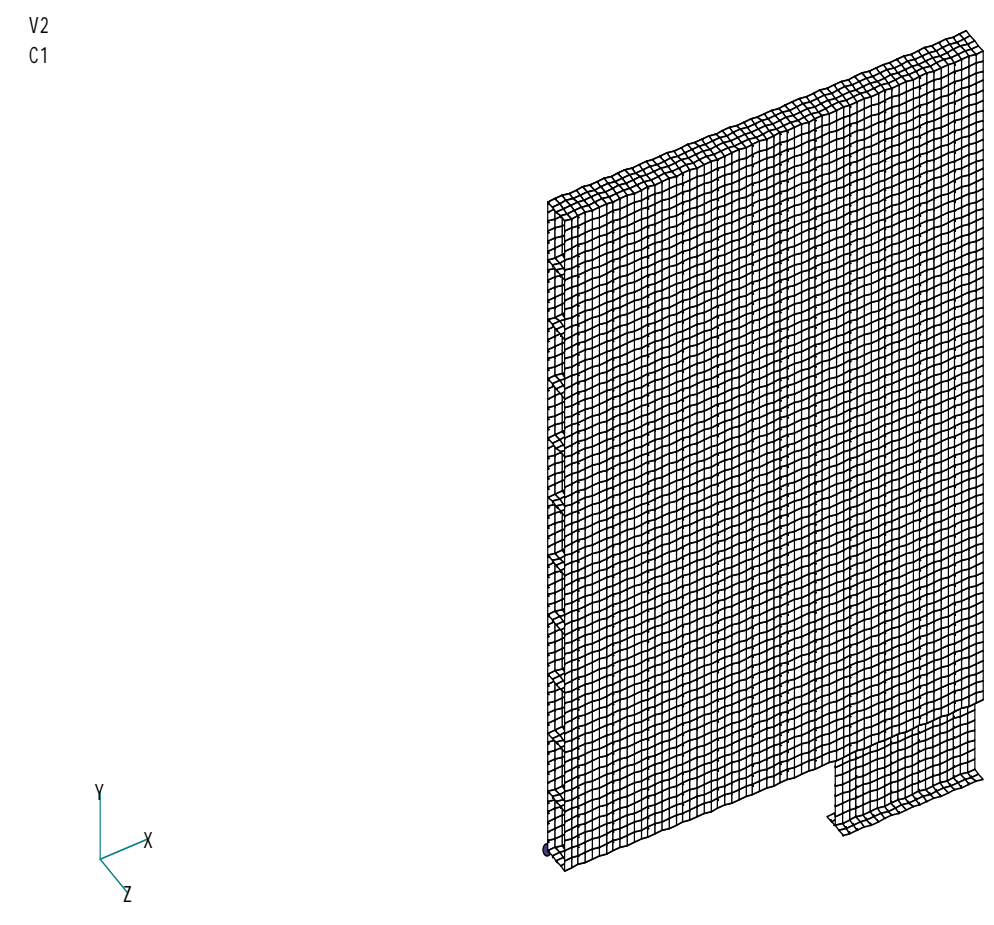

Figure 5.13 Finite element model of racking shear test

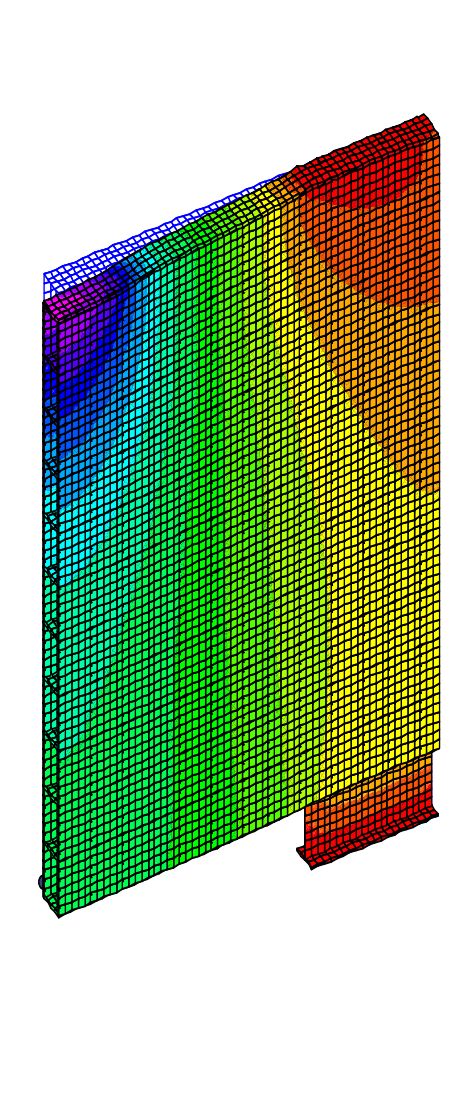

Figure 5.14 Displacement of y direction* under racking shear test

Note: * refer to coordinate given in the figure 


\subsubsection{Experimental versus analytical of in-plane shear $(x y)$ modulus}

The experimental data of FRP components under torsion are compared with the experimental result of FRP decks under racking shear. The percent difference of equivalent in-plane shear modulus from different test methods is determined and given in Table 5.10. Equivalent in-plane shear (xy) modulus from the racking shear test is smaller than that from torsion test MP4 ${ }_{144 \mathrm{~T}}: 2$ and finite element method by about $25.7 \%$ and $37.6 \%$, respectively. Since, the test specimen RS is loaded in the weak direction that provides lower stiffness and also joint affects the stiffness, high percent of difference in modulus is anticipated with test data. Thus, equivalent in-plane shear modulus under the racking shear obviously presents more conservative values than that under torsion test. In addition, slipping during loading at supports can lead to lower stiffness of test specimens.

\subsection{Conclusion}

- Average in-plane strengths of longitudinal and transverse coupon specimens under Vnotched beam testing are 14.01 and 11.50 kips, respectively, which translates to an average equivalent in-plane shear strengths of 0.625 and $0.608 \mathrm{ksi}$, respectively. (Section 5.3.1)

- The moduli obtained from the V-notched beam tests are slightly higher than those of torsion due to size effect of test specimens and test procedure. It is found that torsion test specimens fail under layer delamiantion whereas, cracking between notches are observed and layer delamination on specimens is not found for the V-notched beam test. This may be attributed to size effect. (Section 5.3.1 and 5.3.2)

- In-plane shear modulus provided by the V-notched beam test is possibly less conservative where used in analysis and design of composite members. Normally, it is 
not designed for fabric laminates (only for $0^{\circ}$ and $90^{\circ}$ orientation). In addition, more bending and local punching of $\mathrm{V}$-notched specimens can dominate because of improper set-up on shear apparatus.

- Maximum in-plane shear modulus and joint efficiency of specimens with joints depend on the type of joint mechanisms and are found on the rivet-glue type joining system.

- In-plane shear (xy) modulus of specimen $\mathrm{CB}$ is slightly higher than that of torsion specimens mainly due to test methods. In addition, results from this cantilever beam test can be reasonably used in primary analysis and design as can the results from the torsion test. However, in-plane shear modulus from the cantilever beam test is often very low and unreasonable due to the splitting of test specimens during testing and insufficient fixity at the boundary. (Section 5.3.2.3)

- From the measured performance of the control system, joint efficiency of test specimens under the cantilever beam test is found to be around $80 \%$. (Section 5.3.2.4)

- Average equivalent in-plane shear (xy) modulus of the FRP deck under racking shear is found to be $0.304 \times 10^{6} \mathrm{psi}$. It seems that this value is quite low and overly conservative due to low stiffness in loading direction (weak direction) and joint effect. (Section $5.3 .3)$ 


\section{CHAPTER 6}

\section{OUT-OF-PLANE SHEAR STRENGTH AND STIFFNESS}

\subsection{Introduction}

Deflections of structural members made from FRP composites are significantly influenced by the bending induced shear, especially for low beam span to depth ratio $(\leq 5$ to 8). FRP composite structural members normally have low out-of-plane shear ( $\approx 10$ to $15 \mathrm{ksi})$ to failure, and low shear modulus $\left(\approx 0.5 \times 10^{6} \mathrm{psi}\right)$ especially when compared with bending properties. Therefore, it is important to evaluate out-of-plane shear strength for efficient design and for avoiding catastrophic shear failure in a structural system. In addition, FRP composite material properties, especially orthotropy, can lead to lateral torsional buckling in beams and can lead to premature failures. Therefore, torsional buckling of FRP members has to be avoided through proper evaluation and accounting of material properties and member in design.

Euler-Bernoulli beam theory assumes that straight lines of cross sections perpendicular to the beam neutral axis before deformation remain perpendicular to the tangent line of the beam neutral axis. This beam theory generally yields excellent results for longer span to depth ratios (i.e., $>8$ ). However, the bending behavior of a beam with short span length is different from the bending behavior of a beam predicted by using the Euler Bernoulli beam theory because of the influence of warpage of plane sections due to transverse shear effect and anisotropic cross sectional properties. In addition, the plane section of a beam may not remain plane after bending which is especially true in anisotropic beams. Deflection of a composite beam with a short span has the influence of two main parts: 
1) simple beam bending and 2) transverse shear force. Therefore, out-of-plane shear modulus of a composite material can be evaluated with a high degree of accuracy by decoupling bending and shear deformation effects from deflection results. This approach is particularly accurate for beams with short span length, i.e., span to depth ratio $\leq 5$, and subjected to bending loads.

The main objective of this chapter is to present the experimental results for FRP decks under out-of-plane loads with shear dominance. The test data are presented for both longitudinal and transverse directional cases. Various FRP composite shapes are tested in this study. In addition, discussion of shear leakage across joints and joint efficiency are presented.

\subsection{Experimental Program}

Out-of-plane shear strength and stiffness of an FRP composite deck are experimentally evaluated and presented in this section. Firstly, out-of-plane shear strengths in both $\mathrm{xz}$ and $\mathrm{yz}$ directions are evaluated for coupons, in addition to evaluating single and multi-cell FRP composite decks. Out-of-plane shear moduli in xz and yz directions (refer to Figure 6.1) are carried out using simple beam bending tests. The experimental results are validated and compared with analytical results which are discussed later. Finally, the joint efficiency of test specimens including longitudinal and transverse joints is valuated in Section 6.5 .

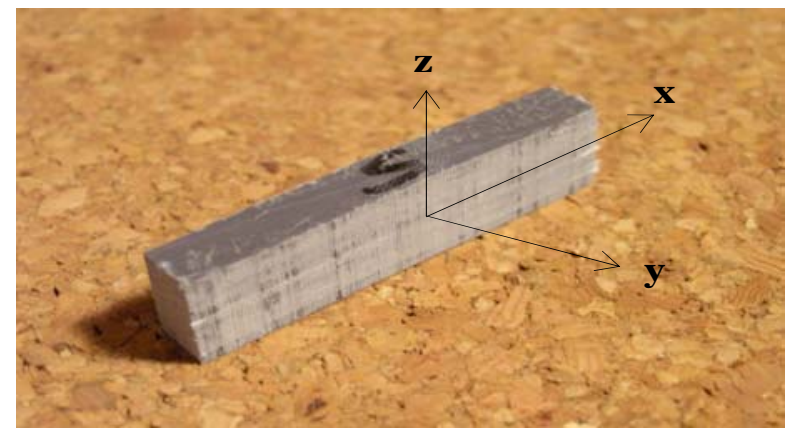

(a) specimen (xz direction)

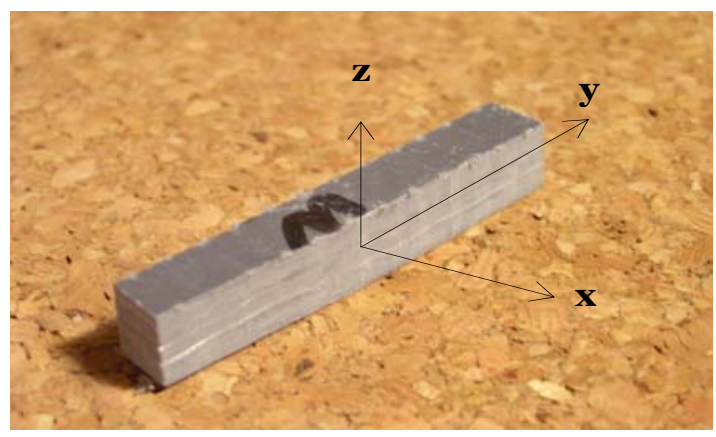

(b) specimen (yz direction)

Figure 6.1 Short beam shear specimens 


\subsubsection{Out-of-Plane Shear Strength}

Out-of-plane shear strength is one of most important properties for analysis and design of FRP composite structures, particularly under transverse loads. Two standard test procedures provided by the American Society for Testing and Materials (ASTM) are: 1) short beam shear test (D2344), and 2) double-notched shear test (D3646-99). However, only the short beam shear test is conducted to evaluate out-of-plane shear strength in $\mathrm{xz}$ and $\mathrm{yz}$ directions at coupon level. Moreover, the short beam shear test is also conducted to evaluate out-of-plane (xz) shear strength at component as well as coupon level. In addition, description of specimens and test set-ups are given in Section 3.7 including equipment, number of specimens, structural shapes, specimen level, specimen preparation and specimen dimensions.

The maximum out-of-plane shear strength of a rectangular cross section based on the simple beam theory is:

$$
\tau_{S}=0.75 \frac{P_{u l t}}{A_{W}}
$$

where, $P_{u l t}$ is a failure load and $A_{w}$ is the web area of a specimen.

\subsubsection{Out-of-Plane Shear Modulus}

Out-of-plane shear modulus can be experimentally evaluated by using deflection and strain data of beam bending tests. Three and four point beam bending tests are conducted to decouple bending effects from shear with specific specimen details given in Section 3.8.

To decouple bending from out-of-plane shear, back-calculation methods are used. The back-calculation method based on deflection and strain-deflection data is presented to illustrate the method. Moreover, results from different back-calculation methods are compared with each other to establish degrees of accuracy of calculation procedures. From 
the back calculation method of experimental deflection data, two approaches are studied: 1) slope (Sotiropoulos 1995) and 2) load step (Zureick 1994). The first approach deals with the experimental load-deflection curves of structural members, especially their slopes. In the second approach, bending and out-of-plane shear stiffness are found in every applied load step and finally, average of those values is used to study experimental bending and out-ofplane shear rigidity. In addition, the back calculation method based on experimental straindeflection results is also used for comparing results with other methods. Coupling between bending and out-of-plane shear rigidity are separated by using bending rigidity obtained from strain data while out-of-plane shear rigidity is calculated by substituting the bending rigidity and experimental deflection data into the deflection equation (refer to Equation (6.2)) which is a function of beam bending. The following section will present additional details of the back-calculation methods.

\subsubsection{Back Calculation Method Based on Experimental Deflections}

To decouple deflections under pure bending from shear, measured deflections under three and four point bending are necessary. Modified Timoshenko beam equations (GangaRao, 1993 and Zureick, 1994) are utilized for this purpose. The bending rigidity of FRP composite beams is obtained from deflection or strain data under four point bending testing. To obtain out-of-plane shear rigidity, bending rigidity is substituted into deflection equations of FRP composite beams under three point bending.

For specimens under three point bending, experimental deflection at mid span $\left(\delta_{m 3}\right)$ being a function of load and rigidity is given as:

$$
\left(\delta_{m 3}\right)=\frac{P L^{3}}{48 D_{b}}+\frac{P L}{4 \kappa D_{s}}
$$


where, $D_{b}$ is bending rigidity $(E I), D_{s}$ is shear rigidity $(\kappa A G), \kappa$ is shear coefficient, $P$ is applied load at midspan and $L$ is the span of the specimen.

If only web shear rigidity is accounted, an approximation of shear coefficient factor is equal to unity. Verification of shear coefficient (Nagaraj, 1994) is found to be close to unity.

$$
\left(\delta_{m 3}\right)=\frac{P L^{3}}{48(E I)_{b}}+\frac{P L}{4(A G)_{W}}
$$

For specimens under four point bending, experimental deflections at mid span and loading distance $(a)$ from supports are:

Deflection at mid span $\left(\delta_{\mathrm{m} 4}\right)$ :

$$
\left(\delta_{m 4}\right)=\frac{P a}{48(E I)_{b}}\left(3 L^{2}-4 a^{2}\right)+(\delta)_{\text {shear }}
$$

Deflection at distance $(a)$ from each support $\left(\delta_{a 4}\right)$ :

$$
\left(\delta_{a 4}\right)=\frac{P a^{2}}{12(E I)_{b}}(3 L-4 a)+(\delta)_{\text {shear }}
$$

where $(\delta)_{\text {shear }}$ is deflection due to shear effect

The distance between the two point loads is not under the influence of shear in a four point bending test. The decoupling of bending and shear is done by subtracting deflection at mid-span, from that at distance $(a)$. Thus, bending rigidity $(E I)_{b}$ is evaluated by substituting measured deflections at mid-span and also at distance (a) from support into Equation (6.5). Bending rigidity is given as:

$$
(E I)_{b}=\frac{P a}{48\left(\delta_{m 4}-\delta_{a 4}\right)}\left(3 L^{2}-12 L a+12 a^{2}\right)
$$


where, $P /\left(\delta_{m 4}-\delta_{a 4}\right)$ is the slope relation between net deflection $\left(\delta_{m 4}-\delta_{a 4}\right)$ and applied load under four point bending.

To evaluate shear rigidity $G A$, bending rigidity $(E I)_{b}$ obtained from Equation (6.6) is substituted into the deflection equation under three point bending given in Equation (6.3) as:

$$
\left(\delta_{m 3}\right)=\frac{P L^{3}}{48\left(\frac{P a}{48\left(\delta_{m 4}-\delta_{a 4}\right)}\left(3 L^{2}-12 L a+12 a^{2}\right)\right)}+\frac{P L}{4(A G)_{w}}
$$

For load step approach, Equation (6.7) is directly used to evaluate out-of-plane shear rigidity by substituting deflection data corresponding to the applied load for each load step.

For slope approach, $\left(P / \delta_{m 3}\right)$ is the slope of the relation between deflection $\delta_{m 3}$ and applied load $P$ under three point bending. Therefore, out-of-plane shear rigidity can be presented in terms of slope and span length as:

$$
\begin{gathered}
\frac{P}{\left(\delta_{m 4}-\delta_{a 4}\right)}=\alpha_{4} \text { and } \frac{P}{\left(\delta_{m 3}\right)_{\exp }}=\alpha_{3} \\
(A G)_{W}=\frac{\alpha_{3} L}{4}\left[\frac{\alpha_{4} a\left(3 L^{2}-12 L a+12 a^{2}\right)}{\alpha_{4} a\left(3 L^{2}-12 L a+12 a^{2}\right)-\alpha_{3} L^{3}}\right]
\end{gathered}
$$

\subsubsection{Back Calculation Method Based on Experimental Strain and Deflections}

Three and four point bending tests provide longitudinal strain data at the top and bottom surface under constant bending moment. The four point bending test data are used to evaluate bending rigidity. Bending rigidity under four point bending is:

$$
E I=\frac{M z}{\varepsilon}
$$




$$
E I=\frac{P a z}{2 \varepsilon}
$$

where, $M$ is a constant bending moment obtained from four point bending test data, $z$ is a distance from the neutral axis to the top or bottom of a cross-section, $P$ is the total applied load on a beam, $a$ is the distance along the beam span between support and applied load under four point bending and $\varepsilon$ is normal strain in a beam.

To evaluate out-of-plane shear rigidity $G A$, bending rigidity $(E I)_{b}$ obtained from Equation (6.11) is substituted into deflection equation of a beam under three point bending in Equation (6.3). Thus, out-of-plane rigidity is given as:

$$
\begin{aligned}
& G A=\frac{P L}{4\left(\delta_{m 3}-\delta_{m 4}\right)} \\
& \delta_{m 4}=\frac{P L^{3}}{48(E I)}
\end{aligned}
$$

Where, $\delta_{m 4}$ is deflection at mid span under three-point bending and $L$ is the test span. The following section will present experimental results of FRP composite deck specimens under three and four point loads. The experimental results of bending and out-of-plane shear rigidity with respect to global deck axis are presented below. 


\subsection{Evaluation of Experimental Results}

Out-of-plane shear strength and modulus are evaluated and reported in this section. Out-of-plane shear strength of FRP deck specimens is presented in Section 6.3.1, while outof-plane shear modulus analysis is given in Section 6.3.2.

\subsubsection{Evaluation of Out-of-Plane Shear Strength}

In this section, out-of-plane shear strength of coupons (short beam) and components are evaluated (xz and yz direction). Maximum applied load, shear strength and failure mode are reported for all test specimens. Short beam shear test data are used to experimentally evaluate out-of-plane shear strength of composite coupon specimens. Longitudinal and transverse coupon tests are conducted under three point bending to obtain out-of-plane shear (yz and xz) strength. To calculate shear strength, maximum failure load and the web area of a specimen are substituted into shear stress relation in Equation (6.1). Thus, shear strengths of all coupons are determined and presented in Tables 6.1 and 6.2.

Table 6.1 Ultimate shear strength of coupon specimens (ProDeck4)

\begin{tabular}{|c|c|c|c|c|c|c|c|c|}
\hline Specimen & h/L & $\begin{array}{c}\mathrm{L} \\
\text { (in) }\end{array}$ & $\begin{array}{c}\text { A } \\
\left(\text { in }^{2}\right)\end{array}$ & $\begin{array}{c}\text { Maximum } \\
\text { load } \\
\text { (lbs) }\end{array}$ & $\begin{array}{c}\text { Shear } \\
\text { stress } \\
\text { (ksi) }\end{array}$ & $\begin{array}{c}\text { Average } \\
\text { shear } \\
\text { stress } \\
\text { (failure) } \\
\text { (ksi) }\end{array}$ & $\begin{array}{l}\text { Standard } \\
\text { deviation }\end{array}$ & $\begin{array}{c}\text { Mode of } \\
\text { failure }\end{array}$ \\
\hline $\mathrm{SCP}_{\mathrm{WT}}: 1$ & 4 & 2 & 0.09375 & 398 & 3.18 & \multirow{6}{*}{2.73} & \multirow{6}{*}{0.271} & \multirow{6}{*}{ delamination } \\
\hline $\mathrm{SCP}_{\mathrm{WT}}: 2$ & 4 & 2 & 0.09375 & 310 & 2.48 & & & \\
\hline $\mathrm{SCP}_{\mathrm{WT}}: 3$ & 4 & 2 & 0.09375 & 350 & 2.80 & & & \\
\hline $\mathrm{SCP}_{\mathrm{WT}}: 4$ & 4 & 2 & 0.09375 & 323 & 2.58 & & & \\
\hline $\mathrm{SCP}_{\mathrm{WT}}: 5$ & 4 & 2 & 0.09375 & 310 & 2.48 & & & \\
\hline $\mathrm{SCP}_{\mathrm{WT}}: 6$ & 4 & 2 & 0.09375 & 354 & 2.83 & & & \\
\hline $\mathrm{SCP}_{\mathrm{WL}}: 1$ & 4 & 2 & 0.09375 & 491 & 3.93 & \multirow{5}{*}{4.10} & \multirow{5}{*}{0.323} & \multirow{5}{*}{ delamination } \\
\hline $\mathrm{SCP} 4_{\mathrm{WL}}: 2$ & 4 & 2 & 0.09375 & 456 & 3.65 & & & \\
\hline $\mathrm{SCP} 4_{\mathrm{WL}}: 3$ & 4 & 2 & 0.09375 & 503 & 4.02 & & & \\
\hline $\mathrm{SCP}_{\mathrm{WL}}: 4$ & 4 & 2 & 0.09375 & 570 & 4.56 & & & \\
\hline $\mathrm{SCP}_{\mathrm{WL}}: 5$ & 4 & 2 & 0.09375 & 545 & 4.36 & & & \\
\hline
\end{tabular}




\begin{tabular}{|c|c|c|c|c|c|c|c|c|}
\hline $\mathrm{SCP}_{\mathrm{WL}}: 6$ & 4 & 2 & 0.09375 & 508 & 4.06 & & & \\
\hline $\mathrm{SCP} 4_{\mathrm{FT}}: 1$ & 4 & 2 & 0.1075 & 520 & 3.63 & \multirow{6}{*}{3.06} & \multirow{6}{*}{0.395} & \multirow{6}{*}{ delamination } \\
\hline $\mathrm{SCP} 4_{\mathrm{FT}}: 2$ & 4 & 2 & 0.1075 & 463 & 3.23 & & & \\
\hline $\mathrm{SCP}_{\mathrm{FT}}: 3$ & 4 & 2 & 0.1075 & 380 & 2.65 & & & \\
\hline $\mathrm{SCP}_{\mathrm{FT}}: 4$ & 4 & 2 & 0.1075 & 442 & 3.08 & & & \\
\hline $\mathrm{SCP}_{\mathrm{FT}}: 5$ & 4 & 2 & 0.1075 & 368 & 2.57 & & & \\
\hline $\mathrm{SCP}_{\mathrm{FT}}: 6$ & 4 & 2 & 0.1075 & 457 & 3.19 & & & \\
\hline $\mathrm{SCP}_{\mathrm{FL}}: 1$ & 4 & 2 & 0.1075 & 590 & 4.12 & \multirow{6}{*}{4.21} & \multirow{6}{*}{0.288} & \multirow{6}{*}{ delamination } \\
\hline $\mathrm{SCP} 4_{\mathrm{FL}}: 2$ & 4 & 2 & 0.1075 & 608 & 4.24 & & & \\
\hline $\mathrm{SCP} 4_{\mathrm{FL}}: 3$ & 4 & 2 & 0.1075 & 608 & 4.24 & & & \\
\hline $\mathrm{SCP} 4_{\mathrm{FL}}: 4$ & 4 & 2 & 0.1075 & 580 & 4.05 & & & \\
\hline $\mathrm{SCP} 4_{\mathrm{FL}}: 5$ & 4 & 2 & 0.1075 & 677 & 4.72 & & & \\
\hline $\mathrm{SCP}_{\mathrm{FL}}: 6$ & 4 & 2 & 0.1075 & 555 & 3.87 & & & \\
\hline
\end{tabular}

Note: $h / L$ is the ratio of height to length of the test span, $L$ is the length of the test span. $A$ is the area of specimen cross section.

Table 6.2 Ultimate shear strength of coupon specimens (ProDeck8)

\begin{tabular}{|c|c|c|c|c|c|c|c|c|}
\hline Specimen & $\mathbf{h} / \mathrm{L}$ & $\begin{array}{l}\text { L } \\
\text { (in) }\end{array}$ & $\begin{array}{c}\text { A } \\
\left(\text { in }^{2}\right)\end{array}$ & $\begin{array}{l}\text { Maximum } \\
\text { load } \\
\text { (lbs) }\end{array}$ & $\begin{array}{c}\text { Shear } \\
\text { stress } \\
\text { (ksi) }\end{array}$ & $\begin{array}{c}\text { Average } \\
\text { shear } \\
\text { stress } \\
\text { (failure) } \\
\text { (ksi }\end{array}$ & $\begin{array}{l}\text { Standard } \\
\text { deviation }\end{array}$ & $\begin{array}{c}\text { Mode of } \\
\text { failure }\end{array}$ \\
\hline SCP8 $8_{\mathrm{FT}}: 1$ & 4 & 2 & 0.1188 & 466 & 2.94 & \multirow{6}{*}{3.07} & \multirow{6}{*}{0.254} & \multirow{6}{*}{ delamination } \\
\hline $\mathrm{SCP} 8_{\mathrm{FT}}: 2$ & 4 & 2 & 0.1188 & 542 & 3.42 & & & \\
\hline $\mathrm{SCP}_{\mathrm{FT}}: 3$ & 4 & 2 & 0.1188 & 462 & 2.92 & & & \\
\hline $\mathrm{SCP}_{\mathrm{FT}}: 4$ & 4 & 2 & 0.1188 & 459 & 2.90 & & & \\
\hline $\mathrm{SCP} 8_{\mathrm{FT}}: 5$ & 4 & 2 & 0.1188 & 454 & 2.87 & & & \\
\hline SCP8 $8_{\mathrm{FT}}: 6$ & 4 & 2 & 0.1188 & 533 & 3.36 & & & \\
\hline $\mathrm{SCP}_{\mathrm{FL}}: 1$ & 4 & 2 & 0.1188 & 775 & 4.89 & \multirow{6}{*}{4.64} & \multirow{6}{*}{0.298} & \multirow{6}{*}{ delamination } \\
\hline $\mathrm{SCP}_{\mathrm{FL}}: 2$ & 4 & 2 & 0.1188 & 767 & 4.84 & & & \\
\hline $\mathrm{SCP}_{\mathrm{FL}}: 3$ & 4 & 2 & 0.1188 & 780 & 4.92 & & & \\
\hline $\mathrm{SCP}_{\mathrm{FL}}: 4$ & 4 & 2 & 0.1188 & 669 & 4.22 & & & \\
\hline $\mathrm{SCP} 8_{\mathrm{FL}}: 5$ & 4 & 2 & 0.1188 & 730 & 4.61 & & & \\
\hline $\mathrm{SCP}_{\mathrm{FL}}: 6$ & 4 & 2 & 0.1188 & 689 & 4.35 & & & \\
\hline
\end{tabular}

Note: $h / L$ is the ratio of height to length of the test span, $L$ is the length of the test span. $A$ is the area of specimen cross section. 
It should be noted that the average shear strength of coupons under short beam shear tests is low due to several factors such as: bond failure, resin cracking, stress concentration and edge effect. In particular, coupons are prepared by cutting them from components resulting in fiber discontinuity and matrix micro-cracks around the cut edges of coupons which led to fiber delamination at low magnitude of applied load.

Only out-of-plane (xz) shear strength of components is evaluated in this study due to the limitation of transverse specimen dimensions. Longitudinal single and multi thin-walled beams are used for testing at component level. Shear stress of components can be determined in the same manner as coupons. Shear strength (xz) of components is easily evaluated by substituting maximum failure load into Equation (6.1). The shear strength test data of all components are presented in Table 6.3.

Table 6.3 Shear strength of component specimens

\begin{tabular}{|c|c|c|c|c|c|c|c|}
\hline Specimen & $\begin{array}{c}\text { W } \\
\text { (in) }\end{array}$ & $\begin{array}{c}\text { L } \\
\text { (in) }\end{array}$ & $\begin{array}{c}\text { h } \\
\text { (in) }\end{array}$ & $\begin{array}{c}\text { L/h } \\
\boldsymbol{A}_{w}\end{array}$ & $\begin{array}{c}\text { Maximum } \\
\left.\text { (in }^{2}\right)\end{array}$ & $\begin{array}{c}\text { Shear stress } \\
\text { loips) }\end{array}$ & (ksi) \\
\hline $\mathrm{SBP}_{\mathrm{S}}$ & 6 & 16 & 4 & 4 & 2.35 & 24.1 & 7.71 \\
\hline $\mathrm{SBP}_{\mathrm{M}}$ & 18 & 16 & 4 & 4 & 4.70 & 54.0 & 8.62 \\
\hline $\mathrm{SBP} 8$ & 12 & 36 & 8 & 4.5 & 3.20 & 34.9 & 8.18 \\
\hline
\end{tabular}

Note: $W, L$ and $h$ are the width, length and height of the test specimens, respectively. $L / h$ is the ratio of length to height of the test specimens and $A_{w}$ is the area of the web portions.

The shear strength of components (refer to Table 6.3) is higher than that of coupons. Size and shape effects are the main factors that lead to high dependence on applied load of components and fail in modes other than layer delamination. Normally, a higher applied load is required to induce specimen failure in web junction i.e., shear and buckling failure as opposed to layer delamination. From the experiments, components have failed in the web/ flange junction due to shear and buckling. Therefore, it is expected that higher load to failure is found in this short beam shear study than the failure load in a coupon. Additional information of failure modes is given in Section 6.3.1.2. 


\subsubsection{Comparison between Out-of-Plane and In-Plane Shear Strength}

From shear strength results of coupons, the average out-of-plane shear strength test data (yz and xz direction) of ProDeck4 flange coupons are compared with average in-plane shear (xy) strength. The average in-plane shear (xy) strength of coupon specimens is obtained from the standard V-notched beam test: D5379. For more information, in-plane shear response of coupons is also provided and discussed in Section 5.3.1. In-plane shear strength is utilized for comparison with the out-of-plane shear strength data in this chapter. Comparison of shear strength is given in Table 6.4.

Table 6.4 Comparison between out-of-plane and in-plane shear strength (coupon)

\begin{tabular}{|c|c|c|c|c|c|c|}
\hline \multirow[t]{2}{*}{ Specimens } & \multirow[t]{2}{*}{ Direction } & \multirow{2}{*}{$\begin{array}{l}\text { Number. } \\
\text { of } \\
\text { specimens }\end{array}$} & \multirow{2}{*}{$\begin{array}{c}\text { Average } \\
\text { experimental } \\
\text { shear strength } \\
\text { (ksi) }\end{array}$} & \multicolumn{2}{|c|}{$\begin{array}{l}\text { (\% ) difference } \\
\text { compared with }\end{array}$} & \multirow{2}{*}{$\begin{array}{c}\text { Average } \\
(\%) \\
\text { difference }\end{array}$} \\
\hline & & & & $\begin{array}{c}*_{V P 4_{L}} \\
(\mathrm{xy})\end{array}$ & $\begin{array}{c}*_{V P} 4_{T} \\
(\mathrm{xy})\end{array}$ & \\
\hline $\mathrm{SCP} 4_{\mathrm{FT}}$ & $\mathrm{yz}$ & 6 & 3.06 & 78.2 & 71.7 & 75.0 \\
\hline $\mathrm{SCP}_{\mathrm{FL}}$ & $\mathrm{XZ}$ & 6 & 4.21 & 70.0 & 61.1 & 65.6 \\
\hline
\end{tabular}

Note: ${ }^{*} V P 4_{L}$ and $V P 4_{T}$ are longitudinal and transverse $\mathrm{V}$-notched test beam specimens, respectively. In-plane shear strengths of specimens $\left(V P 4_{L}\right.$ and $\left.V P 4_{T}\right)$ are provided in Section 5.3.1.

From Table 6.4, it is found that the average out-of-plane shear strength (xz and yz direction) is three to four times lower than that of in-plane shear (xy direction) strength. It is obvious that coupon specimens under short beam shear test failed under delamination of fiber layers. Therefore, out-of-plane shear strength that is obtained from this type of test method might be able to be defined as delaminated shear strength of coupon specimens due to bond failure (fiber and matrix), stress concentration, fiber discontinuity, edge, and size effect. The failure mode of specimens under the standard V notched beam test is totally different from the failure mode found in terms of component failure. More information of in-plane failure mode is discussed in Section 5.3.3. 


\subsubsection{Failure Mode of Out-of-Plane Shear}

As mentioned in Section 6.3.1.1, the failure mode of coupons under out-of-plane shear is delamination of laminae. There is not any significant difference of failure modes between transverse (yz) and longitudinal (xz) test specimens, which is controlled by resin dominance. Small cracks are initially induced under a small magnitude of applied load. When the applied load increases, cracks are easily noticed and longitudinally extended from both ends to the mid length of test specimens. Delamination failure of coupons under short beam shear test is demonstrated in Figure 6.2. For ProDeck4 components, combination of different failure modes is observed in both single and multi-cell type of test specimens. The failure is a combination of shear and web buckling due to the geometry of FRP composite decks. The failure mechanism of component specimens under short beam shear test is presented below where, cracks and delamination of top and bottom flanges are noticed (see Figure 6.3).

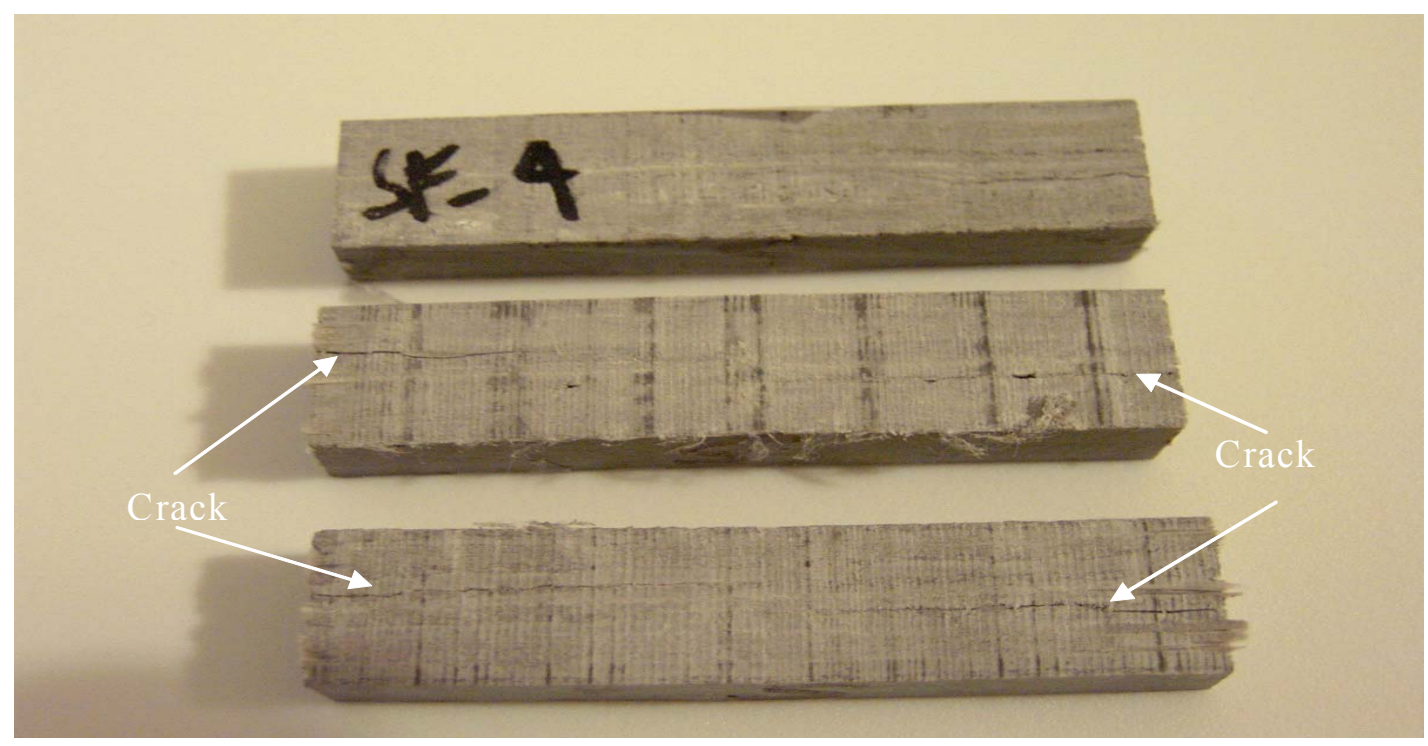

Figure 6.2 Delamination of coupon specimens under short beam shear test 


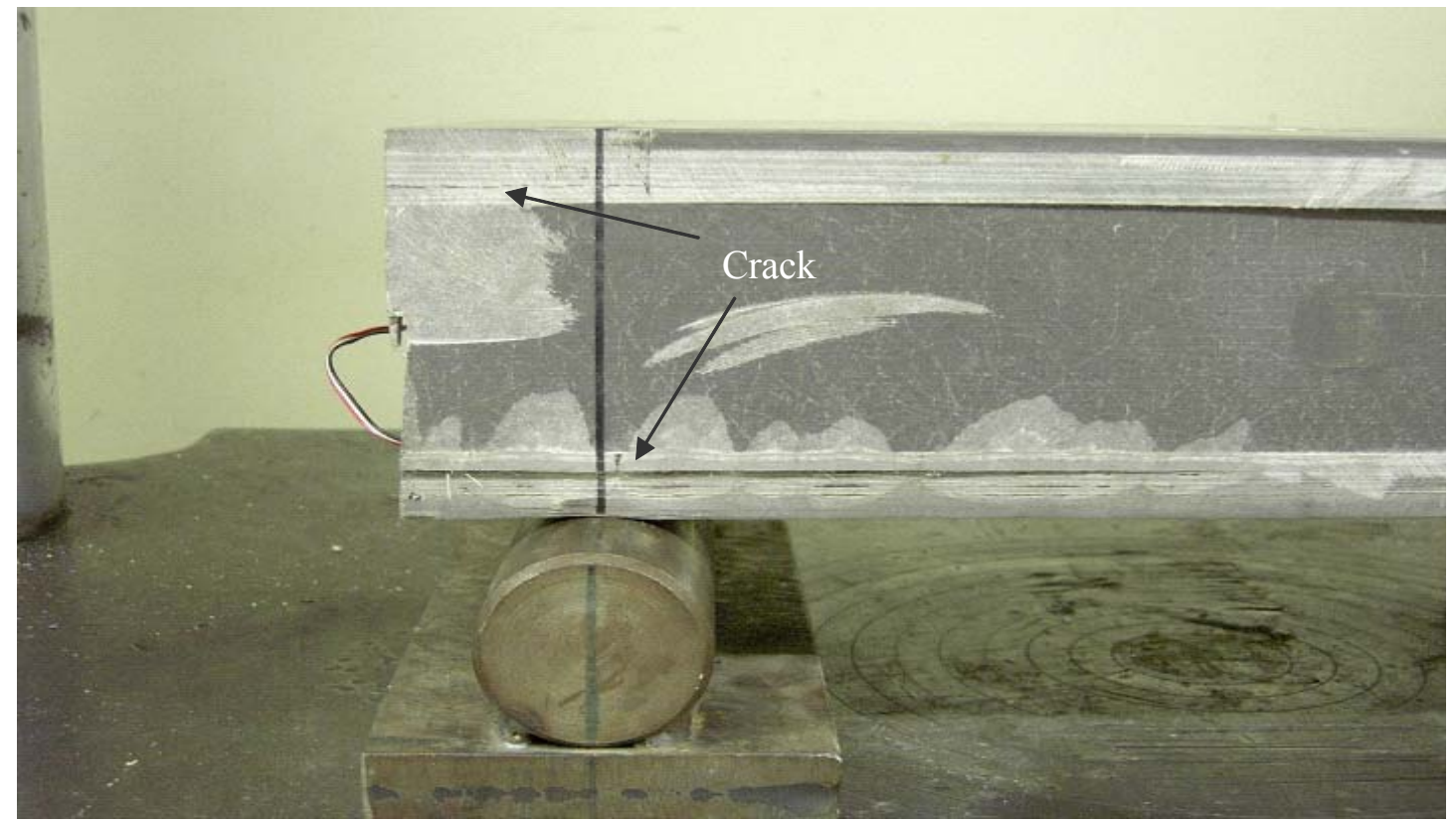

Figure 6.3 Crack and delamination of top and bottom flange

As applied load increases, cracks and delamination are gradually expanded into locations near web-flange junctions while the bottom web started to buckle until specimens completely failed. The failure mode is shown in Figure 6.4.

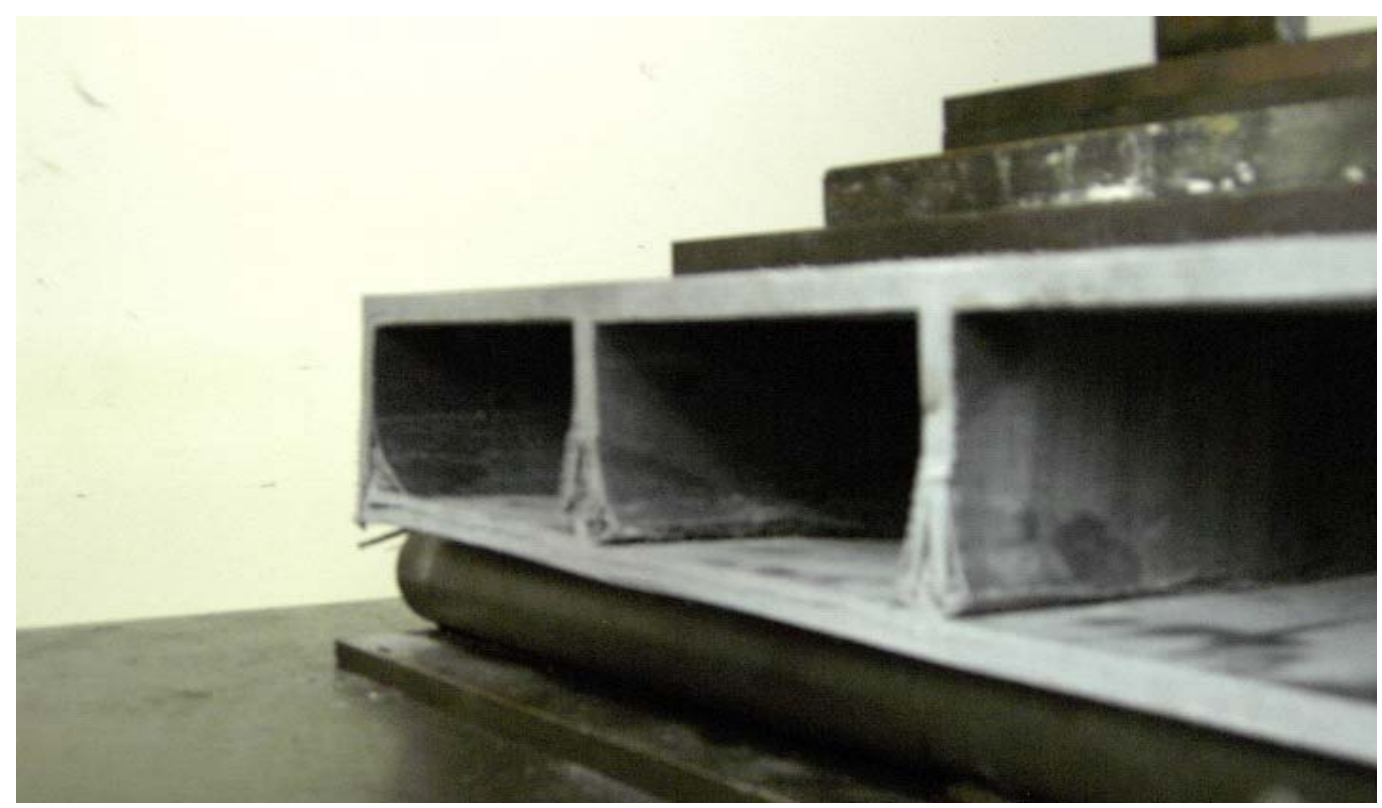

Figure 6.4 Delamination and web-buckling of test specimens 
The above mentioned failure mode of ProDeck4 components is different from that of ProDeck8 component specimens. For ProDeck8, cracks near web-diagonal portions are found before other cracks on the cross section. With increasing applied load, cracks are extended until the bottom web-diagonal junctions start to buckle and shear off from the bottom flange portion.

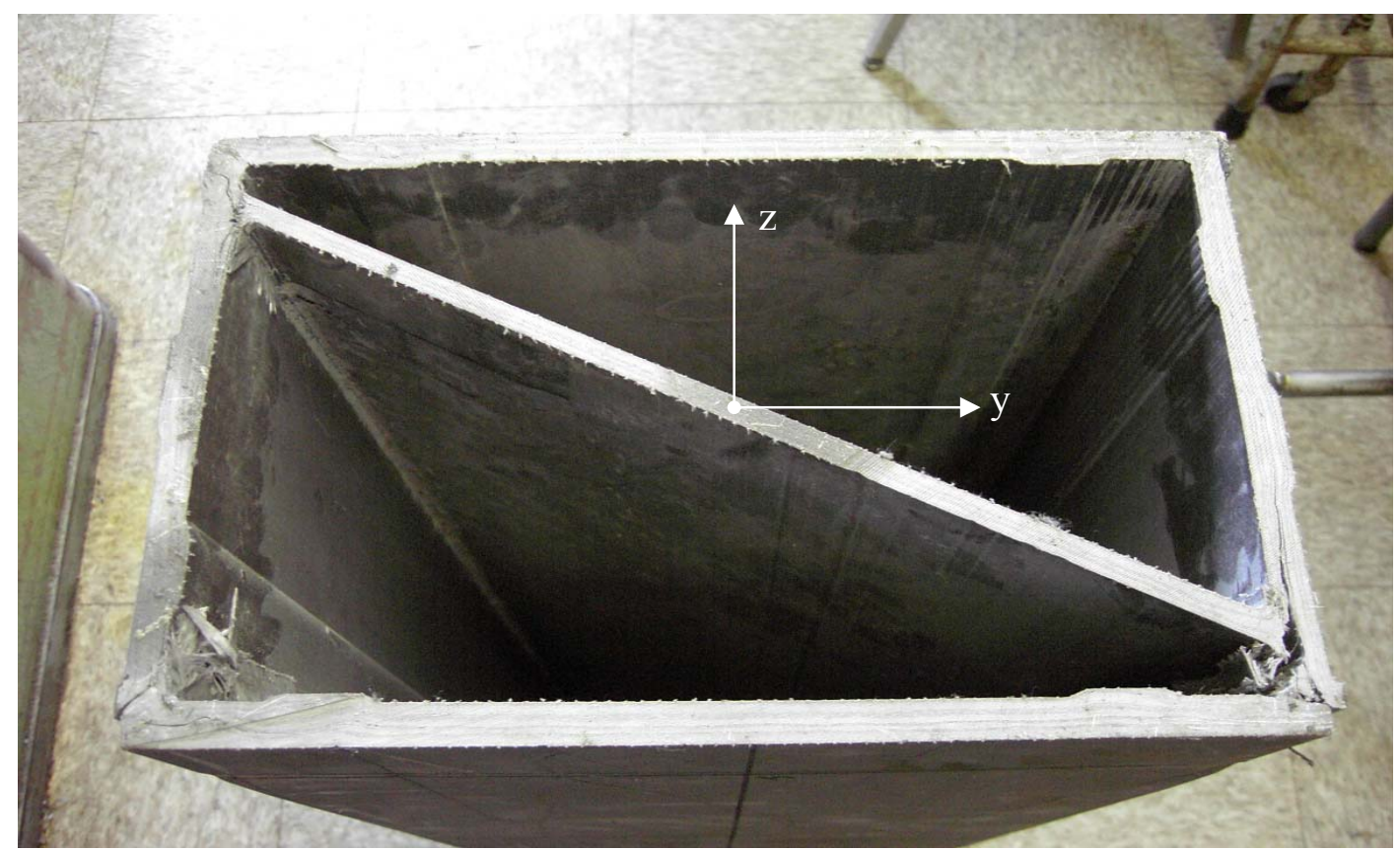

Figure 6.5 Cracks on cross section of ProDeck8 component specimen

\subsubsection{Out-of-Plane Shear Strength}

Coupon data revealed that the failure mode is obviously fabric layer delamination. Out-of-plane shear strength in the xz-direction is higher than that in the yz-direction. This is true for both web and flange. For ProDeck4 specimens, percent differences between the yz and $\mathrm{xz}$ shear strengths of web and flange coupon specimens are about 50.2 and $37.6 \%$, respectively, while the percent difference between the yz and xz shear strength of ProDeck8 flange coupons is about $33.8 \%$. Moreover, the average yz and xz shear strength of ProDeck4 coupon specimens are different from the average xy shear strength obtained from the standard V-notched beam test about $75.0 \%$ and $65.6 \%$, respectively. Because, 1 -D fiber and 
2-D fabric layers are usually laid-up on the xy plane of specimens thus the highest shear strength contribution of composite layers is found in xy direction.

The load versus deflection curve of single $\left(\mathrm{SBP}_{\mathrm{s}}\right)$ and multi-cell $\left(\mathrm{SBP}_{\mathrm{M}}\right)$ is given in Figures 6.6 and 6.7. Load and deflection behavior under short beam shear tests can be described into two stages as: 1) linear behavior is noticed up to $50 \%$ (single cell) and $70 \%$ (multi-cell) of maximum applied load, and 2) non-linear response of load versus deflection presents from about 50\% (single cell ) and 70\% (multi-cell) of the maximum applied load up to failure. From our experimental results of FRP components, only xz shear strength is considered in this study because of the limitation of the specimen dimensions. The shear strength of ProDeck4 multi-cell specimens is higher than that of single cell by about $10.56 \%$ due to the cutting effect on single cell. Fiber discontinuity and shape effect (beam and plate) of test specimens contribute to this difference. In addition, cutting of FRP decks into single cell specimens might have led to fiber bond failure around the cutting edges. The failure mode of the FRP component is a combination of different failure types including shear and buckling failure. It should be noted that out-of-plane shear strength of coupons is significantly lower than that of components due to several factors mentioned in Sections 6.3.1 and 6.3.1.1. 


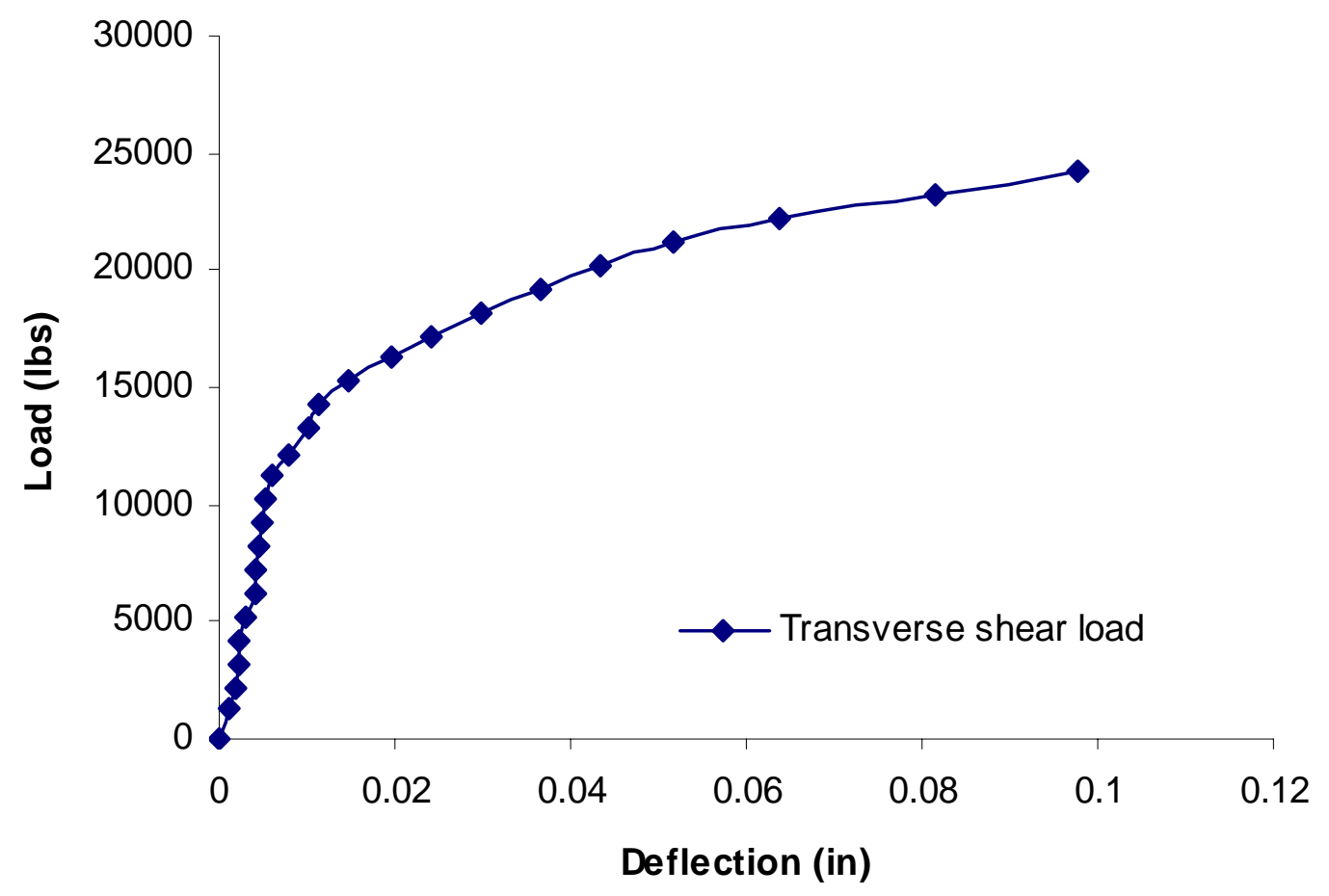

Figure 6.6 Relation between load and deflection $\left(\mathrm{SBP} 4_{\mathrm{S}}\right)$ under short beam shear test

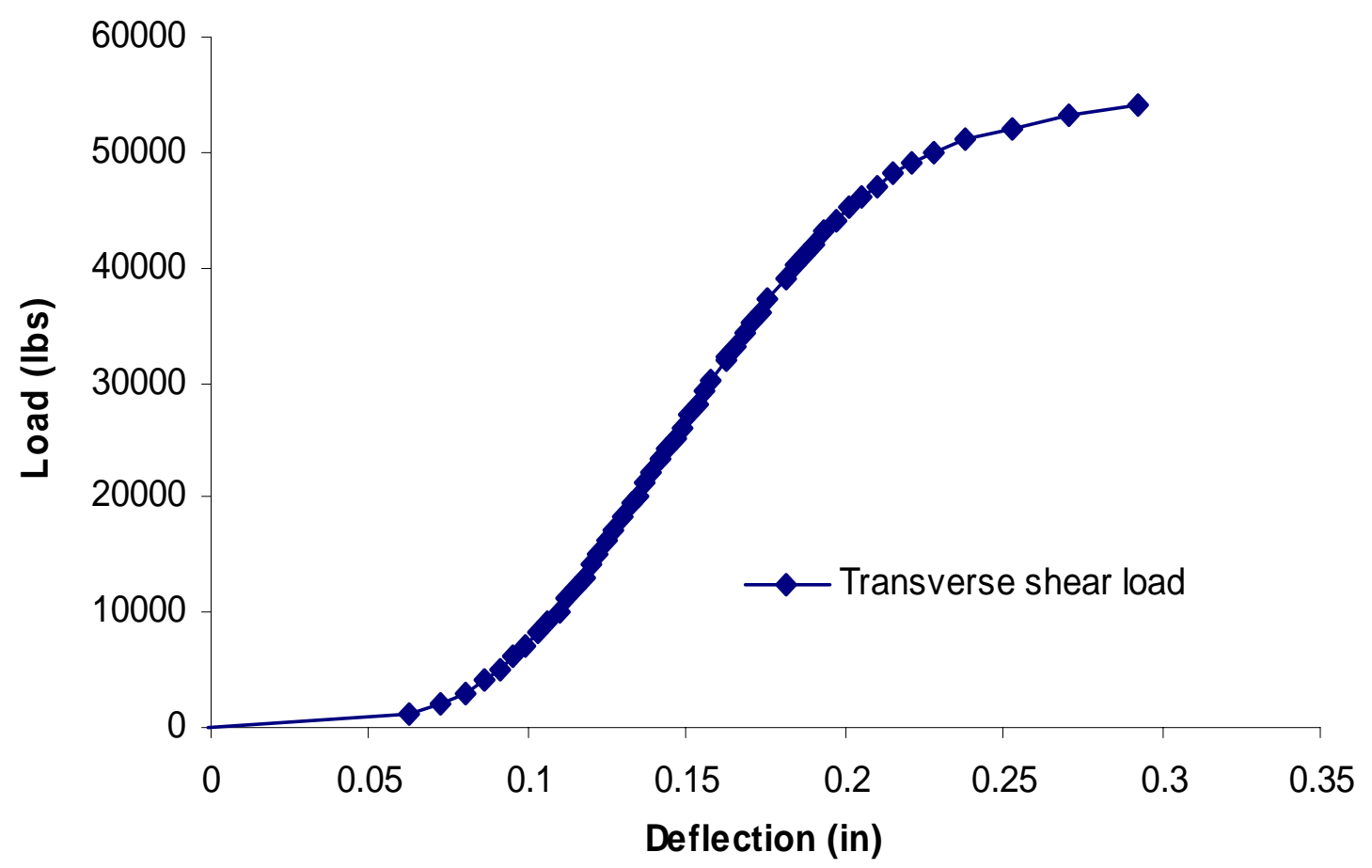

Figure 6.7 Relation between load and deflection $\left(\mathrm{SBP}_{\mathrm{M}}\right)$ under short beam shear test 


\subsubsection{Evaluation of Out-of-Plane Shear Modulus}

Bending tests are conducted in longitudinal and transverse directions of FRP composite deck specimens on single, multi-cell components with no joints, and multi-cell components with joints. Out-of-plane shear rigidities in $\mathrm{xz}$ and yz directions are provided for longitudinal and transverse specimens.

\subsubsection{Out-of-Plane Shear (xz) Modulus}

FRP components with single cell, multi-cell and multi-cell with two joints (top and bottom) along the longitudinal (deck) direction are tested for our evaluations. All specimens are tested within an elastic range up to 10 kips. All specimens are tested with a 48 inch span measured from the mid point of both supports. The applied load of three and four point bending has been gradually increased up to 10 kips.
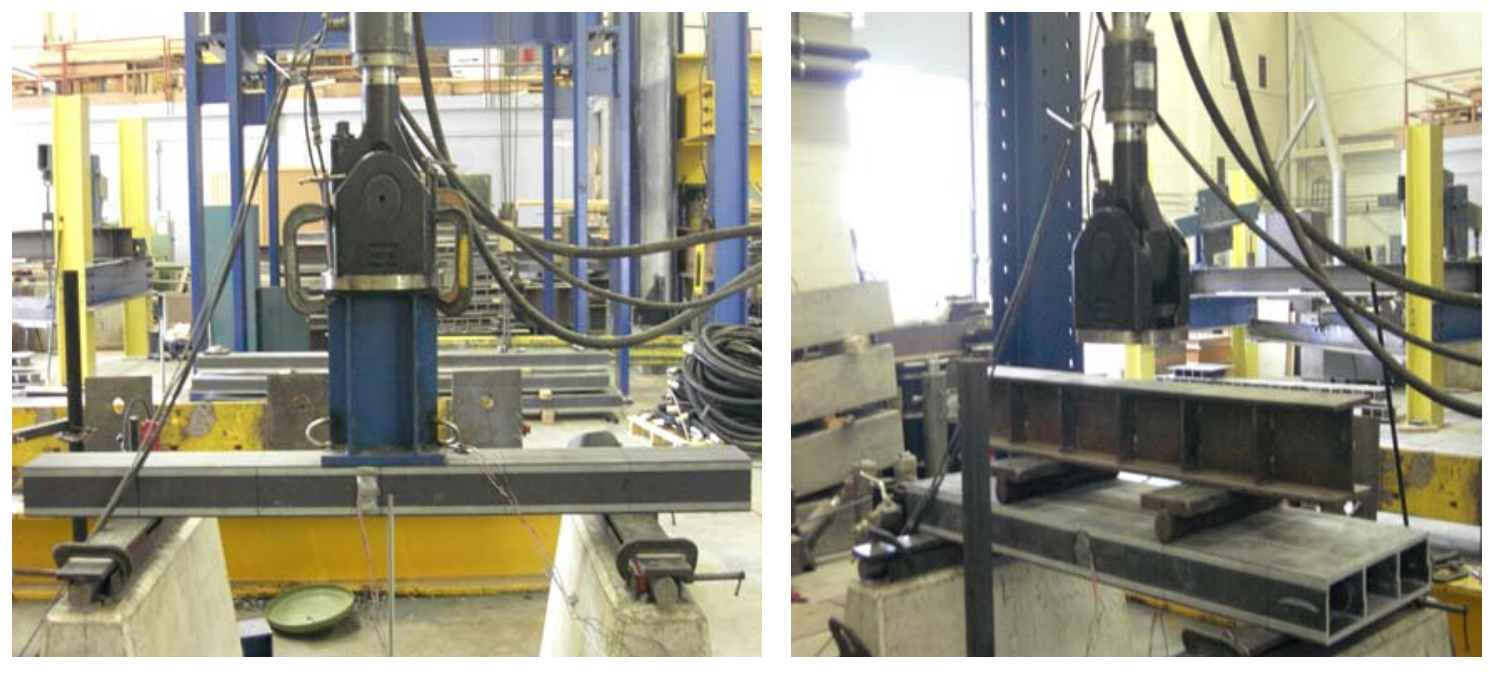

Figure 6.8 Longitudinal specimens under bending test

The experimental evaluation of bending and out-of-plane shear rigidity $G A$ by using the back calculation method based on deflection is presented in Section 6.2.2. To decouple effects of bending and shear, net deflection that is the resultants of the deflection difference between the applied load and the mid-span positions under four point bending is used for this 
purpose. In addition, the load-deflection response of three and four point bending and the load-net deflection response of each specimen are presented in Figures 6.9 through 6.17. Using deflection data from three and four point bending, slopes from the load and deflection relation are determined and summarized in Table 6.5.

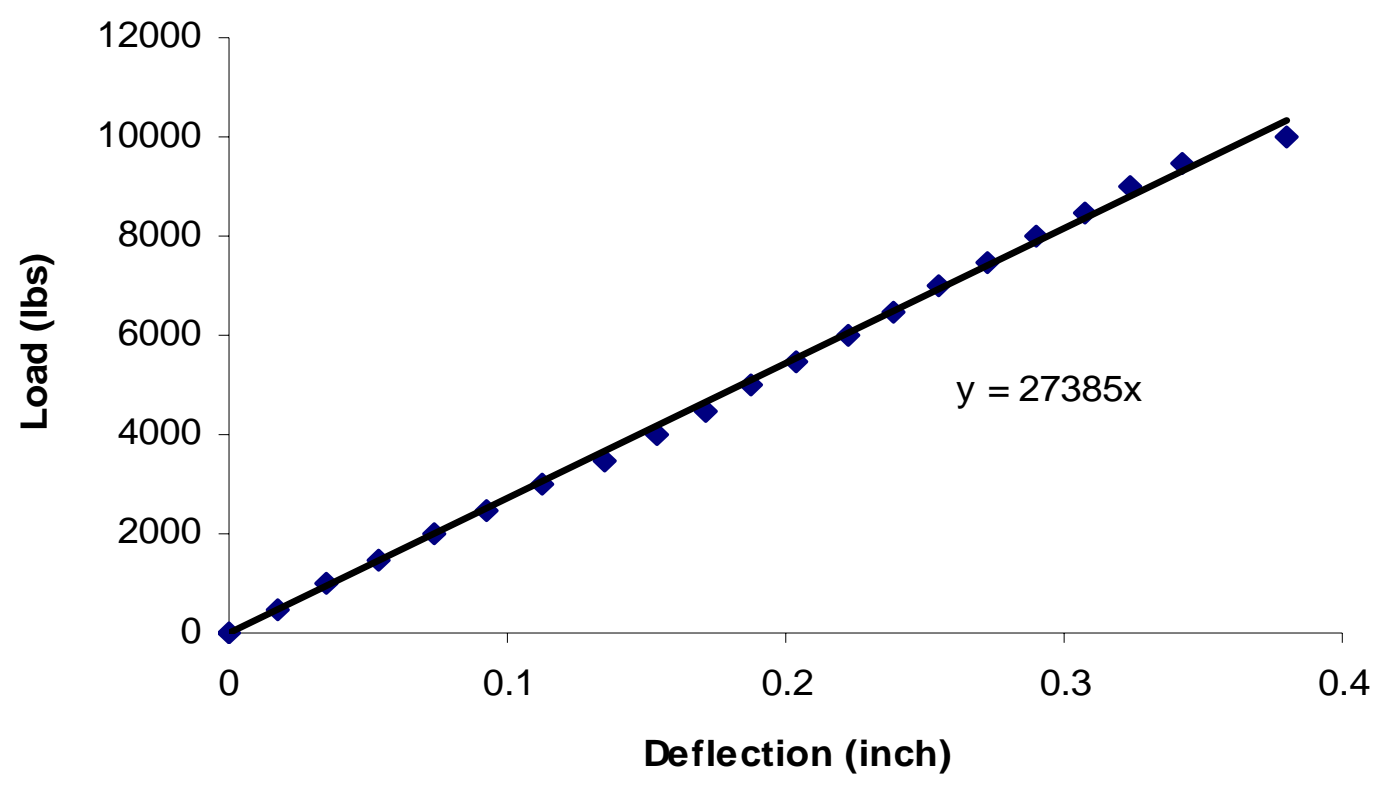

Figure 6.9 Load-deflection curve BP4 $4_{s}$ under 3 point bending

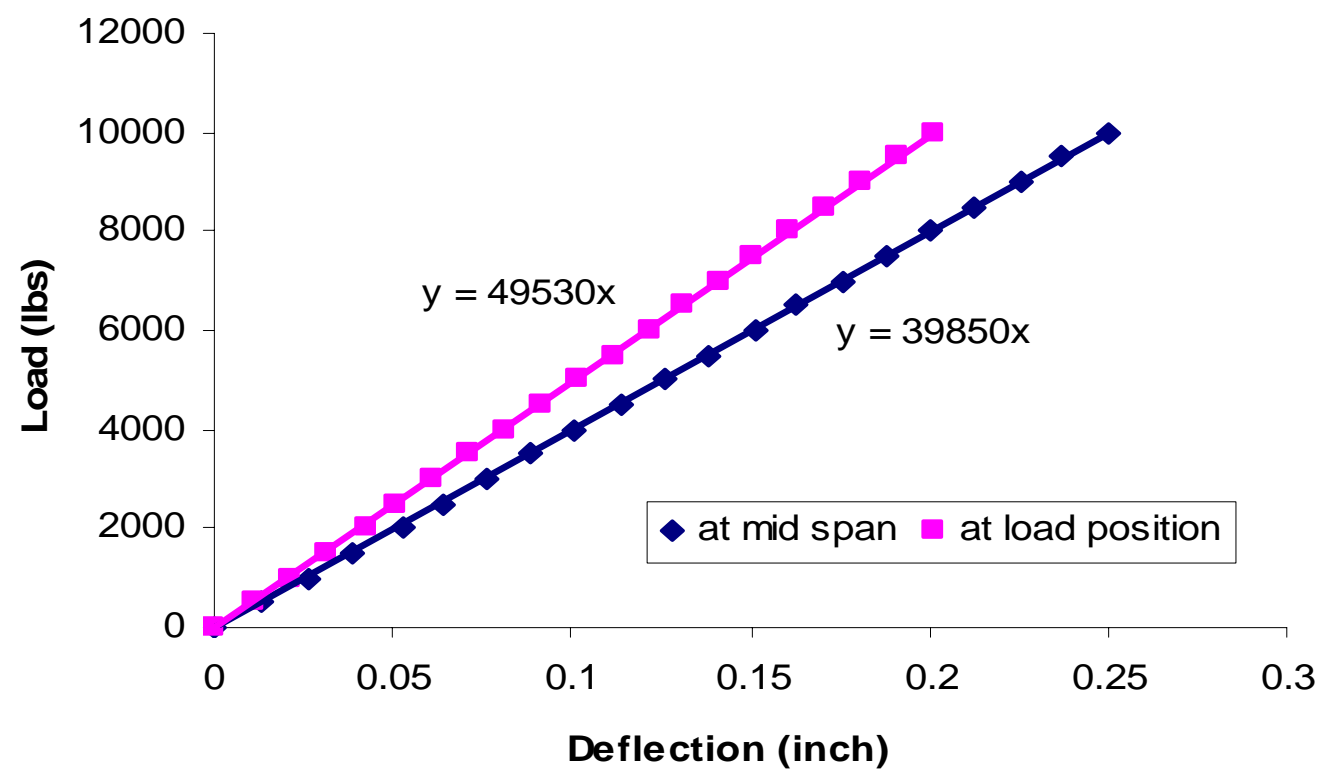

Figure 6.10 Load-deflection curve $B P 4_{s}$ under 4 point bending

Note: subscript (s) is a single cell. 


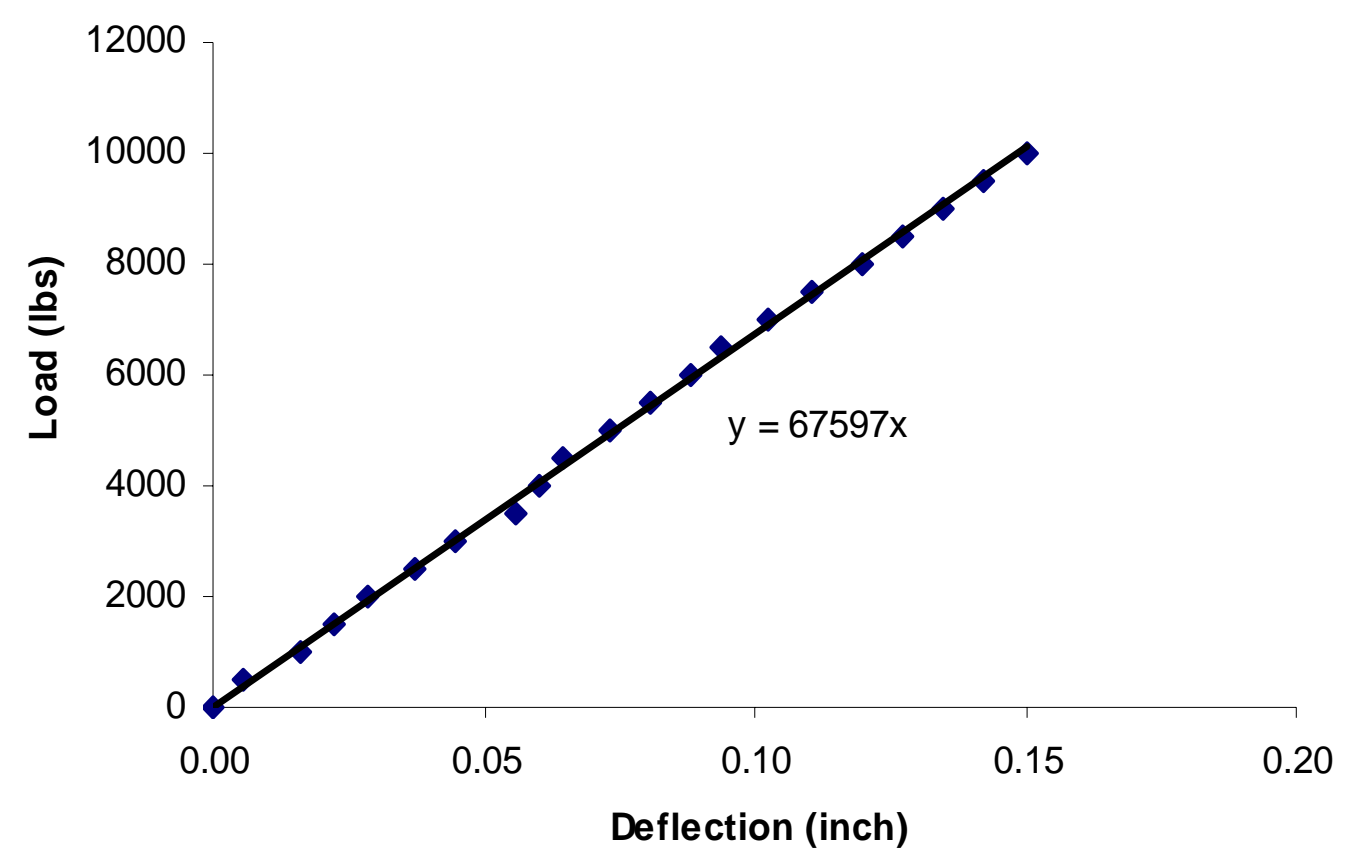

Figure 6.11 Load-deflection curve $B P 4_{M}$ under 3 point bending

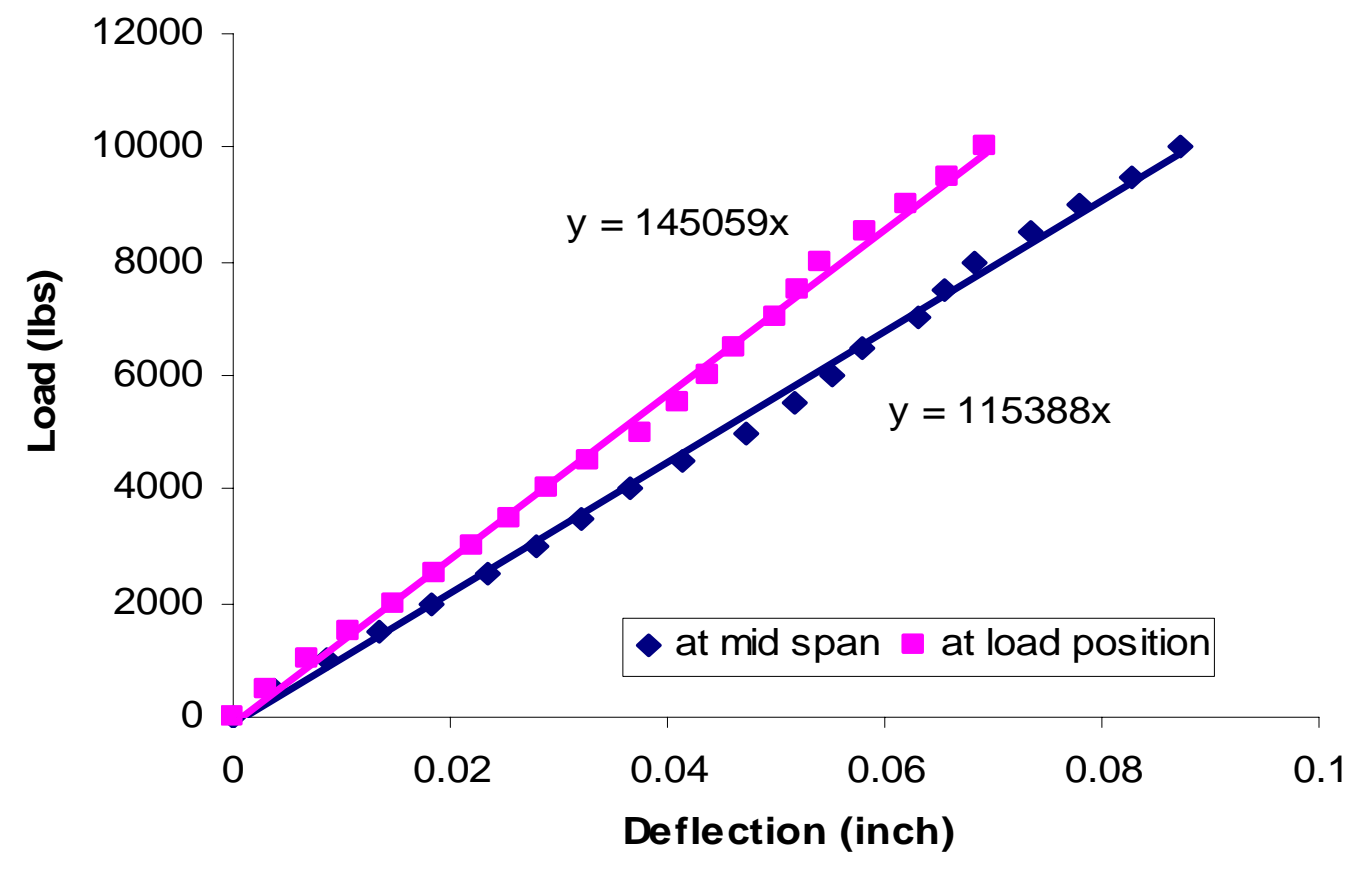

Figure 6.12 Load-deflection curve $\mathrm{BP}_{\mathrm{M}}$ under 4 point bending

Note: subscript (M) is a multi-cell. 


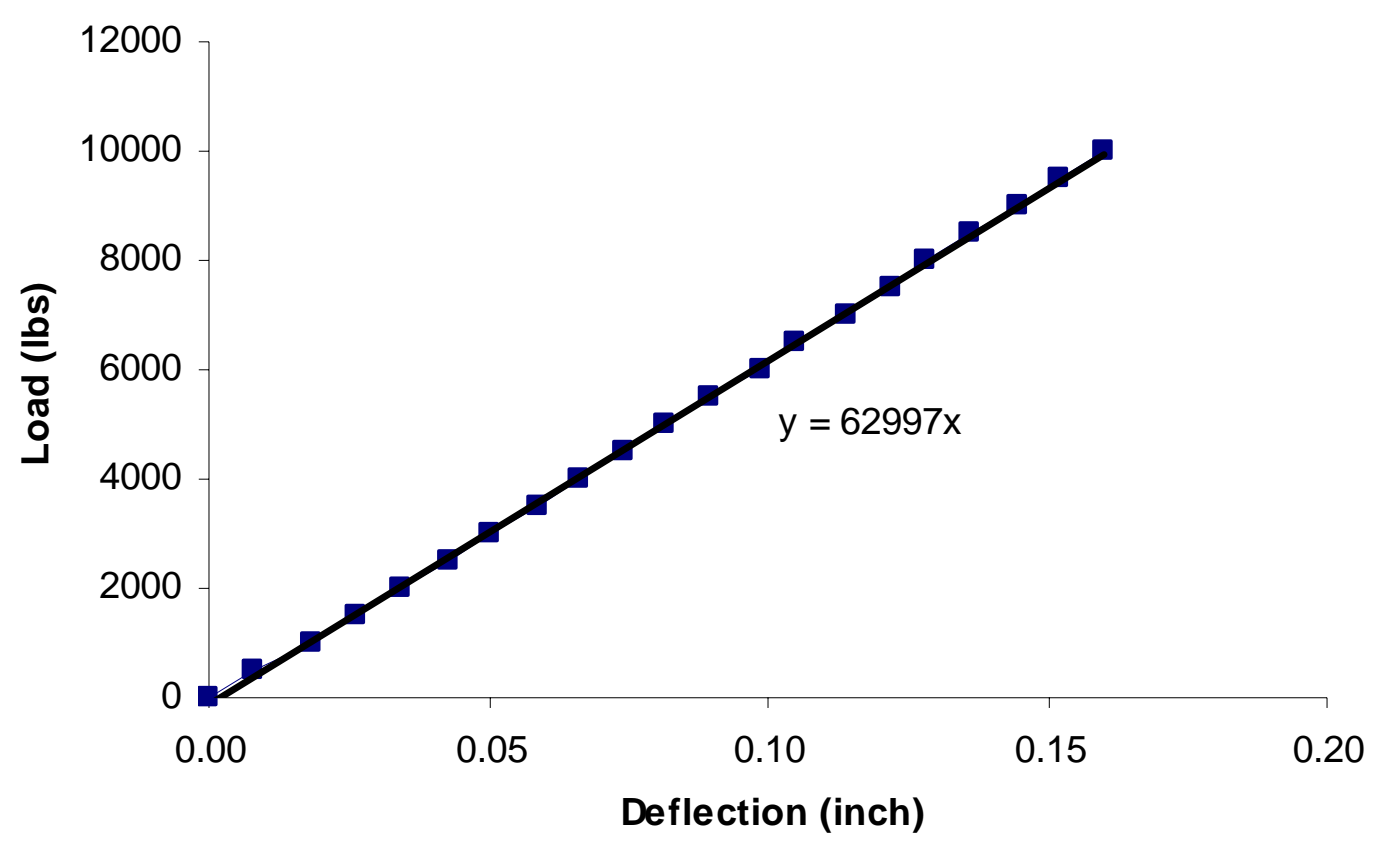

Figure 6.13 Load-deflection curve $B P 4_{M}$ under 3 point bending

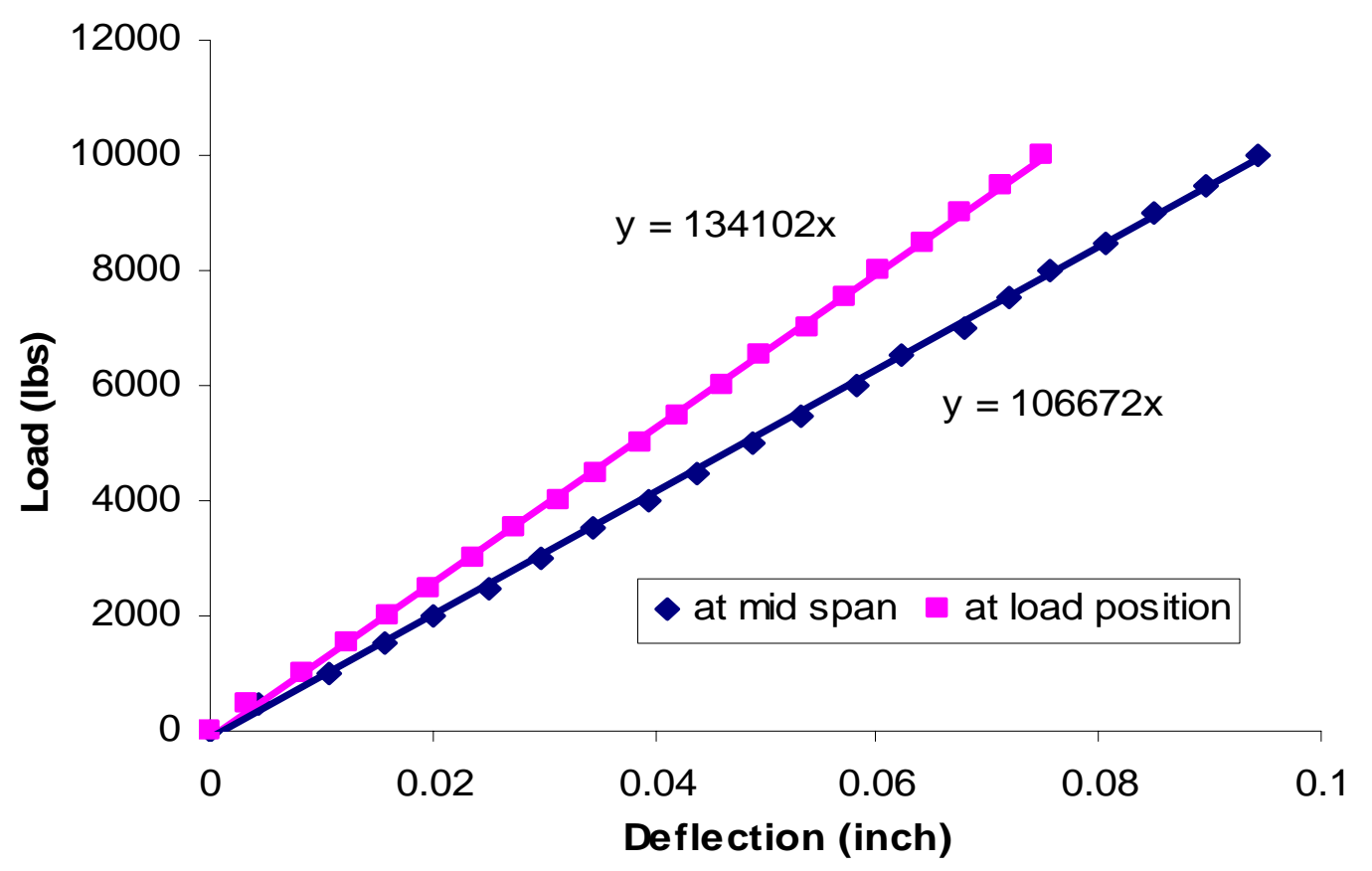

Figure 6.14 Load-deflection curve $B P 4_{M J}$ under 4 point bending

Note: subscript (M) and (MJ) are multi-cell and multi-cell with joints. 


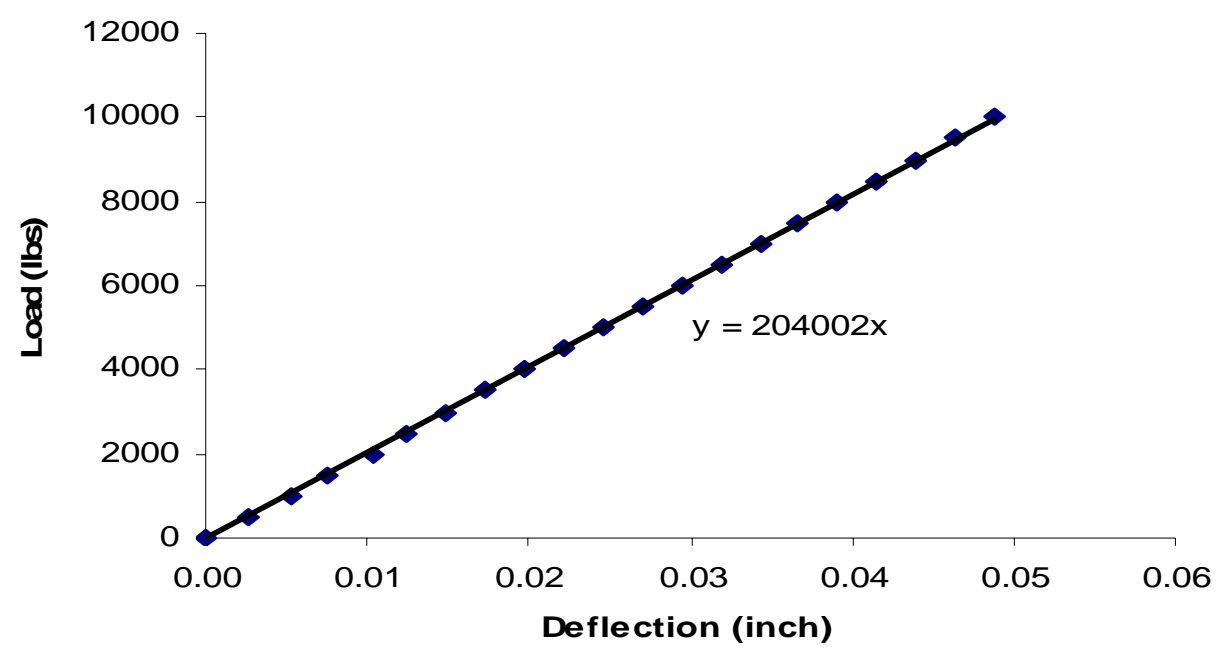

Figure 6.15 Load- net deflection curve $\mathrm{BP}_{\mathrm{S}}$ under 4 point bending

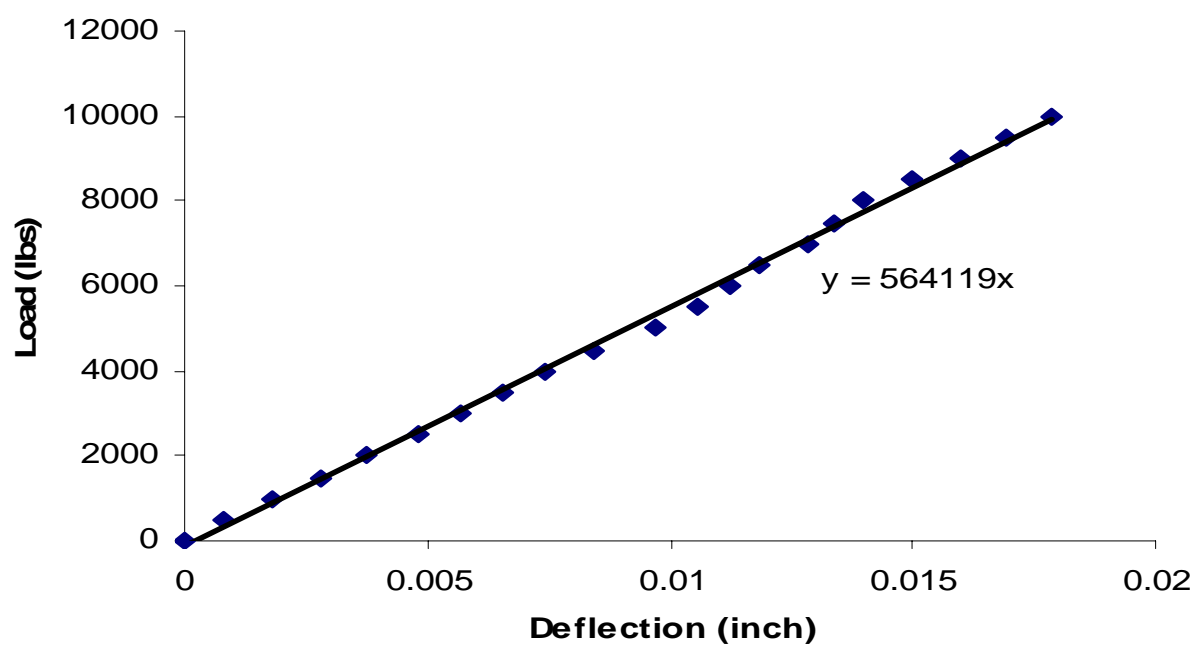

Figure 6.16 Load-net deflection curve $\mathrm{BP}_{\mathrm{M}}$ under 4 point bending

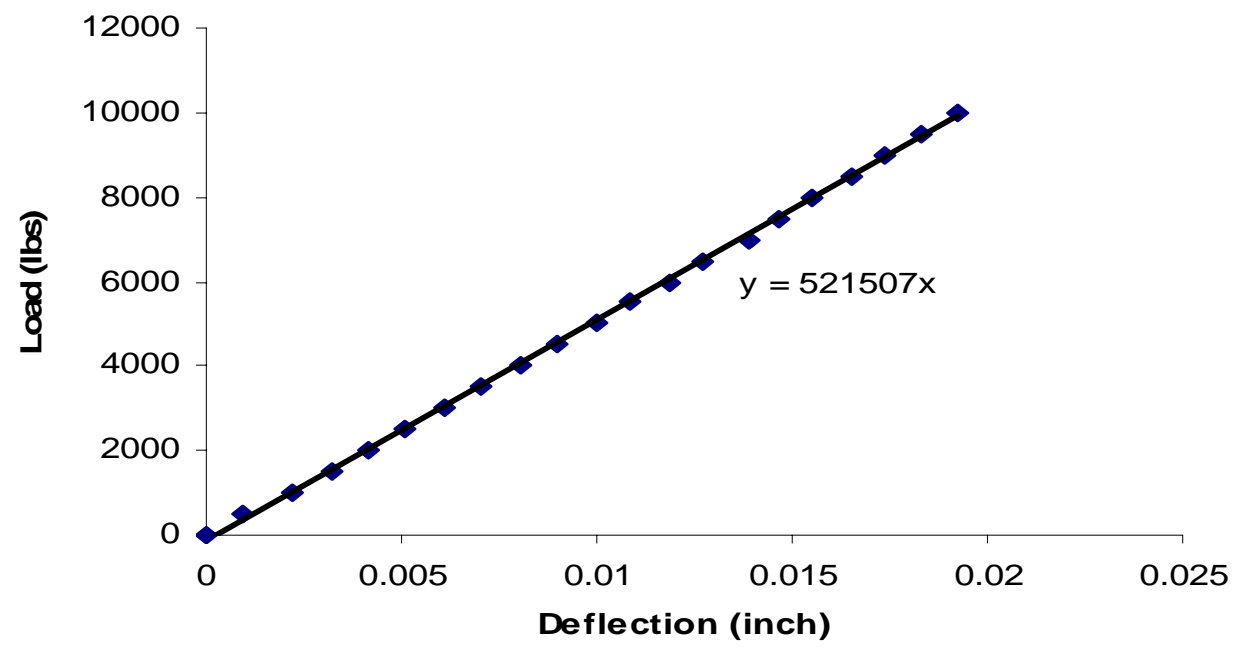

Figure 6.17 Load-net deflection curve $B P 4_{M J}$ under 4 point bending

Note: subscript (S), (M), and (MJ) are single, multi, and multi-cell with joints. 
Table 6.5 Slope of load-deflection curve from three and four point bending test

\begin{tabular}{|c|c|c|c|c|c|c|}
\hline \multirow[t]{2}{*}{ Specimen } & \multicolumn{2}{|c|}{ Three-point } & \multicolumn{4}{|c|}{ Four-point } \\
\hline & $\begin{array}{c}\delta_{\mathrm{m}} / \mathbf{P} \\
\left(\times 10^{-2}\right) \\
(\mathrm{in} / \mathbf{k i p})\end{array}$ & $\begin{array}{c}\text { (slope) } 3 \text { point } \\
\text { (kip/in) }\end{array}$ & $\begin{array}{c}\delta_{\mathrm{m}} / \mathbf{P} \\
\left(\times \mathbf{1 0}^{-2}\right) \\
(\mathbf{i n} / \mathbf{k i p})\end{array}$ & $\begin{array}{c}\delta_{\mathrm{a}} / \mathbf{P} \\
\left(\times 10^{-2}\right) \\
(\text { in/kip })\end{array}$ & $\begin{array}{c}\delta_{\text {net }} / \mathbf{P} \\
\left(\times 10^{-2}\right) \\
(\mathbf{i n} / \mathbf{k i p})\end{array}$ & $\begin{array}{l}\text { (slope) })_{4 \text { point }} \\
\text { (kip/in) }\end{array}$ \\
\hline $\mathrm{BP}_{\mathrm{S}}$ & 3.52 & 27.4 & 2.51 & 2.02 & 0.490 & 204 \\
\hline $\mathrm{BP}_{\mathrm{M}}$ & 1.479 & 67.6 & 0.867 & 0.689 & 0.1773 & 564 \\
\hline $\mathrm{BP} 4_{\mathrm{MJ}}$ & 1.587 & 63.0 & 0.937 & 0.746 & 0.1918 & 522 \\
\hline
\end{tabular}

Note: Slope 3 point is the linear slope of load-deflection at mid-span. Slope ${ }_{4 p o i n t}$ is the linear slope of load-net deflection curve. $\delta_{\mathrm{m}}, \delta_{\mathrm{a}}, \delta_{\text {net }}$ are mid span, applied load and net deflection, respectively. $\mathrm{P}$ is the applied load.

BP4s: ProDeck4 specimen in longitudinal direction (single cell)

$\mathrm{BP}_{\mathrm{M}}$ : ProDeck4 specimen in longitudinal direction (triple cell)

$\mathrm{BP} 4_{\mathrm{M} \mathrm{J}}$ : ProDeck4 specimen in longitudinal direction (triple cell with joints)

From the results shown in Table 6.5, (slope) $)_{3 \text { points }}$ and (slope) $)_{4 \text { points }}$ results are used to evaluate longitudinal bending (x) and out-of-plane shear (xz) rigidity by substituting these values into Equations (6.6) and (6.9). Calculation details based on slope approach of single cell $\left(\mathrm{BP} 4_{\mathrm{s}}\right)$ are given as:

Example: Out-of-plane shear $(\mathrm{xz})$ rigidity for specimen $\left(\mathrm{BP} 4_{\mathrm{s}}\right)$ by slope approach

$L=48$ inch and $a=12$ inch

From Equation (6.6) and Table 6.1

$$
\begin{aligned}
& (E I)_{b}=\frac{P a}{48\left(\delta_{m}-\delta_{a}\right)_{\exp }}\left(3 L^{2}-12 L a+12 a^{2}\right) \\
& (E I)_{b}=\frac{(12 \times 219)}{48}\left(3(48)^{2}-12(12 \times 48)+12(12)^{2}\right) \mathrm{kip}^{2} \mathrm{in}^{2} \\
& (E I)_{b}=8.81 \times 10^{4}{\mathrm{kip}-\mathrm{in}^{2}}^{2}
\end{aligned}
$$

From Equation (6.9) and Table 6.5 


$$
\begin{aligned}
& (A G)_{W}=\frac{\alpha_{3} L}{4}\left[\frac{\alpha_{4} a\left(3 L^{2}-12 L a+12 a^{2}\right)}{\alpha_{4} a\left(3 L^{2}-12 L a+12 a^{2}\right)-\alpha_{3} L^{3}}\right] \\
& (A G)_{W}=\frac{(27.4 \times 48)}{4}\left[\frac{(204 \times 12)\left(3(48)^{2}-12(48 \times 12)+12(12)^{2}\right)}{(204 \times 12)\left(3(48)^{2}-12(48 \times 12)+12(12)^{2}\right)-\left(27.4 \times 48^{3}\right)}\right] \mathrm{kip} \\
& (A G)_{w}=1.159 \times 10^{3} \mathrm{kip}
\end{aligned}
$$

For multi-cell $\mathrm{BP} 4_{\mathrm{M}}$ and $\mathrm{BP} 4_{\mathrm{MJ}}$, following the same procedure as above and using experimental data longitudinal bending (x) and out-of-plane shear (xz) rigidity are presented in Table 6.6. Moreover, effective out-of-plane modulus based on experiments is found by using experimental rigidity over sectional properties. Therefore, equivalent longitudinal and transverse elastic modulus are found from experimental longitudinal (x) and transverse (y) bending rigidity after dividing by the moment of inertia about $\mathrm{y}$ and $\mathrm{x}$ axis, respectively. Also, equivalent out-of-plane shear (xz and yz) moduli are experimental out-of-plane shear (xz) and (yz) rigidity divided by web area in yz and xz plane, respectively. In addition, results based on load steps and finite element approaches are presented herein.

\begin{tabular}{|c|c|c|c|c|c|c|}
\hline \multirow[t]{2}{*}{ Specimen } & \multicolumn{2}{|c|}{$\begin{array}{c}\text { Cross-sectional } \\
\text { properties }\end{array}$} & \multicolumn{2}{|c|}{$\begin{array}{c}\text { Experimental } \\
\text { rigidity }\end{array}$} & \multicolumn{2}{|c|}{$\begin{array}{l}\text { Effective } \\
\text { modulus }\end{array}$} \\
\hline & $\begin{array}{c}A_{w} \\
\left(\text { in }^{2}\right)\end{array}$ & $\begin{array}{c}I \\
\left(\text { in }^{4}\right)\end{array}$ & $\begin{array}{c}(E I)_{\mathrm{b}} \\
\left(\times 10^{4}\right) \\
\left(\mathrm{kip}-\mathrm{in}^{2}\right)\end{array}$ & $\begin{array}{c}(A G)_{\mathrm{w}} \\
\left(\times 10^{3}\right) \\
(\mathrm{kip})\end{array}$ & $\begin{array}{c}\left(E_{\mathrm{x}}\right)_{\text {eff }} \\
\left(\times 10^{6}\right) \\
(\mathrm{psi})\end{array}$ & $\begin{array}{c}\left(G_{\mathrm{Xz}}\right)_{\mathrm{eff}} \\
\left(\times 10^{6}\right) \\
(\mathrm{psi})\end{array}$ \\
\hline $\mathrm{BP}_{\mathrm{S}}$ & 2.35 & 18.65 & 8.81 & 1.159 & 4.72 & 0.493 \\
\hline $\mathrm{BP}_{4}$ & 4.71 & 53.6 & 24.4 & 2.25 & 4.55 & 0.477 \\
\hline $\mathrm{BP} 4_{\mathrm{MJ}}$ & 4.71 & 53.6 & 22.5 & 2.13 & 4.19 & 0.451 \\
\hline
\end{tabular}

Table 6.6 Experimental results (slope approach) of longitudinal bending (x) and out-ofplane shear (xz) modulus

Note: $\mathrm{BP}_{\mathrm{S}}$ : ProDeck4 specimen in longitudinal direction (single cell) $\mathrm{BP} 4_{\mathrm{M}}$ : ProDeck4 specimen in longitudinal direction (triple cell) $\mathrm{BP} 4_{\mathrm{M} \mathrm{J}}$ : ProDeck4 specimen in longitudinal direction (triple cell with joint) 
To verify the experimental results, Equations (6.6) and (6.7) of longitudinal bending (x) and out-of-plane shear (xz) rigidity are used for this purpose in the applied load step approach. Detailed calculations are presented below:

Example: Out-of-plane shear $(\mathrm{xz})$ rigidity for specimen $\left(\mathrm{BP} 4_{\mathrm{s}}\right)$ by load step approach From Equation (6.6)

$L=48$ inch, $a=12$ inch, $\delta_{\mathrm{m} 4}=0.2499$ and $\delta_{\mathrm{a} 4}=0.2011$ at $P=10 \mathrm{kips}$

$$
\begin{aligned}
& (E I)_{b}=\frac{P a}{48\left(\delta_{m}-\delta_{a}\right)}\left(3 L^{2}-12 L a+12 a^{2}\right) \\
& (E I)_{b}=\frac{(12 \times 219)}{48}\left(3(48)^{2}-12(48 \times 12)+12(12)^{2}\right) \mathrm{kip}^{2} \mathrm{in}^{2} \\
& (E I)_{b}=8.81 \times 10^{4} \mathrm{kip}-\mathrm{in}^{2}
\end{aligned}
$$

From Equation (6.3)

$\delta_{\mathrm{m} 3}=0.3595$ at $\mathrm{P}=10 \mathrm{kips}$

$$
\begin{aligned}
& \left(\delta_{m 3}\right)_{\exp }=\frac{P L^{3}}{48(E I)_{b}}+\frac{P L}{4(A G)_{W}} \\
& 0.3595=\frac{10(132)^{3}}{48\left(8.81 \times 10^{4}\right)}+\frac{10 \times 132}{4(A G)_{W}} \\
& (A G)_{w}=5.15 \times 10^{3} \mathrm{kip}
\end{aligned}
$$

The same procedure for every load step is used to obtain results through testing intervals. In addition, out-of-plane shear and elastic modulus for every applied load step is presented in Figures 6.18 through 6.20 and average values are given in Table 6.7. 


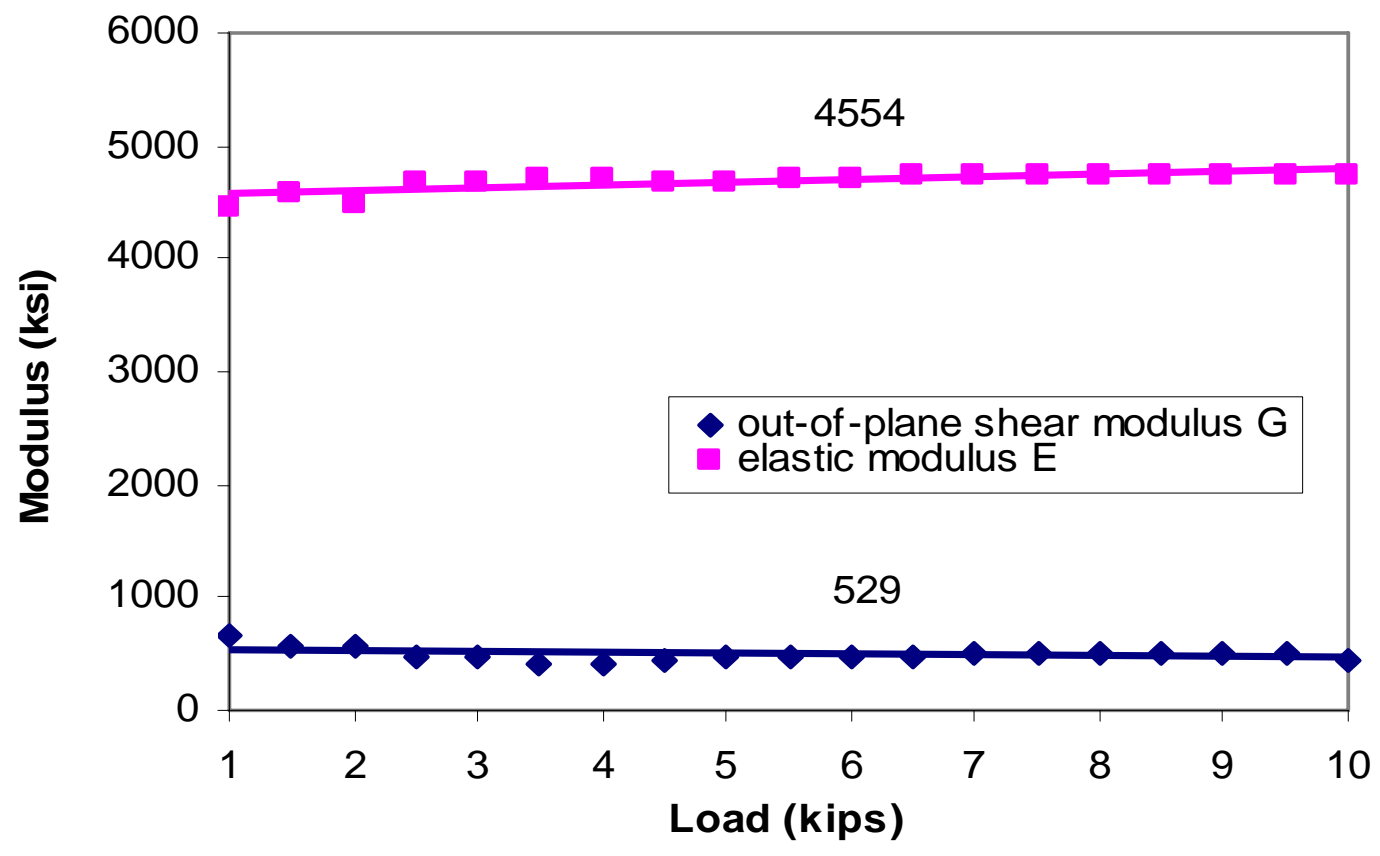

Figure 6.18 Out-of-plane shear and elastic modulus of BP4

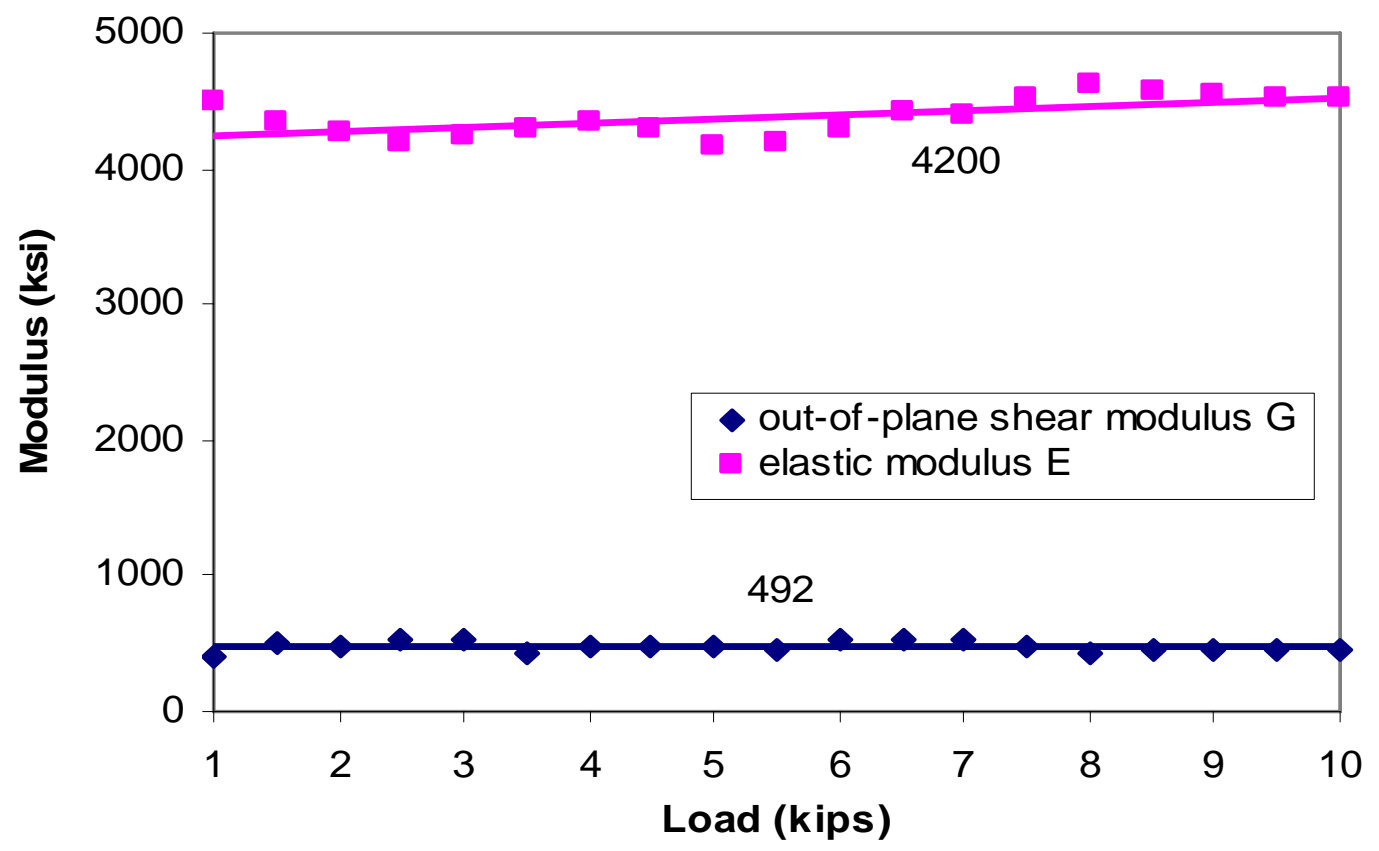

Figure 6.19 Out-of-plane shear and elastic modulus of $B P 4_{M}$ 


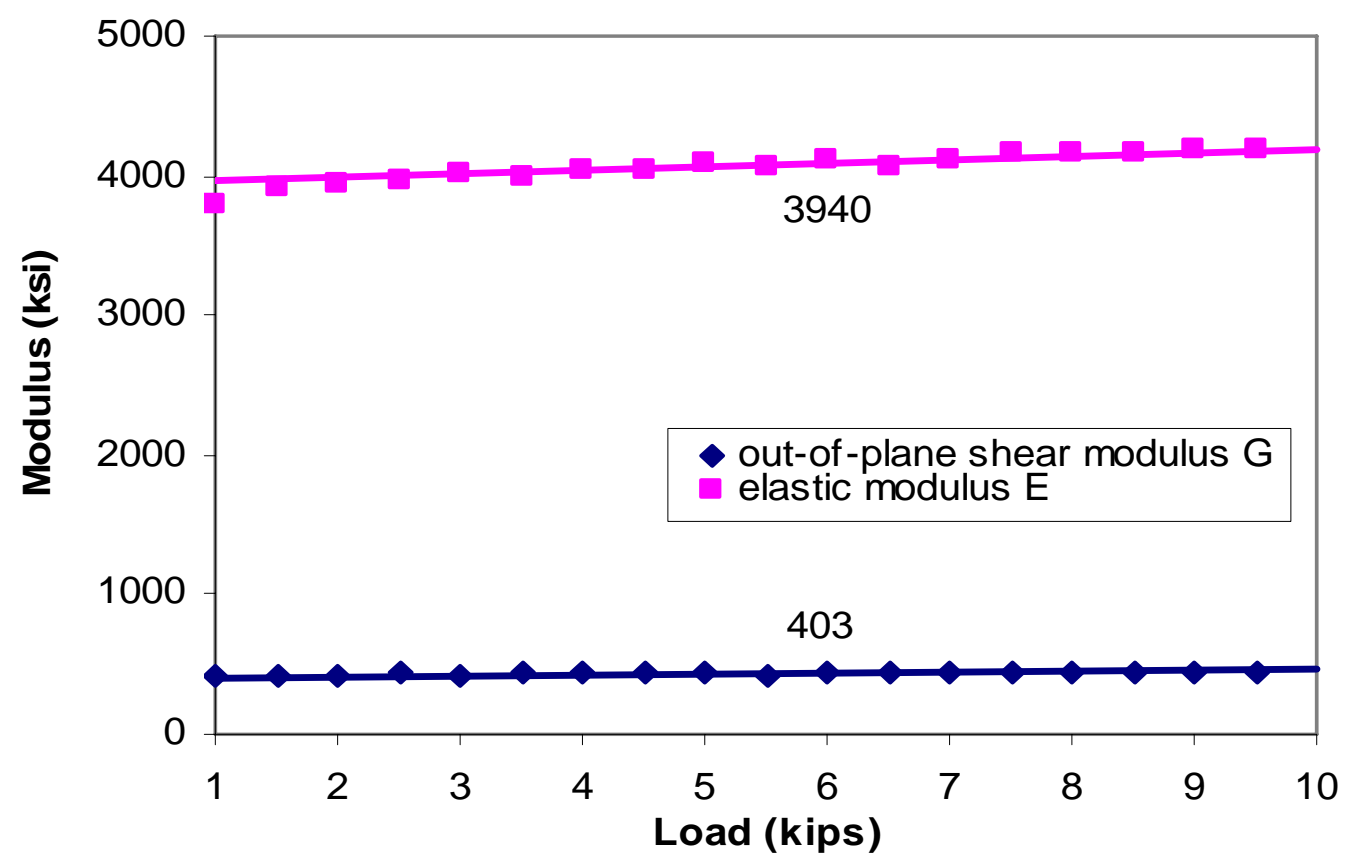

Figure 6.20 Out-of-plane shear and elastic modulus of BP4 $4_{\mathrm{MJ}}$

Table 6.7 Experimental results (load step approach) of longitudinal bending ( $x$ ) and outof-plane shear (xz) modulus

\begin{tabular}{|c|c|c|c|c|c|c|}
\hline \multirow[t]{2}{*}{ Specimen } & \multicolumn{2}{|c|}{$\begin{array}{c}\text { Cross-sectional } \\
\text { properties }\end{array}$} & \multicolumn{2}{|c|}{$\begin{array}{l}\text { Experimental } \\
\text { rigidity }\end{array}$} & \multicolumn{2}{|c|}{$\begin{array}{l}\text { Effective } \\
\text { modulus }\end{array}$} \\
\hline & $\begin{array}{c}A_{w} \\
\left(i^{2}\right)\end{array}$ & $\underset{\left(i^{4}\right)}{I}$ & $\begin{array}{c}(\mathrm{EI})_{\mathrm{b}} \\
\left(\times 10^{4}\right) \\
\left(\mathrm{kip}^{2} \mathrm{in}^{2}\right)\end{array}$ & $\begin{array}{c}(\mathrm{AG})_{\mathrm{w}} \\
\left(\times 10^{3}\right) \\
(\text { kip })\end{array}$ & $\begin{array}{c}\left(E_{x}\right)_{\text {eff }} \\
\left(\times 10^{6}\right) \\
(p s i)\end{array}$ & $\begin{array}{c}\left(G_{\mathrm{xz}}\right)_{\text {eff }} \\
\left(\times 10^{6}\right) \\
(\mathrm{psi})\end{array}$ \\
\hline $\mathrm{BP}_{\mathrm{S}}$ & 2.35 & 18.65 & 8.48 & 1.240 & 4.55 & 0.528 \\
\hline$B P 4_{M}$ & 4.71 & 53.6 & 22.5 & 2.32 & 4.20 & 0.492 \\
\hline $\mathrm{BP} 4_{\mathrm{MJ}}$ & 4.71 & 53.6 & 21.1 & 1.897 & 3.94 & 0.403 \\
\hline
\end{tabular}

Furthermore, longitudinal bending $(\mathrm{x})$ and out-of-plane shear $(\mathrm{xz})$ rigidity results using the back calculation method based on strain-deflection data in Equations (6.11) through (6.13) are evaluated in this section. Calculations based on strain-deflection approach of single cell $\left(\mathrm{BP}_{\mathrm{s}}\right)$ are given to below. 
Example: Out-of-plane shear $(\mathrm{xz})$ rigidity for specimen $\left(\mathrm{BP} 4_{\mathrm{s}}\right)$ by strain step approach

Single cell $\left(\mathrm{BP}_{\mathrm{s}}\right) ; L=48$ inch and $a=12$ inch

From Equation (6.11) and longitudinal strain $\varepsilon=1339 \times 10^{-6} \mathrm{in} / \mathrm{in}$

$$
\begin{aligned}
& E I=\frac{P a z}{2 \varepsilon} \\
& E I=\frac{10 \times 12 \times 2}{2\left(1339 \times 10^{-6}\right)}=8.96 \times 10^{4} \mathrm{kip}-\mathrm{in}^{2}
\end{aligned}
$$

From Equations (6.12) and (6.13) and deflection under three point bending $=0.3595$ in

$$
\begin{aligned}
\delta_{m 4} & =\frac{P L^{3}}{48(E I)} \\
\delta_{m 4} & =\frac{10 \times 48^{3}}{48(8.96) \times 10^{4}}=0.2571 \mathrm{in} \\
G A & =\frac{P L}{4\left(\delta_{m 3}-\delta_{m 4}\right)} \\
G A & =\frac{10 \times 48}{4(0.3595-0.2571)}=1.172 \times 10^{3} \mathrm{kip}
\end{aligned}
$$

\begin{tabular}{|c|c|c|c|c|c|c|c|c|}
\hline \multirow[t]{2}{*}{ Specimen } & \multirow{2}{*}{$\begin{array}{c}\text { Strain } \varepsilon \\
\left(10^{-6}\right. \\
\text { in/in) }\end{array}$} & \multirow{2}{*}{$\begin{array}{c}\text { Deflection } \\
\delta_{m 3} \\
\text { (in) }\end{array}$} & \multicolumn{2}{|c|}{$\begin{array}{c}\text { Cross-sectional } \\
\text { properties }\end{array}$} & \multicolumn{2}{|c|}{$\begin{array}{c}\text { Experimental } \\
\text { rigidity }\end{array}$} & \multicolumn{2}{|c|}{$\begin{array}{l}\text { Effective } \\
\text { modulus }\end{array}$} \\
\hline & & & $\begin{array}{c}A_{w} \\
\left(\text { in }^{2}\right)\end{array}$ & $\underset{\left(\text { in }^{4}\right)}{I}$ & $\begin{array}{c}(E I)_{\mathrm{b}} \\
\left(\times 10^{4}\right) \\
\left(\text { kip-in }{ }^{2}\right)\end{array}$ & $\begin{array}{c}(A G)_{\mathrm{w}} \\
\left(\times 10^{3}\right) \\
(\text { kip })\end{array}$ & $\begin{array}{c}\left(E_{\mathrm{x}}\right)_{\text {eff }} \\
\left(\times 10^{6}\right) \\
(\mathbf{k s i})\end{array}$ & $\begin{array}{c}\left(G_{\mathrm{xz}}\right)_{\mathrm{eff}} \\
\left(\times 10^{6}\right) \\
(\mathrm{psi})\end{array}$ \\
\hline $\mathrm{BP}_{\mathrm{S}}$ & 1339 & 0.3595 & 2.35 & 18.65 & 8.96 & 1.172 & 4.81 & 0.498 \\
\hline $\mathrm{BP}_{\mathrm{M}}$ & 515 & 0.1503 & 4.71 & 53.6 & 23.3 & 2.33 & 4.35 & 0.496 \\
\hline $\mathrm{BP} 4_{\mathrm{MJ}}$ & 525 & 0.1599 & 4.71 & 53.6 & 22.9 & 2.02 & 4.27 & 0.430 \\
\hline
\end{tabular}

For multi-cell $\mathrm{BP} 4_{\mathrm{M}}$ and $\mathrm{BP} 4_{\mathrm{MJ}}$, the same procedure is followed and the results of longitudinal bending $(\mathrm{x})$ and out-of-plane shear $(\mathrm{xz})$ rigidity based on experimental straindeflection are presented in Table 6.8.

Table 6.8 Experimental results based on strain-deflection data of longitudinal bending $(x)$ and out-of-plane shear $(x-z)$ modulus 
Moreover, longitudinal bending (x) and out-of-plane shear (xz) rigidity based on deflection using finite element results are also provided to validate experimental results.

\subsubsection{Numerical Out-of-Plane Shear (xz) Modulus}

As mentioned in Section 4.6.2.2, the two canonical configuration finite element approaches are: 1) the mathematical modeling and 2) physical finite element modeling, depending on the environment in which finite element analysis is used. In this study, the second approach of finite element modeling is also used to model FRP composite deck specimens under desired load conditions.

Finite element models include two model types for each load case: 1) single cell model under three and four point bending load, and 2) multi-cell model without joints along the cell length. Finite element models are given in Figures 6.21 and 6.22. Input properties for modeling are obtained from experimental results at coupon level. Physical behavior of FRP composite deck specimens is modeled into ideal mathematical simulation through elements of orthotropic rectangular shell63 that are provided by ANSYS. Moreover, descriptions of models including the test span models, number of elements and nodes, applied load and boundary conditions, are given in Table 6.19. Moreover, deflections based on finite element results on all specimen models are also presented in Figures 6.23 through 6.26. Therefore, the slope of load-deflection response based on finite element results are determined and reported in Table 6.10.

Table 6.9 Summary of finite element models for three-four point bending

\begin{tabular}{|c|c|c|c|c|c|c|}
\hline \multirow{2}{*}{$\begin{array}{c}\text { Analysis } \\
\text { type }\end{array}$} & \multirow[t]{2}{*}{ Model } & \multirow{2}{*}{$\begin{array}{c}\text { Test } \\
\text { span } \\
\text { (in) }\end{array}$} & \multicolumn{2}{|c|}{ Number of } & \multicolumn{2}{|c|}{ Condition } \\
\hline & & & elements & nodes & load & boundary \\
\hline Static & $\mathrm{BP}_{4}$ & 48 & 3840 & 3880 & 3 point bending & simple support \\
\hline Static & $\mathrm{BP}_{\mathrm{S}}$ & 48 & 3840 & 3880 & 4 point bending & simple support \\
\hline Static & $\mathrm{BP}_{\mathrm{M}}$ & 48 & 9984 & 9894 & 3 point bending & simple support \\
\hline Static & $\mathrm{BP}_{\mathrm{M}}$ & 48 & 9984 & 9894 & 4 point bending & simple support \\
\hline
\end{tabular}




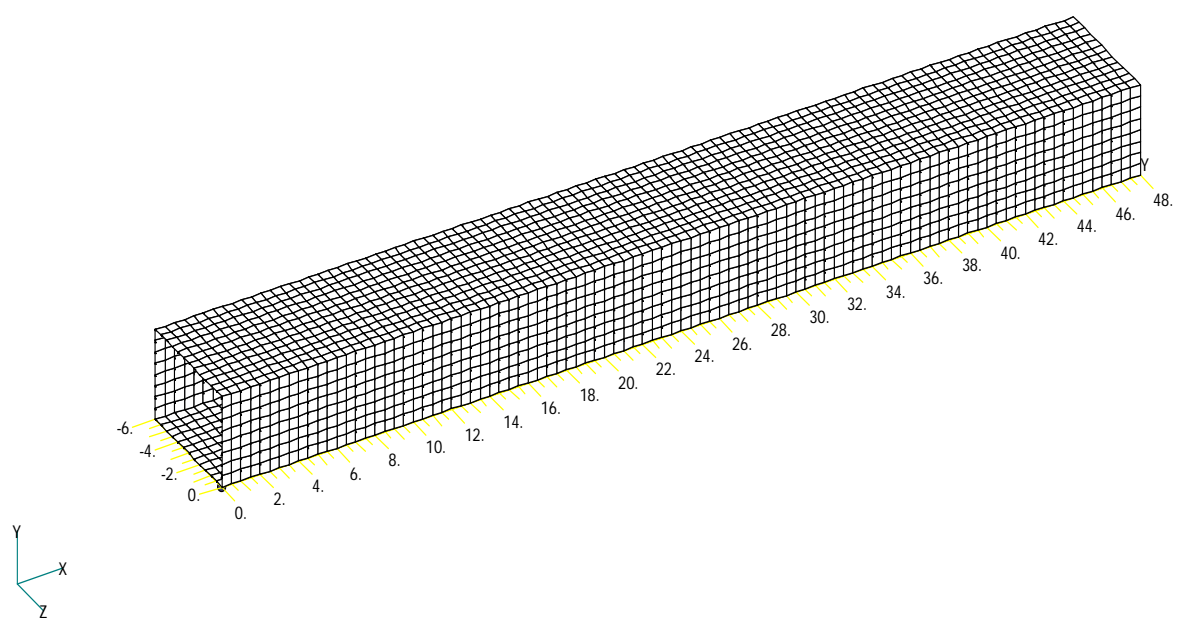

Figure 6.21 Finite element model BP4s

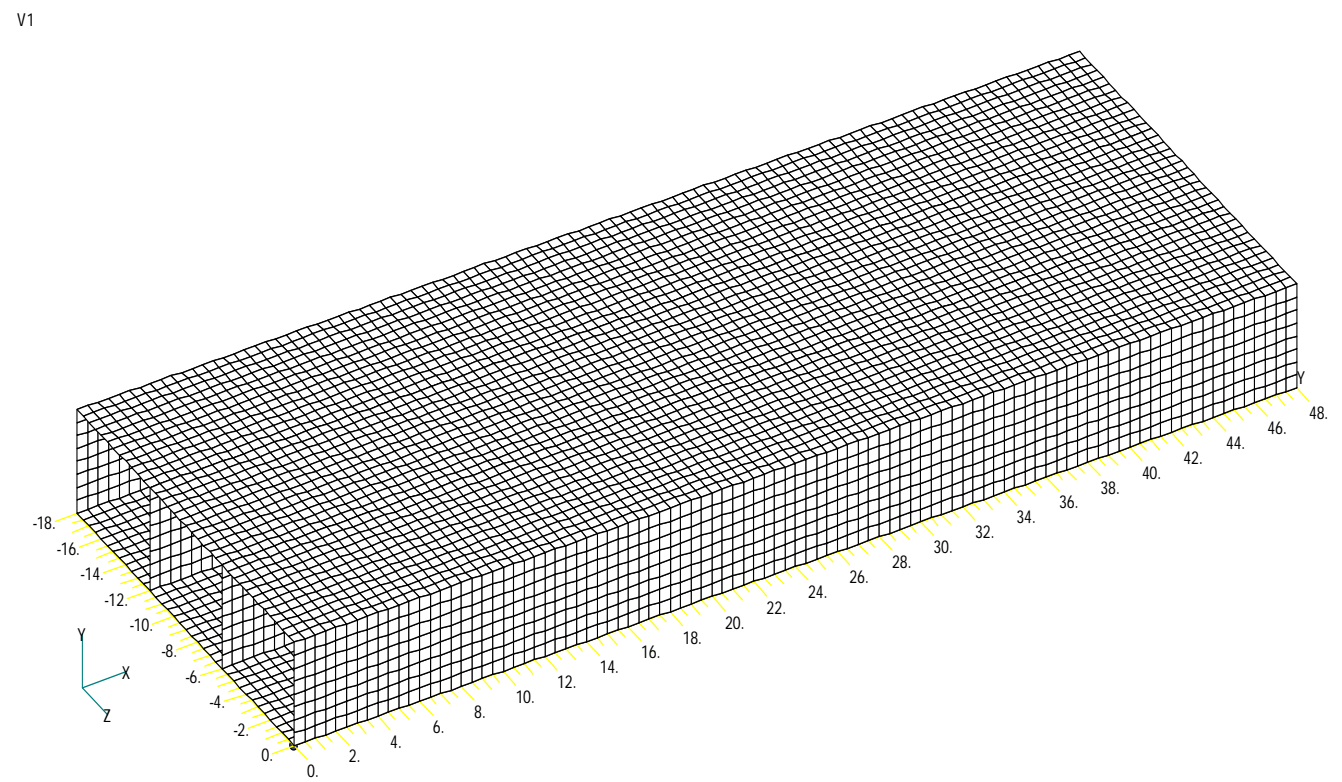

Figure 6.22 Finite element model BP4 $4_{M}$ 


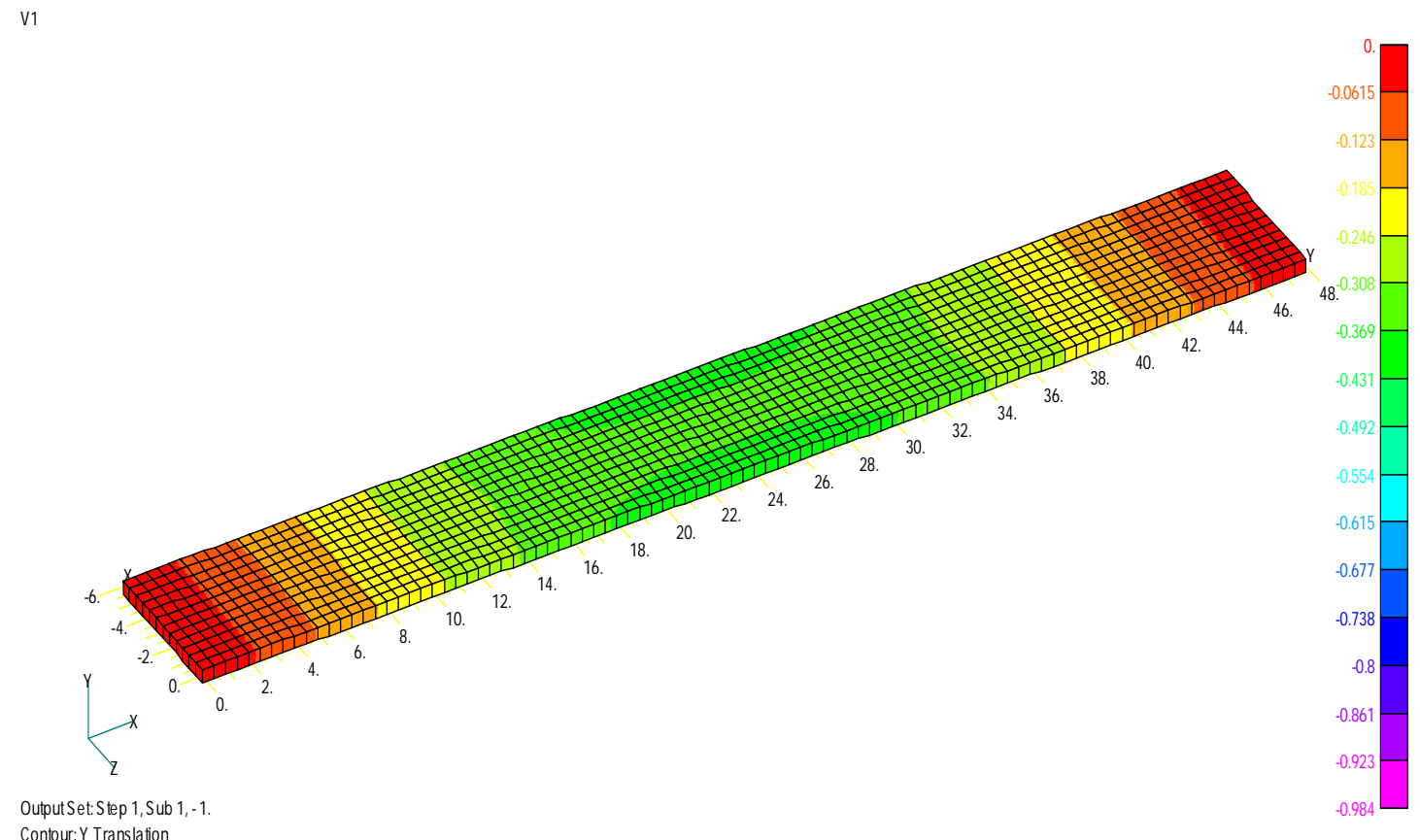

Figure 6.23 Y-deflection of BP4 $4_{s}$ under three-point bending (bottom flange)

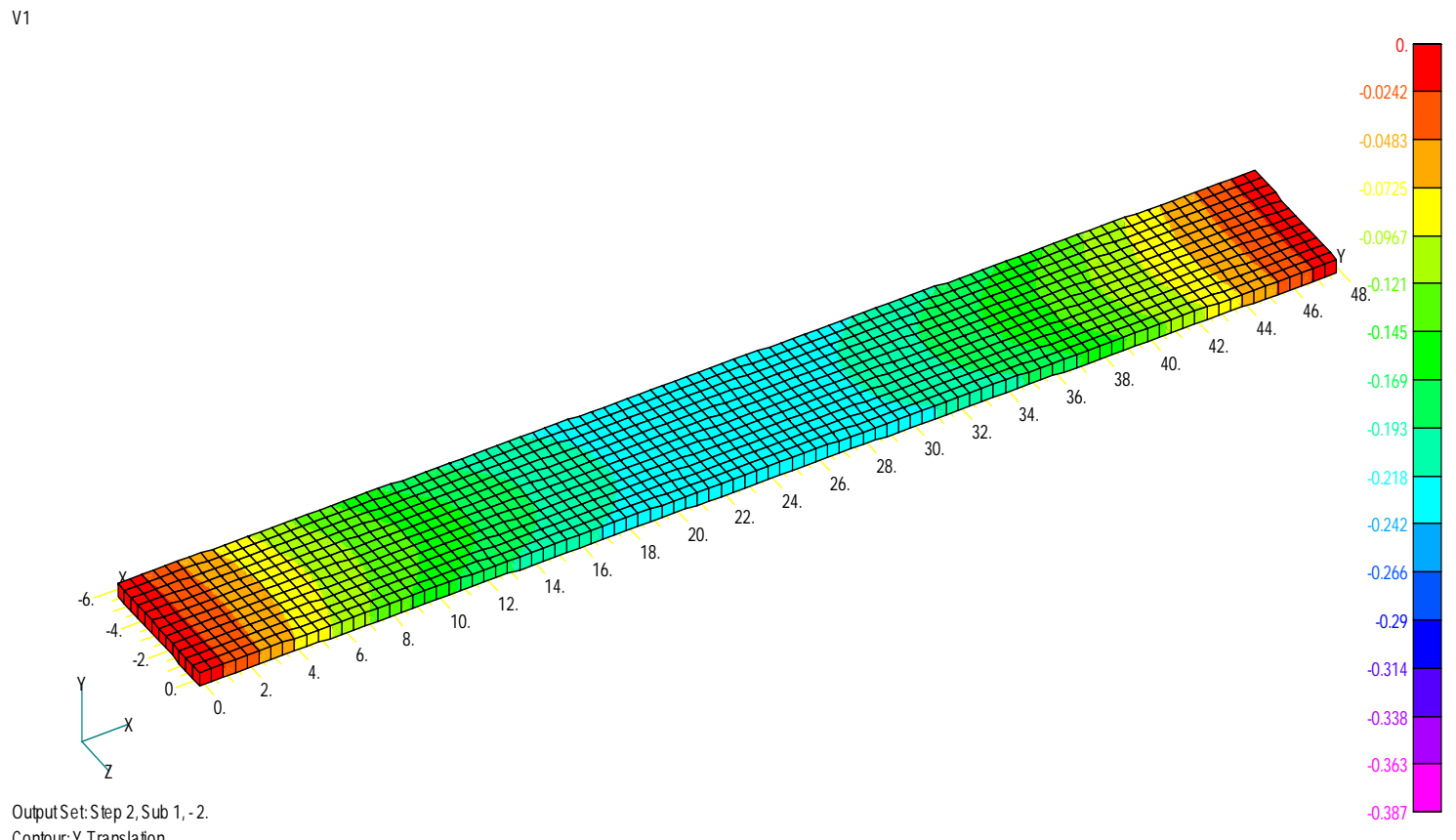

Figure 6.24 Y-deflection of BP4 ${ }_{S}$ under four-point bending (bottom flange) 

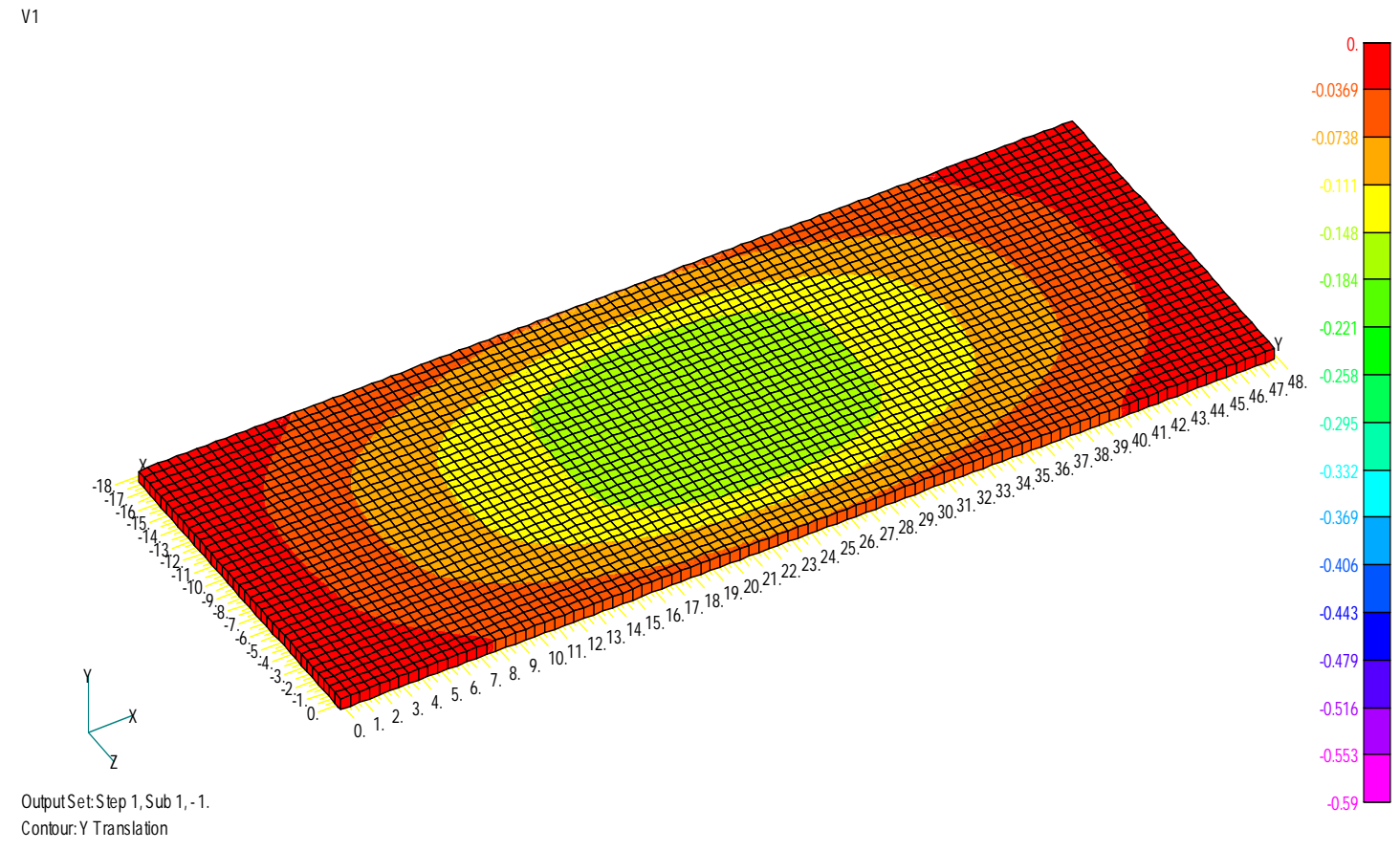

Figure 6.25 Y-deflection of $B P 4_{M}$ under three-point bending (bottom flange)
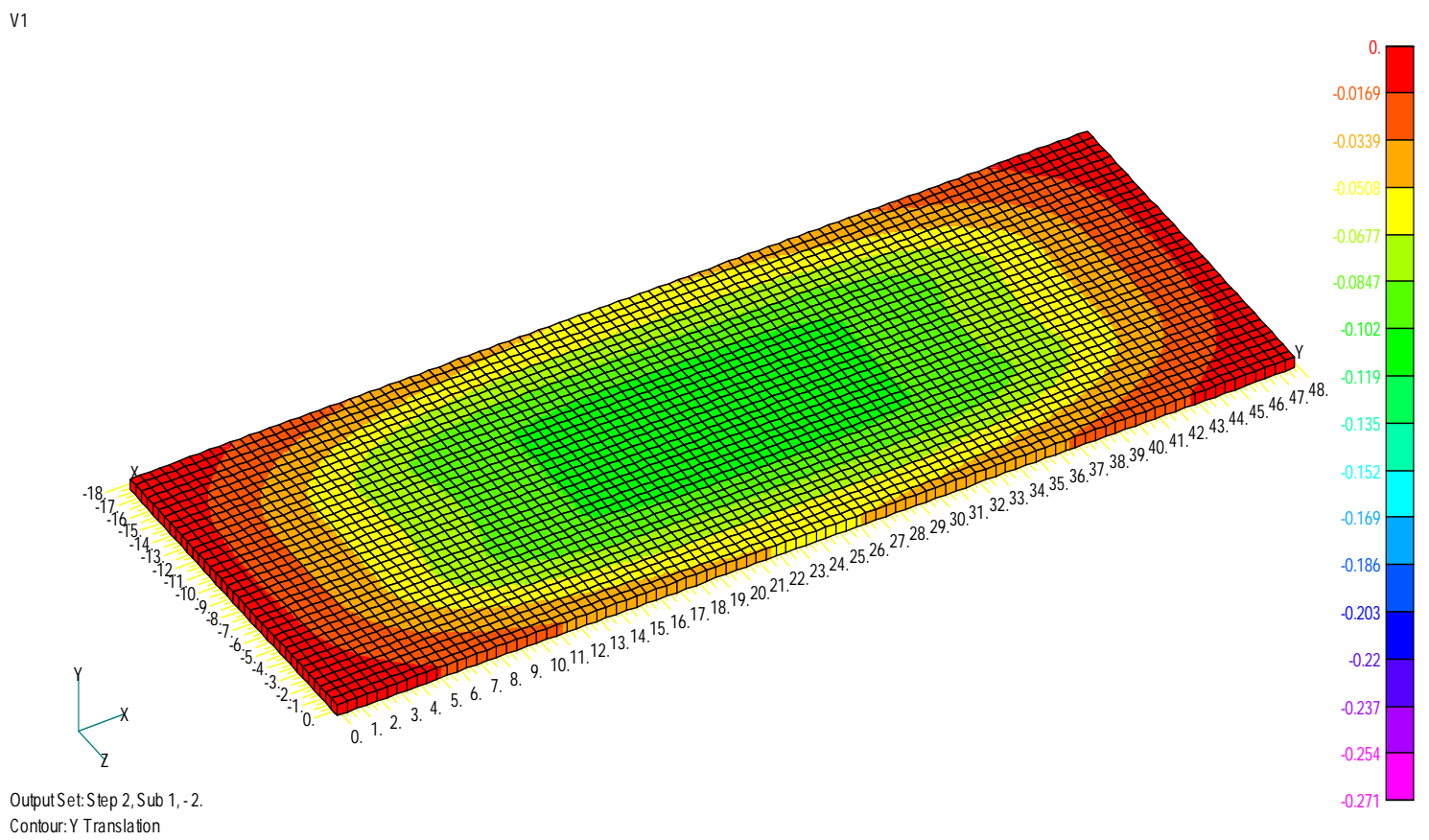

Figure 6.26 Y-deflection of $\mathrm{BP} 4_{\mathrm{M}}$ under four-point bending (bottom flange) 
Table 6.10 Slope of load-deflection curve from three and four point bending tests by FE

\begin{tabular}{|c|c|c|c|c|c|c|}
\hline \multirow[t]{2}{*}{ Specimen } & \multicolumn{2}{|c|}{ Three-point } & \multicolumn{4}{|c|}{ Four-point } \\
\hline & $\begin{array}{c}\delta_{\mathrm{m}} / \mathbf{P} \\
\left(\times 10^{-2}\right) \\
(\mathrm{in} / \mathrm{kin})\end{array}$ & $\begin{array}{c}\text { (slope) }_{3 p o i n t} \\
\text { (kip/in) }\end{array}$ & $\begin{array}{c}\delta_{\mathrm{m}} / \mathbf{P} \\
\left(\times \mathbf{1 0}^{-2}\right) \\
(\mathrm{in} / \mathbf{k i p})\end{array}$ & $\begin{array}{c}\delta_{\mathrm{a}} / \mathbf{P} \\
\left(\times 10^{-2}\right) \\
(\text { in } / \mathbf{k i p})\end{array}$ & $\begin{array}{c}\delta_{\text {net }} / \mathbf{P} \\
\left(\times \mathbf{1 0}^{-2}\right) \\
(\mathrm{in} / \mathrm{kip})\end{array}$ & $\begin{array}{c}\text { (slope) }_{4 p o i n t} \\
\text { (kip/in) }\end{array}$ \\
\hline $\mathrm{BP}_{4}$ & 3.48 & 28.7 & 2.32 & 1.841 & 0.479 & 209 \\
\hline $\mathrm{BP}_{\mathrm{M}}$ & 1.697 & 58.9 & 1.132 & 0.906 & 0.226 & 442 \\
\hline
\end{tabular}

Based on finite element data and further evaluation of longitudinal bending ( $\mathrm{x}$ ) and out-of-plane shear (xz) rigidity, slopes of load-deflection curves are substituted into Equations (6.6) and (6.9). The same procedures as given in the back calculation method based on deflection (slope approach) are followed for experimental data evaluation and comparison. It should be noted that both slope and applied load step approaches yield the same modulus results as calculated from finite element based deflection results because, linear elastic analysis is only used in this study.

\subsubsection{Comparison of Out-of-Plane Shear (xz) Modulus}

In this section, effective longitudinal elastic (x) and out-of-plane shear (xz) modulus found in previous sections are compared with each other. Summary of effective longitudinal elastic (x) and out-of-plane shear (xz) modulus from different methods is presented again and compared in Tables 6.11 and 6.12.

From comparison of experimental results, both longitudinal elastic (x) and out-ofplane shear (xz) modulus of the single cell specimen are slightly higher than those from multi-cell specimens. For the single cell specimen, longitudinal elastic (x) modulus and outof-plane shear (xz) modulus from finite element data are slightly larger than the experimental results. Out-of-plane shear (xz) modulus of multi-cell given by finite element method is also higher than that of experimental data. However, this trend is opposite for results of longitudinal elastic modulus (x). In addition, experimental results of longitudinal elastic (x) and out-of-plane shear (xz) modulus provided by different approaches of the back calculation 
methods are not significantly different form each other. Thus, back calculation methods presented in this study can be reasonably used to experimentally evaluate both longitudinal elastic (x) and out-of-plane shear (xz) modulus. Percent differences between experimental and analytical results of all specimens are evaluated and presented in Table 6.12.

Table 6.11 Summary of longitudinal elastic (x) and out-of-plane shear (xz) modulus

\begin{tabular}{|c|c|c|c|c|c|c|c|}
\hline \multirow[t]{2}{*}{ Specimen } & \multirow[t]{2}{*}{$\begin{array}{c}\text { Based } \\
\text { on }\end{array}$} & \multicolumn{2}{|c|}{$\begin{array}{c}\text { Cross-sectional } \\
\text { properties }\end{array}$} & \multicolumn{2}{|c|}{ Rigidity } & \multicolumn{2}{|c|}{$\begin{array}{l}\text { Effective } \\
\text { Modulus }\end{array}$} \\
\hline & & $\underset{\left(i^{4}\right)}{I}$ & $\begin{array}{c}A_{w} \\
\left(\text { in }^{2}\right)\end{array}$ & $\begin{array}{c}(E I)_{\mathrm{b}} \\
\left(\times 10^{4}\right) \\
\left(k i p-i^{2}\right)\end{array}$ & $\begin{array}{c}(A G)_{\mathrm{w}} \\
\left(\times 10^{3}\right) \\
(\text { kip })\end{array}$ & $\begin{array}{c}\left(E_{\mathrm{x}}\right)_{\mathrm{eff}} \\
\left(\times 10^{6}\right) \\
(\mathrm{psi})\end{array}$ & $\begin{array}{c}\left(G_{\mathrm{xz}}\right)_{\mathrm{eff}} \\
\left(\times 10^{6}\right) \\
(\mathrm{psi})\end{array}$ \\
\hline $\mathrm{BP}_{\mathrm{S}}$ & S-A & 18.65 & 2.35 & 8.81 & 1.159 & 4.72 & 0.493 \\
\hline $\mathrm{BP}_{\mathrm{M}}$ & S-A & 53.6 & 4.71 & 24.4 & 2.25 & 4.55 & 0.477 \\
\hline $\mathrm{BP} 4_{\mathrm{MJ}}$ & S-A & 53.6 & 4.71 & 22.5 & 2.13 & 4.19 & 0.451 \\
\hline $\mathrm{BP} 4_{\mathrm{S}}$ & L-S-A & 18.65 & 2.35 & 8.48 & 1.240 & 4.55 & 0.528 \\
\hline $\mathrm{BP}_{\mathrm{M}}$ & L-S-A & 53.6 & 4.71 & 22.5 & 2.32 & 4.20 & 0.492 \\
\hline $\mathrm{BP} 4_{\mathrm{MJ}}$ & L-S-A & 53.6 & 4.71 & 21.1 & 1.897 & 3.94 & 0.403 \\
\hline $\mathrm{BP}_{\mathrm{S}}$ & S-D & 18.65 & 2.35 & 8.96 & 1.172 & 4.81 & 0.498 \\
\hline $\mathrm{BP}_{4}$ & S-D & 53.6 & 4.71 & 23.3 & 2.33 & 4.35 & 0.496 \\
\hline $\mathrm{BP}_{\mathrm{MJ}}$ & S-D & 53.6 & 4.71 & 22.9 & 2.02 & 4.27 & 0.430 \\
\hline $\mathrm{BP}_{\mathrm{S}}$ & F.E. & 18.65 & 2.35 & 9.03 & 1.28 & 4.84 & 0.544 \\
\hline$B P 4_{M}$ & F.E. & 53.6 & 4.71 & 19.1 & 2.44 & 3.57 & 0.518 \\
\hline
\end{tabular}

Note: S-A : back calculation method based on deflection (slope approach)

L-S-A: back calculation method based on deflection (applied load step approach)

S-D : back calculation method based on strain-deflection

F.E. : finite element method

Table 6.12 Percent differences between experimental and finite element results

\begin{tabular}{|c|c|c|c|c|}
\hline \multirow[t]{2}{*}{ Specimen } & \multirow[t]{2}{*}{ Joints } & \multicolumn{3}{|c|}{ \% Difference of $\left(G_{\mathrm{xz}}\right)_{\text {eff }}$ compared with F.E. } \\
\hline & & $\begin{array}{c}\text { Slope } \\
\text { approach }\end{array}$ & $\begin{array}{l}\text { Load step } \\
\text { approach }\end{array}$ & $\begin{array}{c}\text { Strain- } \\
\text { deflection }\end{array}$ \\
\hline $\mathrm{BP}_{\mathrm{S}}$ & no & 9.38 & 2.94 & 8.46 \\
\hline $\mathrm{BP}_{\mathrm{M}}$ & no & 7.92 & 5.08 & 4.25 \\
\hline $\mathrm{BP} 4_{\mathrm{MJ}}$ & yes & 12.93 & 22.2 & 16.98 \\
\hline
\end{tabular}




\subsubsection{Out-of-Plane Shear (yz) Modulus}

To evaluate transverse bending (y) and out-of-plane shear (yz) rigidity, three and four point bending tests are conducted on transverse specimens with joints. Transverse specimens with joints usually include joints along the specimen width. The number of joints in these test specimens in transverse direction is considered to be an influencing factor in decoupling bending (y) and out-of plane shear (yz) rigidity for specimens with and without joints. For three-point bending, specimens with five joints are considered, while specimens under fourpoint bending are significantly influenced by the number of joints in terms of bending versus shear zone.
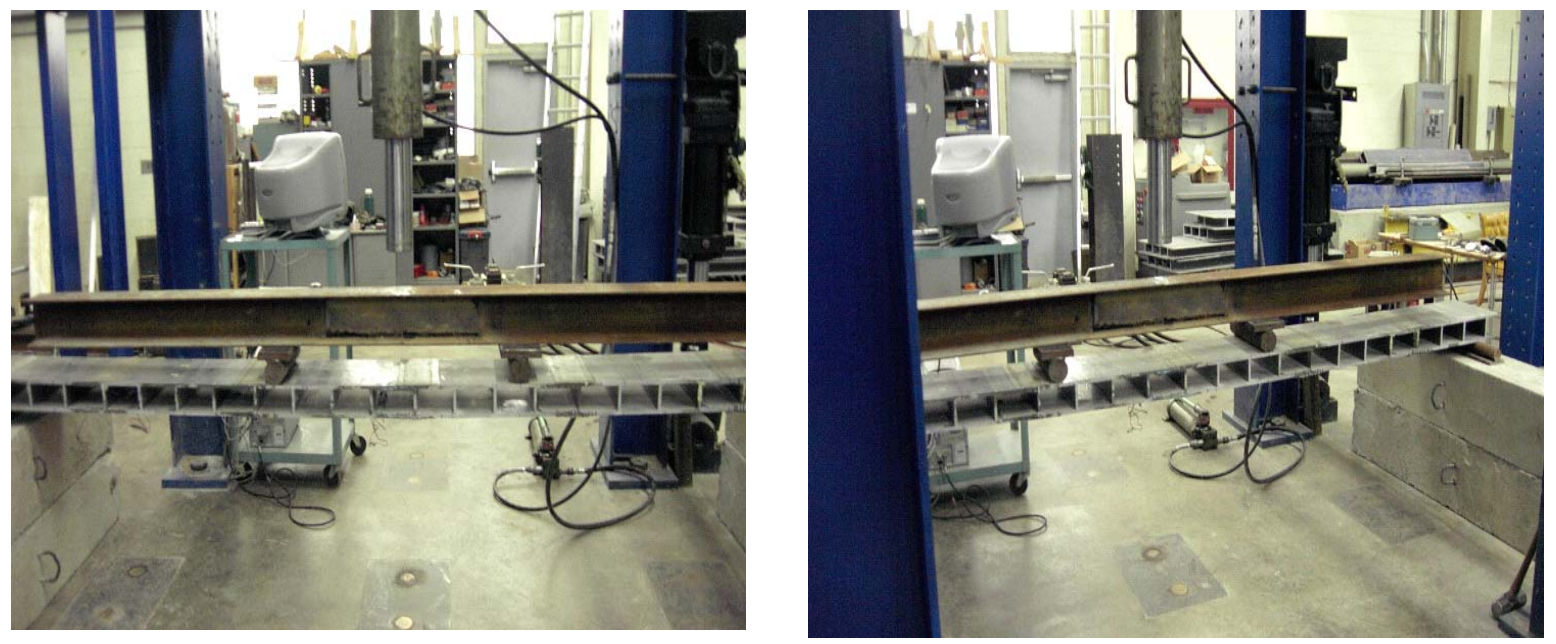

Figure 6.27 Transverse specimens under testing

Three different load cases are tested under four point bending to study the joint efficiency of transverse specimens with joints varying from 1 to 5 . Three different joint cases of four point bending are: 1) five joints under constant bending moment zone, 2) three joints under constant bending moment zone and 3) only one joint under constant bending moment zone. Bending rigidity from different joint cases is extrapolated for bending rigidity of specimens with five joints on bending versus shear zone. Deflection under bending rigidity is calculated and subtracted from experimental deflection under three point bending. 
Deflections by subtracting out-of-plane shear effects are used to evaluate out-of-plane shear rigidity on transverse specimens with five joints.

Simply supported test specimens of 132 inch span length are tested under bending. The back calculation procedure (strain-deflection in Section 6.2.2.2) is used to decouple bending (y) from out-of-plane (yz) rigidity. Based on strain readings from three and four point bending tests, bending rigidity (y) and elastic modulus (y) are determined and given in Table 6.13. The longitudinal strain results in constant shear and bending moment zones showed linear strain distribution and are presented in Figure 6.28. In addition, the strain values at specific loads for three different load cases are given below in Table 6.13.

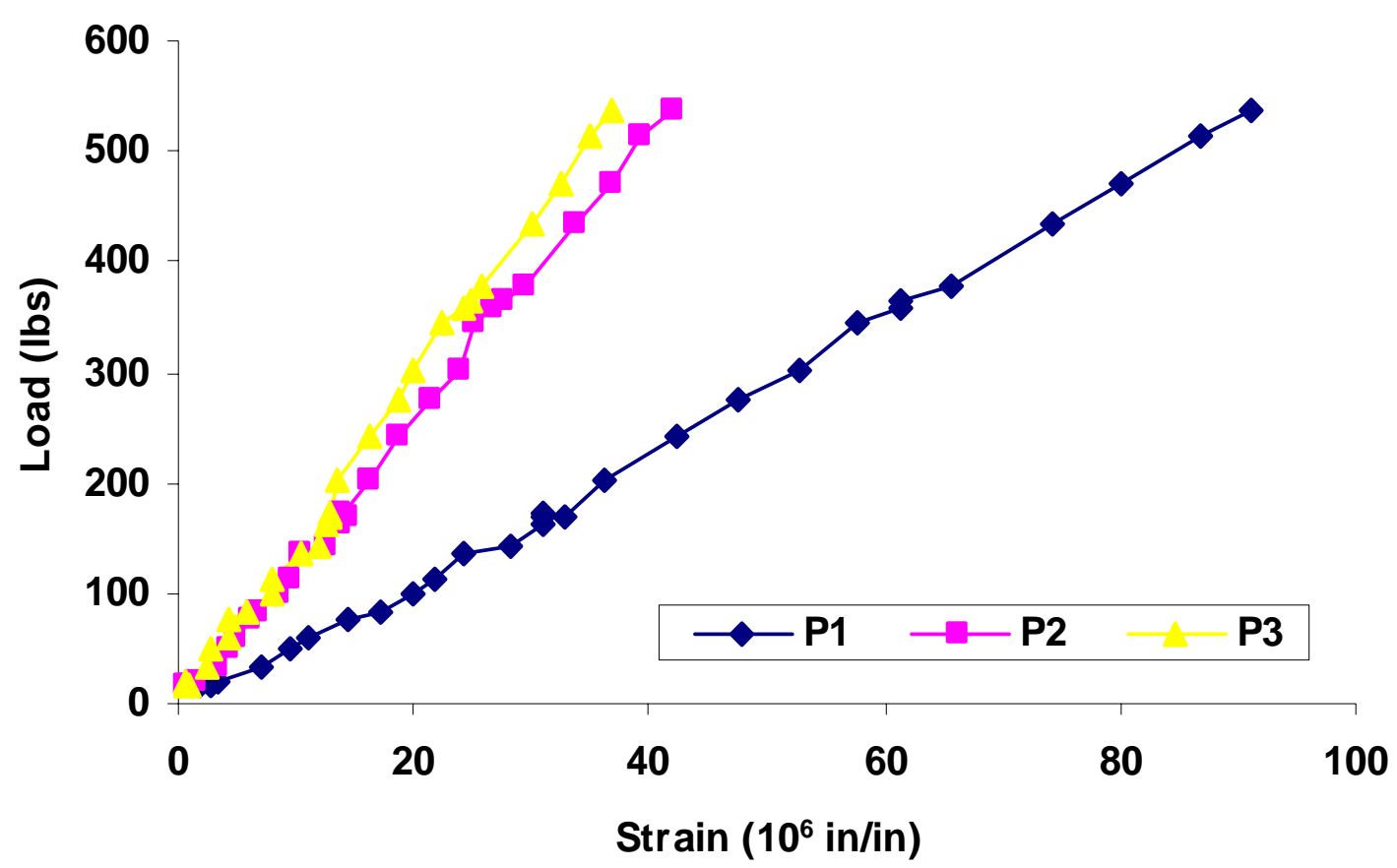

Figure 6.28 Example of linear strain distribution $\left(\mathrm{BP}^{4} \mathrm{~T}_{5 \mathrm{~J}}\right)$

Note: P1: longitudinal strain near support

P2: longitudinal strain between support and mid-span

P3: longitudinal strain at mid-span 
Table 6.13 Experimental results (strain approach) of transverse elastic modulus

\begin{tabular}{|c|c|c|c|c|c|c|c|c|}
\hline \multirow[t]{2}{*}{ Specimen } & \multicolumn{3}{|c|}{$\begin{array}{c}\text { Strain } \\
\left(10^{-6} \text { in/in }\right)\end{array}$} & \multirow[t]{2}{*}{$\begin{array}{c}\text { Load } \\
\text { (lbs) }\end{array}$} & \multirow[t]{2}{*}{$\begin{array}{c}a \\
\text { (in) }\end{array}$} & \multirow[t]{2}{*}{$\underset{\left(\mathrm{in}^{4}\right)}{I}$} & \multirow{2}{*}{$\begin{array}{c}(E I)_{\mathrm{b}} \\
\left(\times 10^{4}\right) \\
(\text { kip-in' })\end{array}$} & \multirow{2}{*}{$\begin{array}{c}\left(E_{\mathrm{y}}\right)_{\text {eff }} \\
\left(\times 10^{6}\right) \\
(\mathrm{psi})\end{array}$} \\
\hline & P1 & P2 & P3 & & & & & \\
\hline $\begin{array}{c}\mathrm{BP} 4 \mathrm{~T}_{5 \mathrm{~J}} \\
\text { (5 joint under bending zone) }\end{array}$ & 28.1 & 12.4 & 12.1 & 143.8 & 12 & 37 & 14.29 & 3.86 \\
\hline $\begin{array}{c}\mathrm{BP} 4 \mathrm{~T}_{3 \mathrm{~J}} \\
\text { (3 joint under bending zone) }\end{array}$ & 30.0 & 59.2 & 38.8 & 153.1 & 33 & 37 & 13.03 & 3.52 \\
\hline $\begin{array}{c}\mathrm{BP} \mathrm{T}_{1 \mathrm{~J}} \\
\text { (1 joint under bending zone) }\end{array}$ & 20.9 & 41.6 & 56.1 & 146.9 & 48 & 37 & 12.57 & 3.39 \\
\hline F.E. & - & - & 8.81 & 41.0 & 30 & 37 & 13.96 & 3.77 \\
\hline
\end{tabular}

The extrapolation of bending rigidity is accomplished by using results in Table 6.13. The bending rigidity of specimens with five joints on bending and shear zone is $12.1 \times 10^{4} \mathrm{ksi}$. In addition, the extrapolation of bending rigidity varying with number of joints is given in Figure 6.27.

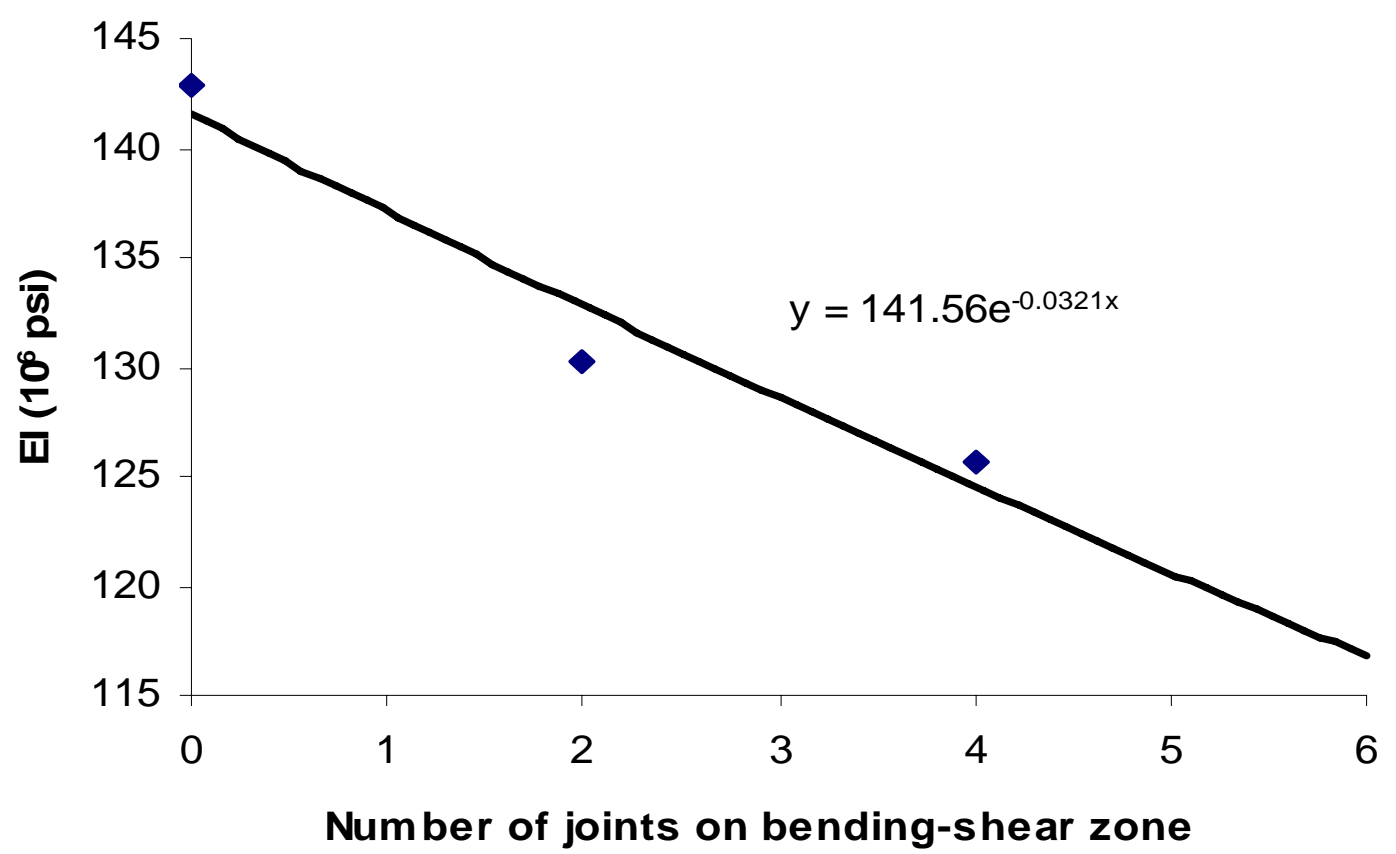

Figure 6.29 Extrapolation curve of bending rigidity for transverse specimen 
To compare out-of-plane shear (yz) rigidity, bending rigidity results from specimens with various joints on bending-shear zone are considered. However, actual values are obtained from (EI) with extrapolation of five joints on bending-shear zone. Experimental results of deflection and out-of-plane shear rigidity (yz) are given in Table 6.14.

Table 6.14 Experimental results (strain approach) of out-of-plane shear (yz) modulus

\begin{tabular}{|c|c|c|c|c|c|}
\hline \multirow[t]{2}{*}{ Case } & \multirow{2}{*}{$\begin{array}{c}A_{w} \\
\left(i^{2}\right)\end{array}$} & \multicolumn{2}{|c|}{ Deflection } & \multirow{2}{*}{$\begin{array}{c}(A G)_{\mathrm{w}} \\
\left(\times 10^{3}\right) \\
(\text { kip) }\end{array}$} & \multirow{2}{*}{$\begin{array}{c}\left(G_{\mathrm{yz}}\right)_{\text {eff }} \\
\left(\times 10^{6}\right) \\
(\mathrm{psi})\end{array}$} \\
\hline & & $\begin{array}{l}(\delta)_{\mathrm{b}} \\
\text { (in) }\end{array}$ & $\begin{array}{l}(\delta)_{\mathrm{S}} \\
\text { (in) }\end{array}$ & & \\
\hline $\begin{array}{c}\text { BP4T* } \\
\text { (EI from } 5 \text { joints on bending and shear zone) }\end{array}$ & 2.67 & 0.1199 & 0.00971 & 1.029 & 0.385 \\
\hline
\end{tabular}

Note: BP4T*: Bending rigidity is obtained by using extrapolation.

\subsubsection{Comparison of Out-of-Plane Shear (yz) Modulus}

Transverse elastic (y) and out-of-plane shear (yz) modulus based on strain and deflection approach of both longitudinal and transverse specimens with joints are summarized and compared in Table 6.15. Out-of-plane shear (yz) modulus is different from out-of-plane shear (xz) modulus by about $22.4 \%$. However, the percent difference between both out-of-plane shear moduli (xz and $\mathrm{yz}$ ) seems to be quite high. Transverse elastic modulus that is used to decouple bending and shear deflection is quite high due to 1) high measured strain value (local strain), 2) low measured deflections, and 3) interpolation results.

Table 6.15 Summary of elastic and out-of-plane shear modulus

\begin{tabular}{|c|c|c|c|c|c|c|}
\hline \multirow[t]{2}{*}{ Specimen } & \multirow[t]{2}{*}{ Direction } & \multirow[t]{2}{*}{$\begin{array}{c}\text { Based } \\
\text { on }\end{array}$} & \multicolumn{2}{|c|}{$\begin{array}{l}\text { Bending rigidity and } \\
\text { elastic modulus }\end{array}$} & \multicolumn{2}{|c|}{$\begin{array}{l}\text { Out-of-plane shear } \\
\text { rigidity and modulus }\end{array}$} \\
\hline & & & $\begin{array}{c}(E)_{\mathrm{b}} \\
\left(\times 10^{4}\right) \\
\left(\text { kip-in }^{2}\right)\end{array}$ & $\begin{array}{c}(E)_{\text {eff }} \\
\left(\times 10^{4}\right) \\
(\text { kip-in })\end{array}$ & $\begin{array}{c}(A G)_{\mathrm{w}} \\
\left(\times 10^{3}\right) \\
(\text { kip) }\end{array}$ & $\begin{array}{c}(G)_{\text {eff }} \\
\left(\times 10^{6}\right) \\
(p s i)\end{array}$ \\
\hline $\mathrm{BP}_{4}$ & Xz-plane & S-D & 23.3 & 0.435 & 23.3 & 0.496 \\
\hline BP4T* & yz-plane & S-D & 12.1 & 0.327 & 1.029 & 0.385 \\
\hline$\%$ difference & & & & 24.8 & & 22.4 \\
\hline
\end{tabular}

Note: BP4T* : Bending rigidity is obtained by an extrapolation value. 


\subsection{Evaluation of Reduction Factors of Bending Rigidity due to Shear Deformation}

The reduction factors of bending rigidity due to shear deformation of FRP deck specimens are considered in this section. These factors are experimentally evaluated by using elastic and out-of-plane shear modulus provided by the back calculation method and finite element method.

To present reduction in bending rigidity due to shear deformation, deflection equations of Timoshenko's beam theory are utilized. The deflection equation of Timoshenko's beam theory that includes deflections due to bending and shears effects is rearranged by writing deflection due to shear effect in terms of deflection due to bending. Therefore, deflection equation with shear effects is reduced to the deflection equation of simple beam bending theory with a reduction coefficient from shear effect. This coefficient presents the effect of shear contribution to bending rigidity under specific load conditions. Using mid-span deflection, total deflection can be written in the general expression as follows:

$\left(\delta_{m}\right)_{t}=\left(\delta_{m}\right)_{b}+\left(\delta_{m}\right)_{s}$

$\frac{\left(\delta_{m}\right)_{b}}{\left(\delta_{m}\right)_{s}}=f_{b s}$

Where, $\left(\delta_{m}\right)_{t}$ is total deflection at the mid-span, $\left(\delta_{m}\right)_{b}$ and $\left(\delta_{m}\right)_{s}$ are deflection of the mid-span due to bending and shear effect, $f_{b s}$ is ratio of deflection due to bending to shear effect. By substituting factor $\left(f_{b s}\right)$ into total deflection, Equation (6.14) is rewritten in terms of deflection due to bending effect and reduction factor.

$$
\begin{aligned}
& \left(\delta_{m}\right)_{t}=\left(\delta_{m}\right)_{b}\left(1+\frac{1}{f_{b s}}\right) \\
& \left(\delta_{m}\right)_{t}=\left(\delta_{m}\right)_{b}\left(1+\frac{1}{f_{b s}}\right)=\frac{\left(\delta_{m}\right)_{b}}{R_{b s}}
\end{aligned}
$$


Where, $R_{b s}$ is introduced to be the reduction factor of beam bending rigidity due to shear deformation under specific load. Using Equation (6.17) and deflection coefficient, reduction factors under three and four point bending are found as:

For three point bending:

$$
R_{b s}=\frac{1}{\left(1+\frac{48(E I)_{b}}{\kappa(A G)_{W} L^{2}}\right)}
$$

For four point bending:

$$
R_{b s}=\frac{1}{\left(1+\frac{48(E I)_{b} L}{a\left(3 L^{2}-4 a^{2}\right) \kappa(A G)_{W}}\right)}
$$

Where, $E I$ is bending rigidity about the bending axis and $(A G)_{w}$ is shear rigidity of beam cross section, $L$ is length of test span, $(a)$ is longitudinal length measured from the support to the applied load position and shear coefficient $(\kappa)$ is given to be 4 and 6 for three and four point bending test, respectively (Zureick, 1994).

Evaluation of reduction factors for ProDeck4 specimens is accomplished by using bending and shears modulus based on experimental and analytical results that are given in the previous Section 6.3. The reduction factors are determined and reported for test spans between 24 and 80 inches in length and 4 inch depth. Also, the reduction factors of ProDeck 4 are evaluated in both longitudinal and transverse directions. The results of reduction factors in this study are presented in Tables 6.16 through 6.22. According to those results, the relation between the reduction factors and the ratio of $L / d$ (test span to height) is demonstrated in Figures 6.30 through 6.36. 
Table 6.16 Shear reduction factor of specimen $\mathrm{BP}_{\mathrm{s}}$ under three point bending

\begin{tabular}{|c|c|c|c|c|c|}
\hline \multirow{2}{*}{$\begin{array}{c}\text { Span } \\
\text { length } \\
\text { (in) }\end{array}$} & \multirow{2}{*}{ L/d } & \multicolumn{4}{|c|}{$\begin{array}{c}\text { Reduction factors of beam } \\
\text { bending rigidity due to shear deformation }\end{array}$} \\
\cline { 3 - 6 } & & $\begin{array}{c}\text { Based on } \\
\text { S-A }\end{array}$ & $\begin{array}{c}\text { Based on } \\
\text { L-S-A }\end{array}$ & $\begin{array}{c}\text { Based on } \\
\text { S-D }\end{array}$ & $\begin{array}{c}\text { Based on } \\
\text { F.E. }\end{array}$ \\
\hline 24 & 6 & 0.3871 & 0.4123 & 0.3856 & 0.4050 \\
\hline 28 & 7 & 0.4623 & 0.4885 & 0.4607 & 0.4809 \\
\hline 32 & 8 & 0.5289 & 0.5550 & 0.5274 & 0.5475 \\
\hline 36 & 9 & 0.5869 & 0.6122 & 0.5855 & 0.6050 \\
\hline 40 & 10 & 0.6369 & 0.6609 & 0.6355 & 0.6541 \\
\hline 44 & 11 & 0.6797 & 0.7022 & 0.6784 & 0.6959 \\
\hline 48 & 12 & 0.7164 & 0.7373 & 0.7152 & 0.7314 \\
\hline 52 & 13 & 0.7477 & 0.7671 & 0.7466 & 0.7616 \\
\hline 56 & 14 & 0.7747 & 0.7925 & 0.7736 & 0.7875 \\
\hline 60 & 15 & 0.7978 & 0.8143 & 0.7969 & 0.8097 \\
\hline 64 & 16 & 0.8178 & 0.8330 & 0.8170 & 0.8288 \\
\hline 68 & 17 & 0.8352 & 0.8492 & 0.8344 & 0.8453 \\
\hline 72 & 18 & 0.8503 & 0.8633 & 0.8496 & 0.8597 \\
\hline 76 & 19 & 0.8636 & 0.8755 & 0.8629 & 0.8722 \\
\hline 80 & 20 & 0.8752 & 0.8863 & 0.8746 & 0.8832 \\
\hline
\end{tabular}

Table 6.17 Shear reduction factor of specimen $B P 4_{M}$ under three point bending

\begin{tabular}{|c|c|c|c|c|c|}
\hline $\begin{array}{c}\text { Span } \\
\text { length } \\
\text { (in) }\end{array}$ & L/d & \multicolumn{4}{|c|}{$\begin{array}{c}\text { Reduction factors of beam } \\
\text { bending rigidity due to shear deformation }\end{array}$} \\
\cline { 3 - 6 } & & $\begin{array}{c}\text { Based on } \\
\text { S-A }\end{array}$ & $\begin{array}{c}\text { Based on } \\
\text { L-S-A }\end{array}$ & $\begin{array}{c}\text { Based on } \\
\text { S-D }\end{array}$ & $\begin{array}{c}\text { Based on } \\
\text { F.E. }\end{array}$ \\
\hline 24 & 6 & 0.3069 & 0.3310 & 0.3243 & 0.3453 \\
\hline 28 & 7 & 0.3760 & 0.4024 & 0.3951 & 0.4179 \\
\hline 32 & 8 & 0.4404 & 0.4680 & 0.4604 & 0.4839 \\
\hline 36 & 9 & 0.4990 & 0.5268 & 0.5192 & 0.5427 \\
\hline 40 & 10 & 0.5515 & 0.5788 & 0.5714 & 0.5943 \\
\hline 44 & 11 & 0.5981 & 0.6245 & 0.6173 & 0.6393 \\
\hline 48 & 12 & 0.6391 & 0.6643 & 0.6575 & 0.6784 \\
\hline 52 & 13 & 0.6751 & 0.6990 & 0.6926 & 0.7123 \\
\hline 56 & 14 & 0.7068 & 0.7293 & 0.7232 & 0.7417 \\
\hline 60 & 15 & 0.7345 & 0.7556 & 0.75 & 0.7672 \\
\hline 64 & 16 & 0.7589 & 0.7787 & 0.7734 & 0.7895 \\
\hline 68 & 17 & 0.7804 & 0.7988 & 0.7939 & 0.8089 \\
\hline 72 & 18 & 0.7994 & 0.8166 & 0.8120 & 0.8260 \\
\hline 76 & 19 & 0.8161 & 0.8322 & 0.8279 & 0.8410 \\
\hline 80 & 20 & 0.8310 & 0.8461 & 0.8421 & 0.8542 \\
\hline
\end{tabular}


Table 6.18 Shear reduction factor of specimen $B P 4_{M J}$ under three point bending

\begin{tabular}{|c|c|c|c|c|c|}
\hline \multirow{2}{*}{$\begin{array}{c}\text { Span } \\
\text { length } \\
\text { (in) }\end{array}$} & \multirow{2}{*}{ L/d } & \multicolumn{4}{|c|}{$\begin{array}{c}\text { Reduction factors of beam } \\
\text { bending rigidity due to shear deformation }\end{array}$} \\
\cline { 3 - 6 } & & $\begin{array}{c}\text { Based on } \\
\text { S-A }\end{array}$ & $\begin{array}{c}\text { Based on } \\
\text { L-S-A }\end{array}$ & $\begin{array}{c}\text { Based on } \\
\text { S-D }\end{array}$ & $\begin{array}{c}\text { Based on } \\
\text { F.E. }\end{array}$ \\
\hline 24 & 6 & 0.3125 & 0.3018 & 0.2973 & 0.3453 \\
\hline 28 & 7 & 0.3822 & 0.3705 & 0.3655 & 0.4179 \\
\hline 32 & 8 & 0.4469 & 0.4346 & 0.4293 & 0.4839 \\
\hline 36 & 9 & 0.5056 & 0.4931 & 0.4878 & 0.5427 \\
\hline 40 & 10 & 0.5580 & 0.5457 & 0.5403 & 0.5943 \\
\hline 44 & 11 & 0.6043 & 0.5924 & 0.5872 & 0.6393 \\
\hline 48 & 12 & 0.6451 & 0.6336 & 0.6286 & 0.6784 \\
\hline 52 & 13 & 0.6809 & 0.6699 & 0.6652 & 0.7123 \\
\hline 56 & 14 & 0.7122 & 0.7018 & 0.6973 & 0.7417 \\
\hline 60 & 15 & 0.7396 & 0.7299 & 0.7256 & 0.7672 \\
\hline 64 & 16 & 0.7637 & 0.7546 & 0.7506 & 0.7895 \\
\hline 68 & 17 & 0.7848 & 0.7763 & 0.7726 & 0.8089 \\
\hline 72 & 18 & 0.8035 & 0.7955 & 0.7920 & 0.8260 \\
\hline 76 & 19 & 0.8200 & 0.8126 & 0.8093 & 0.8410 \\
\hline 80 & 20 & 0.8347 & 0.8277 & 0.8246 & 0.8542 \\
\hline
\end{tabular}

Table 6.19 Shear reduction factor of specimens $B P 4_{s}$ under four point bending

\begin{tabular}{|c|c|c|c|c|c|}
\hline $\begin{array}{c}\text { Span } \\
\text { length } \\
\text { (in) }\end{array}$ & L/d & \multicolumn{4}{|c|}{$\begin{array}{c}\text { Reduction factors of beam } \\
\text { bending rigidity due to shear deformation }\end{array}$} \\
\cline { 3 - 6 } & & $\begin{array}{c}\text { Based on } \\
\text { S-A }\end{array}$ & $\begin{array}{c}\text { Based on } \\
\text { L-S-A }\end{array}$ & $\begin{array}{c}\text { Based on } \\
\text { S-D }\end{array}$ & $\begin{array}{c}\text { Based on } \\
\text { F.E. }\end{array}$ \\
\hline 24 & 6 & 0.3943 & 0.4197 & 0.3929 & 0.4124 \\
\hline 28 & 7 & 0.4698 & 0.4961 & 0.4683 & 0.4885 \\
\hline 32 & 8 & 0.5365 & 0.5625 & 0.5350 & 0.5551 \\
\hline 36 & 9 & 0.5943 & 0.6194 & 0.5928 & 0.6122 \\
\hline 40 & 10 & 0.6439 & 0.6677 & 0.6426 & 0.6609 \\
\hline 44 & 11 & 0.6863 & 0.7085 & 0.6850 & 0.7023 \\
\hline 48 & 12 & 0.7225 & 0.7431 & 0.7213 & 0.7373 \\
\hline 52 & 13 & 0.7534 & 0.7725 & 0.7523 & 0.7671 \\
\hline 56 & 14 & 0.7799 & 0.7975 & 0.7789 & 0.7925 \\
\hline 60 & 15 & 0.8027 & 0.8188 & 0.8018 & 0.8143 \\
\hline 64 & 16 & 0.8223 & 0.8372 & 0.8215 & 0.8330 \\
\hline 68 & 17 & 0.8394 & 0.8531 & 0.8386 & 0.8492 \\
\hline 72 & 18 & 0.8542 & 0.8668 & 0.8534 & 0.8633 \\
\hline 76 & 19 & 0.8671 & 0.8788 & 0.8665 & 0.8756 \\
\hline 80 & 20 & 0.8785 & 0.8893 & 0.8779 & 0.8863 \\
\hline
\end{tabular}


Table 6.20 Shear reduction factor of specimen $B P 4_{M}$ under four point bending

\begin{tabular}{|c|c|c|c|c|c|}
\hline \multirow{2}{*}{$\begin{array}{c}\text { Span } \\
\text { length } \\
\text { (in) }\end{array}$} & L/d & \multicolumn{4}{|c|}{$\begin{array}{c}\text { Reduction factors of beam } \\
\text { bending rigidity due to shear deformation }\end{array}$} \\
\cline { 3 - 6 } & & $\begin{array}{c}\text { Based on } \\
\text { S-A }\end{array}$ & $\begin{array}{c}\text { Based on } \\
\text { L-S-A }\end{array}$ & $\begin{array}{c}\text { Based on } \\
\text { S-D }\end{array}$ & $\begin{array}{c}\text { Based on } \\
\text { F.E. }\end{array}$ \\
\hline 24 & 6 & 0.3134 & 0.3378 & 0.3310 & 0.3522 \\
\hline 28 & 7 & 0.3832 & 0.4098 & 0.4024 & 0.4253 \\
\hline 32 & 8 & 0.4479 & 0.4756 & 0.4680 & 0.4915 \\
\hline 36 & 9 & 0.5066 & 0.5344 & 0.5268 & 0.5502 \\
\hline 40 & 10 & 0.5590 & 0.5862 & 0.5788 & 0.6016 \\
\hline 44 & 11 & 0.6054 & 0.6316 & 0.6245 & 0.6463 \\
\hline 48 & 12 & 0.6461 & 0.6711 & 0.6643 & 0.6850 \\
\hline 52 & 13 & 0.6818 & 0.7054 & 0.6990 & 0.7185 \\
\hline 56 & 14 & 0.7130 & 0.7352 & 0.7293 & 0.7475 \\
\hline 60 & 15 & 0.7404 & 0.7612 & 0.7556 & 0.7726 \\
\hline 64 & 16 & 0.7645 & 0.7839 & 0.7787 & 0.7945 \\
\hline 68 & 17 & 0.7856 & 0.8037 & 0.7988 & 0.8136 \\
\hline 72 & 18 & 0.8042 & 0.8211 & 0.8166 & 0.8303 \\
\hline 76 & 19 & 0.8207 & 0.8364 & 0.8322 & 0.8450 \\
\hline 80 & 20 & 0.8353 & 0.8500 & 0.8461 & 0.8579 \\
\hline
\end{tabular}

Table 6.2 1 Shear reduction factor of specimen $B P 4_{M J}$ under four point bending

\begin{tabular}{|c|c|c|c|c|c|}
\hline $\begin{array}{c}\text { Span } \\
\text { length } \\
\text { (in) }\end{array}$ & L/d & \multicolumn{4}{|c|}{$\begin{array}{c}\text { Reduction factors of beam } \\
\text { bending rigidity due to shear deformation }\end{array}$} \\
\cline { 3 - 6 } & & $\begin{array}{c}\text { Based on } \\
\text { S-A }\end{array}$ & $\begin{array}{c}\text { Based on } \\
\text { L-S-A }\end{array}$ & $\begin{array}{c}\text { Based on } \\
\text { S-D }\end{array}$ & $\begin{array}{c}\text { Based on } \\
\text { F.E. }\end{array}$ \\
\hline 24 & 6 & 0.3190 & 0.3083 & 0.3038 & 0.3522 \\
\hline 28 & 7 & 0.3894 & 0.3776 & 0.3726 & 0.4253 \\
\hline 32 & 8 & 0.4544 & 0.4421 & 0.4368 & 0.4915 \\
\hline 36 & 9 & 0.5132 & 0.5007 & 0.4954 & 0.5502 \\
\hline 40 & 10 & 0.5655 & 0.5532 & 0.5479 & 0.6016 \\
\hline 44 & 11 & 0.6116 & 0.5997 & 0.5946 & 0.6463 \\
\hline 48 & 12 & 0.6521 & 0.6407 & 0.6357 & 0.6850 \\
\hline 52 & 13 & 0.6874 & 0.6766 & 0.6719 & 0.7185 \\
\hline 56 & 14 & 0.7184 & 0.7082 & 0.7037 & 0.7475 \\
\hline 60 & 15 & 0.7454 & 0.7358 & 0.7317 & 0.7726 \\
\hline 64 & 16 & 0.7691 & 0.7602 & 0.7562 & 0.7945 \\
\hline 68 & 17 & 0.7900 & 0.7816 & 0.7779 & 0.8136 \\
\hline 72 & 18 & 0.8083 & 0.8004 & 0.7970 & 0.8303 \\
\hline 76 & 19 & 0.8245 & 0.8172 & 0.8139 & 0.8450 \\
\hline 80 & 20 & 0.8388 & 0.8320 & 0.8290 & 0.8579 \\
\hline
\end{tabular}


Table 6.22 Shear reduction factor of specimens $\mathrm{BP}^{4} \mathrm{~T}_{1 \mathrm{~J}}$

\begin{tabular}{|c|c|c|c|}
\hline \multirow[t]{2}{*}{$\begin{array}{c}\text { Span } \\
\text { length } \\
\text { (in) }\end{array}$} & \multirow[t]{2}{*}{ L/d } & \multicolumn{2}{|c|}{$\begin{array}{l}\text { Reduction factors of beam } \\
\text { bending rigidity due to shear deformation }\end{array}$} \\
\hline & & Three point bending & Four point bending \\
\hline 40 & 10 & 0.4279 & 0.5020 \\
\hline 44 & 11 & 0.4750 & 0.5495 \\
\hline 48 & 12 & 0.5185 & 0.5921 \\
\hline 52 & 13 & 0.5583 & 0.6301 \\
\hline 56 & 14 & 0.5944 & 0.6639 \\
\hline 60 & 15 & 0.6272 & 0.6940 \\
\hline 64 & 16 & 0.6569 & 0.7207 \\
\hline 68 & 17 & 0.6837 & 0.7444 \\
\hline 72 & 18 & 0.7078 & 0.7656 \\
\hline 76 & 19 & 0.7297 & 0.7844 \\
\hline 80 & 20 & 0.7494 & 0.8013 \\
\hline 84 & 21 & 0.7673 & 0.8163 \\
\hline 88 & 22 & 0.7835 & 0.8299 \\
\hline 92 & 23 & 0.7982 & 0.8421 \\
\hline 96 & 24 & 0.8116 & 0.8531 \\
\hline 100 & 25 & 0.8238 & 0.8630 \\
\hline 104 & 26 & 0.8349 & 0.8720 \\
\hline 108 & 27 & 0.8450 & 0.8802 \\
\hline 112 & 28 & 0.8543 & 0.8877 \\
\hline 116 & 29 & 0.8628 & 0.8945 \\
\hline 120 & 30 & 0.8706 & 0.9007 \\
\hline
\end{tabular}




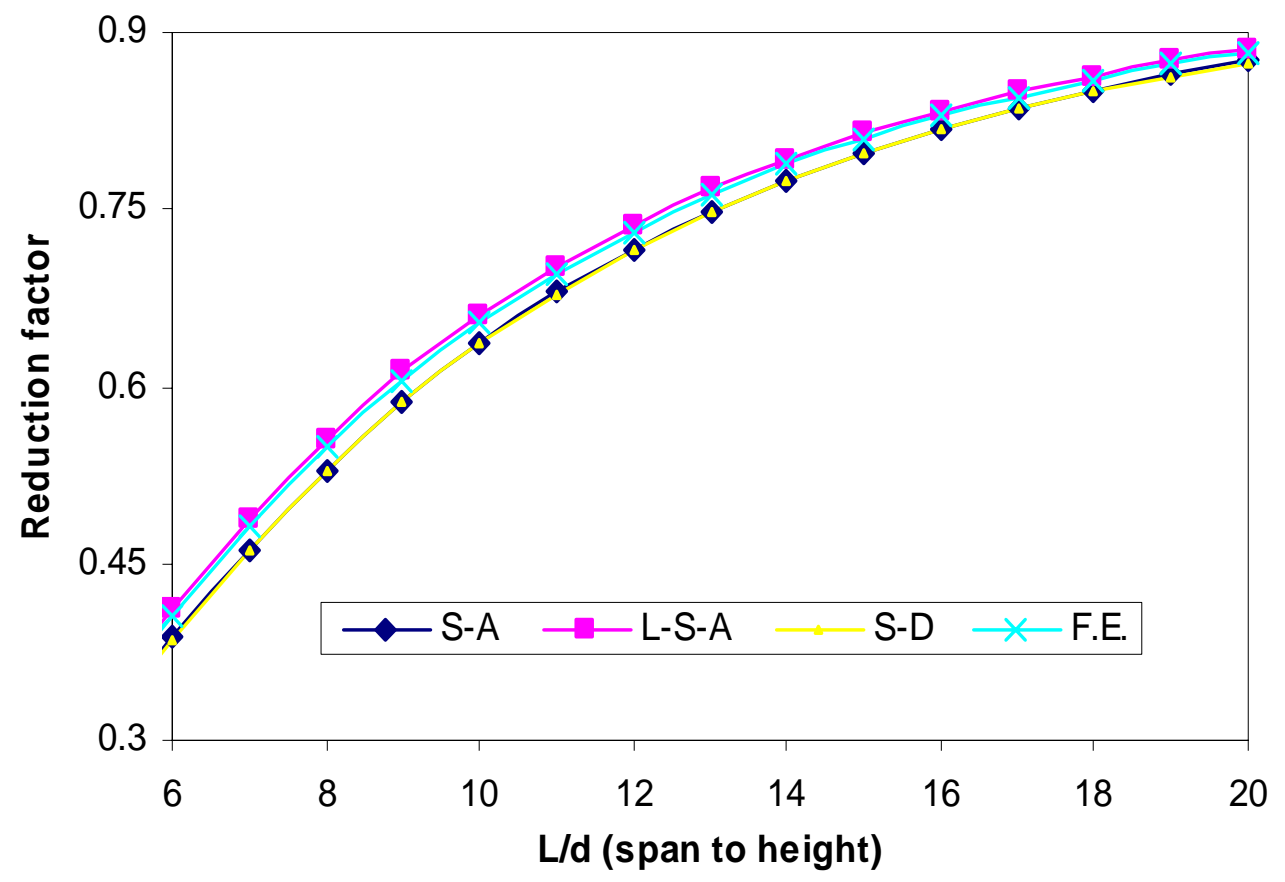

Figure 6.30 Shear reduction factors of $\mathrm{BP}_{\mathrm{S}}$ under three-point bending

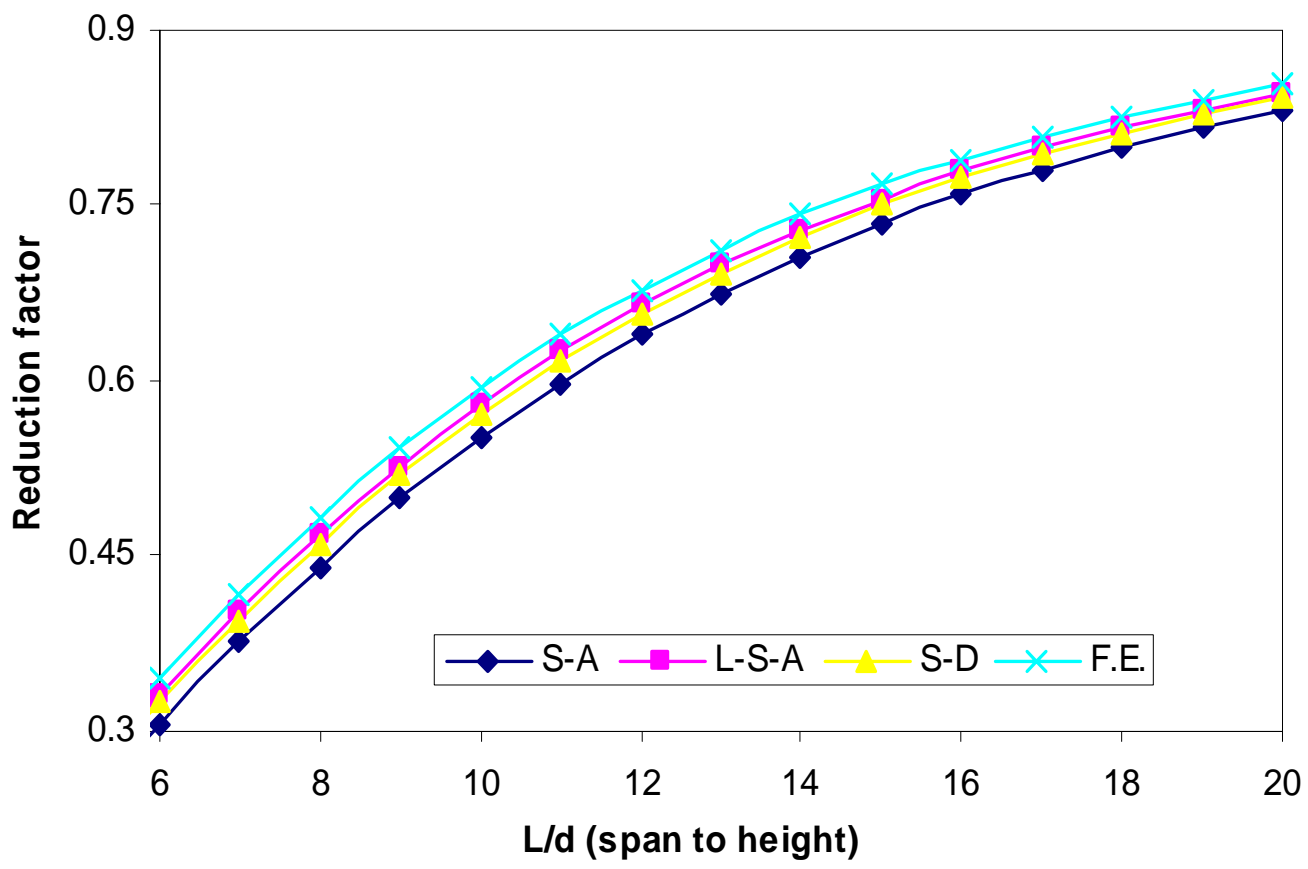

Figure 6.31 Shear reduction factors of $\mathrm{BP}_{\mathrm{M}}$ under three-point bending 


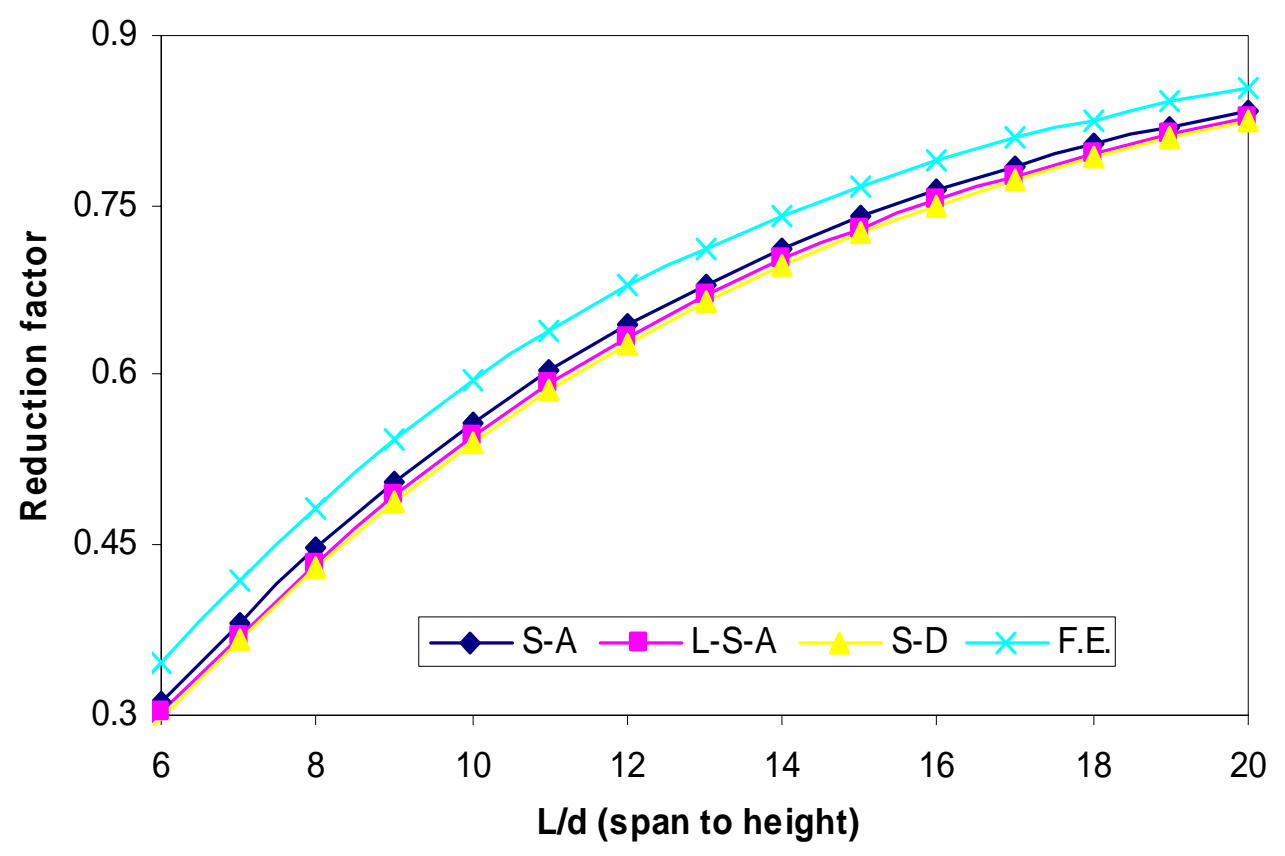

Figure 6.32 Shear reduction factors of $B P 4_{M J}$ under three-point bending

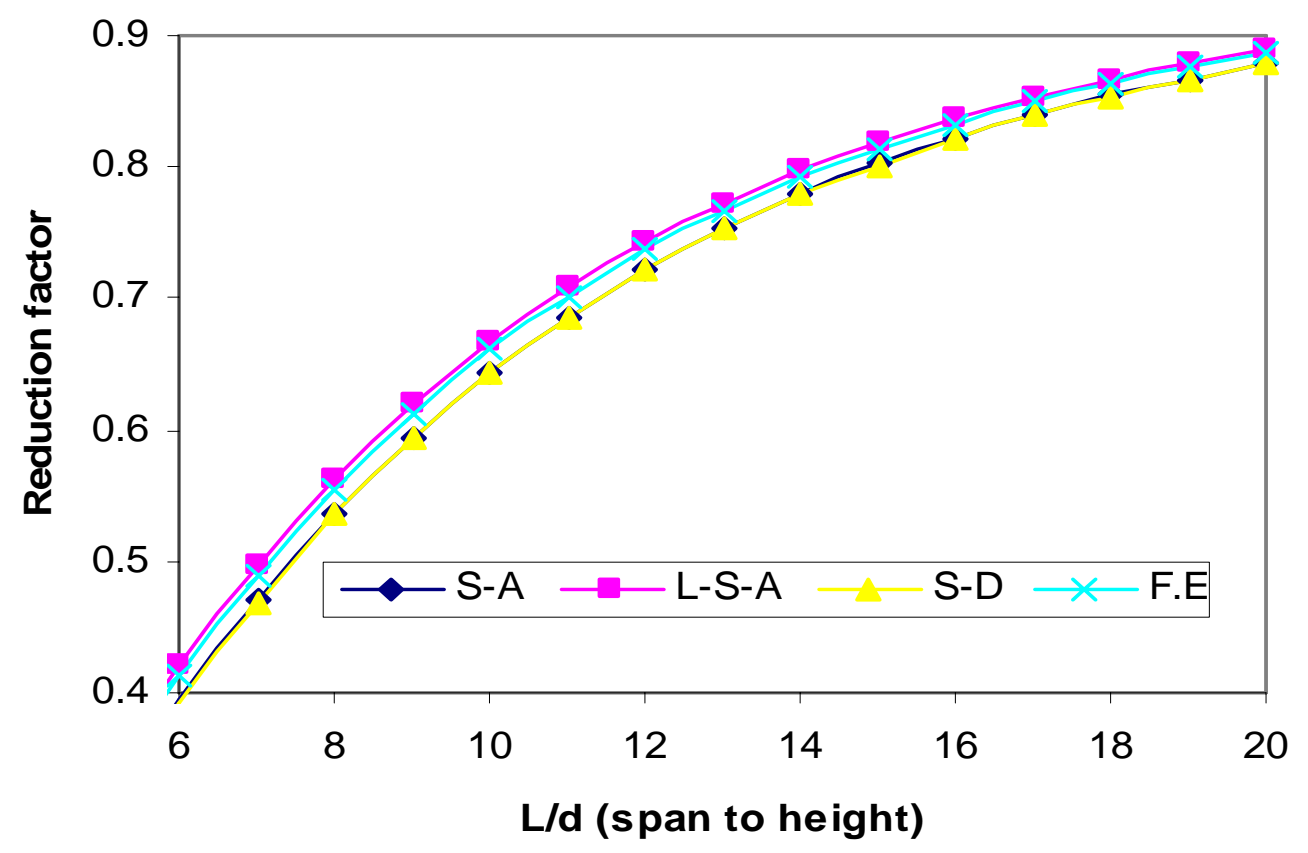

Figure 6.33 Shear reduction factor of $B P 4_{S}$ under four-point bending 


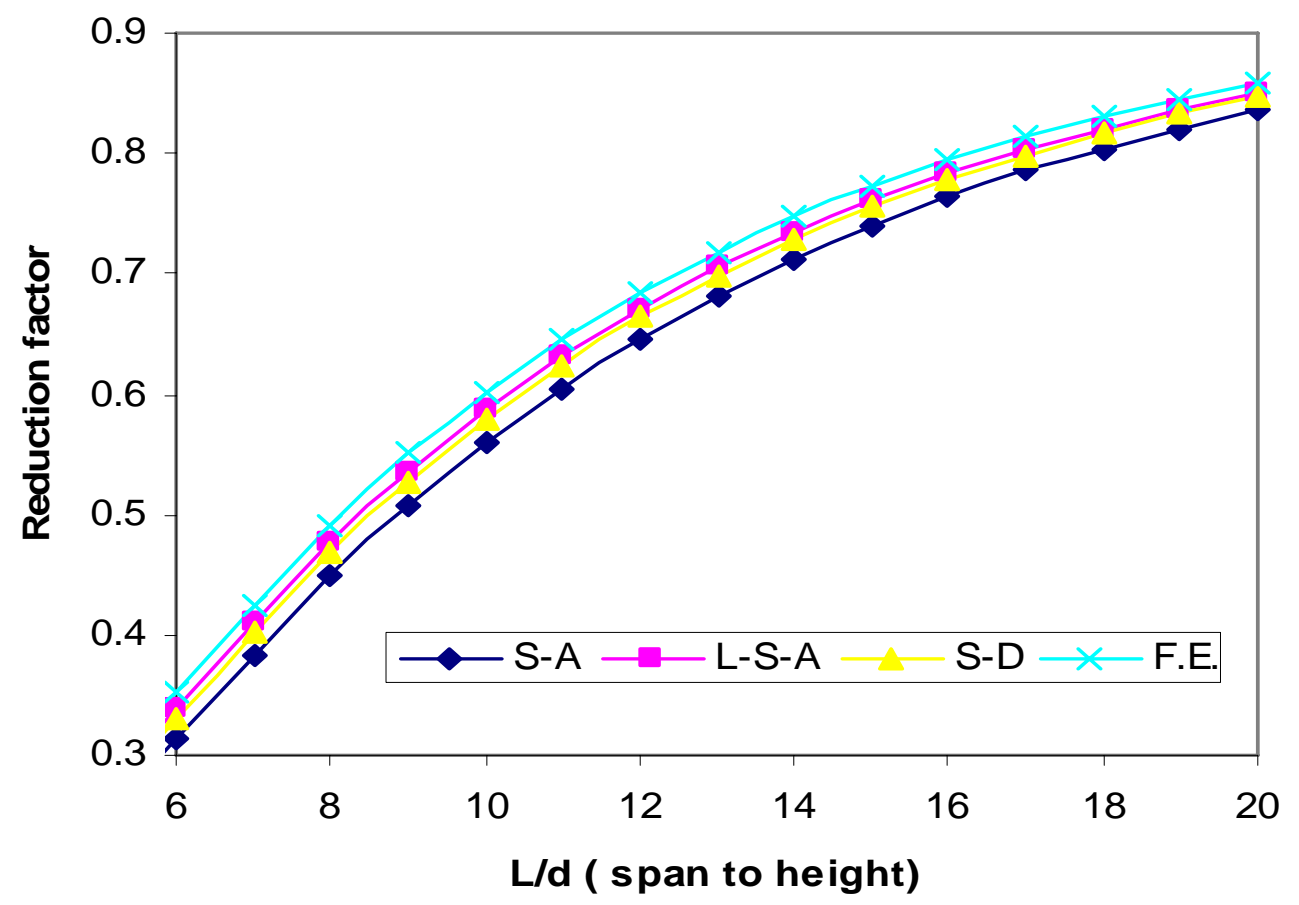

Figure 6.34 Shear reduction factor of $\mathrm{BP}_{\mathrm{M}}$ under four-point bending

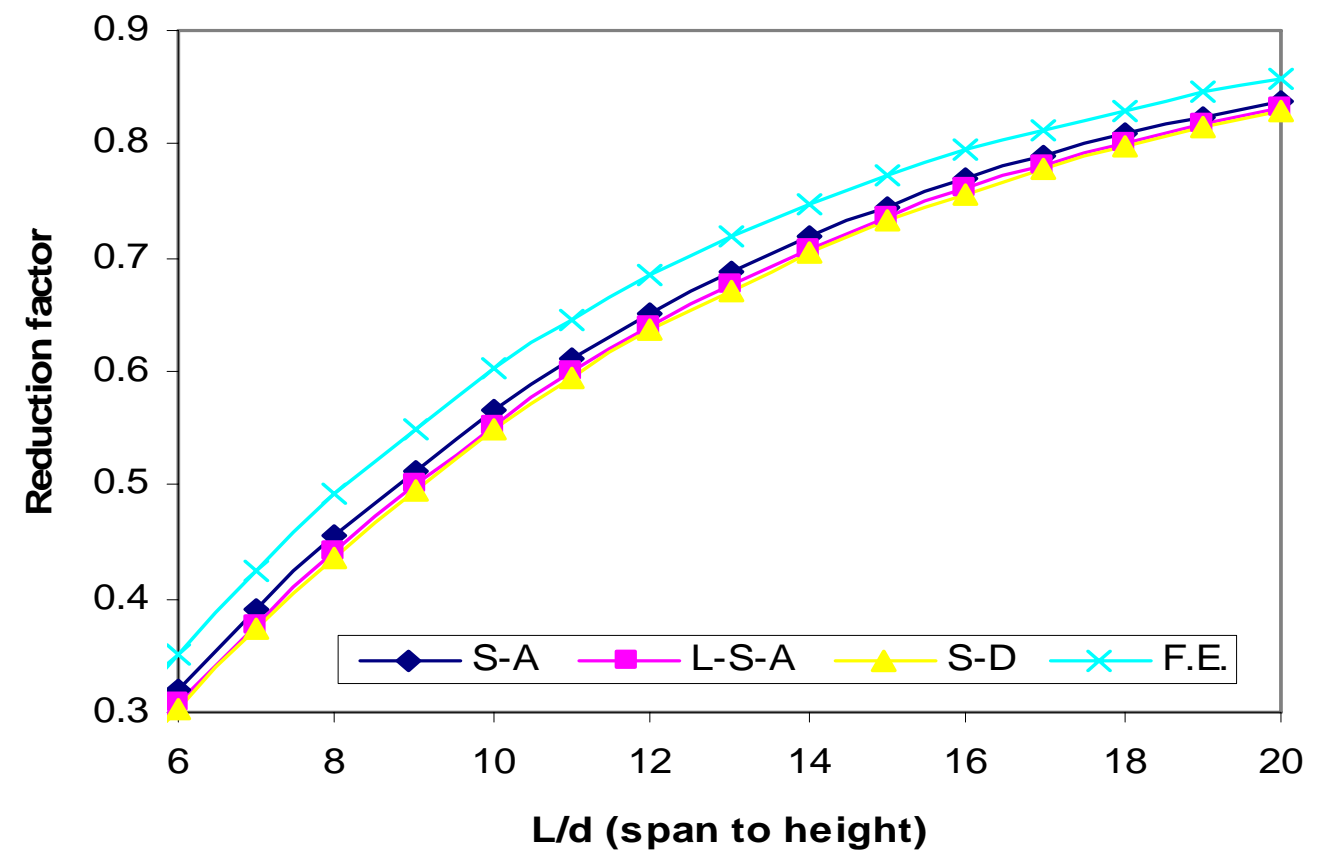

Figure 6.35 Shear reduction factor of $\mathrm{BP}_{\mathrm{MJ}}$ under four-point bending 


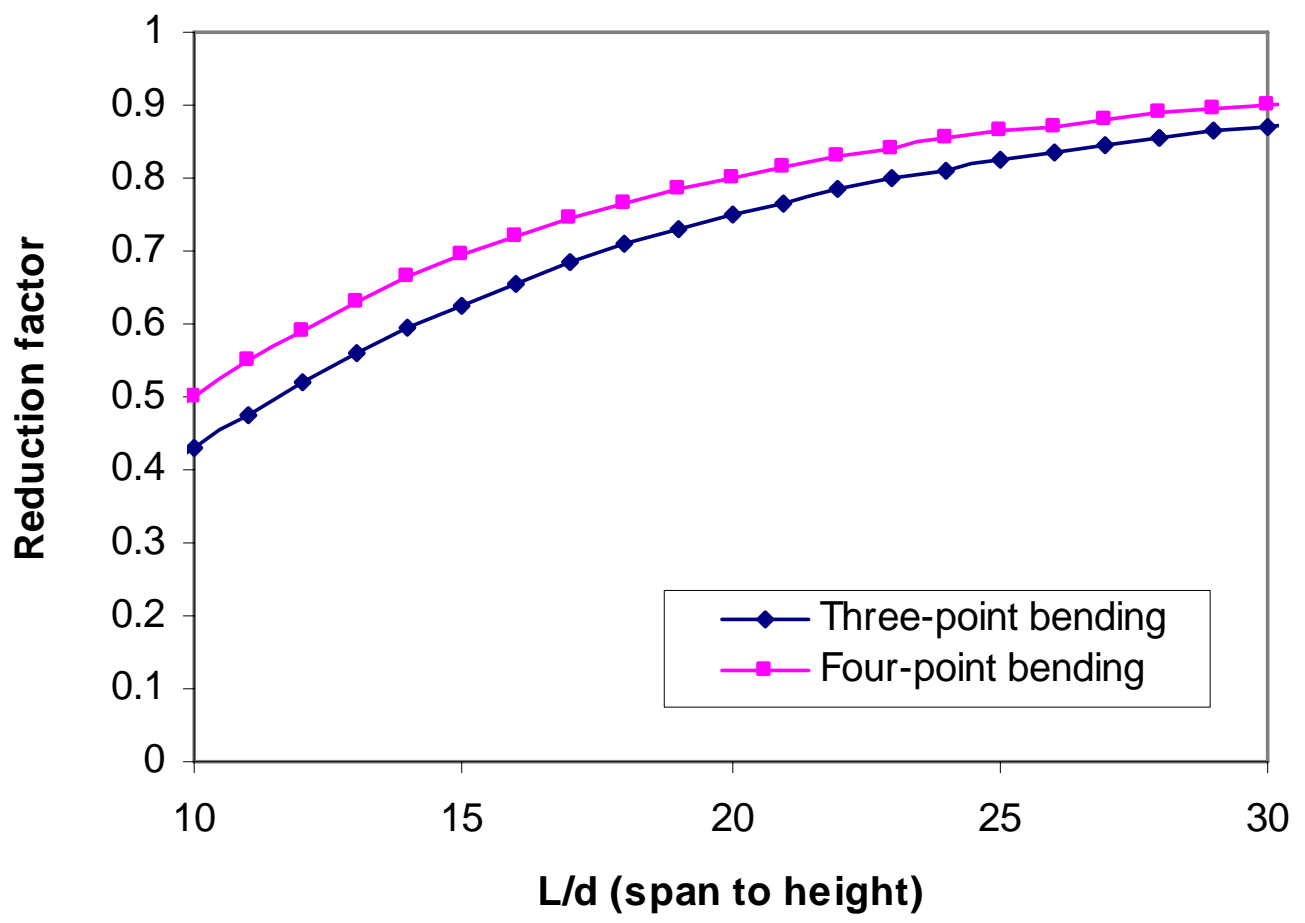

Figure 6.36 Shear reduction factor of $\left(\mathrm{BP}^{4} \mathrm{~T}_{1 \mathrm{~J}}\right)$

The experimental reduction factor for test spans varying from 24 and 80 inches of longitudinal single cell $\left(\mathrm{BP} 4_{\mathrm{S}}\right)$, multi-cell $\left(\mathrm{BP} 4_{\mathrm{M}}\right)$ and multi-cell with joints $\left(\mathrm{BP} 4_{\mathrm{MJ}}\right)$ specimens, under three point bending, ranged from 0.386 to $0.886,0.307$ to 0.846 and 0.297 to 0.835 , respectively. The shear effect is higher for multi-cell specimens than for single cell specimens due to 1) elastic and out-of-plane shear modulus results of single cell are higher than those of multi-cell cross section and 2) shear reduction factor in this study is calculated by using beam theory then, plate action of multi-cell cross sections is neglected. For the finite element results, this factor is found to be 0.405 to 0.883 and 0.345 to 0.854 , for $\mathrm{BP} 4_{\mathrm{S}}$ and $\mathrm{BP} 4_{\mathrm{M}}, \mathrm{BP} 4_{\mathrm{MJ}}$, respectively. The reduction factors are presented for experimental as well as numerical evaluations. Under four point bending, reduction factors based on experiments varied from 0.393 to $0.889,0.313$ to 0.850 and 0.304 to 0.839 for specimens $B P 4_{S}, B P 4_{M}$ and $\mathrm{BP} 4_{\mathrm{MJ}}$, respectively. However, results from finite element range from 0.412 to $0.886,0.352$ to 0.858 and 0.352 to 0.858 for specimens $\mathrm{BP} 4_{\mathrm{S}}, \mathrm{BP} 4_{\mathrm{M}}$ and $\mathrm{BP} 4_{\mathrm{MJ}}$, respectively. The reduction factor under four point bending is nearly same as under three point bending, 
recognizing finite element results are slightly higher than the experimental reduction factor. For the transverse specimen $\mathrm{BP}_{4} \mathrm{~T}_{1 \mathrm{~J}}$, the reduction factors of three and four point bending were found to be $0.427-0.871$ and $0.520-0.901$, respectively.

\subsection{Evaluation of Joint Efficiency}

Joint efficiency (ratio of experimental performance measured from the jointed system over the control system) is obtained by measuring system, strength, stiffness, deflection and strain, and comparing to the control system. The measured performances of the control system are provided by experimental or numerical methods. Longitudinal and transverse specimens under bending loads are evaluated for joint efficiency in this study.

\subsubsection{Joint Efficiency of Longitudinal Specimen}

In this section, joint efficiency under out-of-plane loading of longitudinal specimens with joints is presented in Table 6.23. The results of multi-cell component specimens without joints are used for comparison purposes. The performance measure of the system includes: 1) slope of load-deflection curve 2) strain data and 3) out-of-plane shear stiffness.

Table 6.23 Joint efficiency of longitudinal specimens

\begin{tabular}{|c|c|c|c|c|}
\hline \multirow[t]{2}{*}{ Load condition } & \multirow[t]{2}{*}{$\begin{array}{l}\text { Performace } \\
\text { measures }\end{array}$} & \multicolumn{2}{|c|}{$\begin{array}{c}\text { Values of } \\
\text { Certain items }\end{array}$} & \multirow{2}{*}{$\begin{array}{c}\text { Joint } \\
\text { efficiency } \\
(\%)\end{array}$} \\
\hline & & $\begin{array}{l}\text { Control } \\
\text { system }\end{array}$ & $\begin{array}{l}\text { Jointed } \\
\text { system }\end{array}$ & \\
\hline Three-point bending & \multirow{2}{*}{$\begin{array}{l}\text { Slope } \\
\text { (kip/in) }\end{array}$} & 67.6 & 63.0 & 93.2 \\
\hline Four-point bending & & 564 & 522 & 92.2 \\
\hline Three-point bending & \multirow{2}{*}{$\begin{array}{l}\text { Strain* } \\
\text { (shear) }\end{array}$} & 1076 & 1266 & 85.0 \\
\hline Four-point bending & & 595 & 684 & 86.9 \\
\hline \multirow{2}{*}{$\begin{array}{l}\text { Three and } \\
\text { four point bending }\end{array}$} & \multirow{2}{*}{$\begin{array}{l}\text { Out-of- } \\
\text { plane shear } \\
\text { rigidity } \\
\left(\times 10^{3} \mathrm{kip}\right)\end{array}$} & $\begin{array}{c}2.32 \\
(\mathrm{~L}-\mathrm{S}-\mathrm{A})\end{array}$ & 1.897 & 81.8 \\
\hline & & $\begin{array}{l}2.33 \\
(\mathrm{~S}-\mathrm{D})\end{array}$ & 2.02 & 86.7 \\
\hline
\end{tabular}

Note: L-S-A : back calculation method based on deflection (applied load step approach) S-D : back calculation method based on strain-deflection Strain*: shear strain at bottom flange from rosette strain gages 


\subsubsection{Joint Efficiency of Transverse Specimen}

For transverse specimens under out-of-plane loading, joint efficiency is evaluated using bending rigidity as a performance measure. Transverse specimens with joints located in the bending zone are chosen to be the control systems. The joint efficiency of transverse specimens significantly depends on the number of joints in bending versus shear zone. Two systems include: 1) two joints on bending versus shear zone, and 2) four joints on bending versus shear zone, and are given in Table 6.24.

Table 6.24 Joint efficiency of Transverse specimens

\begin{tabular}{|c|c|c|c|}
\hline \multirow[t]{2}{*}{ Load condition } & \multicolumn{2}{|c|}{$\begin{array}{c}\text { Bending Rigidity } \\
\left(\times 10^{4} \text { kip-in }{ }^{2}\right)\end{array}$} & \multirow{2}{*}{$\begin{array}{c}\text { Joint } \\
\text { efficiency } \\
(\%)\end{array}$} \\
\hline & $\begin{array}{l}\text { Control } \\
\text { system }\end{array}$ & $\begin{array}{c}\text { Interested } \\
\text { system }\end{array}$ & \\
\hline $\begin{array}{c}\text { Two joints in } \\
\text { bending-shear zone }\end{array}$ & 14.29 & 13.03 & 91.2 \\
\hline $\begin{array}{c}\text { Four joints in } \\
\text { bending-shear zone }\end{array}$ & 14.29 & 12.57 & 88.0 \\
\hline
\end{tabular}

\subsection{Discussion of Experimental Results}

Bending and shear behavior of FRP composite decks under three and four point bending in the linear elastic range are studied and reported in this section. For longitudinal specimens, two experimental evaluation methods (back calculation based on deflection and strain-deflection) are used. It is found that out-of-plane shear modulus results based on experimental evaluations are sensitive to net deflection, particularly in case of slope approach. To reduce errors, the applied load step approach is used to evaluate elastic and outof-plane shear modulus for every applied load step since processing of this method leads to variation of results. The finite element approach is used to validate experimental results. The results of both experimental approaches have provided good comparison with data from the finite element approach. In particular, the applied load step approach provided excellent results for out-of-plane shear modulus for specimens $\mathrm{BP} 4_{\mathrm{S}}$ and $\mathrm{BP} 4_{\mathrm{M}}$ compared with the data 
from finite element method. It should be noted that the comparison between the experimental and finite element approach of specimens with joints along the longitudinal direction $\left(\mathrm{BP} 4_{\mathrm{MJ}}\right)$ is not accurate because of the absence of incorporating joint properties in the finite element approach. For transverse specimens, back calculation based on strain-deflection response is used to evaluate bending (y) and out-of-plane (yz) shear rigidity. Elastic modulus (y) and outof-plane shear (yz) modulus for experimental data are quite high due to several reasons, as given in Section 6.3.2.5.

\subsection{Size Limits due to Shear Deformation}

When FRP structural members are subjected to in-plane and out-of-plane shear loading, induced shear stress need to be computed for design. However, several structural issues such as shear deformation, and local-lateral torsional buckling can be established by properly conducting accurate analysis and selecting geometry. For shear deformation due to low ratio ( $\sim 12 \%$ for FRP when compared to $40 \%$ in steel) between the shear modulus and modulus of elasticity, FRP structural members under bending are susceptible to larger shear deformation than in steel. Hence, size limit for beam depth to length ratio has to be established using deflection data. Generally, total deflection of FRP structural members includes: 1) deflection due to bending $\delta_{b}$, and 2) deflection due to shear $\delta_{s}$. To analyze the contribution of shear deformation, total deflection is written in terms of deflection due to bending and shear reduction constant as given in Section 6.4.

$\delta_{t}=\delta_{b}+\delta_{s}$

$\delta_{t}=\delta_{b}\left(1+\frac{\delta_{s}}{\delta_{b}}\right)$

Where, $\delta_{t}$ is the total deflection at mid span, $\delta_{b}$ and $\delta_{s}$ are deflections due to bending and shear , respectively. 
To establish size limits due to shear deformation effect, maximum deflection due shear deformation assumes to be about $15 \%$ of total deflection. Therefore, reduction constant $R$ due to shear in Equation (6.20) is given as:

$\frac{1}{\left(1+\frac{\delta_{s}}{\delta_{b}}\right)}=R=\frac{\delta_{b}}{\delta_{t}}=0.85$

Size limits (depth to length ratio) of several FRP structural members, such as: 1) ProDeck4 single cell, 2) ProDeck4 multi-cell, and 3) ProDeck4 multi-cell with joints under three and four point bending, are determined in this section.

To evaluate depth to length ratios, the reduction factor of beam bending rigidity due to shear deformation based on experimental and finite element data given in Section 6.4 is utilized as given in Equation (6.21). Size limits of ProDeck4 single cell components under three point bending are illustrated in Figure 6.37 for a specific case. From the results given in Tables 6.16 through 6.21, experimental and finite element data are plotted in Figure 6.37.

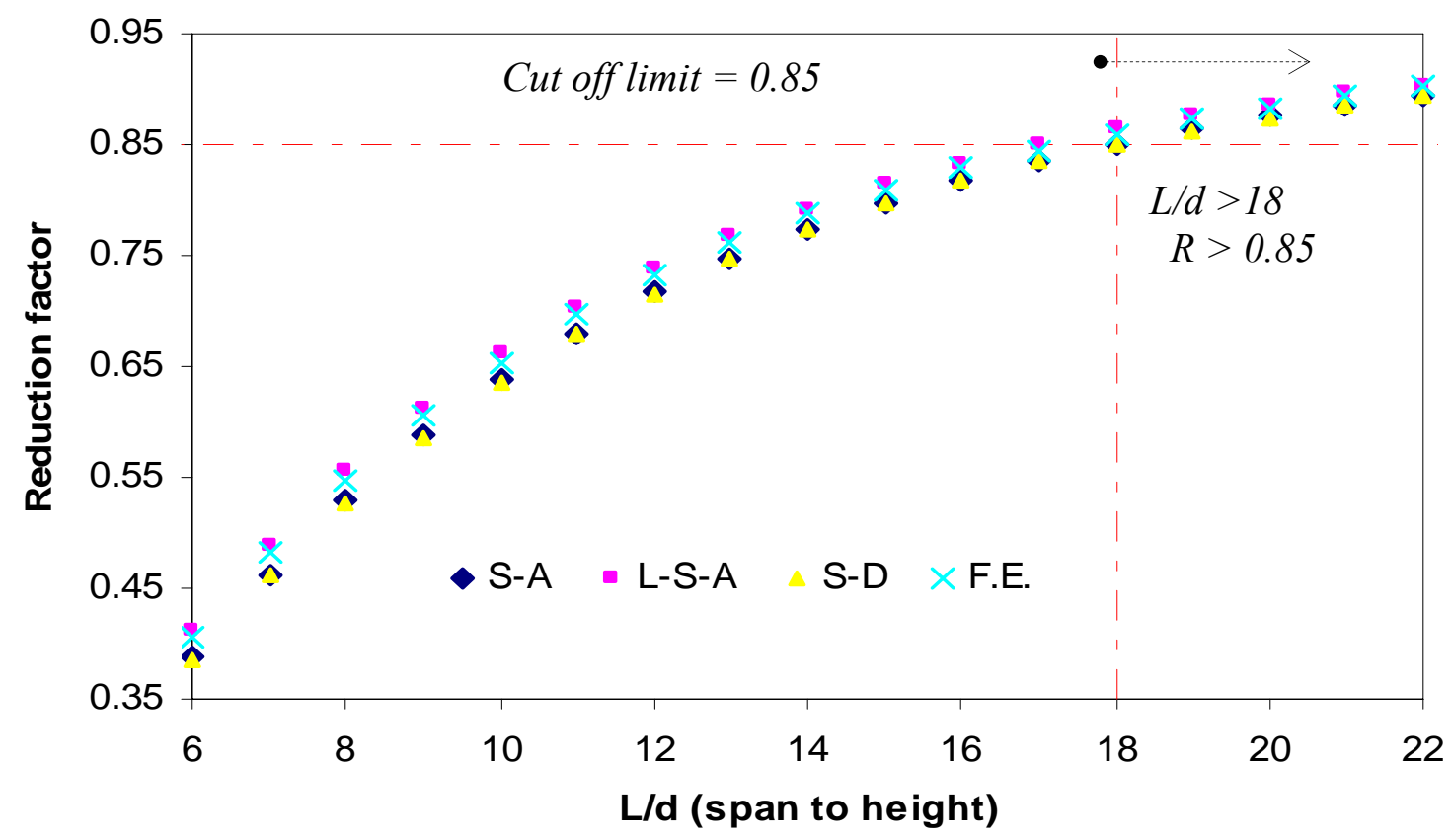

Figure 6.37 Size limit due to shear deformation of single cell specimen 
Under three-point bending:

ProDeck 4 single cell specimen based on experimental data: $L / d>18$

ProDeck4 multi-cell specimen based on experimental data: $L / d>22$

ProDeck4 multi-cell specimen with joints based on experimental data: $L / d>22$

ProDeck4 single cell specimen based on finite element data: $L / d>18$

ProDeck4 multi-cell specimen based on finite element data: $L / d>20$

Under four-point bending:

ProDeck4 single cell specimen based on experimental data: $L / d>18$

ProDeck4 multi-cell specimen based on experimental data: $L / d>21$

ProDeck4 multi-cell specimen with joints based on experimental data: $L / d>22$

ProDeck 4 single cell specimen based on finite element data: $L / d>18$

ProDeck4 multi-cell specimen based on finite element data: $L / d>20$

From this evaluation, size limit due to shear deformation is given in term of depth to length ratio of FRP structural members under three and four point bending loads as follows:

$L / d>18$ (for single cell specimen)

$L / d>22$ (for multi-cell specimen with and without joints)

where, $L$ is test span length of specimen and $d$ is depth of test specimen.

In addition, size limits due to local and torsional buckling are established and discussed in Appendix F. 


\subsection{Conclusion}

- The average out-of-plane shear (yz) strengths of ProDeck4 coupon web and flange specimens are found to be 2.73 and $3.06 \mathrm{ksi}$, respectively. Also, the average out-ofplane shear (xz) strengths of ProDeck4 coupon web and flange specimens are about 4.10 and $4.21 \mathrm{ksi}$, respectively. It should be noted that the percent difference of out-ofplane shear (xz) strength between web and flange is insignificant while in yz plane the difference is significant. Moreover, percent differences between $\mathrm{yz}$ and $\mathrm{xz}$ shear strength of web and flange coupons are about 50.2 and $37.6 \%$, respectively due to higher strength (more fiber) in the strong axis. (Section 6.3.1)

- $\quad$ For ProDeck8 flange coupons, the average out-of-plane shear (yz) and (xz) strengths are reported as 3.07 and $4.64 \mathrm{ksi}$. The percent difference of out-of-plane shear strength between $\mathrm{xz}$ and $\mathrm{yz}$ direction is observed to be about $33.8 \%$. This percent difference is due to the difference of fiber orientation between weak (y-direction) and strong ( $\mathrm{x}$ direction) axis, respectively. (Section 6.3.1)

- It should be noted that the average shear strength of coupons under short beam shear tests is lower than that of components due to several factors such as: bond failure of fibers from resin due to cutting, resin cracking, while cutting stress concentration factor, edge and size effect. In particular, coupons are prepared by cutting them from components. Thus, fiber discontinuity and matrix micro-cracking around the cut edges of coupons lead to fiber delamination at lower magnitude of applied load, than in case of components.

- $\quad$ Average shear strength of out-plane shear (xz and yz direction) strength of ProDeck4 flange coupons is lower than that of in-plane shear (xy direction) strength by a factor of about 3-4 times. 1-D fiber and 2-D fabric layer lay-up on xy plane of specimens has led to the highest shear strength contribution of composite layers in the xy direction. 
- It is found that the failure mode of coupons under short beam shear is due to fiber delamination. Thus, out-of-plane shear strength might be defined as delaminated shear strength of coupon specimens. (Section 6.3.1.1)

- For components, different failure modes (from coupons) are observed during testing leading, to shear and web buckling failure. Cracks and delamination are found on the cross sections and gradually extended into high stress concentration locations near junctions leading to web buckling. (Section 6.3.1.2)

- From the experimental results of components, out-of-plane shear (xz) strength of multicell ProDeck4 is higher than that of a single cell by about $10.56 \%$ due to the contribution of fiber discontinuity (cutting into single cell), bond failure around cut edges and shape effect. (Section 6.3.1.3)

- The equivalent out-of-plane shear $(\mathrm{xz})$ modulus of specimens $\mathrm{BP} 4_{\mathrm{S}}$ based on S-A, L-SA and S-D methods are found to be $0.493 \times 10^{6}, 0.528 \times 10^{6}$ and $0.498 \times 10^{6} \mathrm{psi}$, respectively. In addition, results evaluated from L-S-A presented slightly higher values than those of other methods by about $6-7 \%$, while results evaluated based on S-A and S-D yield the same value as of out-of-plane (xz) shear modulus. However, results from finite element method provided moderately higher (3\% to $9 \%)$ results than the experimental results. (Section 6.3.2.3)

- For multi-cell specimens $\mathrm{BP} 4_{\mathrm{M}}$, out-of-plane shear $(\mathrm{xz})$ modulus is reported as $0.477 \times 10^{6}, 0.492 \times 10^{6}$, and $0.496 \times 10^{6}$ psi based on S-A, L-S-A and S-D methods, respectively. From experimental data evaluation, small difference in out-of-plane shear (xz) modulus is found from each method of evaluation. In addition, experimental data do not differ significantly with finite element results. (Section 6.3.2.3)

- $\quad$ For multi-cell jointed specimens $\left(B P 4_{\mathrm{MJ}}\right)$, shear leakage affected the reduction of outof-plane shear (xz) modulus compared with no-joint specimens $\mathrm{BP} 4_{\mathrm{M}}$. Out-of-plane 
shear (xz) modulus is also evaluated to be $0.451 \times 10^{6}, 0.403 \times 10^{6}$ and $0.430 \times 10^{6} 10^{6} \mathrm{psi}$ based on S-A, L-S-A and S-D methods, respectively. (Section 6.3.2.3 )

- From experimental results, both longitudinal elastic (x) and out-of-plane shear (xz) modulus of single cell specimens are found to be slightly higher those of multi-cell specimens. This tendency also corresponds to results from the finite element method. In addition, the experimental results of longitudinal elastic (x) and out-of-plane shear (xz) modulus provided by different methods have not presented any significant deviation from each other. Thus, the back calculation approaches presented in this study can be reasonably used to evaluate longitudinal elastic (x) and out-of-plane shear (xz) modulus from experimental data. (Section 6.3.2.3)

- Joint efficiency under out-of-plane loading of longitudinal and transverse specimens varied between $80 \%$ and $90 \%$, depending on the control systems that are used for evaluation. (Section 6.5)

- Size limit due to shear deformation is given in term of length to depth ratio of FRP ProDeck 4 under three and four point bending loads as given: $L / d>18$ (for single cell specimen) and $L / d>22$ (for multi-cell specimen with and without joints). (Section 6.7) 


\section{CHAPTER 7}

\section{PUNCHING SHEAR}

\subsection{Introduction}

Punching shear is induced by loads acting perpendicular to the FRP deck (i.e., horizontal plane) leading to punching stresses in the top flange of FRP decking around the perimeter of the loading area. Punching shear is one of the vertical load induced out-of-plane shears, punching through the top flange of a composite deck. Punching forces induce failure of the FRP deck by shearing through the top flange thickness. In addition, the size of loading area (patch or contact area), cross-section and contact shape of the applied load with top flange affect punching shear resistance. The objective is to evaluate punching shear stress on FRP composite decks. A theoretical model for predicting punching shear is proposed herein and validated through our experimental data. Furthermore, comparative analysis between experimental and theoretical results has been provided below.

\subsection{Experimental Program}

Description of specimens, test set-up and procedures such as test equipment, number of specimens, structural shapes, specimen level, specimen preparation and specimen dimensions are discussed in Section 3.9. Analysis of experimental data has highlighted the maximum applied patch load and out-of-plane shear stress resisted by the top flange 
thickness of FRP specimens. Experimental punching shear stress at failure is given as follows:

$$
\tau_{p}=k \frac{P_{u l t}}{A_{P}}
$$

where, $P_{u l t}$ is maximum failure load and $A_{p}$ is the punching area that is a product of multiplying the perimeter of the patch loading imprint and the thickness of the top flange FRP composite deck. Constant $k$ is a modification factor accounting for contact shape, contact material type, and combination of bending and shear. This constant $k$ might vary depending on several mentioned factors. However, constant $k$ is taken as one in the absence of experimental data. Section 7.3 provides a theoretical basis to predict punching shear stress.

\subsection{Theoretical Prediction}

Load-deflection curves under vertical patch loads reveal that each opposite edges of a patch under load (especially rectangular patch) resists different load intensities. Thus, the prediction of maximum theoretical punching stress proposed by Howard (2002) might be inaccurate which can be attributed to the lack of even load distribution over a patch area. Hence, the objective of this section is to propose a theoretical model under maximum punching shear force.

\subsubsection{Stress Prediction}

Several assumptions are necessary to predict maximum punching stress, which are: 1) shear stress contribution of $90^{\circ}$ fibers perpendicular to the FRP composite deck is neglected, 2) shear stress resistance of the resin is neglected, 3) under patch load, contribution of shear stress on each side depends on the area patch load dimension, 4) local fiber bending, buckling and kicking are neglected, 5) all layers of fiber laminates are perfectly bonded together and 6) 
fiber architecture is valid only for unidirectional and/or bi-directional fiber (fabrics) (invalid for stitching fabrics), 7) contribution of mat ( $\left.T_{m a t}\right)$ is assumed to be $62.5 \%$ and 8 ) interaction between the load contact surface and deck flexibility is neglected. However, the theoretical model that is provided below is empirical which is based on specific types of FRP deck specimens.

$\tau_{p}=A_{T}\left(\tau_{m} V_{f}\right)\left[\frac{\sum_{i}^{n} T_{i} \operatorname{Cos}^{2} \theta+T_{m a t}}{T_{\text {total }}}\right]+A_{L}\left(\tau_{m} V_{f}\right)\left[\frac{\sum_{i}^{n} T_{i} \operatorname{Sin}^{2} \theta+T_{\text {mat }}}{T_{\text {total }}}\right]$

where, $\tau_{m}$ is maximum intralaminar shear stress of unidirectional composite, $\theta$ is fiber orientation with respect to longitudinal direction of the FRP composite deck, $V_{f}$ is the fiber volume fraction of the FRP composite, $T_{i}$ is the thickness of the $\mathrm{i}^{\text {th }}$ fiber layer, $T_{\text {total }}$ is total flange thickness, and effective area ratios $\left(A_{L}\right.$ and $\left.A_{T}\right)$ of patch shear stress are defined for ratio of length to width of patch area less than 2 as given below:

$$
\begin{aligned}
& A_{T}=\frac{L^{T}}{2 L^{L}} \\
& A_{L}=1-\frac{L^{T}}{2 L^{L}}
\end{aligned}
$$

where, $L^{T}$ and $L^{L}$ are transverse and longitudinal length of patch area, respectively.

The maximum intralaminar shear is adjusted according to the fiber and fabric reinforcement types. ProDeck4 specimens are used to present theoretical failure analysis under punching shear as follows: 
Example: Theoretical punching shear strength of ProDeck4

ProDeck 4 test specimens are tested under compressive load over the $2 \times 2.5$ inch patch area. Fiber volume fraction $\left(V_{f}\right)$ is about $54 \%$ and $\tau_{\mathrm{m}}$ is about $12 \mathrm{ksi}$. The maximum intralaminar shear stress is provided in Table 1.1 (Barbero, 1998).

From Equation (7.3), the effective contribution area ratios are given:

$$
A_{T}=\frac{L^{T}}{2 L^{L}}=\frac{2}{5} \quad A_{L}=1-\frac{L^{T}}{2 L^{L}}=\frac{3}{5}
$$

$A_{T}=0.4$ and $A_{L}=0.6$

Fiber architecture of ProDeck4 flange is given as:

Table 7.1 Fiber architecture of ProDeck4 flange

\begin{tabular}{|c|c|c|}
\hline Layer & $\begin{array}{c}\text { Fiber } \\
\text { orientation }\end{array}$ & Thickness \\
\hline \multirow{3}{*}{$\begin{array}{c}\text { CDBM } \\
3415\end{array}$} & $0^{\circ}$ & 0.017 \\
\cline { 2 - 3 } & $45^{\circ}$ & 0.0097 \\
\cline { 2 - 3 } & $-45^{\circ}$ & 0.0097 \\
\cline { 2 - 3 } Roving & Mat & 0.014 \\
\hline \multirow{3}{*}{$\begin{array}{c}\text { RDBM } \\
4015\end{array}$} & $45^{\circ}$ & 0.04 \\
\cline { 2 - 3 } & $90^{\circ}$ & 0.012 \\
\cline { 2 - 3 } & $-45^{\circ}$ & 0.019 \\
\cline { 2 - 3 } Roving & Mat & 0.014 \\
\hline \multirow{3}{*}{$\begin{array}{c}\text { Roving } \\
4015\end{array}$} & $45^{\circ}$ & 0.04 \\
\cline { 2 - 3 } & $90^{\circ}$ & 0.012 \\
\cline { 2 - 3 } & $-45^{\circ}$ & 0.019 \\
\cline { 2 - 3 } & Mat & 0.012 \\
\hline Roving & Roving & 0.014 \\
\hline \multirow{3}{*}{$\begin{array}{c}\text { DDBM } \\
4015\end{array}$} & $45^{\circ}$ & 0.04 \\
\cline { 2 - 3 } & $90^{\circ}$ & 0.012 \\
\cline { 2 - 3 } & $-45^{\circ}$ & 0.019 \\
\cline { 2 - 3 } & Mat & 0.012 \\
\hline Roving & Roving & 0.014 \\
\hline \multirow{3}{*}{ CDBM } & $0^{\circ}$ & 0.04 \\
\hline \multirow{3}{*}{3415} & $45^{\circ}$ & 0.0097 \\
\cline { 2 - 3 } & $-45^{\circ}$ & 0.0097 \\
\cline { 2 - 3 } & Mat & 0.014 \\
\hline
\end{tabular}


From the aforementioned assumptions, the shear stress contribution of fibers perpendicular to the punching shear influencing edges is neglected. Five layers of roving, two layers of fibers in $0^{\circ}$ direction, six layers of $\pm 45^{\circ}$ fiber directions with 0.012 inch thickness, and four layers of $\pm 45^{\circ}$ fiber directions with 0.0097 inch thickness are considered in the longitudinal or cell direction. Also, five layers of roving, three layers of $90^{\circ}$ fiber direction, six layers of $\pm 45^{\circ}$ fiber directions with 0.012 inch thickness, and four layers of $\pm 45^{\circ}$ fiber direction with 0.0097 inch thickness are considered in transverse direction. By substituting the above information into Equation (7.2), theoretical punching shear stress is computed as follows:

$$
\begin{aligned}
\tau_{p}= & 0.6(6.5)\left[\frac{\left(2 \times 0.017 \times \operatorname{Cos}^{2} 0^{\circ}\right)+\left(4 \times 0.0097 \times \operatorname{Cos}^{2} 45^{\circ}\right)+\left(6 \times 0.012 \times \operatorname{Cos}^{2} 45^{\circ}\right)+(5 \times 0.014 \times 0.625)}{0.43}\right]+ \\
& 0.4(6.5)\left[\frac{\left(3 \times 0.017 \times \operatorname{Sin}^{2} 90^{\circ}\right)+\left(4 \times 0.0097 \times \operatorname{Sin}^{2} 45^{\circ}\right)+\left(6 \times 0.012 \times \operatorname{Sin}^{2} 45^{\circ}\right)+(5 \times 0.014 \times 0.625)}{0.43}\right]
\end{aligned}
$$

$\tau_{\mathrm{p}}=2.17 \mathrm{ksi}$

Following the above procedure, theoretical punching shear stress to failure of ProDeck8 is also evaluated and presented in Table 7.2.

\begin{tabular}{|c|c|c|c|c|c|c|c|}
\hline \multirow[t]{2}{*}{ Specimen } & \multicolumn{2}{|c|}{ Patch area } & \multicolumn{2}{|c|}{ Patch area ratio } & \multirow{2}{*}{$\begin{array}{c}V_{f} \\
(\%)\end{array}$} & \multirow{2}{*}{$\underset{\text { (ksi) }}{\tau_{\mathrm{m}}}$} & \multirow{2}{*}{$\underset{\text { (ksi) }}{\tau_{p}}$} \\
\hline & $\begin{array}{c}\text { Width } \\
\text { (in) }\end{array}$ & $\begin{array}{l}\text { Length } \\
\text { (in) }\end{array}$ & $\boldsymbol{A}_{T}$ & $A_{L}$ & & & \\
\hline ProDeck4 & 2 & 2.5 & 0.4 & 0.6 & 0.54 & 12 & 2.17 \\
\hline *ProDeck8 & 10 & 20 & 0.25 & 0.75 & 0.45 & 12 & 1.88 \\
\hline
\end{tabular}

Table 7.2 Theoretical results of failure punching shear stress (ProDeck4 and 8)

Note: ProDeck8 is tested over a $10 \times 20$ inch patch area under vertical load on top flange and reported by Howard (2002). $A_{T}$ and $A_{L}$ are effective area ratios of transverse and longitudinal direction, $V_{f}$ is fiber volume fraction of the test specimen, $\tau_{\mathrm{m}}$ is maximum intralaminar shear stress of unidirectional composite and $\tau_{\mathrm{p}}$ is theoretical punching shear stress. 
In the Table 7.2, experimental punching shear stress results of FRP composite decks are presented below and compared with theoretical values, which followed the above procedure.

\subsection{Evaluation of Experimental Results}

In order to verify our theoretical model, FRP composite deck components with and without joints are tested under rectangular patch load. In components without joints, specimens of single cell varied in length. Also, a multi-cell specimen with joints along longitudinal deck cell direction is used in this study. Experimental results of ProDeck8 are used to compare with the theoretical and ProDeck4 results. The relation between punching load versus deflection $\mathrm{PP}_{\mathrm{S} 5}$ is presented (Figure 7.1) herein as an example of composite FRP deck behavior under vertical (punching) loads.

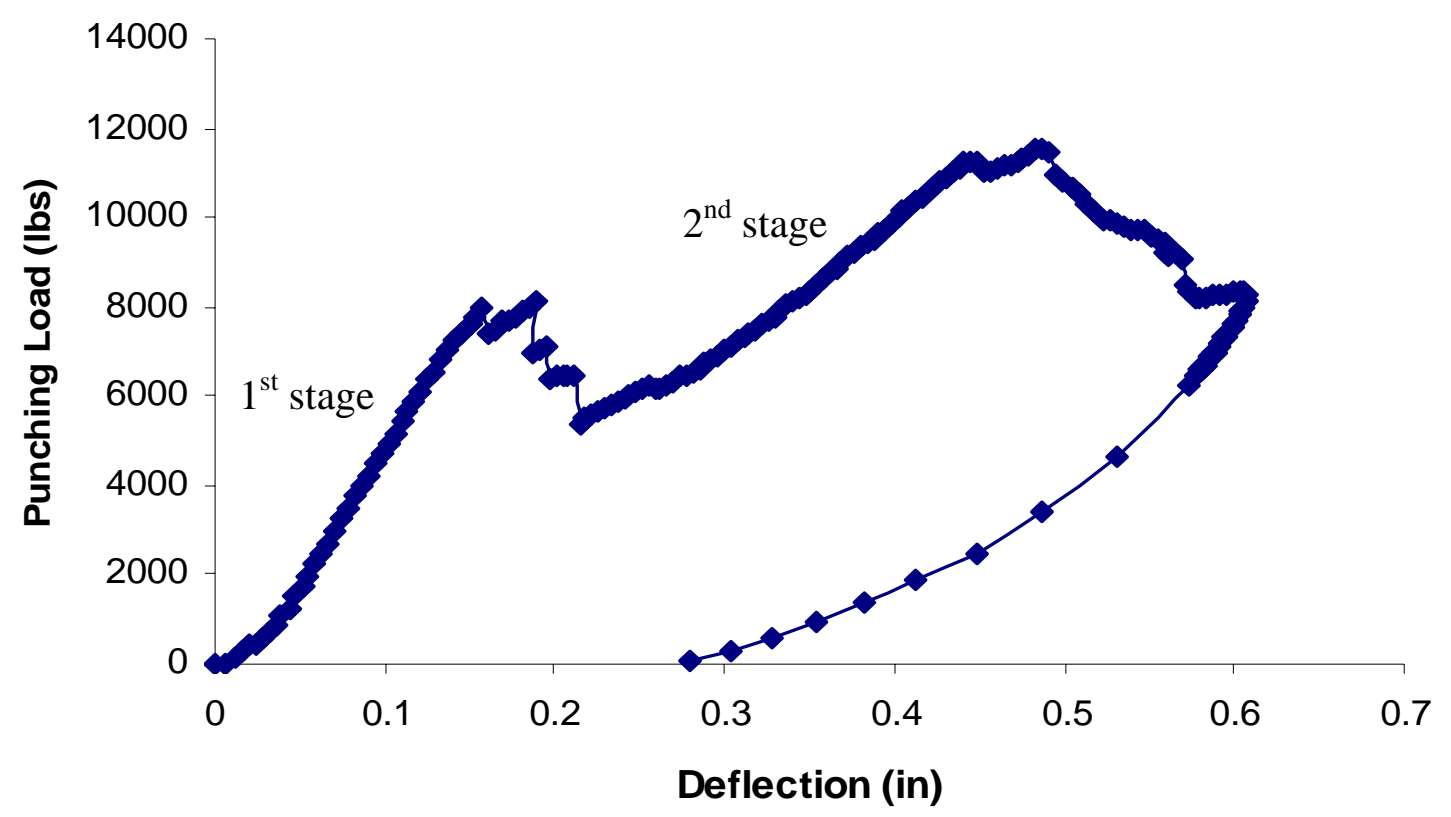

Figure 7.1 Relation between punching load versus deflection $\left(P P 4_{M}\right)$

For single cell specimens, three different test span to depth ratios (3, 4 and 5) are used to study punching shear behavior. Also, multi-cell specimens at component and system level 
are tested on a 24 inch long test span. All specimens are subjected to failure under downward vertical load. Maximum downward load resisted by the top deck flange is defined as punching shear failure load. Comparison of punching shear stress between theoretical and experimental results is presented in Table 7.2.

Table 7.3 Comparison of theoretical and experimental punching shear results

\begin{tabular}{|c|c|c|c|c|c|c|c|}
\hline Specimen & $\begin{array}{l}\text { Test span } \\
\text { (in) }\end{array}$ & $\left(T_{S} / h\right)$ & $\begin{array}{c}A_{P} \\
\left(\text { in }^{2}\right)\end{array}$ & $\begin{array}{c}P_{u l t} \\
\text { (kip) }\end{array}$ & $\begin{array}{c}\left(\tau_{\mathrm{p}}\right)_{\exp } \\
\text { (ksi) }\end{array}$ & $\begin{array}{l}\left(\tau_{\mathrm{p}}\right)_{\mathrm{th}} \\
(\mathbf{k s i})\end{array}$ & $\begin{array}{c}\% \\
\text { difference }\end{array}$ \\
\hline $\mathrm{PP}_{\mathrm{S} 3}$ & 12 & 3 & 3.92 & 8.20 & 2.09 & 2.17 & 3.69 \\
\hline $\mathrm{PP}_{\mathrm{S} 4}$ & 16 & 4 & 3.92 & 8.95 & 2.28 & 2.17 & 4.82 \\
\hline $\mathrm{PP}_{\mathrm{S} 5}$ & 20 & 5 & 3.92 & 9.70 & 2.47 & 2.17 & 12.14 \\
\hline $\mathrm{PP} 4_{\mathrm{M}}$ & 24 & 6 & 3.92 & 11.50 & 2.93 & 2.17 & 25.9 \\
\hline $\mathrm{PP} 4_{\mathrm{MJ}}$ & 24 & 6 & 5.96 & 14.70 & 2.47 & 2.17 & 12.14 \\
\hline PP8P & 120 & 15 & 20 & 36.0 & 1.80 & 1.88 & 4.26 \\
\hline PP8 & 120 & 15 & 20 & 37.0 & 1.90 & 1.88 & 1.05 \\
\hline
\end{tabular}

Note: $\left(T_{s} / h\right)$ is ratio of test span to height of specimen, $P_{u l t}$ is maximum failure load, $A_{p}$ is punching area that is obtained by multiplying perimeter of patch loading area to thickness of FRP composites, $\left(\tau_{\mathrm{p}}\right)_{\exp }$ and $\left(\tau_{\mathrm{p}}\right)_{\mathrm{th}}$ are maximum experimental and theoretical failure punching shear stress.

\subsection{Discussion of Experimental Results}

Behavior of FRP composite test specimens under vertical (punching) load is observed from load versus deflection response. Two stage failure is: 1) punching of the first pair of parallel edges over the patch load area, and 2) punching through the top flange thickness. In the first stage, the linear response of load versus deflection is observed up to failure of first pair of parallel edges over the patch load area. It is followed by a drop in vertical load. In the second stage, response of applied load versus deflection seems to be linearly increasing to a maximum similar to failure response of the other pair of parallel edges over the patch area. After attaining the peak applied load, the intensity of load gradually decreases while 
increasing in deflection. However, vertical deflection suddenly drops when all edges over the patch area near failure. The slope of load versus deflection in the first stage is found to be higher than that of the second stage (refer to Figure 7.1). In the first stage, shear force is distributed over the patch area in different ratios until one of the opposite edges of the patch area fail, while in $2^{\text {nd }}$ stage, the remaining pair supports the vertical load until it punches through the flange thickness.

For single cell specimens, maximum punching load varies in the range 2.09 to 2.47 ksi depending on the span-depth (on cross section) ratio of the test specimens. As the depth to test span ratios increase, maximum failure load increases due to bending of top flange. Mode of failure is either in shear or in bending in accordance with the depth to test span ratios. Behavior of FRP composite is similar to that of conventional materials such as steel and concrete. However, expected maximum punching shear strengths should be higher than those obtained from experiments because single cell specimens are prepared from multi-cell specimens by cutting along the longitudinal direction of FRP composite decks. Therefore, maximum failure loads of single cell specimens $\left(\mathrm{PP}_{\mathrm{S} 3}, \mathrm{PP} 4_{\mathrm{s} 4}\right.$ and $\left.\mathrm{PP} 4_{\mathrm{s} 5}\right)$ are possibly lower than the expected values because fiber damage due to fiber cutting along longitudinal edges (leading to bond failure and fiber delamination) and also due to discontinuity at the corners of test specimens. In addition, theoretical punching stress is predicted to be slightly lower than the experimental punching stress as bending effect is neglected. The punching shear prediction increases when depth to test span ratios increase.

In order to avoid local fiber damage and fiber discontinuity, multi-cell specimen $\mathrm{PP} 4_{\mathrm{M}}$ test data have been evaluated under punching shear load. The maximum punching load and stress are found to be $11.5 \mathrm{kip}$ or $2.93 \mathrm{ksi}$, where the percent difference between theory and experimental results is about $25.9 \%$ due to shape effect (large area of flange and number of webs) and plate action of the top flange. It should be noted that punching shear expression given in Equation (7.2) is considered on fiber strength and fiber architecture and does not 
account for shape effect and plate action. For the component specimens with joints $\mathrm{PP} 4_{\mathrm{MJ}}$, the maximum experimental punching load and stress are higher than the theoretical values by about $12.17 \%$. The lower value of theoretical punching stress is attributed to the flange thickness of the specimen $\mathrm{PP} 4_{\mathrm{MJ}}$ and also to the different fiber architecture of the flange assembly. In addition, experimental punching shear stress of multi-cell cross sections is higher than that of single cell by about $15.6 \%$ due to shape effect (web-stiffening of the multi-cell) and bond failure (single cell) at cutting edges leading to cracks and delamination of the top flange (refer to Figure 7.3). For ProDeck8 specimens, maximum punching shear load and shear stress are found to be about 36.0-37.0 kips and 1.8-1.9 ksi, respectively. These experimental results are compared with theoretical results and the percent difference in theoretical versus experimental results is found to vary between $1.05 \%$ and $4.26 \%$. It should be noted results of ProDeck8 are not really punching shear strength because results are obtained from beam bending test (aspect ratio $=15$ ) to evaluate the maximum load under three point bending. Thus, experimental punching strengths may have been higher than the expected strengths due to bending effect. The key parameter that governs punching shear of the top flange of an FRP deck is the relative stiffness of the flange versus the rectangular block through which load is applied. If the block is flexible, punching shear effects would be lower and vice versa.

\subsection{Failure Mode of Punching Shear}

For single cell specimens $\left(\mathrm{PP}_{\mathrm{S} 3}, \mathrm{PP} 4_{\mathrm{S} 4}\right.$ and $\left.\mathrm{PP} 4_{\mathrm{S} 5}\right)$, cracking around perimeter of the load patch is observed. When applied load increased, layer delamination of the flange increases and expanded through the longitudinal length of the test specimens. Also, cracks around the punching area extend diagonally from the corners of that patch area to the specimen edges. Failure mode of single cell specimens is shown in Figure 7.2. For multi-cell specimens, cracks around the punching area clearly appear in the same manner as in the case 
of single cell specimens. However, layer delamination and diagonal cracks from corners are not observed from test specimens in this experiment. Failure mode of multi-cell specimens is presented in Figure 7.4.

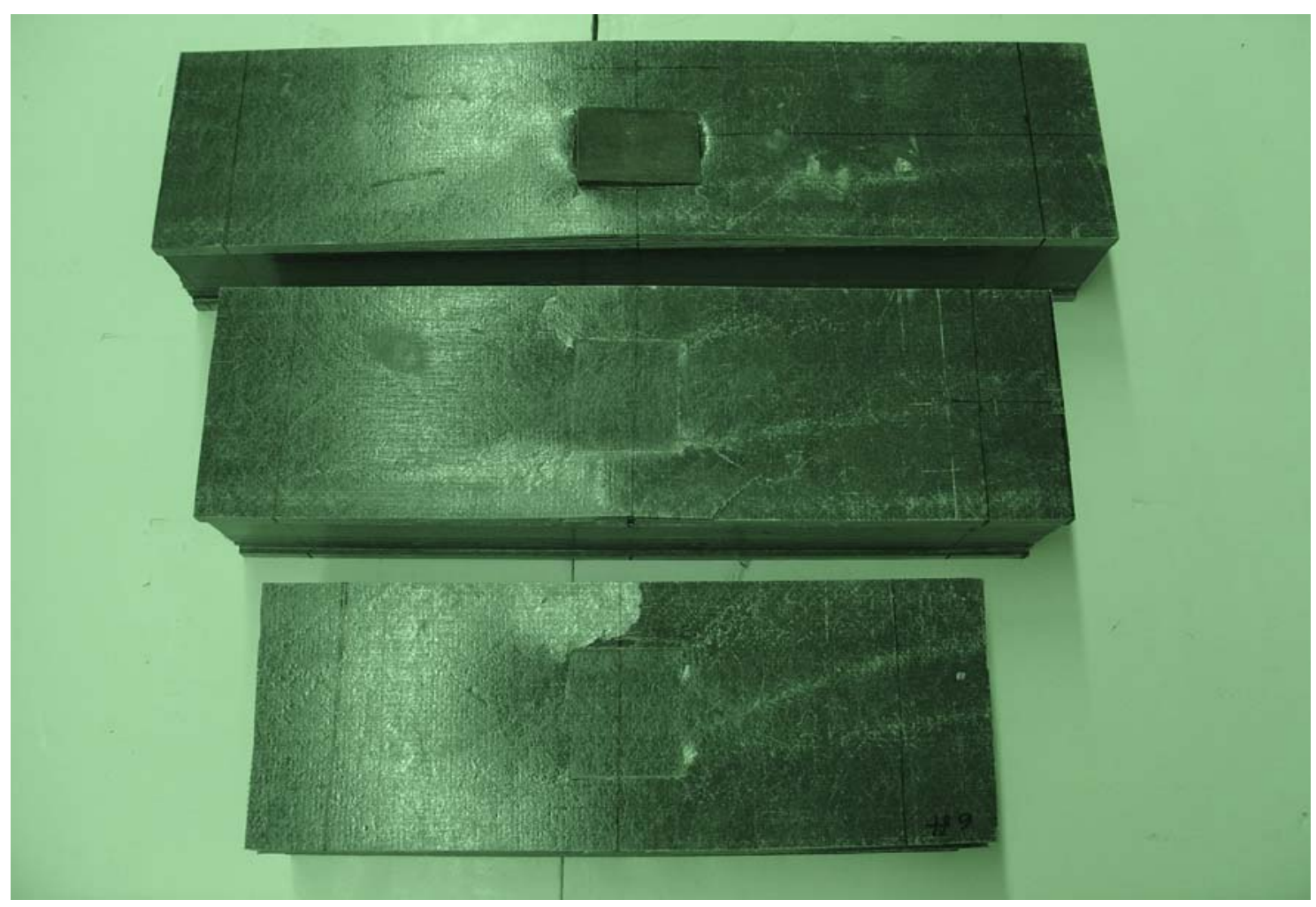

Figure 7.2 Cracks around punching area of single cell specimens

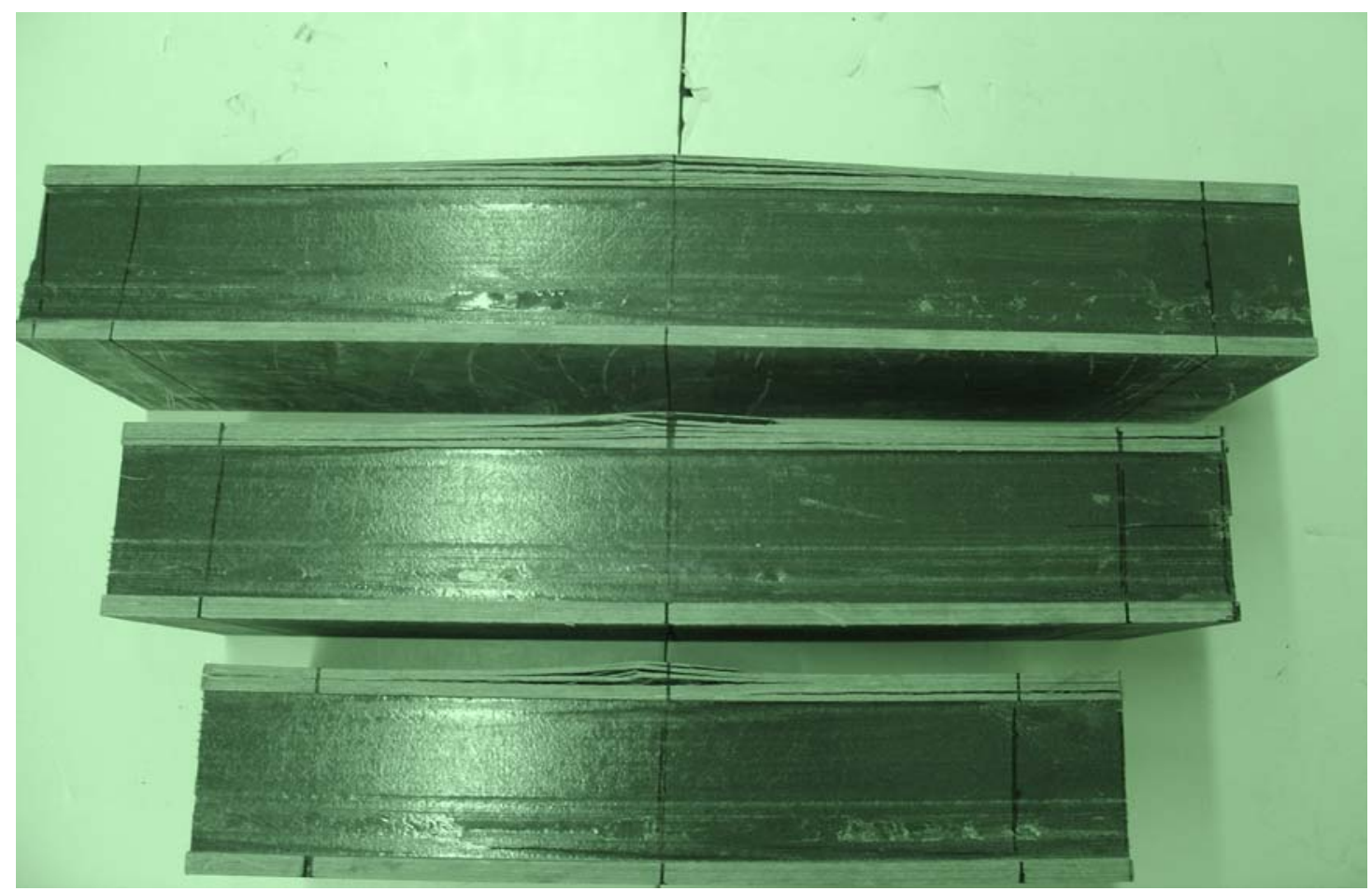

Figure 7.3 Layer delamination of single cell specimens 


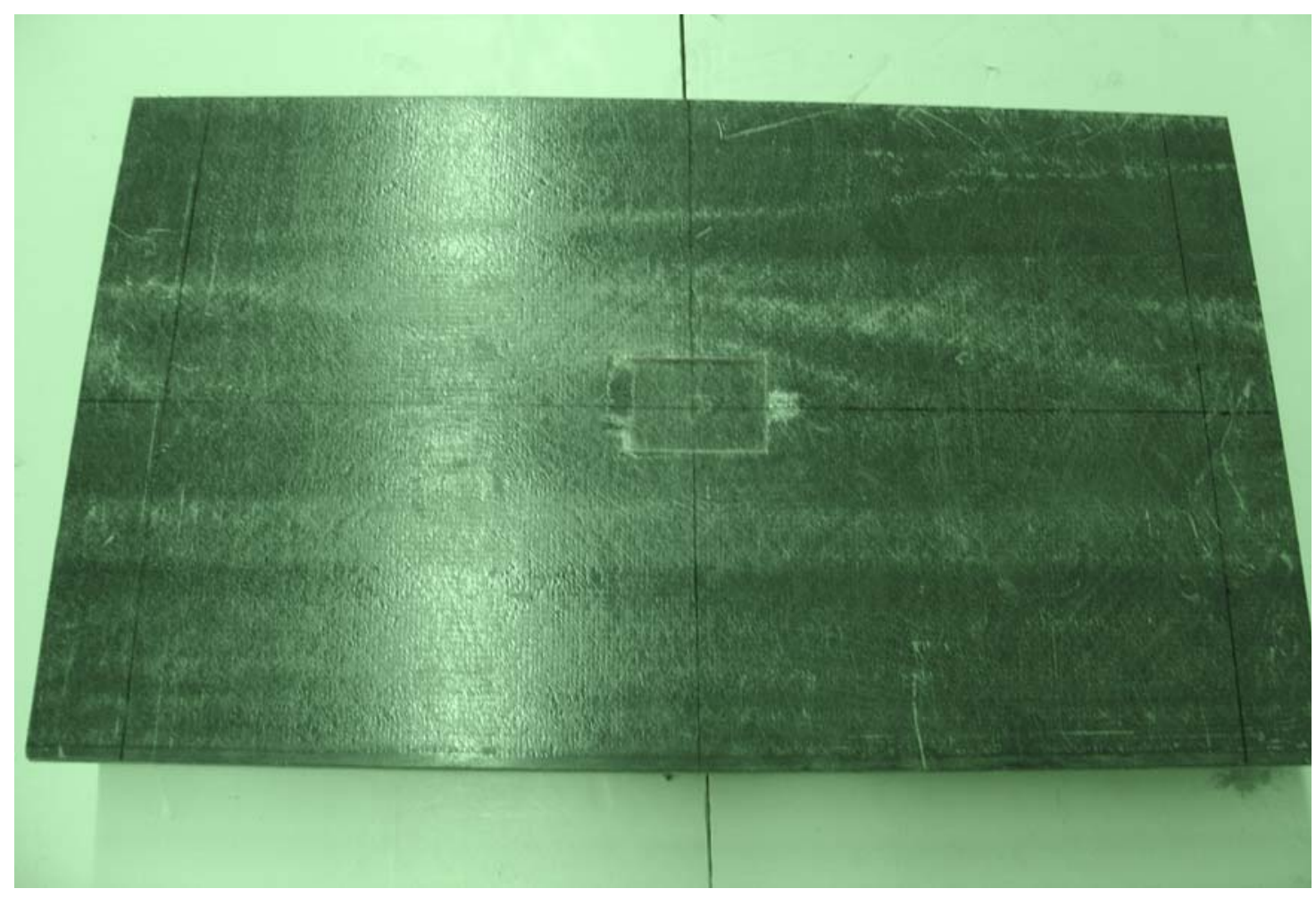

Figure 7.4 Cracks around punching area of multi-cell specimens

\subsection{Conclusion}

- $\quad$ Maximum experimental punching shear stresses of single cell and multi-cell specimens are found to be 2.47 and $2.93 \mathrm{ksi}$, respectively. The bending effect of top flange in single cell specimens has an influence on maximum punching load and it is a function of test span and flange stiffness. (Section 7.4 and 7.5)

- $\quad$ The theoretical model for punching shear strength is predicted with $12-26 \%$ difference from experimental data for multi-cell specimens because shape effect (web-stiffening of the multi-cell) and plate action are not accounted for in this analysis.

- $\quad$ Failure mode of multi-cell ProDeck4 and ProDeck8 specimens is a punching failure only where bending effect is not observed. Failure mode of single cell specimens include two parts: 1) punching failure mode due to downward loading and 2) delamination of fiber layer along specimen edges due to bending effect. (Section 7.6) 


\section{CHAPTER 8}

\section{SHEAR BAHAVIOR OF WEB-FLANGE JUNCTIONS}

\subsection{Introduction}

Shear behavior of FRP beams is studied and simulated using shear strength results obtained from coupon tests. Shear strength data based on the V-notched beam test of coupons are found to overestimate the strength of web-flange junctions. Web-flange junction strength with notches is about one-seventh of the shear strength of coupons using Iosipescu shear test) (Turvey and Zhang 2004). To study the web-flange junction behavior, both open and closed FRP sections are tested under shear-bending effect. Web-flange junction strength is evaluated and compared with the strength obtained from other test procedures such as the V-notched beam (shear) test. To evaluate web-flange shear response, web-flange shear apparatus similar to the one developed by Turvey and Zhang (2004) is built at CFC-WVU with modification. In the following section, an experimental program of web-flange junctions under shearbending effect is discussed.

\subsection{Experimental Program}

Descriptions of specimen dimension, test set-up and procedures including test apparatus, number of specimens, structural shapes, specimen preparation and specimen dimension are given in Section 3.11. In this study, analysis of experimental data is focused on shear force and stress at web-flange junctions. Test specimens and set-up of web-flange 
junction experiments are considered to be proposed cantilever with fixed support at one end and a simple support at the other end as illustrated in Figure 8.1. Also, a concentrated load is applied closer to the fixed-end support. Thus, shear force can be easily determined by beam analysis.

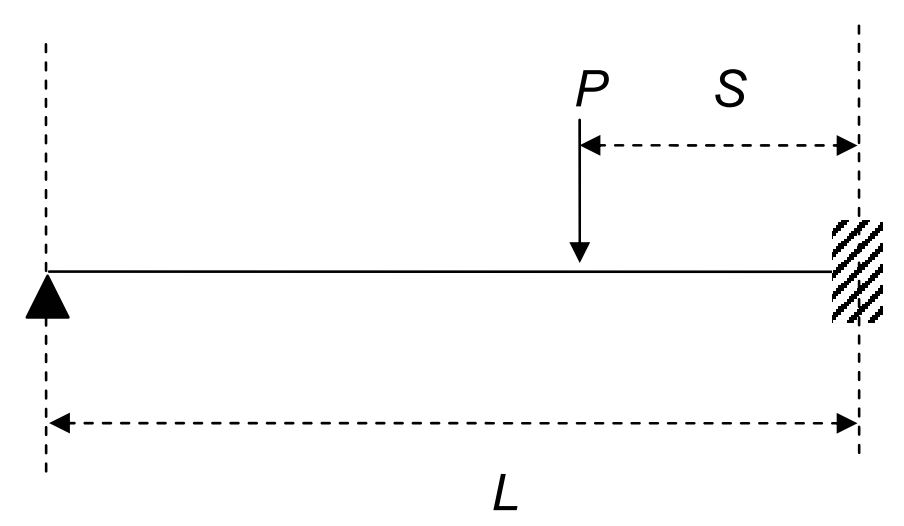

Figure 8.1 Cantilever beam model of web-flange junction test

Shear force and bending moment distribution on web-flange junctions of test specimens are written in terms of test span and loading position as follows:

$$
\begin{aligned}
& V=\frac{2(L+2 s)(L-s)}{2 L^{2}+2 L s-s^{2}} P \\
& M_{\text {end }}=\frac{s(2 L+s)}{2(L+2 s)} V
\end{aligned}
$$

where, $P$ is the applied load and $V$ is an induced shear force on web-junction portions. $M_{\text {end }}$ is a fixed-end bending moment. $L$ is the length of the test span measured from mid point of the fixed-end support to mid point of the simple support. $S$ is the distance measured from the fixed-end support to the loading position. In addition, fixed-end bending moment effect can be reduced by choosing appropriate values of $S$ and $L$. 
For open sections, the test span is taken as 3 inches and the applied load $(P)$ is positioned at 1 inch from the fixed-end support. Shear force is presented in Equation (8.3).

$$
V=\frac{20}{23} P
$$

Shear stress of test specimens is assumed to be uniform over the web depth. Thus, shear stress on web-flange junctions can be determined by using mechanics of material approach. Moreover, cross section of web-flange junctions is considered to be rectangular in shape and maximum shear stress is given as follows:

$$
\tau=\frac{30}{23}\left(\frac{P}{A}\right)
$$

where, $\tau$ is the induced shear stress on web-flange junctions of test specimens at load $P$, and $A$ is cross-section area of web.

For closed sections, the length of the test span is given as 3 inches. Applied load $P$ is transferred from a small beam to both webs of a test specimen. Concentrated loads are positioned at 1 inch away from the fixed-end support. Therefore, shear force is given as:

$$
V=\frac{10}{23} P
$$

Assumptions of shear stress distribution for open cross sections are equally valid for closed sections. The cross section of a closed section at web-flange junctions is also assumed to be a rectangular in shape. Moreover, test span is kept to 4 inches and a concentrated load is applied on the transfer beam that is positioned far away from the fixed-end by about 1 inch. Thus, maximum shear force and stress for each web are presented in Equations (8.6) and (8.7). 
$V=\frac{6}{13} P$

$\tau=\frac{9}{13}\left(\frac{P}{A}\right)$

where, $\tau$ is a maximum shear stress on each web-flange junction of test specimens. $P$ is the maximum applied load and $A$ is the cross-section area of each web-flange portion.

\subsection{Evaluation of Experimental Results}

To evaluate shear strength of web-flange junctions, test specimens are set-up as described before (Section 3.11) and concentrated load is continuously applied to failure. Maximum load is defined as the peak load of test specimens. This maximum load is used to calculate the maximum shear strength on web-flange junctions. Using Equations (8.4) and (8.7), the shear strength of open and closed cross sectional specimens is found. The shear strength computations of open and closed sectional specimens are presented below:

Example: Web-flange junction shear strength of an open cross sectional specimen

An open sectional specimen with dimension 1.433 inches in thickness and 0.375 inches in width is used in this example. The maximum applied load from experimental data is about 4.19 kips. Shear force is evaluated by substituting maximum applied load into Equation (8.3) as:

$$
\begin{aligned}
& V=\frac{20}{23} P \\
& V=\frac{20 \times 4.19}{23}=3.64 \mathrm{kips}
\end{aligned}
$$


Maximum shear stress is obtained from Equation (8.4).

$$
\tau=\frac{3}{2}\left(\frac{V}{A}\right)=\frac{30}{23}\left(\frac{P}{A}\right)
$$

Web area for this specimen is found to be $0.537 \mathrm{in}^{2}$.

$\tau=6.77 \mathrm{ksi}$

Example: Web-flange junction shear strength of a closed cross sectional specimen

A closed section with webs of 1.5 inches in thickness and 0.435 inches in width, is used in this example. From our experimental results, the maximum applied load is recorded as 5.86 kips. By following Equation (8.6), shear stress can be determined as:

$$
V=\frac{6}{13} P=\frac{6}{13}(5.85)=2.70 \text { kips }
$$

Maximum shear stress can be obtained from Equation (8.7).

$$
\tau=\frac{3}{2}\left(\frac{V}{A}\right)=\frac{9}{13}\left(\frac{P}{A}\right)
$$

Web area for this specimen is found to be $0.653 \mathrm{in}^{2}(1.5 \times 0.435)$.

$$
\tau=6.01 \mathrm{ksi}
$$

\begin{tabular}{|c|c|c|c|c|c|c|c|}
\hline \multirow[t]{2}{*}{ Specimen } & \multicolumn{2}{|c|}{ Dimensions } & \multirow{2}{*}{$\begin{array}{l}\text { Max. } \\
\text { load } \\
\text { (kip) }\end{array}$} & \multirow{2}{*}{$\begin{array}{l}\text { Shear } \\
\text { force } \\
\text { (kip) }\end{array}$} & \multirow{2}{*}{$\begin{array}{l}\text { Shear } \\
\text { force/ } \\
\text { width } \\
\text { (kip/in) }\end{array}$} & \multirow{2}{*}{$\begin{array}{l}\text { Max. } \\
\text { shear } \\
\text { stress } \\
\text { (ksi) }\end{array}$} & \multirow{2}{*}{$\begin{array}{c}\text { Avg. } \\
\text { shear } \\
\text { stress } \\
\text { (ksi) }\end{array}$} \\
\hline & $\begin{array}{l}\text { Width } \\
\text { (in) }\end{array}$ & $\begin{array}{l}\text { Thickness } \\
\text { (in) }\end{array}$ & & & & & \\
\hline $\mathrm{WJ}_{\mathrm{O} 1}: 1$ & 0.375 & 1.059 & 2.29 & 1.991 & 1.991 & 7.52 & 7.42 \\
\hline $\mathrm{WJ}_{\mathrm{O} 1}: 2$ & 0.375 & 0.939 & 2.06 & 1.791 & 1.791 & 7.63 & \\
\hline $\mathrm{WJ}_{\mathrm{O} 1}: 3$ & 0.375 & 0.911 & 1.863 & 1.620 & 1.620 & 7.11 & \\
\hline $\mathrm{WJ}_{\mathrm{O} 1.5}: 1$ & 0.375 & 1.433 & 4.19 & 3.64 & 2.43 & 10.17 & 10.56 \\
\hline
\end{tabular}

Following the same procedure, shear stress results of several open and closed FRP cross sections are presented in Table 8.1 and 8.2, respectively.

Table 8.1 Shear stress of web-flange junctions for open cross sections 


\begin{tabular}{|c|c|c|c|c|c|c|c|}
\hline $\mathrm{WJ}_{\mathrm{O} 1.5}: 2$ & 0.375 & 1.434 & 4.00 & 3.48 & 2.32 & 9.70 & \\
\hline $\mathrm{WJ}_{\mathrm{O} 1.5}: 3$ & 0.375 & 1.422 & 4.53 & 3.94 & 2.63 & 11.80 & \\
\hline $\mathrm{WJ}_{\mathrm{O} 2}: 1$ & 0.375 & 1.984 & 5.87 & 5.10 & 2.55 & 10.29 & \multirow[t]{3}{*}{$10.19 * *$} \\
\hline $\mathrm{WJ}_{\mathrm{O} 2}: 2$ & 0.375 & 2.024 & 7.25 & 6.30 & $3.15^{*}$ & $12.46^{*}$ & \\
\hline $\mathrm{WJ}_{\mathrm{O} 2}: 3$ & 0.375 & 1.974 & 5.73 & 4.98 & 2.49 & 10.09 & \\
\hline
\end{tabular}

Note: $\mathrm{WJ}_{\mathrm{O} 1}, \mathrm{WJ}_{\mathrm{O} 2}$, and $\mathrm{WJ}_{\mathrm{O} 3}$ are open cross sections with 1,2 and 3 inch thickness, respectively.* Shear force at failure of specimen $\left(\mathrm{WJ}_{\mathrm{O} 2}: 2\right)$ is much higher than that of other $\mathrm{WJ}_{\mathrm{O} 2}$. It is observed during experiments that failure mode of specimen $\left(\mathrm{WJ}_{\mathrm{O} 2}: 2\right)$ is due to large cracks of flanges while, small cracks near web-flange junctions are noticed. Moreover, failure modes of test specimens in this experiment are discussed in Section 9.6. **Average web-flange shear stress of specimens $\left(\mathrm{WJ}_{\mathrm{O} 2}\right)$ does not include experimental results of specimen $\left(\mathrm{WJ}_{\mathrm{O} 2}: 2\right)$.

Table 8.2 Shear stress of web-flange junctions for closed sections

\begin{tabular}{|c|c|c|c|c|c|c|c|}
\hline \multirow[t]{2}{*}{ Specimen } & \multicolumn{2}{|c|}{ Dimensions } & \multirow{2}{*}{$\begin{array}{l}\text { Max. } \\
\text { load } \\
\text { (kip) }\end{array}$} & \multirow{2}{*}{$\begin{array}{l}\text { Shear } \\
\text { force } \\
\text { (kip) }\end{array}$} & \multirow{2}{*}{$\begin{array}{l}\text { Shear } \\
\text { force/ } \\
\text { width } \\
\text { (kip/in) }\end{array}$} & \multirow{2}{*}{$\begin{array}{c}\text { Max. } \\
\text { shear } \\
\text { stress } \\
\text { (ksi) }\end{array}$} & \multirow[b]{2}{*}{$\begin{array}{c}\text { Avg. } \\
\text { failure } \\
\text { shear } \\
\text { stress } \\
\text { (ksi) }\end{array}$} \\
\hline & $\begin{array}{c}\text { Width } \\
\text { (in) }\end{array}$ & $\begin{array}{l}\text { Thickness } \\
\text { (in) }\end{array}$ & & & & & \\
\hline $\mathrm{WJ}_{\mathrm{C} 1}: 1$ & 0.435 & 1.020 & 1.547 & 1.428 & 1.428 & 4.83 & \multirow[t]{3}{*}{$4.67 *$} \\
\hline $\mathrm{WJ}_{\mathrm{C} 1}: 2$ & 0.435 & 1.022 & 1.447 & 1.336 & 1.336 & 4.51 & \\
\hline $\mathrm{WJ}_{\mathrm{C} 1}: 3$ & 0.435 & 1.010 & 1.008 & 0.930 & 0.930 & 3.18 & \\
\hline $\mathrm{WJ}_{\mathrm{C} 1.5}: 1$ & 0.435 & 1.550 & 2.93 & 2.70 & 1.800 & 6.01 & \multirow[t]{4}{*}{6.26} \\
\hline $\mathrm{WJ}_{\mathrm{C} 1.5}: 2$ & 0.435 & 1.506 & 3.03 & 2.80 & 1.867 & 6.41 & \\
\hline $\mathrm{WJ}_{\mathrm{C} 1.5}: 3$ & 0.435 & 1.492 & 2.95 & 2.72 & 1.813 & 6.29 & \\
\hline $\mathrm{WJ}_{\mathrm{C} 1.5}: 4$ & 0.435 & 1.464 & 2.91 & 2.69 & 1.793 & 6.34 & \\
\hline $\mathrm{WJ}_{\mathrm{C} 2}: 1$ & 0.435 & 2.075 & 3.95 & 3.65 & 1.825 & 6.07 & \multirow[t]{3}{*}{6.08} \\
\hline $\mathrm{WJ}_{\mathrm{C} 2}: 2$ & 0.435 & 2.094 & 4.05 & 3.74 & 1.870 & 6.16 & \\
\hline $\mathrm{WJ}_{\mathrm{C} 2}: 3$ & 0.435 & 2.070 & 3.90 & 3.60 & 1.800 & 6.00 & \\
\hline
\end{tabular}

Note: *Average web-flange shear stress of specimens $\left(\mathrm{WJ}_{\mathrm{c} 1}\right)$ does not include experimental results of specimen $\left(\mathrm{WJ}_{1}: 3\right)$. 
Load versus deflection behavior of open and closed FRP sections under shear is presented in Figures 8.2 and 8.3, respectively. The following section will be discusses in the results.

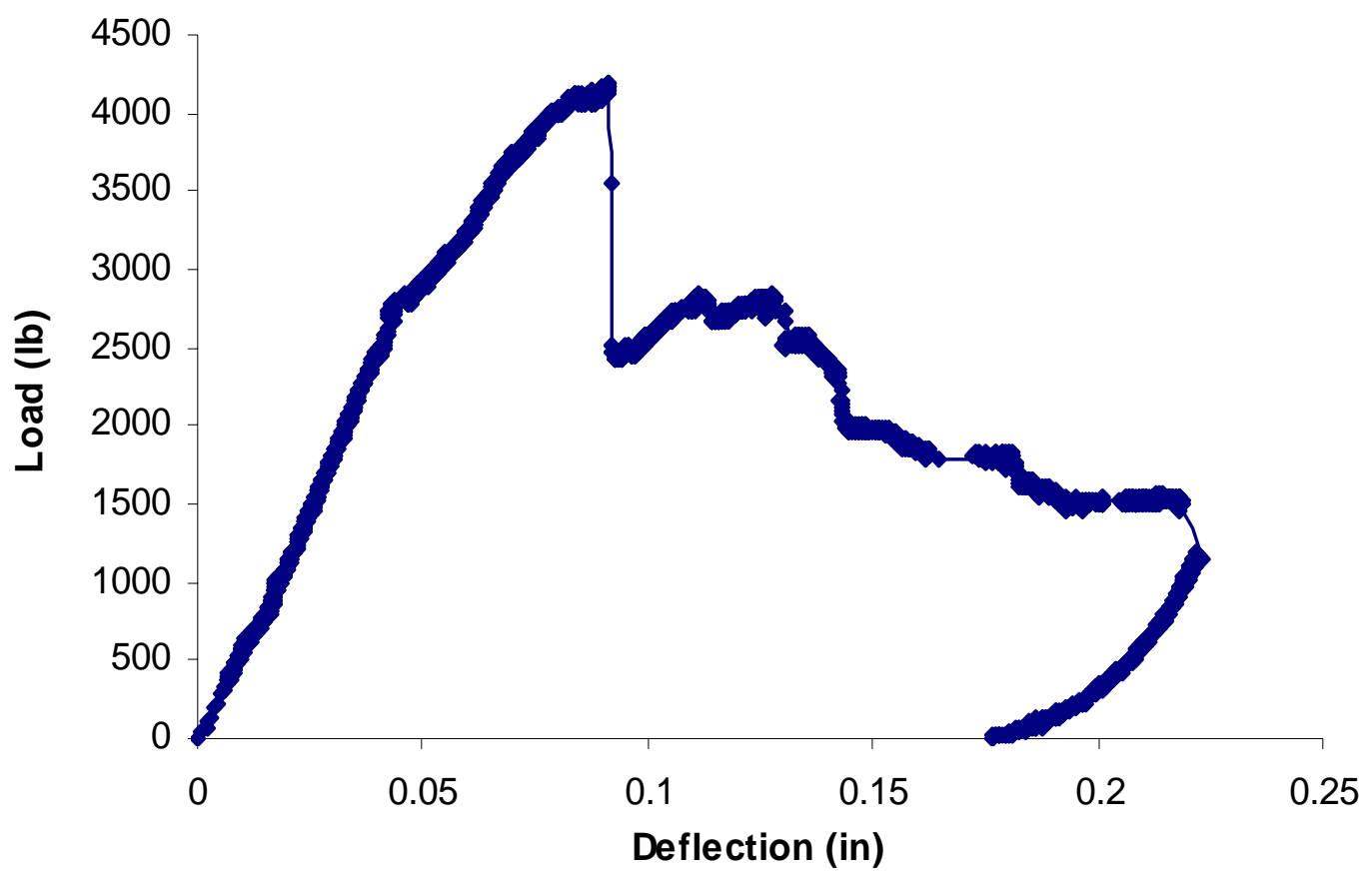

Figure 8.2 Load versus deflection of open cross section specimen $\mathrm{WJ}_{01.5}: 3$

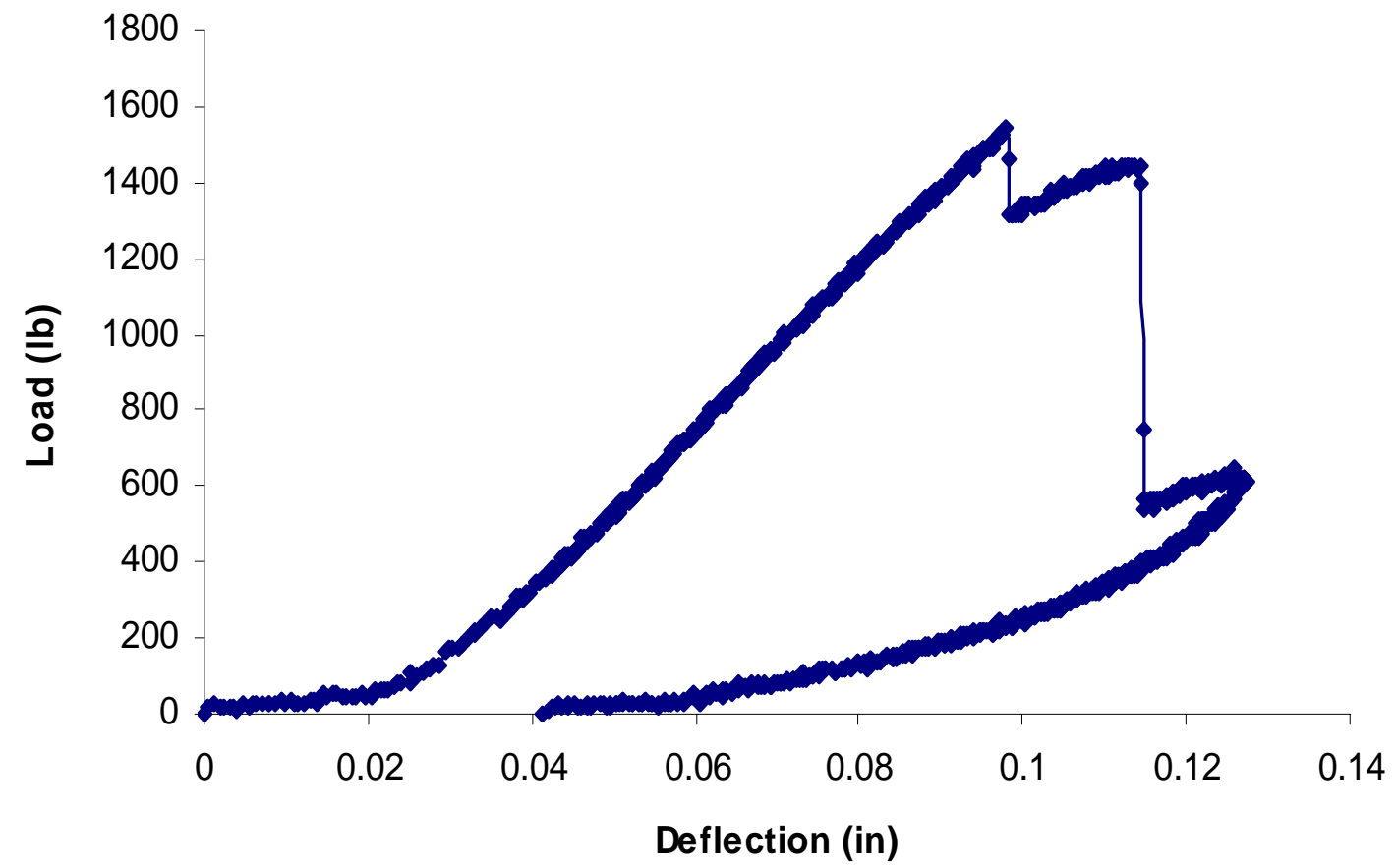

Figure 8.3 Load versus deflection of closed cross section specimen $\mathrm{WJ}_{\mathrm{C} 1}: 3$ 


\subsection{Comparison Web-Shear Strength of Closed Sections}

Experimental shear strength at web-flange junction of a full size FRP section versus V-notched beam test data are presented in Table 8.3. ProDeck4 is the only closed section that was tested in this experimental program.

Table 8.3 Comparison of web-flange junction shear strength

\begin{tabular}{|c|c|c|c|c|c|c|}
\hline \multirow[t]{2}{*}{ Specimens } & \multirow{2}{*}{$\begin{array}{c}\text { Number } \\
\text { of } \\
\text { specimens }\end{array}$} & \multicolumn{3}{|c|}{ Avg. shear } & \multicolumn{2}{|c|}{ \% difference } \\
\hline & & $\begin{array}{c}\text { Force } \\
\text { (kip) }\end{array}$ & $\begin{array}{l}\text { Force } \\
\text { /width } \\
\text { (kip/in) }\end{array}$ & $\begin{array}{c}\text { Stress } \\
\text { (ksi) }\end{array}$ & $\begin{array}{l}\text { with } \\
\text { VP4L* }\end{array}$ & $\begin{array}{c}\text { with } \\
\text { VP4T* }\end{array}$ \\
\hline $\mathrm{WJ}_{\mathrm{C} 1}$ & 2 & 1.382 & 1.382 & 4.67 & 66.7 & 56.8 \\
\hline $\mathrm{WJ}_{\mathrm{C} 1.5}$ & 3 & 2.73 & 1.82 & 6.26 & 55.3 & 42.1 \\
\hline $\mathrm{WJ}_{\mathrm{C} 2}$ & 3 & 3.66 & 1.83 & 6.08 & 56.6 & 43.8 \\
\hline VP4L* & 3 & 2.50 & - & 14.01 & - & - \\
\hline VP4T* & 3 & 2.81 & - & 10.81 & - & - \\
\hline
\end{tabular}

Note: VP4L* and VP4T* are in-plane shear strengths under V-notched beam testing of longitudinal and transverse coupons, respectively.

The maximum percent difference between in-plane shear strength (V-notched beam test) and web-flange junction shear strength is $66.7 \%$. However, this percent difference is determined from the shear strength of $\mathrm{WJ}_{\mathrm{C} 1}$ data that are lower than the shear strengths of $\mathrm{WJ}_{\mathrm{C} 1.5}$ and $\mathrm{WJ}_{\mathrm{C} 2}$. Because, the maximum average stress is found from $\mathrm{WJ}_{\mathrm{C} 1.5}$ specimen type then, maximum percent difference of shear strength should be determined based on the shear strength of specimen $\mathrm{WJ}_{\mathrm{C} 1.5}$. It is found that web-flange junction shear strength based on $\mathrm{WJ}_{\mathrm{C} 1.5}$ data is about $55 \%$ and $42 \%$ lower than the shear strength from in-plane shear strength under V-notched beam testing compared to VP4L and VP4T, respectively. This difference is due to high stress concentration and waving of fiber at the web-flange junctions. In addition, bond failure around cut edges is an important factor in terms of strength reduction. It is clear 
that web-flange shear strength is lower than the shear strength obtained from V-notched beam test by about $50 \%$.

\subsection{Discussion of Experimental Results}

Load versus deflection response from web-flange junction experiment of open sections can be divided into four stages (refer to Figure 8.2): Stage 1) linear load versus deflection behavior and the response is reasonably linear up to about $70 \%$ of the maximum applied load, Stage 2) partial cracking of web-flange portion where non-linear behavior of load versus deflection relation was found up to the failure load. Cracks on web-flange junctions gradually extend until the specimens fails, and the load drops suddenly at the end of $2^{\text {nd }}$ stage, Stage 3) applied load gradually decreases while displacement significantly increases before the specimens completely fail at the end of this stage, and Stage 4) applied load drastically decreases and displacement slightly decreases beyond the third stage before entering to the fourth stage, wherein separation of web from flange takes place.

The average web-flange shear strength to failure of open sections has varied from 7.5 to 10.6 ksi. Maximum web-flange junction shear strength is found in specimen $\mathrm{WJ}_{\mathrm{O} 1}: 3$ while specimen $\mathrm{WJ}_{\mathrm{O} 1.5}: 3$ resulted in the minimum web-flange junction shear strength. However, the average web-flange junction shear strengths in both specimens $\mathrm{WJ}_{\mathrm{O} 1.5}$ and $\mathrm{WJ}_{\mathrm{O} 2}$ are nearly equal. The average shear strength differences in specimens $\mathrm{WJ}_{\mathrm{O} 1}$ and $\mathrm{WJ}_{\mathrm{O} 2}$ have been compared with the shear strength of specimens $\mathrm{WJ}_{\mathrm{O} 1.5}$ which are around $29 \%$ and $3.50 \%$, respectively. Thus, the shear strength of specimens $\mathrm{WJ}_{\mathrm{O} 1}$ under web-flange shear test should not be accepted for use in design due to conservative estimates. Furthermore, it is observed that load versus deflection response is noticeably different between open and closed sectional specimens. Load versus deflection behavior of closed sections under web-flange junction shear test is found to be in three stages: Stage 1) load versus deflection response 
shows smaller movements of the fixed-end support than in open section, leading to a linear response up to the maximum load corresponding to the failure of the first web-flange junctions with a sudden drop in load, Stage 2) applied load gradually increases again until the second web-flange junction fails and the applied load abruptly decreases again, with lower stiffness than in $1^{\text {st }}$ stage, and Stage 3 ) a small increase in applied load over the second slope is followed by gradual decrease in load and displacement (refer to Figure 8.3).

Web-flange junction shear strength of closed sections varies between 4.5 and 6.4 ksi. Maximum and minimum web-flange junction shear strengths are found in specimen $\mathrm{WJ}_{\mathrm{C} 1.5}: 2$ and $\mathrm{WJ}_{\mathrm{C} 1}: 2$, respectively. This is similar to those in open sections. The percent differences in the average shear strength of specimens $\mathrm{WJ}_{\mathrm{C} 1}$ and $\mathrm{WJ}_{\mathrm{C} 2}$ compared to that of specimens $\mathrm{WJ}_{\mathrm{C} 1.5}$ are $25.8 \%$ and $2.88 \%$, respectively. Moreover, web-flange shear strength of closed sections is compared to V-notched beam shear strength of longitudinal and transverse ProDeck4 specimens. The percent differences between web-flange junction shear and Vnotched shear of longitudinal specimens vary from $55 \%$ to $66 \%$ whereas, the percent differences of web-flange junction shear strength compared to V-notched shear of transverse specimens are found to vary between $42 \%$ and $57 \%$. The Web-flange junction shear strength is only one half of the shear strength obtained from flange specimens under V-notched beam tests. Therefore, it seems that web-flange junction strength of closed sections specimens is more realistic and safer for design than the shear strength from V-notched beam testing. 


\subsection{Failure Mode of Web-Flange Junction}

Failure modes of test specimens in both open and closed sections under web-flange junction shear experiments are discussed in this section. From experimental results, most specimens of open and closed type have a similar failure mode and it should be noted that failure mode does not depend on the flange thickness.

For open sections, cracks and layer delamination around web-flange junctions of test specimens are found. These cracks and layer delamination are gradually extended into flange and web with an increase in applied load as shown in Figure 8.4. Moreover, cracks along the specimen thickness have been initiated and extended through the thickness of both front and back side of the web portion as in Figure 8.5. The magnitude of cracks at web-flange junctions has increased with load until the web-flange junction is sheared off.

For closed sections, cracks and layer delamination are similar to those of open sectional specimens. Initially, layer delamination around web-flange junctions is observed. Following delamination, cracks near junctions are extended along the thickness of the webflange portions corresponding to an increase in applied load until shearing off through thickness of web-flange junctions has taken place. Failure of this specimen is presented in Figures 8.6 and 8.7.

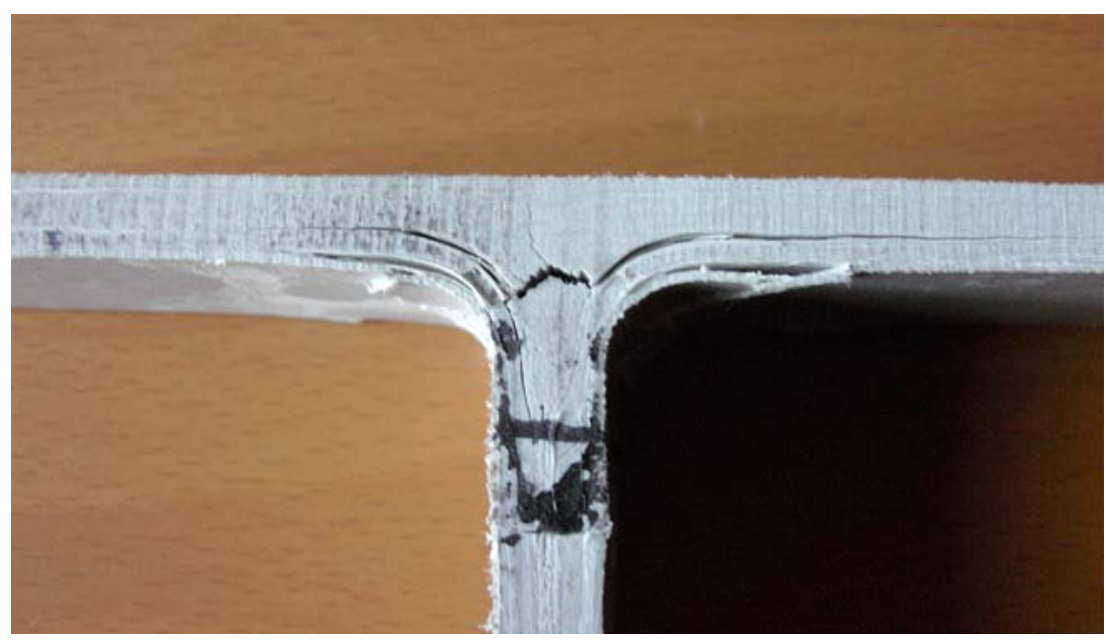

Figure 8.4 Crack and delamination of web-flange junction (open section) 


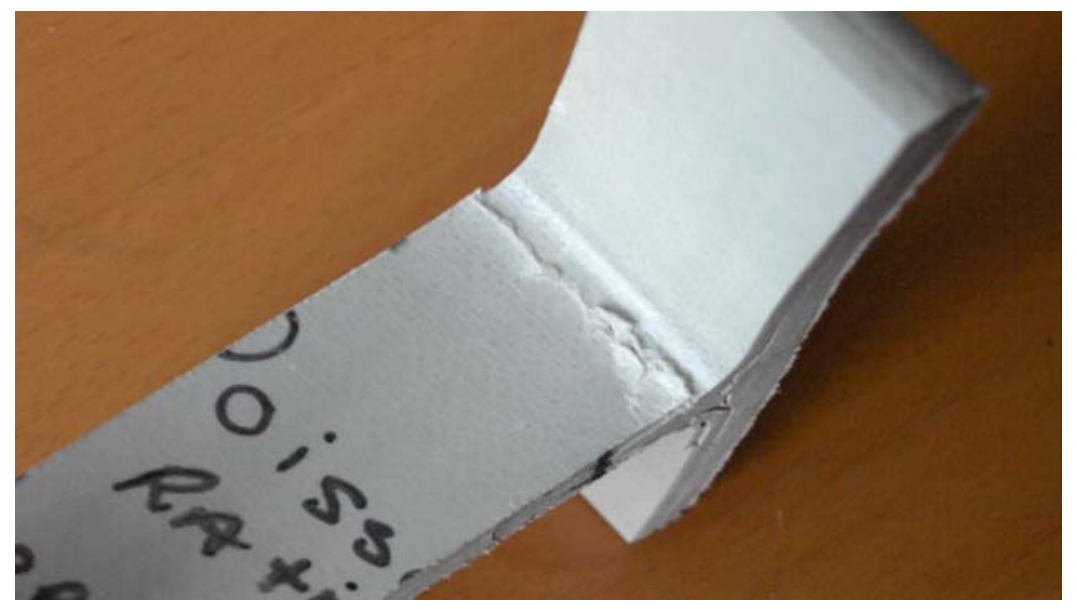

Figure 8.5 Crack through thickness of open sections

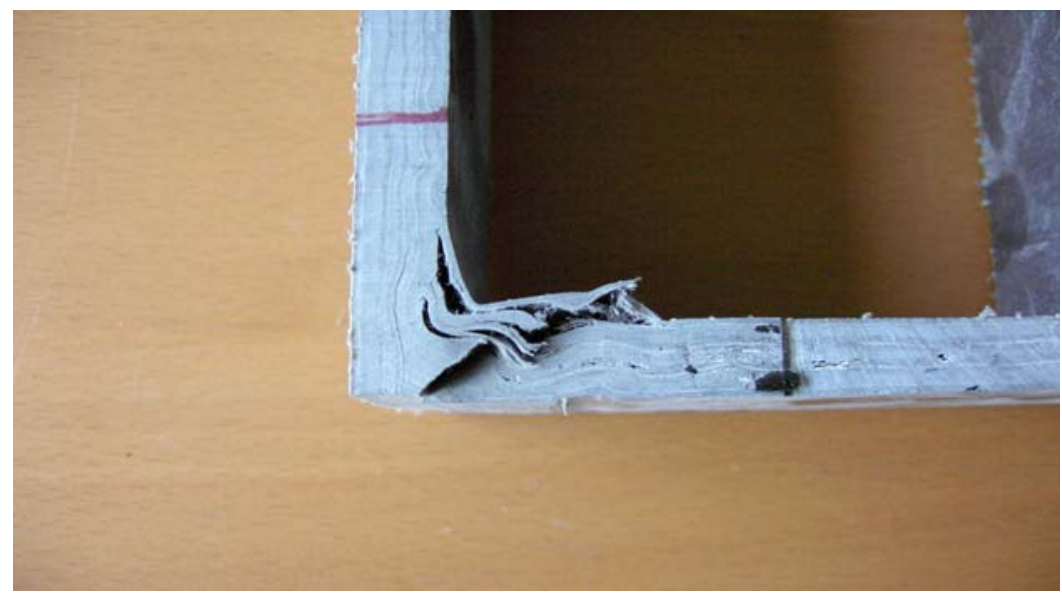

Figure 8.6 Crack and delamination of web-flange junction (closed section)

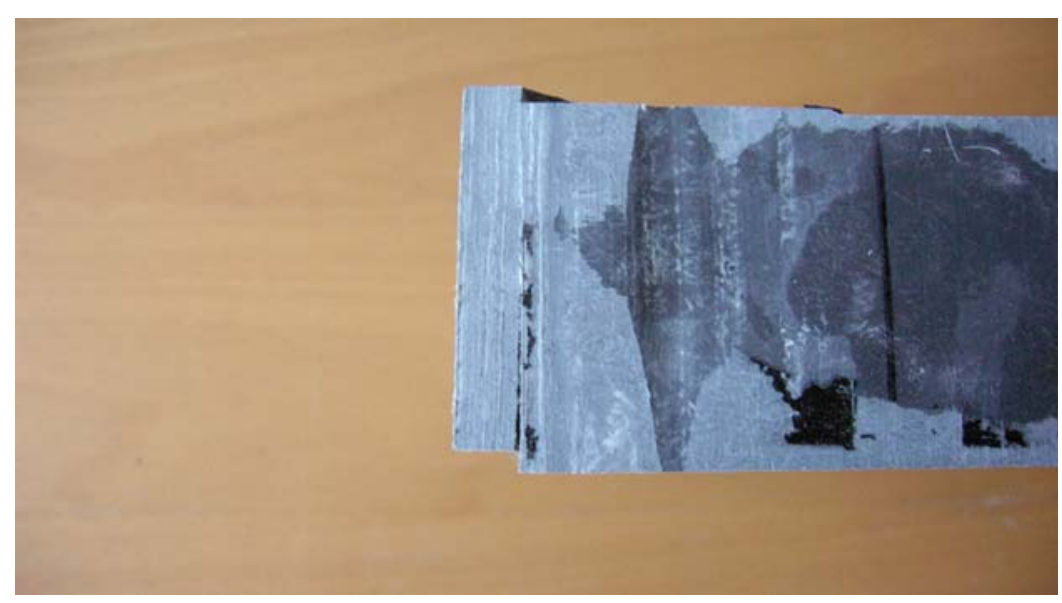

Figure 8.7 Crack through thickness of closed sections 


\subsection{Conclusion}

- The average web-flange shear strength of open sections in this study is found to be between $~ 7.42$ and 10.56 ksi. Also, shear force per unit length of web varies from 1.62 to 2.63 kip/in. (Section 8.3)

- The average web-flange shear strength of closed sections (ProDeck4) is found to be between $~ 4.7$ and $6.3 \mathrm{ksi}$. Also, shear force per unit length of web varies from 0.93 to 1.87 kip/in. (Section 8.3)

- From the experimental results, web-flange shear strength of specimens with 1 inch thickness is lower than that of other specimens (1.5 and 2 inch thickness) for both open and closed sectional specimens. Also, other specimen types (1.5 and 2 inch thickness) do not present any significant difference in failure web-flange shear strength. Failure of web-flange shear strength with smaller thickness (lower than 1 inch thickness) compared to the web width should not be considered for evaluation of web-flange shear strength. (Section 8.4)

- $\quad$ For closed sections (ProDeck4), web-flange shear strength is lower than shear strength from the standard V-notched shear test by about 42-67 \% due to high stress concentration, waving of fiber at the corners of the web-flange junctions and bond failure around cutting edges. It is clear that web-flange shear strength is lower than the shear strength from the V-notched beam testing.

- Web-flange shear strength yields more conservative and realistic shear strength for design purposes than the V-notched beam shear strength. (Section 8.5)

- The failure modes of both open and closed sections are similar. Cracks and layer delamination around web-flange junctions are found and extended along the thickness of the web portion with an increasing in applied loads until web shear-off failure. (Section 8.6) 


\section{CHAPTER 9}

\section{SUMMARY, CONCLUSIONS AND RECOMMENDATIONS}

\subsection{Summary}

In glass fiber reinforced polymer composites, glass fibers/fabrics mainly contribute to tensile, compressive and bending strength, while the component stability and shear transfer within a composite primarily comes from polymer matrix. Other mechanical properties of FRP composites depend on the properties of fiber type and matrix type, fiber volume fraction, orientation of fibers and fabrics, manufacturing process quality and others. Shear modulus of FRP composites is approximately an order of magnitude smaller than the elastic bending, while in metals shear modulus is only 2.5 times smaller than the bending modulus. Most FRP structural members under general loads are likely to fail in shear mode before failing in other modes. To overcome this problem, shear properties including shear behavior of FRP composite structural members under several loading types, have to be thoroughly understood. Hence, an extensive experimental and analytical program has been undertaken to study the shear behavior of FRP composite materials under static loads.

The main focus of this study is to evaluate static shear behavior of FRP composite decks both at coupon and component level. An analytical methodology has been developed to predict the shear performance of FRP composite decks, which has been validated with experimental data. The various types of shear responses that have been evaluated through 
experimental testing are: 1) in-plane shear (both at coupon and component level based on torsion and V-notched shear testing, 2) out-of plane shear (both at coupon and component level) based on short beam shear testing, and 3) punching shear (at component level). In addition, other structural parameters such as local deflection, web-buckling strength and failure modes at web-flange junction have been experimentally evaluated. The analytical methodology that is used herein to validate the experimental data is mainly based on the orthotropic plate theory, finite element method and conventional strength of materials approach.

The shear responses of FRP deck components and systems obtained from extensive experimental data and analytical evaluation are presented herein.

\subsubsection{In-plane shear behavior under torsion test}

The in-plane shear properties of FRP deck coupons and components under torsion have been evaluated for shear rigidity $(G J)$, shear modulus $\left(G_{x y}\right)$ and shear strain $\left(\gamma_{x y}\right)$. At coupon level, the effects of fiber architecture, aspect ratio (b/t), and shape on shear behavior of coupon have been studied. At component level, in-plane shear responses of multicellular thin walled FRP bridge deck components (Prodeck 4 and Prodeck 8) for single cell and multi-cell (3-cell) system were evaluated. The effect of joints on the shear response of FRP components is also studied. In addition, FE analysis at system level including plate action in both longitudinal and transverse directions has been carried out, under torsion and in-plane shear force. 


\section{Coupons - Experimental Data versus Theoretical Results}

\section{$\underline{\text { Effect of Fiber Architecture }}$}

- The in-plane shear modulus of plates with 2D/3D fabrics is about $40 \%$ higher than that in FRP coupons reinforced with only with unidirectional fibers. The lower shear modulus in FRP plates with unidirectional rovings is attributed to lack of $\pm 45^{0} / 90^{0}$ fibers. Also, coupons with 2D/3D fabrics have higher stiffness under in-plane shear due to overlap of fibers/fabrics (i.e., higher friction) leading to lower strains, thereby resulting in higher shear modulus than in FRP plates with unidirectional rovings.

- $\quad$ Experimental results indicate that there is no significant difference in equivalent inplane (xy) shear modulus whether test specimens are cut in longitudinal or transverse direction.

\section{Effect of Aspect Ratio}

- $\quad$ The experimental data revealed about $10 \%$ increase in in-plane (xy) shear modulus with an increase in width to thickness ratio (b/t) from 2 to 10. (Section 4.6.1.2), regardless of fiber architecture (i.e., 1D, 2D or 3D).

- $\quad$ FRP plates with unidirectional fibers (aspect ratio ranging from 2 to 10), SCLT over estimated the experimental shear modulus by about 8\%. (Section 4.6.1.1)

- For plates with 2D fabrics, in-plane shear strains based on SCLT are about 20\% higher than the experimental data because of the following reasons: 1) SCLT assumes perfect bond of lamina, 2) SCLT neglects stress concentration effect, and 3) SCLT neglects loss of load transfer due to fiber discontinuity created by cutting of samples. (Section 4.6.1.4)

- In case of circular rebars, the shear modulus increases as the diameter decreases because the core material in a rebar contributes more in smaller diameter bars to 
overall structural properties than in large diameter bars. This difference is attributed to “shear lag” phenomenon.

- In case of rectangular sandwich coupons, shear modulus has increased by about 50\% with 50\% increase in aspect ratio (i.e., $b / t=1 \sim 7$ ) mainly due to the plate action.

\section{Effect of Shape}

- The shear modulus of circular sections is found to be about $10 \%$ more than the rectangular plates (note: the shear modulus is based on per unit fiber volume fraction).

- The shear modulus for sandwich plates as expected is about 10 times less than the shear modulus for solid plates because of poor bonding between the core and facial sheet in sandwich coupons.

- There is no significant difference in shear behavior between circular rebars and tubes.

\section{$\underline{\text { Shear Strain }}$}

- $\quad$ Regardless of fabric architecture (not unidirectional fiber alone), aspect ratio and shape, the ultimate in-plane shear strain under torsion in FRP composites is found to be about $10,000 \mu \varepsilon$ which is attributed to the bond failure strain limit in FRP composites.

\section{Component Level - Experimental Data versus Theoretical Results}

\section{Effect of Geometry}

- $\quad$ There is no significant difference in in-plane shear modulus between single cell and multi-cell components because the component property is independent of the number of cells, except a small reduction in single cell components due to fiber debonding to fiber cutting.

- The torsional rigidity of a 3-cell component without joint is about $20 \%$ higher than that of a single cell component. This increase is attributed to the effects of geometry, 
fiber cutting in single cell case, and interaction of adjoining cells in a multi-cell case as opposed to a single cell case.

- $\quad$ No significant difference in shear modulus between Prodeck 4 (3-cell component) and Prodeck 8 (2-cell component) because the fiber volume fraction ( 50\%) and fiber architecture for both components are nearly identical. (see Table 4.14)

\section{$\underline{\text { Effect of Joint }}$}

- The torsional rigidity of a multi-(3) cell component with joints is found to be only $8 \%$ more than the single cell component. It should be noted that the torsional rigidity of FRP components decreases, in the presence of joints, due to lack of $100 \%$ joint efficiency.

- $\quad$ For longitudinal multi-cell components (3-cell) without joints, the torsional rigidity is about $14 \%$ higher than that with joints.

- There is no significant difference in shear modulus between longitudinal and transverse components with joints.

- $\quad$ Equivalent in-plane shear modulus computations of FRP components based on SCLT and finite element method have resulted in good agreement with the experimental data but for the transverse specimen COP4 $4_{18 \mathrm{~T}}$. Specimens COP4 $4_{18 \mathrm{~T}}$ resulted in lower inplane experimental shear modulus due to joints because the present SCLT does not account for joint effects. However, small percent difference in in-plane (xy) shear modulus does lead to higher percent difference in stress and strain values. (Sections 4.6.2.2 and 4.6.2.3).

- $\quad$ SCLT and finite element analysis predicted about 20\%-30\% lower shear strain compared to the experimental data. Such differences are attributed to the assumptions of perfect continuity of materials through specimens and full load transfer. In 
addition, SCLT does not account for structural geometry effect (joint efficiency) of diagonal bracing (Section 4.6.2.3).

- $\quad$ In-plane (xy) shear strain based on SCLT yields good accuracy only for locations near mid-plane (xz) passing through the thickness in each cross section of a structural member and far away from the ends of a structural member (boundaries). SCLT gives only a constant strain for each layer (xy plane) through the thickness of structural portions. Therefore, theoretical strains at locations far away from the mid-plane (xz) passing through the thickness of cross section are somewhat different from the experimental strain. Also, complex stress distribution is found near the boundaries (applied torque at both ends) of the FRP structural members. (Section 4.6.2.3), which result in erroneous experimental data.

- $\quad$ Regardless of type of loads (torsion or in-plane shear loads), the torsional rigidity per unit width of a system that has multi-cells (plate type) is about $20 \%$ higher than a component that has single cell (beam type). Here the system is assumed to have $100 \%$ load transfer from one component to another i.e., joint efficiency is about $100 \%$.

- $\quad$ Assuming $80 \%$ joint efficiency, the torsional rigidity per unit width of the FRP system (with joints and plate action) is about 6\% higher than the FRP component that has only beam effect. 


\subsubsection{In-plane shear behavior under V-notched, cantilever and racking shear test}

\section{Coupon Level - Experimental Data}

- The in-plane shear failure behavior of coupons under V-notched testing was different from that under torsion test. It is found that under torsion, the coupons have delamiantion within the FRP coupon layers while vertical cracking is developed in the V-notched test specimens.

- $\quad$ The in-plane shear stress predicted as per V-notched shear test is about $12 \mathrm{ksi}$ and shear modulus is about $0.6 \times 10^{6} \mathrm{psi}$. It is found that shear properties (shear modulus and shear strength) predicted from V-notched test method are higher (about 18\%) than those evaluated from torsion test data. This is attributed to the fabrics of reinforced laminates that have $0^{\circ}$ and $90^{\circ}$ orientations (Section 5.3.1.1 and 5.3.2), i.e., fabrics contributed to vertical additional vertical shear resistance.

\section{Shear Strain}

- $\quad$ The ultimate in-plane shear strain in V-notched test specimens $(20,000 \mu \varepsilon)$ is found to be about 2 times that from torsion test specimens.

\section{Component Level - Experimental versus Theoretical Results}

- $\quad$ The joint efficiency for different types of joints (riveted, glued and riveted+ glued) under in-plane load is found through cantilever shear testing. It is found that joint efficiency for riveted specimens is about $78 \%$ while that of glued specimens is about $85 \%$. The specimen that has both rivets and glue has joint efficiency of about $90 \%$ and performed well compared to other types of joints. 
- $\quad$ Equivalent in-plane shear (xy) modulus under shear loading perpendicular to the cell direction (cantilever test) is found to be about 38\% higher than the case where loading is parallel to the cell direction (racking shear test). This is due to the presence of more joints (i.e., less joint efficiency), leading to poor load transfer in the racking shear test specimen.

- $\quad$ The average equivalent in-plane shear (xy) modulus of FRP deck under racking shear is found to be overly conservative due to low stiffness in loading direction (weak direction) and joint effect. (Section 5.3.3)

- $\quad$ The shear modulus predicted by finite element model correlated well with the cantilever test specimens that did not have any joints.

\subsubsection{Out-of-plane shear strength and stiffness}

\section{Coupon Level - Experimental Data}

- $\quad$ Average out-plane shear strength in the $\mathrm{xz}$ and yz direction (3 to $4 \mathrm{ksi}$ ) from coupon testing is much lower (about 3-4 times) than that of in-plane shear (xy direction) strength, because fiber/fabric layers in 1D/2D/3D composites are usually laid-up on the xy plane of FRP specimens. Hence, higher shear strength is found in the xy direction when compared with the average shear strength in the $\mathrm{xz}$ and $\mathrm{yz}$ direction. Such discrepancy is attributed to several factors such as: bond failure, resin cracking, stress concentration factor, edge effect, lack of 3-D fiber and size shape effect.

- The failure modes in all coupons are found to be delamination of layers, hence the ultimate out of plane shear strength might be limited by the interface shear failure between the fiber and matrix, especially in the absence of out-of-plane fibers (3-D stitch) that keep the layers in xy direction together. 


\section{Component Level - Experimental versus Analytical Data}

- The out-of-plane shear (xz) strength of multi-cell component is about $10 \%$ higher than that of a single cell because of fabric cutting in single cell specimens leading to fiber discontinuity and bond failure around cut edges. (Section 6.3.1.3)

- $\quad$ The out-of-plane shear modulus (xz) for single and multi cell components is about 0.51 and 0.43 msi, respectively. This small difference may be attributed to shear leakage in multi cell components.

- $\quad$ The out-of-plane shear moduli ( $\mathrm{xz}$ and $\mathrm{yz}$ ) based on finite element method are found to be in good agreement (within 10\%) with the experimental data (Section 6.3.2.3).

- $\quad$ The failure mode in FRP components under out-of-plane loading is found to be mainly web buckling. Cracks and delamination are found on component cross sections which gradually extend into high stress concentration locations near junctions. (Section 6.3.1.2)

- It is found that joint efficiency under out-of-plane loading for longitudinal and transverse components is about $80 \%$ to $90 \%$, depending on the control system that is used to evaluate static response including type of joints. (Section 6.5)

- The span to depth ratio (L/d) for single cell and multi cell components under three and four point bending loads with $15 \%$ shear deformation should be $L / d>18$ (for single cell specimen) and $L / d>22$ (for multi-cell specimen with and without joints) respectively (Section 6.7) 


\subsubsection{Punching shear}

\section{Component Level - Experimental Data}

- The punching shear strength of composite components is found to be half of the out of plane shear strength, and 5 times lower than that of in-plane shear strength. During punching test, the top most fiber/fabric layer that is present in the flange absorbs maximum load (more of local effect) while in in-plane or out-of-plane shear testing, the component as whole absorbs the load (more of a global effect).

- It is found that with an increase in aspect ratio (3 to 5), the punching shear strength increased by about $15 \%$ increase.

- $\quad$ The ultimate punching shear strength between single and multi cell components differed by about $20 \%$. The average punching shear strength of single cell component is about $2.3 \mathrm{ksi}$ while that of multi cell component is about $3 \mathrm{ksi}$.

- $\quad$ Failure mode of single cell specimens included two parts: 1) punching failure mode, 2) delamination of fabric layers along the test specimen edges due to bending effect. (Section 7.6). Failure mode in multi-cell component, however, is only due to punching failure.

- The punching shear strength values from theory are about 12 to $26 \%$ off when compared with the experimental data for multi-cell specimens because of shape effect (web-stiffening of the multi-cell) and neglect of plate action. 


\subsubsection{Web-flange shear strength}

\section{Component Level - Experimental Test Results}

- The average web-flange shear strength of closed sections (ProDeck4) is found to be between 4.5 to $6 \mathrm{ksi}$ and the shear force per unit length of web varies from 0.93 to 1.87 kip/in. (Section 8.3).

- From the experimental data, it is found that the web-flange shear strength of both open and closed specimens with 1 inch thickness is lower (about 25\%) than that of specimens with 1.5 and 2 inch thickness. There was no significant difference in web-flange shear failure within the test specimens that have 1.5 to 2 inch thickness.

- For closed sections (ProDeck4), web-flange shear strength is found to be about $42-67 \%$ lower than the shear strength from the standard V-notched shear test. This is because of high stress concentration due to waving of fibers at the corners of the web-flange junctions and bond failure around the cutting edges.

- $\quad$ The failure modes for both open and closed sections are similar. First cracks and delamination of layers around web-flange junctions are initiated and extended, with an increase in load, along the thickness of the web until the web shears-off. (Section 8.6)

\subsubsection{Web Buckling}

- Average effective length (K) for specimens with multiple webs (2 to 4 ) is found to be 1.0 when compared to single web specimen, which is about 0.85 .

- Linear behavior of stress versus strain is observed under web buckling load. The longitudinal strain at buckling stress is between 4226 and $6680 \mu$ in/in. (Section F.6)

- $\quad$ The failure mode of specimens under web buckling is mainly due to cracking and fiber delamination at web-flange junction. (Section F.7) 
- $\quad$ Size limit due to local-lateral buckling of a flange in ProDeck4 single- and multi-cell components based on finite element analysis are (Section F.8):

Single cell specimen under assumed failure torque of 108 in-kip is:

$d_{w} / t_{w}<8$ and $b_{f} / t_{f}<11$

Multi-cell specimen under assumed failure torque of 360 in-kip is:

$d_{w} / t_{w}<8.5$ and $b_{f} / t_{f}<12$

\subsubsection{Local deflection}

- It is found that local deflection of the top flange under bending loads is partially fixed due to webs at close intervals.

- Our extensive experiment test data revealed found that maximum local deflection of top flange between two contiguous webs is $\delta_{\text {local }}=\frac{0.8 P(L)^{3}}{48 E I}$ which indicates that under simply supported condition, for $10 \%$ shear deformation the rigidity of the top flange between the web is about $20 \%$

- The maximum local deflection limit (deflection between two contiguous webs) limit state in a composite system is restricted to be $\mathrm{s} / 100$, s being distance between contiguous webs. This limit state is based on preventing wearing surface cracking. 


\subsection{Conclusions}

\section{Experimental Test Results}

- In-plane shear modulus of fabric based composite (2D/3D) components (fiber volume fraction $\sim 50 \%$ ) based on different shear tests is found to be about $0.55 \times 10^{6}$ psi while outof-plane shear modulus in $\mathrm{xz}$ and $\mathrm{yz}$ direction is around $0.45 \times 10^{6}$ and $0.25 \times 10^{6} \mathrm{psi}$, respectively.

- In-plane shear strength of FRP composite deck components under V-notched beam test is found to be about $12 \mathrm{ksi}$ and the corresponding failure shear strain is about $20,000 \mu \varepsilon$.

- Shear strength of FRP composite deck components under torsion test is found to be about $6 \mathrm{ksi}$ and the corresponding failure shear strain at top surface is about $10,000 \mu \varepsilon$.

- Out-of-plane shear strength of FRP composite deck components under short beam shear test is found to be $8 \mathrm{ksi}$.

- Punching shear strength of ProDeck4 is about 3 ksi.

- Web-flange shear strength of ProDeck4 is found to be about 4.5-6 ksi.

- The web buckling strength of composite components increased from 8 ksi to $12 \mathrm{ksi}$ as the number of webs decreased from 4 to 1 . When the number of webs increases, the specimen behaves as a beam under uniform load. Hence, the webs behave as supports of top flange with multiple webs, whereas in case of single web case the specimen is subjected to a concentrated load only.

- The maximum local deflection limit (deflection between two contiguous webs) in composite deck systems is found to be $\mathrm{s} / 100$, s being the distance between contiguous webs. 


\section{Analytical Model (SCLT \& FE)}

- In-plane shear modulus computations of FRP components based on SCLT and finite element method have resulted in good agreement with the experimental data. However, SCLT and finite element model predicted about 20\%-30\% lower shear strain compared to experimental data. Results from finite element method are generated using stiffer elements than the actual specimens. In case of results from SCLT, the method does not account for the joint flexibility of the cross section.

- In-plane (xy) shear strain based on SCLT yields good accuracy only for locations near mid-plane (xz) passing through the thickness of a structural member and far away from the ends of structural members (boundaries). In-plane shear strains based on SCLT rely on assumptions that strains are constant throughout for a given laminae (xy-plane) in structural members. Therefore, in-plane shear strains based on SCLT are quite inaccurate for any positions that are located far away from mid-plane (xz-plane) passing through the thickness of each structure portion (webs and flanges).

\section{Plate Action versus Beam Effect}

- Plate action in a composite system under torsional and/or in-plane loadings is only about $20 \%$ higher than a component that has no plate action (i.e., only beam effect) while in case of an isotropic system, the plate action is about $100 \%$ of the beam effect. The lower plate action in composite systems is attributed to the fact that composites, being orthotropic, have different Poisson's effect in transverse and longitudinal directions. Due to low Poisson's ratio in the transverse directions, the composite plate system has more of a cylindrical bending effect which is more or less same as bending due beam effect and thus only $20 \%$ higher than that of beam effect (due to plate action).

- Assuming $100 \%$ load transfer between one component to another (i.e., joint efficiency being $100 \%$ ), the plate effect was about $20 \%$ higher than the beam effect. In case of $80 \%$ 
of joint efficiency, the plate effect has been reduced to 6\% higher than the FRP beam effect.

\section{Joint Efficiency}

- Average joint efficiency of FRP composite deck components under different shear tests is found to be about $80 \%$.

\section{Size Effect}

- The span to depth ratio (L/d) for multi-cell components under three and four point bending loads should be as follows: $L / d>22$ (Section 6.7).

- Size limit due to local-lateral buckling of flange for ProDeck4 under failure torque of 360 in-kip is: $d_{w} / t_{w}<8.5$ and $b_{f} / t_{f}<12$

\subsection{Recommendations}

Experimental and theoretical studies on shear behavior of FRP bridge deck composites at coupon, component and system levels, have led to the following recommendations:

- The shear modulus in composite components is about $1 / 7^{\text {th }}$ to $1 / 8^{\text {th }}$ of bending modulus which can be further improved by enhancing resin properties, and using three dimensionally stitched fabrics.

- $\quad$ The failure shear strain in a composite can be further enhanced by improving bond strain (between fiber/fabric and resin) through addition of nanoparticles to bulk resins.

- $\quad$ The web-flange junction failure can be prevented in composite components by stitching the part in the thickness direction during pultrusion process.

- $\quad$ More experiments and analytical models (i.e., width to thickness of flange, and depth to thickness of web) should be performed to optimize size effects. 
- $\quad$ Theoretical models predicting shear strength at failure in composite components should be developed.

- $\quad$ Shear response in other FRP bridge deck (honeycomb and multi-cell decks etc) should be evaluated so as to establish design specifications.

- $\quad$ Standard test methods for in-plane and out-of-plane shear at coupon, component, and system should be developed.

- $\quad$ Rigorous failure criteria must be developed and energy absorption capacity must be studied for FRP composite components. In addition, performance of FRP composite decks under severe and aging conditions has to be evaluated. 


\section{REFERENCES}

ASTM D 2344 (1982), “Apparent Interlaminar Shear Strength of Parallel Fiber Composites by Short-Beam Method,” pp. 43-45.

ASTM D 5379/ D5379M, (1993), "Shear Properties of Composite Materials by the VNotched Beam Method,” pp. 235-247.

Bank, L.C., and Mosallam, A.S.,(1991). "Linear and Nolinear Response of Pultruded FRP Frames Subjected to Static Loads,” MD-Vol.29, Plastics and Plastic Composites: Material Properties, part Performance, and Process Simulation, ASME

Barbero, E.J., (1998), "Introduction to Composite Materials Design," Taylor \& Francis Inc.: Philadelphia, PA., USA.

Barbero, E.J., Tomblin, J., (1994), “A Phenomenological Design Equation for FRP Columns with Interaction Between Local and Global Buckling," Thin-Walled Structures, 18, 117-131, 1994.

Bauld, N. R. Jr., and Tzeng, L.S., (1984), “ A Vlasov Theory for Fiber-Reinforced Beams with Thin-walled Open Cross Sections,” Journal of Solids Structures. Vol. 20, No. 3 pp. 277-297.

Boresi, A., Richard S., Omar S., (1993) “Advanced Mechanics of Materials,” John Wiley \& Sons, Inc., New York, NY., USA.

Camomile, A., and Swanson, S.R., (2002) "Torsion of Thin Orthotropic Open Sections,” Journal of Composite Materials. Vol.36, No.2, pp. 195-210

Clarke, J.L., (1996), “Structural Design of Polymer Composites," EUROCOMP Design Code and Handbook, London, UK.

Deepthi, P., (2004), "Structural Performance of Low-Profile FRP Composite Cellular Modules”, Master's Thesis, Department of Civil Engineering, West Virginia University, Morgantown.

Felippa, C.A., (2001), “Introduction to Finite Element Methods" University of Colorado, Boulder.

GangaRao, H.V.S and Nagaraj V., (1993) "Characterization of GFRP Pultruded Box Beams Under Static and Fatigue Loads,” SAMPE Quarterly (Journal of Advanced Materials), v24, July, p3-9

GangaRao, H.V.S., Sotiropoulos, S., Mongi A.,(1994), “Theoretical and Experimental Evaluation of FRP Components and Systems,” Journal of Structural Engineering, Vol 120, n2, February, pp.464-485. 
GangRao, H.V.S., Thippeswamy, H., Shekar, V. and Craigo, C.(1999), “Development of Glass Fiber Reinforced Polymer Composite Bridge Deck,” SAMPE Journal, Vol35, n4.

GangaRao, H.V.S., Shekar, V., (2002), "Specifications for FRP Highway Bridge Applications: Acceptance Test Specifications for FRP Decks and Superstructures," CFC Report to USDOT-FHWA, West Virginia University.

Gjelsvik, A., (1981), “The Theory of Thin Walled Bars,” John Wiley \& Sons, Inc., New York, NY., USA.

Hyer, M.W. (1998), "Stress Analysis of Fiber-Reinforced Composite Materials," International edition, WCB/McGraw-Hill, Singapore.

Howard, I., (2002), "Development of Lightweight FRP Bridge Deck Designs and Evaluations," Master's Thesis, Department of Civil Engineering, West Virginia University, Morgantown.

Jones, R.M. (1975), “Mechanics of Composite Materials,” Hemisphere Publishing Co.

Kollar, L.P. and Pluzsik, A. (2002), “Analysis of Thin-Walled Composite Beam with Arbitrary Lay up”, Journal of Reinforced Plastics and Composites, Vol.21, pp. 14231465.

Kumar,P., Chandrashekhara, K., and Nanni,A., (2001), "Testing and Evaluation of Components for a Composite Bridge Deck," Journal of Reinforced Plastics and Composites.

Lopez-Anido, Roberto., (1995), “Analysis and Design of Orthotropic Plates Stiffened by Laminated Beams for Bridge Superstructures,” Ph.D Dissertation, Dept. of Civil and Environmental Engineering, West Virginia University, Morgantown.

Lopez-Anido, Roberto, Piyush Dutta, John Bouzoun, Steve Morton, Bahram Shahrooz, Issam Harik (1999),"Proceedings of the $44^{\text {th }}$ National SAMPE Symposium,” Vol 44, Azusa, CA, pp.1666-1675.

Mallick, P.K, "Fiber Reinforced Composites: Materials, Manufacturing, and Design," Marcel Dekker, Inc.: New York, USA, 1993.

Makkapati, S.,(1994), “Compressive Strength of Pultruded Structural Shapes,” M.S. Thesis, Department of Mechanical Engineering, West Virginia University, Morgantown.

Massa, J.C. and Barbero, E.J. (1998), “A Strength of Materials Formulation for Thin Walled Composite Beams with Torsion,” Journal of Composite Materials, Vol. 32, pp. 1560-1594.

Matthews, F.L., and Rawlings, R.D., (1994), “Composite Materials: Engineering and Science,” Chapman \& Hall, London. UK. 
Megson, T.H.G. (1999), “Aircraft Structures for Engineering Students,” 3 rd edition, Elsevier (Singapore) Pte Ltd, Singapore.

Murray, N.W.(1984), "Introduction to the Theory of Thin-Walled Structures”, Oxford University Press, New York.

Nagaraj, V., (1994), "Static and Fatigue Response of Pultruded FRP Beams without and with Splice Connections," M.S Thesis, Department of Civil and Environmental Engineering, West Virginia University, Morgantown.

Nystrom, H.E., Watkins, S.E., Nanni, A. and Murray, S. (2003), "Financial Viablility of Fiber-Reinforced Polymer (FRP) bridges,” Journal of Management in Engineering, pp.2-8.

Righman, J., (2002), "Development of an Innovative Connection for FRP Bridge Decks to Steel Girders,” M.S. Thesis, Department of Civil and Environmental Engineering, West Virginia University, Morgantown.

Saadatmanesh, H., and Ehsani, M.R., (1998), "Fiber Composites in Infrastructure," Proceedings of the Second International Conference on Composites in Infrastructure, ICCI ’98, Vol II, Tucson, Arizona, USA.

Sankar, B.V. (1993), “A Beam Theory for Laminated Composites and Application to Torsion Problems,” Journal of Applied Mechanics, Vol.60, pp. 246-248.

Savoia, M. and Tullini, N. (1993),"Torsional Response of inhomogenous and multilayered composite beams,” Composite Structures, Vol. 25, pp. 587-594.

Schniepp, T.J., (2002), “Design Manual Development for a Hybrid, FRP Double-Web Beam and Characterization of Shear Stiffness in FRP Composite Beams," M.S. Thesis, Department of Engineering Science and Mechanics, Virginia Polytechnic and State University, Blacksburg.

Shekar, V., (2000), “Advancement in FRP Composites using 3-D Stitched Fabrics and Enhancement in FRP Bridge Deck Component Properties,” M.S. Thesis, Dept. of Civil and Environmental Engineering, West Virginia University, Morgantown.

Skudra, A.M., Bulavs, F.Ya., Gurvich, M.R. and Kruklinsh, A.A. (1991), "Structural Analysis of Composite Beam Systems,” Technomic Publishing Company, Inc., Lancaster, Pennsylvania.

Sonti, S.S., (1997), "Evaluation of Joint Efficiency and Performance of Multi-Cellular Deck Panel,” M.S. Thesis, Department of Civil and Environmental Engineering, West Virginia University, Morgantown.

Sonti, S.S., and Barbero. E.J., (1995), "Determination of Shear Properties for RP Pultruded Composites,” Journal of Reinforced Plastics and Composites, Vol. 14, April, pp. 390-401. 
Sotiropoulos, S., (1995), "Performance of FRP Components and Connections for Bridge Deck Systems,” Ph.D Dissertation, Dept. of Civil and Environmental Engineering, West Virginia University, Morgantown.

Swanson, S.R., (1997), “Introdution to Design and Analysis with Advance Composite Materials,” Prentice-Hall Inc, Upper Saddle River, New Jerry.

Vasiliev, V.V., (1993), “Mechanics of Composite Structures,” Taylor \& Francis Ltd, London, UK.

Vedam, V.R., (1997),“Characterization of Composite Material Bridge,” M.S. Thesis, Department of Civil and Environmental Engineering, West Virginia University, Morgantown.

Wang, C.K., (1992), “Reinforced Concrete Design,” 5 ed., Harper Collins Publishers, NewYork, NY.

Whitney, J.M., (1987), "Structural Analysis of Laminated Anisotropic Plates," Technomic Publishing Company, Inc. Lancaster, Pennsylvania, USA.

Zenkert, D., (1997),“The Handbook of Sandwich Construction,” Engineering Materials Advisory Services Ltd, UK.

Zureick, A., Kahn, L.F., and Bandy, B.J., (1994), “Tests on Deep I-Shape Pultruded Beams," $49^{\text {th }}$ Annual Conference, Composites Institute, The Society of the Plastics Industry, Inc., February 7-9,pp 8c1-8c6. 


\section{APPENDIX A:}

\section{Simplified Classical Lamination Theory for In-Plane Shear (xy)}

Modulus

\section{A.1 Introduction}

Classical lamination theory is based on stress and deformation hypothesis. This approach is quite involved and required many computations. Simplified classical lamination theory for bending stiffness, known as the approximate classical lamination theory (ACLT) was developed and proposed by Nagaraj 1994. Therefore, simplified classical lamination theory for torsional shear rigidity is an extension of ACLT, as developed in this study. In addition, percent differences of results compared between simplified classical lamination, experimental and finite element approach are providing adequate accuracy to evaluate torsional stiffness and equivalent in-plane shear modulus of both ProDeck4 and 8.

\section{A.2 Simplified Classical Lamination Theory}

From classical lamination theory, stress and strain relations of composite lamina under in-plane stress conditions can be presented in both material and global coordinates (see Figure A.1) as:

In material coordinate system: 


$$
\left[\begin{array}{l}
\sigma_{1} \\
\sigma_{2} \\
\sigma_{3}
\end{array}\right]=\left[\begin{array}{ccc}
Q_{11} & Q_{12} & 0 \\
Q_{12} & Q_{22} & 0 \\
0 & 0 & Q_{66}
\end{array}\right]\left[\begin{array}{c}
\varepsilon_{1} \\
\varepsilon_{2} \\
\gamma_{12}
\end{array}\right]
$$

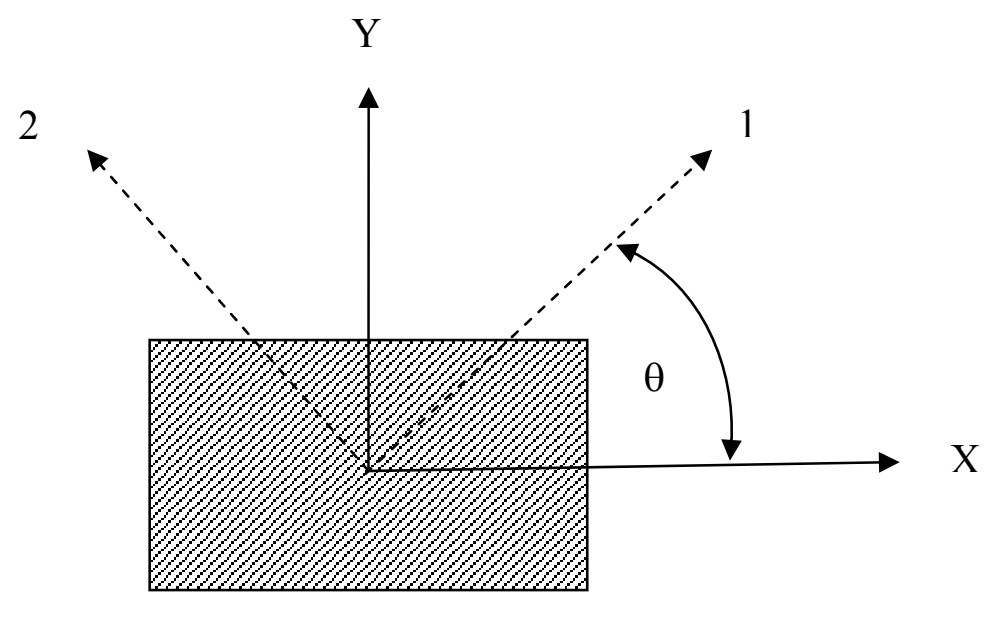

\section{Figure A1. X-Y global and 1-2 material coordinate}

Where, $\sigma_{1}$ is normal stress in the fiber direction and $\sigma_{2}$ is normal stress in perpendicular to fiber direction. Also, $\sigma_{3}$ is in-plane shear stress. $\varepsilon_{1}$ is normal strain in fiber direction and $\varepsilon_{2}$ is normal strain in perpendicular to the fiber direction. $\gamma_{12}$ is in-plane shear strain. $Q_{11}$ and $Q_{22}$ are the lamina stiffness in the fiber and perpendicular to fiber direction, respectively. $Q_{12}$ is in-plane coupling due to Possion's effect. $Q_{66}$ is in-plane shear stiffness of lamina under plane stress condition.

The constitutive equation of an arbitrarily oriented composite lamina under the state of plane stress condition was given in Equation (A.2).

In global coordinate system:

$$
\left[\begin{array}{c}
\sigma_{x} \\
\sigma_{y} \\
\tau_{x y}
\end{array}\right]=\left[\begin{array}{lll}
\overline{Q_{11}} & \overline{Q_{12}} & \overline{Q_{16}} \\
\overline{Q_{12}} & \overline{Q_{22}} & \overline{Q_{26}} \\
\overline{Q_{16}} & \overline{Q_{26}} & \overline{Q_{66}}
\end{array}\right]\left[\begin{array}{c}
\varepsilon_{x} \\
\varepsilon_{y} \\
\gamma_{x y}
\end{array}\right]
$$


Where, $\sigma_{\mathrm{x}}$ and $\sigma_{\mathrm{y}}$ are normal stresses in $\mathrm{x}$ and $\mathrm{y}$ direction, respectively. $\tau_{\mathrm{xy}}$ is in-plane shear stress. Also, $\varepsilon_{\mathrm{x}}$ and $\varepsilon_{\mathrm{y}}$ are normal strains in $\mathrm{x}$ and $\mathrm{y}$ direction. $\gamma_{\mathrm{xy}}$ is in-plane shear strain.

Several assumptions were proposed to simplify an original classical lamination theory. These assumptions were presented as: 1) composite laminates are under torsion 2) no restraints at both ends of composite laminates (free-free condition) is possible and 3) normal stresses in $\mathrm{x}$ and $\mathrm{y}$ direction are assumed to be zero. By using these assumptions, the constitutive in Equation (A.2) is simplified and presented below:

In global coordinate system:

$\left[\begin{array}{c}0 \\ 0 \\ \tau_{x y}\end{array}\right]=\left[\begin{array}{lll}\overline{Q_{11}} & \overline{Q_{12}} & \overline{Q_{16}} \\ \overline{Q_{12}} & \frac{\overline{Q_{22}}}{Q_{26}} & \frac{\overline{Q_{26}}}{Q_{66}}\end{array}\right]\left[\begin{array}{c}\varepsilon_{x} \\ \varepsilon_{y} \\ \gamma_{x y}\end{array}\right]$

To present relation of in-plane shear stress and strain, $\varepsilon_{\mathrm{x}}$ and $\varepsilon_{\mathrm{y}}$ are rewritten in terms of $\gamma_{\mathrm{xy}}$ by solving first two simultaneous equations of constitutive relation in Equation (A.3).

$$
\begin{aligned}
& \varepsilon_{x}=\frac{\left(\overline{Q_{26}} \overline{Q_{12}}-\overline{Q_{22}} \overline{Q_{16}}\right)}{\left(\overline{Q_{11}} \overline{Q_{22}}-\overline{Q_{26}}{ }^{2}\right)} \gamma_{x y} \\
& \varepsilon_{y}=-\frac{\left(\overline{Q_{26}} \overline{Q_{11}}-\overline{Q_{12}} \overline{Q_{16}}\right)}{\left(\overline{Q_{11}} \overline{Q_{22}}-{\overline{Q_{12}}}^{2}\right)} \gamma_{x y}
\end{aligned}
$$

Also, in-plane shear stress and strain relation is given as:

$$
\tau_{x y}=\overline{Q_{16}} \varepsilon_{x}+\overline{Q_{26}} \varepsilon_{y}+\overline{Q_{66}} \gamma_{x y}
$$


To write in-plane shear stress in term of shear strain, normal strains in Equations (A.4) and (A.5) are substituted into in-plane shear stress and strain in Equation (A.6) leading to:

$$
\tau_{x y}=\left(\frac{\overline{Q_{16}}\left(\overline{Q_{26}} \overline{Q_{12}}-\overline{Q_{22}} \overline{Q_{16}}\right)}{\left(\overline{Q_{11}} \overline{Q_{22}}-\overline{Q_{12}{ }^{2}}\right)}-\frac{\overline{Q_{26}}\left(\overline{Q_{26}} \overline{Q_{11}}-\overline{Q_{12}} \overline{Q_{16}}\right)}{\left(\overline{Q_{11} \overline{Q_{22}}}-\overline{Q_{12}{ }^{2}}\right)}+\overline{Q_{66}}\right) \gamma_{x y}
$$

Lamina stiffness in global coordinates are written in directional sine, cosine and local lamina stiffness as: [10]

$$
\left[\begin{array}{c}
\overline{\mathrm{Q}_{11}} \\
\overline{\mathrm{Q}_{22}} \\
\overline{\mathrm{Q}_{12}} \\
\overline{\mathrm{Q}_{66}} \\
\overline{\mathrm{Q}_{16}} \\
\overline{\mathrm{Q}_{21}}
\end{array}\right]=\left[\begin{array}{c}
m^{4} Q_{11}+2 m^{2} n^{2} Q_{12}+n^{4} Q_{22}+4 m^{2} n^{2} Q_{66} \\
n^{4} Q_{11}+2 m^{2} n^{2} Q_{12}+m^{4} Q_{22}+4 m^{2} n^{2} Q_{66} \\
m^{2} n^{2} Q_{11}+\left(m^{4}+n^{4}\right) Q_{12}+m^{2} n^{2} Q_{22}-4 m^{2} n^{2} Q_{66} \\
m^{2} n^{2} Q_{11}-2 m^{2} n^{2} Q_{12}+m^{2} n^{2} Q_{22}+\left(m^{2}-n^{2}\right)^{2} Q_{66} \\
m^{3} n Q_{11}+\left(m n^{3}-m^{3} n\right) Q_{12}-m n^{3} Q_{22}+2\left(m n^{3}-m^{3} n\right) Q_{66} \\
m n^{3} Q_{11}+\left(m^{3} n-m n^{3}\right) Q_{12}-m^{3} n Q_{22}+2\left(m^{3} n-m n^{3}\right) Q_{66}
\end{array}\right]
$$

Global lamina stiffness in Equation (A.8) was substituted into in-plane shear stress and strain relation in Equation (A.7). Thus, in-plane shear modulus of shear stress and strain relation can be presented in terms of lamina stiffness in material coordinate system.

$$
\tau_{x y}=\left(\frac{\left(m^{2}+n^{2}\right)^{4}\left(Q_{12}^{2}-Q_{11} Q_{22}\right) Q_{66}}{\left(m^{2}-n^{2}\right)^{2}\left(Q_{12}^{2}-Q_{11} Q_{22}\right)-4 m^{2} n^{2}\left(Q_{11}+2 Q_{12}+Q_{22}\right) Q_{66}}\right) \gamma_{x y}
$$

Where, $\mathrm{m}$ is $\operatorname{Cos}[\theta], \mathrm{n}$ is $\operatorname{Sin}[\theta]$ and $\theta$ is angle of rotation from $\mathrm{x}-\mathrm{y}$ coordinate to coincide with 1-2 material coordinate as in Figure A.1. Directional sine (n) and cosine (m) were substituted into Equation (A.9) resulting in: 


$$
\tau_{x y}=\left(\frac{\left(Q_{12}^{2}-Q_{11} Q_{22}\right) Q_{66}}{(\operatorname{Cos} 2 \theta)^{2}\left(Q_{12}^{2}-Q_{11} Q_{22}\right)-(\operatorname{Sin} 2 \theta)^{2}\left(Q_{11}+2 Q_{12}+Q_{22}\right) Q_{66}}\right) \gamma_{x y}
$$

From plane stress condition, lamina stiffness that is result of elastic modulus and Possion's ratio are defined as given in Equations (A.11) through (A.14).

$$
\begin{aligned}
& Q_{11}=\frac{E_{11}}{1-v_{12} v_{21}} \\
& Q_{22}=\frac{E_{22}}{1-v_{12} v_{21}} \\
& Q_{12}=\frac{v_{12} E_{22}}{1-v_{12} v_{21}}=\frac{v_{21} E_{11}}{1-v_{12} v_{21}} \\
& Q_{66}=G_{12}
\end{aligned}
$$

To simplify in-plane shear modulus, lamina stiffness in Equations (A.11) through (A.14) was substituted into stress and strain relation in Equation (A.10). Neglecting square and product terms of Poisson's effects, simplified stress and strain relation based on classical lamination theory is given as:

$$
\begin{aligned}
& \tau_{x y}=\left(\frac{G_{12}\left(E_{11} E_{22}\right)}{(\operatorname{Cos} 2 \theta)^{2}\left(E_{11} E_{22}\right)+G_{12}(\operatorname{Sin} 2 \theta)^{2}\left(E_{11}+E_{22}+2 v_{21} E_{11}\right)}\right) \gamma_{\mathrm{xy}} \\
& \tau_{x y}=\left(\frac{1}{(\operatorname{Cos} 2 \theta)^{2}\left(\frac{1}{G_{12}}\right)+(\operatorname{Sin} 2 \theta)^{2}\left(\frac{1}{E_{11}}+\frac{1}{E_{22}}+\frac{2 v_{21}}{E_{22}}\right)}\right) \quad \gamma_{x y}=G_{x y} \gamma_{x y}
\end{aligned}
$$


where, $\theta$ is the angle of rotation of $x-y$ coordinate to coincide with 1-2 material coordinate, $E_{11}$ is longitudinal modulus of lamina, $E_{22}$ is traverse modulus of lamina, $G_{12}$ is in-plane shear modulus and $v_{21}$ is in-plane Poisson's ratio.

To generate simplified classical lamination stiffness of composite laminates, the Kirchhoff's hypothesis used in classical lamination theory is also used in this proposed methodology. The Kirchhoff's hypothesis states that despite the deformation caused by the applied load, lines normal to horizontal plane through the thickness remain straight and normal to the deformed geometric mid-plane and do not change in length. Thus, in-plane shear strain at any location through thickness is a combination of constant in-plane shear strain and linear variation of twisting curvature at mid plane section. Also, strain combination is separated to formulate a stiffness matrix of composite laminates. This combination is presented as:

$$
\begin{aligned}
& \gamma_{x y}(x, y, z)=\gamma_{x y}^{0}(x, y)+z \kappa_{x y}^{0}(x, y) \\
& \tau_{x y}=G_{x y} \gamma_{x y}=G_{x y}\left(\gamma_{x y}^{0}(x, y)+z \kappa_{x y}^{0}(x, y)\right) \\
& \tau_{x y} z=z G_{x y} \gamma_{x y}=z G_{x y}\left(\gamma_{x y}^{0}(x, y)+z^{2} \kappa_{x y}^{0}(x, y)\right)
\end{aligned}
$$

Where, $\gamma_{x y}^{0}(x, y)$ is a reference surface in-plane shear strain and $\kappa_{x y}^{0}(x, y)$ is a reference surface twisting curvature. $\mathrm{z}$ is the distance of $\mathrm{z}$-direction on laminated cross section. To formulate composite stiffness, Equations (A.18) and (A.19) are integrated through the thickness of cross-section.

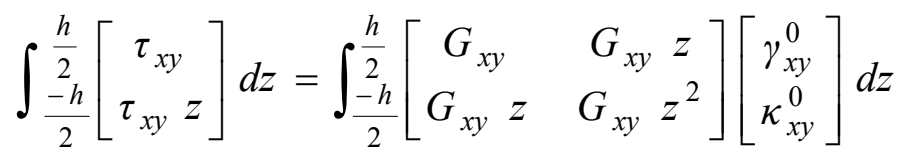




$$
\left[\begin{array}{l}
N_{x y} \\
M_{x y}
\end{array}\right]=\left[\begin{array}{cc}
D_{S S} & D_{s W} \\
D_{S W} & D_{W W}
\end{array}\right]\left[\begin{array}{c}
\gamma_{x y}^{0} \\
\kappa_{x y}^{0}
\end{array}\right]
$$




\section{APPENDIX B:}

\section{Torsion Constants of Non-Circular Structural Shapes}

\section{B.1 Introduction}

To evaluate in-plane shear modulus, torsional constants of any structural shapes used in this study are calculated. The purpose of this section is to evaluate torsional constants of various cross sections; i.e., rectangular solid, circular tube, and closed profiles with single and multi-cells.

\section{B.2 Open profiles}

The torsion constant of rectangular solid cross section based on Saint Venant torsion theory depends on cross-sectional dimensions as following:

For isolated plate:

$$
J=\frac{b t^{3}}{3}
$$

where, $b$ is width of cross section and $t$ is thickness of cross section

The torsion constants of rectangular coupon samples in this study are calculated and given in Table B.1 below.

\section{B.3 Closed profiles}

For circular cross section, torsional constant or polar moment of inertia is obtained by subtracting the circular solid polar moments of inertia between outer and inner radius. 
For solid circular bar:

$J=\frac{\pi r^{4}}{2}$

For circular tube:

$J=\frac{\pi\left(r_{\text {out }}-r_{\text {in }}\right)^{4}}{2}$

where, $r$ is radius of cross-section, $r_{\text {out }}$ is outer radius of tube and $r_{\text {in }}$ is inner radius of tube

Table B.1 Torsion constant of rectangular coupon

\begin{tabular}{|c|c|c|c|c|}
\hline Specimen & $\begin{array}{l}\text { Width } \\
\text { to thickness }\end{array}$ & $\begin{array}{l}\text { Width } \\
\text { (in) }\end{array}$ & $\begin{array}{l}\text { Thickness } \\
\text { (in) }\end{array}$ & $\begin{array}{c}\text { Torsion } \\
\text { constant }(J) \\
\left.\text { (in }^{4}\right)\end{array}$ \\
\hline $\mathrm{C}_{1} \mathrm{D}_{4 \mathrm{~L}}$ & 4 & 1 & 0.250 & 0.00521 \\
\hline $\mathrm{C}_{1} \mathrm{D}_{6 \mathrm{~L}}$ & 6 & 1.5 & 0.250 & 0.00781 \\
\hline $\mathrm{C}_{1} \mathrm{D}_{8 \mathrm{~L}}$ & 8 & 2.0 & 0.250 & 0.01042 \\
\hline $\mathrm{C}_{1} \mathrm{D}_{10 \mathrm{~L}}$ & 10 & 2.5 & 0.250 & 0.01302 \\
\hline $\mathrm{C}_{1} \mathrm{D}_{4 \mathrm{~T}}$ & 4 & 1 & 0.250 & 0.00521 \\
\hline $\mathrm{CP} 4_{2.3 \mathrm{~L}}$ & 2.3 & 1 & 0.435 & 0.0274 \\
\hline $\mathrm{CP} 4_{4 \mathrm{~L}}$ & 4 & 1.688 & 0.435 & 0.0453 \\
\hline $\mathrm{CP}_{6 \mathrm{~L}}$ & 6 & 2.489 & 0.435 & 0.0683 \\
\hline $\mathrm{CP} 4_{8 \mathrm{~L}}$ & 8 & 3.476 & 0.435 & 0.0954 \\
\hline $\mathrm{CP} 4_{10 \mathrm{~L}}$ & 10 & 4.180 & 0.435 & 0.1147 \\
\hline $\mathrm{CP} 4_{2.3 \mathrm{~T}}$ & 2.3 & 1 & 0.435 & 0.0267 \\
\hline $\mathrm{CP}_{2 \mathrm{~L}}$ & 2 & 1 & 0.45 & 0.0304 \\
\hline $\mathrm{CP}_{2 \mathrm{~T}}$ & 2.2 & 1 & 0.50 & 0.0417 \\
\hline $\mathrm{CP}_{4 \mathrm{~L}}$ & 4 & 1 & 0.275 & 0.00693 \\
\hline $\mathrm{CP}_{4 \mathrm{~T}}$ & 4 & 1 & 0.275 & 0.00693 \\
\hline \multicolumn{5}{|l|}{$\mathrm{CXM}_{2 \mathrm{~L}}$} \\
\hline \multicolumn{5}{|l|}{$\mathrm{CXM}_{10 \mathrm{~L}}$} \\
\hline C3D $D_{L}$ & & & & \\
\hline
\end{tabular}


Table B.2 Torsion constant of circular bar and tube

\begin{tabular}{|c|c|c|c|c|}
\hline Specimen & $\begin{array}{c}\text { Diameter } \\
\text { (in) }\end{array}$ & $\begin{array}{c}\text { Thickness } \\
\text { (in) }\end{array}$ & $\begin{array}{c}\text { Cross sectional area } \\
\text { (in }^{2} \text { ) }\end{array}$ & $\begin{array}{c}\text { Torsion constant (J) } \\
\text { (in) }^{4}\end{array}$ \\
\hline $\mathrm{CSB}_{0.5}$ & 0.5 & - & 0.1963 & 0.00614 \\
\hline $\mathrm{CSB}_{1}$ & 1.0 & - & 0.785 & 0.0982 \\
\hline $\mathrm{CT}$ & 1.0 & 0.15 & 0.385 & 0.0746 \\
\hline
\end{tabular}

$\underline{\text { Single cell rectangular thin-walled cross section: }}$

The torsional constant of a single cell rectangular cross section is defined as:

$$
J=\frac{4 A^{4}}{\oint \frac{d s}{t}}
$$

where $\mathrm{A}$ is the area enclosed by the profile, $\mathrm{s}$ is distance measured around profile, and $\mathrm{t}$ is thickness of cross-section. In case of ProDeck 4 specimens, $\mathrm{S}_{\text {flange }}$ and $\mathrm{S}_{\mathrm{web}}$ of a single cell cross section are 5.845 and 3.57 in, respectively. In addition, thickness of flange and web are 0.43 and 0.375 in, respectively.

$$
J=\frac{4 A^{4}}{\oint \frac{d s}{t}}=\frac{4(5.845 \times 3.57)^{2}}{\frac{2 \times 5.845}{0.43}+\frac{2 \times 3.57}{0.375}}=37.7 \mathrm{in}^{4}
$$

Multi-cell rectangular thin-walled cross section:

The torsion constant of multi-cell rectangular cross section can not be calculated by using fundamental equation given for single cell cross-section. Additional equation must be added to obtain a set of simultaneous equations. Relation between applied torque and rate of twist are provided as:

For $i^{\text {th }}$ cell: 


$$
\bar{\theta}_{i}=\left(\oint \frac{T_{i}}{2 A G} \frac{d s}{t}\right)_{i}
$$

To illustrate the above theory through a numerical example, triple cell rectangular thin-walled cross-section of ProDeck4 is used for this purpose. The additional equation is required to solve this problem. An assumption involves the rate of twist and compatibility of displacement in each cell which is given in Equation (B.6) below:

$$
\bar{\theta}_{1}=\bar{\theta}_{2}=\bar{\theta}_{3} \text { and } \varphi_{i}=\frac{T_{i}}{\overline{G \theta}}
$$

From Equation (B.5), integration around $\mathrm{i}^{\text {th }}$ cell yields:

$$
\bar{\theta}_{i}=\left(\oint \frac{T}{2 A G} \frac{d s}{t}\right)_{i}=\frac{1}{2 G A_{i}}\left[-T_{i-1} \int \frac{d s}{t}+T_{i} \oint \frac{d s}{t}-T_{i-1} \int \frac{d s}{t}\right]
$$

Simultaneous equations of $\mathrm{i}^{\text {th }}$ cell are written in unknowns $\varphi_{i}$. Then, Equations (B.6) can be rewritten in $A_{i}\left(\mathrm{i}^{\text {th }}\right.$ cell) to conveniently solve algebraic simultaneous equations later. Thus, equation for $A_{i}\left(\mathrm{i}^{\text {th }}\right.$ cell $)$ is rearranged and given as:

$$
2 A_{i}=-\left(\frac{S_{w}}{t_{w}}\right)_{i} \varphi_{i-1}+\left(\frac{2 S_{f}}{t_{f}}+\frac{2 S_{w}}{t_{w}}\right)_{i} \varphi_{i}-\left(\frac{S_{w}}{t_{w}}\right)_{i} \varphi_{i+1}
$$

For $1^{\text {st }}$ cell:

$$
2 A_{1}=\left(\frac{2 S_{f}}{t_{f}}+\frac{2 S_{w}}{t_{w}}\right)_{1} \varphi_{1}-\left(\frac{S_{w}}{t_{w}}\right)_{1} \varphi_{2}
$$

For $2^{\text {nd }}$ cell:

$$
2 A_{2}=-\left(\frac{S_{w}}{t_{w}}\right)_{2} \varphi_{1}+\left(\frac{2 S_{f}}{t_{f}}+\frac{2 S_{w}}{t_{w}}\right)_{2} \varphi_{2}-\left(\frac{S_{w}}{t_{w}}\right)_{2} \varphi_{3}
$$


For $3^{\text {rd }}$ cell:

$$
2 A_{3}=-\left(\frac{S_{w}}{t_{w}}\right)_{3} \varphi_{2}+\left(\frac{2 S_{f}}{t_{f}}+\frac{2 S_{w}}{t_{w}}\right)_{3} \varphi_{3}
$$

From ProDeck4 dimensions, $\mathrm{S}_{\mathrm{f}}$ and $\mathrm{S}_{\mathrm{w}}$ are 5.845 and 3.57 inch. In addition, thickness of flange and web portions is 0.43 and 0.375 inch. Then, $\mathrm{S}_{\mathrm{f}}, \mathrm{S}_{\mathrm{w}}$, thickness and enclosed area are substituted into Equations (B.8) through (B.10). A set of simultaneous equations are presented as following:

$$
\left[\begin{array}{l}
41.7 \\
41.7 \\
41.7
\end{array}\right]=\left[\begin{array}{ccc}
\left(\frac{2 \times 5.845}{0.43}+\frac{2 \times 3.57}{0.375}\right) & -\left(\frac{3.57}{0.375}\right) & 0 \\
-\left(\frac{3.57}{0.375}\right) & \left(\frac{2 \times 5.845}{0.43}+\frac{2 \times 3.57}{0.375}\right) & -\left(\frac{3.57}{0.375}\right) \\
0 & -\left(\frac{3.57}{0.375}\right) & \left(\frac{2 \times 5.845}{0.43}+\frac{2 \times 3.57}{0.375}\right)
\end{array}\right]\left[\begin{array}{l}
\varphi_{1} \\
\varphi_{2} \\
\varphi_{3}
\end{array}\right]
$$

Solutions of simultaneous equations (B.12) are written in matrix form as below.

$$
\left[\begin{array}{l}
\varphi_{1} \\
\varphi_{2} \\
\varphi_{3}
\end{array}\right]=\left[\begin{array}{l}
1.190 \\
1.393 \\
1.190
\end{array}\right]
$$

Hence, the torsion constant of a multi-celled rectangular thin-walled cross-section is given below.

$$
J=2 \sum \varphi_{i} A_{i}
$$

where, $\varphi_{i}$ are solutions of a set of simultaneous equations and $A_{i}$ are enclosed area of a single cell.

$J=2(1.190+1.393+1.190)(5.845 \times 3.57)=157.4$ in $^{4}$ 
Moreover, the torsional constant of multi-cellular triangular thin-walled cross section can be obtained by using the same procedure as well as multi-cell rectangular thin-walled cross section. Triangular double cell thin-walled cross section of ProDeck8 is used as an illustrative example in this section.

\section{For multi-cell rectangular cross section:}

Addition of Equation (B.6) is also used in this section. $\mathrm{S}_{\mathrm{f}}, \mathrm{S}_{\mathrm{w}}$, and $\mathrm{S}_{\mathrm{d}}$ of ProDeck8 are 11.55 in, 7.5 in and 14.24 inch, respectively. Thickness of flange, web and diagonal portions are $0.5,0.45$ and 0.275 inch, respectively. Also, an enclosed triangular area is $43.3125 \mathrm{in}^{2}$. Therefore, a set of simultaneous equations is written and given as:

$$
\left[\begin{array}{l}
86.625 \\
86.625
\end{array}\right]=\left[\begin{array}{cc}
92.1 & -52.4 \\
-52.4 & 92.1
\end{array}\right]\left[\begin{array}{l}
\varphi_{1} \\
\varphi_{2}
\end{array}\right]
$$

Solutions of simultaneous equations are written in a matrix form as:

$$
\left[\begin{array}{l}
\varphi_{1} \\
\varphi_{2}
\end{array}\right]=\left[\begin{array}{l}
2.178 \\
2.178
\end{array}\right]
$$

From Equation (B.13), the constant torsion of multi-cellular triangular thin-walled crosssection is:

$J=2(0.5 \times 11.55 \times 7.5)(2.178+2.178)=377$ in $^{4}$ 


\section{APPENDIX C:}

\section{Evaluation of Composite Stiffness Using SCLT}

\section{C.1 Introduction}

To evaluate torsional stiffness, laminate stiffness must be calculated through material properties. Lamina properties are calculated by using mechanics of materials approach known as the rule-of-mixture. Results of lamina properties were used to formulate laminated stiffness using SCLT approach. Summary of stiffness evaluations using SCLT is presented below: 1) computation of material properties, 2) determination of composite thickness, 3) computation of fiber volume fraction, 4) evaluation of lamina properties, 5) computation of $\mathrm{G}_{\mathrm{xy}}$ of lamina, 6) computation of $\mathrm{G}_{\mathrm{xy}}$ of laminate fabric, and 7) computation of laminate stiffness $D_{s s} D_{s w}$ and $D_{w w}$ for each component. Laminate stiffnesses of ProDeck4 and 8 were determined to evaluate torsional stiffness of composite structural members in chapter 4 .

\section{C.2 Computation of Material Properties}

The material properties include elastic modulus, shear modulus and density of fiber/fabrics and matrix. Fiber and matrix properties are generally obtained from the manufacturer. For this research, properties of glass fiber and matrix used to produce FRP composite deck samples are taken as: 
Elastic modulus of glass fiber $\left(\mathrm{E}_{\mathrm{f}}\right)=10.5 \times 10^{6} \mathrm{psi}$

Elastic modulus of matrix fiber $\left(E_{m}\right)=0.49 \times 10^{6}$ psi

Shear modulus of glass fiber $\quad\left(G_{f}\right)=4.0 \times 10^{6}$ psi

Shear modulus of matrix fiber $\left(G_{m}\right)=0.2 \times 10^{6}$ psi

It should be noted that the above fiber and matrix properties are used in both ProDeck 4 and 8 .

Poisson's ratio for fiber and matrix are given by [10] as following:

Poisson's ratio of fiber:

$v_{f}=\frac{E_{f}}{2 G_{f}}-1$

$v_{f}=\frac{10.5 \times 10^{6}}{2\left(4.0 \times 10^{6}\right)}-1=0.312$

Poisson's ratio of matrix:

$v_{m}=\frac{E_{m}}{2 G_{m}}-1$

$v_{m}=\frac{4.9 \times 10^{5}}{2\left(2.0 \times 10^{5}\right)}=0.225$

\section{C.3 Determination of Composite Thickness}

For FRP composite deck systems, flange and web are commonly fabricated with unidirectional fibers (roving), randomly oriented fibers (chopped strand mat) and fabrics. Generally, accuracy of thickness given by the manufacturer depends on the manufacturing process. However, for example, $40 \mathrm{oz} / \mathrm{yd} 2$ of fabric yields through pultrusion a composite of about (approximate) 0.045 inch thickness, and 3 rovings/inch can result in a composite of about 0.03 inch thickness. Thickness and nominal weight of each lamina type are provided by the manufacturer and summarized in Tables C.1 through C.3. 


\section{C.4 Computation of Fiber Volume Fraction}

In general, definition of fiber volume fraction is percentage of volume of fibers in a unit volume of lamina. Based on the thickness and weight of fiber/fabrics of each ply in a composite part, fiber volume fraction is computed as follows:

For roving (continuous fiber), roving lamina consists of unidirectional fiber spaced across the width of lamina. Fiber volume fraction is computed from the total area of fibers occupied as a percentage of total cross sectional area of each layer. In addition, diameter (D) of fiber given by Raftoyiann is:

$$
v_{f}=\frac{n \pi D^{2}}{4 b t}
$$

CSM (Continuous Strand Mat) consists of chopped glass fiber oriented arbitrarily in a mat form. While, fabric is given in the form of knitted cloth with fibers orientating in specified angles with respect to the principal structural coordinate system.

$$
v_{f}=\frac{W_{f}}{\rho_{f} L_{V}}
$$

Where, $\mathrm{n}$ is number of bundles, $\mathrm{b}$ is width of laminate (in), $\mathrm{t}$ is thickness of composite layer (in), $\rho_{\mathrm{f}}$ is density of fiber $\left(0.094 \mathrm{lb} / \mathrm{in}^{3}\right), \mathrm{Y}$ is yield (a number in yards which weighs $\left.1 \mathrm{lb}\right), W_{f}$ is weight of CSM/Fabrics per square foot (lb) and $L_{v}$ is volume of $1 \mathrm{in}^{2}$ composite laminate $\left(\mathrm{in}^{3}\right) . v_{f}$ is fiber volume fraction. Tables C.1 through C.3 also summarize the product specifications of CDBM 3415, DDBM 4015 and 113 yield roving. It should be noted that a very small percentage of stitched yarn is also included in each, but its mechanical properties are negligible. 
Table C.1 Fiber volume fraction for CDBM 3415 laminate

\begin{tabular}{|c|c|c|c|c|c|}
\hline $\begin{array}{c}\text { Fiber } \\
\boldsymbol{\theta}\end{array}$ & $\begin{array}{c}\text { Nominal weight } \\
\mathbf{( o z / y d}^{\mathbf{2}} \mathbf{)}\end{array}$ & $\begin{array}{c}\text { Thickness } \\
(\mathbf{i n c h )}\end{array}$ & $\begin{array}{c}\mathbf{W}_{\mathbf{f}} \\
\mathbf{( \mathbf { l b } )}\end{array}$ & $\begin{array}{c}\mathbf{L}_{\mathbf{v}} \\
\mathbf{( i n}^{3} \mathbf{)}\end{array}$ & $\begin{array}{c}\mathbf{V}_{\mathbf{f}} \\
(\mathbf{i n c h})\end{array}$ \\
\hline 0 & 15.71 & 0.017 & 0.109 & 2.448 & 0.4737 \\
\hline+45 & 9.04 & 0.0097 & 0.063 & 1.397 & 0.4798 \\
\hline-45 & 9.04 & 0.0097 & 0.063 & 1.397 & 0.4798 \\
\hline CFM & 13.5 & 0.014 & 0.094 & 2.016 & 0.5155 \\
\hline
\end{tabular}

Table C.2 Fiber volume fraction for DDBM 4015 laminate

\begin{tabular}{|c|c|c|c|c|c|}
\hline $\begin{array}{c}\text { Fiber } \\
\theta \\
\end{array}$ & $\begin{array}{c}\text { Nominal weight } \\
\left(\mathbf{o z} / \mathbf{y d}^{2}\right)\end{array}$ & $\begin{array}{c}\text { Thickness } \\
\text { (inch) }\end{array}$ & $\begin{array}{r}W_{\text {f }} \\
(\mathbf{l b}) \\
\end{array}$ & $\begin{array}{c}\mathbf{L}_{\mathrm{v}} \\
\left(\mathrm{in}^{3}\right)\end{array}$ & $\begin{array}{c}V_{f} \\
\text { (inch) }\end{array}$ \\
\hline+45 & 11.44 & 0.012 & 0.0794 & 1.728 & 0.4888 \\
\hline 90 & 17.28 & 0.019 & 0.12 & 2.736 & 0.4666 \\
\hline-45 & 11.44 & 0.012 & 0.0794 & 1.728 & 0.4888 \\
\hline CFM & 13.5 & 0.014 & 0.094 & 2.016 & 0.5155 \\
\hline
\end{tabular}

Table C.3 Fiber volume fraction for 113 roving layer

\begin{tabular}{|c|c|c|c|c|c|}
\hline $\begin{array}{c}\text { Fiber } \\
\theta\end{array}$ & $\begin{array}{c}\text { Nominal weight } \\
\left(\mathbf{o z} / \mathbf{y d}^{\mathbf{2}}\right)\end{array}$ & $\begin{array}{c}\text { Thickness } \\
\text { (inch) }\end{array}$ & $\begin{array}{l}\mathbf{W}_{\mathrm{f}} \\
\text { (lb) }\end{array}$ & $\begin{array}{l}\mathbf{L}_{v} \\
\left(\text { in }^{3}\right)\end{array}$ & $\begin{array}{c}V_{\mathrm{f}} \\
\text { (inch) }\end{array}$ \\
\hline 0 & & 0.04 & & & 0.442 \\
\hline
\end{tabular}

\section{C.5 Evaluation of Lamina Properties}

Lamina is a flat arrangement of unidirectional fibers or woven fabrics embedded in a matrix. The elastic properties of lamina are influenced by the elastic properties of the fiber and matrix. By using micro-mechanics, mechanics of materials approach known as the ruleof-mixture principles is used to evaluate lamina properties. Later, simplified approach is used to evaluate of $G_{x y}$ as a next step. Thus, fiber volume fraction, fiber and matrix modulus were substituted into rule of mixture. To provide an illustrative example, calculation details of laminate CDBM 3415 for the first lamina $0^{\circ}\left(\mathrm{V}_{\mathrm{f}}=0.4737\right)$ are presented as follows: 


$$
\begin{aligned}
& E_{11}=E_{f} V_{f}+E_{m}\left(1-V_{f}\right) \\
& =\left(10.5 \times 0.4737 \times 10^{6}\right)+\left(4.9 \times(1-0.4737) \times 10^{5}\right) \\
& E_{11}=5.23 \times 10^{6} \mathrm{psi} \\
& E_{22}=\frac{E_{f} E_{m}}{E_{m} V_{f}+E_{f}\left(1-V_{f}\right)} \\
& =\frac{\left(10.5 \times 4.9 \times 10^{6} \times 10^{5}\right)}{\left(4.9 \times 0.4737 \times 10^{5}\right)+\left(10.5 \times(1-0.4737) \times 10^{6}\right)} \\
& E_{22}=0.893 \times 10^{6} \mathrm{psi} \\
& G_{12}=\frac{G_{f} G_{m}}{G_{m} V_{f}+G_{f}\left(1-V_{f}\right)} \\
& =\frac{\left(4.0 \times 2.0 \times 10^{6} \times 10^{5}\right)}{\left(2.0 \times 0.4737 \times 10^{5}\right)+\left(4.0 \times(1-0.4737) \times 10^{6}\right)} \\
& G_{12}=0.363 \times 10^{6} \mathrm{psi} \\
& v_{12}=v_{f} V_{f}+v_{m}\left(1-V_{f}\right) \\
& v_{12}=(0.3125 \times 0.4737)+(0.225 \times(1-0.4737)) \\
& v_{12}=0.266 \\
& v_{21}=v_{12} \frac{E_{22}}{E_{11}} \\
& v_{21}=\frac{0.2664 \times 893471}{5231561} \\
& v_{21}=0.0455
\end{aligned}
$$

Following the same procedure, lamina properties of other laminas such as DDBM 4015 and 113 roving can be calculated and presented in Tables C.4 through C.6. It should be 
noted that ProDeck4 flange and web portion are also composed of three lamina types, CDBM 3415, DDBM 4015 and 113 yield roving. In addition, thickness and fiber volume fraction of each lamina are the same values of both flange and web portions. Therefore, the results of each lamina can be used in every portion of ProDeck4.

Table C.4 Lamina properties of CDBM 3415

\begin{tabular}{|c|c|c|c|c|c|}
\hline $\begin{array}{c}\text { Fiber } \\
\text { orientation }\end{array}$ & $\begin{array}{c}\boldsymbol{E}_{\mathbf{1 1}} \\
\mathbf{( p s i )}\end{array}$ & $\begin{array}{c}\boldsymbol{E}_{\mathbf{2 2}} \\
(\mathbf{p s i})\end{array}$ & $\begin{array}{c}\boldsymbol{G}_{\mathbf{1 2}} \\
\mathbf{( p s i )}\end{array}$ & $\mathbf{v}_{\mathbf{1 2}}$ & $\mathbf{v}_{\mathbf{2 1}}$ \\
\hline 0 & 5231561 & 893471 & 363635 & 0.266447 & 0.045505 \\
\hline+45 & 5292312 & 902998 & 367488 & 0.266978 & 0.045553 \\
\hline-45 & 5292312 & 902998 & 367488 & 0.266978 & 0.045553 \\
\hline & $\begin{array}{c}\boldsymbol{E}_{\mathbf{1 1}} \\
\mathbf{( p s i )}\end{array}$ & $\begin{array}{c}\boldsymbol{E}_{\mathbf{2 2}} \\
(\mathbf{p s i})\end{array}$ & $\begin{array}{c}\boldsymbol{E}_{\text {ran }} \\
\mathbf{( p s i )}\end{array}$ & $\begin{array}{c}\boldsymbol{G}_{\text {ran }} \\
\mathbf{( p s i )}\end{array}$ & $\boldsymbol{v}_{\text {ran }}$ \\
\hline$(\mathrm{CFM})$ & 5649794 & 963446 & 2720826 & 947086 & 0.43642 \\
\hline
\end{tabular}

Table C.5 Lamina properties of DDBM 4015

\begin{tabular}{|c|c|c|c|c|c|}
\hline $\begin{array}{c}\text { Fiber } \\
\text { orientation }\end{array}$ & $\begin{array}{c}\boldsymbol{E}_{\mathbf{1 1}} \\
(\mathbf{p s i})\end{array}$ & $\begin{array}{c}\boldsymbol{E}_{\mathbf{2 2}} \\
\mathbf{( p s i )}\end{array}$ & $\begin{array}{c}\boldsymbol{G}_{\mathbf{1 2}} \\
\mathbf{( p s i )}\end{array}$ & $\mathbf{v}_{\mathbf{1 2}}$ & $\mathbf{v}_{\mathbf{2 1}}$ \\
\hline+45 & 5383088 & 917617 & 373398.3 & 0.267772 & 0.045645 \\
\hline 90 & 5160586 & 882593 & 359235.7 & 0.265827 & 0.045463 \\
\hline-45 & 5383088 & 917617 & 373398.3 & 0.267772 & 0.045645 \\
\hline & $\begin{array}{c}\boldsymbol{E}_{\mathbf{1 1}} \\
\mathbf{p s i})\end{array}$ & $\begin{array}{c}\boldsymbol{E}_{\mathbf{2 2}} \\
\mathbf{( p s i )}\end{array}$ & $\begin{array}{c}\boldsymbol{E}_{\text {ran }} \\
\mathbf{( p s i )}\end{array}$ & $\begin{array}{c}\boldsymbol{G}_{\text {ran }} \\
(\mathbf{p s i})\end{array}$ & $\boldsymbol{v}_{\text {ran }}$ \\
\hline$(\mathrm{CFM})$ & 5649794 & 963446 & 2720826 & 947086 & 0.43642 \\
\hline
\end{tabular}

Table C.6 Lamina properties of 113 Yield Roving

\begin{tabular}{|c|c|c|c|c|c|}
\hline $\begin{array}{c}\text { Fiber } \\
\text { orientation }\end{array}$ & $\begin{array}{c}\boldsymbol{E}_{\mathbf{1 1}} \\
(\mathbf{p s i})\end{array}$ & $\begin{array}{c}\boldsymbol{E}_{\mathbf{2 2}} \\
(\mathbf{p s i})\end{array}$ & $\begin{array}{c}\boldsymbol{G}_{\mathbf{1 2}} \\
\mathbf{( p s i )}\end{array}$ & $\mathbf{v}_{\mathbf{1 2}}$ & $\mathbf{v}_{\mathbf{2 1}}$ \\
\hline 0 & 4914420 & 846833 & 344768 & 0.263675 & 0.045435 \\
\hline
\end{tabular}




\section{C.6 Computation of $G_{x y}$ of Lamina}

From lamina properties, simplified in-plane shear modulus of each lamina can be calculated by substituting lamina properties and fiber orientation angle into Equations (C.10) through (C.12). To be an example, lamina of CDBM 3415 with fiber orientation $0^{\circ}$ was presented for this purpose.

$$
\begin{aligned}
g_{x y}^{s} & =\frac{(\operatorname{Cos} 2 \theta)^{2}}{G_{12}} \\
& =(\operatorname{Cos} 0)^{2}\left(\frac{1}{363635}\right) \\
g_{x y}^{s} & =2.75 \times 10^{-6} \\
g_{x y}^{n} & =(\operatorname{Sin} 2 \theta)^{2}\left(\frac{1}{E_{11}}+\frac{1}{E_{22}}+\frac{2 v_{21}}{E_{22}}\right) \\
& =\left(\operatorname{Sin} 0^{\circ}\right)^{2}\left(\frac{1}{893471}+\frac{1}{5231561}+\frac{2(0.0455)}{893471}\right) \\
g_{x y}^{n} & =0 \\
G_{x y} & =\left(\frac{1}{g_{x y}^{s}+g_{x y}^{n}}\right) \\
G_{x y} & =3.63 \times 10^{6} \mathrm{psi} \\
& =\left(\frac{1}{2.75 \times 10^{-6}+0}\right)
\end{aligned}
$$

Following the same procedure, $G_{x y}$ results of other lamina layers are calculated and given in Tables C.7 through C.9. It should be noted that these results can be used to evaluate torsional stiffness of both flange and web. 
Table C.7 In-plane shear properties of CDBM 3415

\begin{tabular}{|c|c|c|c|c|}
\hline $\begin{array}{c}\text { Fiber } \\
\text { orientation }\end{array}$ & $\begin{array}{c}\text { Thickness } \\
\text { (inch) }\end{array}$ & $\left.\mathbf{( g}_{\mathbf{x y}}\right)^{\mathbf{s}}$ & $\left.\mathbf{( g}_{\mathbf{x y}}\right)^{\mathbf{n}}$ & $\begin{array}{c}\boldsymbol{G}_{\boldsymbol{x y}} \\
(\mathbf{p s i})\end{array}$ \\
\hline 0 & 0.017 & $2.75 \times 10^{-6}$ & 0 & 363635 \\
\hline+45 & 0.0097 & $2.03 \times 10^{-15}$ & $1.40 \times 10^{-6}$ & 715682 \\
\hline-45 & 0.0097 & $2.03 \times 10^{-15}$ & $1.40 \times 10^{-6}$ & 715682 \\
\hline$(\mathrm{CFM})$ & 0.014 & & & 947086 \\
\hline
\end{tabular}

Table C.8 In-plane shear properties of DDBM 4015

\begin{tabular}{|c|c|c|c|c|}
\hline $\begin{array}{c}\text { Fiber } \\
\text { orientation }\end{array}$ & $\begin{array}{c}\text { Thickness } \\
(\mathbf{i n c h})\end{array}$ & $\left.\mathbf{( g}_{\mathbf{x y}}\right)^{\mathbf{s}}$ & $\left.\mathbf{( g}_{\mathbf{x y}}\right)^{\mathbf{n}}$ & $\begin{array}{c}\boldsymbol{G}_{\boldsymbol{x y}} \\
(\mathbf{p s i})\end{array}$ \\
\hline+45 & 0.012 & $2.00 \times 10^{-15}$ & $1.38 \times 10^{-6}$ & 727256 \\
\hline 90 & 0.019 & $2.78 \times 10^{-6}$ & $2.76 \times 10^{-14}$ & 359236 \\
\hline-45 & 0.012 & $2.00 \times 10^{-15}$ & $1.38 \times 10^{-6}$ & 727256 \\
\hline$(\mathrm{CFM})$ & 0.014 & & & 947086 \\
\hline
\end{tabular}

Table C.9 In-plane shear properties of 113 Yield Roving

\begin{tabular}{|c|c|c|c|c|}
\hline $\begin{array}{c}\text { Fiber } \\
\text { orientation }\end{array}$ & $\begin{array}{c}\text { Thickness } \\
\text { (inch) }\end{array}$ & $\left.\mathbf{( g}_{\mathbf{x y}}\right)^{\mathbf{s}}$ & $\left.\mathbf{( g}_{\mathbf{x y}}\right)^{\mathbf{n}}$ & $\begin{array}{c}\boldsymbol{G}_{\boldsymbol{x y}} \\
(\mathbf{p s i})\end{array}$ \\
\hline 0 & 0.04 & $2.90 \times 10^{-6}$ & 0 & 344768 \\
\hline
\end{tabular}

\section{C.7 Computation of $G_{x y}$ of Laminate Fabric}

From results in Tables C.7 through C.9, simplified in-plane shear stiffness of laminated composite can be evaluated by using average values of all laminas.

$\left(G_{x y}\right)_{\text {fabric }}=\frac{\sum_{k=1}^{N}\left[\left(G_{x y}^{k}\right)_{\text {lamina }} \times\left(t^{k}\right)\right]}{\sum_{k=1}^{N}\left(t^{k}\right)}$

Where, $\mathrm{N}$ is number of lamina in fabric and $\mathrm{t}^{\mathrm{k}}$ is thickness of each lamina in fabric. 
CDBM 3415 laminate fabric:

$\left(G_{x y}\right)_{\text {fabric }}=\frac{(363635 \times 0.017)+(715682 \times 0.0097)+(715682 \times 0.0097)+(947086 \times 0.014)}{(0.017+0.0097+0.0097+0.014)}$

$\left(G_{x y}\right)_{\text {fabric }}=661215 \mathrm{psi}$

DDBM 4015 laminate fabric:

$\left(G_{x y}\right)_{\text {fabric }}=\frac{(727256 \times 0.012)+(359236 \times 0.019)+(727256 \times 0.012)+(947086 \times 0.014)}{(0.012+0.019+0.012+0.014)}$

$\left(G_{x y}\right)_{\text {fabric }}=658576$ psi

Continuous 113 Roving:

$\left(G_{x y}\right)_{\text {fabric }}=344768 \mathrm{psi}$

\section{C.8 Computation of Laminate Stiffness $D_{s s}, D_{s w}$ and $D_{w w}$}

Macro-mechanical approach is used to calculate global laminate rigidity $D$ to evaluate torsional strength and stiffness of FRP composite structural shapes. The Kirchhoff hypothesis used in classical lamination theory is also used in the simplified classical lamination approach for torsional strength and stiffness. The Kirchhoff's hypothesis states that despite the deformation caused by the applied load, lines normal to horizontal plane through thickness remain straight and normal to the deformed geometric mid-plane and do not change in length. Therefore, laminate rigidities given in Equations (A.20) and (A.21) were evaluated in both flange and web portions of ProDeck4 as:

$$
\begin{aligned}
& D_{s s}=\sum_{k=1}^{N} G_{x y}^{k} t_{k}=G_{x y}^{k} t_{k}+G_{x y}^{1} t_{1}+G_{x y}^{2} t_{2}+G_{x y}^{3} t_{3}+\ldots+G_{x y}^{N} t_{N} \\
& D_{s w}=0 \quad \text { since, symmetrical lay-up of both flange and web portions }
\end{aligned}
$$




$$
\begin{aligned}
D_{w w} & =\sum_{k=1}^{N} G_{x y}^{k}\left(\bar{\xi}_{k}^{2} t_{k}+\frac{t_{k}^{3}}{12}\right) \\
& =G_{x y}^{1}\left(\bar{\xi}_{1}^{1} t_{1}+\frac{t_{1}^{3}}{12}\right)+G_{x y}^{2}\left(\bar{\xi}_{2}^{2} t_{2}+\frac{t_{2}^{3}}{12}\right)+G_{x y}^{2}\left(\bar{\xi}_{3}^{2} t_{3}+\frac{t_{3}^{3}}{12}\right)+\ldots+G_{x y}^{2}\left(\bar{\xi}_{10}^{2} t_{10}+\frac{t_{10}^{3}}{12}\right)
\end{aligned}
$$

Moreover, laminated rigidities $\mathrm{D}_{\mathrm{ss}}, \mathrm{D}_{\mathrm{sw}}$ and $\mathrm{D}_{\mathrm{ww}}$ of ProDeck4 were summarized and tabulated in Tables C.10 and C.11

Table C.10 $D_{s s}, D_{s w}$ and $D_{w w}$ of ProDeck4 flange

\begin{tabular}{|c|l|c|c|c|c|c|c|}
\hline Layers & Types & $\begin{array}{c}\mathbf{t} \\
\left(\times \mathbf{1 0}^{-2}\right)\end{array}$ & $\begin{array}{c}\xi^{\mathbf{k}} \\
(\mathbf{i n})\end{array}$ & $\begin{array}{c}\left(\mathbf{G}_{\mathbf{x y}}\right)_{\text {fabric }} \\
\left(\times \mathbf{1 0}^{\mathbf{5}}\right) \\
(\mathbf{p s i})\end{array}$ & $\begin{array}{c}\boldsymbol{D}_{\mathbf{s s}} \\
(\mathbf{l b}-\mathbf{i n})\end{array}$ & $\begin{array}{c}\boldsymbol{D}_{\mathbf{s}} \\
(\mathbf{l b})\end{array}$ & $\begin{array}{c}\boldsymbol{D}_{w w} \\
(\mathbf{l b} / \mathbf{i n})\end{array}$ \\
\hline 1 & CDBM & 5.04 & -0.1907 & 6.61 & 33314 & -6353 & 1219 \\
\hline 2 & Roving & 4 & -0.1455 & 3.45 & 13800 & -2008 & 294 \\
\hline 3 & DDBM & 5.7 & -0.097 & 6.59 & 37539 & -3644 & 364 \\
\hline 4 & Roving & 4 & -0.0485 & 3.45 & 13800 & -669 & 34.3 \\
\hline 5 & DDBM & 2.85 & -0.01425 & 6.59 & 18782 & -268 & 5.09 \\
\hline 6 & DDBM & 2.85 & 0.01425 & 6.59 & 18782 & 268 & 5.09 \\
\hline 7 & Roving & 4 & 0.0485 & 3.45 & 13800 & 669 & 34.3 \\
\hline 8 & DDBM & 5.7 & 0.097 & 6.59 & 37563 & 3644 & 364 \\
\hline 9 & Roving & 4 & 0.1455 & 3.45 & 13800 & 2008 & 294 \\
\hline 10 & CDBM & 5.04 & 0.1907 & 6.61 & 33314 & 6353 & 1219 \\
\hline Sum & & 0.4318 & & & 234494 & 0 & 3830 \\
\hline
\end{tabular}


Table C.11 $D_{s s}, D_{s w}$ and $D_{w w}$ of ProDeck4 web

\begin{tabular}{|c|l|c|c|c|c|c|c|}
\hline Layers & Types & $\begin{array}{c}\mathbf{t} \\
\left(\times \mathbf{1 0}^{-2}\right)\end{array}$ & $\begin{array}{c}\xi^{\mathrm{K}} \\
(\mathbf{i n})\end{array}$ & $\begin{array}{c}\left(\mathbf{G}_{\mathbf{x y}} \mathbf{f}_{\mathbf{f a b r i c}}\right. \\
\left(\times \mathbf{1 0}^{5}\right)\end{array}$ & $\begin{array}{c}\boldsymbol{D}_{s s} \\
(\mathbf{p s i})\end{array}$ & $\begin{array}{c}\boldsymbol{D}_{\mathbf{s}} \\
(\mathbf{l b}-\mathbf{i n})\end{array}$ & $\begin{array}{c}\boldsymbol{D}_{w w} \\
(\mathbf{l b} / \mathbf{i n})\end{array}$ \\
\hline 1 & CDBM & 7.05 & -0.15225 & 6.61 & 48601 & -7095 & 1100 \\
\hline 2 & Roving & 4 & -0.097 & 3.45 & 13800 & -1339 & 131.7 \\
\hline 3 & DDBM & 5.7 & -0.0485 & 6.59 & 37539 & -1821 & 98.5 \\
\hline 4 & Roving & 2 & -0.01 & 3.45 & 6900 & -69 & 0.92 \\
\hline 5 & Roving & 2 & 0.01 & 3.45 & 6900 & 69 & 0.92 \\
\hline 6 & DDBM & 5.7 & 0.0485 & 6.59 & 37539 & 1821 & 98.5 \\
\hline 7 & Roving & 4 & 0.097 & 3.45 & 13800 & 1339 & 131.7 \\
\hline 8 & DDBM & 7.05 & 0.15225 & 6.61 & 48601 & 7095 & 1100 \\
\hline Sum & & 0.375 & & & 213679 & 0 & 2661 \\
\hline
\end{tabular}

Following the same procedure, laminate rigidities of ProDeck8 can be evaluated for each portion. Fabric laminates that were used for making composite ProDeck8 include with CDBM3415, CDB400 and roving. Then, properties of CDBM3415 that were provided for ProDeck4 also can be used in this section. Thus, properties of CDB400 and roving for ProDeck8 were presented in Tables C.12 through C.14 as:

Table C.12 Fiber volume fraction for CDBM 3415 laminate

\begin{tabular}{|c|c|c|c|c|c|}
\hline $\begin{array}{c}\text { Fiber } \\
\boldsymbol{\theta}\end{array}$ & $\begin{array}{c}\text { Nominal weight } \\
\mathbf{( o z}_{\mathbf{y} \mathbf{y d}^{\mathbf{2}} \mathbf{)}}\end{array}$ & $\begin{array}{c}\text { Thickness } \\
(\mathbf{i n c h )}\end{array}$ & $\begin{array}{c}\mathbf{W}_{\mathbf{f}} \\
\mathbf{( \mathbf { l b } )}\end{array}$ & $\begin{array}{c}\mathbf{L}_{\mathbf{v}} \\
\mathbf{( i n}^{\mathbf{3}} \mathbf{)}\end{array}$ & $\begin{array}{c}\mathbf{V}_{\mathbf{f}} \\
(\mathbf{i n c h})\end{array}$ \\
\hline 0 & 15.71 & 0.0184 & 0.109 & 2.65 & 0.4376 \\
\hline+45 & 9.04 & 0.0106 & 0.063 & 1.53 & 0.4380 \\
\hline-45 & 9.04 & 0.0106 & 0.063 & 1.53 & 0.4380 \\
\hline CFM & 13.5 & 0.0159 & 0.094 & 2.29 & 0.5155 \\
\hline
\end{tabular}


Table C.13 Fiber volume fraction for CDB 400 laminate

\begin{tabular}{|c|c|c|c|c|c|}
\hline $\begin{array}{c}\text { Fiber } \\
\boldsymbol{\theta}\end{array}$ & $\begin{array}{c}\text { Nominal weight } \\
\left.\mathbf{( o z}_{\mathbf{y d}} \mathbf{d}^{\mathbf{2}}\right)\end{array}$ & $\begin{array}{c}\text { Thickness } \\
\text { (inch) }\end{array}$ & $\begin{array}{c}\mathbf{W}_{\mathbf{f}} \\
\mathbf{( l b )}\end{array}$ & $\begin{array}{c}\mathbf{L}_{\mathbf{v}} \\
\left.\mathbf{( i n}^{\mathbf{3}}\right)\end{array}$ & $\begin{array}{c}\mathbf{V}_{\mathbf{f}} \\
(\mathbf{i n c h})\end{array}$ \\
\hline 0 & 16.58 & 0.0195 & 0.115 & 2.81 & 0.4354 \\
\hline+45 & 12.19 & 0.0144 & 0.085 & 2.07 & 0.4368 \\
\hline-45 & 12.19 & 0.0144 & 0.085 & 2.07 & 0.4368 \\
\hline
\end{tabular}

Table C.14 Fiber volume fraction for roving layer

\begin{tabular}{|c|c|c|c|c|c|}
\hline $\begin{array}{c}\text { Fiber } \\
\boldsymbol{\theta}\end{array}$ & $\begin{array}{c}\text { Nominal weight } \\
\mathbf{( o z}_{\mathbf{y} \mathbf{y d}^{\mathbf{2}} \mathbf{)}}\end{array}$ & $\begin{array}{c}\text { Thickness } \\
\text { (inch) }\end{array}$ & $\begin{array}{c}\mathbf{W}_{\mathbf{f}} \\
\mathbf{( l b )}\end{array}$ & $\begin{array}{c}\mathbf{L}_{\mathbf{v}} \\
\mathbf{( i n}^{\mathbf{3}} \mathbf{)}\end{array}$ & $\begin{array}{c}\mathbf{V}_{\mathbf{f}} \\
\mathbf{( i n c h )}\end{array}$ \\
\hline 0 & & 0.0212 & & & 0.49 \\
\hline
\end{tabular}

In addition, lamina properties were evaluated by substituting fiber volume fraction, fiber and matrix modulus into Equations (C.5) through (C.9). Lamina properties were presented in Tables C.15 through C.17. It should be noted that these results can be used to evaluate torsional stiffness of flange, web and diagonal portions.

Table C.15 Lamina properties of CDBM 3415

\begin{tabular}{|c|c|c|c|c|c|}
\hline $\begin{array}{c}\text { Fiber } \\
\text { orientation }\end{array}$ & $\begin{array}{c}\boldsymbol{E}_{\mathbf{1 1}} \\
(\mathbf{p s i})\end{array}$ & $\begin{array}{c}\boldsymbol{E}_{\mathbf{2 2}} \\
\mathbf{( p s i )}\end{array}$ & $\begin{array}{c}\boldsymbol{G}_{\mathbf{1 2}} \\
(\mathbf{p s i})\end{array}$ & $\mathbf{v}_{\mathbf{1 2}}$ & $\mathbf{v}_{\mathbf{2 1}}$ \\
\hline 0 & 4870129 & 840704 & 342288 & 0.263288 & 0.04545 \\
\hline+45 & 4874856 & 841354 & 342551 & 0.263329 & 0.04545 \\
\hline-45 & 4874856 & 841354 & 342551 & 0.263329 & 0.04545 \\
\hline & $\boldsymbol{E}_{\mathbf{1 1}}$ & $\boldsymbol{E}_{\mathbf{2 2}}$ & $\boldsymbol{E}_{\mathbf{r a n}}$ & $\boldsymbol{G}_{\text {ran }}$ & $\mathbf{v}_{\text {ran }}$ \\
\hline$(\mathrm{CFM})$ & 5649794 & 963446 & 2720826 & 947086 & 0.4364 \\
\hline
\end{tabular}

Table C.16 Lamina properties of CDB 400

\begin{tabular}{|c|c|c|c|c|c|}
\hline $\begin{array}{c}\text { Fiber } \\
\text { orientation }\end{array}$ & $\begin{array}{c}\boldsymbol{E}_{\mathbf{1 1}} \\
(\mathbf{p s i})\end{array}$ & $\begin{array}{c}\boldsymbol{E}_{\mathbf{2 2}} \\
\mathbf{( p s i )}\end{array}$ & $\begin{array}{c}\boldsymbol{G}_{\mathbf{1 2}} \\
\mathbf{( p s i )}\end{array}$ & $\mathbf{v}_{\mathbf{1 2}}$ & $\mathbf{v}_{\mathbf{2 1}}$ \\
\hline 0 & 4848106 & 837689 & 341068 & 0.2631 & 0.04546 \\
\hline+45 & 4862752 & 839692 & 341878 & 0.2632 & 0.04545 \\
\hline-45 & 4862752 & 839692 & 341878 & 0.2632 & 0.04545 \\
\hline
\end{tabular}


Table C.17 Lamina properties of 113 Yield Roving

\begin{tabular}{|c|c|c|c|c|c|}
\hline $\begin{array}{c}\text { Fiber } \\
\text { orientation }\end{array}$ & $\begin{array}{c}\boldsymbol{E}_{\mathbf{1 1}} \\
\mathbf{( p s i )}\end{array}$ & $\begin{array}{c}\boldsymbol{E}_{\mathbf{2 2}} \\
\mathbf{( p s i )}\end{array}$ & $\begin{array}{c}\boldsymbol{G}_{\mathbf{1 2}} \\
\mathbf{( p s i )}\end{array}$ & $\mathbf{v}_{\mathbf{1 2}}$ & $\mathbf{v}_{\mathbf{2 1}}$ \\
\hline 0 & 5394900 & 919555 & 374181 & 0.2679 & 0.04566 \\
\hline
\end{tabular}

To evaluate simplified in-plane shear stiffness, lamina properties were substituted into Equations (C.10) through (C.12). Summary of in-plane shear stiffness in each composite laminate were given in Tables C.18 through C.20.

Table C.18 In-plane shear properties of CDBM 3415

\begin{tabular}{|c|c|c|c|c|}
\hline $\begin{array}{c}\text { Fiber } \\
\text { orientation }\end{array}$ & $\begin{array}{c}\text { Thickness } \\
\text { (inch) }\end{array}$ & $\left.\mathbf{( g}_{\mathbf{x y}}\right)^{\mathbf{s}}$ & $\left.\mathbf{( g}_{\mathbf{x y}}\right)^{\mathbf{n}}$ & $\begin{array}{c}\boldsymbol{G}_{\boldsymbol{x y}} \\
(\mathbf{p s i})\end{array}$ \\
\hline 0 & 0.0184 & $2.92 \times 10^{-6}$ & 0 & 342288 \\
\hline+45 & 0.0106 & $2.18 \times 10^{-15}$ & $1.50 \times 10^{-6}$ & 665899 \\
\hline-45 & 0.0106 & $2.18 \times 10^{-15}$ & $1.50 \times 10^{-6}$ & 665899 \\
\hline$(\mathrm{CFM})$ & 0.0159 & & & 947086 \\
\hline
\end{tabular}

Table C.19 In-plane shear properties of CDB 400

\begin{tabular}{|c|c|c|c|c|}
\hline $\begin{array}{c}\text { Fiber } \\
\text { orientation }\end{array}$ & $\begin{array}{c}\text { Thickness } \\
\text { (inch) }\end{array}$ & $\left.\mathbf{( g}_{\mathbf{x y}}\right)^{\mathbf{s}}$ & $\left.\mathbf{( g}_{\mathbf{x y}}\right)^{\mathbf{n}}$ & $\begin{array}{c}\boldsymbol{G}_{\boldsymbol{x y}} \\
(\mathbf{p s i})\end{array}$ \\
\hline 0 & 0.0195 & $2.93 \times 10^{-6}$ & 0 & 341068 \\
\hline+45 & 0.0144 & $2.18 \times 10^{-15}$ & $1.50 \times 10^{-6}$ & 664532 \\
\hline-45 & 0.0144 & $2.18 \times 10^{-15}$ & $1.50 \times 10^{-6}$ & 664532 \\
\hline
\end{tabular}

Table C.20 In-plane shear properties of 113 Yield Roving

\begin{tabular}{|c|c|c|c|c|}
\hline $\begin{array}{c}\text { Fiber } \\
\text { orientation }\end{array}$ & $\begin{array}{c}\text { Thickness } \\
\text { (inch) }\end{array}$ & $\left.\mathbf{( g}_{\mathbf{x y}}\right)^{\mathbf{s}}$ & $\left.\mathbf{( g}_{\mathbf{x y}}\right)^{\mathbf{n}}$ & $\begin{array}{c}\boldsymbol{G}_{\boldsymbol{x y}} \\
(\mathbf{p s i})\end{array}$ \\
\hline 0 & 0.0212 & $2.67 \times 10^{-6}$ & 0 & 374182 \\
\hline
\end{tabular}

Using Equation (C.13), in-plane shear stiffness of each laminate can be obtained from averaged in-plane shear stiffness values of those laminate. These simplified in-plane shear 
stiffness were used to evaluate fabric laminate rigidities $D_{s s}, D_{s w}$ and $D_{w w}$ of ProDeck8. In addition, laminated rigidities were given in Tables C.21 through C.24.

CDBM3415 laminated fabric:

$\left(\mathrm{G}_{\mathrm{xy}}\right)_{\text {fabric }}=639168 \mathrm{psi}$

CDB400 laminated fabric:

$\left(\mathrm{G}_{\mathrm{xy}}\right)_{\text {fabric }}=533941 \mathrm{psi}$

Continuous Roving:

$\left(\mathrm{G}_{\mathrm{xy}}\right)_{\text {fabric }}=344768 \mathrm{psi}$

Using Equations (A.20) and (A.21), laminate rigidities of ProDeck8 were evaluated and given in Tables C.21 through C.24.

Table C.21 $D_{s s}, D_{s w}$ and $D_{w w}$ of ProDeck8 flange (thickness 0.5 inch)

\begin{tabular}{|c|l|c|c|c|c|c|c|}
\hline Layers & Types & $\begin{array}{c}\mathbf{t} \\
\left(\times \mathbf{1 0}^{-2}\right) \\
(\mathbf{i n})\end{array}$ & $\begin{array}{c}\boldsymbol{\xi}^{\mathrm{k}} \\
(\mathbf{i n})\end{array}$ & $\begin{array}{c}\left(\mathbf{G}_{\mathbf{x y}}\right)_{\text {fabric }} \\
\left(\times \mathbf{1 0}^{\mathbf{5}}\right) \\
(\mathbf{p s i})\end{array}$ & $\begin{array}{c}\boldsymbol{D}_{\mathbf{s s}} \\
(\mathbf{l b}-\mathbf{i n})\end{array}$ & $\begin{array}{c}\boldsymbol{D}_{\boldsymbol{s w}} \\
(\mathbf{l b})\end{array}$ & $\begin{array}{c}\boldsymbol{D}_{w w} \\
(\mathbf{l b} / \mathbf{i n})\end{array}$ \\
\hline 1 & CDBM & 5.55 & -0.222 & 6.392 & 35476 & -7884 & 1761 \\
\hline 2 & Roving & 2.12 & -0.1839 & 3.742 & 7933 & -1459 & 269 \\
\hline 3 & CDB & 4.83 & -0.1492 & 5.34 & 25792 & -3847 & 579 \\
\hline 4 & CDB & 4.83 & -0.1009 & 5.34 & 25792 & -2601 & 267 \\
\hline 5 & Roving & 2.12 & -0.0661 & 3.742 & 7933 & -524 & 35 \\
\hline 6 & CDB & 5.55 & -0.0278 & 5.34 & 29637 & -822 & 30.4 \\
\hline 7 & CDB & 4.11 & 0.0206 & 5.34 & 21947 & 451 & 12.36 \\
\hline 8 & Roving & 2.12 & 0.0517 & 3.742 & 7933 & 410 & 21.5 \\
\hline 9 & CDBM & 5.55 & 0.0901 & 6.392 & 35476 & 3195 & 297 \\
\hline 10 & CDBM & 5.55 & 0.1456 & 6.392 & 35476 & 5163 & 761 \\
\hline 11 & Roving & 2.12 & 0.1839 & 3.742 & 7933 & 1459 & 269 \\
\hline 12 & CDBM & 5.55 & 0.222 & 6.392 & 35476 & 7884 & 1761 \\
\hline sum & & 0.5 & & & 276803 & 1424 & 6063 \\
\hline
\end{tabular}


Table C.22 $D_{s s}, D_{s w}$ and $D_{w w}$ of ProDeck8 flange (thickness 0.45 inch)

\begin{tabular}{|c|c|c|c|c|c|c|c|}
\hline Layers & Types & $\begin{array}{c}t \\
\left(\times 10^{-2}\right) \\
(\text { in }) \\
\end{array}$ & $\begin{array}{l}\xi^{\kappa} \\
\text { (in) }\end{array}$ & $\begin{array}{c}\left(\mathbf{G}_{\mathrm{xy}}\right)_{\text {fabric }} \\
\left.(\times \mathbf{1 0})^{5}\right) \\
(\mathrm{psi}) \\
\end{array}$ & $\begin{array}{c}D_{s s} \\
(\mathbf{l b}-\mathbf{i n})\end{array}$ & $\begin{array}{l}D_{s w} \\
\text { (lb) }\end{array}$ & $\begin{array}{c}D_{w w} \\
\text { (lb/in) }\end{array}$ \\
\hline 1 & CDBM & 3.05 & -0.210 & 6.392 & 19496 & -4089 & 859 \\
\hline 2 & Roving & 2.12 & -0.1839 & 3.742 & 7933 & -1459 & 269 \\
\hline 3 & CDB & 4.83 & -0.1492 & 5.34 & 25792 & -3847 & 579 \\
\hline 4 & CDB & 4.83 & -0.1009 & 5.34 & 25792 & -2601 & 267 \\
\hline 5 & Roving & 2.12 & -0.0661 & 3.742 & 7933 & -524 & 35 \\
\hline 6 & CDB & 5.55 & -0.0278 & 5.34 & 29637 & -822 & 30.4 \\
\hline 7 & CDB & 4.11 & 0.0206 & 5.34 & 21947 & 451 & 12.36 \\
\hline 8 & Roving & 2.12 & 0.0517 & 3.742 & 7933 & 410 & 21.5 \\
\hline 9 & CDBM & 5.55 & 0.0901 & 6.392 & 35476 & 3195 & 297 \\
\hline 10 & CDBM & 5.55 & 0.1456 & 6.392 & 35476 & 5163 & 761 \\
\hline 11 & Roving & 2.12 & 0.1839 & 3.742 & 7933 & 1459 & 269 \\
\hline 12 & CDBM & 3.05 & 0.210 & 6.392 & 19496 & -4089 & 859 \\
\hline sum & & 0.45 & & & 244843 & 1424 & 4258 \\
\hline
\end{tabular}

Table C.23 $D_{s s}, D_{s w}$ and $D_{w w}$ of ProDeck8 web

\begin{tabular}{|c|c|c|c|c|c|c|c|}
\hline Layers & Types & $\begin{array}{c}t \\
\left(\times 10^{-2}\right) \\
(\text { in })\end{array}$ & $\begin{array}{l}\xi^{\mathrm{k}} \\
\text { (in) }\end{array}$ & $\begin{array}{c}\left(\mathbf{G}_{\mathrm{xy}}\right)_{\text {fabric }} \\
\left.(\times \mathbf{1 0})^{5}\right) \\
(\mathrm{psi}) \\
\end{array}$ & $\begin{array}{c}D_{s s} \\
(l b-i n)\end{array}$ & $\begin{array}{l}D_{s w} \\
\text { (lb) }\end{array}$ & $\begin{array}{c}D_{w w} \\
\text { (lb/in) }\end{array}$ \\
\hline 1 & CDBM & 5.55 & -0.1915 & 6.392 & 35476 & -6793 & 1310 \\
\hline 2 & Roving & 2.12 & -0.1531 & 3.742 & 7933 & -1215 & 186.3 \\
\hline 3 & CDB & 5.55 & -0.1148 & 6.392 & 35476 & -4072 & 477 \\
\hline 4 & CDB & 5.55 & -0.0593 & 6.392 & 35476 & -2103 & 133.8 \\
\hline 5 & CDB & 3.15 & -0.01577 & 5.34 & 16840 & -266 & 5.58 \\
\hline 6 & CDB & 1.6765 & 0.00838 & 5.34 & 8953 & 75.0 & 0.839 \\
\hline 7 & Roving & 2.12 & 0.0242 & 3.742 & 7933 & 191.6 & 4.92 \\
\hline 8 & CDBM & 5.55 & 0.06572 & 6.392 & 35476 & 2331 & 162.3 \\
\hline 9 & CDBM & 5.55 & 0.1212 & 6.392 & 35476 & 4300 & 530 \\
\hline 10 & Roving & 2.12 & 0.1596 & 3.742 & 7933 & 1266 & 202 \\
\hline 11 & CDBM & 5.55 & 0.1979 & 6.392 & 35476 & 7021 & 1399 \\
\hline Sum & & 0.4449 & & & 262445 & 736 & 4411 \\
\hline
\end{tabular}


Table C.24 $D_{s s}, D_{s w}$ and $D_{w w}$ of ProDeck8 diagonal

\begin{tabular}{|c|c|c|c|c|c|c|c|}
\hline Layers & Types & $\begin{array}{c}t \\
\left(\times 10^{-2}\right) \\
(\text { in })\end{array}$ & $\begin{array}{l}\xi^{\kappa} \\
\text { (in) }\end{array}$ & $\begin{array}{c}\left(G_{x y}\right)_{\text {fabric }} \\
\left(\times 10^{5}\right) \\
(p s i)\end{array}$ & $\begin{array}{c}D_{s s} \\
\text { (lb-in) }\end{array}$ & $\begin{array}{l}D_{s w} \\
\text { (lb) }\end{array}$ & $\begin{array}{c}D_{w w} \\
\text { (lb/in) }\end{array}$ \\
\hline 1 & CDBM & 5.55 & -0.10975 & 6.39200 & 35476 & -3893 & 436 \\
\hline 2 & Roving & 2.65 & -0.06875 & 3.74200 & 9916 & -682 & 47.5 \\
\hline 3 & CDBM & 5.55 & -0.02775 & 6.39200 & 35476 & -984 & 36.4 \\
\hline 4 & CDBM & 5.55 & 0.02775 & 6.39200 & 35476 & 984 & 36.4 \\
\hline 5 & Roving & 2.65 & 0.06875 & 3.74200 & 9916 & 682 & 47.5 \\
\hline 6 & CDBM & 5.55 & 0.10975 & 6.39200 & 35476 & 3893 & 436 \\
\hline Sum & & 0.275 & & & 161735 & 0 & 1041 \\
\hline
\end{tabular}

\section{C.9 Laminate Stiffness $D_{s s}, D_{s w}$ and $D_{w w}$ of Circular Tube}

This circular tube was made from unidirectional fiber with 35 percent of fiber volume fraction $\left(V_{f}\right)$ then, the circular tube can be considered to be a single lamina that has a total thickness equal to wall thickness of circular tube specimen CT.

Material Properties (Fiber and Matrix) are provided in Section C.2 as:

Elastic modulus of glass fiber $\left(\mathrm{E}_{\mathrm{f}}\right)=10.5 \times 10^{6} \mathrm{psi}$

Elastic modulus of matrix fiber $\left(\mathrm{E}_{\mathrm{m}}\right)=4.9 \times 10^{5} \mathrm{psi}$

Shear modulus of glass fiber $\quad\left(G_{f}\right)=4.0 \times 10^{6}$ psi

Shear modulus of matrix fiber $\left(G_{m}\right)=2.0 \times 10^{5}$ psi

From Equations (C.1) and (C.2)

$$
\begin{aligned}
& v_{\mathrm{f}}=\frac{\mathrm{E}_{\mathrm{f}}}{2 \mathrm{G}_{\mathrm{f}}}-1=\frac{10.5 \times 10^{6}}{2\left(4.0 \times 10^{6}\right)}-1=0.312 \\
& v_{\mathrm{m}}=\frac{\mathrm{E}_{\mathrm{m}}}{2 \mathrm{G}_{\mathrm{m}}}-1=\frac{4.9 \times 10^{5}}{2\left(2.0 \times 10^{5}\right)}=0.225
\end{aligned}
$$

Thickness of a single lamina $=0.15$ inch and fiber volume fraction $V_{f}=35 \%$ 
To evaluate lamina properties, substituting $V_{f}$ into Equations (C.5) through (C.9)

$$
\begin{aligned}
& E_{11}=E_{f} V_{f}+E_{m}\left(1-V_{f}\right)=\left(10.5 \times 0.35 \times 10^{6}\right)+\left(4.9 \times(1-0.35) \times 10^{5}\right) \\
& E_{11}=3.99 \times 10^{6} \mathrm{psi} \\
& E_{22}=\frac{E_{f} E_{m}}{E_{m} V_{f}+E_{f}\left(1-V_{f}\right)}=\frac{\left(10.5 \times 4.9 \times 10^{6} \times 10^{5}\right)}{\left(4.9 \times 0.35 \times 10^{5}\right)+\left(10.5 \times(1-0.35) \times 10^{6}\right)} \\
& E_{22}=7.35 \times 10^{5} \mathrm{psi} \\
& G_{12}=\frac{G_{f} G_{m}}{G_{m} V_{f}+G_{f}\left(1-V_{f}\right)}=\frac{\left(4.0 \times 2.0 \times 10^{6} \times 10^{5}\right)}{\left(2.0 \times 0.35 \times 10^{5}\right)+\left(4.0 \times(1-0.35) \times 10^{6}\right)} \\
& \mathrm{G}_{12}=2.99 \times 10^{5} \mathrm{psi} \\
& v_{12}=v_{f} V_{f}+v_{m}\left(1-V_{f}\right)=(0.3125 \times 0.35)+(0.225 \times(1-0.35)) \\
& v_{12}=0.2556 \\
& v_{21}=v_{12} \frac{E_{22}}{E_{11}}=\frac{0.2556 \times 735368}{3993500} \\
& 0.04707
\end{aligned}
$$

$G_{x y}$ are computed by substituting lamina properties and fiber orientation angle into Eqs.10, 11 and 12. However, this circular thin-walled tube is unidirectional fiber composite then, $G_{x y}$ is equal $G_{12}$.

$G_{x y}=G_{12}=2.99 \times 10^{6} \mathrm{psi}$

Because of unidirectional fiber, Only $D_{s S}$ is necessarily found to evaluate torsional stiffness. Thus laminate stiffness $D_{s s}$ is given as:

$$
\begin{aligned}
& D_{s s}=\sum_{k=1}^{N} G_{x y}^{k} t_{k}=G_{x y}^{k} t_{k}+G_{x y}^{1} t_{1}+G_{x y}^{2} t_{2}+G_{x y}^{3} t_{3}+\ldots+G_{x y}^{N} t_{N} \\
& D_{s s}=G_{12} \times \text { total thickness }=0.15 \times 299626 \\
& D_{s s}=4.49 \times 10^{4} \mathrm{lb} / \mathrm{in}
\end{aligned}
$$




\section{APPENDIX D:}

\section{Compatibility Relation of Closed section}

\section{D.1 Compatibility Relation}

Compatibility relation between warping displacement and in-plane shear strain at mid-plane of cross-section in Equation (4.32) was derived by using shear strain and displacement relationships as given below:

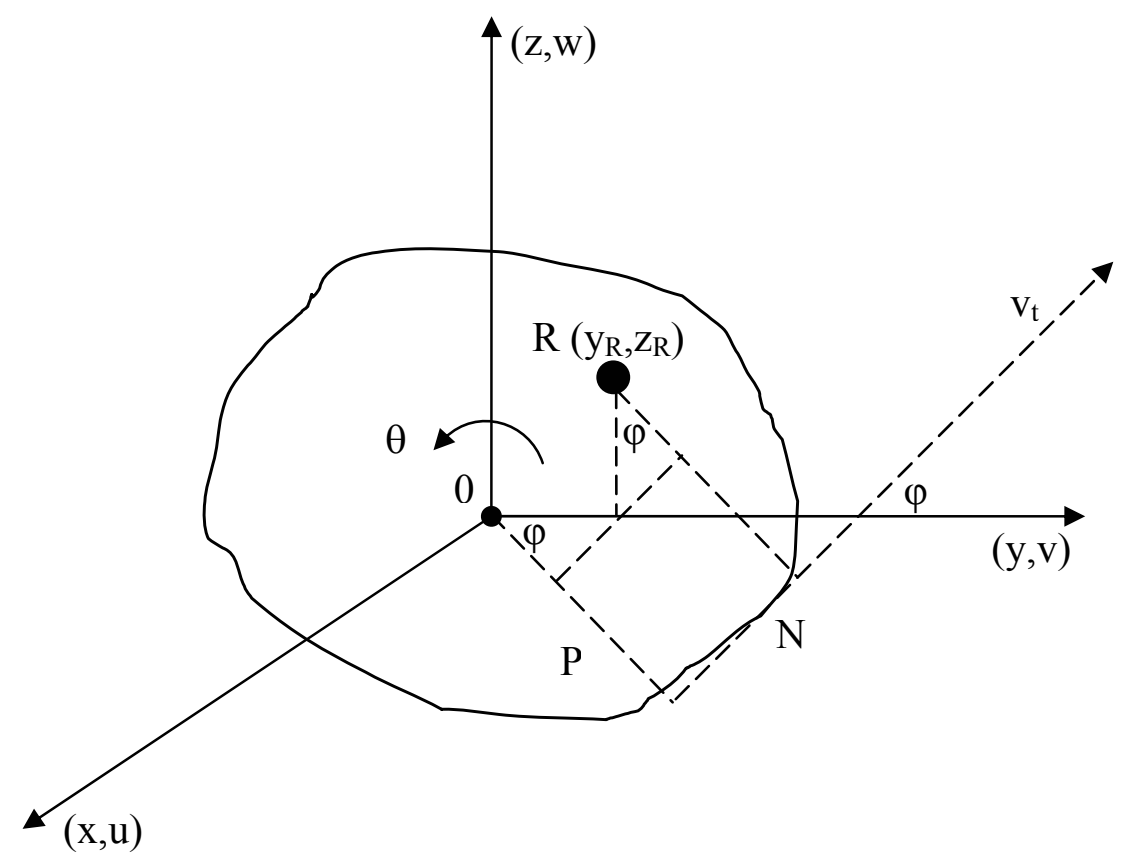

Figure D.1 Coordinate on thin-walled cross section

From Figure D.1, general in-plane shear strain on wall of thin-walled structural members was given: 
$\gamma=\left(\frac{\partial u}{\partial s}+\frac{\partial v_{t}}{\partial x}\right)$

Where, $\mathrm{u}$ is displacement along longitudinal axis (x-direction), $\mathrm{v}$ is displacement along transverse direction (y-direction), $\mathrm{z}$ is displacement along transverse direction ( $\mathrm{z}$-direction), $\mathrm{v}_{\mathrm{t}}$ is tangential displacement of any point $\mathrm{N}$.

During any displacement, the assume cross section of the beam cross section is maintained by a system of closely spaced diaphragms which are rigid in their own plane. Thus there is no resistance to axial displacement and the cross section moves as a rigid body in its own plane then, displacement of any point being completely specified by translations (v,w) and rotation $\theta$ (Megson, 1998).

$v_{t}=p \theta+v \operatorname{Cos} \varphi+w \operatorname{Sin} \varphi$

$\frac{\partial v_{t}}{\partial x}=p \frac{\partial \theta}{\partial x}+\frac{\partial v}{\partial x} \operatorname{Cos} \varphi+\frac{\partial w}{\partial x} \operatorname{Sin} \varphi$

By substituting Equation (D.3) into Equation (D.1), in-plane shear strain is presented as follows:

$\gamma=\left(\frac{\partial u}{\partial s}+p \frac{\partial \theta}{\partial x}+\frac{\partial v}{\partial x} \operatorname{Cos} \varphi+\frac{\partial w}{\partial x} \operatorname{Sin} \varphi\right)$

Integrating Equation (D.4) with respect to s from the chosen origin for s

$$
\int_{0}^{s} \gamma d s=\int_{0}^{s}\left(\frac{\partial u}{\partial s}+p \frac{\partial \theta}{\partial x}+\frac{\partial v}{\partial x} \operatorname{Cos} \varphi+\frac{\partial w}{\partial x} \operatorname{Sin} \varphi\right) d s
$$


$\int_{0}^{s} \gamma d s=\int_{0}^{s} \frac{\partial u}{\partial s} d s+p \int_{0}^{s} \frac{\partial \theta}{\partial x} d s+\frac{\partial v}{\partial x} \int_{0}^{s} d y+\frac{\partial w}{\partial x} \int_{0}^{s} d z$

(D.6)

Therefore, compatibility relation between warping displacement and in-plane shear strain at mid-plane of cross-section is given below:

$$
\int_{0}^{s} \gamma_{x y}^{0} d s=\left(u_{s}-u_{0}\right)+2\left(A_{0 S}\right) \frac{d \theta}{d x}+z_{R} \frac{d v}{d x}\left(y_{s}-y_{0}\right)+y_{R} \frac{d w}{d x}\left(z_{s}-z_{0}\right)
$$




\section{APPENDIX E:}

\section{In-Plane Shear Lamina Stiffness $\left(G_{x y}\right)$}

More details of matrix domination on in-plane shear stiffness of lamina is given as:

Rule of mixture

$$
\begin{aligned}
& E_{11}=E_{f} V_{f}+E_{m}\left(1-V_{f}\right) \\
& E_{22}=\frac{E_{f} E_{m}}{E_{m} V_{f}+E_{f}\left(1-V_{f}\right)} \\
& G_{12}=\frac{G_{f} G_{m}}{G_{m} V_{f}+G_{f}\left(1-V_{f}\right)} \\
& v_{21}=v_{12} \frac{E_{22}}{E_{11}}
\end{aligned}
$$

Lamina shear stiffness that is derived in Appendix $\mathrm{C}$ is given as:

$$
\begin{aligned}
& \tau_{x y}=\left(\frac{1}{(\operatorname{Cos} 2 \theta)^{2}\left(\frac{1}{G_{12}}\right)+(\operatorname{Sin} 2 \theta)^{2}\left(\frac{1}{E_{11}}+\frac{1}{E_{22}}+\frac{2 v_{21}}{E_{22}}\right)}\right) \gamma_{x y} \\
& g_{x y}^{s}=\frac{(\operatorname{Cos} 2 \theta)^{2}}{G_{12}}
\end{aligned}
$$


$g_{x y}^{n}=(\operatorname{Sin} 2 \theta)^{2}\left(\frac{1}{E_{11}}+\frac{1}{E_{22}}+\frac{2 v_{21}}{E_{22}}\right)$

Substituting rule of mixture (Equations E.1 through E.4) into lamina shear stiffness (Equations E.6 and E.7) is given:

$$
g_{x y}^{s}=\frac{(\operatorname{Cos} 2 \theta)^{2}}{\frac{G_{f} G_{m}}{G_{m} V_{f}+G_{f}\left(1-V_{f}\right)}}=\frac{(\operatorname{Cos} 2 \theta)^{2}}{\frac{G_{f} G_{m}}{G_{m} V_{f}+G_{f} V_{m}}}
$$

From fiber and matrix stiffness in Appendix C, $G_{f} / G_{m} \sim 20$

$$
\begin{gathered}
g_{x y}^{s}=\frac{(\operatorname{Cos} 2 \theta)^{2}}{\frac{G_{m}}{\frac{G_{m}}{G_{f}} V_{f}+V_{m}}=\frac{(\operatorname{Cos} 2 \theta)^{2}}{\frac{G_{m}}{20}+V_{m}}} \\
g_{x y}^{n}=(\operatorname{Sin} 2 \theta)^{2}\left(\frac{1}{E_{11}}+\frac{1}{E_{22}}+\frac{2 v_{21}}{E_{22}}\right)
\end{gathered}
$$

From fiber and matrix stiffness in Appendix C, $E_{f} / E_{m} \sim 21.4$ and $v_{12} \sim 0.266$

$$
\begin{aligned}
& g_{x y}^{n}=(\operatorname{Sin} 2 \theta)^{2}\left(\frac{1}{E_{f} V_{f}+E_{m}\left(1-V_{f}\right)}+\frac{1}{\frac{E_{f} E_{m}}{E_{m} V_{f}+E_{f}\left(1-V_{f}\right)}}+\frac{2 v_{12} \frac{E_{22}}{E_{11}}}{E_{22}}\right) \\
& g_{x y}^{n}=(\operatorname{Sin} 2 \theta)^{2}\left(\frac{1.532}{E_{f} V_{f}+E_{m} V_{m}}+\frac{1}{\frac{E_{m}}{\frac{V_{f}}{21.4}+V_{m}}}\right)
\end{aligned}
$$




$$
g_{x y}^{s}+g_{x y}^{n}=(\operatorname{Sin} 2 \theta)^{2}\left(\frac{1.532}{E_{f} V_{f}+E_{m} V_{m}}+\frac{1}{\frac{E_{m}}{\frac{V_{f}}{21.4}+V_{m}}}\right)+\left(\frac{(\operatorname{Cos} 2 \theta)^{2}}{\frac{G_{m}}{\frac{V_{f}}{20}+V_{m}}}\right)
$$

For $0^{\circ}$ and $90^{\circ}$ lamina, In-plane shear stiffness of lamina is given as:

$$
g_{x y}^{s}+g_{x y}^{n}=\left(\frac{1}{\frac{G_{m}}{\frac{V_{f}}{20}+V_{m}}}\right) \text { and } G_{x y}=\frac{1}{g_{x y}^{s}+g_{x y}^{n}}=\frac{G_{m}}{\frac{V_{f}}{20}+V_{m}}
$$

For $45^{\circ}$ and $-45^{\circ}$ lamina, In-plane shear stiffness of lamina is given as:

$$
\begin{aligned}
& g_{x y}^{s}+g_{x y}^{n}=\left(\frac{1.532}{E_{f}\left(V_{f}+\frac{E_{m}}{E_{f}} V_{m}\right)}+\frac{1}{\frac{E_{f}}{21.4}+V_{m}}\right) \\
& g_{x y}^{s}+g_{x y}^{n}=\frac{1.532 E_{m}+E_{f}\left(V_{f}+\frac{V_{m}}{21.4}\right)\left(\frac{V_{f}}{21.4}+V_{m}\right)}{\frac{E_{m} E_{f}\left(V_{f}+\frac{V_{m}}{21.4}\right)}{1.532}+\left(V_{f}+\frac{V_{m}}{21.4}\right)\left(\frac{V_{f}}{21.4}+V_{m}\right)} \\
& \left.G_{x y}=\frac{1}{g_{x y}^{s}+g_{x y}^{n}}=\frac{E_{m}\left(V_{f}+\frac{V_{m}}{21.4}\right)}{\frac{1.4}{21.4}}\right)
\end{aligned}
$$


$G_{x y}=\frac{E_{m}}{\frac{0.0716}{\left(V_{f}+\frac{V_{m}}{21.4}\right)}+\left(\frac{V_{f}}{21.4}+V_{m}\right)}$

In-plane shear stiffness of laminas is dominated by modulus of matrix and matrix volume fraction. 


\section{APPENDIX F:}

\section{Web Buckling}

\section{F.1 Introduction}

In the analysis and design of FRP composite bridge deck systems, evaluation of web failure under vertical (buckling) loads is necessary to check for potential web buckling failure under concentrated wheel loads corresponding to HS 25 loading. Web buckling stress is calculated from equations provided by composite structural handbook code, e.g., EUROCOMP code. It is found that web-buckling stress computed from those equations provided in handbooks is over predicting experimental web-buckling load (Punyamurthula, 2004). In this chapter, the web-bucking strengths (failure loads) of different specimen types are experimentally evaluated. FRP specimens were tested under uniform load except for single web specimens schematically illustrated in Figures F.1 and F.2. For single web specimens, concentrated load is applied on the top flange surface. In the following section, our experimental program has been elaborated. The main objective of this chapter is to evaluate web-bucking strength using web-buckling expression for FRP composite decks based on Euler's buckling equation.

\section{F.2 Experimental Program}

Test specimens, set-up and procedures including test equipment, number of specimens, structural shapes, specimen preparation and specimen dimension are described 
and given in Section 3.10. To evaluate web bucking strength, results of applied loads are focused on the experimental data in this study. Test specimens are modeled and analyzed as a column under a concentrated load without eccentricity.

For double web specimens, modeling is done as a simply supported beam under uniform load. Thus, support reactions of the double web beam model are used to evaluate web buckling load and stress. Moreover, modular four web components without and with joints are tested under buckling loads. Modular specimens are simplified as continuous over three equal spans. Support reactions are calculated and the maximum reaction is defined as a maximum web buckling load of this module (refer to Figure F.2). Web buckling load and stress for each case (as mentioned above) are presented as follows:

For single web specimens, the maximum applied load $P$ is equal to the web buckling load. Experimental web buckling stress is equal to the resultant of web buckling load to nominal web area $A$.

$$
\sigma_{b}=\frac{P}{A}
$$

For double web specimens, web buckling load is equal to support reactions. Since, test specimens are modeled as simple beams, then web buckling load is found to be an half of the maximum applied load. Thus, experimental web buckling stress can be written in terms of maximum applied load as:

Support reactions:

$$
\begin{aligned}
& R_{o}=\frac{W L}{2}=\frac{P}{2} \\
& \sigma_{b}=\frac{P}{2 A}
\end{aligned}
$$




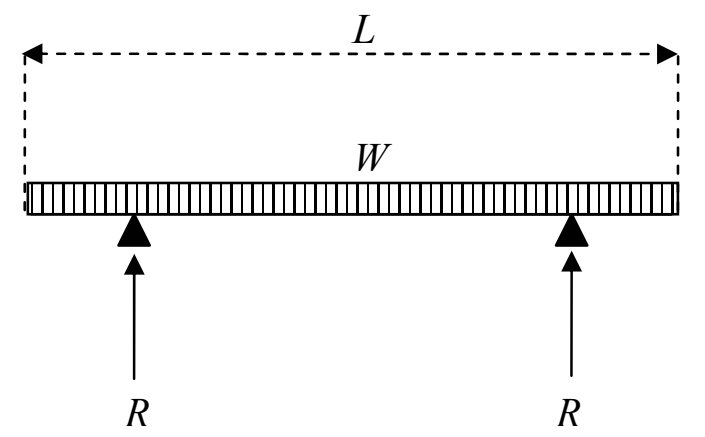

Figure F.1 Simple beam model of double web specimens

where, $W$ is uniform load distributed an the entire test span and $L$ is the length of test specimens while $P$ is a total applied load and $A$ is a cross sectional area of web.

For modules, a continuous beam model is illustrated in Figure F.2. Support reactions of a continuous beam under uniform load are calculated. These support reactions are used to evaluate web buckling shear stress.

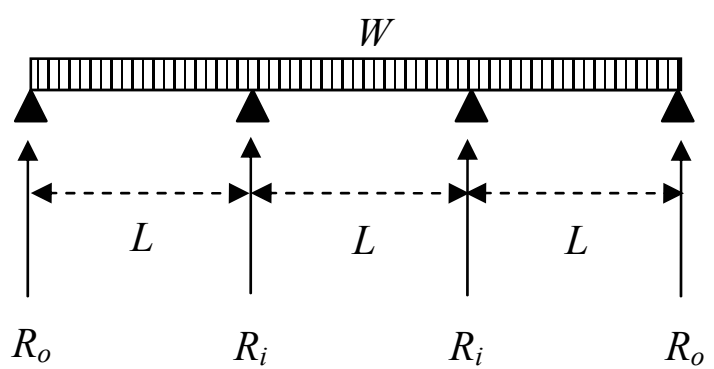

Figure F.2 Continuous beam model of module specimens

Internal and external support reactions of a continuous beam model under uniform load are presented in terms of span length $L$, uniform loading value $W$ and maximum applied $\operatorname{load}(P=3 W L)$.

External reactions:

$R_{o}=\frac{2 W L}{5}=\frac{2 P}{15}$ 
Internal reactions:

$$
R_{i}=\frac{11 W L}{10}=\frac{11 P}{30}
$$

From support reactions, web buckling stress is given by the bucking of internal webs as:

$$
\sigma_{b}=\frac{11 W L}{10 A}=\frac{11 P}{30 A}
$$

where, A is a cross sectional area of the web portion.

To present the limit of critical flexural stress in the web, web buckling stress relation provided by EUROCOMP code (EUROCOMP code, 1996) is presented herein and used to compare with the experimental results. Local web-buckling shear stress of orthotropic materials is presented as:

$$
\begin{gathered}
\sigma_{b}=\frac{k \pi^{2} D}{d_{w}^{2} t_{w}} \\
D=\frac{E_{y} t^{3}}{12\left(1-v^{2}\right)}
\end{gathered}
$$

If the web may be assumed to be clamped to the flange, then constant $(k)$ can be determined by linear interpolation of results given below:

$$
\begin{array}{ll}
k=50 & \text { if } D_{y} / D_{x}=1 \\
k=20 & \text { if } D_{y} / D_{x}=0.5
\end{array}
$$

where, $\sigma_{b}$ is web buckling stress, $t_{w}$ is thickness of the web, $d_{w}$ is depth of the web, $E_{\mathrm{y}}$ is Young's modulus in transverse direction and $v$ is Poisson's ratio. 


\section{F.3 Evaluation of Experimental Results}

Equations (F.1) through (F.6) are used to experimentally evaluate web-buckling strength. Buckling test data are presented in Table F.1. In addition, web buckling strengths computed from EUROCOMP code, (EUROCOMP code, 1996) equations are also given and the equations are validated through experimental results.

Table F.1 Experimental web-buckling strength

\begin{tabular}{|c|c|c|c|c|c|c|c|c|}
\hline \multirow[b]{2}{*}{ Specimen } & \multirow{2}{*}{$\begin{array}{l}\text { No. } \\
\text { of } \\
\text { web }\end{array}$} & \multirow[t]{2}{*}{ Level } & \multicolumn{6}{|c|}{ Web portion } \\
\hline & & & $\begin{array}{l}\text { Width } \\
\text { (in) }\end{array}$ & $\begin{array}{l}\text { Thickness } \\
\text { (in) }\end{array}$ & $\begin{array}{l}\text { Max. } \\
\text { load } \\
\text { (kip) }\end{array}$ & $\begin{array}{c}\text { Buckling } \\
\text { load } \\
\text { (kip) }\end{array}$ & $\begin{array}{c}\text { Buckling } \\
\text { stress } \\
\text { (ksi) }\end{array}$ & $\begin{array}{c}\text { Avg.buckling } \\
\text { stress } \\
\text { (ksi) } \\
\end{array}$ \\
\hline $\mathrm{WB}_{\mathrm{C} 1}: 1$ & 1 & $\mathrm{C}$ & 0.963 & 0.375 & 4.10 & 4.10 & 11.35 & 12.02 \\
\hline $\mathrm{WB}_{\mathrm{C} 1}: 2$ & & & 0.979 & 0.375 & 4.59 & 4.59 & 12.50 & \\
\hline $\mathrm{WB}_{\mathrm{C} 1}: 3$ & & & 0.982 & 0.375 & 4.50 & 4.50 & 12.22 & \\
\hline $\mathrm{WB}_{\mathrm{CO} 2}: 1$ & 2 & Co & 0.941 & 0.375 & 6.64 & 3.32 & 9.41 & 9.68 \\
\hline $\mathrm{WB}_{\mathrm{CO} 2}: 2$ & & & 0.954 & 0.375 & 7.12 & 3.56 & 9.95 & \\
\hline $\mathrm{WB}_{\mathrm{CO} 4: 1}$ & 4 & Co & 0.886 & 0.375 & 8.05 & 2.95 & 8.88 & 8.75 \\
\hline $\mathrm{WB}_{\mathrm{CO} 4: 2}$ & & & 0.965 & 0.375 & 8.50 & 3.12 & 8.62 & \\
\hline $\mathrm{WB}_{\mathrm{J} 2}: 1$ & 2 & $\mathrm{~J}$ & 0.960 & 0.375 & 8.02 & 4.01 & 11.14 & 11.11 \\
\hline $\mathrm{WB}_{\mathrm{J} 2}: 2$ & & & 0.980 & 0.375 & 8.13 & 4.07 & 11.07 & \\
\hline $\mathrm{WB}_{\mathrm{J} 4}: 1$ & 4 & $\mathrm{~J}$ & 0.997 & 0.375 & 9.76 & 3.58 & 9.58 & 9.52 \\
\hline $\mathrm{WB}_{\mathrm{J} 4}: 2$ & & & 0.982 & 0.375 & 9.50 & 3.48 & 9.45 & \\
\hline
\end{tabular}

Note: C, Co and J are coupon, component and component with joint level of test specimens, respectively.

Web buckling strength is predicted using EUROCOMP code equations (refer to Equations (F.7) and (F.8)). For ProDeck4, thickness of the web $\left(t_{w}\right)$ is 0.375 inch, depth of the web $\left(d_{w}\right)$ is 3.14 inch, Young's modulus in transverse direction $\left(E_{y}\right)$ (Punyamurthula, 2004) is $1.2 \times 10^{6}$ psi and Poisson's ratio $(v)$ is about 0.25 . By substituting these data, theoretical web bucking strength is found to be: 
Using linear interpolation, boundary constant $(k)$ and $D_{y} / D_{x}$ is about 10 and 0.33 (refer to Section 4.7, Equation (4.26), EUROCOMP code, 1996), respectively.

$$
\begin{aligned}
& D=\frac{\left(1.2 \times 10^{6}\right)(0.375)^{3}}{12\left(1-0.25^{2}\right)}=5625 \mathrm{lb}-\text { in } \\
& \sigma_{b}=\frac{5625 \times \pi^{2} \times 10}{(0.375)(3.14)^{2}}=150 \mathrm{ksi}
\end{aligned}
$$

In this study, it should be noted that theoretical web-buckling strength provided by EUROCOMP code is much higher than the experimental data. The above result clearly presents that theoretical critical web-buckling strength resulted in inaccurate prediction for FRP composite bridge decks.

To predict a more accurate buckling strength of ProDeck4 web, Euler's column equation is still used. Using experimental results, effective column length factors accounting properly for end restraints are established for ProDeck4 specimens.

\section{F.4 Numerical Results by Finite Element Method}

Web specimens are modeled using orthotropic shell 63 (rectangular) provided by ANSYS. Simply supported boundary conditions at the ends are used for web-buckling models. In addition, the inputs of the mechanical properties of test specimens (elastic modulus) are provided by (Punyamurthula, 2004). In-plane shear modulus for finite element modeling is obtained from the average experimental coupon data under torsion. 
Table F.2 Experimental web-buckling strength (F.E.)

\begin{tabular}{|c|c|c|c|c|c|c|}
\hline \multirow{2}{*}{ Specimen } & \multicolumn{6}{|c|}{ Web portion } \\
\cline { 2 - 7 } & $\begin{array}{c}\text { Width } \\
\text { (in) }\end{array}$ & $\begin{array}{c}\text { Thickness } \\
\text { (in) }\end{array}$ & $\begin{array}{c}\text { No. } \\
\text { Node }\end{array}$ & $\begin{array}{c}\text { No. } \\
\text { Element }\end{array}$ & $\begin{array}{c}\text { Buckling } \\
\text { load } \\
\text { (kip) }\end{array}$ & $\begin{array}{c}\text { Buckling } \\
\text { stress } \\
\text { (ksi) }\end{array}$ \\
\hline $\mathrm{WB}_{\mathrm{C} 1}$ & 1 & 0.375 & 343 & 288 & 5.06 & 13.49 \\
\hline $\mathrm{WB}_{\mathrm{CO} 2}$ & 1 & 0.375 & 504 & 432 & 4.15 & 11.07 \\
\hline $\mathrm{WB}_{\mathrm{CO} 4}$ & 1 & 0.375 & 510 & 416 & 3.65 & 9.73 \\
\hline
\end{tabular}

From Tables F.1 and F.2, percent differences between experimental and finite element data are found to be about $12.5 \%$ for specimens $\left(\mathrm{WB}_{\mathrm{CO} 2}\right)$. Slightly higher buckling strength using finite element model is attributed several assumptions i.e., perfect continuity of materials, full load transfer, and neglecting edge effects (specimen cutting). With a review to attain better theoretical correlation for experimental data, the above mentioned factors will be accounted for in the web-bucking prediction expression (Section F.5) and will be reflected in terms of effective length (factor $K$ ).
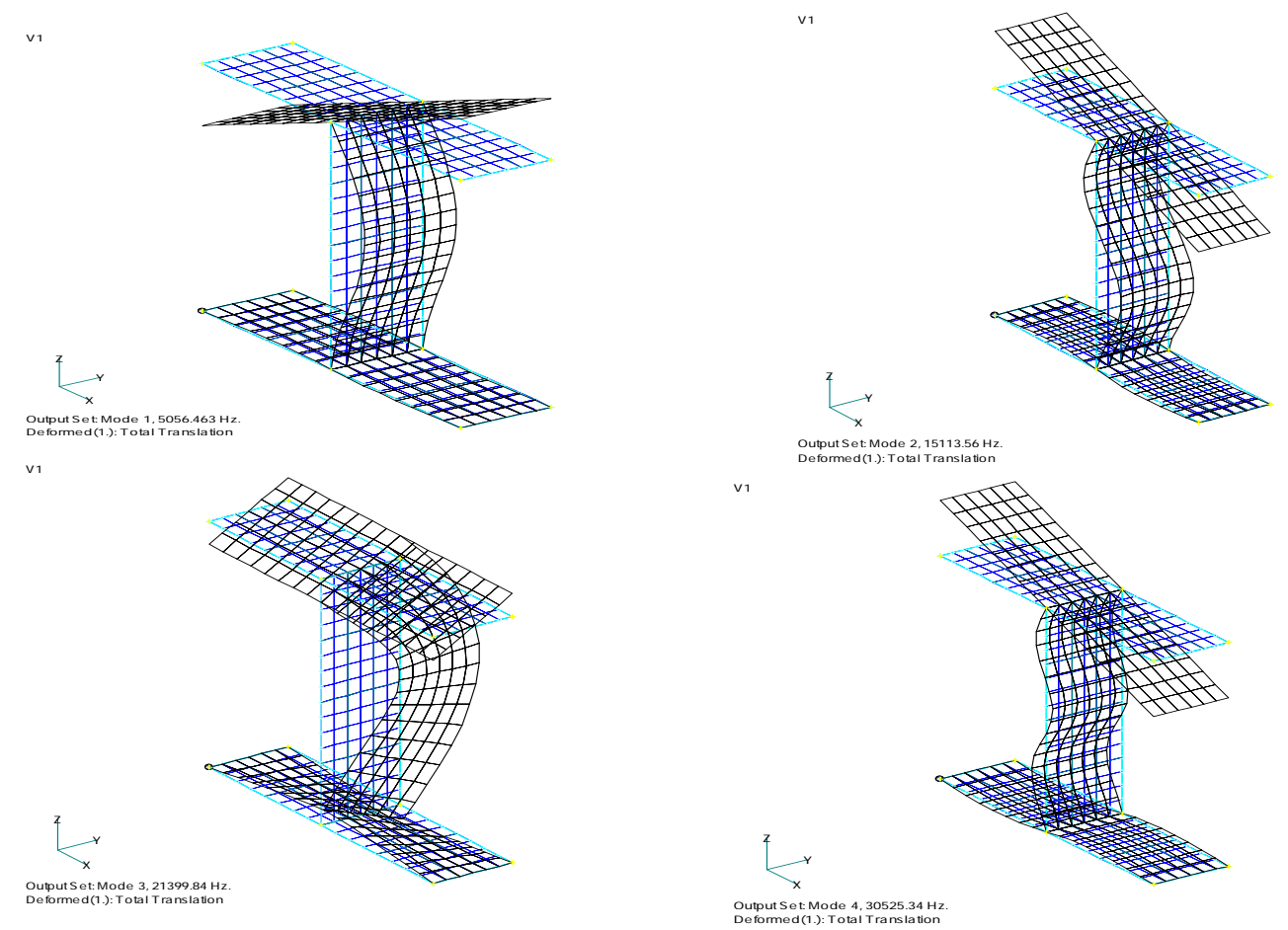

Figure F.3 Web-buckling mode of single web 

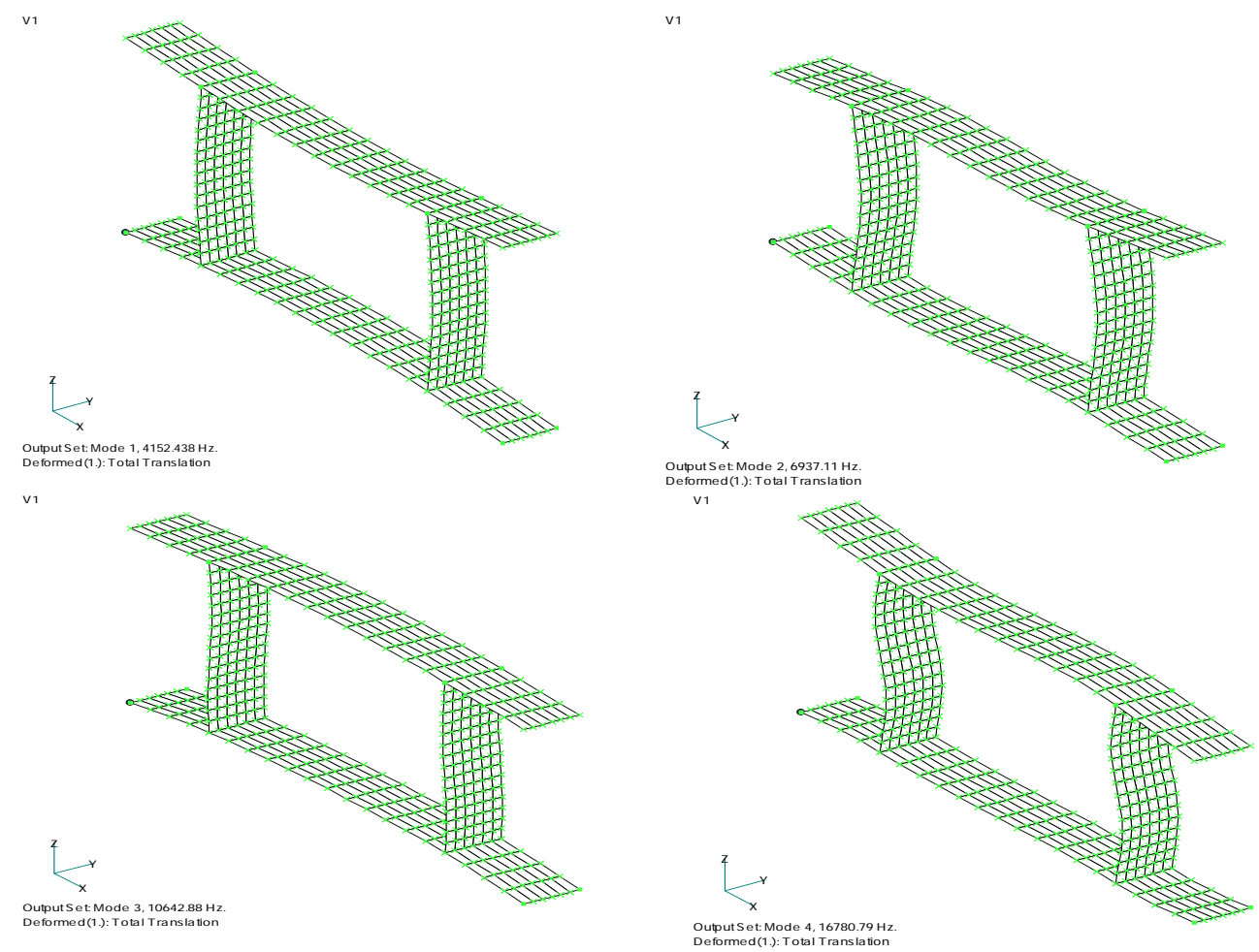

Figure F.4 Web-buckling mode of double web

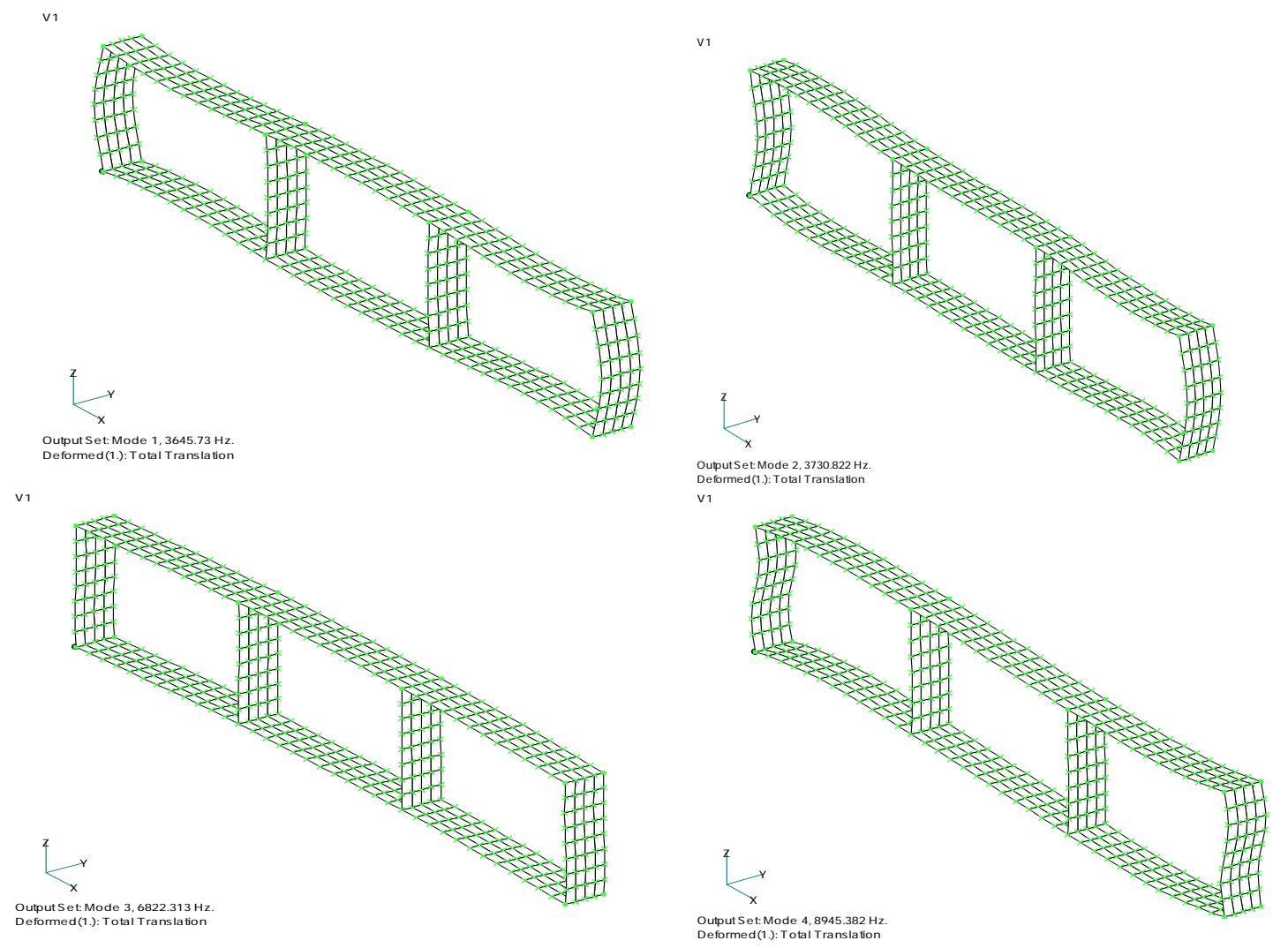

Figure F.5 Web-buckling mode of module 


\section{F.5 Prediction of Web-Buckling Strength}

Fundamental expressions using the elastic theory of column buckling are applicable because stress versus strain behavior in FRP members is nearly linear. Buckling of FRP webs is a function of effective length and slenderness ratio later. Unlike conventional materials as steel or aluminum, webs of ProDeck4 can not be clearly identified with a proportional limit. The effective length of problems can be established, however, from the experimental data. Therefore, the relation between critical stress and slenderness ratio of an FRP web can be presented using experimental effective length.

To arrive at critical web-buckling load, the governing equation of composite plate is used for this purpose (Whitney, 1987). One inch wide models have been used as composite columns under compression loads. A global deformation mode of web is assumed to arrive at displacement. It should be noted that the classical governing equation (refer to Equation (F.10)) is used to derive buckling load limits (Whitney, 1987).

$$
\frac{\partial^{2} M_{y}}{\partial y^{2}}+\frac{2 \partial^{2} M_{y z}}{\partial y \partial z}+\frac{\partial^{2} M_{z}}{\partial z^{2}}+N_{y} \frac{\partial^{2} w}{\partial y^{2}}+2 N_{y z} \frac{\partial^{2} w}{\partial y \partial z}+N_{z} \frac{\partial^{2} w}{\partial z^{2}}+q=0
$$

In this study, web specimens are only constrained at the ends (entire short sides). While, web edges along length (long sides) are free to rotate and deflect. Boundary conditions of web specimens lead to cylindrical bending mode (function of y only) under applied compression loads on the short sides. Thus, governing equation of a plate under cylindrical bending is simplified into one dimensional equation. If a web is modeled as one dimensional structural member, then Equation (F.10) can be simplified and given as follows:

$$
\begin{aligned}
& \frac{\partial^{2} M_{y}}{\partial y^{2}}+N_{y} \frac{\partial^{2} w}{\partial y^{2}}=0 \\
& M_{y}=E_{y} I \frac{\partial^{2} w}{\partial y^{2}}
\end{aligned}
$$


Displacement $(w)$ is assumed to be $W_{m} \operatorname{Sin}(m \pi y / K L)$ and substituted into Equation (F.12). For critical buckling load, $N_{y}$ will be a critical buckling load when constant $(m)$ of the assumed displacement function is a minimum value, i.e., $m=1$.Thus, the critical buckling load based on Euler's equation is given as:

$$
N_{y}=\frac{E_{y} I \pi^{2}}{(K L)^{2}}
$$

In addition, closed-form two dimensional plate buckling expression (Kollar, 2002) for an orthogonal plate is modified for this study. The principle of the stationary potential energy is used to generate a system of algebraic simultaneous equations. Minimum eigenvalue of the above algebraic simultaneous equations is found to obtain buckling load.

The internal strain energy of symmetrical laminates is given as (Whitney, 1987):

$U=\frac{1}{2} \int_{0}^{x} \int_{0}^{y}\left[\begin{array}{l}D_{11}\left(\frac{\partial^{2} w^{0}}{\partial x^{2}}\right)^{2}+D_{22}\left(\frac{\partial^{2} w^{0}}{\partial y^{2}}\right)^{2}+D_{66}\left(\frac{\partial^{2} w^{0}}{\partial x y}\right)^{2} \\ +2\left(D_{12} \frac{\partial^{2} w^{0}}{\partial x^{2}} \frac{\partial^{2} w^{0}}{\partial y^{2}}+D_{16} \frac{\partial^{2} w^{0}}{\partial x^{2}} \frac{\partial^{2} w^{0}}{\partial x y}+D_{26} \frac{\partial^{2} w^{0}}{\partial y^{2}} \frac{\partial^{2} w^{0}}{\partial x y}\right)\end{array}\right] d y d x$

The external work due to applied load is (Timoshenko, 1961):

$\Omega=\frac{1}{2} \int_{0}^{x} \int_{0}^{y}\left[N_{x}\left(\frac{\partial^{2} w^{0}}{\partial x^{2}}\right)^{2}+N_{y}\left(\frac{\partial^{2} w^{0}}{\partial y^{2}}\right)^{2}+2 N_{x y}\left(\frac{\partial w^{0}}{\partial x} \frac{\partial w^{0}}{\partial y}\right)\right] d y d x$

where, $N_{x}=-\lambda N_{x o}, N_{y}=-\lambda N_{y o}, N_{x y}=-\lambda N_{x y o}, \lambda$ is load parameter. Displacement $\mathrm{w}^{0}$ is assumed to be equal to $A X_{i}(x) Y_{j}(y)$.

The principle of stationary potential energy is:

$$
\frac{\partial(\Omega+U)}{\partial A}=0
$$


For special case, symmetrical orthotropic lay-up (only $D_{11}, D_{12}, D_{22}$, and $D_{66}$ are not zero) under uniform compressive load in the $\mathrm{y}$ direction, $\mathrm{N}_{\mathrm{xo}}$ is assumed to be zero. Plate is under simply supported conditions (Refer to Figure F.6), thus displacement function is simplified to be double sine function as $A \operatorname{Sin}\left(x / L_{x}\right) \operatorname{Sin}\left(y / L_{y}\right)$. Closed-form buckling solution for this special case is given (Kollar, 2002):

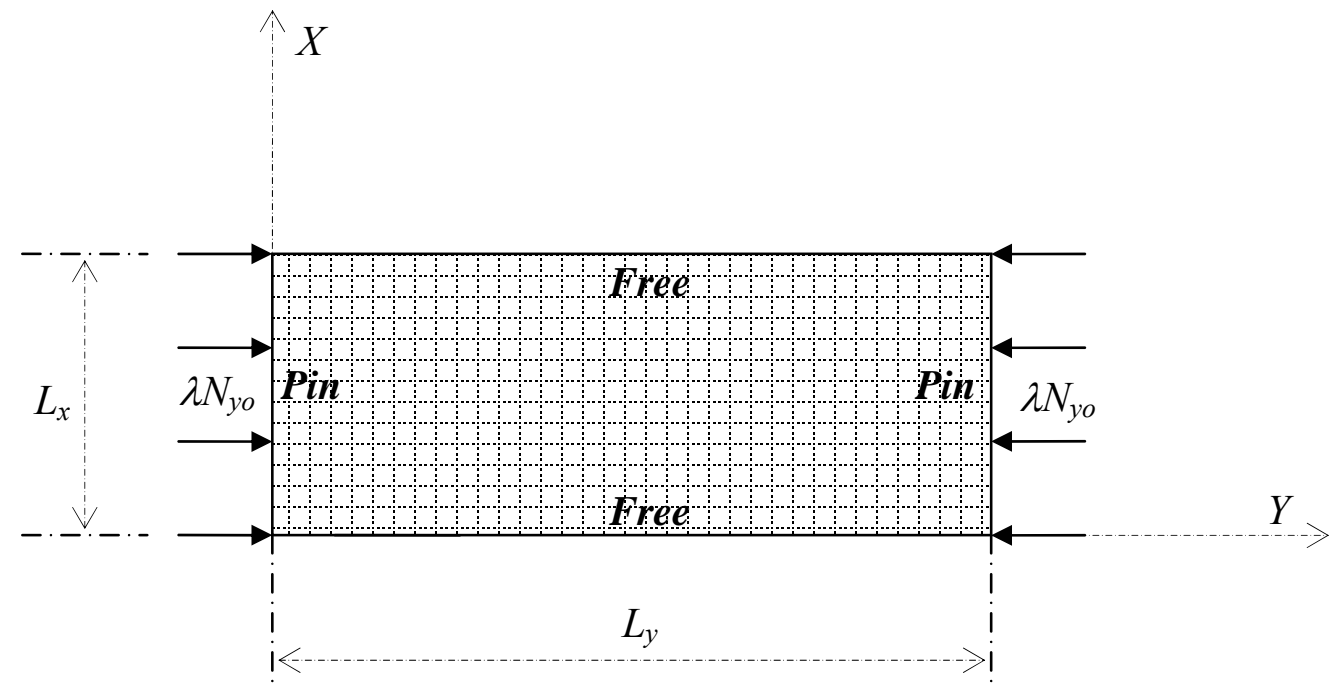

Figure F.6 Two-dimensional plate under buckling load

$$
\begin{aligned}
& N_{c r}=D_{22}\left(\frac{\alpha_{3}^{4}}{\alpha_{4}^{4} L_{y}{ }^{2}}\right)+D_{11}\left(\frac{\alpha_{1}^{4} L_{y}{ }^{2}}{\alpha_{4}^{4} L_{x}^{4}}\right)^{2}+2\left(D_{12}+2 D_{16}\right)\left(\frac{\alpha_{5}}{L_{x}^{4}}\right) \\
& \alpha_{1}=j \pi, \alpha_{3}=i \pi, \alpha_{4}=(j \pi)^{2}, \alpha_{5}=(i \pi)^{2}, L_{y}=i l_{y}, L_{x}=j l_{x} \\
& i, j=1,2,3 \ldots
\end{aligned}
$$

In this study, boundary conditions of edges parallel to the y direction are free. Equation (F.17) is simplified to be independent for $\mathrm{x}$ direction. Thus, simplified buckling load expression is:

$$
\begin{aligned}
& N_{c r}=D_{22} \pi^{2}\left(\frac{i}{L_{y}}\right)^{2} \\
& i=1,2,3 \ldots
\end{aligned}
$$


Using simplified classical lamination theory for bending $\left(D_{22}=E_{y} I\right)$, minimum eigenvalue is obtained from minimum $(i=1)$.

$$
N_{c r}=E_{y} I\left(\frac{\pi}{L_{y}}\right)^{2}
$$

It should be noted that two-dimensional refined buckling equation is simplified under special condition (cylindrical bending) and equal to Equation (F.13). From Equation (F.13), test specimens may be not truly pin type boundaries, partial fixity is presented on experimental results. To calculate effective length factor $(K)$ of web, experimental buckling loads are substituted into Equation (F.13). The results of effective length factor are reported in Table F.3.

From the above results, the average effective length factor of Prodeck 4 specimens varies between 0.850 and 1.00 depending on types of specimens. For specimens at component level, average effective length factors are slightly different from those that $(K=1)$ represent effective length factors of ProDeck4. Therefore, buckling strength of ProDeck4 specimens can be predicted by using Equation (F.13) with $(K=1)$. It should be noted that this buckling strength is computed using conventional Euler's buckling strength with pin-pin end conditions. Moreover, strength results using effective length factor $(K=1)$ is slightly lower than buckling strength of experiments. Using effective length factor $(K=1)$ will yield a conservative buckling strength for ProDeck4 specimens. However, partial fixity is presented on coupon specimens. From experimental results, an average effective length factor of coupons is found to be 0.85 for ProDeck4 coupon specimens. 
Table F.3 Effective length factor (K)

\begin{tabular}{|c|c|c|c|c|c|c|c|c|}
\hline \multirow[t]{2}{*}{ Specimen } & \multirow[t]{2}{*}{$\begin{array}{l}\text { Width } \\
\text { (in) }\end{array}$} & \multirow[t]{2}{*}{$\begin{array}{l}\text { Thickness } \\
\text { (in) }\end{array}$} & \multirow{2}{*}{$\begin{array}{c}\text { I } \\
10^{-3} \\
\left(\text { in }^{4}\right)\end{array}$} & \multirow{2}{*}{$\begin{array}{c}\text { Exp. } \\
\text { buckling } \\
\text { load } \\
\text { (kip) }\end{array}$} & \multicolumn{2}{|c|}{$\begin{array}{l}\text { Effective length } \\
\text { factor }\end{array}$} & \multirow{2}{*}{$\begin{array}{c}\text { Exp. } \\
\text { buckling } \\
\text { stress } \\
\text { (ksi) }\end{array}$} & \multirow{2}{*}{$\begin{array}{c}\text { Theo. } \\
\text { buckling } \\
\text { stress } \\
\text { (ksi) }\end{array}$} \\
\hline & & & & & $K$ & Avg. $K$ & & \\
\hline $\mathrm{WB}_{\mathrm{C} 1}: 1$ & 0.963 & 0.375 & 4.23 & 4.10 & 0.874 & \multirow[t]{3}{*}{0.850} & 11.35 & 12.01 \\
\hline $\mathrm{WB}_{\mathrm{C1}}: 2$ & 0.979 & 0.375 & 4.30 & 4.59 & 0.833 & & 12.50 & 12.01 \\
\hline $\mathrm{WB}_{\mathrm{C} 1}: 3$ & 0.982 & 0.375 & 4.32 & 4.50 & 0.843 & & 12.22 & 12.03 \\
\hline $\mathrm{WB}_{\mathrm{CO} 2}: 1$ & 0.941 & 0.375 & 4.14 & 3.32 & 0.961 & \multirow[t]{2}{*}{0.947} & 9.41 & 8.69 \\
\hline $\mathrm{WB}_{\mathrm{CO} 2}: 2$ & 0.954 & 0.375 & 4.19 & 3.56 & 0.934 & & 9.95 & 8.68 \\
\hline $\mathrm{WB}_{\mathrm{CO} 4: 1}$ & 0.886 & 0.375 & 3.89 & 2.95 & 0.989 & \multirow[t]{2}{*}{0.996} & 8.88 & 8.67 \\
\hline $\mathrm{WB}_{\mathrm{CO} 4}: 2$ & 0.965 & 0.375 & 4.24 & 3.12 & 1.003 & & 8.62 & 8.68 \\
\hline $\mathrm{WB}_{\mathrm{S} 2}: 1$ & 0.960 & 0.375 & 4.22 & 4.01 & 0.883 & \multirow[t]{2}{*}{0.884} & 11.14 & 8.68 \\
\hline $\mathrm{WB}_{\mathrm{S} 2}: 2$ & 0.980 & 0.375 & 4.31 & 4.07 & 0.885 & & 11.07 & 8.69 \\
\hline $\mathrm{WB}_{\mathrm{S} 4}: 1$ & 0.997 & 0.375 & 4.38 & 3.58 & 0.952 & \multirow[t]{2}{*}{0.955} & 9.58 & 8.68 \\
\hline $\mathrm{WB}_{\mathrm{S} 4}: 2$ & 0.982 & 0.375 & 4.32 & 3.48 & 0.958 & & 9.45 & 8.69 \\
\hline
\end{tabular}

Buckling stress can be written in term of slenderness ratio as:

$$
\begin{aligned}
& \sigma_{y}=\frac{E_{y} \pi^{2}}{\left(K \frac{L}{r}\right)^{2}} \\
& I=A r^{2}
\end{aligned}
$$

where, $A$ is area of cross section, $r$ is the least radius of gyration of the cross sectional area.

To evaluate limits of slenderness ratio, average buckling stresses and effective length factors for each case are substituted into Equation (F.20). Average experimental buckling stresses are found to be 12.02 and $9.76 \mathrm{ksi}$ for coupon and other specimens, respectively. Transverse elastic modulus is given as $1.2 \times 10^{6} \mathrm{psi}$ (Punyamurthula, 2004). Thus, slenderness ratios $(L / r)$ for buckling strength are evaluated to be 36.9 and 34.8 kips for coupon and other specimen types (double and forth web), respectively. Therefore, the relation between buckling stress and the slenderness ratio is given in Figure F.7. 


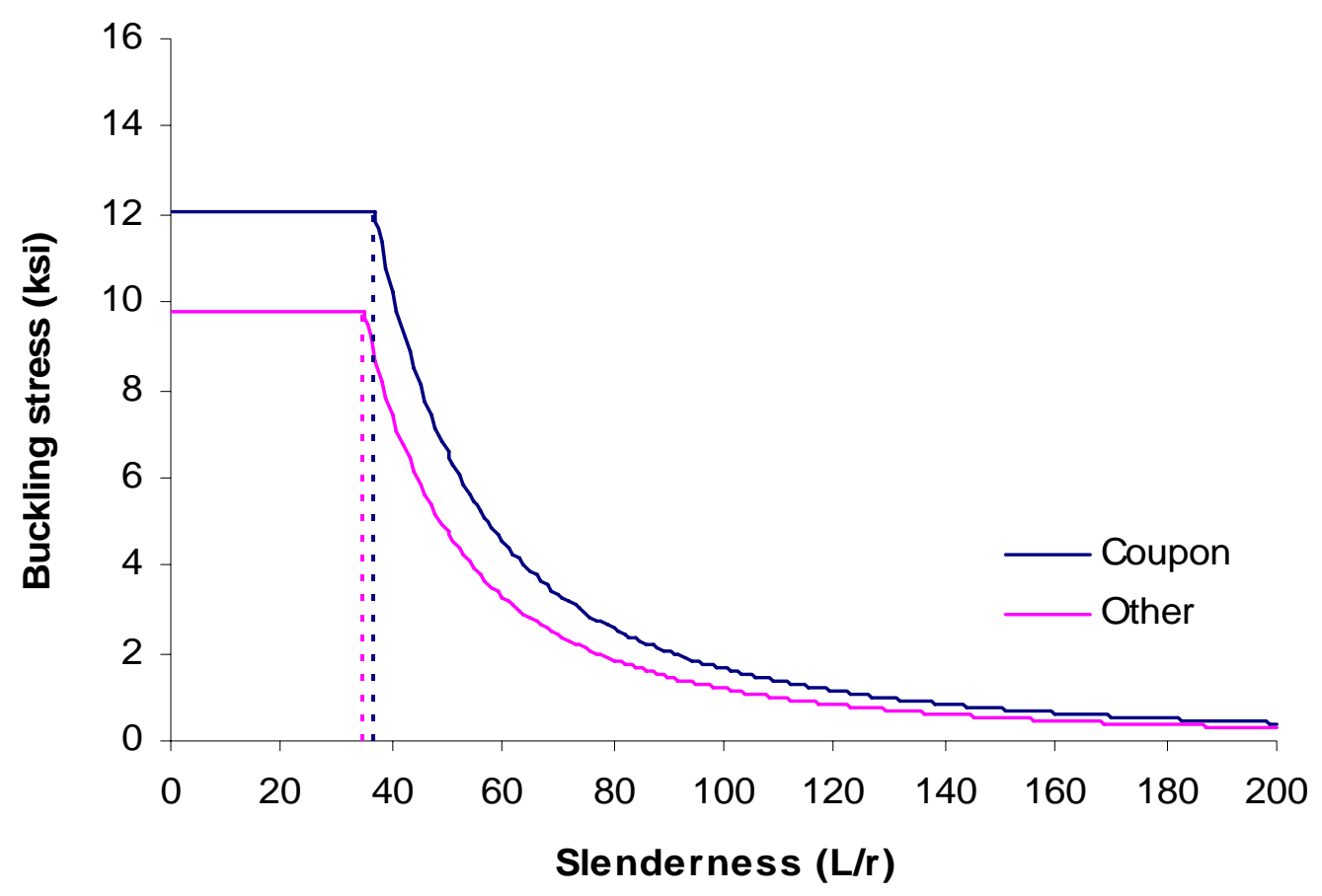

Figure F.7 Relation between buckling stress and slenderness ratio of ProDeck4

\section{F.6 Comparison of Buckling Strength}

In this section, the results of web buckling strength in Section F.3 are compared with other types of specimens. In addition, ProDeck 4 specimens with dimensions of $30 \times 29$ inches (Punyamurthula, 2004) and ProDeck8 specimens with 12 inches in width (Howard, 2002), tested under compression load of patch area with dimensions of $10 \times 20$ inches, are compared to the results from ProDeck4. Comparison of the results of buckling strength is reported in Table F.4. 
Table F.4 Comparison of web-buckling

\begin{tabular}{|l|c|c|c|c|c|}
\hline \multicolumn{1}{|c|}{ Specimen } & $\begin{array}{c}\text { Avg. max } \\
\text { applied } \\
\text { load } \\
\text { (kip) }\end{array}$ & $\begin{array}{c}\text { Avg. max } \\
\text { buckling } \\
\text { load } \\
\text { (kip) }\end{array}$ & $\begin{array}{c}\text { Avg. } \\
\text { buckling } \\
\text { stress } \\
\text { (ksi) }\end{array}$ & $\begin{array}{c}\text { Avg. } \\
\text { longitudinal } \\
\text { strain } \\
(\mathbf{1 0} \text {-6 in/in) }\end{array}$ & $\begin{array}{c}\text { \% stress } \\
\text { difference } \\
\text { (compared to } \\
\text { single web) }\end{array}$ \\
\hline $\mathrm{WB}_{\mathrm{C} 1}$ & 4.40 & 4.40 & 12.03 & 5860 & - \\
\hline $\mathrm{WB}_{\mathrm{CO} 2}$ & 6.88 & 3.44 & 9.68 & 6880 & 19.53 \\
\hline $\mathrm{WB}_{\mathrm{CO} 4}$ & 8.28 & 3.04 & 8.75 & 4822 & 27.3 \\
\hline $\mathrm{WB}_{\mathrm{S} 2}$ & 8.08 & 4.04 & 11.11 & 4226 & 7.65 \\
\hline $\mathrm{WB}_{\mathrm{S} 4}$ & 9.63 & 3.53 & 9.51 & 6142 & 20.9 \\
\hline ProDeck4 [ ] & 138 & 1.469 & 3.92 & - & 67.4 \\
\hline Polyester [ ] & 45 & 22.5 & 5.36 & - & 55.4 \\
\hline Vinyl Ester [ ] & 48 & 24 & 5.71 & - & 52.5 \\
\hline Vinyl Ester [ ] & 55 & 27.5 & 6.55 & - & 45.6 \\
\hline
\end{tabular}

From the test results, it shows that buckling strengths (stress) of ProDeck4 specimen is higher than that of ProDeck8 specimens by about 2 times, while, the percent stress differences between each ProDeck4 specimens vary between $7.65 \%$ and $20.9 \%$. Additional discussions are given in Section F.6 later.

\section{F.7 Discussion of Experimental Results}

The longitudinal stress and strain of web is found to be linear up to failure for specimen in Figure F.8. Web-buckling strengths of ProDeck4 have varied between 8.75 and $12.03 \mathrm{ksi}$. Maximum web-buckling strength is found on the result of single web specimens. When number of webs on test specimens increases (specimens $\mathrm{WB}_{\mathrm{CO} 2}$ and $\mathrm{WB}_{\mathrm{CO} 4}$ ), it is found that web-buckling strength slightly decreases compared to single web specimens. The multi-cell specimens are modeled as beams under uniform load. Thus, webs are subjected to reaction and moment whereas single web specimens are subjected to a concentrated load, only. 


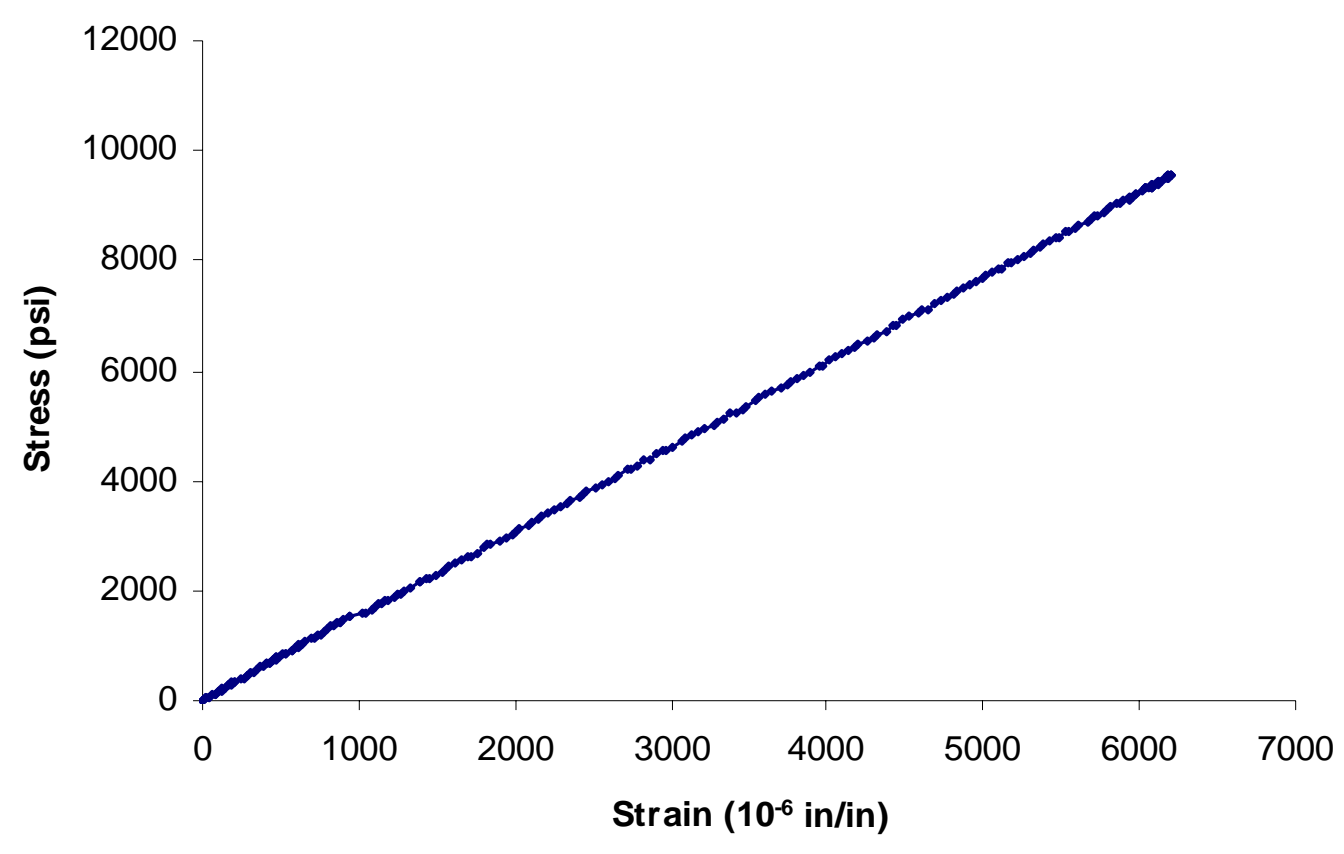

Figure F.8 Stress-strain relation of ProDeck4 single web specimen

Webs of test specimens are loaded till they bent and fail under bending moment. The magnitude of concentrated load is reduced when specimens are subjected to bending loads. For test specimens with joint $\mathrm{WB}_{\mathrm{J} 2}$ and $\mathrm{WB}_{\mathrm{J} 4}$, web-buckling strengths of those specimens are less than those of single web specimens as well as component specimens $\mathrm{WB}_{\mathrm{CO} 2}$ and $\mathrm{WB}_{\mathrm{CO} 4}$. This can be attributed to a phenomenon similar to specimens $\mathrm{WB}_{\mathrm{CO} 2}$ and $\mathrm{WB}_{\mathrm{CO} 4}$. When, web-buckling strength is compared between a component without and with joint specimens, it clearly shows that strength of test specimens with joints is slightly higher than those of specimens without joints because of thicker flanges in the case of jointed specimen. Thus test specimens with joints can support higher buckling load and bending moment than specimens without joints. Longitudinal strains at failure are between 4226 and $6680 \mu$ in/in depending on specimen types. The buckling stress comparison between specimens $\mathrm{WB}_{\mathrm{C} 1}$ and ProDeck4 specimens $(30 \times 29 \mathrm{inch})$ is about $67.4 \%$ thus, buckling stress of these specimens [ ] can not be accepted due to crippling failure. 


\section{F.8 Failure Mode of Web Buckling}

Failure modes of all test specimens are nearly identical to each other. When applied load increases to a maximum, crack and fiber delamination on web junction are observed and extended along the longitudinal direction of the web until test specimen failed. An example of web-buckling failure of a test specimen is presented in Figure F.9.

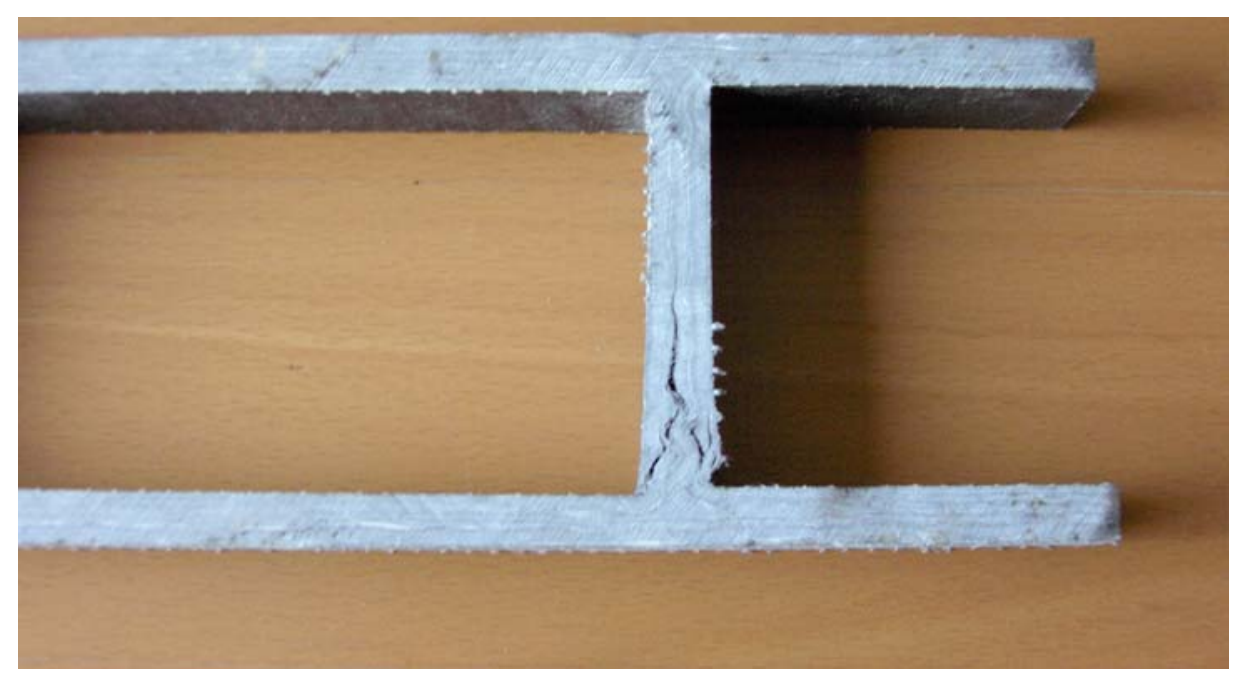

Figure F.9 Failure mode of web buckling

In ProDeck4 specimens $(30 \times 29$ inches $)$, cracks beneath the patch load area are noticed. Also, cracks are formed at the bottom surface of the flange portion. The failure mode of ProDeck4 specimens $(30 \times 29$ inches $)$ is due to web cripling rather web buckling (Punyamurthula, 2004). Web cripling of specimens is presented in Figure F.10. From the failure mode of test specimens, it should be noted that web buckling strength of FRP bridge decks in this study should not be obtained from component specimens with dimensions $30 \times 29$ inches, since web crippling failure is induced and lead to failure of test specimens later. 


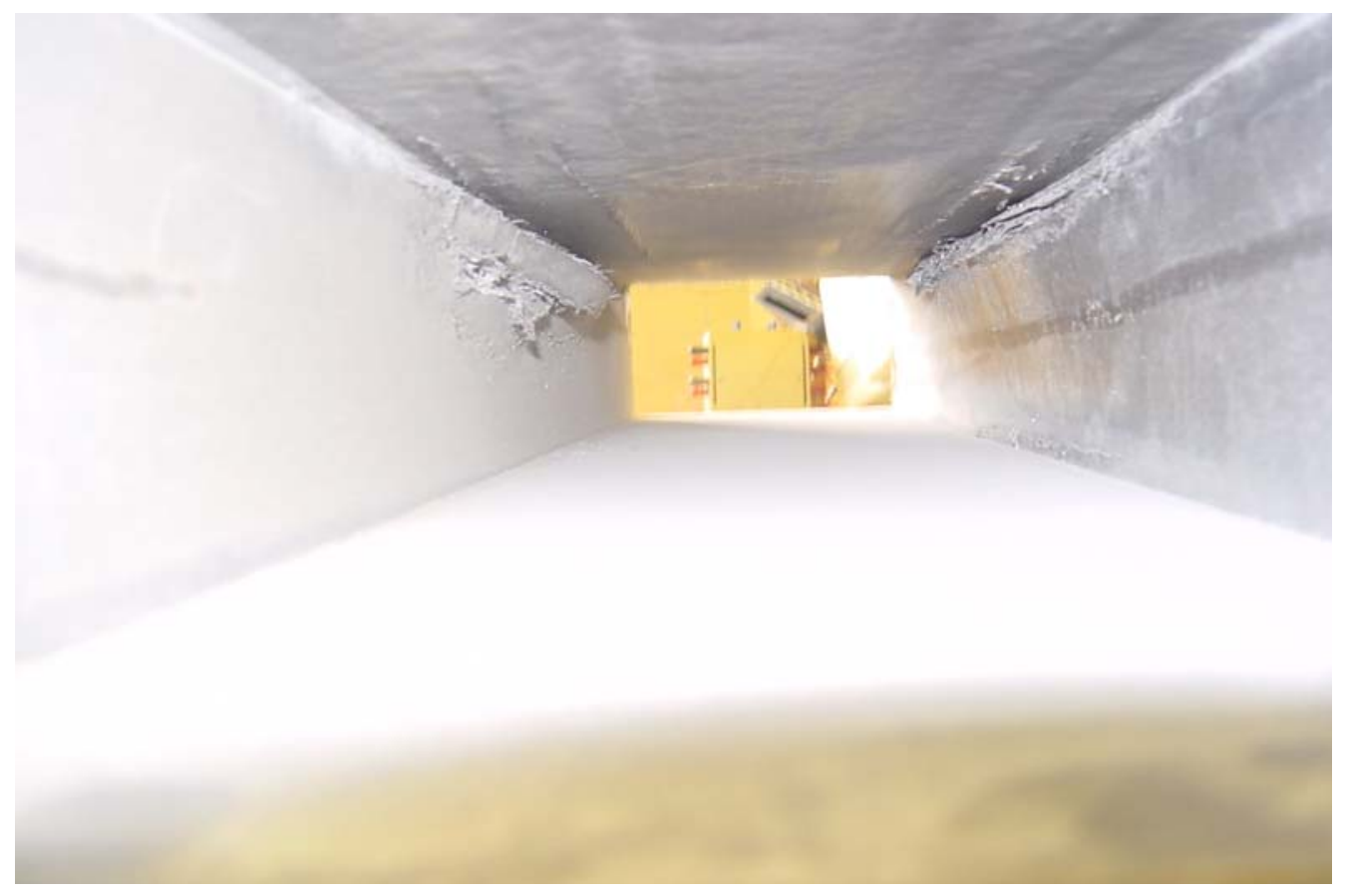

Figure F.10 Failure mode of web crippling (Punyamurthula, 2004)

\section{F.9 Size Limits due to Local Buckling}

For thin-walled FRP structural members, stiffness is relatively low and the walls are thin thus, buckling is one of major considerations in design. Local buckling analysis of FRP structural members is very complicated, the solutions are not found in simple form and not explicit (Kollar, 2003). Thus, finite element or finite strip method are used in the buckling analyses. The size limit for web (depth to thickness) and flange (width to thickness) ratio under torsional loading is presented herein in order to prevent local buckling near web-flange junctions (refer to Figure F.11). 

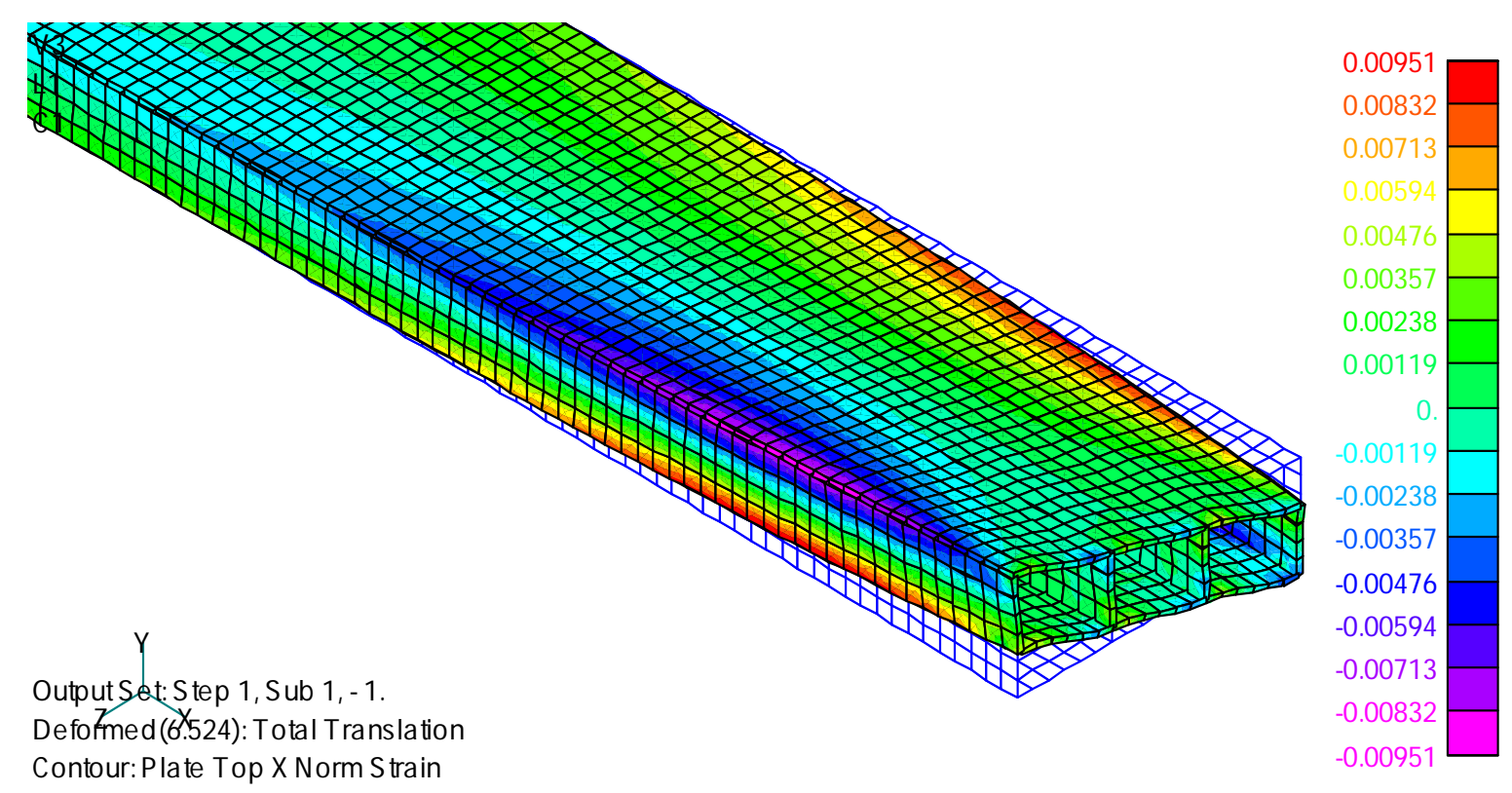

Figure F.11 High longitudinal strains at flange-web junctions

The local-lateral bucking strain of flange for a multi-cellular bridge deck component under bending was found to be about $5939 \times 10^{-6}$ in/in and $5400 \times 10^{-6}$ in/in for ProDeck4 and 8, respectively (Punyamurtula, 2004 and Howard, 2002). This strain used herein to establish size limits buckling in FRP ProDeck4. Using finite element analysis, thickness of flange and web vary while width of flange and web are still constant. Finite element strain data are compared to experimental local buckling strain (cut-off limit) for establishing size limits. From finite element results given in Figures F.12 through F.15, the size limits of single and multi-cell ProDeck4 cross sections are:

ProDeck4 single cell specimen under applied torque 108000 lbs-in:

$d_{w} / t_{w}<7.8$ and $b_{f} / t_{f}<11$

ProDeck4 multi-cell specimen under applied torque 360000 lbs-in:

$d_{w} / t_{w}<8.5$ and $b_{f} / t_{f}<12$

ProDeck8 multi-cell specimen under applied torque 450000 lbs-in:

$d_{w} / t_{w}<30$ and $b_{f} / t_{f}<34$ 
where, $d_{w}$ and $t_{w}$ are width and thickness of web, respectively. $b_{f}$ and $t_{f}$ are width and thickness of flange, respectively.

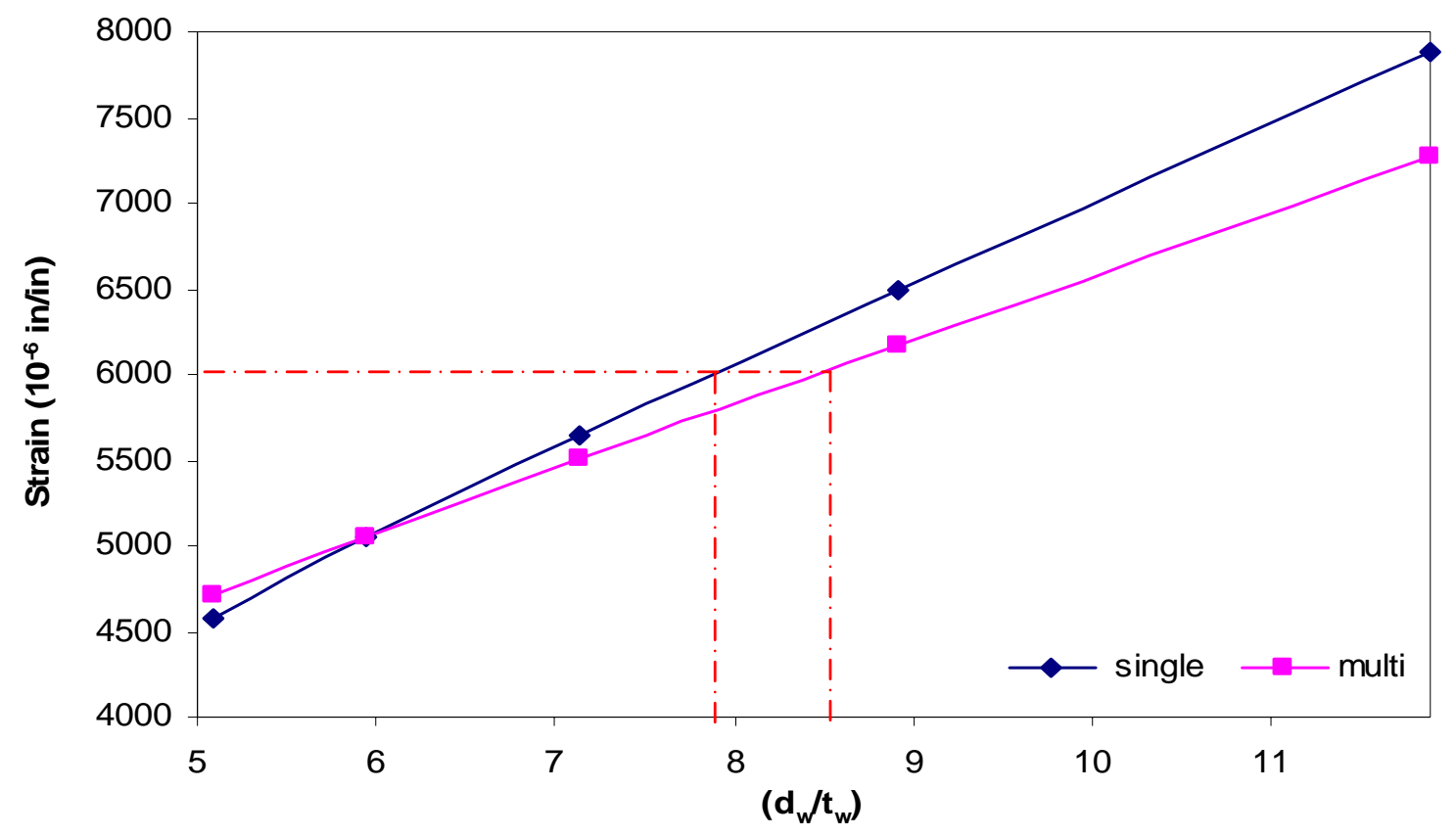

Figure F.12 Size limit $\left(d_{w} / t_{w}\right)$ for multi-cell ProDeck4

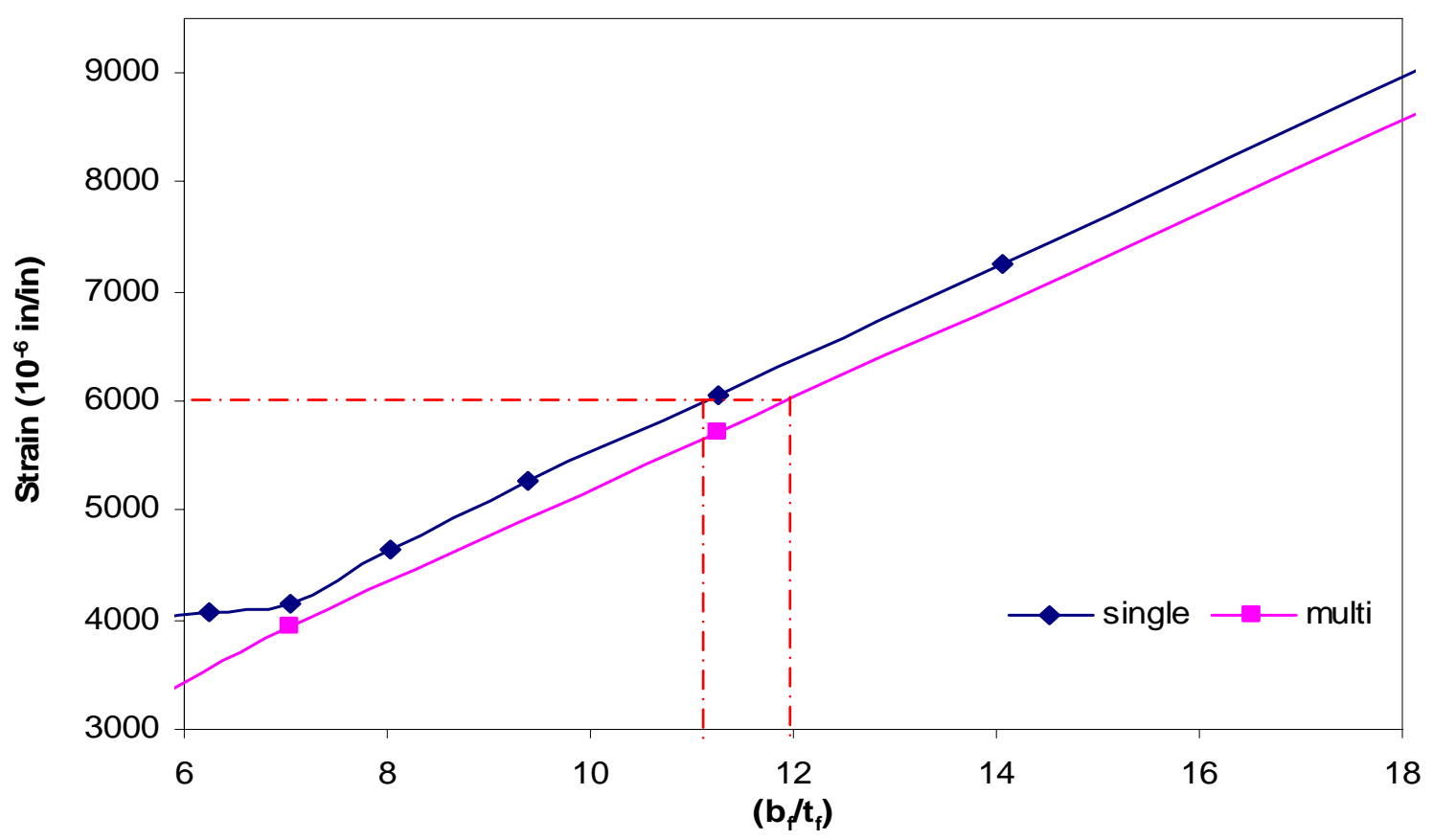

Figure F.13 Size limit $\left(b_{f} / t_{f}\right)$ for multi-cell ProDeck4 


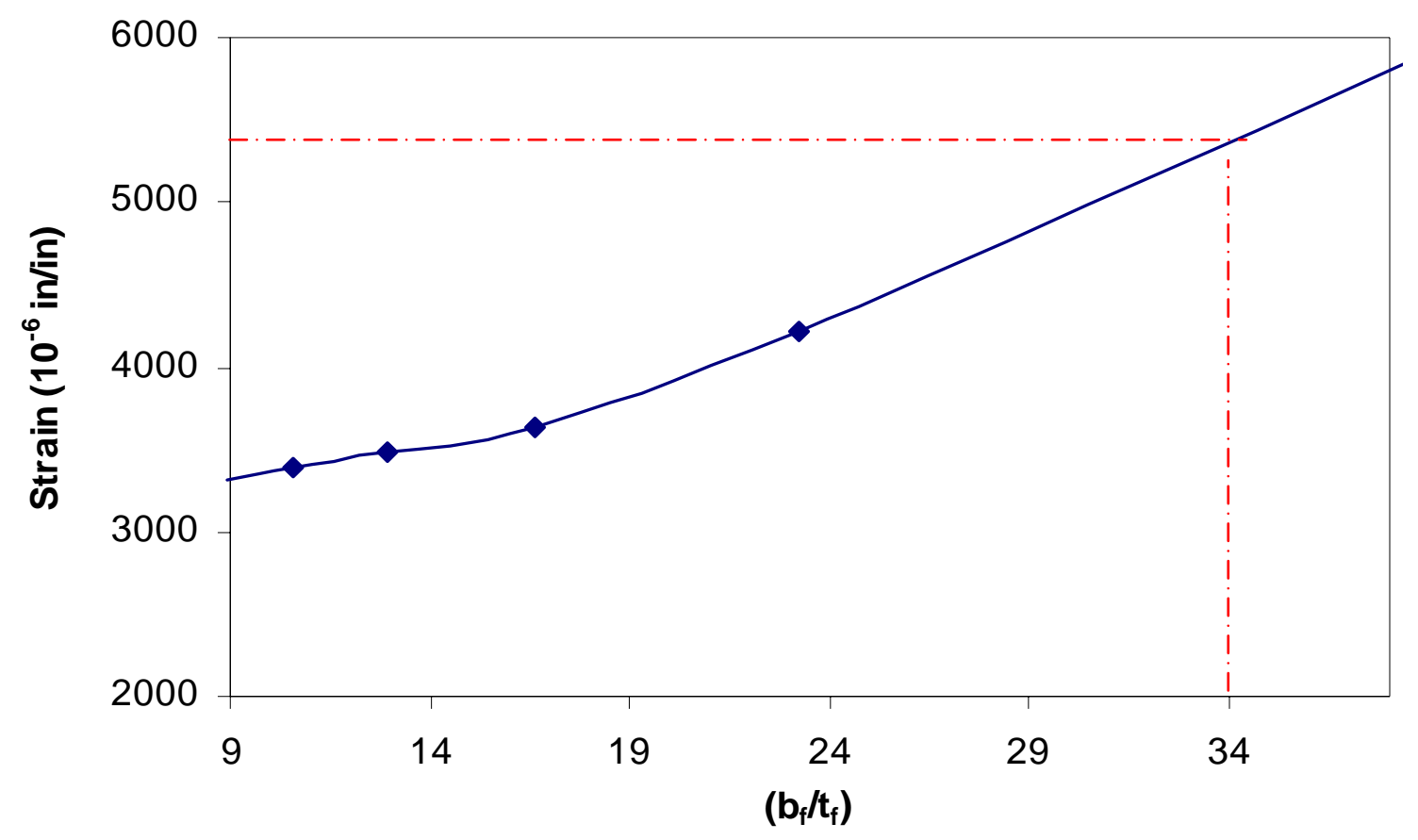

Figure F.14 Size limit $\left(b_{f} / t_{f}\right)$ for ProDeck8

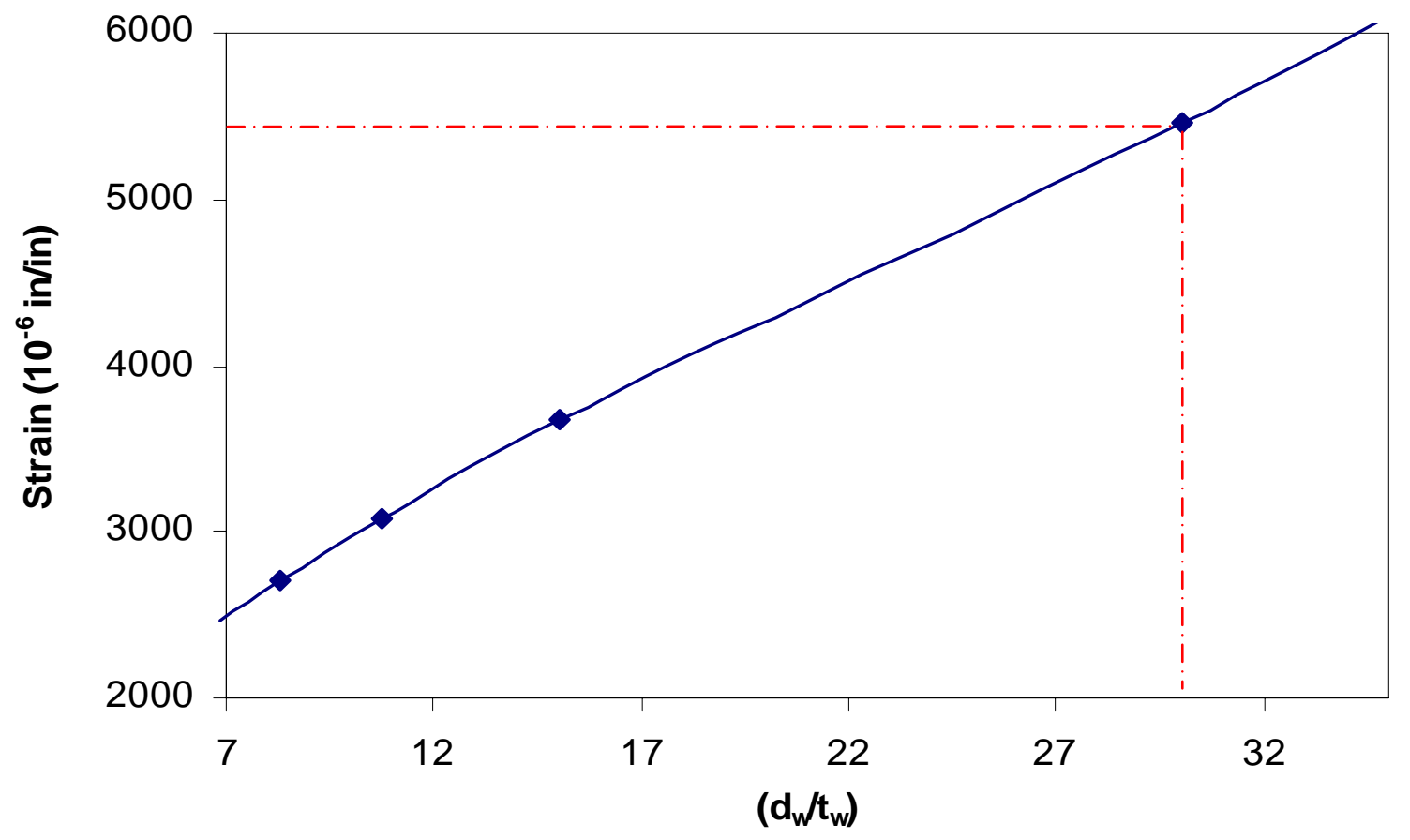

Figure F.15 Size limit $\left(d_{w} / t_{w}\right)$ for ProDeck8 


\section{F.10 Conclusion}

- $\quad$ Buckling load and critical strength of ProDeck4 web specimens vary from 8.62 to 12.50 ksi, respectively. (Section F.3)

- $\quad$ Average effective length factors $(K)$ based on an expression of Euler's buckling load vary between 0.850 and 1.00 . To predict buckling stresses, average effective lengths $(K)$ are correlated to be 0.85 and 1.00 for coupon and other specimen types of ProDeck4, respectively. (Section F.4)

- Linear behavior of stress versus strain is clearly observed even under web buckling load. Also, longitudinal strain at buckling stress is between $4226 \times 10^{-6}$ and $6680 \times 10^{-6}$ in/in. (Section F.6)

- The failure mode of specimens under web buckling is due to cracking and fiber delamination on web junction. (Section F.7)

- $\quad$ Size limit due to local-lateral buckling of flange for ProDeck4 single and multi-cell components using finite element analysis are (Section F.8):

Single cell specimen under applied torque 108000 lbs-in: $d_{w} / t_{w}<7.8$ and $b_{f} / t_{f}<11$

Multi-cell specimen under applied torque 360000 lbs-in: $d_{w} / t_{w}<8.5$ and $b_{f} / t_{f}<12$

- $\quad$ Size limit due to local-lateral buckling of flange for ProDeck8 multi-cell components are (Section F.8):

Multi-cell specimen under applied torque 450000 lbs-in: $d_{w} / t_{w}<30$ and $b_{f} / t_{f}<34$ 


\section{APPENDIX: G}

\section{LOCAL DEFLECTION}

\section{G.1 Introduction}

Local deflection (the displacement of the top flange between two contiguous webs stiffening the top flange) of an FRP composite decks is one of most important parameters that requires accurate quantification from serviceability view point. The objective of evaluating local deflection in FRP composite decks is to design a deck in a manner to prevent excessive curvature of the top flange of an FRP composite deck to prevent delamination of wearing surfaces from the flange (Howard 2002).

To design FRP deck systems, local deflection induced by moving vertical loads must be satisfied within certain limits. To satisfy this deflection limit, local deflection is generally computed under a patch load of AASHTO HS25 truck tire print. FRP deck modules are tested under patch load inducing bending of the FRP deck flange. An applied patch load simulating a truck tire is positioned on the top flange of an FRP test specimens at critical locations. Deflection and strain of both top and bottom flange are monitored to find local deflection. Experimental program of test specimens under patch load are discussed in the following section. 


\section{G.2 Experimental Program}

Details of specimen dimensions, number of specimens, test set-up and preparation are discussed in Section 3.12. Bending tests of components are conducted to find local deflection of test specimens. Concentrated and uniformly distributed loads are applied through Baldwin machine to obtain load versus deflection data. Two boundary conditions, simply supported and rigid base supports, are developed to collect top flange and web deflections and strains.

Top flange portion of the mid span (between contiguous webs) is modeled as a single span beam on simple and fixed end supports. Effective span length factor $(a)$ is evaluated by substituting experimental deflection into the classical beam deflection expressions as given in Table G.1. For simply supported conditions, local (experimental) deflections of test specimens are found from the difference in the deflection between the top and bottom flange of a deck. For rigid base conditions, local deflection of test specimens is obtained from the mid-span deflection of the top flange.

Table G.1 Classical deflection expression under bending

\begin{tabular}{|c|c|c|}
\hline \multirow{2}{*}{$\begin{array}{c}\text { Boundary condition } \\
\text { of flange portion }\end{array}$} & Load condition* \\
\cline { 2 - 3 } & uniform distribution & concentrated at mid span \\
\hline Simple support & $\delta_{\exp }=\frac{5 P(a L)^{3}}{384 E I}$ & $\delta_{\exp }=\frac{P(a L)^{3}}{48 E I}$ \\
\hline Fixed end & $\delta_{\exp }=\frac{P(a L)^{3}}{384 E I}$ & $\delta_{\exp }=\frac{P(a L)^{3}}{192 E I}$ \\
\hline
\end{tabular}

Note: $* \delta_{\exp }$ is experimental local deflection, $P$ is applied load, $L$ is test span of top flange (Figure G.1), $a$ is effective span length factor, $E$ is elastic modulus and $I$ is moment of inertia about bending axis of top flange cross section. 


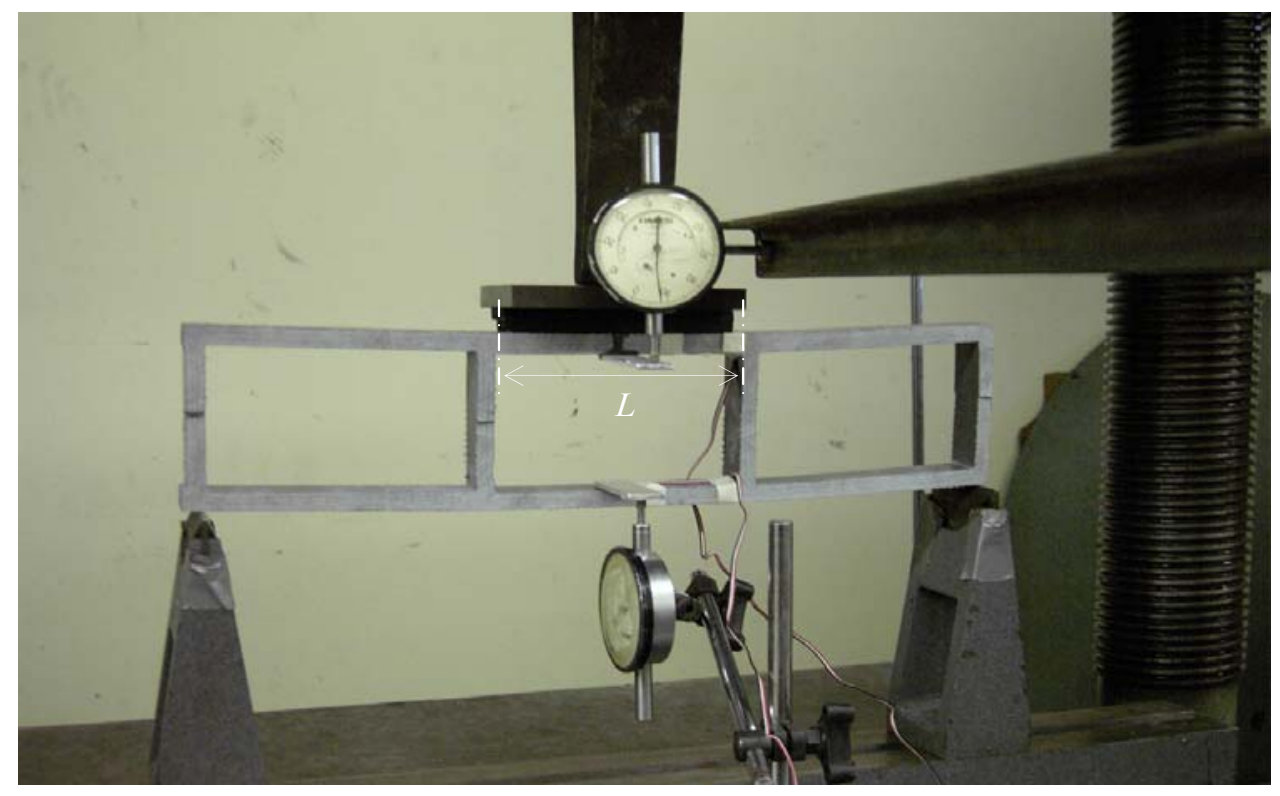

Figure G.1 Test span $(L)$ of top flange

To account for shear deformation, effective span length factor $(a)$ derived from the expressions in Table G.1 are multiplied (Refer to section 6.4). Effective span length accounting for shear deformation $\left(a_{s}\right)$ is written in terms of total deflection as:

$$
\begin{aligned}
& \frac{\delta_{b}}{\delta_{b}+\delta_{s}}=\frac{\left(a_{s} L\right)^{3}}{(a L)^{3}}=\left(1-\frac{b}{100}\right) \\
& a_{s}=\left(\sqrt[3]{1-\frac{b}{100}}\right) a
\end{aligned}
$$

Where, $(b)$ is the percent deflection due to shear effect and $(a)$ is the effective span length factor, $\delta_{b}$ is beam deflection due to bending and $\delta_{s}$ is beam deflection due to shear deformation.

Relation between bending moment and strain of simple beam is used to evaluate effective span length factors that include top flange shear effects. Effective span length factor (a) (without shear deformation) can be found by substituting the experimental strain corresponding to applied load, i.e., equations as given in Table G.2. 
Table G.2 Strain expression due to bending

\begin{tabular}{|c|c|c|}
\hline $\begin{array}{c}\text { Boundary condition } \\
\text { of flange portion }\end{array}$ & Lniform distribution & concentrated at mid span \\
\cline { 2 - 3 } & $\varepsilon_{\exp }=\frac{P(a L) c}{8 E I}$ & $\varepsilon_{\exp }=\frac{P(a L) c}{4 E I}$ \\
\hline Simple support & $\varepsilon_{\exp }=\frac{P(a L) c}{24 E I}$ & $\varepsilon_{\exp }=\frac{P(a L) c}{8 E I}$ \\
\hline Fixed end & & \\
\hline
\end{tabular}

Note: $\varepsilon_{\exp }$ is experimental strain, $P$ is applied load, $L$ is test span of top flange, $(a)$ is effective span length factor, $(c)$ is distance from the neutral axis to the top or bottom surface depending on position of strain gage, $E$ is elastic modulus and $I$ is moment of inertia about bending axis of top flange cross section.

\subsection{Evaluation and Discussion of Experimental Results}

Experimental deflection and strain data for each load case and boundary conditions are given in Table G.3. Effective span length factors are evaluated (see Table G.4) using experimental data and expression in Tables G.1 and G.2. From experimental results, effective span length factors with shear deformation are selected to establish local deflection limits. Local deflection of the experimental results $\left(\mathrm{LDP}_{4}: 3, \mathrm{LDP}_{4}: 5, \mathrm{LDP}_{4}: 7, \mathrm{LDPJ}_{4}: 3, \mathrm{LDPJ}_{4}: 5\right.$ ,LDP $8: 1$, LDS:1, and LDS:3) with 10 percent of shear deformation (Refer to Table G.5), local deflection of the top flange between both contiguous webs are used to generate limit on location deflection:

Limit of local deflection is proposed to be $\delta_{\text {limit }}=\frac{s}{100}$

From Table G.5, it is found that local deflection of the top flange is found to be partially fixed. This percent fixity of top flange is written in terms of effective length factors with shear deformation $\left(a_{s}\right)$. Thus, percent fixity of the top flanges between contiguous webs 
can be obtained from effective length factor with shear deformation $\left(a_{s}\right)$ influencing bending. Using simple support condition with $10 \%$ deflection due to shear deformation, it is found that, the effective length factors with shear deformation of ProDeck4 specimens vary between 0.75 and 0.88 . Thus, the average percent fixity of ProDeck4 $\left(\mathrm{LDP}_{4}: 3, \mathrm{LDP}_{4}: 5, \mathrm{LDP}_{4}: 7\right.$, $\mathrm{LDPJ}_{4}: 3, \mathrm{LDPJ}_{4}: 5$ ) under simply supported conditions is about $20 \%$.

Experimental results of ProDeck4 under AASHTO HS 25 truck load are used for this purpose to validate the limits of local deflection. ProDeck4 specimens are modeled as continuous supports at the bottom flange. Also specimens are uniformly loaded for $400 \mathrm{lbs}$ at the mid cell of the top flange. The test span is found to be 5.85 inches. Transverse elastic modulus of flange portion is found by testing under tension and given as $\sim 2.5 \times 10^{6}$ psi. Moment of inertia of top flange is determined to be $0.00663 \mathrm{in}^{4}$. Average effective span length factor is 0.8 in terms of a simply supported condition. Thus, local deflection under simply supported condition can be found as:

$$
\begin{aligned}
& \delta=\frac{5 P(a L)^{3}}{384 E I} \\
& \delta=\frac{5 \times 400 \times(0.80 \times 5.85)^{3}}{384\left(2.5 \times 0.00663 \times 10^{6}\right)} \\
& \delta=0.0322 \text { inch } \\
& \delta=\frac{S}{181.7}<\frac{S}{100}
\end{aligned}
$$

To determine local deflection due to HS 25 truck load, applied load is found to be 0.725 kip/in and substituted into Equation (G.4).

Induced $\delta_{H S 25}=\frac{5 \times 725 \times(0.80 \times 5.85)^{3}}{384\left(2.5 \times 0.00663 \times 10^{6}\right)}=0.0584$ inch

$\mathrm{S}$ in local deflection limit is considered between center and center of contiguous webs. Thus, $\mathrm{S}$ is equal 6 inch for ProDeck4 decks. 
Induced $\delta_{H S 25}<\operatorname{limit} \frac{S}{100}=\frac{6.00}{100}=0.06$ inch

Local deflection limit that is proposed in this study is satisfied for AAHTO HS25 truck loading. However, using strain data generated from local deflections, it is found that results are quite different from the deflection data. This may be attributed to strain data that are used for this purpose, might be only local strain of top flange of the FRP composite laminated layer. Response obtained from strain data is not satisfactory for local deflection in terms of ProDeck4 with the fiber/fabrics architecture as given in Appendix C. For field application, it should be noted that polymer concrete wearing surfaces will improve local stiffness and the effective local area over which load gets distributed; thus local deflection and strain would be reduced, resulting in slightly lower than the above proposed limit state.

\section{G.4 Conclusion}

- Using deflection data, local deflection limit state is proposed to be one percent of span (distance between two contiguous). However, the results based on strain data are found to be less accurate for generating the local deflection limit.

- It is found that local deflection of the top flange is under partial fixity due to contiguous webs. Under simple support condition accounted for $10 \%$ deflection due to shear deformation, the average percent fixity of ProDeck4 is about $20 \%$. 
Table 9.3 Deflection and Strain data

\begin{tabular}{|c|c|c|c|c|c|c|c|c|c|c|c|}
\hline \multirow[t]{2}{*}{ Specimen } & \multicolumn{2}{|c|}{ Support } & \multicolumn{3}{|c|}{ Loading } & \multirow[t]{2}{*}{$\begin{array}{c}\mathrm{E}\left(10^{6}\right) \\
(\mathrm{psi})\end{array}$} & \multirow[t]{2}{*}{$\begin{array}{l}\text { I } \\
\left(\mathrm{in}^{4}\right)\end{array}$} & \multicolumn{2}{|c|}{$\begin{array}{c}\text { Deflection@ mid span } \\
\text { (in) }\end{array}$} & \multicolumn{2}{|c|}{$\begin{array}{c}\text { Strain } \\
\left(10^{-6} \text { in/in }\right)\end{array}$} \\
\hline & Type & $\begin{array}{l}\text { Span } \\
\text { (in) }\end{array}$ & $\begin{array}{c}\text { Load } \\
\text { (lb) }\end{array}$ & Type & $\begin{array}{l}\text { Span } \\
\text { (in) }\end{array}$ & & & Top & Bottom & Top & Bottom \\
\hline $\mathrm{LDP}_{4}: 1$ & S.S & 17.5 & 160 & UDL & 5.85 & 1.2 & 0.00663 & 0.05 & 0.254 & 1403 & 727 \\
\hline $\mathrm{LDP}_{4}: 2$ & S.S & 17.5 & 150 & point & 5.85 & 1.2 & 0.00663 & 0.059 & 0.265 & 2432 & 947 \\
\hline $\mathrm{LDP}_{4}: 3$ & S.S & 6 & 400 & UDL & 5.85 & 1.2 & 0.00663 & 0.060 & 0.012 & 1995 & 32 \\
\hline $\mathrm{LDP}_{4}: 4$ & S.S & 6 & 300 & point & 5.85 & 1.2 & 0.00663 & 0.087 & 0.008 & 3096 & 57 \\
\hline $\mathrm{LDP}_{4}: 5$ & C.S. (4) & 3@5.85 & 400 & UDL & 5.85 & 1.2 & 0.00663 & 0.052 & 0.009 & 1985 & 32 \\
\hline $\mathrm{LDP}_{4}: 6$ & C.S. (4) & 3@5.85 & 300 & point & 5.85 & 1.2 & 0.00663 & 0.083 & 0.011 & 3057 & 76 \\
\hline $\mathrm{LDP}_{4}: 7$ & R.S & 18 & 400 & UDL & 5.85 & 1.2 & 0.00663 & 0.030 & - & 1843 & - \\
\hline $\mathrm{LDP}_{4}: 8$ & R.S & 18 & 200 & point & 5.85 & 1.2 & 0.00663 & 0.027 & - & 1700 & - \\
\hline $\mathrm{LDP}_{4}: 9$ & S.S & 17.5 & 2000 & UDL & 18 & 1.2 & 0.00663 & 0.045 & - & - & - \\
\hline $\mathrm{LDP}_{4}: 10$ & R.S & 18 & 2000 & UDL & 18 & 1.2 & 0.00663 & 0.080 & - & 1258 & - \\
\hline $\mathrm{LDP}_{4}: 11$ & R.S & 18 & 2000 & UDL & 6.5 & 1.2 & 0.00663 & 0.128 & - & 4221 & - \\
\hline $\mathrm{LDPJ}_{4}: 1$ & S.S & 17.5 & 150 & UDL & 5.85 & 1.2 & 0.00663 & 0.041 & 0.221 & 1070 & 713 \\
\hline $\mathrm{LDPJ}_{4}: 2$ & S.S & 17.5 & 150 & point & 5.85 & 1.2 & 0.00663 & 0.043 & 0.227 & 1709 & 622 \\
\hline $\mathrm{LDPJ}_{4}: 3$ & S.S & 6 & 400 & UDL & 5.85 & 1.2 & 0.00663 & 0.053 & 0.013 & 1855 & 82 \\
\hline $\mathrm{LDPJ}_{4}: 4$ & S.S & 6 & 300 & point & 5.85 & 1.2 & 0.00663 & 0.082 & 0.008 & 2884 & 90 \\
\hline
\end{tabular}




\begin{tabular}{|c|c|c|c|c|c|c|c|c|c|c|c|}
\hline LDPJ $_{4}: 5$ & C.S (4) & $3 @ 6$ & 400 & UDL & 5.85 & 1.2 & 0.00663 & 0.050 & 0.015 & 1754 & 154 \\
\hline LDPJ $_{4}: 6$ & C.S (4) & $3 @ 6$ & 300 & point & 5.85 & 1.2 & 0.00663 & 0.076 & 0.008 & 2833 & 146 \\
\hline LDPJ $_{4}: 7$ & R.S & 18 & 400 & UDL & 5.85 & 1.2 & 0.00663 & 0.042 & - & 1623 & - \\
\hline LDPJ $_{4}: 8$ & R.S & 18 & 200 & point & 5.85 & 1.2 & 0.00663 & 0.039 & - & 1695 & - \\
\hline LDPJ $_{4}: 9$ & S.S & 17.5 & 2000 & UDL & 18 & 1.2 & 0.00663 & 0.042 & - & - & - \\
\hline LDPJ $_{4}: 10$ & R.S & 18 & 2000 & UDL & 18 & 1.2 & 0.00663 & 0.064 & - & $528 *$ & - \\
\hline LDPJ $_{4}: 11$ & R.S & 18 & 2000 & UDL & 6.5 & 1.2 & 0.00663 & 0.125 & - & 3194 & - \\
\hline LDP $_{8}: 1$ & S.S & 12 & 400 & UDL & 11 & 1.8 & 0.01042 & 0.044 & 0.007 & 2227 & 79 \\
\hline LDP $_{8}: 2$ & S.S & 12 & 150 & point & 11 & 1.8 & 0.01042 & 0.057 & 0.011 & 6224 & 182 \\
\hline LDP $_{8}: 3$ & R.S & 12 & 400 & UDL & 11 & 1.8 & 0.01042 & 0.172 & - & 2384 & 119 \\
\hline LDP $_{8}: 4$ & R.S & 12 & 150 & point & 11 & 1.8 & 0.01042 & 0.25 & - & 6667 & 102 \\
\hline LDS :1 & S.S & 10 & 400 & UDL & 8 & 1.2 & 0.00759 & 0.045 & 0.010 & 1709 & 65 \\
\hline LDS :2 & S.S & 10 & 300 & point & 8 & 1.2 & 0.00759 & 0.073 & 0.024 & 3325 & 76 \\
\hline LDS :3 & R.S & 10 & 400 & UDL & 8 & 1.2 & 0.00759 & 0.058 & - & 2467 & 609 \\
\hline LDS :4 & R.S & 10 & 300 & point & 8 & 1.2 & 0.00759 & 0.064 & - & 3359 & 524 \\
\hline
\end{tabular}

Note: S.S.,R.S., and C.S. are simply, rigid and continuous supports, UDL and point are uniform distribution and point load.

* strain at $1000 \mathrm{lb}$ 
Table 9.4 Effective span length factor (a)

\begin{tabular}{|c|c|c|c|c|c|c|}
\hline \multirow[t]{3}{*}{ Specimen } & \multicolumn{3}{|c|}{ Based on deflection data } & \multicolumn{3}{|c|}{ Based on strain data } \\
\hline & \multirow[t]{2}{*}{$\delta_{\text {exp }}$} & \multicolumn{2}{|c|}{ Factor $(a)$} & \multirow{2}{*}{$\varepsilon_{e x p}$} & \multicolumn{2}{|c|}{ Factor $(a)$} \\
\hline & & simple & fixed & & simple & fixed \\
\hline $\mathrm{LDP}_{4}: 1$ & 0.204 & 2.01 & 3.44 & 1403 & 1.370 & 4.11 \\
\hline $\mathrm{LDP}_{4}: 2$ & 0.206 & 1.761 & 2.79 & 2432 & 0.855 & 1.709 \\
\hline $\mathrm{LDP}_{4}: 3$ & 0.048 & 0.914 & 1.563 & 1995 & 0.526 & 1.577 \\
\hline $\mathrm{LDP}_{4}: 4$ & 0.079 & 1.015 & 1.611 & 3096 & 0.549 & 1.097 \\
\hline $\mathrm{LDP}_{4}: 5$ & 0.043 & 0.881 & 1.506 & 1985 & 0.523 & 1.570 \\
\hline $\mathrm{LDP}_{4}: 6$ & 0.072 & 0.984 & 1.563 & 3057 & 0.542 & 1.084 \\
\hline $\mathrm{LDP}_{4}: 7$ & 0.030 & 0.781 & 1.336 & 1843 & 0.486 & 1.457 \\
\hline $\mathrm{LDP}_{4}: 8$ & 0.027 & 0.813 & 1.290 & 1700 & 0.448 & 0.896 \\
\hline $\mathrm{LDPJ}_{4}: 1$ & 0.180 & 1.969 & 3.37 & 1070 & 1.128 & 3.38 \\
\hline $\mathrm{LDPJ}_{4}: 2$ & 0.184 & 1.372 & 2.18 & 1709 & 0.600 & 1.201 \\
\hline $\mathrm{LDPJ}_{4}: 3$ & 0.040 & 0.860 & 1.470 & 1855 & 0.489 & 1.467 \\
\hline $\mathrm{LDPJ}_{4}: 4$ & 0.074 & 0.993 & 1.577 & 2884 & 0.511 & 1.022 \\
\hline $\mathrm{LDPJ}_{4}: 5$ & 0.035 & 0.822 & 1.406 & 1754 & 0.462 & 1.387 \\
\hline $\mathrm{LDPJ}_{4}: 6$ & 0.068 & 0.966 & 1.533 & 2833 & 0.502 & 1.004 \\
\hline $\mathrm{LDPJ}_{4}: 7$ & 0.042 & - & - & 1623 & 0.428 & 1.283 \\
\hline $\mathrm{LDPJ}_{4}: 8$ & 0.039 & - & - & 1695 & 0.447 & 0.893 \\
\hline $\mathrm{LDP}_{8}: 1$ & 0.037 & 0.464 & 0.794 & 2227 & 0.405 & 1.215 \\
\hline $\mathrm{LDP}_{8}: 2$ & 0.044 & 0.592 & 0.940 & 6224 & 0.849 & 1.698 \\
\hline $\mathrm{LDP}_{8}: 3$ & 0.172 & 0.775 & 1.325 & 2384 & 0.325 & 0.976 \\
\hline $\mathrm{LDP}_{8}: 4$ & 0.25 & 1.041 & 1.652 & 6667 & 1.213 & 2.43 \\
\hline LDS :1 & 0.035 & 0.493 & 0.842 & 1709 & 0.231 & 0.692 \\
\hline LDS :2 & 0.049 & 0.519 & 0.824 & 3325 & 0.224 & 0.449 \\
\hline LDS :3 & 0.058 & 0.583 & 0.997 & 2467 & 0.250 & 0.749 \\
\hline LDS :4 & 0.064 & 0.493 & 0.899 & 3359 & 0.227 & 0.453 \\
\hline
\end{tabular}


Table 9.5 Effectiveness span length Factor $\left(a_{s}\right)$ (including effect of shear deformation)

\begin{tabular}{|c|c|c|c|c|c|c|c|c|c|c|c|c|}
\hline \multirow[t]{3}{*}{ Specimen } & \multicolumn{12}{|c|}{ Effectiveness span length Factor $\left(a_{s}\right)$} \\
\hline & \multicolumn{2}{|c|}{$0 \%$ shear } & \multicolumn{2}{|c|}{$10 \%$ shear } & \multicolumn{2}{|c|}{$15 \%$ shear } & \multicolumn{2}{|c|}{$20 \%$ shear } & \multicolumn{2}{|c|}{$25 \%$ shear } & \multicolumn{2}{|c|}{$30 \%$ shear } \\
\hline & simple & fixed & simple & fixed & simple & fixed & simple & fixed & simple & fixed & simple & fixed \\
\hline $\mathrm{LDP}_{4}: 1$ & 2.01 & 3.44 & 1.9406 & 3.3213 & 1.9040 & 3.2586 & 1.8659 & 3.1934 & 1.8262 & 3.1254 & 1.7847 & 3.0544 \\
\hline $\mathrm{LDP}_{4}: 2$ & 1.761 & 2.790 & 1.7002 & 2.6937 & 1.6681 & 2.6429 & 1.6348 & 2.5900 & 1.6000 & 2.5349 & 1.5636 & 2.4773 \\
\hline $\mathrm{LDP}_{4}: 3$ & 0.914 & 1.563 & 0.8825 & 1.5091 & 0.8658 & 1.4806 & 0.8485 & 1.4510 & 0.8304 & 1.4201 & 0.8115 & 1.3878 \\
\hline $\mathrm{LDP}_{4}: 4$ & 1.015 & 1.611 & 0.9800 & 1.5554 & 0.9615 & 1.5260 & 0.9422 & 1.4955 & 0.9222 & 1.4637 & 0.9012 & 1.4304 \\
\hline $\mathrm{LDP}_{4}: 5$ & 0.881 & 1.506 & 0.8506 & 1.4540 & 0.8345 & 1.4266 & 0.8178 & 1.3980 & 0.8004 & 1.3683 & 0.7822 & 1.3372 \\
\hline $\mathrm{LDP}_{4}: 6$ & 0.984 & 1.563 & 0.9500 & 1.5091 & 0.9321 & 1.4806 & 0.9135 & 1.4510 & 0.8940 & 1.4201 & 0.8737 & 1.3878 \\
\hline $\mathrm{LDP}_{4}: 7$ & 0.781 & 1.336 & 0.7540 & 1.2899 & 0.7398 & 1.2656 & 0.7250 & 1.2402 & 0.7096 & 1.2138 & 0.6935 & 1.1862 \\
\hline $\mathrm{LDP}_{4}: 8$ & 0.813 & 1.29 & 0.7849 & 1.2455 & 0.7701 & 1.2220 & 0.7547 & 1.1975 & 0.7387 & 1.1720 & 0.7219 & 1.1454 \\
\hline $\mathrm{LDPJ}_{4}: 1$ & 1.969 & 3.37 & 1.9010 & 3.2537 & 1.8652 & 3.1923 & 1.8279 & 3.1284 & 1.7890 & 3.0618 & 1.7483 & 2.9922 \\
\hline $\mathrm{LDPJ}_{4}: 2$ & 1.372 & 2.18 & 1.3247 & 2.1048 & 1.2997 & 2.0650 & 1.2737 & 2.0237 & 1.2465 & 1.9807 & 1.2182 & 1.9356 \\
\hline $\mathrm{LDPJ}_{4}: 3$ & 0.86 & 1.47 & 0.8303 & 1.4193 & 0.8147 & 1.3925 & 0.7984 & 1.3646 & 0.7814 & 1.3356 & 0.7636 & 1.3052 \\
\hline $\mathrm{LDPJ}_{4}: 4$ & 0.993 & 1.577 & 0.9587 & 1.5226 & 0.9406 & 1.4938 & 0.9218 & 1.4640 & 0.9022 & 1.4328 & 0.8817 & 1.4002 \\
\hline $\mathrm{LDPJ}_{4}: 5$ & 0.822 & 1.406 & 0.7936 & 1.3575 & 0.7787 & 1.3319 & 0.7631 & 1.3052 & 0.7468 & 1.2774 & 0.7299 & 1.2484 \\
\hline $\mathrm{LDPJ}_{4}: 6$ & 0.966 & 1.533 & 0.9327 & 1.4801 & 0.9151 & 1.4522 & 0.8968 & 1.4231 & 0.8777 & 1.3928 & 0.8577 & 1.3612 \\
\hline $\mathrm{LDPJ}_{4}: 7$ & - & - & - & - & - & - & - & - & - & - & - & - \\
\hline $\mathrm{LDPJ}_{4}: 8$ & - & - & - & - & - & - & - & - & - & - & - & - \\
\hline $\mathrm{LDP}_{8}: 1$ & 0.4640 & 0.7940 & 0.4480 & 0.7666 & 0.4395 & 0.7521 & 0.4307 & 0.7371 & 0.4216 & 0.7214 & 0.4120 & 0.7050 \\
\hline $\mathrm{LDP}_{8}: 2$ & 0.5920 & 0.9400 & 0.5716 & 0.9076 & 0.5608 & 0.8904 & 0.5496 & 0.8726 & 0.5379 & 0.8540 & 0.5256 & 0.8346 \\
\hline $\mathrm{LDP}_{8}: 3$ & 0.7750 & 1.3250 & 0.7483 & 1.2793 & 0.7341 & 1.2551 & 0.7194 & 1.2300 & 0.7041 & 1.2038 & 0.6881 & 1.1765 \\
\hline $\mathrm{LDP}_{8}: 4$ & 1.0410 & 1.6520 & 1.0051 & 1.5950 & 0.9861 & 1.5649 & 0.9664 & 1.5336 & 0.9458 & 1.5009 & 0.9243 & 1.4668 \\
\hline LDS :1 & 0.4930 & 0.8420 & 0.4760 & 0.8129 & 0.4670 & 0.7976 & 0.4577 & 0.7816 & 0.4479 & 0.7650 & 0.4377 & 0.7476 \\
\hline LDS :2 & 0.5190 & 0.8240 & 0.5011 & 0.7956 & 0.4916 & 0.7805 & 0.4818 & 0.7649 & 0.4715 & 0.7487 & 0.4608 & 0.7316 \\
\hline LDS :3 & 0.5830 & 0.9970 & 0.5629 & 0.9626 & 0.5523 & 0.9444 & 0.5412 & 0.9255 & 0.5297 & 0.9058 & 0.5176 & 0.8852 \\
\hline LDS :4 & 0.4930 & 0.8990 & 0.4760 & 0.8680 & 0.4670 & 0.8516 & 0.4577 & 0.8346 & 0.4479 & 0.8168 & 0.4377 & 0.7982 \\
\hline
\end{tabular}




\section{APPENDIX: H \\ Closed Form Series Solution Approach of One and Two Dimensional \\ Laminationed Composites}

\section{H.1 Introduction}

Series solution method (GangaRao, et al.,) assumes that a solution is a combination of Fourier series with undetermined coefficients and $n^{\text {th }}$ order polynomial series with unknown constants, where the value of $n$ depends on the order of the differential equation. Fourier series with undetermined coefficients will play a major role in a manner similar to displacement shape functions satisfying natural boundaries, while polynomial series with unknown constants will be satisfying actual boundary conditions of a boundary value problem in conjunction with Fourier series term. In our proposed method, the undetermined coefficients modifying displacement shape functions as product terms are simultaneously solved as functions of the undetermined Fourier coefficients and also satisfying the governing differential. The major objective herein is to extend a closed-form series solution approach proposed by authors regarding analysis of laminated composite beams and plates with arbitrary boundary conditions under out-of-plane loading.

\section{H.2 Basic Method}

Hiven a system of differential equations with boundary conditions, an assumed solution is a combination of Fourier series with undetermined coefficients and a complete set 
or $\mathrm{n}^{\text {th }}$ order polynomial series satisfying boundary conditions; where $\mathrm{n}$ is equal to the order of the differential to be solved through this procedure.

The undetermined coefficients are to be found by requiring that the trial solution satisfies the differential equation, leading to an infinite set of simultaneous equations with undetermined coefficients as unknowns. The infinite set of simultaneous equations can be truncated to a certain level, depending upon the accuracy requirements.

Consider the following static equations defined in a domain, $\Omega$ :

$R=w f$

Where $R$ denotes a general linear differential operator involving spatial derivatives of an unknown function $w$ to be determined from governing equation, and $f$ pertains to chosen function satisfying the prescribed boundary conditions of a boundary value problem. On the boundary $S$ of domain $\Omega, w$ will have to satisfy certain boundary conditions.

For one dimensional problems of small deformation analysis of determinate and indeterminate beams with arbitrary leading, assume Fourier series solution with $n-1^{\text {th }}$ order polynomials are:

$W(x)=\sum_{k=1,2,3 \ldots}^{\infty} w_{k}\left[\operatorname{Sin} \frac{k \pi \pi}{L}\right]+\sum_{j=1,2,3 \ldots}^{n} c_{j} x^{j-1}$

Satisfying the $\mathrm{n}$ boundary conditions results in $c_{j}$ of Equation (H.2) as a function of $w_{k}$ and the inhomogeneous quantities at the boundary. Therefore Equation (H.2) can be written as:

$W(x)=\sum_{k=1,2,3 \ldots}^{\infty} w_{k}\left[\operatorname{Sin} \frac{k \pi \pi}{L}+\psi_{k}(x)\right]$

Where, $\psi_{\mathrm{k}}$ is associated with the complete set of polynomials of order (n-1) and $L$ is the length of a beam. 
For two dimensional problems with small deformations, i.e., plate bending with arbitrary boundary conditions and arbitrary out-of-plane loading, a fourth order partial differential equation with two independent variables is valid. However, Fourier series solutions coupled with $(n-1)^{\text {th }}$ order polynomials in a plate (n equals to four in both directions) are assumed in a manner similar to beam problems; however, the assumed solution with two sets of trigonometric functions and two fourth order polynomials, as in Equation (H.3), are needed. Thus, a Fourier series solution with $(n-1)^{\text {th }}$ order polynomials is given as:

$$
W(x, y)=\sum_{k=1,2,3 \ldots}^{\infty} \sum_{m=1,2,3 \ldots}^{\infty} w_{k m}\left[\operatorname{Sin} \frac{k x \pi}{L}+\psi_{k}(x)\right]\left[\operatorname{Sin} \frac{m y \pi}{L}+\psi_{m}(y)\right]
$$

The unknown coefficients $w_{k}$ and $w_{k m}$ in Equations (H.3) and (H.4) corresponding to beam and plate bending problem, respectively, are solved by inserting assumed series solutions into the governing differential equation corresponding to that of a boundary value problem. After invoking orthogonal conditions of trigonometry functions, constants $w_{k}$ and $w_{k m}$ are determined.

To illustrate the methodology and convergence of series solutions, two cases, (bendinH of beams and plates) have been discussed below:

\section{H.3 One Dimensional Problem}

Long laminated composite beams with arbitrary boundary conditions under transverse loading are considered in this section. The governing differential equation is:

$$
\frac{\partial^{2} M_{x}}{\partial x^{2}}+q(x)=0
$$

Where, $M_{x}=$ bending moment and $q(x)$ is transverse loading. 
For constitutive relations, classical lamination plate theory (CLPT) is used to formulate stiffness of laminated composite materials. In addition, in-plane applied force is assumed to be zero. Bending-twisting coupling can be decoupled because deflection of a laminated composite beam is a function of span directional variable $(\mathrm{x})$. The compact form of laminated composite material stiffness and compliance is given below as:

$\left[\begin{array}{l}N \\ M\end{array}\right]=\left[\begin{array}{ll}A & B \\ B & D\end{array}\right]\left[\begin{array}{l}\varepsilon \\ \kappa\end{array}\right]$

Assuming in-plane loading to be zero

$$
\begin{aligned}
& {\left[\begin{array}{l}
\varepsilon \\
\kappa
\end{array}\right]=\left[\begin{array}{ll}
a & b \\
b & d
\end{array}\right]\left[\begin{array}{c}
0 \\
M
\end{array}\right]} \\
& d M=\kappa \\
& {\left[\begin{array}{l}
\kappa_{x} \\
\kappa_{y} \\
\kappa_{x y}
\end{array}\right]=\left[\begin{array}{lll}
d_{11} & d_{12} & d_{16} \\
d_{12} & d_{22} & d_{26} \\
d_{16} & d_{26} & d_{66}
\end{array}\right]\left[\begin{array}{c}
M_{x} \\
0 \\
0
\end{array}\right]} \\
& \kappa_{x}=d_{11} M_{x}
\end{aligned}
$$

Substituting $M_{x}$ from (Equation (H.10)) into the governing equation of beam (Equation (H.5)), yields:

$$
\begin{aligned}
& \frac{\partial^{2} M_{x}}{\partial x^{2}}=\frac{1}{d_{11}} \frac{\partial^{2} \kappa_{x}}{\partial x^{2}}=-q(x) \quad \text { where } \kappa_{x}=-\frac{\partial^{2} w^{0}}{\partial x^{2}} \\
& \frac{\partial^{4} w^{0}}{\partial x^{4}}=\frac{q(x)}{\left(d_{11}\right)^{-1}}
\end{aligned}
$$


An assumed series solution with arbitrary boundary conditions is:

$W(x)=\sum_{k=1,2,3, \ldots}^{\infty} W_{k}\left[\operatorname{Sink} \pi \frac{x}{L}+\left(C_{0}+C_{1} x+C_{2} x^{2}+C_{3} x^{3}\right)\right]$

Where, constants $C_{0}, C_{1}, C_{2}$ and $C_{3}$ are solved by satisfying boundary conditions of the problem and $\mathrm{L}$ is the length of a beam.

Substituting assumed series solution (Equation (H.13)) with polynomials satisfying arbitrary boundary conditions into Equation (H.12) Hives:

$d_{11}^{-1} \sum_{\mathrm{k}=1,2,3 \ldots}^{\infty} \mathrm{W}_{\mathrm{k}}\left[\left[\frac{\mathrm{k} \pi}{\mathrm{L}}\right]^{4} \operatorname{Sin} \mathrm{k} \pi \frac{\mathrm{x}}{\mathrm{L}}\right]=q(x)$

Applied loading $\mathrm{q}(\mathrm{x})$ is expanded into sine series and substituted into (Equation H.14) to find $W_{i}$ after invoking orthogonality conditions.

$W_{i}=\left[\frac{L}{i \pi}\right]^{4} \frac{q_{i}}{d_{11}^{-1}}$

Thus, the general deflection solution of long laminated composite beam is given as:

$W(x)=\sum_{i=1,2,3 \ldots}^{\infty}\left[\frac{L}{i \pi}\right]^{4} \frac{q_{i}}{d_{11}^{-1}}\left[\operatorname{Sini} \pi \frac{x}{L}+\left(C_{0}+C_{1} x+C_{2} x^{2}+C_{3} x^{3}\right)\right]$

Where, loading coefficient $q_{i}$ is obtained by expanding applied loading into sine series.

The following deflection solutions based on the proposed series solution of long laminated composite beams for several boundary and load conditions are given: 
1. Simple supports under uniform distribution load $q(x)=q_{0}$

$W(x)=\sum_{i=1,3 \ldots}^{\infty}\left[\frac{1}{i \pi}\right]^{5} \frac{4 q_{0} L^{4}}{d_{11}^{-1}}\left[\operatorname{Sin} i \pi \frac{x}{L}\right]$

2. Fix-end supports under linear distribution load $q(x)=q_{0}(1-x / L)$

$W(x)=\sum_{k=1,2,3 \ldots}^{\infty}\left[\frac{1}{i \pi}\right]^{5} \frac{2 q_{0} L^{4}}{d_{11}^{-1}}\left[\operatorname{Sin} i \pi \frac{x}{L}-\left(i \pi\left(1-\frac{x}{L}\right) \frac{x}{L}\right)\right]$

3. Fixed-pin supported beam under uniform distribution load $q(x)=q_{0}$

$W(x)=\sum_{k=1,3, \ldots}^{\infty}\left[\frac{1}{i \pi}\right]^{5} \frac{4 q_{0} L^{4}}{d_{11}^{-1}}\left[\operatorname{Sini} \pi \frac{x}{L}-\left(i \pi\left(\frac{x}{L}-\frac{3}{2}\left(\frac{x}{L}\right)^{2}+\frac{1}{2}\left(\frac{x}{L}\right)^{2}\right)\right)\right]$

4. Fixed-ends beam under half span of uniform distribution load $q(x)=q_{0}$

$$
\begin{aligned}
W(x)= & \frac{1}{d_{11}^{-1}} \sum_{i=1,3 \ldots}^{\infty} \frac{2 q_{0} L^{4}}{(i \pi)^{5}}\left[\operatorname{Sin}\left(\frac{i x \pi}{L}\right)-i \frac{x}{L}\left(1-\frac{x}{L}\right) \pi\right]+ \\
& \frac{1}{d_{11}^{-1}} \sum_{j=, 2,4 \ldots}^{\infty} \frac{2 q_{0} L^{4}}{(j \pi)^{5}}\left[\operatorname{Sin}\left(\frac{j x \pi}{L}\right)-j \frac{x}{L}\left(1-\frac{x}{L}\right)\left(1-\frac{2 x}{L}\right) \pi\right]
\end{aligned}
$$

To demonstrate applicability of our proposed method to a long laminated composite beam with carbon fiber lay up $\left[ \pm 45^{\mathrm{f}}{ }_{2} / 0_{6}\right]_{\mathrm{s}}$ by having $A_{11}=215.17 \mathrm{MN} / \mathrm{m}, A_{12}=32.74 \mathrm{MN} / \mathrm{m}$, $A_{22}=48.17 \mathrm{MN} / \mathrm{m}, A_{66}=36.01 \mathrm{MN} / \mathrm{m}, D_{11}=45.3 \mathrm{~N} . \mathrm{m}, D_{12}=19.52$ N.m, $D_{22}=25.26$ N.m, and $D_{66}=20.62$ N.m, $20 \mathrm{~mm}$ in width, total thickness of $2 \mathrm{~mm}$, span length of $200 \mathrm{~mm}$, and uniform distribution load $1 \mathrm{~N} / \mathrm{mm}$, deflections and bending moments are provided in Tables H.1. In addition, the data from the proposed technique are compared with the exact solution as shown in Table H.1. 
Table H.1 Deflection and Bending Moment of Long Laminated Composite Beams

\begin{tabular}{|c|c|c|c|c|c|c|}
\hline \multirow{2}{*}{ term } & \multicolumn{3}{|c|}{$\begin{array}{c}\text { Deflection (mm) } \\
\text { @ mid span }\end{array}$} & \multicolumn{3}{c|}{$\begin{array}{c}\text { Moment (N-m) } \\
\text { @ mid span }\end{array}$} \\
\cline { 2 - 7 } & $\begin{array}{c}\text { p-p } \\
\text { (uf) }\end{array}$ & $\begin{array}{c}\text { f-f } \\
\text { (uf) }\end{array}$ & $\begin{array}{c}\text { f-p } \\
\text { (uf) }\end{array}$ & $\begin{array}{c}\text { p-p } \\
\text { (uf) }\end{array}$ & $\begin{array}{c}\text { f-f } \\
\text { (uf) }\end{array}$ & $\begin{array}{c}\text { f-p } \\
\text { (uf) }\end{array}$ \\
\hline 1 & 34.6 & 7.42 & 14.22 & 5.16 & 1.875 & 2.69 \\
\hline 2 & 34.5 & 6.94 & 13.82 & 4.96 & 1.643 & 2.48 \\
\hline 3 & 34.5 & 6.92 & 13.79 & 5.01 & 1.679 & 2.51 \\
\hline 4 & 34.5 & 6.90 & 13.79 & 4.99 & 1.664 & 2.50 \\
\hline Exact & 34.5 & 6.90 & 13.79 & 5.00 & 1.667 & 2.50 \\
\hline
\end{tabular}

Note: $\mathrm{p}=$ pin support, $\mathrm{f}=$ fix support, $\mathrm{u}=$ uniform load, and $\mathrm{fl}=$ full span lenHth

For long laminated composite beams with first order shear deformation (FSDT), the governing differential equation is:

$$
\begin{aligned}
& \frac{\partial Q_{x}}{\partial x}+N+q(x, y)=0 \\
& \frac{\partial M_{x}}{\partial x}-Q_{x}=0
\end{aligned}
$$

Constitutive relations for the first order shear deformation theory (FSDT) are:

$$
\begin{aligned}
& {\left[\begin{array}{c}
\varepsilon \\
\partial \phi
\end{array}\right]=\left[\begin{array}{ll}
a & b \\
b & d
\end{array}\right]\left[\begin{array}{l}
N \\
M
\end{array}\right]} \\
& {\left[\begin{array}{l}
\phi_{x}^{0}+\theta_{x} \\
\phi_{y}^{0}+\theta_{y}
\end{array}\right]=K^{-1}\left[\begin{array}{ll}
a_{44} & a_{45} \\
a_{45} & a_{55}
\end{array}\right]\left[\begin{array}{c}
Q_{x} \\
Q_{y}
\end{array}\right]} \\
& {\left[\begin{array}{l}
\phi_{x}^{0}+\theta_{x} \\
\phi_{y}^{0}+\theta_{y}
\end{array}\right]=K^{-1}\left[\begin{array}{ll}
a_{44} & a_{45} \\
a_{45} & a_{55}
\end{array}\right]\left[\begin{array}{c}
Q_{x} \\
0
\end{array}\right]} \\
& \left(\phi_{x}^{0}+\theta_{x}\right)=K^{-1}\left(a_{44}\right) Q_{x}
\end{aligned}
$$


$\left(\phi_{x}^{0}+\frac{\partial w^{0}}{\partial x}\right)=K^{-1}\left(a_{44}\right) Q_{x}$

Assuming in-plane force $N=0$

$\left[\begin{array}{c}\varepsilon \\ \partial \phi\end{array}\right]=\left[\begin{array}{ll}a & b \\ b & d\end{array}\right]\left[\begin{array}{c}0 \\ M\end{array}\right]$

$b M=\varepsilon$

$d M=\partial \phi$

$\frac{\partial \phi_{x}}{\partial x}=d_{11} M_{x}$

Substituting Equations (H.26) and (H.31) into Equations (H.21) is given:

$\frac{\partial M_{x}}{\partial x}-Q_{x}=d_{11}^{-1} \frac{\partial^{2} \phi_{x}}{\partial x^{2}}-K\left(a_{44}^{-1}\right)\left(\phi_{x}^{0}+\frac{\partial w^{0}}{\partial x}\right)=0$

$\frac{\partial w^{0}}{\partial x}=\left(\frac{a_{44}}{K d_{11}} \frac{\partial^{2} \phi_{x}}{\partial x^{2}}-\phi_{x}^{0}\right)$

$\frac{\partial^{2} w^{0}}{\partial x^{2}}=\left(\frac{a_{44}}{K d_{11}} \frac{\partial^{3} \phi_{x}}{\partial x^{3}}-\frac{\partial \phi_{x}^{0}}{\partial x}\right)$

From Equations (H.21) and (H.26)

$\frac{\partial Q_{x}}{\partial x}=K\left(a_{44}^{-1}\right)\left(\frac{\partial \phi_{x}^{0}}{\partial x}+\frac{\partial^{2} w^{0}}{\partial x^{2}}\right)=-q(x)$

Substituting Equation (H.33) into (H.34) is given:

$$
\frac{\partial Q_{x}}{\partial x}=K\left(a_{44}^{-1}\right)\left(\frac{\partial \phi_{x}^{0}}{\partial x}+\frac{a_{44}}{K d_{11}} \frac{\partial^{3} \phi_{x}}{\partial x^{3}}-\frac{\partial \phi_{x}^{0}}{\partial x}\right)=-q(x)
$$


$d_{11}^{-1} \frac{\partial^{3} \phi_{x}}{\partial x^{3}}=-d_{11}^{-1} \frac{\partial^{4} W_{b}}{\partial x^{4}}=-q(x)$

From the above equation, it should be noted that $\phi_{\mathrm{x}}$ is only dependent of bending effect. Therefore, deflection solution due to bending effect is the same with deflection solution in the previous section.

$$
\begin{aligned}
& W_{b}(x)=\sum_{i=1,2,3 \ldots}^{\infty} W_{i}\left[\operatorname{Sini} \pi \frac{x}{L}+\left(C_{0}+C_{1} x+C_{2} x^{2}+C_{3} x^{3}\right)\right] \\
& W_{i}=\left[\frac{L}{i \pi}\right]^{4} \frac{q_{i}}{d_{11}^{-1}}
\end{aligned}
$$

Where, constants $C_{0}, C_{1}, C_{2}$, and $C_{3}$ are solved by satisfying boundary conditions of the problem and $L$ is the length of a beam.

From (Equation (H.33)), deflection of a beam due to bending and shear effect is given below:

$$
\begin{aligned}
& \frac{\partial^{2} w^{0}}{\partial x^{2}}=\left(\frac{a_{44}}{K d_{11}} \frac{\partial^{3} \phi_{x}}{\partial x^{3}}-\frac{\partial \phi_{x}^{0}}{\partial x}\right) \\
& \frac{\partial^{3} \phi_{x}}{\partial x^{3}}=-\frac{\partial^{4} W_{b}}{\partial x^{4}}=-\sum_{i=1,2,3 \ldots}^{\infty} \frac{q_{i}}{d_{11}^{-1}}\left[\frac{L}{i \pi}\right]^{4} \operatorname{Sini} \pi \frac{x}{L} \\
& \frac{\partial \phi_{x}}{\partial x}=-\frac{\partial^{2} W_{b}}{\partial x^{2}}=\sum_{i=1,2,3, \ldots}^{\infty} \frac{q_{i}}{d_{11}^{-1}}\left[\frac{L}{i \pi}\right]^{2}\left[\operatorname{Sin} k \pi \frac{x}{L}-2 C_{2}-6 C_{3} x\right]
\end{aligned}
$$

Substituting Equations (H.40) and (H.41) into Equation (H.39) is given as:

$$
\frac{\partial^{2} w^{0}}{\partial x^{2}}=\left(-\sum_{i=1,2,3 \ldots}^{\infty} \frac{q_{i}}{d_{11}^{-1}}\left[\frac{L}{i \pi}\right]^{4} \frac{a_{44}}{K d_{11}} \operatorname{Sini} \pi \frac{x}{L}-\sum_{i=1,2,3, \ldots}^{\infty} \frac{q_{i}}{d_{11}^{-1}}\left[\frac{L}{i \pi}\right]^{2}\left[\operatorname{Sini} \pi \frac{x}{L}-2 C_{2}-6 C_{3} x\right]\right)
$$


Assume Fourier series solution with $n-1^{\text {th }}$ order polynomials is:

$\mathrm{W}_{0}(\mathrm{x})=\mathrm{W}_{\mathrm{b}}(\mathrm{x})+\mathrm{W}_{\mathrm{s}}(\mathrm{x})=\sum_{n=1,2,3 \ldots}^{\infty} W_{i}\left[\operatorname{Sin} n \pi \frac{x}{L}+\left(C_{0}+C_{1} x+C_{2} x^{2}+C_{3} x^{3}\right)\right]$

Substituting Equation (H.43) into Equation (H.42) is Hiven as:

$$
\begin{aligned}
& \sum_{n=1,2,3 \ldots}^{\infty}\left[\frac{n \pi}{L}\right]^{2} w_{n}\left[\operatorname{Sin} n \pi \frac{x}{L}+\left(2 C_{2}+6 C_{3} x\right)\right]= \\
& \left(\sum_{i=1,2,3 \ldots}^{\infty} \frac{q_{m}}{d_{11}^{-1}}\left[\frac{L}{i \pi}\right]^{4} \frac{a_{44}}{K d_{11}} \operatorname{Sin} i \pi \frac{x}{L}+\sum_{i=1,2,3 \ldots}^{\infty} \frac{q_{i}}{d_{11}^{-1}}\left[\frac{L}{i \pi}\right]^{2}\left[\operatorname{Sin} i \pi \frac{x}{L}-2 C_{2}-6 C_{3} x\right]\right) \\
& {\left[\frac{i \pi}{L}\right]^{2} w_{i}+\sum_{n=1,2, \ldots}^{\infty}\left[\frac{2 i \pi}{L}\right] w_{n}\left[C_{2}(1-\operatorname{Cos} i \pi)-3 C_{3} L \operatorname{Cos} i \pi\right]=} \\
& \frac{q_{m}}{d_{11}^{-1}}\left[\frac{L}{i \pi}\right]^{2}-\frac{q_{m} a_{44}}{K}\left[\frac{L}{i \pi}\right]^{4}-\sum_{i=1,2,3 \ldots}^{\infty} \frac{q_{m}}{d_{11}^{-1}}\left[\frac{L}{i \pi}\right]^{2}\left[C_{2}(1-\operatorname{Cos} i \pi)-3 C_{3} L \operatorname{Cos} i \pi\right]
\end{aligned}
$$

Solving for coefficients (w) from (Equation (H.45)) yields deflection coefficient of the proposed series solution under bending and shear effects.

For bending strip plate (length $(y)>>$ width $(x)$ ) problems, the deflection shape of a strip is a cylindrical surface and only a function of a shortest direction (x). Then, all derivatives of the governing equations with independent y variable are zero. The governing plate equations are simplified into the governing equation of a rectangular plane strain bending plate problem as well as bending beam problem.

$$
\begin{aligned}
& \frac{\partial N_{x}}{\partial x}=0 \\
& \frac{\partial N_{x y}}{\partial x}=0 \\
& \frac{\partial^{2} M_{x}}{\partial x^{2}}+q(x, y)=0
\end{aligned}
$$


Classical lamination plate theory (CLPT) is used to formulate laminated composite plate strip stiffness, utilizing classical constitutive relations as:

$\left[\begin{array}{l}N_{x} \\ N_{y} \\ N_{x y} \\ M_{x} \\ M_{y} \\ M x_{y}\end{array}\right]=\left[\begin{array}{llllll}A_{11} & A_{12} & A_{16} & B_{11} & B_{12} & B_{16} \\ A_{12} & A_{22} & A_{26} & B_{12} & B_{22} & B_{26} \\ A_{16} & A_{26} & A_{66} & B_{16} & B_{26} & B_{66} \\ B_{11} & B_{12} & B_{16} & D_{11} & D_{12} & D_{16} \\ B_{12} & B_{22} & B_{26} & D_{12} & D_{22} & D_{26} \\ B_{16} & B_{26} & B_{66} & D_{16} & D_{26} & D_{66}\end{array}\right]\left[\begin{array}{c}\varepsilon_{x}^{0} \\ \varepsilon_{y}^{0} \\ \gamma_{x y}^{0} \\ \kappa_{x}^{0} \\ \kappa_{y}^{0} \\ \kappa_{x y}^{0}\end{array}\right]$

From the governing equations (Equation (H.46) of bending strip plate problem)

$$
\begin{aligned}
& \frac{\partial N_{x}}{\partial x}=\frac{\partial\left(A_{11} \varepsilon_{x}^{0}+A_{16} \gamma_{x y}^{0}+B_{11} \kappa_{x}^{0}\right)}{\partial x}=A_{11} \frac{\partial^{2} u^{0}}{\partial x^{2}}+A_{16} \frac{\partial^{2} v^{0}}{\partial x^{2}}-B_{11} \frac{\partial^{3} w^{0}}{\partial x^{3}}=0 \\
& \frac{\partial N_{x y}}{\partial x}=\frac{\partial\left(A_{16} \varepsilon_{x}^{0}+A_{66} \gamma_{x y}^{0}+B_{11} \kappa_{x}^{0}\right)}{\partial x}=A_{16} \frac{\partial^{2} u^{0}}{\partial x^{2}}+A_{66} \frac{\partial^{2} v^{0}}{\partial x^{2}}-B_{16} \frac{\partial^{3} w^{0}}{\partial x^{3}}=0 \\
& \frac{\partial^{2} M_{x}}{\partial x^{2}}=\frac{\partial^{2}\left(B_{11} \varepsilon_{x}^{0}+B_{16} \varepsilon_{x y}^{0}+D_{11} \kappa_{x}^{0}\right)}{\partial x^{2}}=B_{11} \frac{\partial^{3} u^{0}}{\partial x^{3}}+B_{16} \frac{\partial^{3} v^{0}}{\partial x^{3}}-D_{11} \frac{\partial^{4} w^{0}}{\partial x^{4}}=-q(x)
\end{aligned}
$$

From Equations (H.48) and (H.49)

$$
\begin{aligned}
& \frac{\partial^{2} u^{0}}{\partial x^{2}}=\left(\frac{B_{11} A_{66}-B_{16} A_{16}}{A_{11} A_{66}-A_{16}^{2}}\right) \frac{\partial^{3} w^{0}}{\partial x^{3}} \\
& \frac{\partial^{2} v^{0}}{\partial x^{2}}=-\left(\frac{B_{11} A_{16}-B_{16} A_{11}}{A_{11} A_{66}-A_{16}^{2}}\right) \frac{\partial^{3} w^{0}}{\partial x^{3}} \\
& {\left[D_{11}+B_{16}\left(\frac{B_{11} A_{16}-B_{16} A_{11}}{A_{11} A_{66}-A_{16}^{2}}\right)-B_{11}\left(\frac{B_{11} A_{66}-B_{16} A_{16}}{A_{11} A_{66}-A_{16}^{2}}\right)\right] \frac{\partial^{4} w^{0}}{\partial x^{4}}=q(x)} \\
& {\left[D_{11}+B_{16}\left(\frac{B_{11} A_{16}-B_{16} A_{11}}{A_{11} A_{66}-A_{16}^{2}}\right)-B_{11}\left(\frac{B_{11} A_{66}-B_{16} A_{16}}{A_{11} A_{66}-A_{16}^{2}}\right)\right]=E^{*}}
\end{aligned}
$$




$$
\left[E^{*}\right] \frac{\partial^{4} w^{0}}{\partial x^{4}}=q(x)
$$

Substituting assumed Fourier series solution with cum polynomials that satisfied boundary conditions, into Equation (H.55) and expanding applied loading into Fourier series for shear-beam yields:

$$
W_{k}=\left[\frac{L}{i \pi}\right]^{4} \frac{q_{i}}{E^{*}}
$$

Then, deflection of a laminate composite strip (plate) is given below:

$$
W(x)=\sum_{i=1,2,3 \ldots}^{\infty}\left[\frac{L}{i \pi}\right]^{4} \frac{q_{i}}{E^{*}}\left[\operatorname{Sin} i \pi \frac{x}{L}+\left(C_{0}+C_{1} x+C_{2} x^{2}+C_{3} x^{3}\right)\right]
$$

It should be noted that the proposed series solution of a composite plate is written in the same form as those of composite beam except for flexural stiffness. To demonstrate applicability of our proposed method to a laminated composite beam with lay up $\left[ \pm 45_{2}^{\mathrm{f}} / 0_{6}\right]_{\mathrm{s}}$ by having $A_{11}=215.17 \mathrm{MN} / \mathrm{m}, A_{12}=32.74 \mathrm{MN} / \mathrm{m}, A_{22}=48.17 \mathrm{MN} / \mathrm{m}, A_{66}=36.01 \mathrm{MN} / \mathrm{m}, D_{11}=$ 45.3 N.m, $D_{12}=19.52$ N.m, $D_{22}=25.26$ N.m, and $D_{66}=20.62$ N.m, $200 \mathrm{~mm}$ in width, total thickness of $2 \mathrm{~mm}$, and uniform distribution load $1 \mathrm{~N} / \mathrm{mm}$, deflections are provided in Table H.2. In addition, the data from the proposed technique are compared with the exact solution as shown in Tables H.2. 
Table H.2 Deflection and Bending Moment of Strip Laminated Composite Plate

\begin{tabular}{|c|c|c|c|c|c|c|c|c|}
\hline \multirow[t]{2}{*}{ term } & \multicolumn{4}{|c|}{$\begin{array}{c}\text { Deflection (mm) } \\
\text { @ mid span }\end{array}$} & \multicolumn{4}{|c|}{$\begin{array}{c}\text { Moment (N-m) } \\
\text { @ mid span }\end{array}$} \\
\hline & $\begin{array}{l}\text { p-p } \\
\text { (ul) }\end{array}$ & $\begin{array}{c}\text { f-f } \\
\text { (ul) }\end{array}$ & $\begin{array}{l}\text { f-p } \\
\text { (ul) }\end{array}$ & $\begin{array}{l}\text { f-f } \\
\text { (hl) }\end{array}$ & $\begin{array}{l}\text { f-f } \\
\text { (ul) }\end{array}$ & $\begin{array}{l}\text { f-p } \\
\text { (ul) }\end{array}$ & $\begin{array}{l}\text { f-p } \\
\text { (ul) }\end{array}$ & $\begin{array}{l}f-f \\
\text { (hl) }\end{array}$ \\
\hline 1 & 4.62 & 0.990 & 1.897 & 0.495 & 5.16 & 1.875 & 2.69 & 0.938 \\
\hline 2 & 4.60 & 0.927 & 1.845 & 0.463 & 4.96 & 1.643 & 2.48 & 0.822 \\
\hline 3 & 4.60 & 0.922 & 1.841 & 0.461 & 5.01 & 1.679 & 2.51 & 0.839 \\
\hline 4 & 4.60 & 0.920 & 1.840 & 0.460 & 4.99 & 1.664 & 2.50 & 0.832 \\
\hline Exact & 4.60 & 0.920 & 1.840 & 0.460 & 5.00 & 1.667 & 2.50 & 0.833 \\
\hline
\end{tabular}

Note: $\mathrm{p}=$ pin support, $\mathrm{f}=$ fix support, $\mathrm{u}=$ uniform load, $\mathrm{fl}=$ full span lenHth and $\mathrm{hl}=$ half span length

\section{H.4 Two Dimensional Problem}

Laminated composite rectangular plates with arbitrary boundary conditions under transverse loading are considered in this section. The governing differential equation of a rectangular plate is:

$$
\frac{\partial^{2} M_{x}}{\partial x^{2}}+2 \frac{\partial^{2} M_{x y}}{\partial x y}+\frac{\partial^{2} M_{y}}{\partial y^{2}}+q(x, y)=0
$$

Where, $q(x, y)=$ applied transverse force.

For constitutive relations, classical lamination plate theory (CLPT) is used to formulate laminated composite rectangular plate stiffness. To decoupling between in-plane and out-of -plane deformation, symmetrical lay up is considered

$$
\left[\begin{array}{l}
M_{x} \\
M_{y} \\
M_{x y}
\end{array}\right]=\left[\begin{array}{lll}
D_{11} & D_{12} & D_{16} \\
D_{12} & D_{22} & D_{26} \\
D_{16} & D_{26} & D_{66}
\end{array}\right]\left[\begin{array}{c}
\kappa_{x}^{0} \\
\kappa_{y}^{0} \\
\kappa_{x y}^{0}
\end{array}\right]
$$


Therefore, coupling between in-plane and out-of-plane deformations do not exist for this laminate plate.

$$
\begin{aligned}
& M_{x}=D_{11} \kappa_{x}^{0}+D_{12} \kappa_{y}^{0}+D_{16} \kappa_{x y}^{0}=-D_{11} \frac{\partial^{2} w^{0}}{\partial x^{2}}-D_{12} \frac{\partial^{2} w^{0}}{\partial y^{2}}-2 D_{16} \frac{\partial^{2} w^{0}}{\partial x \partial y} \\
& M_{y}=D_{12} \kappa_{x}^{0}+D_{22} \kappa_{y}^{0}+D_{26} \kappa_{x y}^{0}=-D_{12} \frac{\partial^{2} w^{0}}{\partial x^{2}}-D_{22} \frac{\partial^{2} w^{0}}{\partial y^{2}}-2 D_{26} \frac{\partial^{2} w^{0}}{\partial x \partial y} \\
& M_{x y}=D_{16} \kappa_{x}^{0}+D_{26} \kappa_{y}^{0}+D_{66} \kappa_{x y}^{0}=-D_{16} \frac{2 \partial^{2} w^{0}}{\partial x^{2}}-D_{26} \frac{\partial^{2} w^{0}}{\partial y^{2}}-2 D_{66} \frac{\partial^{2} w^{0}}{\partial x \partial y}
\end{aligned}
$$

Substituting Equation (H.59) into the governing equation of plate (Equation (H.60)) is given:

$$
D_{11} \frac{\partial^{4} w^{0}}{\partial x^{4}}+4 D_{16} \frac{\partial^{4} w^{0}}{\partial x^{3} \partial y}+2\left(D_{12}+2 D_{16}\right) \frac{\partial^{4} w^{0}}{\partial x^{2} \partial y^{2}}+4 D_{26} \frac{\partial^{4} w^{0}}{\partial x^{4}}+D_{22} \frac{\partial^{4} w^{0}}{\partial x \partial y^{3}}=q(x, y)
$$

For two dimensional problems as in terms of small deformation analysis of a plate with arbitrary boundary conditions and arbitrary loading, Fourier series solutions coupled with $(n-1)^{\text {th }}$ order polynomials (in a plate $\mathrm{n}$ equals to four in both directions) are assumed in a manner similar to beam problems; however, the assumed solution with two sets of trigonometric functions and two fourth order polynomials are needed to solve the problem. Thus, a Fourier series solution with $(\mathrm{n}-1)^{\text {th }}$ order polynomials is given as:

$$
W(x, y)=\sum_{k=1,2,3 \ldots}^{\infty} \sum_{m=1,2,3 \ldots}^{\infty} w_{k l}\left[\operatorname{Sin} \frac{k x \pi}{a}+\psi_{k}(x)\right]\left[\operatorname{Sin} \frac{m y \pi}{b}+\psi_{L}(y)\right]
$$

The unknown coefficients $w_{k l}$ are solved by inserting assumed series solutions into the governing differential equations corresponding to each problem. After invoking orthogonal conditions of trigonometry functions, constants $w_{k}$ and $w_{k l}$ are determined.

$$
W(x, y)=\sum_{k=1,2,3 \ldots m=1,2,3 \ldots}^{\infty} \sum_{k m}^{\infty}\left[\operatorname{Sin} \frac{k x \pi}{a}+C_{0}+C_{1} x+C_{2} x^{2}+C_{3} x^{3}\right]\left[\operatorname{Sin} \frac{m y \pi}{b}+C_{4}+C_{5} y+C_{6} y^{2}+C_{7} y^{3}\right]
$$




$$
\begin{aligned}
& \frac{\partial^{4} w}{\partial x^{4}}=\sum_{\mathrm{k}=1,2,3}^{\infty} \sum_{m=1,2,3 \ldots}^{\infty} \mathrm{w}_{\mathrm{k} m}\left(\frac{\mathrm{k} \pi}{\mathrm{a}}\right)^{4}\left[\operatorname{Sin} \frac{\mathrm{k} \pi \mathrm{x}}{\mathrm{a}}\right]\left[\operatorname{Sin} \frac{m \pi \mathrm{y}}{\mathrm{b}}+\mathrm{C}_{4}+\mathrm{C}_{5} y+\mathrm{C}_{6} \mathrm{y}^{2}+\mathrm{C}_{7} \mathrm{y}^{3}\right] \\
& \frac{\partial^{4} w}{\partial x^{3} \partial y}=\sum_{\mathrm{k}=1,2,3 . m=1,2,3 \ldots}^{\infty} \sum_{\mathrm{k} m}^{\infty}\left[-\left(\frac{\mathrm{k} \pi}{\mathrm{a}}\right)^{3} \operatorname{Cos} \frac{\mathrm{k} \pi \mathrm{x}}{\mathrm{a}}+6 \mathrm{C}_{3}\right]\left[\left(\frac{m \pi}{\mathrm{b}}\right) \operatorname{Cos} \frac{m \pi \mathrm{y}}{\mathrm{b}}+\mathrm{C}_{5}+2 \mathrm{C}_{6} \mathrm{y}+3 \mathrm{C}_{7} \mathrm{y}^{2}\right] \\
& \left.\frac{\partial^{4} w}{\partial x^{2} \partial y^{2}}=\sum_{\mathrm{k}=1,2,3, m=1,2,3 \ldots}^{\infty} \sum_{\mathrm{k} m}^{\infty}\left[\frac{\mathrm{k} \pi}{\mathrm{a}}\right)^{2} \operatorname{Sin} \frac{\mathrm{k} \pi \mathrm{x}}{\mathrm{a}}+2 \mathrm{C}_{2}+6 \mathrm{C}_{3} \mathrm{x}\right]\left[\left(\frac{m \pi}{\mathrm{b}}\right)^{2} \operatorname{Sin} \frac{m \pi \mathrm{y}}{\mathrm{b}}+2 \mathrm{C}_{6}+6 \mathrm{C}_{7} \mathrm{y}\right] \\
& \left.\frac{\partial^{4} w}{\partial x \partial y^{3}}=\sum_{\mathrm{k}=1,2,3 . m=1,2,3 \ldots}^{\infty} \sum_{\mathrm{k} m}^{\infty}\left[\frac{\mathrm{k} \pi}{\mathrm{a}}\right) \operatorname{Cos} \frac{\mathrm{k} \pi \mathrm{x}}{\mathrm{a}}+\mathrm{C}_{1}+2 \mathrm{C}_{2} x+3 \mathrm{C}_{3} \mathrm{x}_{3}{ }_{3}\right]\left[-\left(\frac{m \pi}{\mathrm{b}}\right)^{3} \operatorname{Cos} \frac{m \pi \mathrm{y}}{\mathrm{b}}+6 \mathrm{C}_{7}\right] \\
& \frac{\partial^{4} w}{\partial y^{4}}=\sum_{\mathrm{k}=1,2,3 . . .}^{\infty} \sum_{m=1,2,3 \ldots}^{\infty} \mathrm{w}_{\mathrm{k} m}\left[\operatorname{Sin} \frac{\mathrm{k} \pi \mathrm{x}}{\mathrm{a}}+\mathrm{C}_{0}+\mathrm{C}_{1} x+\mathrm{C}_{2} \mathrm{x}^{2}+\mathrm{C}_{3} \mathrm{x}^{3}\right]\left(\frac{m \pi}{\mathrm{b}}\right)^{4}\left[\operatorname{Sin} \frac{m \pi \mathrm{y}}{\mathrm{b}}\right]
\end{aligned}
$$

Substituting Equations (H.64) through (H.68) into Equation (H.63), expanding applied loading into sine series, and applying orthogonality conditions are given: 
$\frac{a b}{4}\left[D_{11}\left(\frac{i \pi}{a}\right)^{4}+2\left(D_{12}+2 D_{66}\right)\left(\frac{i \pi}{a}\right)^{2}\left(\frac{j \pi}{b}\right)^{2}+D_{22}\left(\frac{j \pi}{b}\right)^{4}\right] w_{i j}+$

$D_{11} \frac{a b}{2} \sum_{m=1,2,3 \ldots}^{\infty} w_{i m}\left(\frac{i \pi}{a}\right)^{4}\left(\frac{1}{j \pi}\right)^{3}\left[(1-\operatorname{Cos} j \pi)(j \pi)^{2} C_{4}-b\left(2 b C_{6}+\operatorname{Cosj} \pi\left(-2 b C_{6}+(j \pi)^{2}\left(C_{5}+b C_{6}\right)+b^{2}\left(-6+(j \pi)^{2} C_{7}\right)\right)\right)\right]+$

$D_{22} \frac{a b}{2} \sum_{k=1,2,3 \ldots}^{\infty} w_{k j}\left(\frac{j \pi}{b}\right)^{4}\left(\frac{1}{i \pi}\right)^{3}\left[(1-\operatorname{Cos} k \pi)(i \pi)^{2} C_{0}-a\left(2 a C_{2}+\operatorname{Cosi} \pi\left(-2 a C_{2}+(i \pi)^{2}\left(C_{1}+a C_{2}\right)+b^{2}\left(-6+(i \pi)^{2} C_{3}\right)\right)\right)\right]+$

$-2\left(D_{12}+2 D_{66}\right) a b \sum_{k=1,2,3 \ldots}^{\infty} w_{k j}\left(\frac{j \pi}{b}\right)^{2}\left(\frac{1}{i \pi}\right)\left[C_{2}-\operatorname{Cosi} \pi\left(C_{2}+3 a C_{3}\right)\right]+$

$-2\left(D_{12}+2 D_{66}\right) a b \sum_{m=1,2,3 \ldots}^{\infty} w_{i m}\left(\frac{i \pi}{a}\right)^{2}\left(\frac{1}{j \pi}\right)\left[C_{6}-C_{0 s j} \pi\left(C_{6}+3 b C_{7}\right)\right]+$

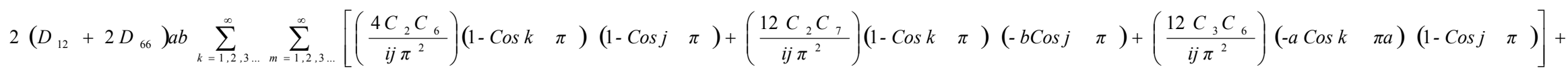

$2\left(D_{12}+2 D_{66}\right)(a b)^{2} \sum_{k=1,2,3 \ldots}^{\infty} \sum_{m=1,2,3 \ldots}^{\infty} w_{k m}\left(\frac{36 C_{3} C_{7}}{i j \pi^{2}}\right)(\operatorname{Cos} k \pi C)(\operatorname{Cos} j \pi C)+$

$-4 D_{16} \sum_{k}^{\infty} \sum_{m}^{\infty}\left(\frac{k \pi}{a}\right)^{3}\left(\frac{m \pi}{b}\right)\left[\frac{a(1-\operatorname{Cos}(i-k) \pi)}{2(i-k) \pi}+\frac{a(1-\operatorname{Cos}(i+k) \pi)}{2(i+k) \pi}\right]\left[\frac{b(1-\operatorname{Cos}(j-m) \pi)}{2(j-m) \pi}+\frac{b(1-\operatorname{Cos}(j+m) \pi)}{2(j+m) \pi}\right] w_{k m}$

$-4 D_{16} \sum_{k}^{\infty} \sum_{m}^{\infty}\left(\frac{k \pi}{a}\right)^{3}\left[\frac{a(1-\operatorname{Cos}(i-k) \pi)}{2(i-k) \pi}+\frac{a(1-\operatorname{Cos}(i+k) \pi)}{2(i+k) \pi}\right]\left[\frac{b\left(\left(j \pi j^{2} C_{5}-6 b^{2} C_{7}\right)\right.}{\left(j \pi j j^{3}\right.}+\frac{b \operatorname{Cos}\left(j-\pi o\left(\left(j \pi j{ }^{2} C_{5}+2 b\left(j \pi\left(^{2} C_{6}-6 b^{2} C_{7}+3\left(b j \pi b^{2} C_{7}\right)\right.\right.\right.\right.\right.}{\left(j \pi j{ }^{3}\right.}\right] w_{k m}$

$-4 D_{16} \sum_{k}^{\infty} \sum_{m}^{\infty}\left(\frac{m \pi}{b}\right)\left[\frac{a(1-\operatorname{Cos}(i \pi o)}{i \pi}\right]\left[\frac{b(1-\operatorname{Cos}(j-m) \pi)}{2(j-m) \pi}+\frac{b(1-\operatorname{Cos}(j+m) \pi)}{2(j+m) \pi}\right] 6 C_{3} w_{k m}$

$-4 D_{16} \sum_{k}^{\infty} \sum_{m}^{\infty}\left[\frac{a(1-\operatorname{Cos}(i \pi)}{i \pi}\right]\left[\frac{b\left(\left(j \pi j{ }^{2} C_{5}-6 b^{2} C_{7}\right)\right.}{\left(j \pi j^{3}\right.}-\frac{b \operatorname{Cos}\left(j \pi o\left(j \pi j{ }^{2} C_{5}+2 b\left(j \pi\left(^{2} C_{6}-6 b^{2} C_{7}+3\left(b j \pi b^{2} C_{7}\right)\right.\right.\right.\right.}{j \pi j{ }^{3}}\right] 6 C_{3} w_{k m}$

$-4 D_{26} \sum_{k}^{\infty} \sum_{m}^{\infty}\left(\frac{k \pi}{a}\right)\left(\frac{m \pi}{b}\right)^{3}\left[\frac{a(1-\operatorname{Cos}(i-k) \pi)}{2(i-k) \pi}+\frac{a(1-\operatorname{Cos}(i+k) \pi)}{2(i+k) \pi}\right]\left[\frac{b(1-\operatorname{Cos}(j-m) \pi)}{2(j-m) \pi}+\frac{b(1-\operatorname{Cos}(j+m) \pi)}{2(j+m) \pi}\right] w_{k m}$

$-4 D_{26} \sum_{k}^{\infty} \sum_{m}^{\infty}\left(\frac{m \pi}{b}\right)^{3}\left[\frac{b(1-\operatorname{Cos}(j-m) \pi)}{2(j-m) \pi}+\frac{b(1-\operatorname{Cos}(j+m) \pi)}{2(j+m) \pi}\right]\left[\frac{a\left(\left(i \pi i^{2} C_{1}-6 a^{2} C_{3}\right)\right.}{\left(i \pi i^{3}\right.}+\frac{a \operatorname{Cos}\left(i \pi^{3}\left(\left(i \pi i^{2} C_{1}+2 a\left(i \pi\left(^{2} C_{2}-6 b^{2} C_{3}+3\left(a i \pi a^{2} C_{3}\right)\right.\right.\right.\right.\right.}{\left(i \pi i{ }^{3}\right.}\right] w_{k m}$

$-4 D_{26} \sum_{k}^{\infty} \sum_{m}^{\infty}\left(\frac{k \pi}{a}\right)\left[\frac{b(1-\operatorname{Cos}(j-\pi o)}{j \pi}\right]\left[\frac{a(1-\operatorname{Cos}(i-k) \pi)}{2(i-k) \pi}+\frac{a(1-\operatorname{Cos}(i+k) \pi)}{2(i+k) \pi}\right] 6 C_{7} w_{k m}$

$-4 D_{26} \sum_{k}^{\infty} \sum_{m}^{\infty}\left[\frac{a(1-\operatorname{Cos}(j \pi))}{j \pi}\right]\left[\frac{a\left((i \pi)^{2} C_{1}-6 a^{2} C_{3}\right)}{(i \pi)^{3}}-\frac{a \operatorname{Cos}(i \pi)\left((i \pi)^{2} C_{5}+2 a(i \pi)^{2} C_{2}-6 a^{2} C_{3}+3(a i \pi)^{2} C_{3}\right)}{(i \pi)^{3}}\right] 6 C_{7} w_{k m}$

$=\mathrm{q}_{i j} \frac{a b}{4}$ 
If bending-twisting couplings are neglected, the above general deflection solution is simplified and deflection solution of laminated composite rectangular plates under out-of plane loading and several boundary conditions are given below:

1. Simple-Simple-Simple-Simple:

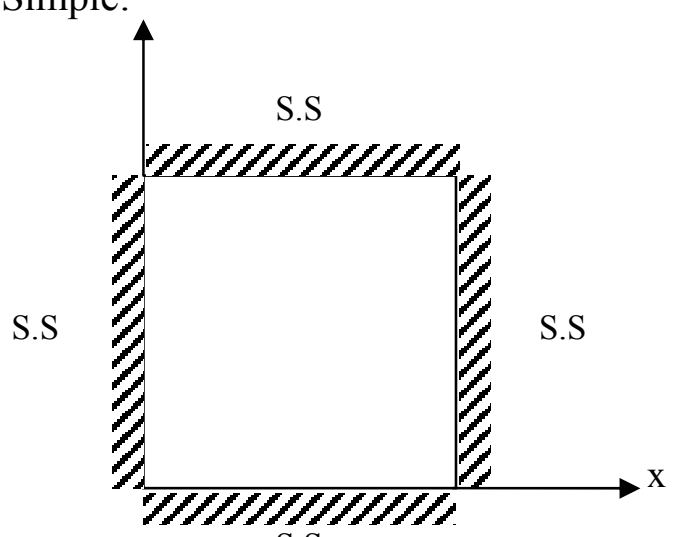

$\mathrm{S} . \mathrm{S}$

$$
\begin{aligned}
& W(x, y)=\sum_{k=1,3 \ldots}^{\infty} \sum_{l=1,3 \ldots}^{\infty} w_{k m}\left[\operatorname{Sin} \frac{k x \pi}{a}\right]\left[\operatorname{Sin} \frac{m y \pi}{b}\right] \\
& w_{k m}=\frac{q_{k m}}{D_{11}\left(\frac{k \pi}{a}\right)^{4}+2\left(D_{12}+2 D_{66}\right)\left(\frac{k m \pi^{2}}{a b}\right)^{2}+D_{22}\left(\frac{m \pi}{b}\right)^{4}}
\end{aligned}
$$

2. Simple-Fix-Simple-Fix:

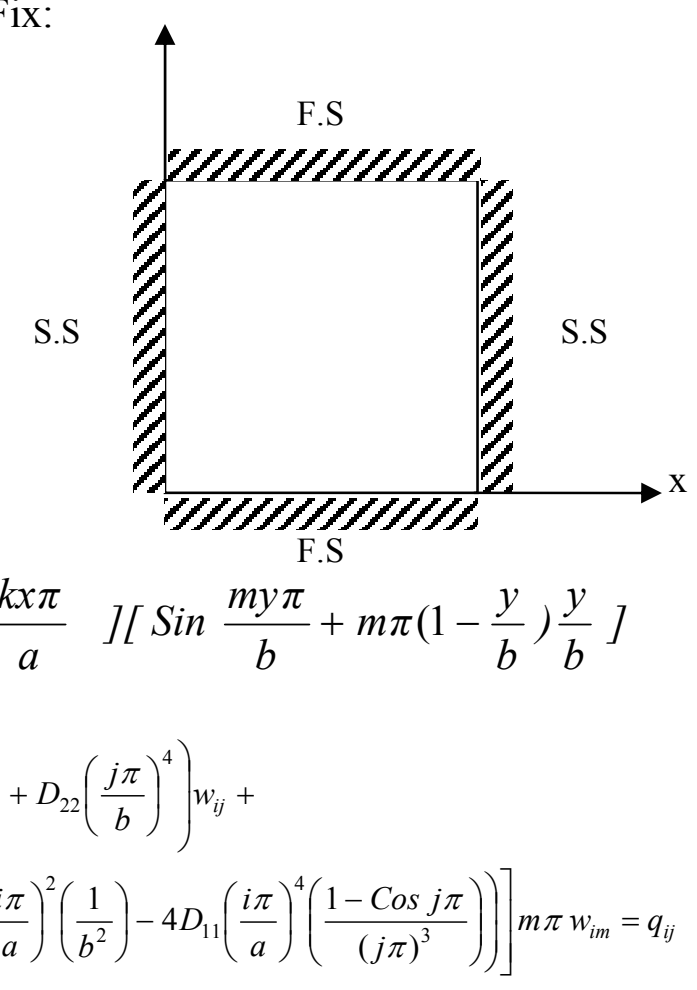


3. Simple-Fix- Simple-Simple:

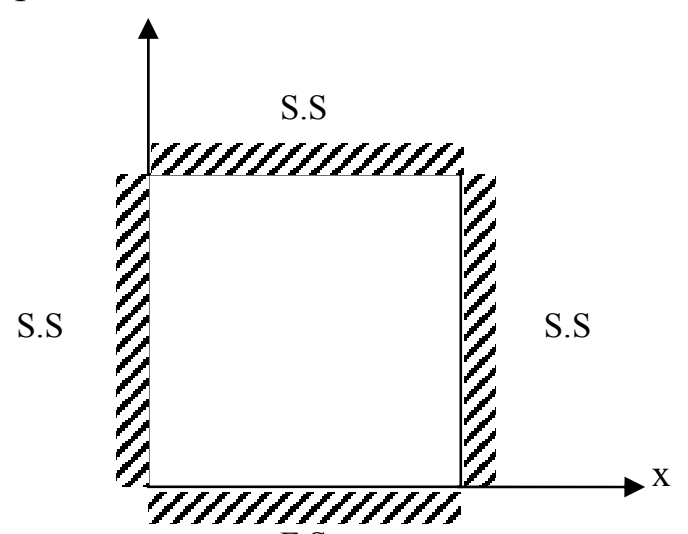

F.S

$$
\begin{aligned}
& W(x, y)=\sum_{k=1}^{\infty} \sum_{m=1 . .}^{\infty} w_{k m}\left[\operatorname{Sin} \frac{k x \pi}{a}\right]\left[\operatorname{Sin} \frac{m y \pi}{b}+m \pi\left(1-\frac{2 y}{b}\right)\left(1-\frac{y}{b}\right) \frac{y}{b}\right] \\
& \frac{a b}{4}\left(D_{11}\left(\frac{i \pi}{a}\right)^{4}+2\left(D_{12}+2 D_{66}\right)\left(\frac{i j \pi^{2}}{a b}\right)^{2}+D_{22}\left(\frac{j \pi}{b}\right)^{4}\right) w_{i j}+ \\
& -\sum_{m=1, . .}^{\infty}\left[\left(12\left(D_{12}+2 D_{66}\right)\left(\frac{1+\operatorname{Cosj} \pi}{b j \pi}\right)\left(\frac{i \pi}{a}\right)^{4}\left(\frac{a}{2}\right)-6 D_{11}\left(\frac{i \pi}{a}\right)^{4}\left(\frac{a b}{2}\right)\left(\frac{1+\operatorname{Cosj} \pi}{(j \pi)^{3}}\right)\right)\right] m \pi w_{i m}=\frac{a b}{4} q_{i j}
\end{aligned}
$$

4. Fix-Fix-Simple-Simple supports

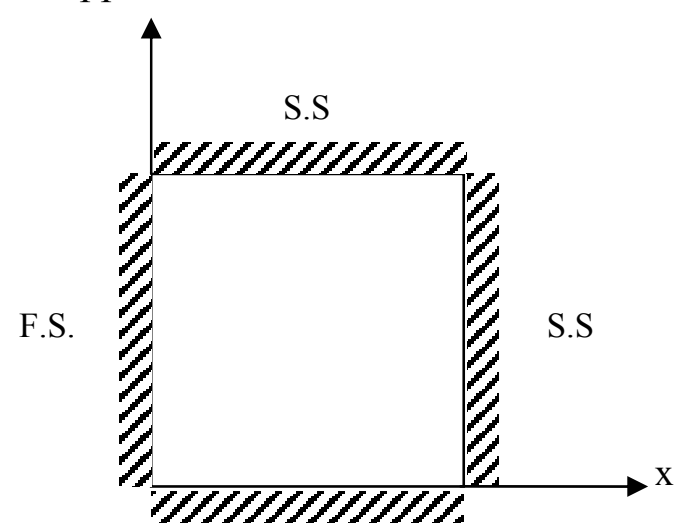

F.S

$$
\begin{aligned}
& \mathrm{W}(\mathrm{x}, \mathrm{y})=\sum_{k=1}^{\infty} \sum_{m=1 . .}^{\infty} w_{k m}\left[\operatorname{Sin} \frac{k x \pi}{a}+k \pi\left(1-\frac{2 x}{a}\right)\left(1-\frac{x}{a}\right) \frac{x}{a}\right]\left[\operatorname{Sin}^{m} \frac{m \pi}{b}+m \pi\left(1-\frac{2 y}{b}\right)\left(1-\frac{y}{b}\right) \frac{y}{b}\right] \\
& \frac{a b}{4}\left(D_{11}\left(\frac{i \pi}{a}\right)^{4}+2\left(D_{12}+2 D_{66}\right)\left(\frac{i j \pi^{2}}{a b}\right)^{2}+D_{22}\left(\frac{j \pi}{b}\right)^{4}\right) w_{i j}+ \\
& -\sum_{m=1, . . .}^{\infty}\left[\left(12\left(D_{12}+2 D_{66}\right)\left(\frac{i \pi}{a}\right)^{2}\left(\frac{a}{2}\right)\left(\frac{1+\operatorname{Cos} j \pi}{b j \pi}\right)-6 D_{11}\left(\frac{i \pi}{a}\right)^{4}\left(\frac{a b}{2}\right)\left(\frac{1+\operatorname{Cos} j \pi}{(j \pi)^{3}}\right)\right)\right] m \pi w_{i m} \\
& -\sum_{k=1,,}^{\infty}\left[\left(12\left(D_{12}+2 D_{66}\right)\left(\frac{j \pi}{b}\right)^{2}\left(\frac{b}{2}\right)\left(\frac{1+\operatorname{Cosi} \pi}{a i \pi}\right)-6 D_{22}\left(\frac{j \pi}{b}\right)^{4}\left(\frac{a b}{2}\right)\left(\frac{1+\operatorname{Cos} i \pi}{(i \pi)^{3}}\right)\right)\right] k \pi w_{k j}+ \\
& \sum_{k=1,, m=1, \ldots . .}^{\infty} \sum^{\infty}\left[72\left(D_{12}+2 D_{66}\right)\left(\frac{1+\operatorname{Cosi} \pi}{a i}\right)\left(\frac{1+\operatorname{Cos} j \pi}{b j}\right)\right] k m w_{k m}=q_{i j} \frac{a b}{4}
\end{aligned}
$$


5. Fix-Fix-Fix-Simple

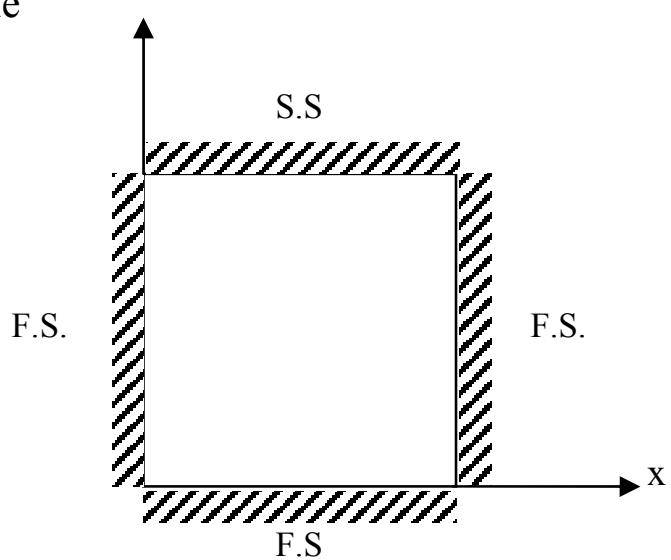

F.S

$W(x, y)=\sum_{k=1}^{\infty} \sum_{m=1 . .}^{\infty} w_{k m}\left[\operatorname{Sin} \frac{k x \pi}{a}+k \pi\left(1-\frac{x}{a}\right) \frac{x}{a}\right]\left[\operatorname{Sin} \frac{m y \pi}{b}+m \pi\left(1-\frac{2 y}{b}\right)\left(1-\frac{y}{b}\right) \frac{y}{b}\right]$

$\frac{a b}{4}\left(D_{11}\left(\frac{i \pi}{a}\right)^{4}+2\left(D_{12}+2 D_{66}\right)\left(\frac{i j \pi^{2}}{a b}\right)^{2}+D_{22}\left(\frac{j \pi}{b}\right)^{4}\right) w_{i j}+$

$-\sum_{m=1, . .}^{\infty}\left[\left(12\left(D_{12}+2 D_{66}\right)\left(\frac{i \pi}{a}\right)^{2}\left(\frac{a}{2}\right)\left(\frac{1+\operatorname{Cos} j \pi}{b j \pi}\right)-6 D_{11}\left(\frac{i \pi}{a}\right)^{4}\left(\frac{a b}{2}\right)\left(\frac{1+\operatorname{Cos} j \pi}{(j \pi)^{3}}\right)\right)\right] m \pi w_{i m}$

$-\sum_{k=1, . .}^{\infty}\left[\left(2\left(D_{12}+2 D_{66}\right)\left(\frac{j \pi}{b}\right)^{2}\left(\frac{b}{a}\right)\left(\frac{1-\operatorname{Cos} i \pi}{i \pi}\right)-D_{22}\left(\frac{j \pi}{b}\right)^{4}(a b)\left(\frac{1-\operatorname{Cos} i \pi}{(i \pi)^{3}}\right)\right)\right] k \pi w_{k j}+$

$\sum_{k=1, . . m=1, \ldots}^{\infty} \sum^{\infty}\left[24\left(D_{12}+2 D_{66}\right)\left(\frac{1-\operatorname{Cos} i \pi}{a i}\right)\left(\frac{1+\operatorname{Cos} j \pi}{b j}\right)\right] k m w_{k m}=q_{i j} \frac{a b}{4}$

6. Fix- Fix-Fix-Fix

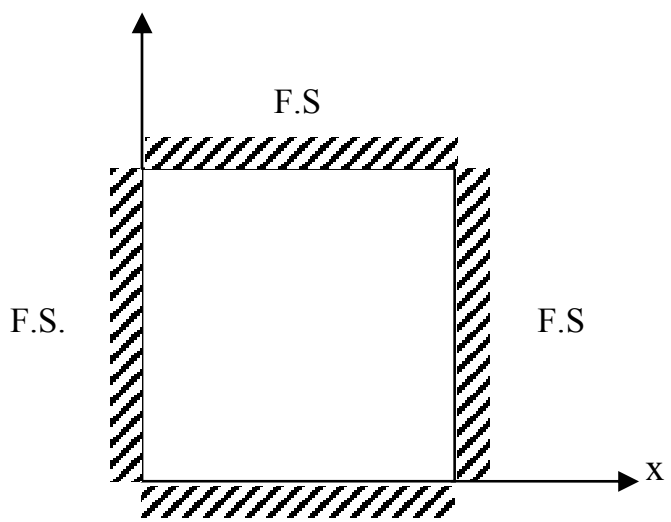

F.S

$W(x, y)=\sum_{k=1}^{\infty} \sum_{m=1 . .}^{\infty} w_{k m}\left[\operatorname{Sin} \frac{k x \pi}{a}+k \pi\left(1-\frac{x}{a}\right) \frac{x}{a}\right]\left[\operatorname{Sin} \frac{m y \pi}{b}+m \pi\left(1-\frac{y}{b}\right) \frac{y}{b}\right]$ 


$$
\begin{aligned}
& \left(D_{11}\left(\frac{i \pi}{a}\right)^{4}+2\left(D_{12}+2 D_{66}\right)\left(\frac{i j \pi^{2}}{a b}\right)^{2}+D_{22}\left(\frac{j \pi}{b}\right)^{4}\right) w_{i j}+ \\
& -\sum_{m=1,3 . .}^{\infty}\left[\left(\frac{8}{a b}\left(D_{12}+2 D_{66}\right)\left(\frac{i \pi}{a b}\right)^{2}\left(\frac{1-\operatorname{Cos} j \pi}{j \pi}\right)-4 D_{11}\left(\frac{i \pi}{a}\right)^{4}\left(\frac{1-\operatorname{Cos} j \pi}{(j \pi)^{3}}\right)\right)\right] m \pi w_{i m} \\
& -\sum_{k=1,3 . .}^{\infty}\left[\left(\frac{8}{a b}\left(D_{12}+2 D_{66}\right)\left(\frac{j \pi}{a b}\right)^{2}\left(\frac{1-\operatorname{Cos} i \pi}{i \pi}\right)-4 D_{22}\left(\frac{j \pi}{b}\right)^{4}\left(\frac{1-\operatorname{Cos} i \pi}{(i \pi)^{3}}\right)\right)\right] k \pi w_{k j}+ \\
& \sum_{k=1,3 . . .}^{\infty} \sum_{m=1,3 . . .}^{\infty}\left[\frac{32 \pi^{2}}{(a b)^{2}}\left(D_{12}+2 D_{66}\right)\left(\frac{1-\operatorname{Cos} i \pi}{i \pi}\right)\left(\frac{1-\operatorname{Cos} j \pi}{j \pi}\right)\right] k m w_{k m}=q_{i j}
\end{aligned}
$$

To demonstrate applicability of our proposed method to rectangular laminated composite plates under all fixed boundaries with lay up $\left[ \pm 45_{2}^{\mathrm{f}} / 0_{6}\right]_{\mathrm{s}}$ by having $A_{11}=215.17$ $\mathrm{MN} / \mathrm{m}, A_{12}=32.74 \mathrm{MN} / \mathrm{m}, A_{22}=48.17 \mathrm{MN} / \mathrm{m}, A_{66}=36.01 \mathrm{MN} / \mathrm{m}, D_{11}=45.3 \mathrm{~N} . \mathrm{m}, D_{12}=19.52$ N.m, $D_{22}=25.26$ N.m, and $D_{66}=20.62$ N.m, total thickness of $2 \mathrm{~mm}, 200 \mathrm{~mm}$ in length (x direction), 200,400,600,800 and $1000 \mathrm{~mm}$ in length (y direction) and uniform distribution load $0.05 \mathrm{~N} / \mathrm{mm}^{2}$, deflections are provided in Tables H.3.

Table H3. Deflection of Rectangular Laminated Composite Plate with All Fixed Boundaries

\begin{tabular}{|c|c|c|c|c|c|}
\hline \multirow{2}{*}{ term } & \multicolumn{5}{|c|}{ Deflection (mm) } \\
& \multicolumn{5}{|c|}{ (mid span } \\
\cline { 2 - 6 } & $\mathbf{b}$ & $\mathbf{b}$ & $\mathbf{b}$ & $\mathbf{b}$ & $\mathbf{b}$ \\
\hline 1 & 3.459 & 6.149 & 6.719 & 6.91 & 6.997 \\
\hline 2 & 2.514 & 4.165 & 4.044 & 3.831 & 3.688 \\
\hline 3 & 2.497 & 4.451 & 4.803 & 4.975 & 5.1045 \\
\hline 4 & 2.467 & 4.337 & 4.501 & 4.434 & 4.346 \\
\hline 5 & 2.462 & 4.363 & 4.614 & 4.681 & 4.741 \\
\hline 6 & 2.457 & 4.346 & 4.56 & 4.557 & 4.523 \\
\hline 7 & 2.456 & 4.35 & 4.585 & 4.62 & 4.644 \\
\hline
\end{tabular}




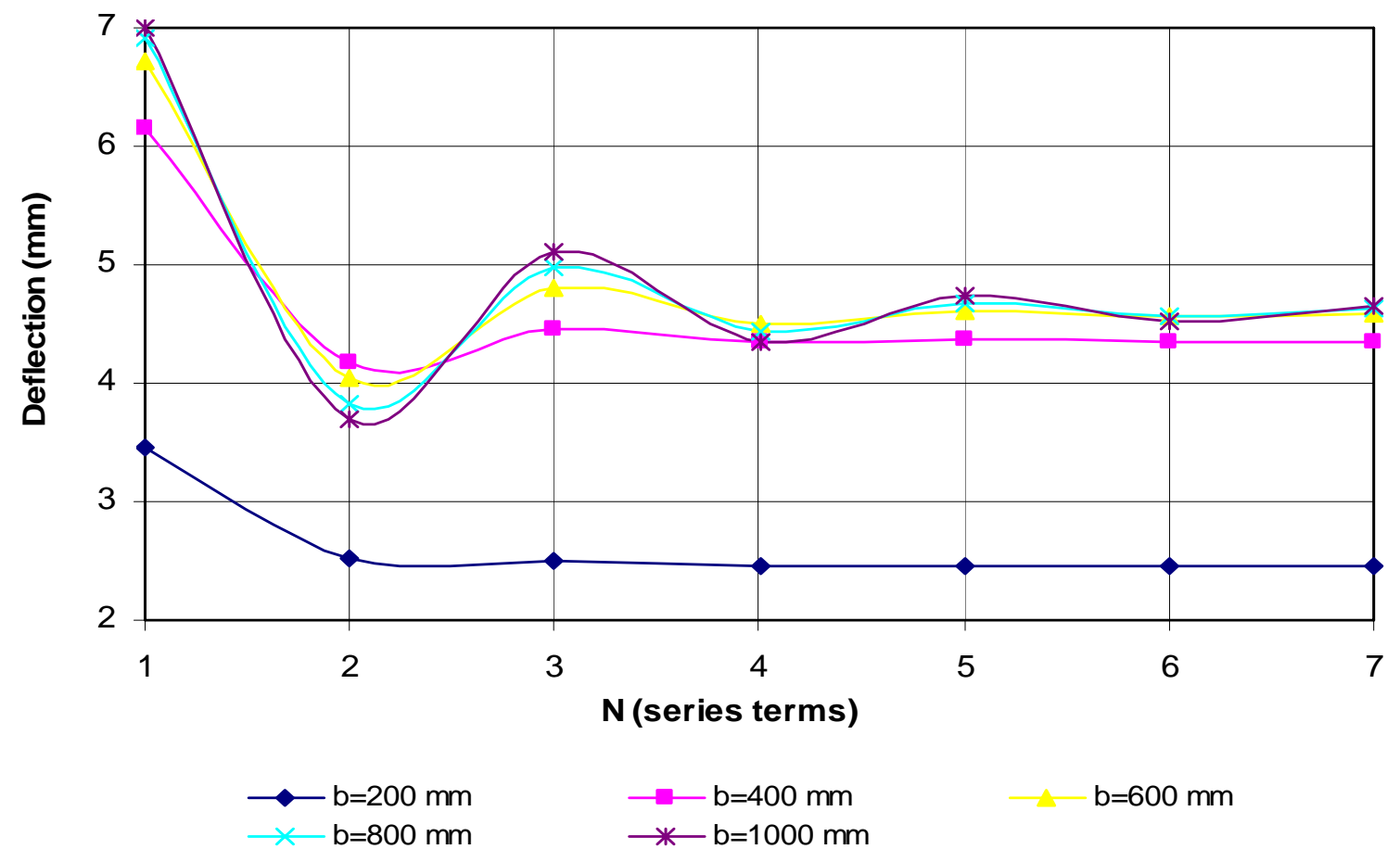

Figure H.1 Convergence of deflection in Table H.3

\section{H.5 Conclusion}

The closed-form series solution approach for one and two dimensional static thin laminated composite problems with arbitrary boundary conditions under out-of-plate loadings are presented herein. This closed-form series solution approach leads to a summation equation of fast convergence. The validity of the procedure and the accuracy of solutions are demonstrated through comparisons with existing element solution data. This closed-form series solution approach leads to a summation equation 


\section{H.6 Reference}

1. H.V.S. GangaRao and C.C. Spyrakos, Closed form Series Solutions of Boundary Value Problems with Variable Properties. Computer \& Structures. 23, 211-215 (1986).

2. H.V.S. GangaRao and C.C. Spyrakos, A Series Solution Algorithm for Initial Boundary-Value Problems with Variable Properties. Computer \& Structures. 26, 581585 (1987).

3. H.V.S. GangaRao and C.C. Spyrakos, Fourier Polynomial Series Solutions of Initial Boundary Value Problems. Proceedings of $11^{\text {th }}$ IMACS World Congress on Partial Differential Equations, Oslo, Norway, AuHust, 5-9 (1985).

4. H.V.S. GangaRao and V.K. Chaudhary, Analysis of Skew and Triangular Plates in Bending. Computer \& Structures. 28(2), 223-235 (1988).

5. H.V.S. GangaRao and H.J. Farran, Macro-Element Analysis of Skewed and Triangular Orthotropic Thin Plates with Beam Boundaries. Computer \& Structures. 22 (3), 211-215 (1986).

6. H.V.S. GangaRao, A.A. Elmeged and V.K. Chaudhary, Macroapproach for ribbed and Grid plate systems. Journal of Engineering Mechanics Division. 101(1), 23-43 (1975). 